University of Louisville ThinkIR: The University of Louisville's Institutional Repository

Electronic Theses and Dissertations

$5-2019$

\title{
Synthetic methods and biological applications of nitrogen heterocycles to compounds of biological interest.
}

Jarrid Ronnebaum

University of Louisville

Follow this and additional works at: https://ir.library.louisville.edu/etd

Part of the Organic Chemistry Commons

\section{Recommended Citation}

Ronnebaum, Jarrid, "Synthetic methods and biological applications of nitrogen heterocycles to compounds of biological interest." (2019). Electronic Theses and Dissertations. Paper 3152.

https://doi.org/10.18297/etd/3152

This Doctoral Dissertation is brought to you for free and open access by ThinkIR: The University of Louisville's Institutional Repository. It has been accepted for inclusion in Electronic Theses and Dissertations by an authorized administrator of ThinkIR: The University of Louisville's Institutional Repository. This title appears here courtesy of the author, who has retained all other copyrights. For more information, please contact thinkir@louisville.edu. 
Synthetic Methods and Biological ApPlications of Nitrogen Heterocycles to COMPOUNDS OF BIOLOGICAL INTEREST

By

Jarrid Ronnebaum

M.S., University of Louisville 2018

\author{
A Dissertation \\ Submitted to the Faculty of the \\ College of Arts and Sciences of the University of Louisville \\ in Partial Fulfillment of the Requirements \\ for the Degree of \\ Doctor of Philosophy \\ in Chemistry
}

Department of Chemistry

University of Louisville

Louisville, Kentucky

May 2019 
(C) 2019 by Jarrid Ronnebaum

All rights reserved 

Synthetic Methods and Biological ApPlications of Nitrogen Heterocycles to COMPOUNDS OF BIOLOGICAL INTEREST

\author{
By \\ Jarrid Ronnebaum \\ M.S., University of Louisville 2018
}

A Dissertation Approved on

April 23, 2019

Dr. Frederick A. Luzzio

(Dissertation Director)

Dr. Sachin Handa

Dr. Craig A. Grapperhaus

Dr. David J. Schultz 


\section{ACKNOWLEDGEMENTS}

First and foremost, I must thank Dr. Frederick A. Luzzio for his mentorship during my graduate studies. He has passed along not only a multitude of skills and techniques, but also his drive to push the boundaries of chemical knowledge and his passion for chemistry. I would also like to thank my current and former lab mates Paige Monsen and Dr. Pravin Patil for their assistance in my endeavors and the many enjoyable hours we spent together in the lab. I would like to thank Dr. Honda, Dr. Grapperhaus, and Dr. Schultz as they were gracious enough to sit on my thesis advisory committee and provide their insights that allowed me to improve my thesis work. None of this would have been possible without the funding provided by the University of Louisville through the graduate teaching assistantships.

There are also many people outside of the university that have aided me in this journey. I would like to start with my wife, Kaitlin, whose unwavering love and support has allowed me to pursue this endeavor as we begin our lives together. I cannot give enough thanks to my family: especially my mother, Nancy, along with my stepfather, Mark, who have raised me to be the person I am today and has always encouraged me to pursue my dreams. 


\begin{abstract}
SynthetiC Methods AND BiologicAl APPliCATIONS OF NitROGEN HETEROCYCLES tO COMPOUNDS OF BIOLOGICAL INTEREST

Jarrid Ronnebaum
\end{abstract}

April 23, 2019

Thalidomide analogues were synthesized utilizing optimized click conditions from 3-azidoglutarimide and an array of arylacetylenes or $N$-ethynyl $/ N$-propargyl phthalimide derivatives. The intermediate, 3-azidoglutarimde, was pivotal and yielded a new and scalable synthesis. The reaction conditions utilized a copper sulfate/sodium ascorbate system in aqueous tetrahydrofuran to propagate the dipolar cycloaddition reactions between the azidoglutarimide and the alkynyl coupling partners. The first explored substrates were substituted arylalkynes to optimize the click reaction. Arylalkynes selected were to exhibit similar electron deficient rings to mimic phthalimide. Along with the synthesis of click thalidomide analogues, click analogue of the antiangiogenic and more potent teratogenic thalidomide analogue EM-12 was prepared.

The isoindolinone group can act interchangeably with the $N$-phthaloyl nitrogen protecting group in amino acids. Amino acid intermediates using the $N$-isoindolinone group are used to make natural and unnatural a-amino acid derivatives using a two-carbon synthon. Selective benzylic oxidation was performed with the $N$-isoindolinone group being converted to the $N$-phthaloyl group (65-98\%), which could be conveniently removed with hydrazine. For preparation of $\mathrm{N}$-isoindolinone protected amino acids, an array of side 
chains was installed on the isoindolinone-protected glycine equivalent. This was accomplished through selective deprotonation to demonstrate the utility of the $N$-protected isoindolinone synthon (51-93\%). Selective oxidation is employed on the benzylic $N$ isoinodolinone with Oxone ${ }^{\circledR} / \mathrm{KBr}$ and successfully converted the $N$-isoindolinone group to the $N$-phthaloyl group in simple substrates, but substrates bearing unsaturated or electronrich side chains respond poorly to the oxidation.

The alkoxylation of chiral $N$-phenethyl hydroxyisoindolinones were synthesized with diethylaminosulfur trifluoride and an array of primary and secondary alcohols. The mechanism by which synthesis alkoxyisoindolinones are synthesized is through generation of an $\mathrm{N}$-acyliminium ion to allow alkoxylation. The alkoxylated product exhibits a diastereomeric ratio influenced by the chiral $N$-phenethyl with a favored diastereomer. The stereochemistry and mixture of diastereomers were observed through this reaction. 


\section{TABLE OF CONTENTS}

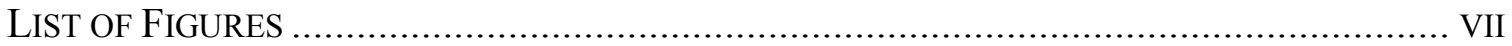

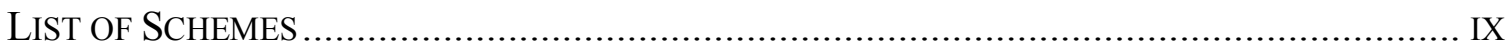

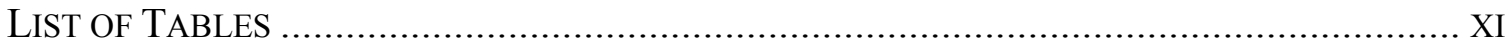

PART A. SYNTHESIS OF “CLICK” THALIDOMIDE ANALOGUES ......................................... 1

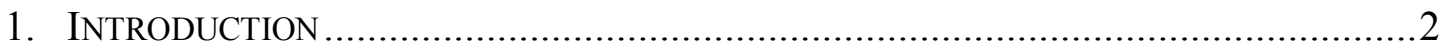

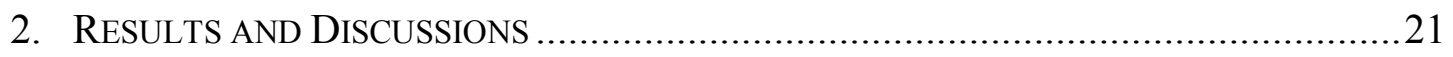

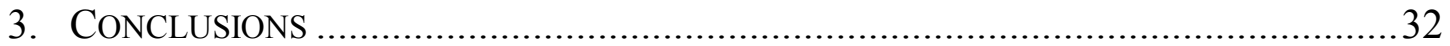

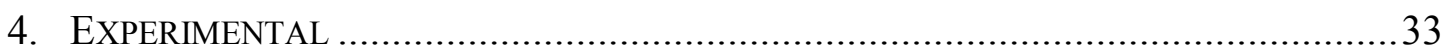

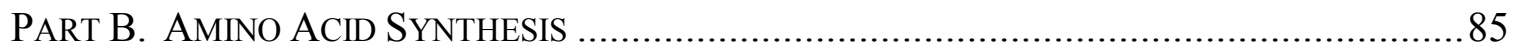

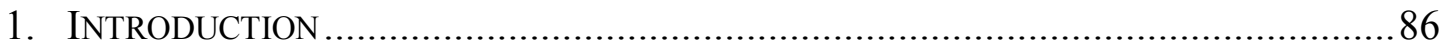

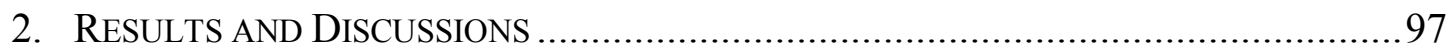

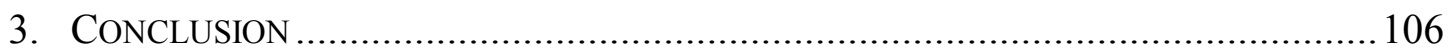

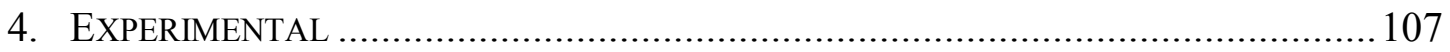

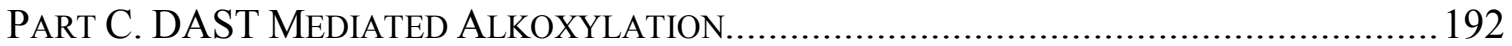

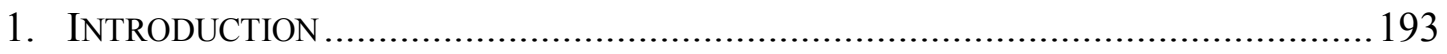

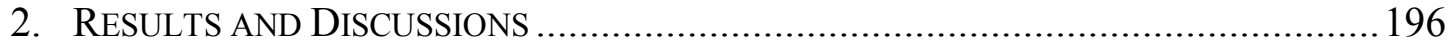

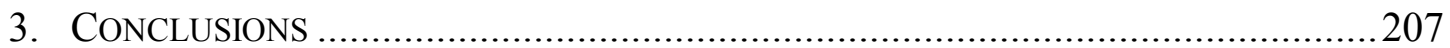

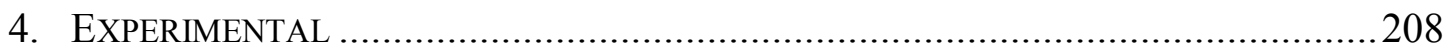

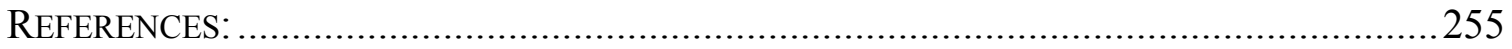

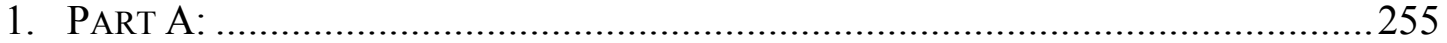

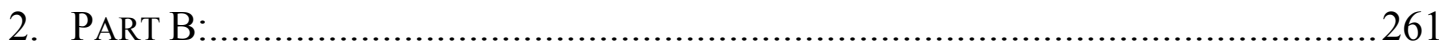

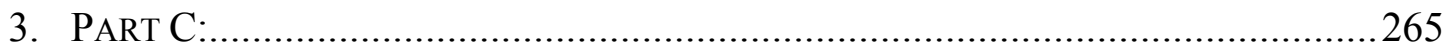

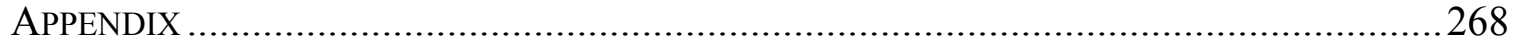

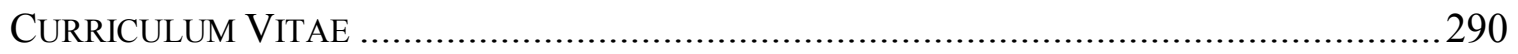




\section{LIST OF FIGURES}

Figure 1. Thalidomide chemical structure ........................................................

Figure 2. PROTAC bearing a thalidomide to downregulate BRD4 .............................. 6

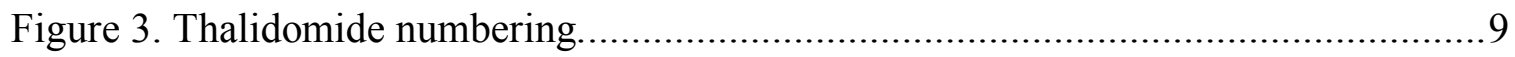

Figure 4. Structural conformation of EM-12 ............................................... 10

Figure 5. Thalidomide derivative synthesized by Jönsson. ...................................... 10

Figure 6 . Thalidomide derivates that lack planarity within the phthalimide ring............11

Figure 7. Chemie researchers synthesizing derivatives to determine teratogenic. ...........12

Figure 7. Polyhalogenated thalidomide derivatives. ........................................... 13

Figure 8. Potential thionylthalidomide derivatives from Lawesson's reagent. ................ 14

Figure 9. Thalidomide derivatives synthesized by He and coworkers........................... 14

Figure 10. Thalidomide derivatives tailored towards TNF- $\alpha$ inhibition through PDE4

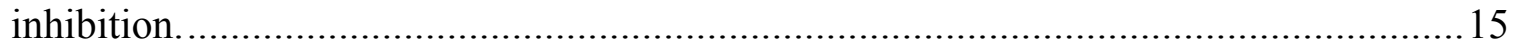

Figure 12. Chemical structure of lenalidomide.................................................... 17

Figure 13. Thalidomide derivatives bearing 3' substitution ................................... 18

Figure 14. $\mathrm{N}$-substituted thalidomide derivatives. ............................................. 19

Figure 15. PROTAC developed to target the downregulation of Sirt2 ..........................20

Figure 16. Number of publications on unnatural $\alpha$-amino acids. ...............................86

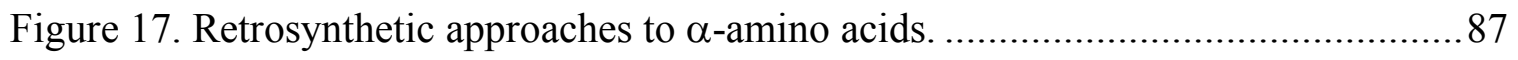

Figure 18. Biologically active structures that bear unnatural amino acids....................90 
Figure 19. Two phenylalanine mimics

Figure 20. Oxazole converted to a carboxylic acid............................................. 103

Figure 21. The observational difference in ${ }^{1} \mathrm{H}$ NMR ............................................. 105

Figure 22. Alkoxyisoindolinone products that are active biological compounds........... 193

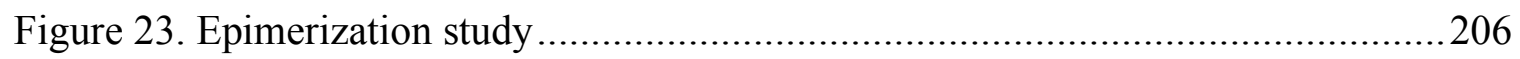




\section{LIST OF SCHEMES}

Scheme 1. Hydrolytic breakdown cascade of thalidomide in biological $\mathrm{pH} . . . \ldots \ldots \ldots \ldots \ldots . . . . . .8$

Scheme 2. Synthetic approach of thalidomide derivatives by He and coworkers.

Scheme 3. Preparation of azidoglutarimide

Scheme 4. Synthesis of $N$-propargyl isoindolinone.

Scheme 5. Synthesis of $N$-propargyl isoindolinone.

Scheme 6. Synthesis of N-ethynyl phthalimide and isoindolinone. .26

Scheme 7. Proposed synthesis of $N$-ethynyl isoindolinone from $N$-ethynyl phthalimide. 29

Scheme 8. Proposed synthesis of "click" EM-12 from the "click" thalidomide. 30

Scheme 9. Click reaction mechanism to generate the 1,4-substituted 1,2,3-triazole.

Scheme 10. General approach by O'Donnell et al. to synthesize $\alpha$-amino acids. 94

Scheme 11. General approach by Myers et al. to synthesize $\alpha$-amino acids.

Scheme 12. Modified approach by Saghiyan et al. to synthesize enantiomerically pure $\alpha-$ amino acids. 96

Scheme 13. Preparation of $N$-isoindolinone esters.

Scheme 14. Preparation of the mono-alkylation of the $N$-isoindolinone amino acid derivative. .98

Scheme 15. Benzylic oxidation of isoindolinone napthalene derivative.

Scheme 16. Benzylic oxidation of isoindolinone oxazole derivative 104

Scheme 17. Conversion of $N$-phthaloyl phenylalanine to a standard $N$-BOC phenylalanine derivative 105 
Scheme 18. Plausible DAST mediated mechanism

Scheme 19. DAST mediated ether formation presented by Johnson.

Scheme 20. DAST mediated alkoxylation.

Scheme 21. Preparation of Hydroxyisoindolinone.

Scheme 22. Proposed $\mathrm{S}_{\mathrm{N}}$ 2-like reaction mechanism utilizing DAST

Scheme 23. Proposed mechanism utilizing DAST .202

Scheme 24. Preparation of $(S)$-3-oxo-2-((S)-1-phenylethyl)isoindolin-1-yl acetate......205 


\section{LIST OF TABLES}

Table 1. Cycloaddition products of arylacetylenes with 3-azidoglutarimde.

Table 2. Cycloaddition products of $\mathrm{N}$-propargyl phthalimide/isoindolinone with 3azidoglutarimde

Table 3. Cycloaddition products of $\mathrm{N}$-ethynyl phthalimide/isoindolinone with 3azidoglutarimde

Table 4. Alkylation of the $N$-isoindolinone protected esters

Table 5. Oxidation of the $N$-isoindolinone esters to yield $N$-phthaloyl amino acid derivatives.

Table 6. Products from hydroxyisoindolinone and alcohol with diethylaminosulfur trifluoride. .198

Table 7. Products from hydroxyisoindolinone and alcohol with camphorsulfonic acid. 204 


\section{PART A. SYNTHESIS OF "CLICK” THALIDOMIDE ANALOGES}




\section{Introduction}

Thalidomide, developed initially as a sedative, is responsible for one of the most tragic histories in the era of drug discovery, but has since been reassessed for new purposes that have been proven beneficial. Thalidomide was synthesized and sold as "Contergan" by Chemie Grunenthal, a West German Pharmaceutical company, and patented in $1956^{1}$. Thalidomide was claimed to possess sedative properties and was prescribed to treat morning sickness for pregnant women in 46 countries $^{2}$. Lenz ${ }^{3}$ and McBride 4 independently reported in the early 60 's that thalidomide was associated with pregnancies resulting in children being born with major congenital abnormalities ${ }^{3-6}$. The severity of the birth defects recorded ranges from internal organs being deformed, cleft lip, to amelia or phocomelia. Amelia being the total lack of a limb and phocomelia being that the hand or foot attached near trunk. More than 12,000 children were affected by the teratogenic effects of thalidomide and therefore the drug was removed from the United Kingdom in late 1961. A short time after thalidomide was completely removed from the majority of the worlds markets by 1962. During the time of thalidomide distribution, an increased rate of miscarriages was reported as well ${ }^{7}$. Though thalidomide was shown to be an incredibly potent embryotoxin, it was still being used in some countries where it portrayed significant efficacy.

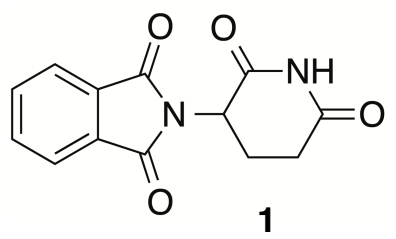

Figure 1. Thalidomide chemical structure.

Thalidomide, shortly after its removal form the market as a drug, was reported by Sheskin in $1965^{8}$ to be very effective in treating erythema nodosum leprosum (ENL), the 
skin lesions associated with leprosy.s The World Health Organization confirmed its beneficial effect in thousands of men for ENL after the initial report by Sheskin. In 1980, Sheskin reported the efficiency of thalidomide in ENL as over 99\% effective in 4522 patients ${ }^{9}$. Typically, positive responses were observed within a $24-48$ hour time period including the improvement of symptoms ${ }^{9}$ such as: lesions, fever, and night sweats. Despite thalidomides' positive impact on ENL, side effects occurred, ranging from headaches to polyneuritis. Following conclusion of treatment, the numbness in patients' extremities tended to subside. In patients with ENL, Tumor Necrosis Factor $\alpha$ (TNF- $\alpha$ ) and Interferon $\gamma(\mathrm{IFN}-\gamma)$ were elevated, but upon thalidomide administration levels of both cytokines were decreased ${ }^{10}$. TNF- $\alpha$ is a molecule that plays a crucial role in inflammation, making its inhibition particularly useful for inflammatory diseases. This observation led to the interest in thalidomide for its immunomodular effects.

Thalidomide through the 80 's and into the early 90 's underwent very little change in its structure while being clinically evaluated in ENL and multiple other skin diseases. Due to its ban in many countries, only small sample cases were conducted to show thalidomide aided in the ailments of Behcet's disease ${ }^{11}$, rheumatoid arthritis ${ }^{12}$, systemic lupus erythematosus ${ }^{13}$, and graft versus host disease. ${ }^{14,15}$ Considering the severity and unknown mode of action for thalidomide's teratogenicity, the use of this drug in many autoimmune diseases was only considered once outside of clinical trials, with the only exception being ENL. Thalidomide's structure was first altered in response to the discovery of its ability to inhibit TNF- $\alpha$. Alterations of the glutarimide moiety lead to the first derivatives of thalidomide's structure and were synthesized to increase its inhibitory effects on TNF$\alpha .^{16,17}$ 
Three decades have passed since one of the initial uses of thalidomide for antitumor properties was reported in 1965 by Olsen et $\mathrm{al}^{18}$ by using thalidomide on individuals with a range of advanced cancers. In 1999, Singhal et al ${ }^{19}$ reported the reexamination of thalidomide for its antitumor properties in refractory multiple myeloma. While multiple myeloma accounts for approximately 10 percent of hematological cancers, it is incurable with conventional chemotherapy. Multiple myeloma often sees a relapse of the cancer after high-doses of chemotherapy and angiogenesis can accelerate tumor progression of hematological cancers. Thalidomide and its anti-angiogenic properties have been effective in slowing tumor progression in the treatment of refractory multiple myeloma. In the 1999 study, thalidomide was used for a small group of refractory multiple myeloma patients and 10 percent of patients showed complete remission and a third was observed to have at least a $25 \%$ reduced paraprotein level. Since the first in vivo efficacy of thalidomide in refractory multiple myeloma, thalidomide has been shown to be most effective when given in a combination of thalidomide with another anticancer drug. In most cases, the combination of drugs is better than using solely thalidomide or using solely the combinatory drug. ${ }^{20} \mathrm{~A}$ specific case included the use of thalidomide with low doses of dexamethasone, in which it was used to treat advanced multiple myeloma and proved to be more potent than either of them individually. Using the combination drug approach, the technique of using thalidomide with melphalan or cyclophosphamide has also shown to be potent combination therapies to obtain remission of multiple myeloma.

In 2010, Ito and $\mathrm{Ando}^{21}$ used a novel thalidomide beads approach to discover that thalidomide binds selectively through the glutarimide ring to the $\mathrm{N}$-terminus of the protein cereblon (CRBN). CRBN is a protein of the ubiquitin E3 cullin 4-RING ligase (CRL4) 
complex containing the proteins; damaged DNA-binding protein 1 (DDB1), cullin 4 protein (Cul4), and CRBN to form the complex CUL4A ${ }^{\mathrm{CRBN}}$. Ubiquitin complexes tag proteins to be decomposed by a proteasome, effectively downregulating a specific protein. The immunomodulatory drugs (IMiDs), consisting of thalidomide, lenalidomide, and pomalidamide, have been shown to bind $\mathrm{CRBN}$ and aid in the selective ubiquitination of proteins in the CUL4A ${ }^{\text {CRBN }}$ complex. The CUL4A ${ }^{\text {CRBN }}$ is useful in maintaining metabolic homeostasis through degradation of glutamine synthetase in hepatic cells, where glutamine is at high concentration. ${ }^{22}$ The binding of thalidomide acts as an allosteric regulator to cereblon and downregulates proteins that control the expression of growth factors responsible for teratogenic properties. ${ }^{21}$ Though teratogenic properties exist, there is a benefit of both thalidomide and lenalidomide in treating multiple myeloma through the binding and the downregulation of Ikaros family zinc finger protein (IKZF) 1 and IKZF3. ${ }^{23,24}$ In contrast, when bound in the CRBN pocket lenalidomide also downregulates casein kinase $1 \mathrm{~A} 1(\mathrm{CK} 1 \alpha)$ post translationally ${ }^{25}$ This provides a structural basis to make new drug targets that possess the glutarimide moiety while utilizing the CRL4 ${ }^{\text {CRBN }}$ ubiquitin complex in an opportunistic manner. This technique gives insight in to the potential mode of action in which thalidomide acts as an anticancer agent.

Thalidomide most recently has been being explored for targeted protein knockdown. Chemicals capable of inducing protein degradation are seen as a potential drug candidate due to their ability to induce a chemical knockdown of a targeted protein. Of one specific chemically induced knockdown, thalidomide is used with a paired chimeric molecule used as PROTACs (Proteolysis-Targeting Chimeras). Thalidomide is currently being investigated to act as one portion of a PROTAC to invoke an E3 ubiquitin ligase. ${ }^{26}$ This is 
completed through thalidomide acting as a ligand of the cereblon protein to facilitate use of the E3 ubiquitin complex in targeted protein ubiquitination. PROTACs containing the thalidomide ligand and another inhibitory ligand is proximate to the ubiquitin complex and the new protein to induce poly-ubiquitylation. This poly-ubiquitylation has a down regulation of a new protein through the chimeric ligand and was first reported in down regulating bromodomain-containing protein 4, BRD4 (Figure 2). Since the applicability of PROTACs, 2, being used for down regulation of BRD4, a class of PROTACs have been used on a range of differing proteins.

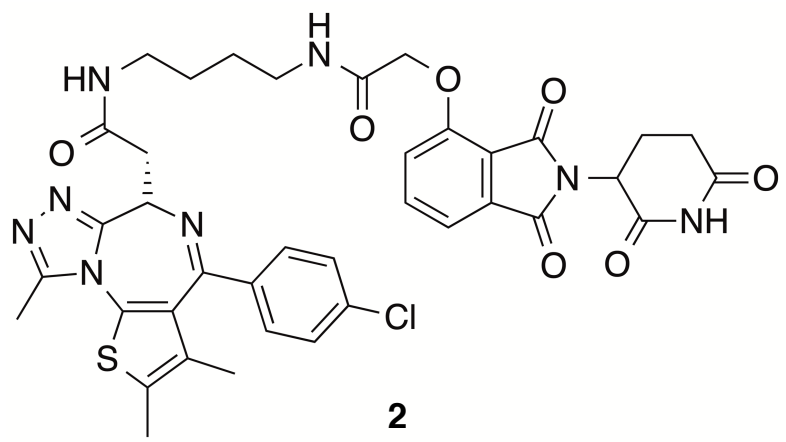

Figure 2. PROTAC bearing a thalidomide to downregulate BRD4.

The metabolic pathway by which thalidomide possesses both antiangiogenic and teratogenic nature has gone through many hypothetical metabolic pathways. While thalidomide has been shown to inhibit TNF- $\alpha$ synthesis, there has been no link to correlate the inhibition of TNF- $\alpha$ with its teratogenic activity. On the other hand, thalidomide's antiangiogenic activity shows correlation toward its ability to act as a teratogen independently of its immunosuppressant/immunomodulatory activity. One of the first hypothesized mechanisms of action of thalidomide being a teratogen was proposed by Jönsson in $1972 .{ }^{27}$ Jönsson proposed that the teratogenic action of thalidomide was through the intercalation in DNA through a stacked complex that allows for a flat phthalimide ring 
to form with the deoxyguanosine. It was hypothesized that thalidomide would bind to guanine-rich sites, however linking this to teratogenicity was a hard pathway to justify due to the lack of specificity of intercalation on specific gene expressing regions. Other mechanisms have been explored to explain the teratogenicity nature of thalidomide including: reactive oxidative stress-inducing cell death, chondrogenesis, and nerve toxicity/neural crest loss. ${ }^{28-33}$ Through the years thalidomide's beneficial pharmacological effects included anti-tumor promoting activity, anti-angiogenic activity, anti-viral activity, and hypoglycemic activity. Regulation of certain cytokines; TNF- $\alpha$, interleukins $2,4,5,6$, 10 , and 12 , and interferon- $\gamma$, affect the population of T-cells and the hypothesis was that this stemmed from the regulation of TNF- $\alpha .{ }^{34-35}$ While all of these have been observed, finding a direct mode of action for any of these has never been completely elucidated, but has been a major reason for synthesizing derivatives of thalidomide as a means of elucidating a specific mechanism.

Thalidomide is a highly crystalline compound and is relatively insoluble in most organic solvents. While being mostly soluble in highly polar organic solvents; dimethylsulfoxide, dimethylformamide, and pyridine, thalidomide has poor aqueous solubility and has instability under physiological $\mathrm{pH}$. The instability stems from the chemical transformations that do occur in the form of racemization at the enolizable $3^{\prime}$ position on the glutarimide ring and hydrolysis of thalidomide. The general hydrolytic cascade demonstrates the breakdown of thalidomide under biological $\mathrm{pH}$ and begins with either the opening of the phthaloyl or glutarimide ring (Scheme 1). Looking at the lefthand side of the cascade, the partial hydrolysis of the phthaloyl ring yields first a carboxybenzamidic acid glutarimide $\mathbf{3}$ derivative which under complete hydrolysis yields 


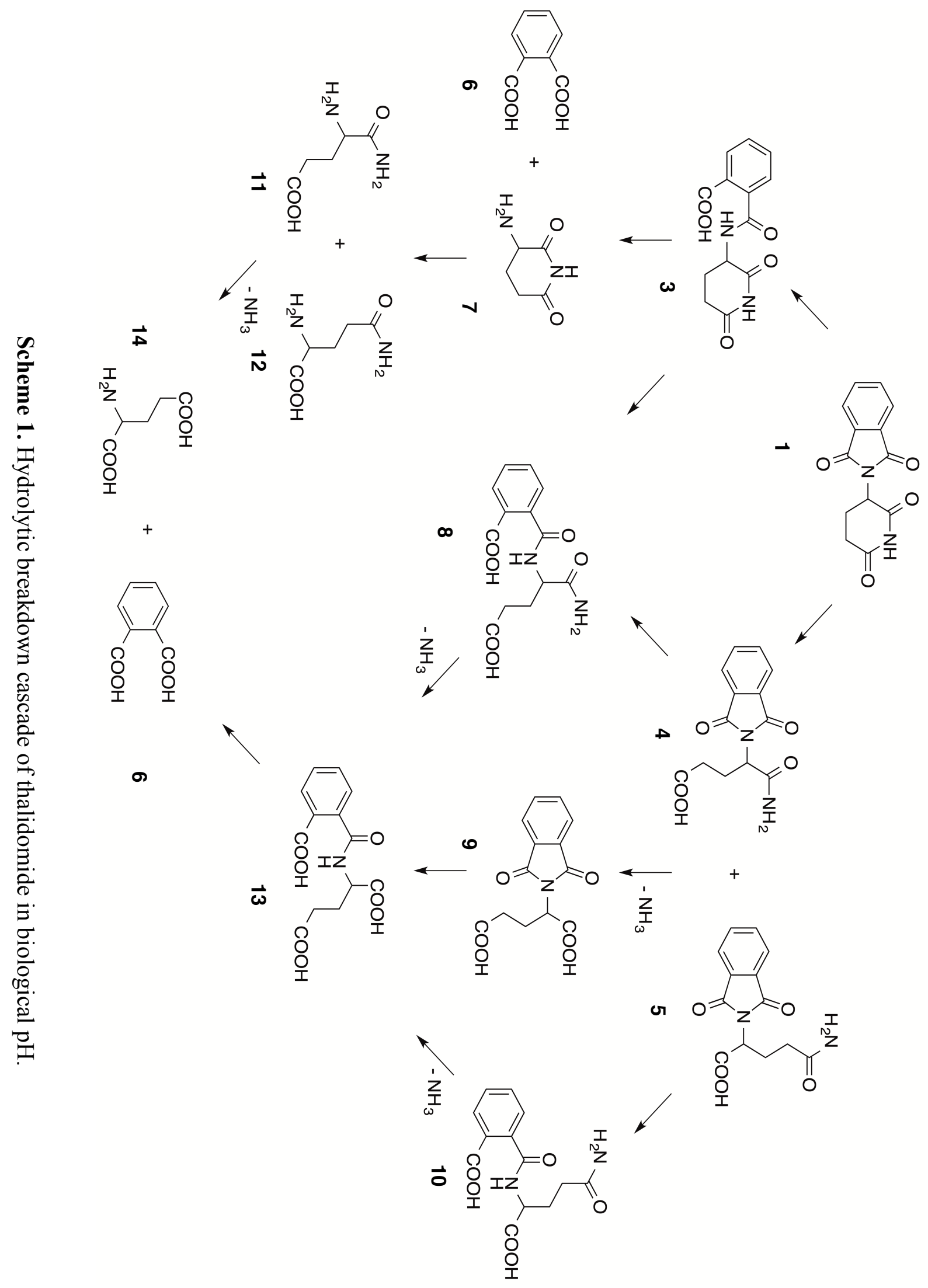


$o$-phthalic acid 6 and aminoglutarimide 7. Glutarimide 7 undergoes hydrolysis to yield either glutamine $\mathbf{1 2}$ or isoglutamine $\mathbf{1 1}$ that both can suffer hydrolytic cleavage to yield glutamic acid 14. Though phthalimide hydrolysis is plausible, complete hydrolysis of the glutarimide ring is equally plausible to yield either $N$-phthaloyl glutamine 5 or $N$-phthaloyl isoglutamine $\mathbf{4}$ and can be seen on the right-hand side of cascade. Hydrolytic cleavage of 4/5 yields $N$-phthaloyl glutamic acid 9 or hydrolysis of the phthaloyl to synthesize the carboxybenzamidic acid derivatives $\mathbf{8 / 1 0}$. Complete hydrolysis of $\mathbf{8}$ or $\mathbf{1 0}$ would yield both 11 and 12, respectively. A mixture of the opening of the glutarimide ring and phthaloyl ring is plausible as well and can be seen as intermediates deviating from the cascades aforementioned, but all processes of the hydrolytic breakdown result in $\mathbf{6}$ and $\mathbf{1 4}$.

Although thalidomide itself initially was notorious as a potent embryotoxin, it has since been highly beneficial to the medicinal community through utilization of its derivatives. Thalidomide has a unique numbering by which derivatives are denoted through giving first priority numbering to the phthalimide ring followed by the glutarimide ring denoted with a prime numbering (Figure 3). The first derivative of thalidomide was accomplished through removing a benzylic carbonyl, also known as EM-12 15 (Figure 4). ${ }^{36}$ EM-12 has been observed to be a more potent teratogen than thalidomide in the New

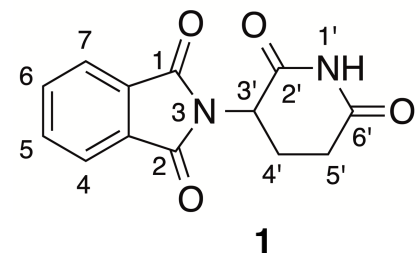

Figure 3. Thalidomide numbering. 


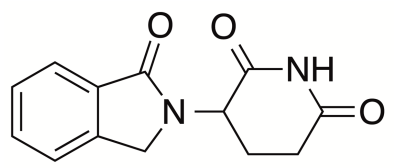

15

Figure 4. Structural conformation of EM-12.

Zealand white rabbit. Since a multitude of thalidomide analogues have been synthesized in an attempt to gain an understanding of its teratogenic properties and mechanism of action. An early set of thalidomide-based compounds were made and tested by Jönsson in 1972 to attempt to discern what chemical properties are necessary for teratogenicity. ${ }^{27}$ Of the compounds tested by Jönsson (Figure 5), teratogenic studies of the compounds were conducted on rabbits, chickens, and Wistar rats and organized according to malformation<smiles>O=C1CC(N2C(=O)c3ccccc3C2=O)CC(=O)N1</smiles>

16<smiles></smiles>

17<smiles>Nc1cccc2c1C(=O)N(C1CCC(=O)NC1=O)C2=O</smiles>

18<smiles>O=C1CCC(N2C(=O)c3cccc(O)c3C2=O)C(=O)N1</smiles>

19<smiles>O=C1CCC(N2C(=O)C3CCCCC3C2=O)C(=O)N1</smiles>

21<smiles>O=C1CCC(N2C(=O)c3ccc(O)cc3C2=O)C(=O)N1</smiles>

20<smiles>O=C1CCC(N2C(=O)C3C4CCC(C4)C3C2=O)C(=O)N1</smiles>

22

Figure 5. Thalidomide derivative synthesized by Jönsson to determine chemical structure requirements for thalidomide.

and fetal resorption. This study was able to shine light on species dependent teratogenicity which was seen in the $4^{\prime}$-phthalimido analogue $\mathbf{1 6}$ by causing limb malformations in the chicken but no observable malformations in the Wistar rat. A set of molecules containing 
benzyl substitution in 4-nitrothalidomide $\mathbf{1 7}$ and the reduction partner 4-aminothalidomide 18 both caused malformations and fetal resorption in rabbit. Hydroxylated thalidomide analogues on the benzene ring in both 4- and 5-Hydroxythalidomide 19 and 20 both caused limb malformations in the chick embryo. Non-planar phthalimide derivatives, cycloalkylor tetrahydrophthalimide $\mathbf{2 2}$ and $\mathbf{2 1}$ respectfully, were both found to be non-teratogenic. To further understand the role of planarity on the "phthalimide" side, a group from the University of Bonn made partial planar analogues that lacked conjugation similar to compounds proposed by Jonsson (Figure 6) ${ }^{37}$ The partially planar alkyl derivatives 23 and $\mathbf{2 4}$ proved not to be teratogenic will the dithia compound $\mathbf{2 5}$ showed to be teratogenic. The attempts from the group atBonn to prove or disprove the intercalation theory based upon having planar molecules was neither solidified or disproved.

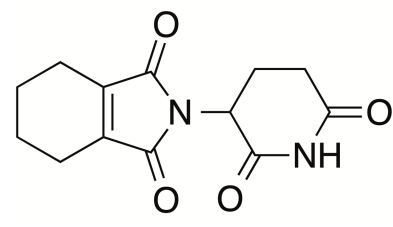

23

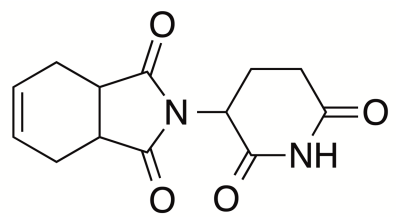

24

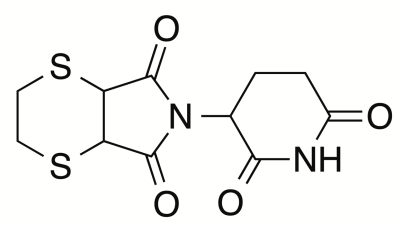

25

Figure 6. Thalidomide derivates that lack conjugation and planarity within the phthalimide ring.

Researchers from Grunenthal Research Center evaluated thalidomide derivatives for teratogenic activity. ${ }^{38}$ The compounds, EM-12, EM-136 26, EM-255 27, EM-8 28, EM87 29, were tested using the New Zealand white rabbit for teratogenic studies. Of all the compounds tested, $\mathbf{1 5}$ was found to be more teratogenic than thalidomide and the most teratogenic overall. While $\mathbf{1 5}$ was the most teratogenic, $\mathbf{2 6}$ was comparable to thalidomide in teratogenicity followed by $\mathbf{2 7}, \mathbf{2 8}$, and 29 respectively (Figure 7.). While 15 was included in the study with New Zealand white rabbits, EM-12 was already a known teratogen when tested in non-human primate species. Teratogenicity studies were 
complicated in nature due to the species-dependent nature of thalidomide. ${ }^{39-42}$ While some animals exposed to thalidomide, like the New Zealand White (NZW) rabbits and Wistar Rats, parented offspring with phocomelia/amelia, certain species such as non-NZW rabbits resorb malformed fetus in utero. As well, rodents tend to show a varying range of results and being mouse strain specific for teratogenic results. ${ }^{43,44}$ With thalidomide having species dependent teratogenic properties, studies were conducted on a range of non-human primates as the morphology of non-human primates is most analogous to humans. Many

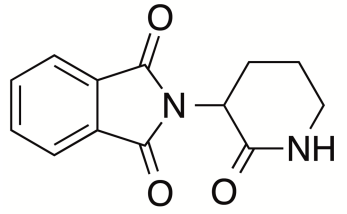

$26(\mathrm{EM}-136)$

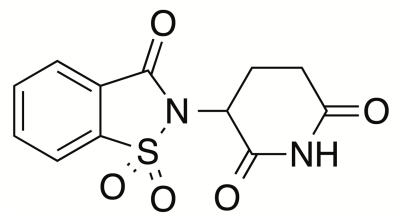

$28(\mathrm{EM}-8)$<smiles>O=C1NCCCC1N1Cc2ccccc2C1=O</smiles>

$27(\mathrm{EM}-255)$

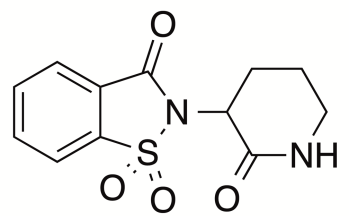

29 (EM-87)

Figure 7. Chemie researchers synthesizing derivatives to determine teratogenic requisites.

non-human primates have been tested with thalidomide throughout history with a vast majority displaying phocomelia/amelia in offspring. Difficulties arise while studying rabbits and non-human primates including the fact that they typically produce small litter and gestation can take a long time, such as the case of non-human primates. In rodents as well as rabbits and non-human primates, the embryo cultures exposed to thalidomide does not provide a way to monitor limb formation progress. Zebrafish and chick embryo cultures have provided insight and adequate models to examine the limb formation progress. 45,46 
While individual thalidomide derivatives were seen to be teratogenic, the efficacy of thalidomide's treatment for symptoms of ENL were noted to coincide with the decrease of elevated levels of TNF- $\alpha$ in patients with ENL. This observance led to the synthesis of thalidomide derivatives targeted for the downregulation of TNF- $\alpha$ to aid in the treatment of symptoms for ENL. TNF- $\alpha$ is a member of the TNF family that consists of cell surface and secreted molecules that mediate host defense and immune regulation. TNF- $\alpha$ is mainly produced by $\mathrm{T}$ cells and macrophages in response to multiple stimuli that relate to proinflammatory properties. Several novel polyhalogenated thalidomide derivatives 30-32 were reported with the goal of synthesizing thalidomide derivatives with improved TNF- $\alpha$ suppression (Figure 7) ${ }^{47}$ Of the polyhalogenated derivatives, tetrafluorothaldiomide $\mathbf{3 0}$ was reported to show suppression of TNF- $\alpha$ and was observed to be more potent than thal-

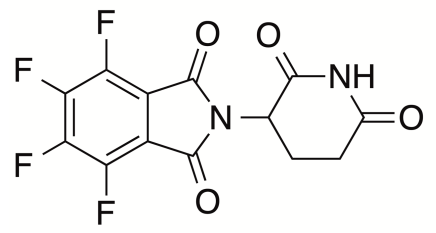

30

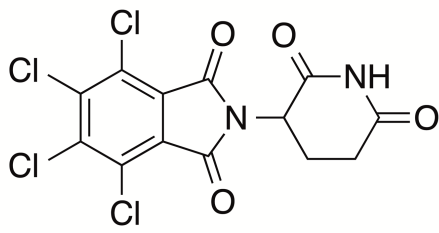

31<smiles>O=C1CCC(N2C(=O)c3c(Br)c(Br)c(Br)c(Br)c3C2=O)C(=O)N1</smiles>

32

Figure 7. Polyhalogenated thalidomide derivatives.

idomide under similar circumstances. It was also able to reach IC values within the single digits compared to that of thalidomide which was over $200 \mathrm{nM}$. Also, a number of thionothalidomide derivatives 33-35 have been synthesized by replacing one of the four carbonyls with a sulfur (Figure 8).$^{48}$ These derivatives were synthesized using Lawesson's reagent under different reaction conditions to yield either dithiothalidomide $\mathbf{3 3 / 3 5}$ in pyridine, or trithiothalidomide $\mathbf{3 4}$ in a mixture of morpholine and toluene. 
<smiles>CCCC1CCC(=S)NC1=S</smiles><smiles>O=C1c2ccccc2C(=S)N1C1CCC(=S)NC1=S</smiles><smiles>CS(=O)(=O)c1ccccc1C1CCC(=S)NC1=O</smiles>

Figure 8. Potential thionolthalidomide derivatives from treatment of thalidomide with Lawesson's reagent.

Derivatives of thalidomide specifically tailored towards downregulation of TNF- $\alpha$ were being explored during the early 1990's by He and co-workers in development of a therapeutic for graft vs. host disease. ${ }^{49}$ Derivatives synthesized by He and co-workers for<smiles>NC1CCC(=O)NC1=O</smiles>

36<smiles>O=C1OC(=O)c2ccccc21</smiles>

37<smiles>[R16]C1CCC(=O)NC1=O</smiles>

38

Scheme 2. Synthetic approach of thalidomide derivatives by He and coworkers.<smiles>O=C1CCC(N2C(=O)c3cccc(O)c3C2=O)C(=O)N1</smiles>

39<smiles>O=C1CCC(N2C(=O)c3ccc(O)cc3C2=O)C(=O)N1</smiles>

42<smiles>Nc1cccc2c1C(=O)N(C1CCC(=O)NC1=O)C2=O</smiles>

40<smiles>Nc1ccc2c(c1)C(=O)N(C1CCC(=O)NC1=O)C2=O</smiles>

43<smiles>O=C1CCC(N2C(=O)c3cccc([N+](=O)[O-])c3C2=O)C(=O)N1</smiles>

41<smiles>O=C1CCC(N2C(=O)c3ccc([N+](=O)[O-])cc3C2=O)C(=O)N1</smiles>

44<smiles>O=C1CCC(N2C(=O)c3cccnc3C2=O)C(=O)N1</smiles>

45<smiles>O=C1CCC(N2C(=O)c3ccncc3C2=O)C(=O)N1</smiles>

46

Figure 9. Thalidomide derivatives synthesized by He and coworkers. 
TNF- $\alpha$ suppression consisted of minor substitutions to the phthaloyl ring while keeping the glutarimide ring intact (Scheme 2). The phthaloyl derivatives entailed the addition of functional groups; nitro, amino and hydroxyl, or adding a nitrogen within the benzyl ring. The thalidomide derivatives 39-46 were synthesized easily from 3-aminoglutarimide 36 and the partner substituted phthalic anhydride 37. Some of the compounds (Figure 9) were shown to be promising in the TNF- $\alpha$ suppression of human peripheral blood lymphocytes, while also being tested for proficiency in graft vs. host disease in animal models.

Shortly after the reporting of He and co-worker's compounds, Kaplan and Sampaio patented thalidomide and analogues in 1995 for the treatment of abnormal TNF- $\alpha$ levels. ${ }^{50}$ Tested within their patent were hydrolytic breakdown by-products of thalidomide and EM12. In looking for potent TNF- $\alpha$ inhibitors, Celgene published a set of molecules that were inspired by the hydrolytic breakdown of thalidomide to determine whether thalidomide or a natural metabolite is more potent in inhibiting TNF- $\alpha .^{51,52}$ One such pathway for hydrolytic breakdown of thalidomide under biological $\mathrm{pH}$ occurs through the hydrolytic opening of the glutarimide ring. The hydrolysis of the glutarimide ring was the basis for design of a class of molecules that were seen to inhibit not only TNF- $\alpha$ but more specifically the phosphodiesterase (PDE) 447 (Figure 10). ${ }^{53}$ PDE4 is a major enzyme that
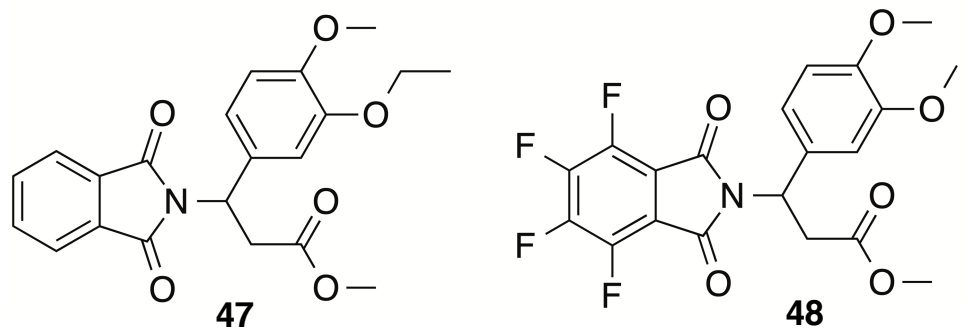

Figure 10. Thalidomide derivatives tailored towards TNF- $\alpha$ inhibition through PDE4 inhibition. 
is responsible for a majority of TNF- $\alpha$ production in monocytes. This garnered much attention and led to multiple derivatives including a potent TNF- $\alpha$ inhibitor that contained a tetrafluorinated phthaloyl ring 48 . Research into utilizing metabolite inspired thalidomide derivatives has led to the discovery of the commercial drug Apremalist, 49 a PDE4 inhibitor used to treat psoriasis (Figure 11). ${ }^{54}$

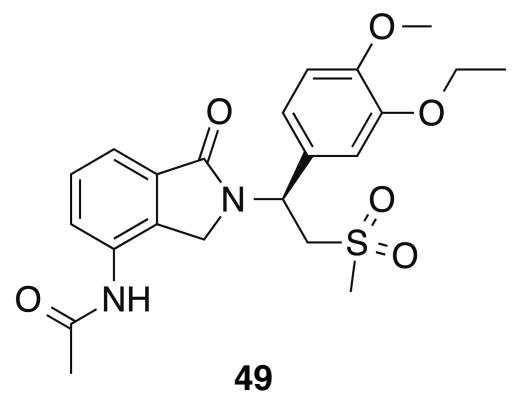

Figure 11. Apremalist chemical structure based off thalidomide derived PDE4 inhibitors. In the quest for PDE4 inhibitors, Celgene also reported one of the most notable derivatives of thalidomide; lenalidomide, $\mathbf{5 0}$ (Figure 12), an analogue of thalidomide. ${ }^{55}$ Being structurally similar to $\mathbf{1 5}$, it is an anticancer drug for multiple myeloma (MM) and myelodysplastic syndrome (MDS) that has brought thalidomide and its analogues officially back to the market in 1998. Initial studies of $\mathbf{5 0}$ were performed to synthesize TNF- $\alpha$ inhibitors that did contain the teratogenic nature of thalidomide. As noted from the study in 1999 by Singhal et al. ${ }^{19}$, a study to show the efficacy of thalidomide at reducing tumor growth specifically, multiple myeloma. Lenalidomide was also tested for its ability to reduce tumor growth and showed more potency and effectiveness at treating myelodysplastic syndrome. Due to the teratogenic nature of thalidomide, testing the teratogenicity of $\mathbf{5 0}$ was tested with pregnant New Zealand white rabbits. ${ }^{56}$ Dosing of te animals ranged from $0-20 \mathrm{mg} / \mathrm{kg} /$ day during the 7-19 day gestation period and no fetal malformations were noted at this dosing, and not until approaching toxic dosing levels did 
fetal malformations become observed. $\mathbf{5 0}$ has also been extensively studied in similar biological studies that thalidomide is active in TNF- $\alpha$ inhibition, ${ }^{57}$ anti-cancer properties, and binding within CRBN. ${ }^{25}$

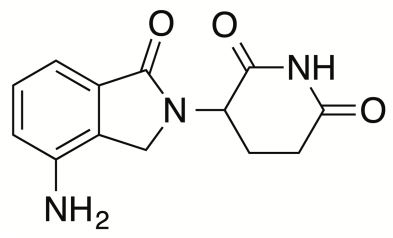

50

Figure 12. Chemical structure of lenalidomide.

Thalidomide possesses an enolizable $\alpha$-proton on the glutarimide ring off of carbon $3^{\prime}$ and undergoes racemization in vitro. The racemization properties of thalidomide complicate the understanding as to whether or not a single enantiomer is a more potent teratogen. Configurationally stable analogues of thalidomide have been synthesized and studied to understand if a specific enantiomer has the higher biological activity. Substitution of the proton with deuterium on the enantiomeric carbon is a small change but generates a configurationally stable enantiomer, $\mathbf{5 1}$ and $\mathbf{5 4}$. Other substitutions of the proton on the 3' position include fluorine $\mathbf{5 2}$ and $\mathbf{5 5}$ and methyl substitutions $\mathbf{5 3}$ and $\mathbf{5 6}$ which can be resolved to yield enantiomerically pure analogues of thalidomide that do not contain an easily racemizable carbon position (Figure 13) ${ }^{58-61}$ While the latter have been synthesized as enantiomerically pure analogues, a racemic mixture of a dimethyl and trimethyl has been synthesized to determine if $3^{\prime}$ substitution generates biologically active compounds. 
<smiles>[2H]C(C1CCC(=O)NC1=O)N1C(=O)c2ccccc2C1=O</smiles><smiles>[2H][C@@]1(N2C(=O)c3ccccc3C2=O)CCC(=O)NC1=O</smiles>

54<smiles>O=C1CCC(N2C(=O)c3ccccc3C2=O)(C(F)(F)F)C(=O)N1</smiles><smiles>O=C1CCC(F)(N2C(=O)c3ccccc3C2=O)C(=O)N1</smiles>

52<smiles>O=C1CC[C@@](F)(N2C(=O)c3ccccc3C2=O)C(=O)N1</smiles>

55

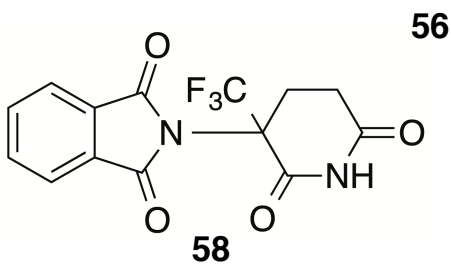

Figure 13. Thalidomide derivatives bearing 3 ' substitution to reduce racemization.

Derivatives bearing substitution off of the benzyl ring of the phthalimide portion, was shown to be successful by lenalidomide and substitution off of the phthalimide has been greatly explored for anticancer and angiogenic activity. Multiple examples were reported by a group in the Molecular Pharmacology Section of the NCI in collaboration with University of Leipzeig group. The compounds were linked to the amino acid derivatives off of the free nitrogen on the glutarimide ring through an ester linkage, 59-62 (Figure 14) ${ }^{62}$ The amino acid-derived thalidomide analogues and a hydroxymethylated glutarimide thalidomide analogue proved to be potent inhibitors in the rat aortic ring assay. The most potent were the $\mathrm{N}$-hydroxymethylatedthalidomide $\mathbf{5 9}$ and the pheylalanine ester derivative $\mathbf{6 0}$ were shown to be significantly more potent. Under hydrolytic conditions, $\mathbf{5 9}$ would convert to thalidomide the usual mechanism of action was exhibited. 
<smiles>O=C1CCC(N2C(=O)c3ccccc3C2=O)C(=O)N1CO</smiles>

59

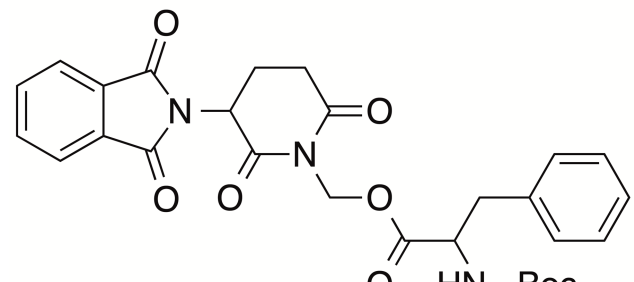

$61 \mathrm{O} \quad \mathrm{HN}-\mathrm{Boc}$
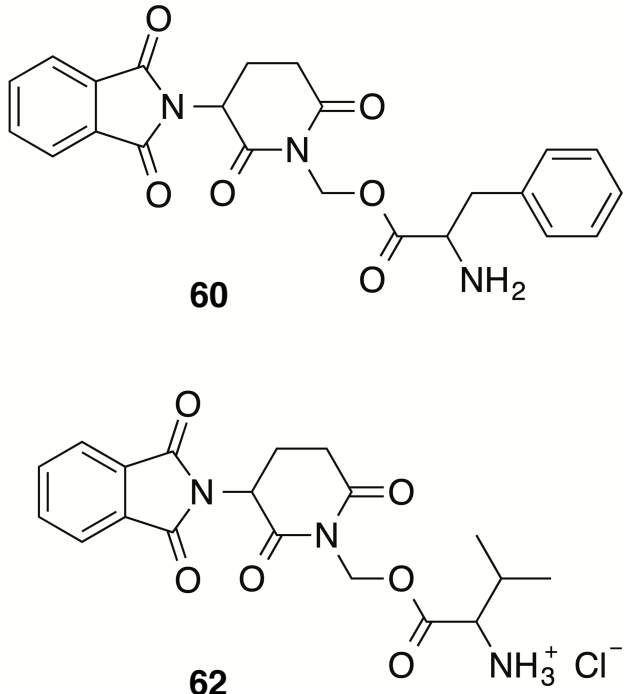

Figure 14. $N$-substituted thalidomide derivatives.

When evaluating the derivatives of thalidomide that have been synthesized for thalidomide, the substitution on thalidomide or the replacement of atoms in this molecule has been highly explored. A few core structural features seem to be apparent: an intact phthalimide or phthalimidine ring connected to a glutarimide ring of the C-3' position and the glutarimide containing both carbonyls with the nitrogen bearing a proton. Extensive reviews of many classes of derivatives synthesis have been completed. ${ }^{63}$ While many derivatives have been studied, one area that has not been completely explored is a linker between the phthalimide and glutarimide rings. The linker between the two would resemble that of a "fleximer" concept which has been proven useful in nucleoside chemistry. Whereby an additional heteroatom inserted between a nucleoside sugar and heterocycle base has been shown to be beneficial. ${ }^{64}$

One such way that a "fleximer" has shown to be beneficial is the 1,2,3-triazole ring in sugar chemistry. The 1,2,3-triazole ring has been reported extensively and is synthesized through a copper catalyzed reaction with an azide paired with an alkyne. The triazole ring is capable of acting as an isosteric amide bond and can aide in hydrogen bonding, providing 
a more potent compound. The ease of synthesis of the triazole has been used for thalidomide analogues where substitution is seen off of the glutarimide ring nitrogen and off of the benzylic positions of the phthalimide ring. Compounds containing a triazole component of the phthalimide ring have been explored in the use of PROTAC's. PROTAC's with triazole derivatives has been prepared where both the substitution on the phthalimide contributes as either the azide or alkyne as a partner for the click reaction. ${ }^{65} \mathrm{~A}$ PROTAC, $\mathbf{6 3}$ bearing the triazole have shown biological efficacy in the downregulation of sirtuin protein (2) that results in the hyperacetylation of the microtubule framework (Figure 15). Although the compounds contain a triazole either on the glutarimide or phthalimide, a triazole acting as a linker between a phthalimide and glutarimide could yield interesting biological properties.

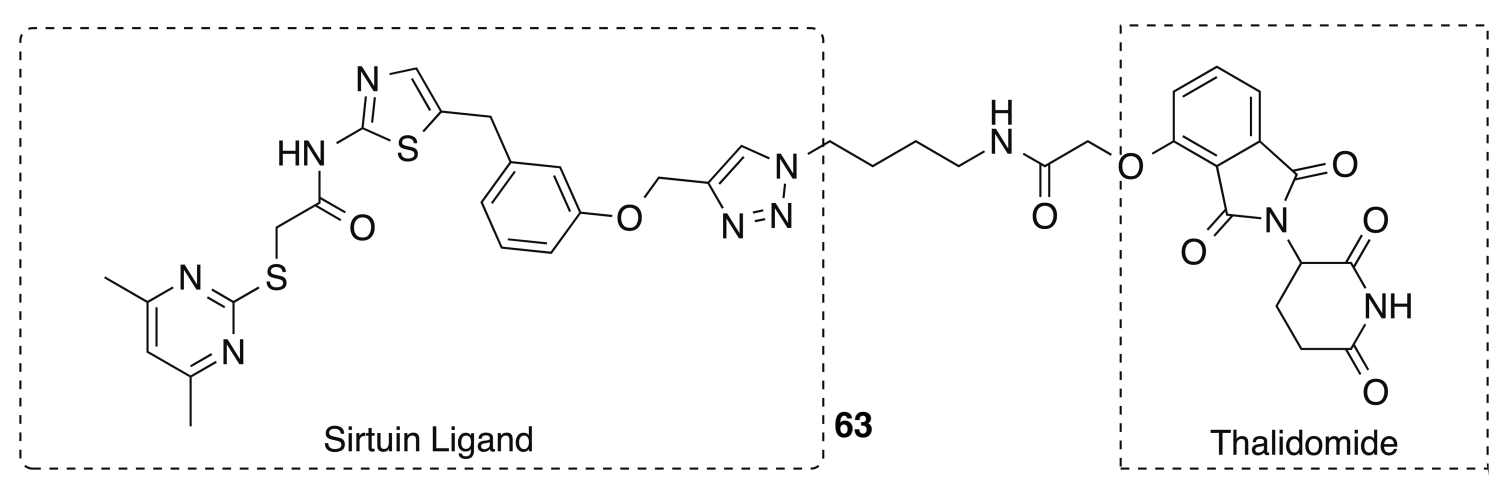

Figure 15. PROTAC developed to target the downregulation of Sirt2.

Herein we describe the synthesis of a class of "click" thalidomide analogues that possess a triazole linker between the glutarimide and the phthalimide/phthalimide mimic. Synthesis of 3-azido glutarimide is described as a partner for all click thalidomide analogues described herein. Utilizing commercially-available alkynes with a novel 3azidoglutarimide reacting partner, a base reaction condition was developed with a simple adjustment of conditions. Under optimized conditions, preparation of triazole spacer click 
analogues of thalidomide and EM-12 were demonstrated utilizing their respective $\mathrm{N}$ alkynyl phthaloyl/isoindolinone. Homologues containing a triazole-methylene spacer were synthesized as well to determine whether the size of space contributes to overall reactivity. As well, a range of electron deficient fluorinated phenyl acetylene rings were used to act as phthaloyl mimics when paired with the azido-glutarimide. ${ }^{66}$

\section{Results and Discussions}

The route to the synthesis of 1,2,3-triazole derived thalidomide analogues utilizes a 3-azido-substituted glutarimide 66. Commercially available glutarimide undergoes bromination alpha to the carbonyl when glutarimide $\mathbf{6 4}$ is reacted with molecular bromine in a sealed vessel with chloroform at $100{ }^{\circ} \mathrm{C}$ in a Kugelröhr oven. The bromoglutarimide 65 was subjected immediately to an azidation reaction after removal of the chloroform due to the sensitivity of $\mathbf{6 5}$, in which decomposition is observable by crude mass calculations through purification with column chromatography. Azidation of the crude $\alpha$-bromo lactam $\mathbf{6 5}$ is accomplished by adding an excess of sodium azide and allowing the reaction to stir as a purple-blue reaction in acetone. Upon purification, by gravity column chromatography, a mixture of desired 3-azido glutarimide 66 and unreacted 65 was observed and subsequently the mixture of both delete is subjected to azidation again through the aforementioned conditions. Undergoing an additional azidation reaction, purification of $\mathbf{6 6}$ by gravity column chromatography gives an off-white crystalline product with no starting material present (53\%) (Scheme 3). 


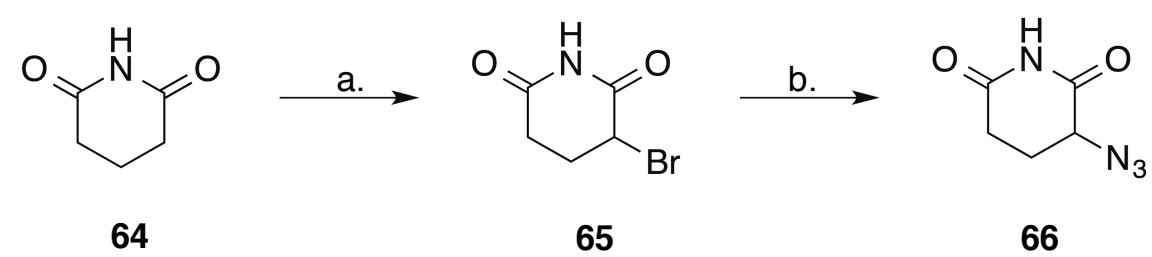

Scheme 3. Preparation of azidoglutarimide. Reagents/Conditions: (a) $\mathrm{Br}_{2} / \mathrm{CHCl}_{3} / 100$

${ }^{\circ} \mathrm{C} / 45 \mathrm{~min}$; (b) $\mathrm{NaN}_{3} / \mathrm{Me}_{2} \mathrm{CO} / \mathrm{rt} / 16 \mathrm{~h}$ (53\% from glutarimide).

Azido glutarimide $\mathbf{6 6}$ is theoretically able to undergo a copper catalyzed azidoalkyne "click" cycloaddition reaction with an alkyne. The reactivity of $\mathbf{6 6}$ was attempted utilizing TMS protected $N$-alkynyl phthalyl synthesized by a method provided by Davies et $\mathrm{a}^{67} \mathrm{~A}$ range of conditions were explored utilizing differing solvent condition and determining the correct copper source such as; acetone, DMSO: $\mathrm{H}_{2} \mathrm{O}$, THF: $\mathrm{H}_{2} \mathrm{O}$, and copper (I)iodide, and copper (II) sulfate. The reaction conditions that generated detectable product were copper sulfate $(.1$ molecular ratio) with sodium ascorbate $(.15$ molecular ratio) in an aqueous THF $\left(9: 1 \mathrm{H}_{2} \mathrm{O}\right)$ solvent system. Utilizing these conditions, phenylacetylene was used as a reactant along with $\mathbf{6 6}$ to demonstrate the reactions applicability with aryl acetylenes. Utilizing $\mathrm{CuSO}_{4}(0.1$ equiv. $)$ and sodium ascorbate $(0.15$ equiv.) in aqueous THF as optimized conditions, $\mathbf{6 6}$ was reacted with phenylacetylene $\mathbf{6 7}$ to undergo a click reaction to synthesize pure white crystalline product in modest yield (78\%) upon purification by gravity column chromatography. Upon optimizing the reaction conditions with 67, a range of fluorinated arylacetylenes 68-71 were paired with 66 after taking into consideration the potency of fluorinated analogues of thalidomide in literature. Fluorinated arylacetylenes also contain an electron deficient ring similar to the electronics of benzyl ring within phthalimide. The azido glutarimide and fluorinated arylacetylenes 
were reacted under optimized conditions to yield white crystalline products after purification by column chromatography in yields ranging from 76-98\% (Table 1).

Table 1. Cycloaddition products of arylacetylenes with 3-azidoglutarimde.

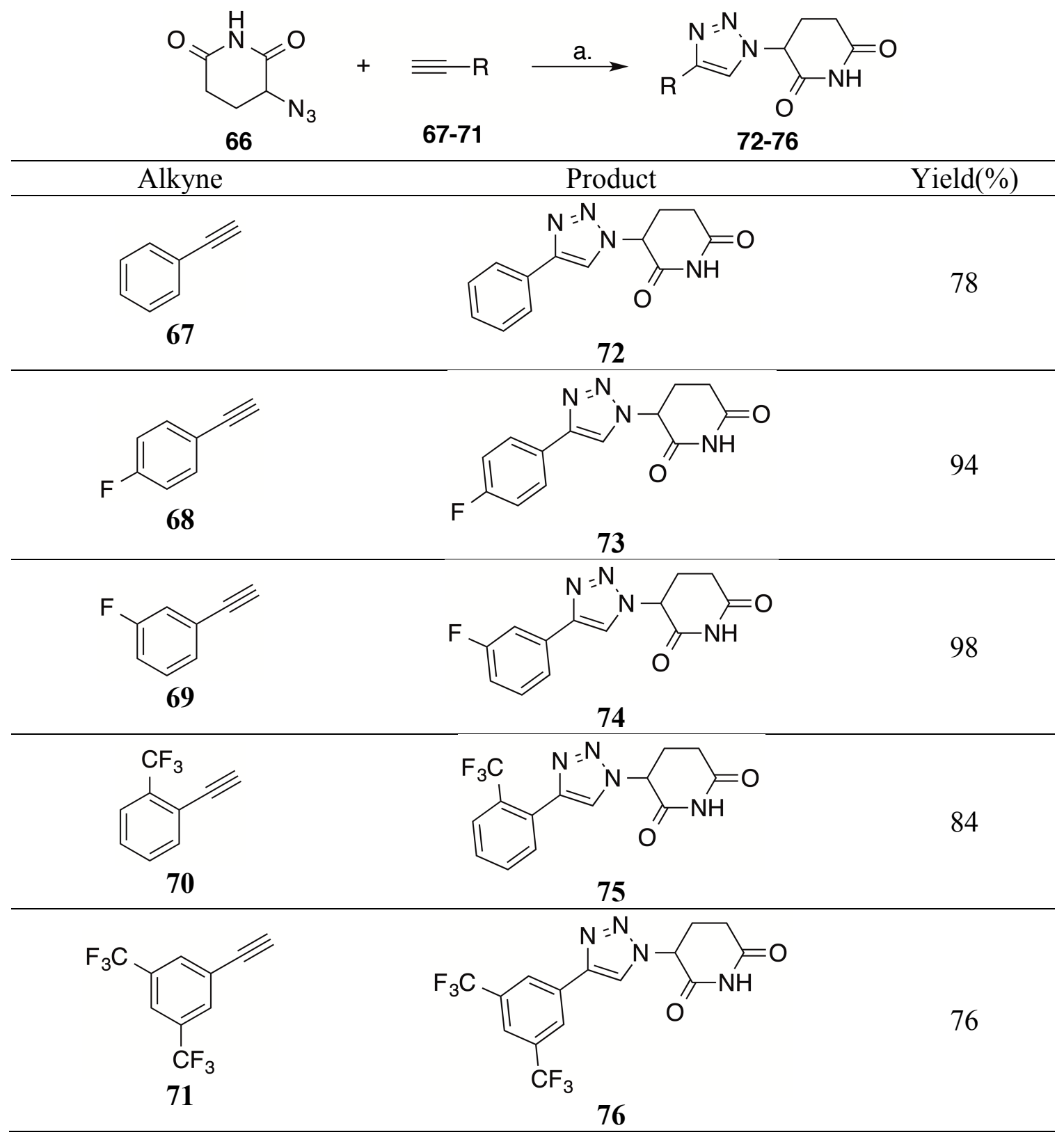

Reagents/conditions: (a) $\mathrm{CuSO}_{4} /$ sodium ascorbate/THF/ $\mathrm{H}_{2} \mathrm{O} / \mathrm{rt} / 16 \mathrm{~h}$.

In order to synthesize triazole linker thalidomide analogues, $\mathrm{N}$-ethynyl and $\mathrm{N}$ propargyl reacting pairs for thalidomide analogues were prepared (Scheme 4). The $\mathrm{N}$ - 
propargyl phthalimide $\mathbf{7 8}$ was prepared through a base-generated nitrogen anion with cesium carbonate in acetonitrile. The base generated anion was reacted in situ with the electrophile, propargyl bromide, and gave $\mathbf{7 8}$ as an off-white solid in good yield (69\%).

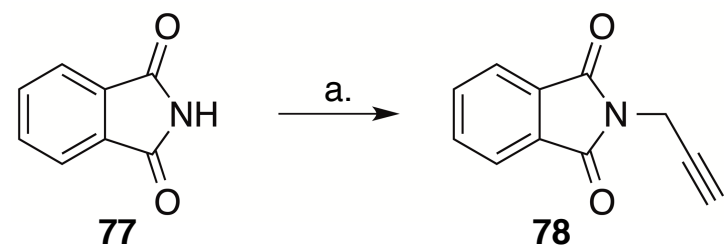

Scheme 4. Synthesis of $N$-propargyl isoindolinone. Reagents/conditions: (a) propargyl bromide $/ \mathrm{Cs}_{2} \mathrm{CO}_{3} / \mathrm{MeCN} / 80{ }^{\circ} \mathrm{C} / 2 \mathrm{~h}(69 \%)$

While isoindolinone $\mathbf{7 9}$ is commercially available, a one-pot reduction of phthalimide 77 was performed using tin under Lewis acid conditions. Stirring $\mathbf{7 7}$ under reflux with tin in acetic acid and concentrated hydrochloric acid yielded isoindolinone $\mathbf{7 9}$ in a yield (39\%), similar to that previously reported. Propargylation of isoindolinone was accomplished by the same base-generated nitrogen anion with cesium carbonate and propargyl bromide as the electrophile to yield $N$-propargyl isoindolinone $\mathbf{8 0}$ as a white solid in good yield (65\%) (Scheme 5).<smiles>O=C1NC(=O)c2ccccc21</smiles>

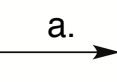

$77^{\mathrm{O}}$<smiles>O=C1NCc2ccccc21</smiles>

79
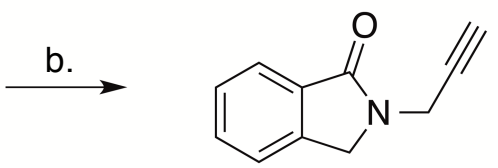

80

Scheme 5. Synthesis of $N$-propargyl isoindolinone. Reagents/conditions: (a)propargyl bromide $/ \mathrm{Cs}_{2} \mathrm{CO}_{3} / \mathrm{MeCN} / 80{ }^{\circ} \mathrm{C} / 2 \mathrm{~h}(65 \%)$

The homomethylene click thalidomide analogue was synthesized using 78/80 and 66. The reaction conditions utilized were the same as those previously described, with copper sulfate ( 0.1 equiv) and sodium ascorbate ( 0.15 equiv) in aqueous THF with stirring 
at room temperature for 16 hours. The reaction of azidoglutarimide with $N$-propargyl phthalimide/isoindolinone yielded white crystalline product in 67 and $61 \%$ yields respectively (Table $\mathbf{2}$ ).

Table 2. Cycloaddition products of $\mathrm{N}$-propargyl phthalimide/isoindolinone with 3azidoglutarimde

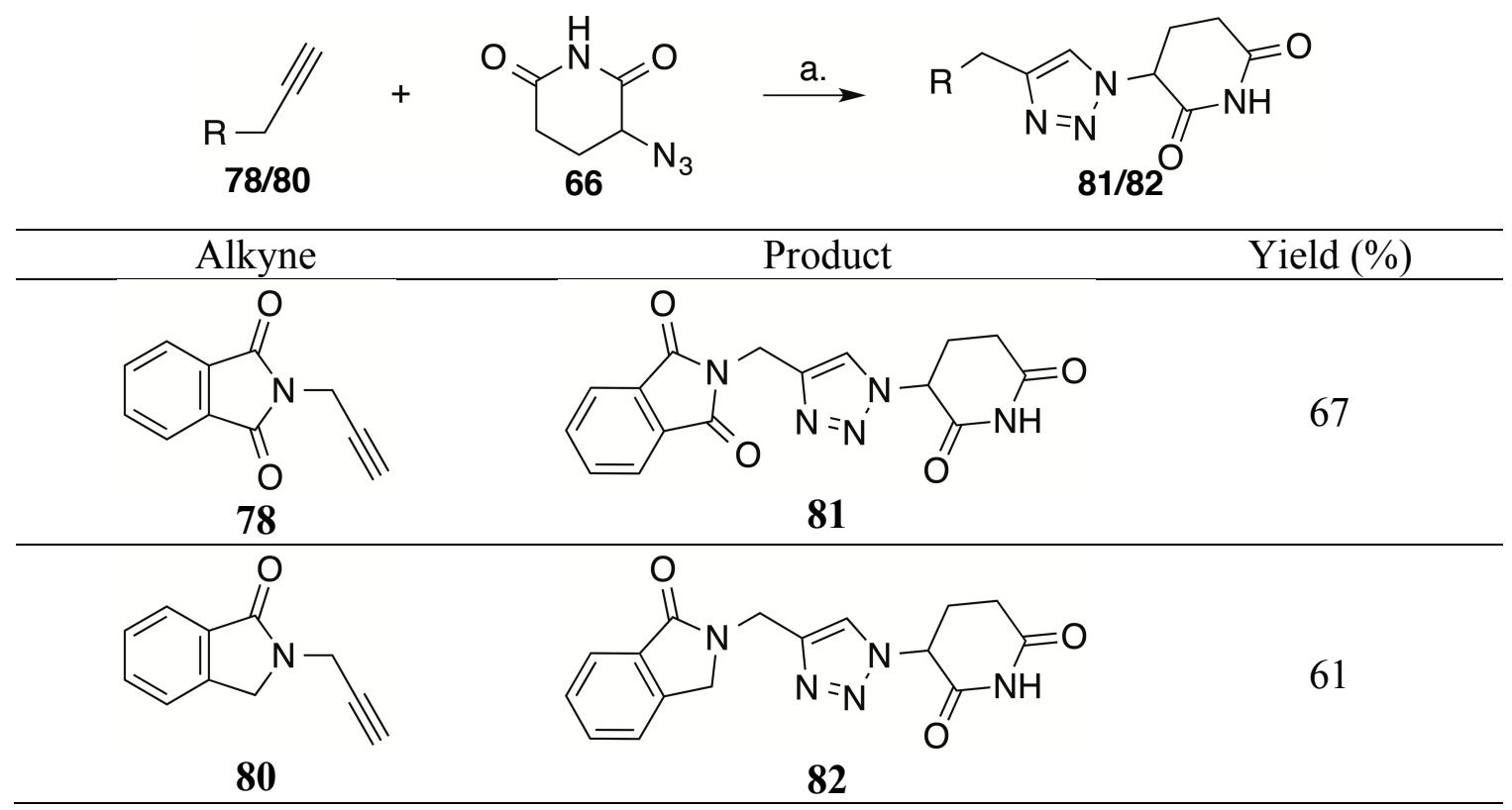

Reagents/conditions: (a) $\mathrm{CuSO}_{4} /$ sodium ascorbate/THF/ $\mathrm{H}_{2} \mathrm{O} / \mathrm{rt} / 16 \mathrm{~h}$.

The $N$-ethynyl phthalimide/isoindolinone $\mathbf{8 4 / 8 6}$ are synthesized to give thalidomide/EM-12 analogue bearing only the triazole linker between the glutarimide and phthalimide/ isoindolinone (Scheme 6). The synthesis of the $\mathbf{8 4}$ utilized TMS-acetylene under conditions described by Davies. ${ }^{66}$ In performing this method, phthalimide is stirred with copper acetate, pyridine, and ethynyltrimethylsilane under an oxygen atmosphere and afforded intermediate, 2-((trimethylsilyl)ethynyl)isoindoline-1,3-dione $\mathbf{8 3}$ as a crystalline solid. The intermediate $\mathbf{8 3}$ is desilylated with $\mathrm{TBAF}$ in acetic acid and provided a moderately unstable 2-ethynylisoindoline-1,3-dione 84 in a moderate yield (55\% over two steps). Ethynylation of the isoindolinone was performed using copper acetate as a catalyst 
with sodium carbonate and pyridine present in toluene under an oxygen atmosphere. The reaction which proceeded over an hour, while stirring at $70{ }^{\circ} \mathrm{C}$, turned from a blue to a bright green reaction in which TMS-acetylene was added and the reaction was stirred for 4 hours resulting in a bright green to a black suspension. After filtering the black suspension with Celite ${ }^{\circledR}$, purification of 2-((trimethylsilyl)ethynyl)isoindolin-1-one $\mathbf{8 5}$ was done by flash column chromatography to give fluffy white solid. The $N$-isoindolinone proton is less<smiles>O=C1NC(=O)c2ccccc21</smiles>

77<smiles>O=C1NCc2ccccc21</smiles>

79

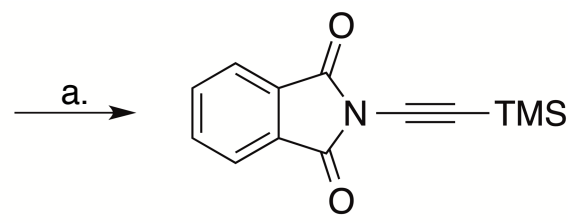

83

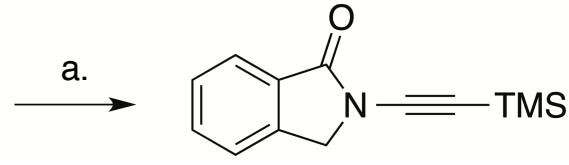

85<smiles>C#CN1C(=O)c2ccccc2C1=O</smiles>

84

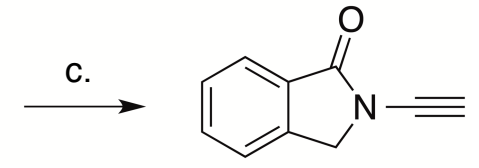

86

Scheme 6. Synthesis of N-ethynyl phthalimide (top) and isoindolinone (bottom).

Reagents/Conditions: (a) ethynyltrimethylsilane/ $\mathrm{Cu}(\mathrm{OAc})_{2} / \mathrm{O}_{2} /$ pyridine $/ \mathrm{Na}_{2} \mathrm{CO}_{3} / 70{ }^{\circ} \mathrm{C} / 16$

h (83, 59\%; 85, 22\%); (b) TBAF/THF/AcOH/rt/16 h (84, 94\%); (c) TBAF/THF/rt/16 h

$(\mathbf{8 5}, 92 \%)$

acidic than that of the N-phthalimide proton and is giving a less reactive starting material for ethynylation under the conditions proposed by Davies, but product is still observed in a lower yield compared to the phthalimide. While the ethynylation of isoindolinone is not as facile, generating the desilylated product $\mathbf{8 6}$ was easily accomplished using TBAF in THF to give a crystalline solid after purification by column chromatography $(20 \%$ over two steps). 
Freshly prepared $\mathbf{8 4}$ and $\mathbf{8 6}$, due to relative instability, were immediately used in the cycloaddition reaction with azido glutarimide (Table 3). The reaction conditions for cycloaddition were the same as those previously describeed, with copper sulfate $(0.10$ molar equiv) and sodium ascorbate( 0.15 molar equiv) in aqueous THF and stirring at room temperature for 16 hours. The reaction of $\mathbf{6 6}$ with 84 yielded "click" thalidomide as white Table 3. Cycloaddition products of $N$-ethynyl phthalimide/isoindolinone with 3azidoglutarimde

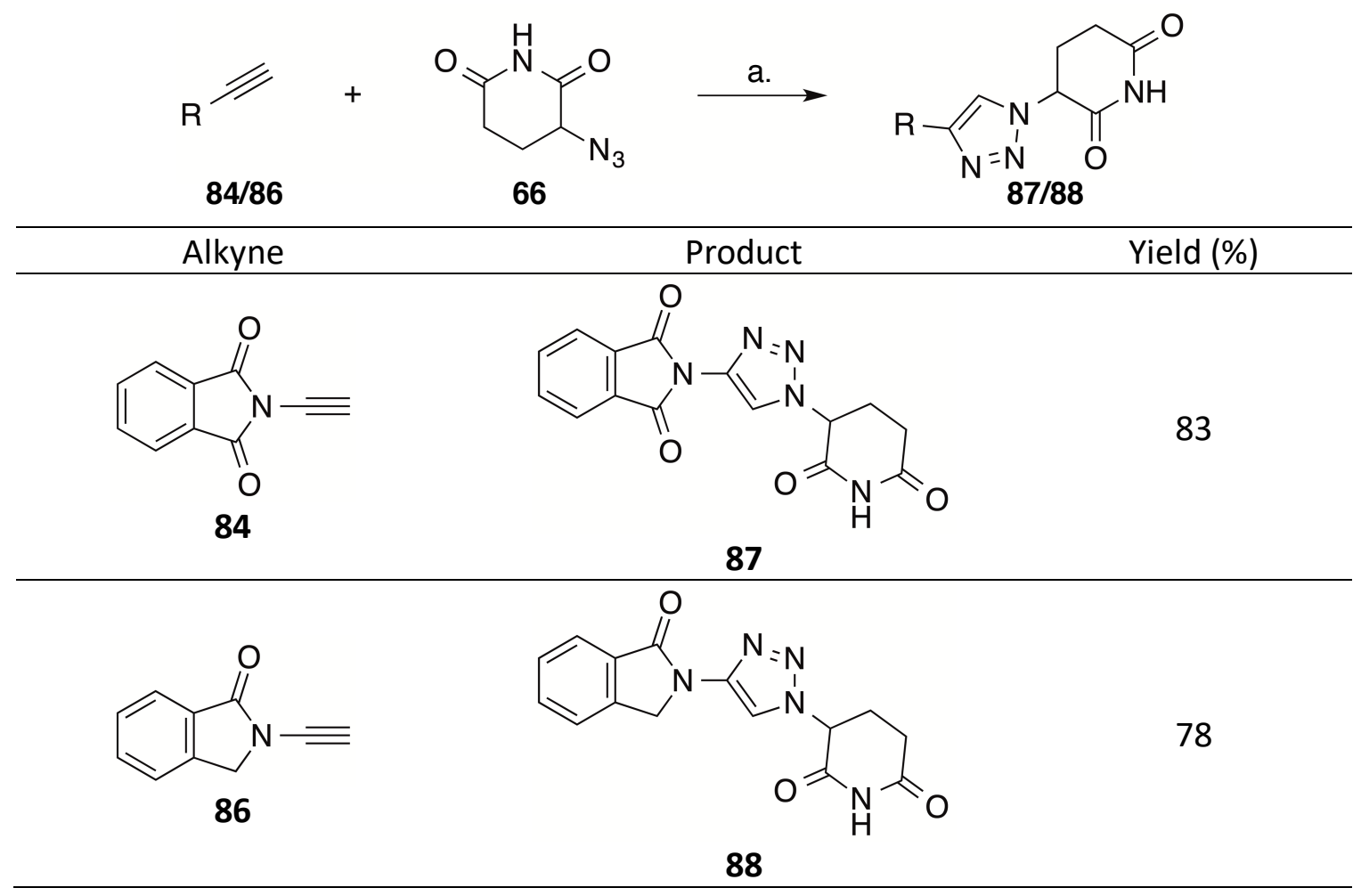

Reagents/conditions: (a) $\mathrm{CuSO}_{4} /$ sodium ascorbate $/ \mathrm{THF} / \mathrm{H}_{2} \mathrm{O} / \mathrm{rt} / 16 \mathrm{~h}$.

crystalline product at good yield, $83 \%$ respectively. As well, reaction of 86 was immediately reacted with $\mathbf{6 6}$ under the same reaction conditions. The product utilizing the $N$-ethynyl isoindolinone afforded the "click" EM-12 analogue $\mathbf{8 8}$ as white crystalline solid at a moderate yield of $78 \%$. While both were purified by column chromatography, neither compound is very soluble in most organic solvents. 
While exploring the synthesis of the $N$-ethynyl isoindolinone for the "click" EM12 analogue, alternative pathways were explored before utilizing the Davies ${ }^{61}$ method for ethynylation. Initial attempts to synthesize $N$-ethynyl isoindolinone involved which utilized the TMS protected $\mathrm{N}$-ethynyl phthalimide and synthesizing the TMS protected $\mathrm{N}$ ethynyl isoindolinone through reduction of a carbonyl, thiolation of the alcohol, and subsequent desulfurization to overall reduce a carbonyl to a methylene (Scheme 7). Reduction of the single carbonyl was attempted with sodium borohydride in methanol but was unsuccessful in synthesizing the hydroxylactam, and the reaction by TLC showed complete decomposition. Another reduction utilizing an aluminum amalgam was successful in generating the TMS protected $N$-ethynyl hydroxylactam. The TMS protected $N$-ethynyl phthalimide was stirred in a reaction of THF: $\mathrm{H}_{2} \mathrm{O}(9: 1)$ while strips of aluminum, washed in diethyl ether then dipped into a solution of $\mathrm{HgCl}_{2}$, were added. The reaction proceeded for 30 minutes by which all starting material was consumed to afford the TMS protected $N$-ethynyl hydroxylactam 90. Lactam 90 was subjected to phenylthiation by using thiophenol in slight excess (1.2 equiv) with a crystal of $p$ toluenesulfonic acid. The reaction mixture was stirred in dichloromethane ( 2 hours) while being monitored by TLC, and after purification contained no detectable TMS or alkynyl protons in ${ }^{1} \mathrm{H}$ NMR. 


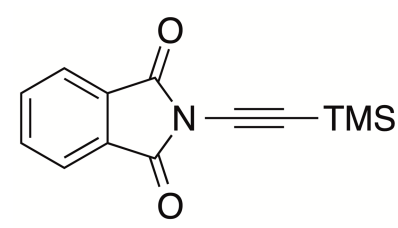

83

a.

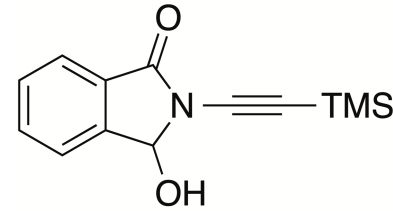

90

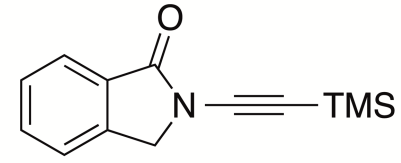

85

b.
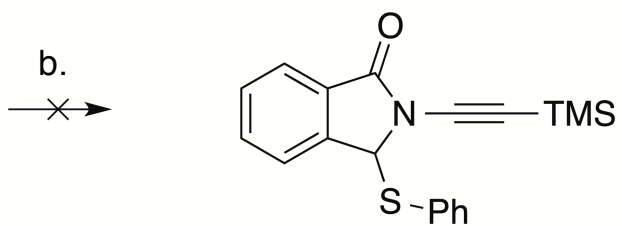

91

Scheme 7. Proposed synthesis of $N$-ethynyl isoindolinone from $N$-ethynyl phthalimide.

Reagents/Conditions: (a)Al/ $\mathrm{HgCl}_{2} / \mathrm{THF}: \mathrm{H}_{2} \mathrm{O}$ (9:1)/RT/30 min (b) Thiophenol(1.2)/TsOH/ $\mathrm{DCM} / \mathrm{RT} / 24 \mathrm{hr}$.

As well, attempts to synthesize "click" EM-12 from "click" thalidomide was explored in an approach similar to the conversion of thalidomide to EM-12 (Scheme 8). The approach is comparable that attempted when converting $\mathrm{N}$-ethynyl phthalimide to isoindolinone. First, the glutarimide nitrogen of the "click" thalidomide is protected with $p$-methoxybenzyl chloride (PMB) in order to reduce the reactivity of the glutarimide ring. After protection of the glutarimide with the PMB group, a chemoselective aluminum amalgam-mediated reduction of the phthalimide to the hydroxy lactam, followed by phenylthiation and desulfurization would yield "click" EM-12. The base-mediated protection of "click" thalidomide with $p$-methoxybenzyl chloride was accomplished with cesium carbonate in acetonitrile over $16 \mathrm{hr}$. The crude reaction mixture was purified to yield PMB "click" thalidomide 92 as a crystalline product in modest yield (48\%). Following the protection, 92 was exposed an aluminum amalgam ( $\mathrm{Al} / \mathrm{Hg})$, aluminum strips treated with $\mathrm{HgCl}_{2}$ solution, in THF: $\mathrm{H}_{2} \mathrm{O}$ (9:1) for 2 hours. The crude mixture was filtered 
and the $N$-PMB hydroxylactam 93 was afforded as the only product with no observable reduction of the glutarimide carbonyls. Direct treatment of 93 with thiophenol in dichloromethane with $p$-toluenesulfonic acid (catalytic) gave no detectable thiolated product by NMR.

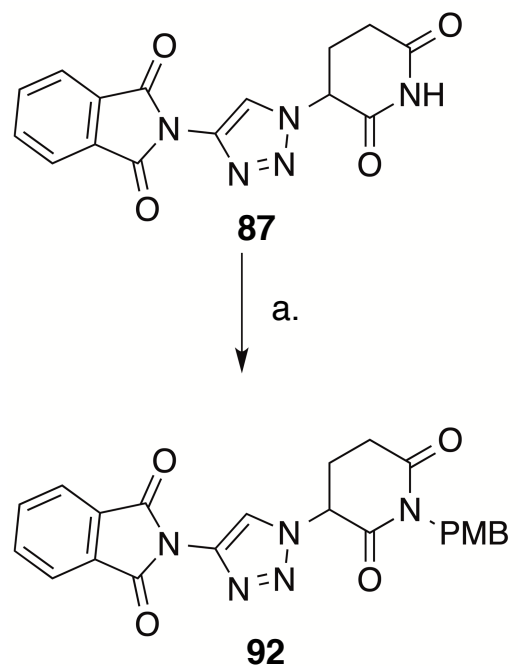

b.

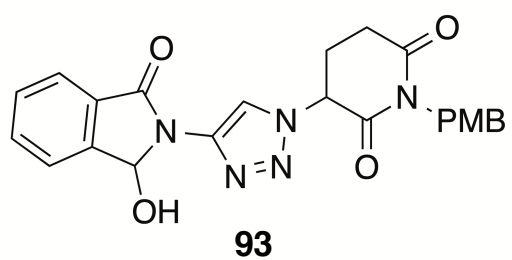<smiles>O=C1CCC(n2cc(N3Cc4ccccc4C3=O)nn2)C(=O)N1</smiles>

88

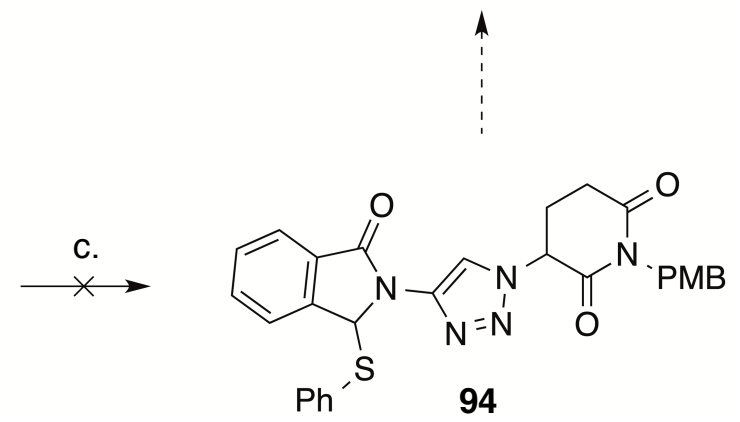

Scheme 8. Proposed synthesis of "click" EM-12 from the "click" thalidomide. Reagents conditions (a)PMB-Cl(1.2 equiv)/MeCN/RT/6 hr(48\%) (b)Al/ $\mathrm{HgCl}_{2} / \mathrm{THF}: \mathrm{H}_{2} \mathrm{O}$ (9:1)/RT/ $30 \mathrm{~min}$ (b)Thiophenol(1.2)/TsOH/ DCM/RT/24 hr 

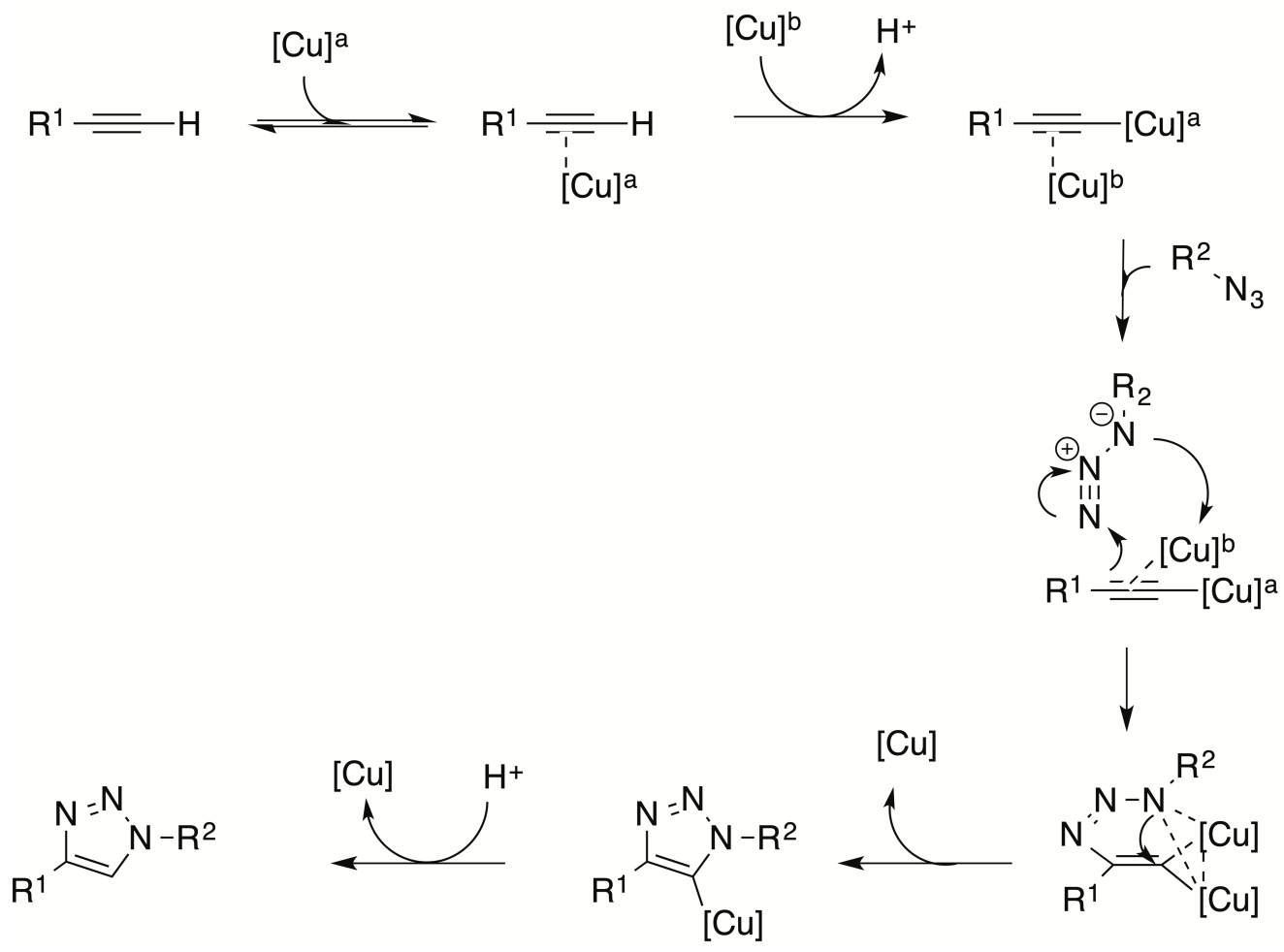

Scheme 9. Click reaction mechanism to generate the 1,4-substituted 1,2,3-triazole.

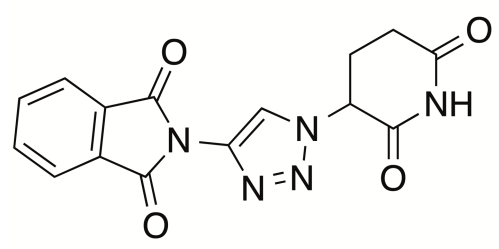

87

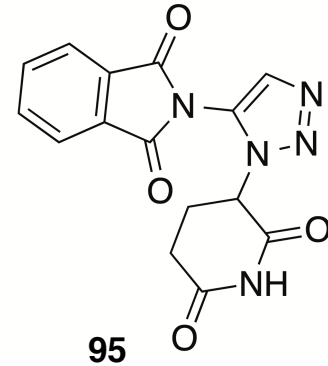

Figure 15. Regiochemistry of cycloaddition chemistry could yield either 1,4- or 1,5substituted "click" thalidomide analogues.

The regiochemistry of dipolar cycloaddition click reactions have the ability to yield one of two products, 1,4- or 1,5- triazole substitution among the ring (Figure 15). The click thalidomide analogues (81-82, 87-88) display the 1,4- substitution on the 1,2,3-triazole ring. The 1,4-substitution is a result of the copper (I) catalyst mediating a dinuclear copper intermediate to exclusively give the 1,4- arrangement (Scheme 9). ${ }^{68}$ 


\section{Conclusions}

Synthetic routes to click thalidomide analogues are detailed utilizing a novel 3azidoglutarimide. The direct and homomethylene analogues of click thalidomide were done through the dipolar cycloaddition reaction with known $N$-ethynyl/propargyl phthalimide. In synthesizing the EM-12 derivatives, $N$-ethynyl/propargyl isoindolinones weas synthesized to create the direct and homomethylene analoge of EM-12. To further explore the reactivity of 3-azidoglutarimide, analogues encompassing the fluorinated aryl acetylenes were chosen to mimic the electronic effects of the phthalimide group. The click thalidomide analogues will be evaluated in a full range of bioassay types. (For publication see Appendices p. 271) 


\section{Experimental}

General. Solvents and reagents are ACS grade and were used as commercially supplied. Analytical thin-layer chromatography (TLC) utilized $0.25 \mathrm{~mm}$ pre-cut glass-backed plates (Merck, Silica Gel 60 F254). Thin-layer chromatograms were visualized during chromatographic and extraction runs by rapidly dipping the plates in anisaldehyde/ethanol/sulfuric acid stain or phosphomolybdic acid/ ethanol stain and heating (hot plate). Gravity-column chromatography was carried out using silica gel 60 (E. Merck 7734, 70-230 mesh). Flash-column chromatography was carried out using silica gel 60 (E. Merck 9385-9, 230-400 mesh) using compressed nitrogen. Nuclear magnetic resonance $\left({ }^{1} \mathrm{H}\right.$ and ${ }^{13} \mathrm{C}$ NMR) spectra were recorded with Varian VNMRS 400, 500, or 700 $\mathrm{MHz}$ instruments using $\mathrm{CDCl}_{3}$ as a solvent and TMS as internal standard. Infrared spectra (FTIR) were recorded with a PerkinElmer Spectrum 100 instrument and spectral values are reported as $\mathrm{cm}^{-1}$.

\section{3-Azidopiperidine-2,6-dione. 66}

To a $48 \mathrm{~mL}$ glass pressure reaction vessel fitted with a Teflon screw cap was added piperidine-2,6-dione $(2.00 \mathrm{~g}, 17.7 \mathrm{mmol})$ and $\mathrm{Br}_{2}(2.82 \mathrm{~g}, 0.90 \mathrm{~mL}, 17.7 \mathrm{mmol})$ in chloroform $(15 \mathrm{~mL})$. The reaction mixture was then heated in a Kugelröhr oven at $110^{\circ} \mathrm{C}$ (45 min). The solvent was removed and the crude bromoglutarimide, 65, was then dissolved in acetone $(5 \mathrm{~mL})$ followed by the addition of sodium azide $(3.44 \mathrm{~g}, 53.1 \mathrm{mmol})$ whereupon the reaction mixture turned blue-purple. The reaction mixture was stirred at room temperature $(24 \mathrm{~h})$ and then directly applied to a gravity silica gel column. Elution with hexane/ethyl acetate (1:1) gave a mixture of unreacted $\mathbf{6 5}$ and product 66 (1:1). The mixture of 66 and unreacted 65 was again dissolved in acetone $(5 \mathrm{~mL})$ and sodium azide 
(1.15 g, $17.7 \mathrm{mmol})$ was added and stirring of the blue-purple reaction mixture was continued at room temperature $(24 \mathrm{~h})$. Column chromatography (hexane/ethyl acetate, 1:1) of the reaction mixture gave pure 3-azidopiperidine-2,6-dione, 66, as an off-white amorphous solid (1.44 g, 53\% from glutarimide): mp 144-145 C; Rf 0.24 (TLC stains blue with heat); ${ }^{1} \mathrm{H}$ NMR $\left(400 \mathrm{MHz}, \mathrm{CDCl}_{3}\right) \delta 4.21(\mathrm{dd}, \mathrm{J}=9.6 \mathrm{~Hz}, 8.4 \mathrm{~Hz}, 1 \mathrm{H}), 2.78$ (dt, J=18.4 $\mathrm{Hz}, 5.6 \mathrm{~Hz}, 1 \mathrm{H}) 2.63-2.54(\mathrm{~m}, 1 \mathrm{H}), 2.23-2.16(\mathrm{~m}, 1 \mathrm{H}), 2.04-1.95(\mathrm{~m}, 1 \mathrm{H}) .{ }^{13} \mathrm{C} \mathrm{NMR}(400$ $\left.\mathrm{MHz}, \mathrm{CDCl}_{3}\right) \delta 170.7,169.2,58.2,29.1,24.0$. FTIR (neat) 3090, 2112, 1710, $1676 \mathrm{~cm}^{-1}$; HRMS (ESI-TOF) m/z [M+H]+ calcd for $\mathrm{C}_{5} \mathrm{H}_{6} \mathrm{~N}_{4} \mathrm{O}_{2}$ : 155.0491, Found: 155.0569. 


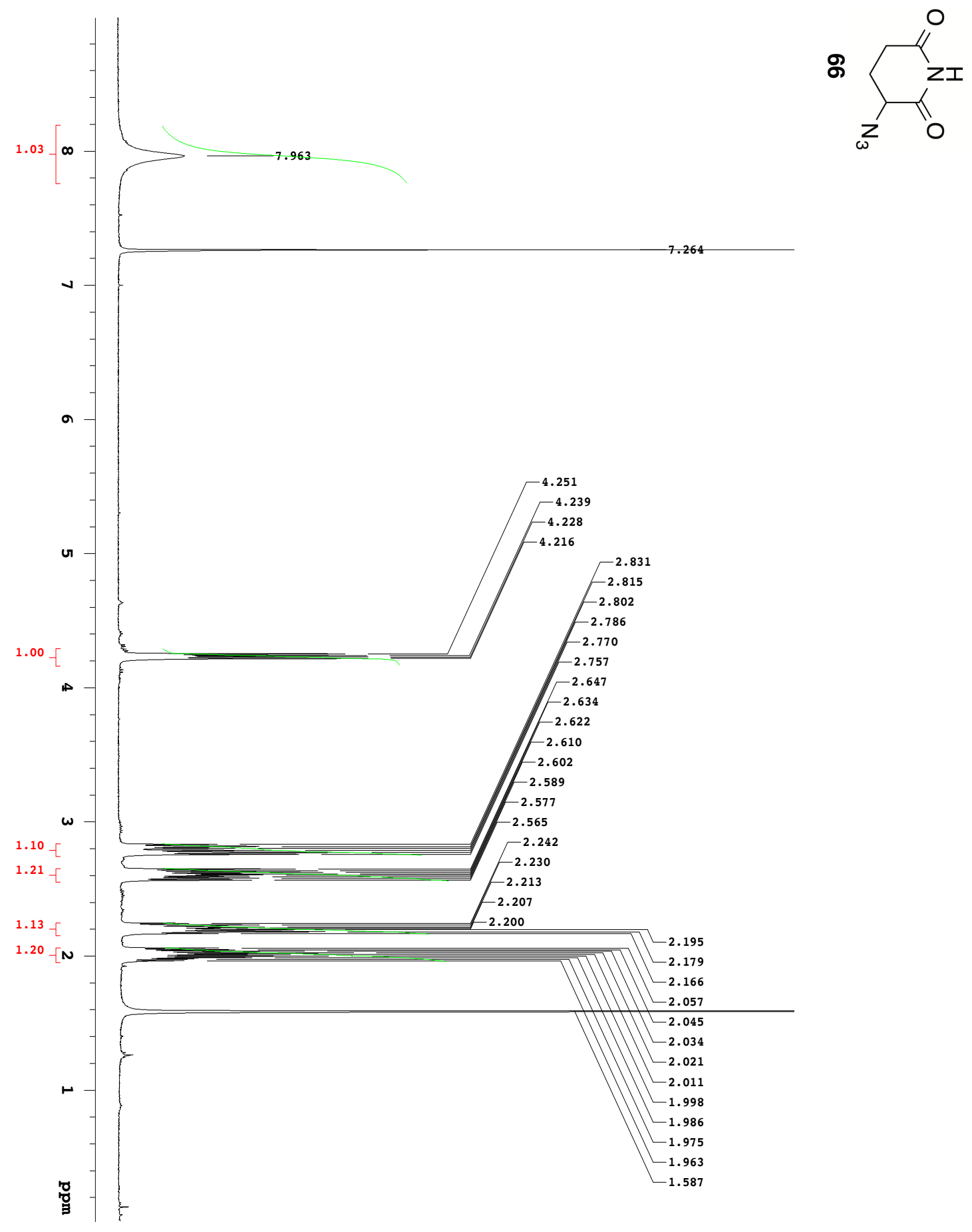




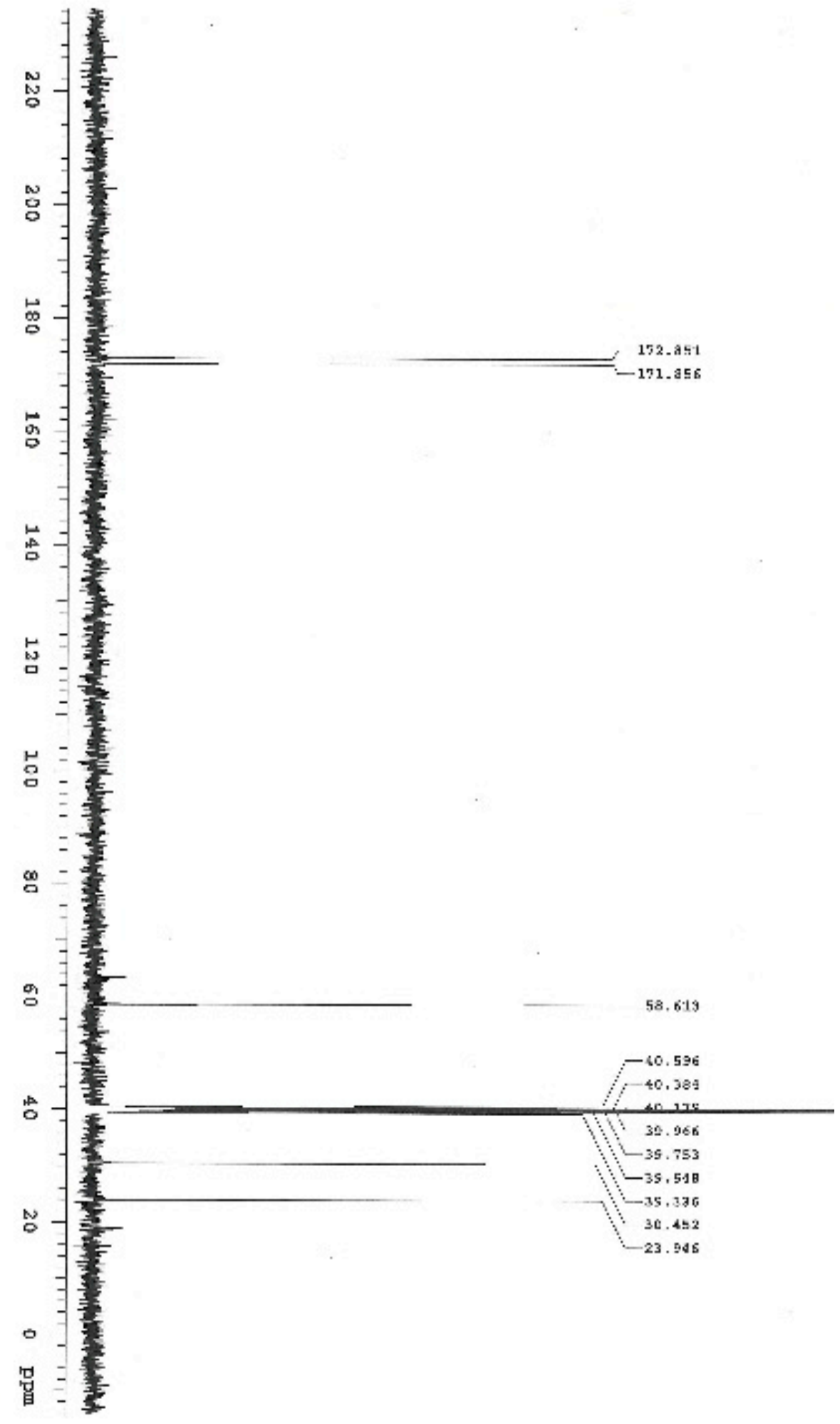



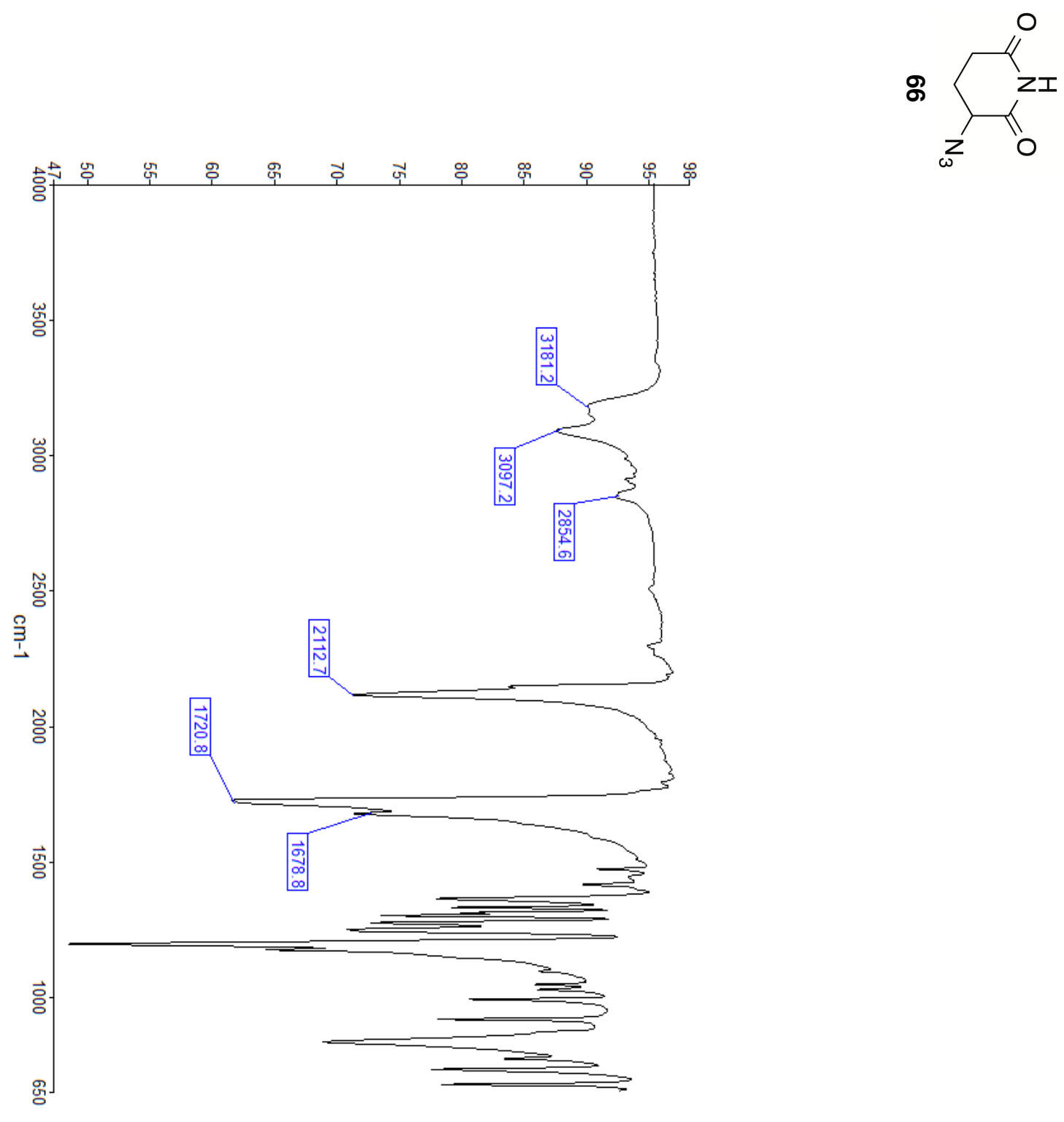


\section{General procedure for the preparation of click compounds: 72-76}

To a stirred solution of 3-azidopiperidine-2,6-dione, $66(20.0 \mathrm{mg}, 0.13 \mathrm{mmol})$ and arylalkyne 67-71 $(0.143 \mathrm{mmol})$ in tetrahydrofuran $(750 \mathrm{~mL})$ was added aqueous copper sulfate $(52 \mathrm{mM}, 0.013 \mathrm{mmol}, 250 \mathrm{~mL})$. Sodium ascorbate $(12.8 \mathrm{mg}, 0.065 \mathrm{mmol})$ was then added ten minutes after the addition of the $\mathrm{CuSO}_{4}$ solution. The reaction mixture was stirred $(16 \mathrm{~h})$ at room temperature followed by direct application to a gravity silica gel column and elution with chloroform/methanol (95:5). Combination and concentration of the chromatographic fractions gave the pure triazoles 72-76 as white or off-white amorphous solids.

\section{3-(4-Phenyl-1H-1,2,3-triazol-1-yl)piperidine-2,6-dione. 72}

3-(4-Phenyl-1H-1,2,3-triazol-1-yl)piperidine-2,6-dione $\mathbf{7 2}$ was obtained as a white amorphous solid (26 mg, 78\%): mp 208-210 ${ }^{\circ} \mathrm{C}$; $\mathrm{R}_{\mathrm{f}} 0.28$ (chloroform/methanol, 9:1); ${ }^{1} \mathrm{H}$ NMR (400 MHz, DMSO-d6) $\delta 11.25$ (s, 1H), 8.66 (s, 1H), 7.82-7.84 (d, J=7.2 Hz, 2H), 7.42-7.46 (m, 2H), 7.30-7.34 (m, 1H), $5.84(\mathrm{dd}, \mathrm{J}=13.2,5.2 \mathrm{~Hz}, 1 \mathrm{H}), 2.83-2.91(\mathrm{~m}, 1 \mathrm{H})$ 2.65-2.76 (m, 2H) 2.34-2.36 (m, 1H); ${ }^{13} \mathrm{C}$ NMR (100 MHz, DMSO-d6): $\delta$ 172.8, 169.9, 146.7, 131.0, 129.4, 128.4, 125.5, 122.0, 59.6, 31.1, 24.8: IR (neat) 3090, 2930, 1732, 1699, $1676 \mathrm{~cm}^{-1}$; HRMS (ESI-TOF) m/z [M+H]+; calcd for $\mathrm{C}_{13} \mathrm{H}_{13} \mathrm{~N}_{4} \mathrm{O}_{2}$ : 257.1039, Found: 257.1140 . 


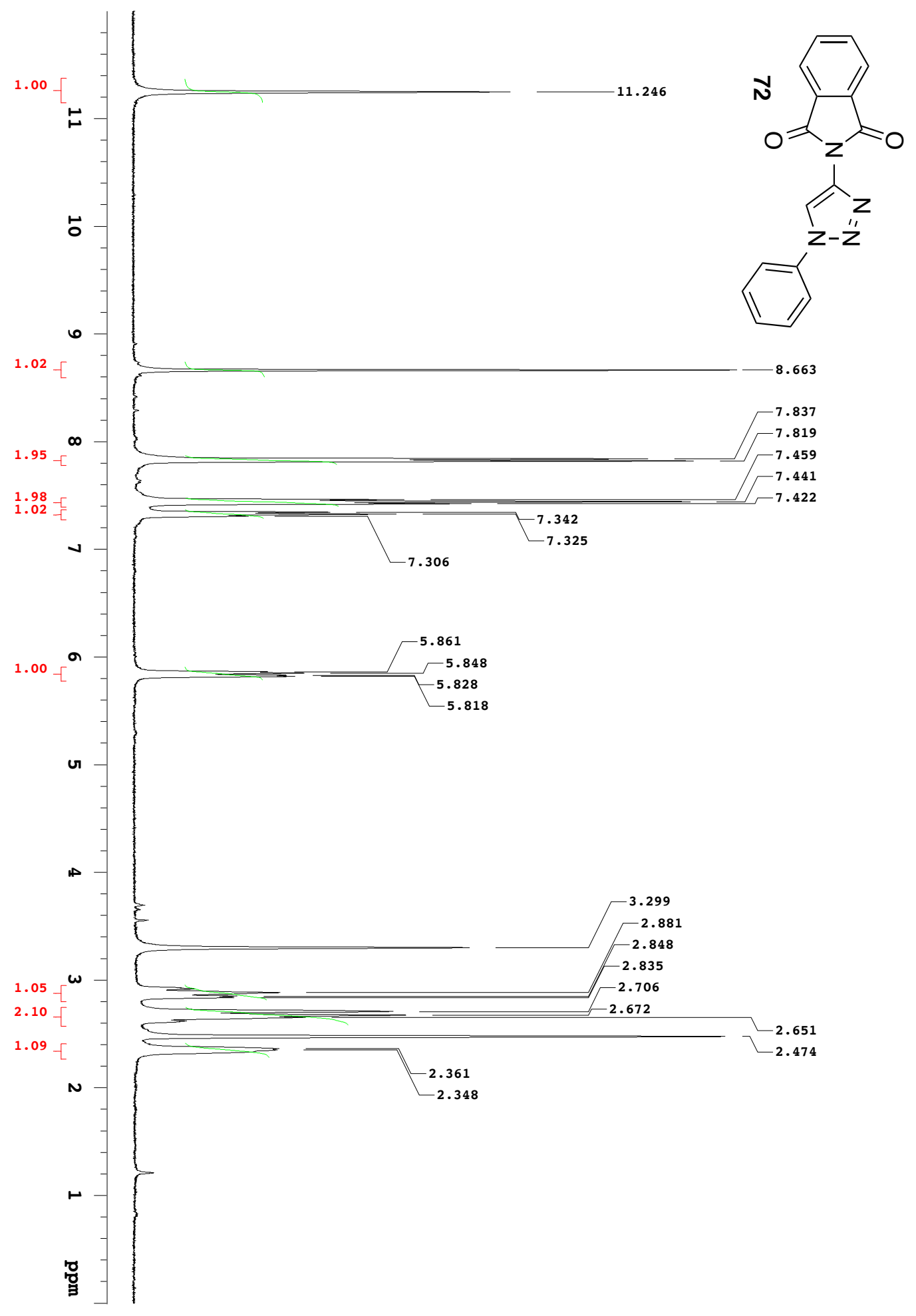




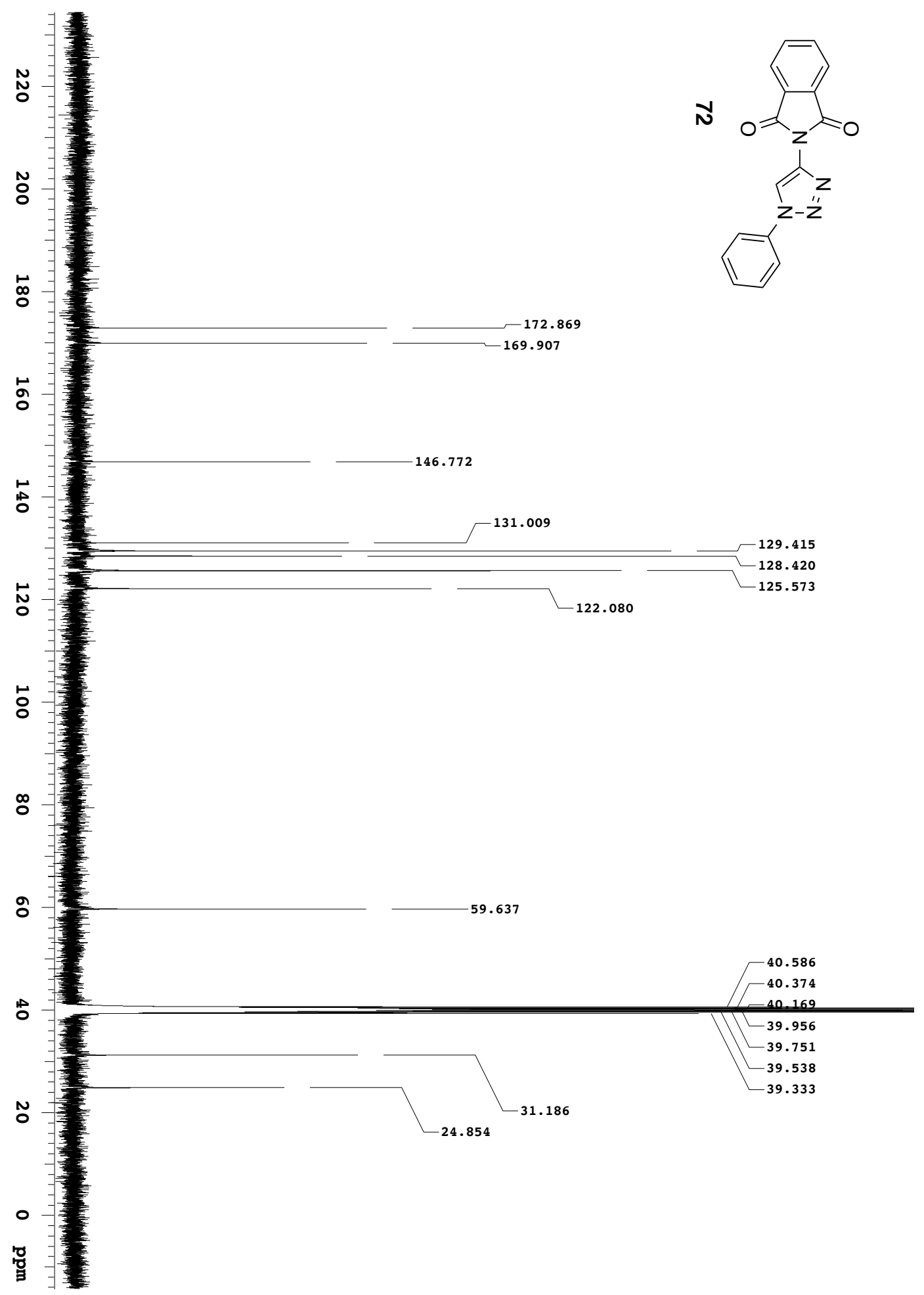




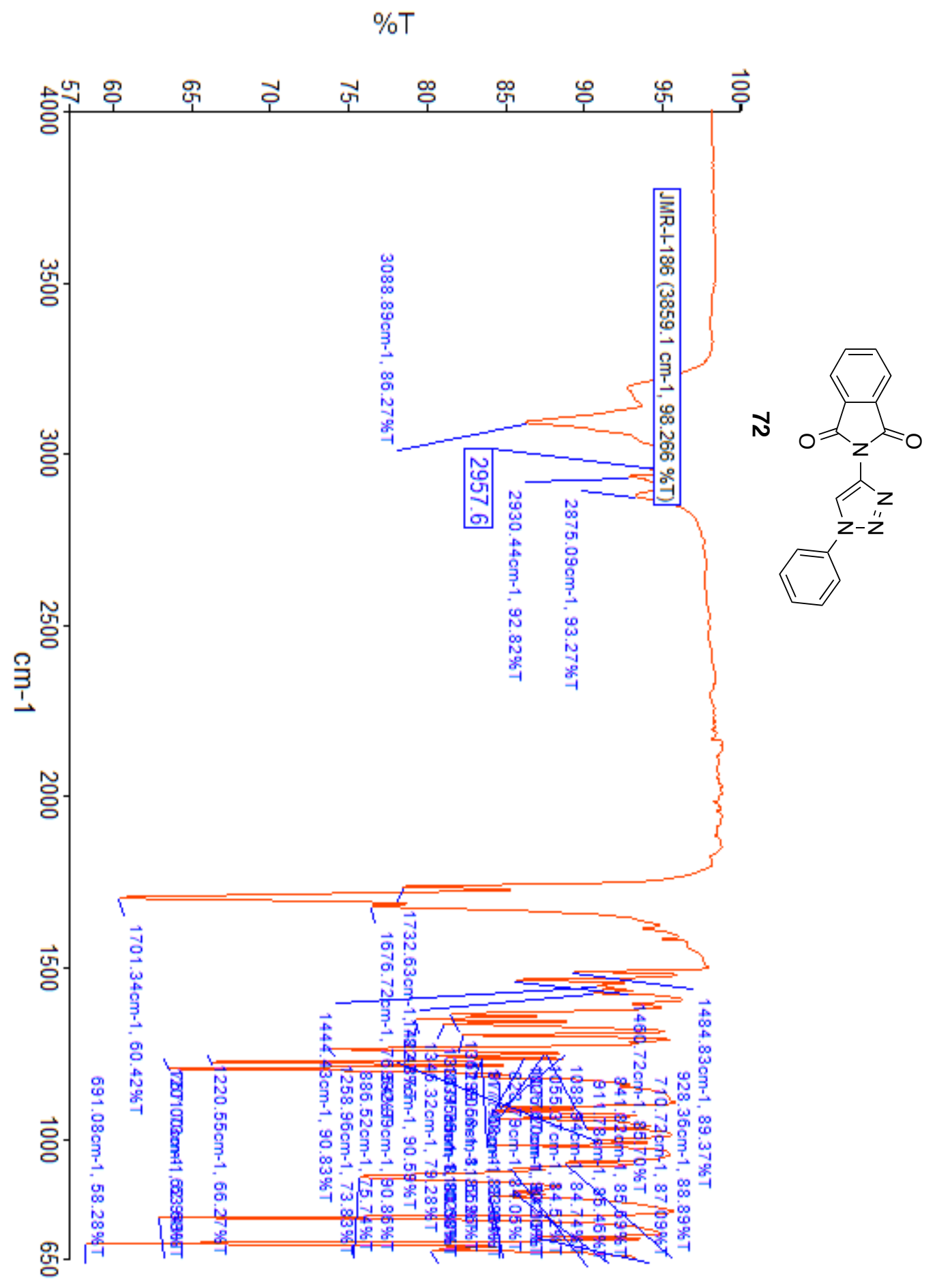


3-(4-(4-Fluorophenyl)-1H-1,2,3-triazol-1-yl)piperidine- 2,6-dione. 73

3-(4-(4-Fluorophenyl)-1H-1,2,3-triazol-1-yl)piperidine-2,6-dione 73 was obtained as a white amorphous solid (64 mg, 94\%): $\mathrm{mp} 221-222^{\circ} \mathrm{C}$; $\mathrm{R}_{\mathrm{f}} 0.32$ (chloroform/methanol, 9:1); ${ }^{1} \mathrm{H}$ NMR (400 MHz, DMSO-d6) $\delta 11.24(\mathrm{~s}, 1 \mathrm{H}), 8.64$ (s, 1H) 7.84-7.88 (m, 2H)

7.25-7.30 (m, 2H), $5.83(\mathrm{dd}, \mathrm{J}=12.4,4.8 \mathrm{~Hz}, 1 \mathrm{H}), 2.82-2.90(\mathrm{~m}, 1 \mathrm{H}), 2.62-2.70(\mathrm{~m}, 2 \mathrm{H})$, 2.32-2.35 (m, 1H) ${ }^{13} \mathrm{C}$ NMR (100 MHz, DMSO- d6): $\delta$ 172.8, 169.8, 163.5, 161.0, 145.8, $127.6(\mathrm{~d}, \mathrm{~J}=7.6 \mathrm{~Hz}), 122.0,116.4$ (d, J=22.0 Hz), 59.6, 31.1, 24.8. IR (neat) 3194, 3105, 2916, 1731, $1708 \mathrm{~cm}^{-1}$. HRMS (ESI-TOF) m/z [M+H]+; calcd for $\mathrm{C}_{13} \mathrm{H}_{12} \mathrm{FN}_{4} \mathrm{O}_{2}: 275.0944$, Found: 275.1014 . 


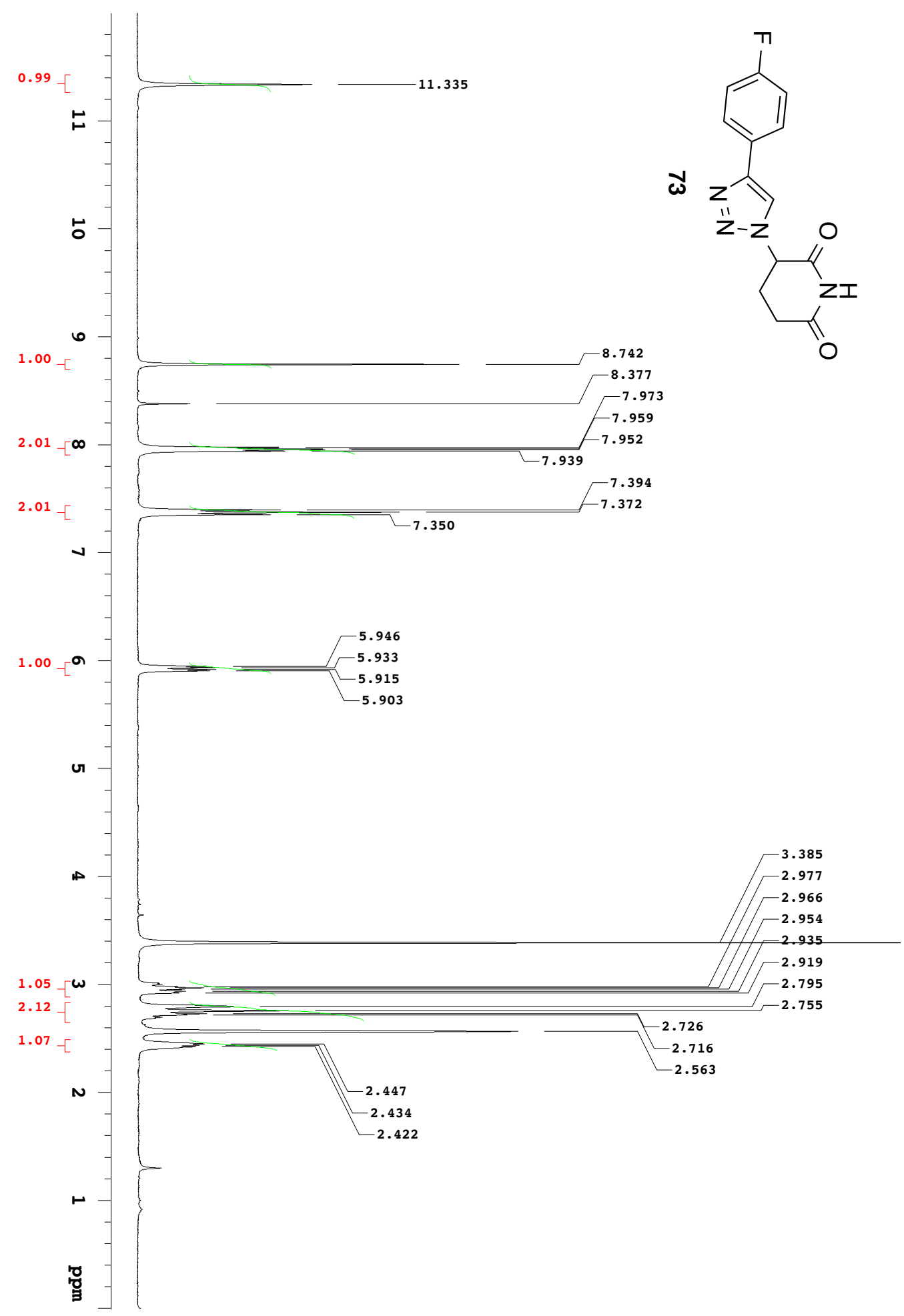




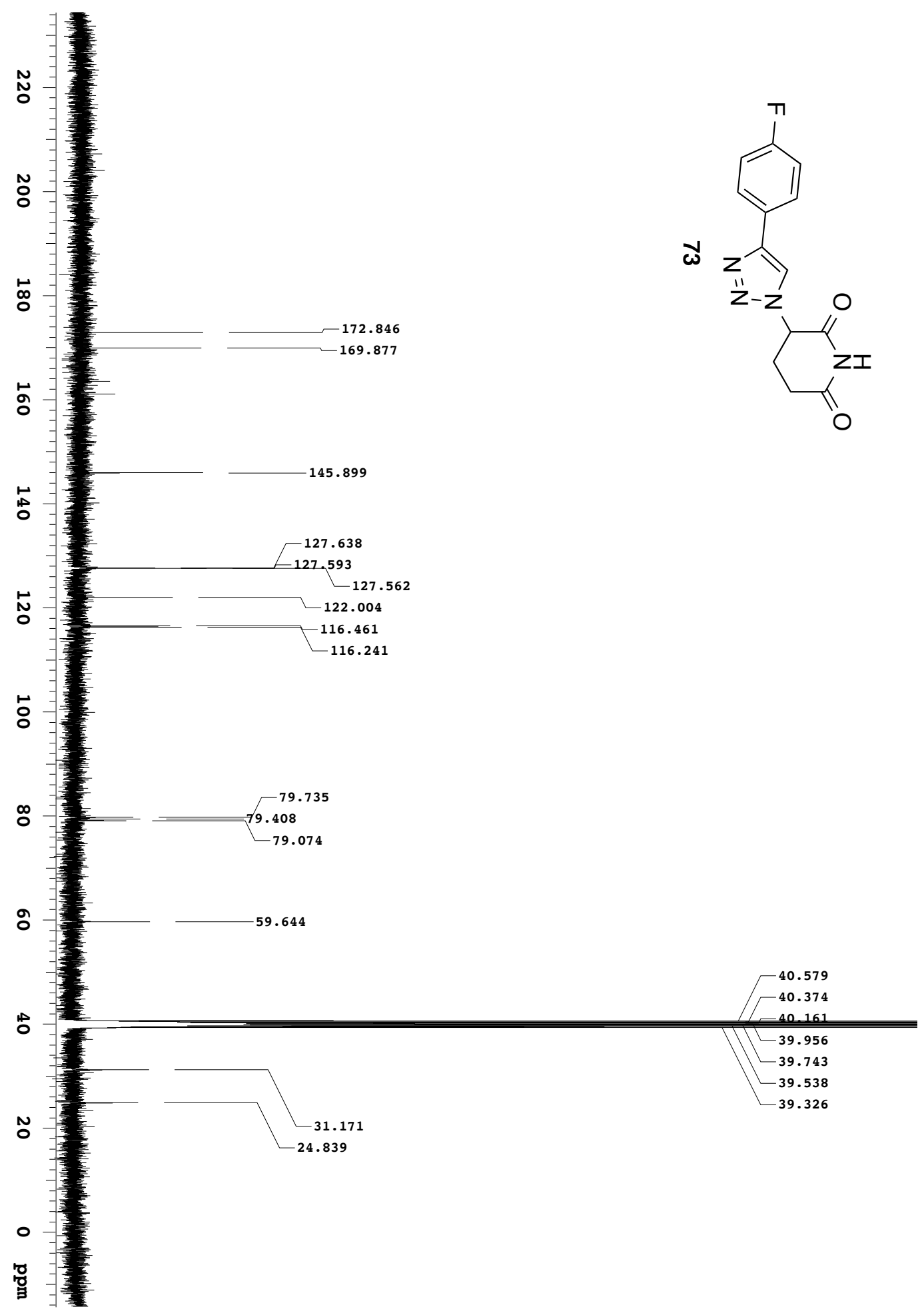




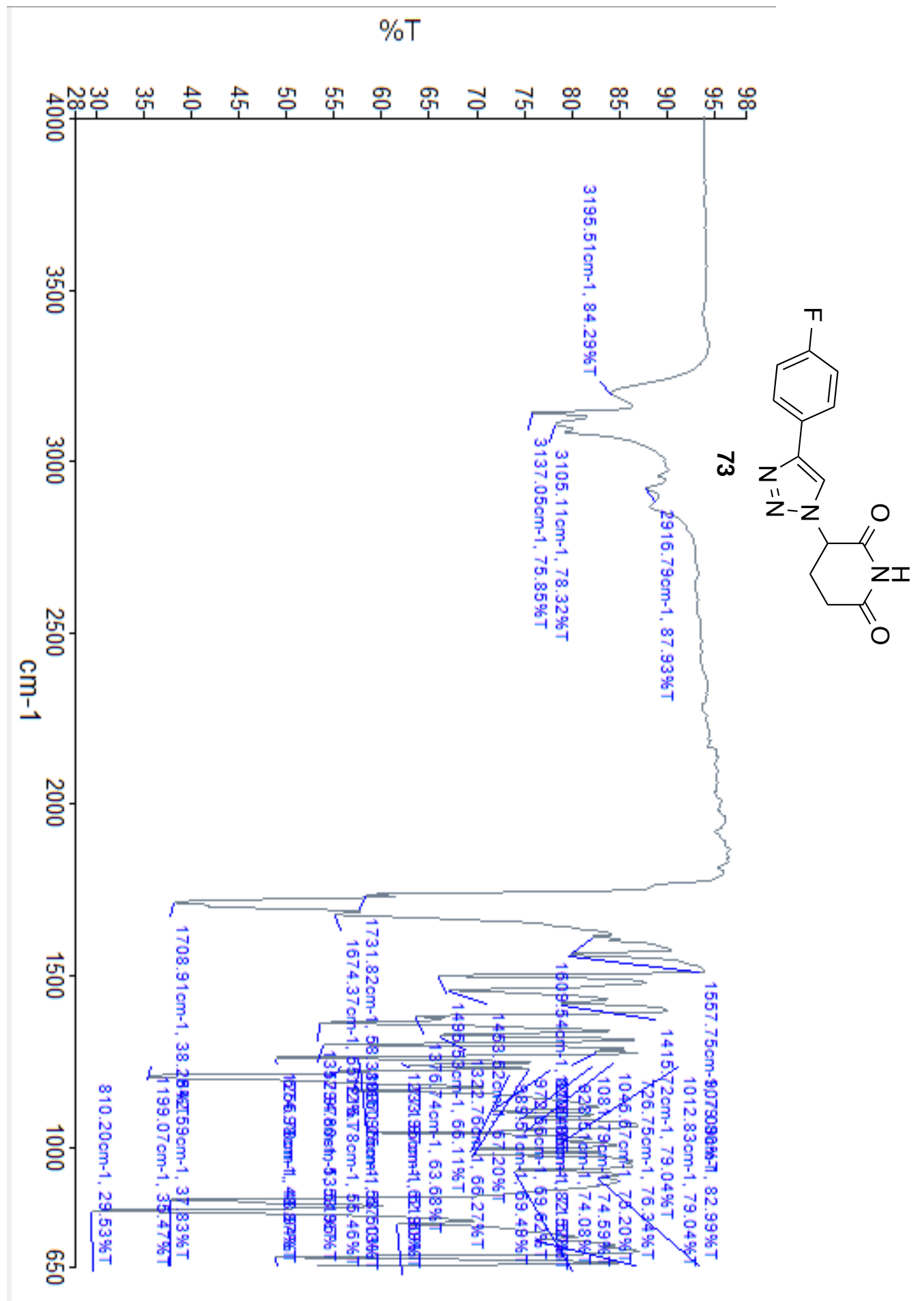




\section{3-(4-(3-Fluorophenyl)-1H-1,2,3-triazol-1-yl)piperidine- 2,6-dione. 74}

3-(4-(3-Fluorophenyl)-1H-1,2,3-triazol-1-yl)piperidine-2,6-dione 74 was obtained as a white solid (35 mg, 98\%): mp 199-201 ${ }^{\circ} \mathrm{C}$; $\mathrm{R}_{\mathrm{f}} 0.375$ (chloroform/methanol, 9:1); ${ }^{1} \mathrm{H}$ NMR (400 MHz, DMSO-d6) $\delta 11.25(\mathrm{~s}, 1 \mathrm{H}), 8.74(\mathrm{~s}, 1 \mathrm{H}), 7.65-7.69(\mathrm{~m}, 1 \mathrm{H}), 7.46-7.51(\mathrm{~m}, 2 \mathrm{H})$, 7.13-7.18 (m, 1H), $5.85(\mathrm{dd}, \mathrm{J}=12.4,4.4 \mathrm{~Hz}, 1 \mathrm{H}), 2.83-2.89(\mathrm{~m}, 1 \mathrm{H}), 2.62-2.71(\mathrm{~m}, 2 \mathrm{H})$, 2.34-2.37 (m, 1H) ${ }^{13} \mathrm{C}$ NMR (100 MHz, DMSO-d6): $\delta$ 172.9, 169.8, 164.2, 161.8, 145.7, 132.4 (d, J=154.9 Hz), 122.9, 121.6, 115.2 (d, J=21.3 Hz), 112.1 (d, J=15.9 Hz), 59.7, 31.1, 24.8. IR (neat) 3098, 2917, 2853, 1732, $1705 \mathrm{~cm}^{-1}$. HRMS (ESI-TOF) m/z [M+H]+; calcd for $\mathrm{C}_{13} \mathrm{H}_{12} \mathrm{FN}_{4} \mathrm{O}_{2}: 275.0944$, Found: 275.0837 . 


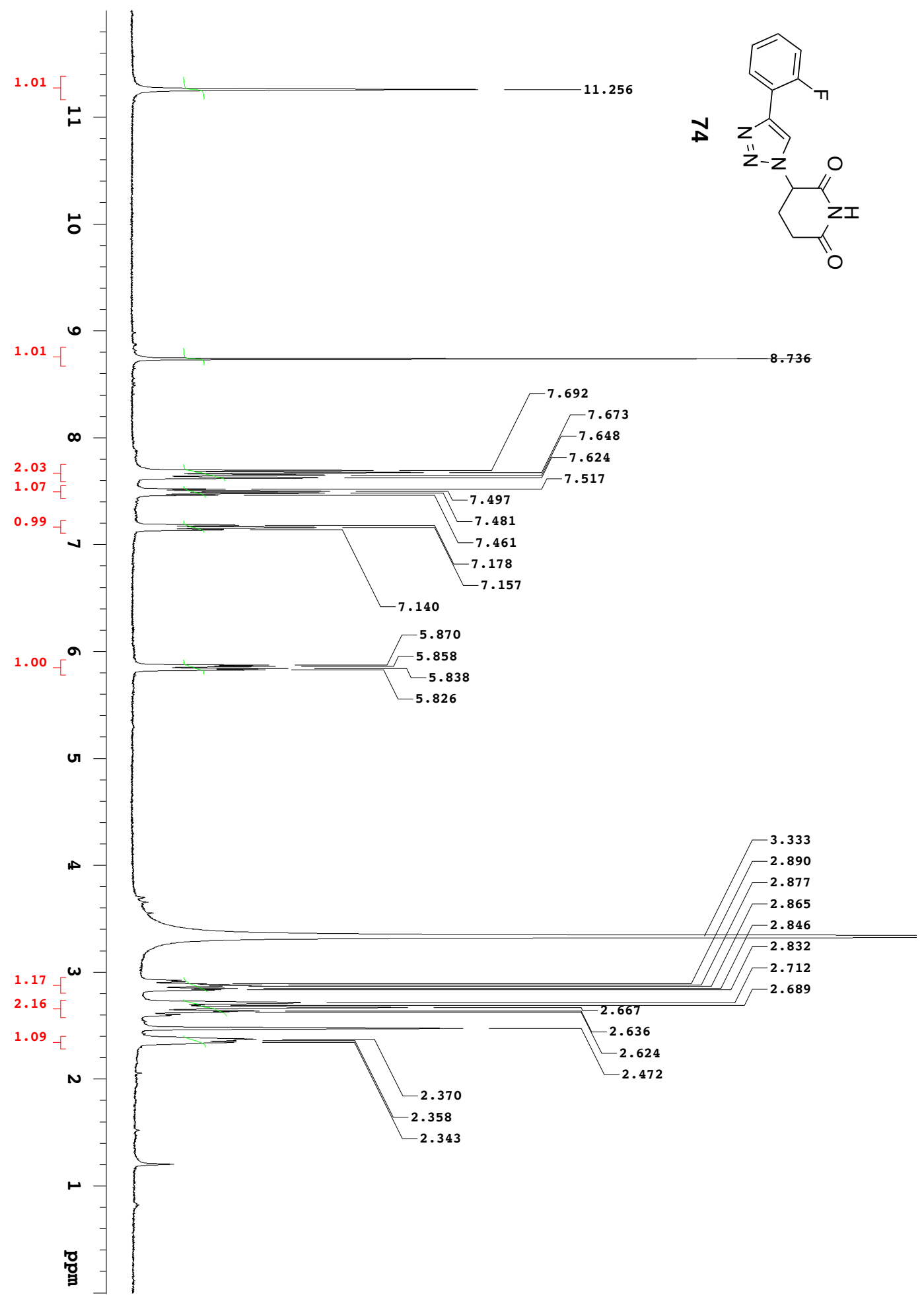




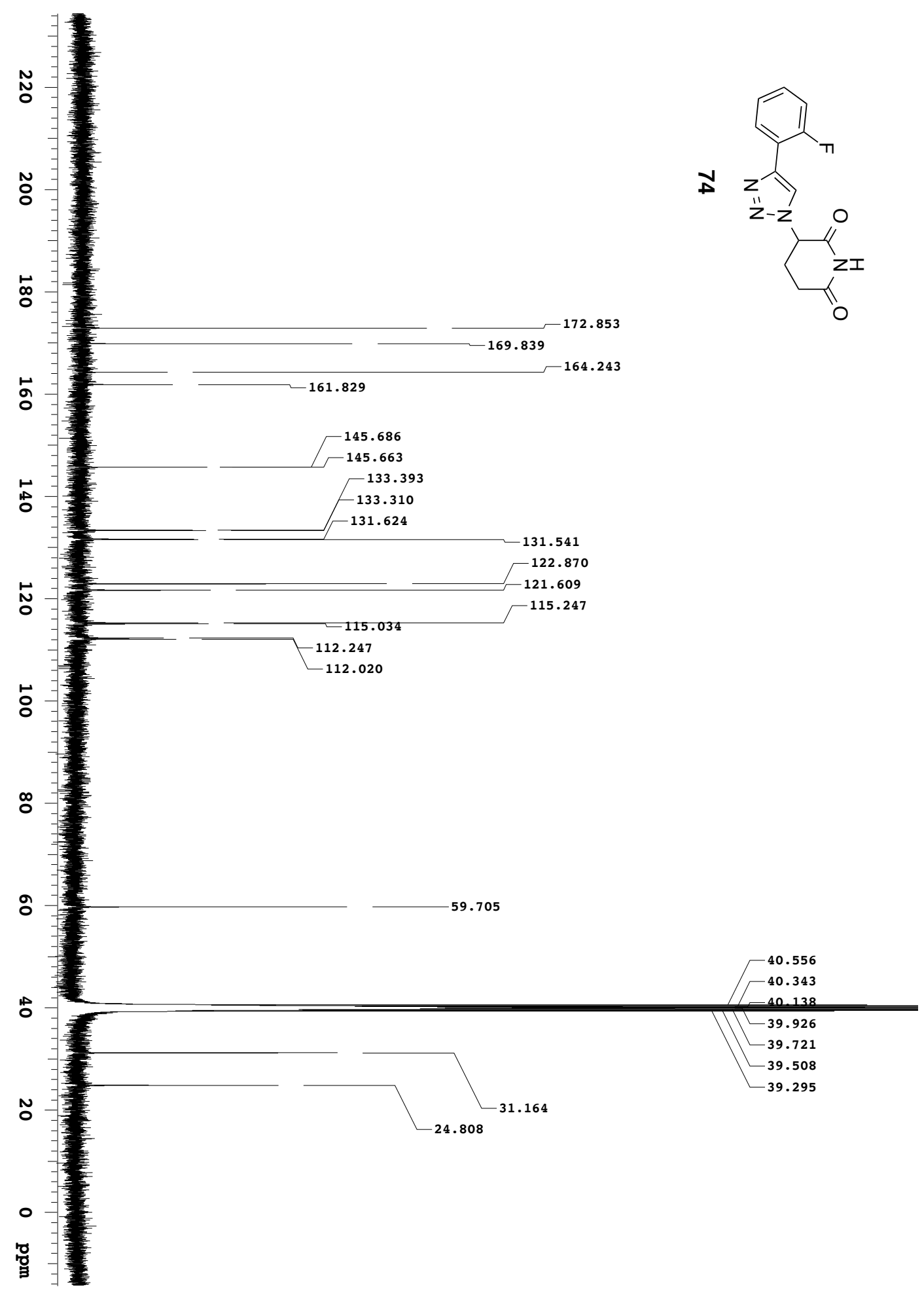




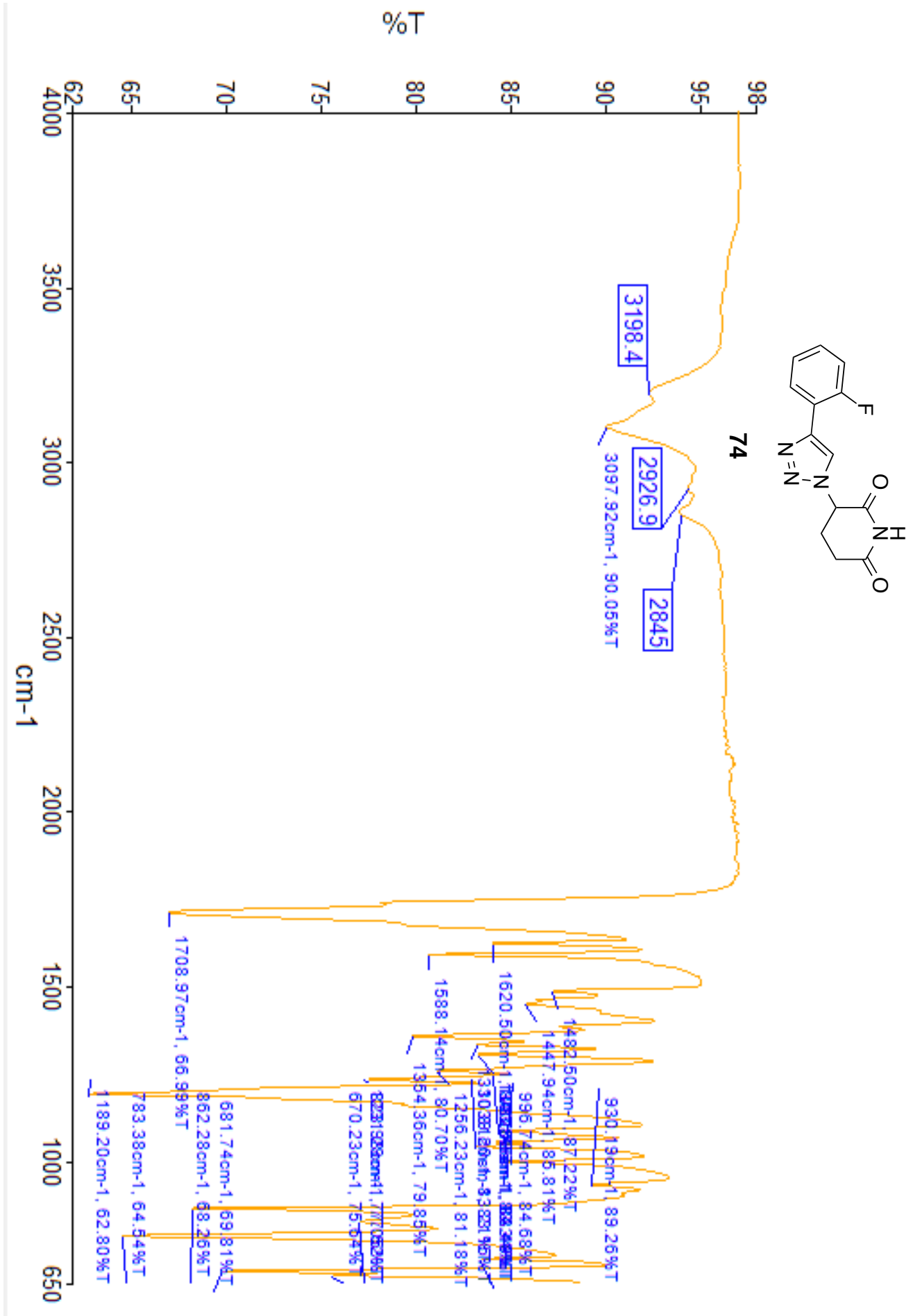


3-(4-(2-(Trifluoromethyl)phenyl)-1H-1,2,3-triazol-1-yl) piperidine-2,6-dione. 75

3-(4-(2-(Trifluoromethyl)phenyl)-1H-1,2,3-triazol-1-yl)piperidine-2,6-dione $\mathbf{7 5}$ was obtained as a white solid (36 mg, 84\%): $\mathrm{mp} 155-157^{\circ} \mathrm{C}$; $\mathrm{R}_{\mathrm{f}} 0.37$ (chloroform/methanol, 9:1); ${ }^{1} \mathrm{H}$ NMR (400 MHz, DMSO-d ) $\delta 11.23$ (s, 1H), 8.41 (s, 1H), 7.74-7.85 (m, 3H), 7.60$7.63(\mathrm{~m}, 1 \mathrm{H}), 5.89$ (dd, J=12.8, 5.2 Hz, 1H), 2.83-2.90 (m, 1H), 2.65-2.78 (m, 2H), 2.31$2.36(\mathrm{~m}, 1 \mathrm{H}){ }^{13} \mathrm{C}$ NMR (100 MHz, DMSO- d6): $\delta 172.9,169.8,143.7,133.1,132.2,129.8$ (q, J=2.2 Hz), 129.3, 126.8 (q, J=30.4 Hz), 126.7 (q, J=6.1 Hz), 124.8 (q, J=3.1 Hz), 124.4 (q, J=271.8 Hz), 59.7, 31.2, 24.8. IR (neat) 3220, 3094, 2957, 1732, $1701 \mathrm{~cm}^{-1}$. HRMS (ESI-TOF) m/z [M-H] $]^{-}$; calcd for $\mathrm{C}_{14} \mathrm{H}_{10} \mathrm{~F}_{3} \mathrm{~N}_{4} \mathrm{O}_{2}$ : 323.0756 , Found: 323.0714 . 


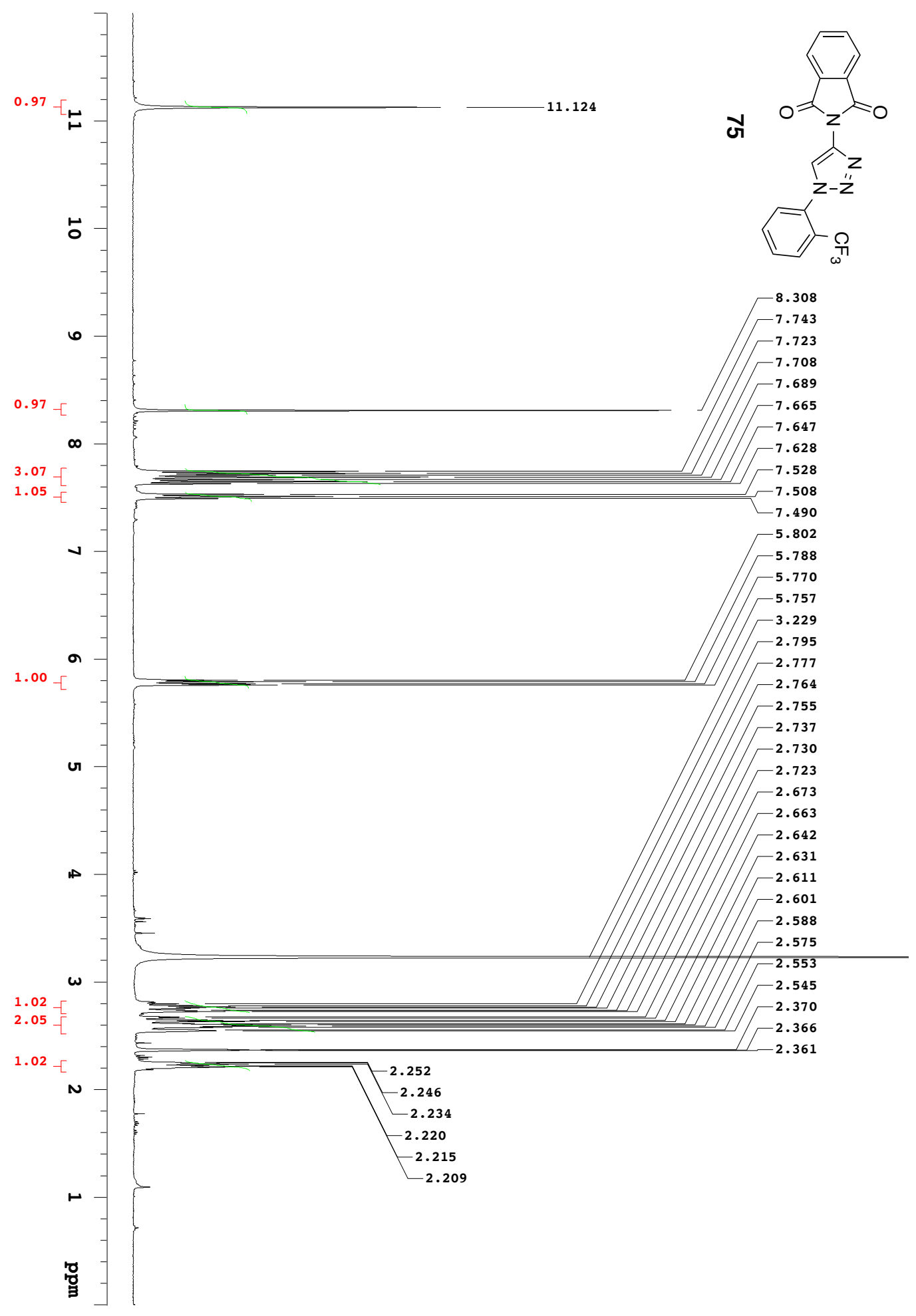




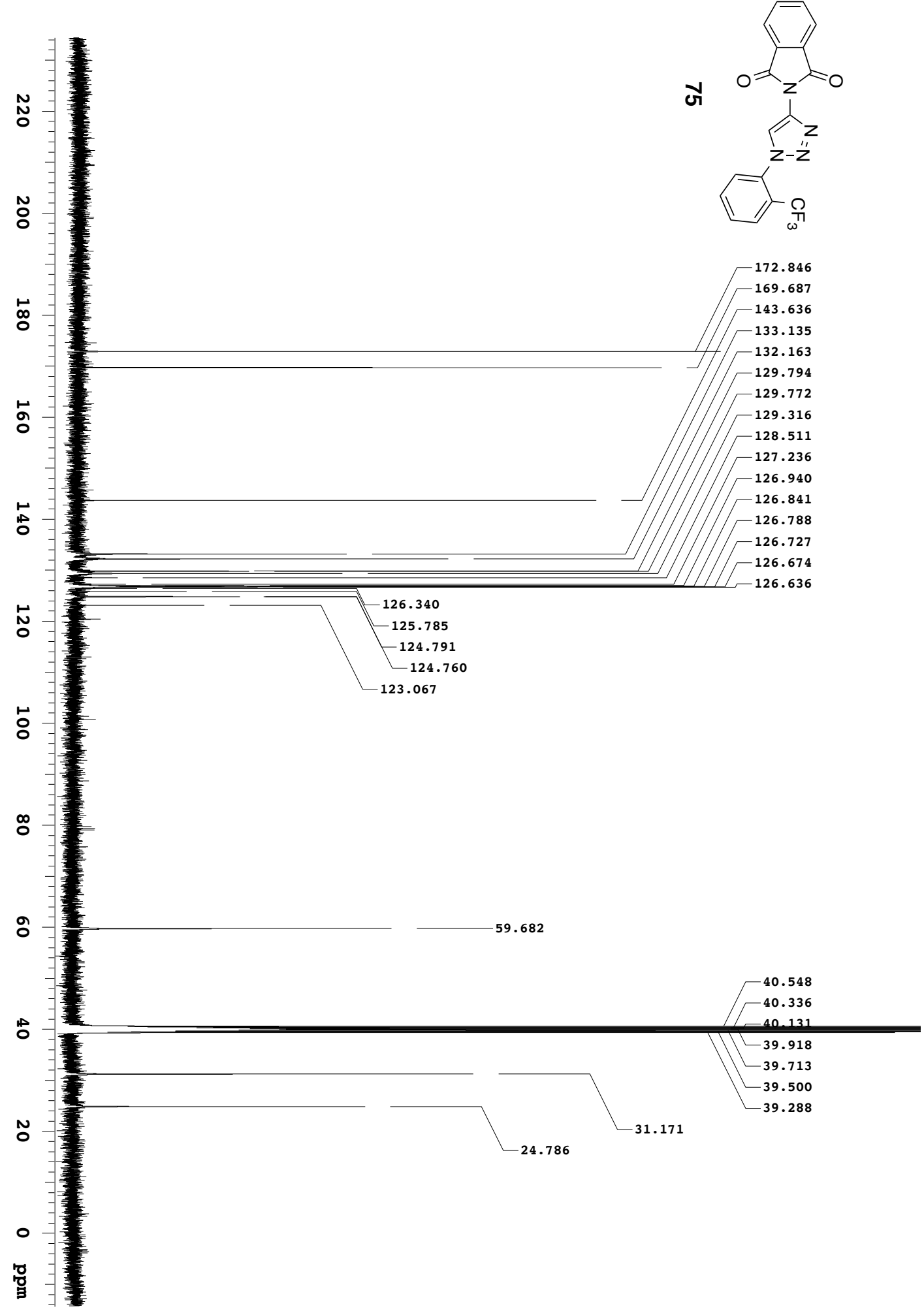




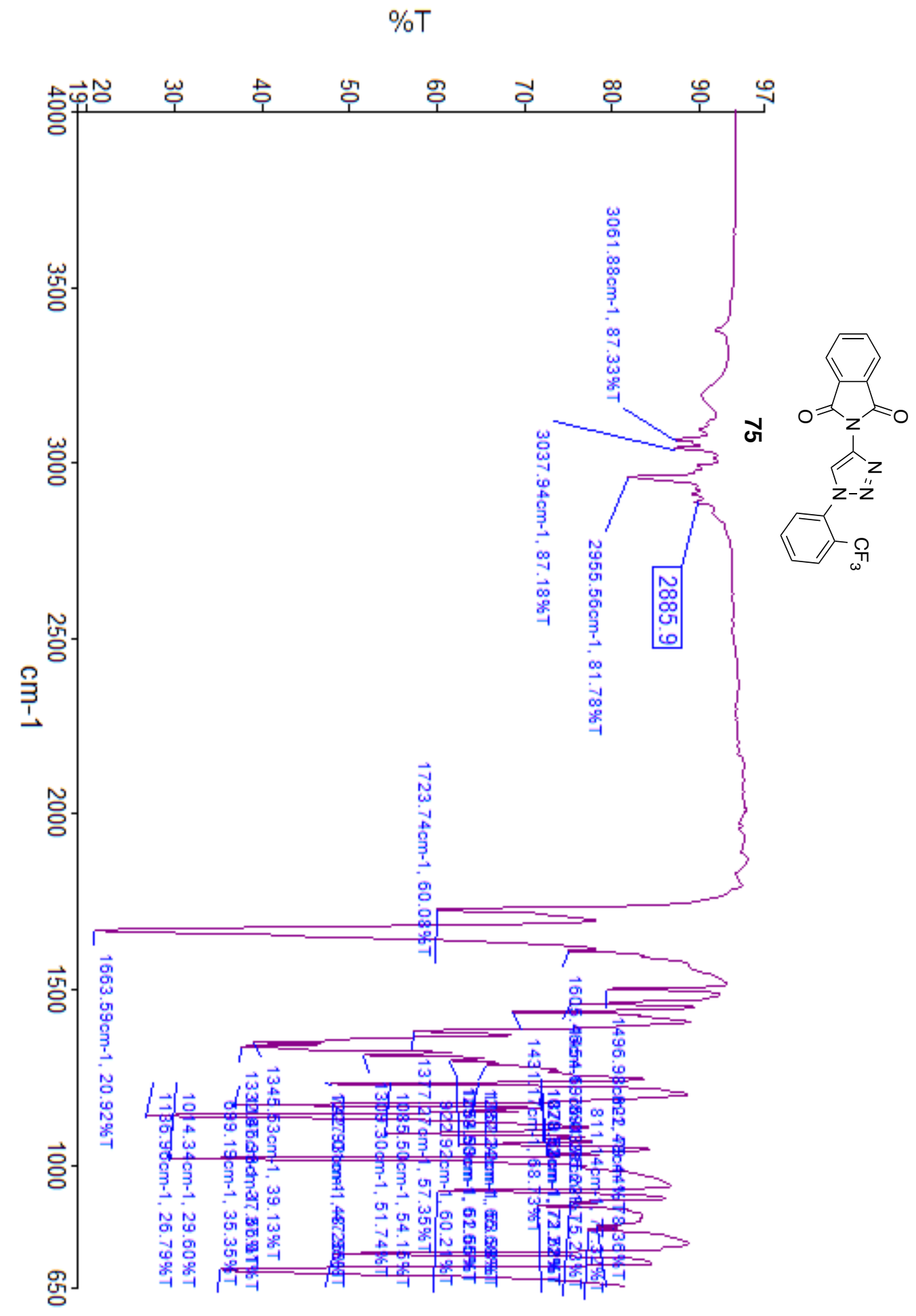


3-(4-(3,5-Bis(trifluoromethyl)phenyl)-1H-1,2,3-triazol-1-yl)piperidine-2,6-dione. 76 3-(4-(3,5-bis(Trifluoromethyl)phenyl)-1H-1,2,3-triazol-1-yl)piperidine-2,6-dione 76 was obtained as a white solid (38 $\mathrm{mg}, 76 \%$ ): $\mathrm{mp} 115-117^{\circ} \mathrm{C} ; \mathrm{R}_{\mathrm{f}} 0.29$ (chloroform/methanol, 9:1); ${ }^{1} \mathrm{H}$ NMR (400 MHz, DMSO-d6) $\delta 11.29$ (s, 1H), 9.07 (s, 1H), 8.50 (s, 2H), 8.07 (s, 1H), $5.91(\mathrm{dd}, \mathrm{J}=12.8,5.2 \mathrm{~Hz}, 1 \mathrm{H}), 2.84-2.89(\mathrm{~m}, 1 \mathrm{H}), 2.66-2.73(\mathrm{~m}, 2 \mathrm{H}), 2.38-2.41(\mathrm{~m}$, 1H) ${ }^{13} \mathrm{C}$ NMR (100 MHz, DMSO-d6): $\delta$ 172.8, 169.7, 144.1, 133.5, 131.5 (q, J=32.6 Hz), 125.7, 124.2, 123.2 (q, J=271.9 Hz), 121.7, 59.8, 31.1, 24.7. IR (neat) 3219, 3094, 2872, 1733, $1704 \mathrm{~cm}^{-1}$. HRMS (ESI-TOF) m/z [M-H]-; calcd for $\mathrm{C}_{15} \mathrm{H}_{9} \mathrm{~F}_{6} \mathrm{~N}_{4} \mathrm{O}_{2}$ 391.0630, Found: 391.0707. 


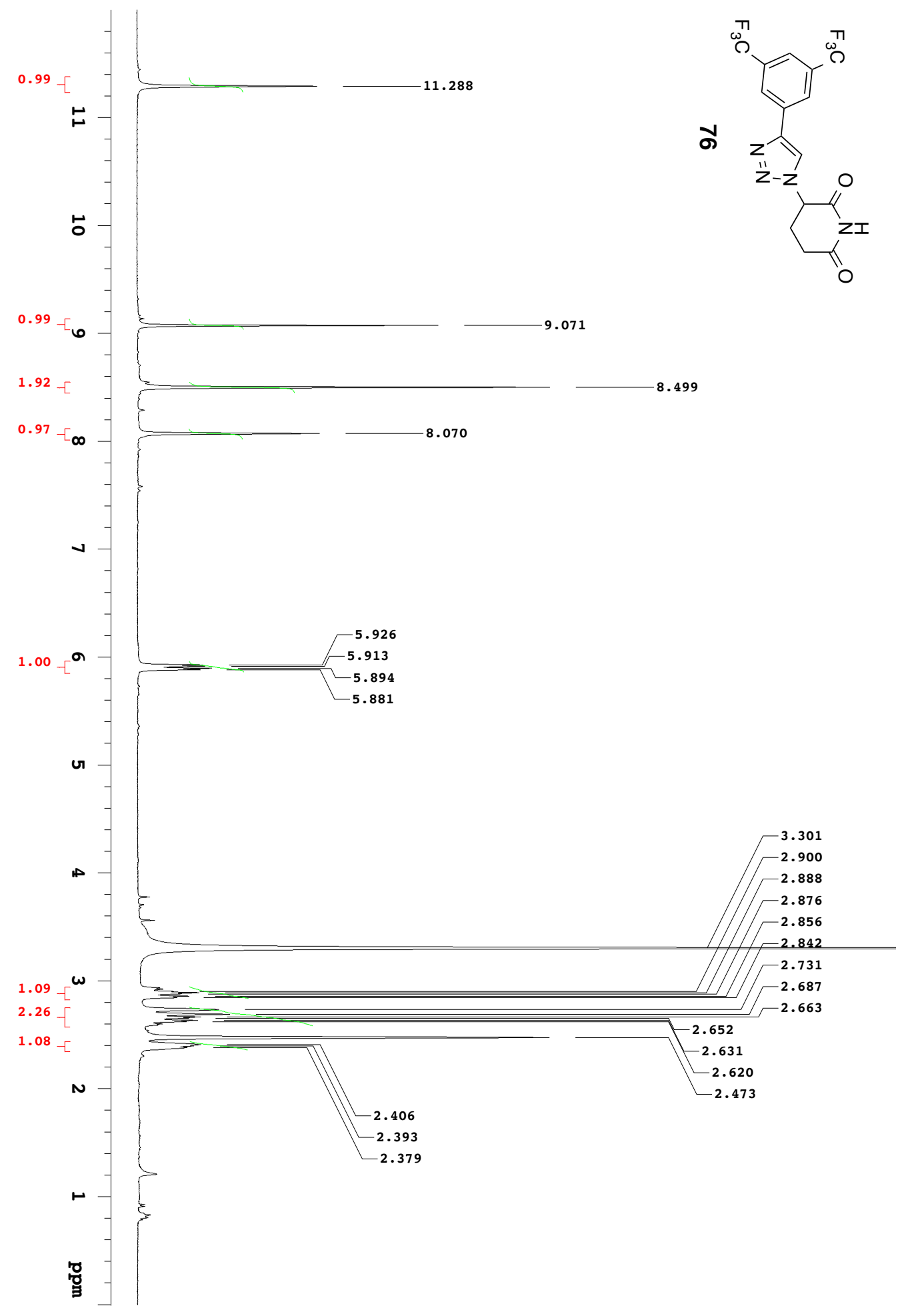




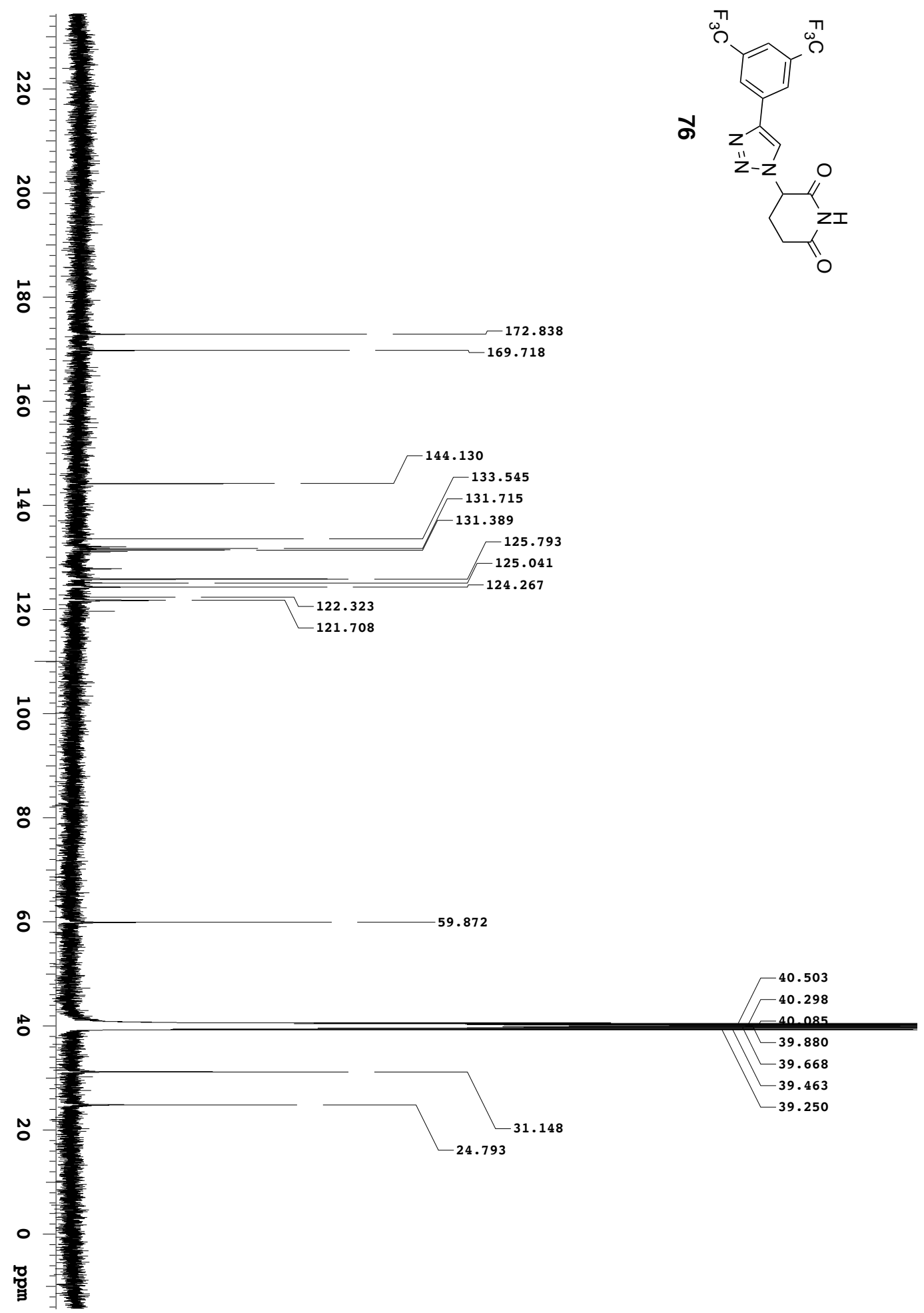




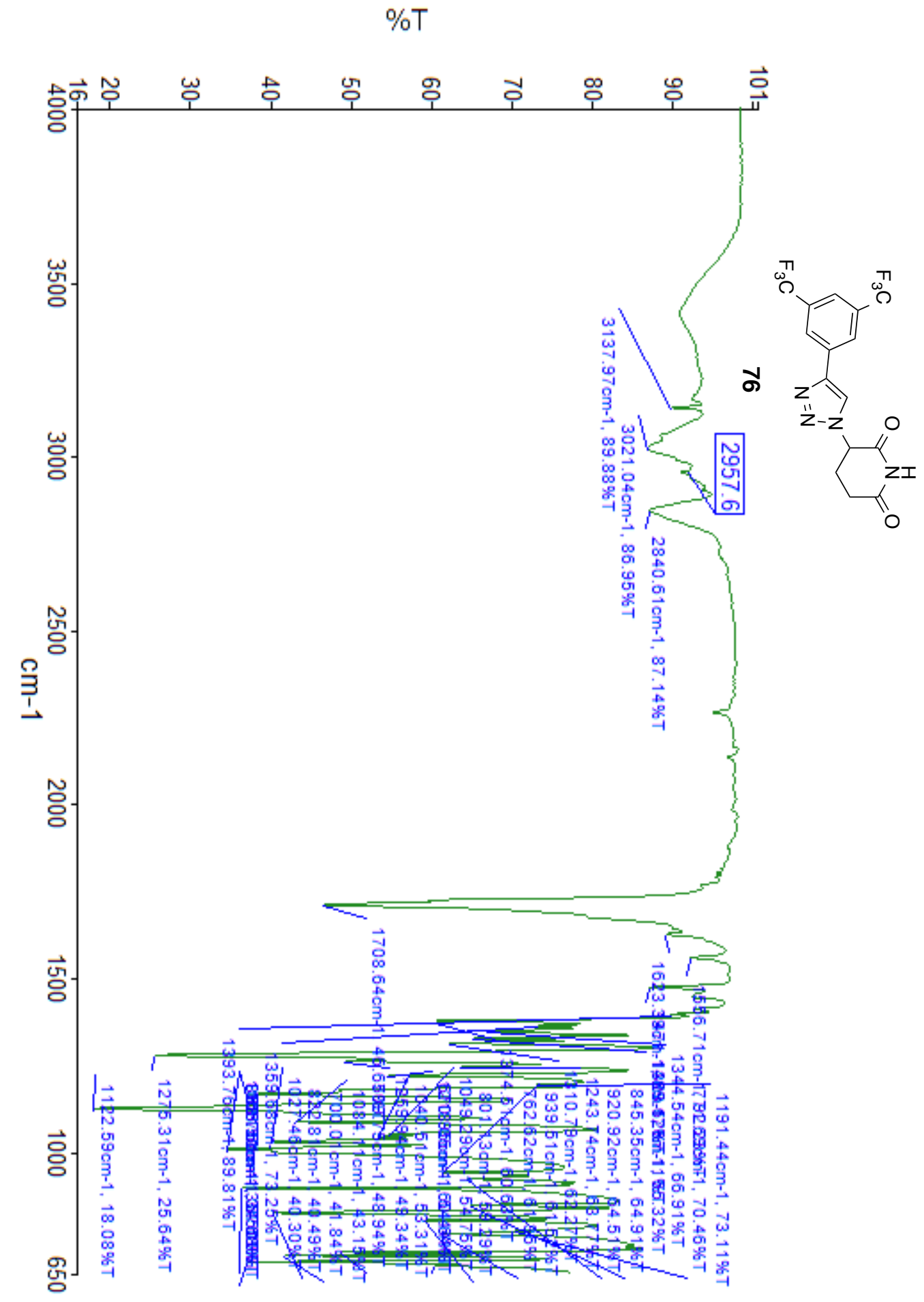




\section{2-(Prop-2-yn-1-yl)isoindoline-1,3-dione. 78}

Prepared by the method of Clayton (69\%): ${ }^{67} \mathrm{mp} 146-148{ }^{\circ} \mathrm{C}\left(\right.$ Lit.36 149-150 $\left.{ }^{\circ} \mathrm{C}\right)$. The spectroscopic data was consistent with the literature: ${ }^{67}{ }^{1} \mathrm{H}$ NMR $\left(400 \mathrm{MHz}, \mathrm{CDCl}_{3}\right) \delta 7.80$ $7.91(\mathrm{~m}, 2 \mathrm{H}), 7.74-7.76(\mathrm{~m}, 2 \mathrm{H}), 4.47(\mathrm{~s}, 2 \mathrm{H}), 2.24(\mathrm{~s}, 1 \mathrm{H})$.

\section{2-(Prop-2-yn-1-yl)isoindolin-1-one. 80}

Isoindolin-1-one 21 (250 mg, $1.85 \mathrm{mmol})$ was dissolved in acetonitrile (9 mL) and cesium carbonate $(2.40 \mathrm{~g}, 7.39 \mathrm{mmol})$ was added followed by propargyl bromide $(308 \mathrm{~mL}, 2.77$ mmol). The reaction mixture was stirred at reflux $(2 \mathrm{~h})$. The reaction mixture was then dissolved in $\mathrm{CH}_{2} \mathrm{Cl}_{2}(10 \mathrm{~mL})$ and washed with water $(315 \mathrm{~mL})$. The organic layer was dried $\left(\mathrm{Na}_{2} \mathrm{SO}_{4}\right)$, filtered and concentrated under reduced pressure. Gravity-column chromatography of the residual oil (hexane/ethyl/acetate, 2:1) gave $\mathbf{8 0}$ as a yellow solid (205 mg, 65\%): mp 79-81 ${ }^{\circ} \mathrm{C} ; \mathrm{R}_{\mathrm{f}} 0.66$ (ethyl acetate); ${ }^{1} \mathrm{H}$ NMR (400 MHz, $\left.\mathrm{CDCl}_{3}\right) \delta 7.82$ (d J=8.0 Hz, 1H), $7.52(\mathrm{dd} \mathrm{J}=8.0,7.2 \mathrm{~Hz}, 1 \mathrm{H}) 7.41-7.45(\mathrm{~m}, 2 \mathrm{H}), 4.47(\mathrm{~s}, 2 \mathrm{H}), 4.24(\mathrm{~s}, 2 \mathrm{H})$, $2.28(\mathrm{~s}, 1 \mathrm{H}) .{ }^{13} \mathrm{C} \mathrm{NMR}\left(100 \mathrm{MHz}, \mathrm{CDCl}_{3}\right) \delta 167.9,141.2,132.1,131.6,128.1,123.8$, 122.8, 78.1, 72.5, 49.1, 31.7. IR (neat) 3290, 3243, 2118, $1701 \mathrm{~cm}^{-1}$; HRMS (ESI-TOF) $\mathrm{m} / \mathrm{z}[\mathrm{M}+\mathrm{H}]+$; calculated for $\mathrm{C}_{11} \mathrm{H}_{10} \mathrm{NO}: 172.0762$, Found: 172.0857 . 


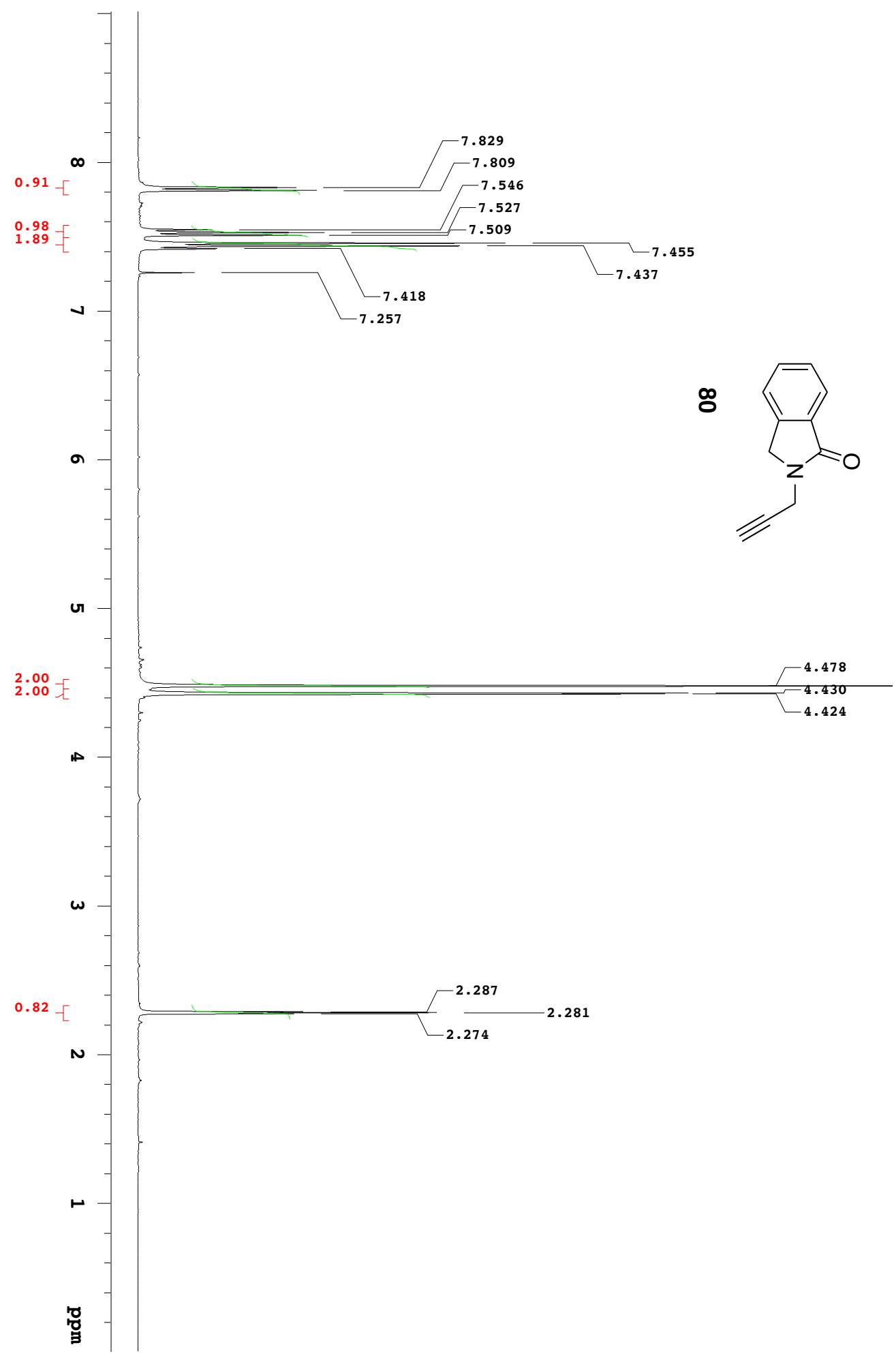




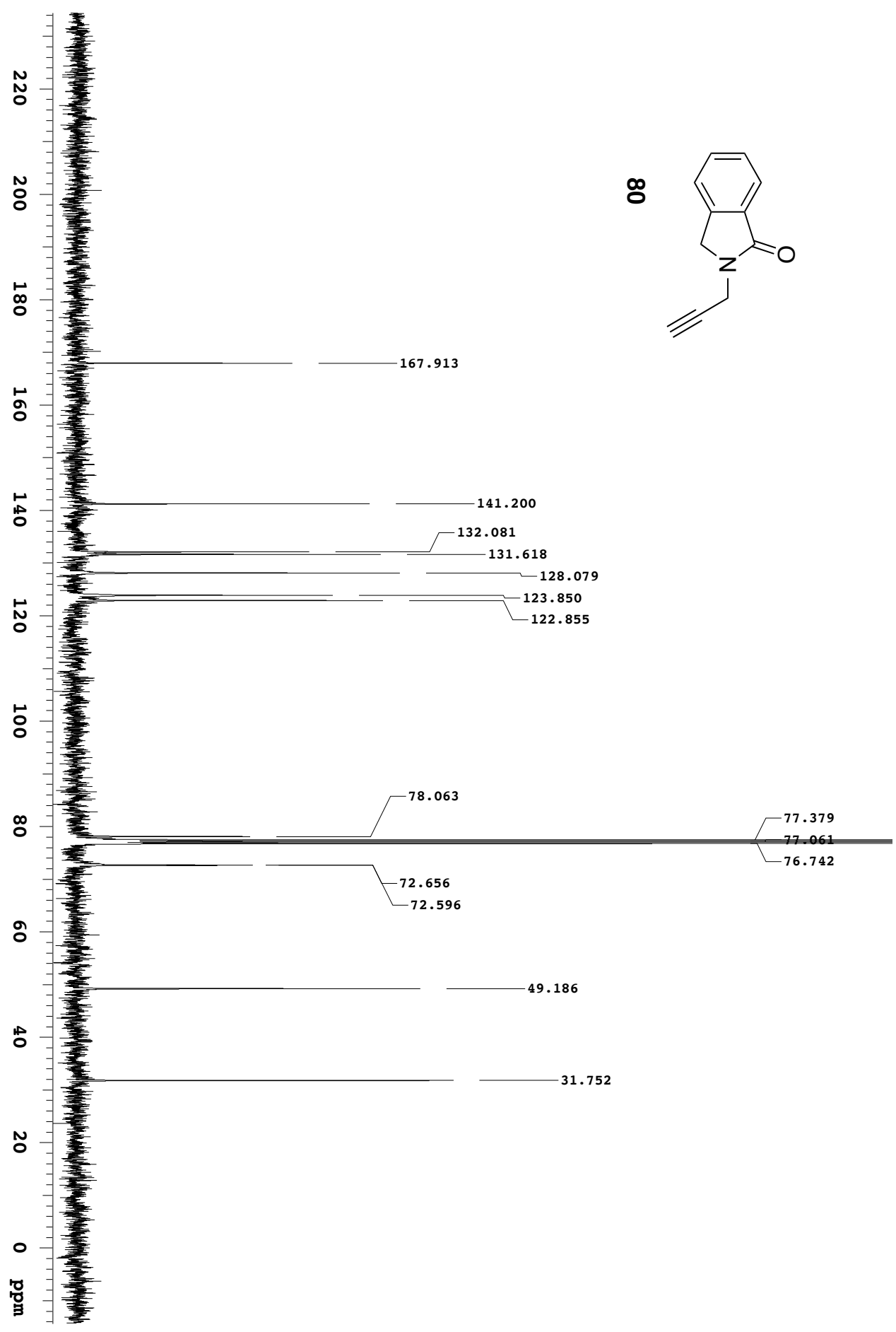




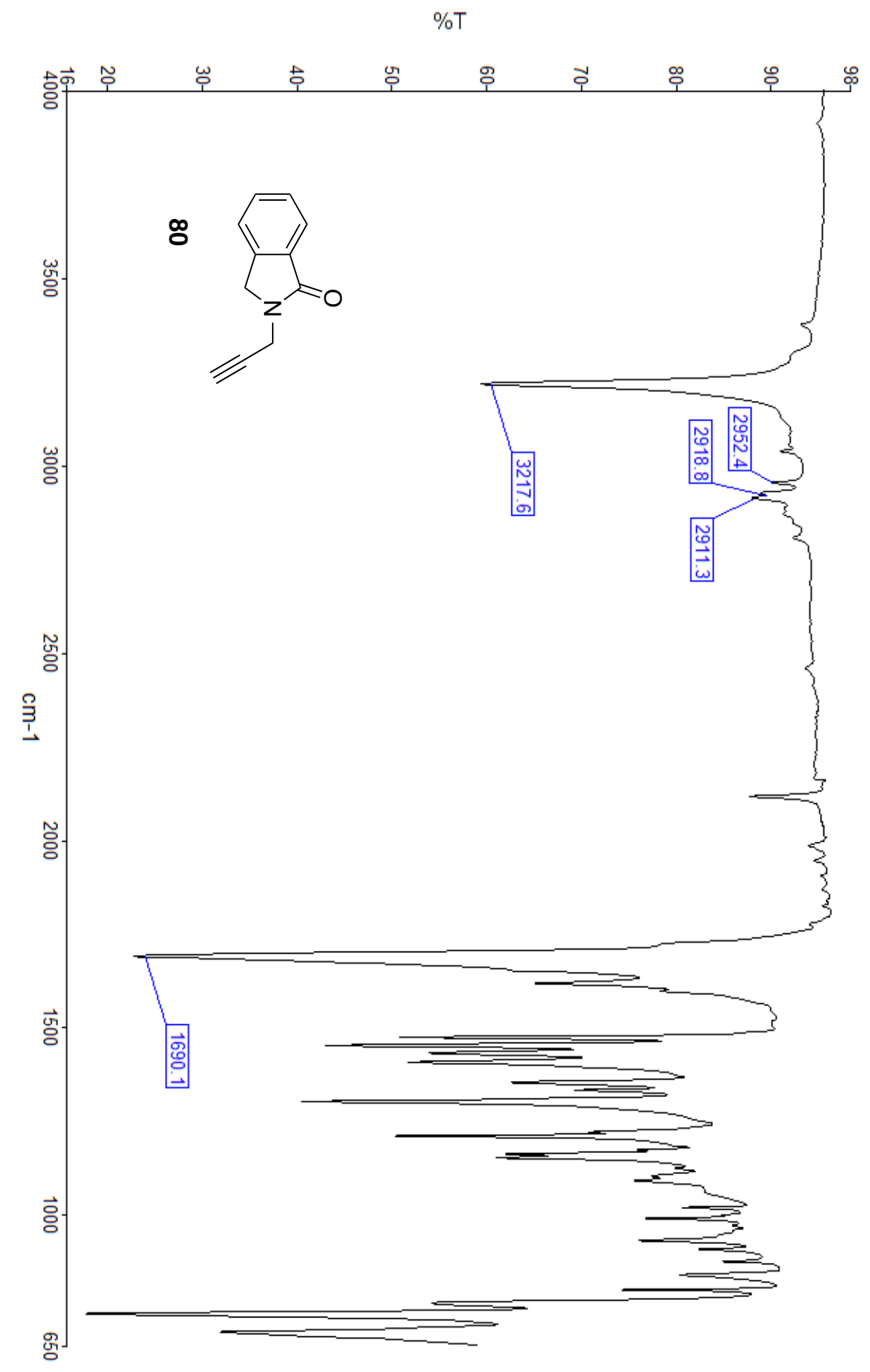




\section{2-(2-(Trimethylsilyl)ethynyl)isoindoline-1,3-dione. 83}

Prepared by the method of Davies $(59 \%):{ }^{65} \mathrm{mp} 92-94{ }^{\circ} \mathrm{C}$ (Lit.65 94-96 ${ }^{\circ} \mathrm{C}$ ). The spectroscopic data was consistent with the literature: ${ }^{65}{ }^{1} \mathrm{H} \mathrm{NMR}\left(400 \mathrm{MHz}, \mathrm{CDCl}_{3}\right) \delta 7.90$ $7.93(\mathrm{~m}, 2 \mathrm{H}), 7.78-7.81(\mathrm{~m}, 2 \mathrm{H}), 0.273(\mathrm{~s}, 9 \mathrm{H})$.

\section{2-(2-(Trimethylsilyl)ethynyl)isoindolin-1-one. 85}

To a $250 \mathrm{~mL}$ round bottom flask $\mathrm{Cu}(\mathrm{OAc}) 2(76.4 \mathrm{mg}, 0.42 \mathrm{mmol})$, isoindolin-1-one (1.00 g, $7.51 \mathrm{mmol}), \mathrm{Na} 2 \mathrm{CO} 3(216 \mathrm{mg}, 4.2 \mathrm{mmol})$, and $4 \AA$ molecular sieves $(2.0 \mathrm{~g})$ were combined. A solution of pyridine $(324 \mathrm{~mL}, 4.2 \mathrm{mmol})$ in toluene $(30 \mathrm{~mL})$ was added to the reaction flask followed by sweeping with three volumes of $\mathrm{O}_{2}$. The reaction flask was placed in an oil bath and stirred for $1 \mathrm{~h}\left(70^{\circ} \mathrm{C}\right)$ until the reaction mixture was a bright green color. A solution of ethynyltrimethylsilane $(298 \mathrm{~mL}, 2.1 \mathrm{mmol})$ in dry toluene $(2 \mathrm{~mL})$ was added to the mixture over $30 \mathrm{~min}$. The reaction mixture was allowed to stir (4 h) during which time the reaction mixture changed to a black suspension. The reaction mixture was filtered through Celite ${ }^{\circledR}$, concentrated under reduced pressure and purified by flash column chromatography (hexane/ethyl acetate, 5:1) to yield $\mathbf{8 5}$ as a fluffy white amorphous solid (106 mg, 22\%): mp 134-136 ${ }^{\circ} \mathrm{C} ; \mathrm{R}_{\mathrm{f}} 0.33$ (hexane/ethyl acetate, 4:1); ${ }^{1} \mathrm{H}$ NMR (400 MHz, $\left.\mathrm{CDCl}_{3}\right) \delta 7.89(\mathrm{~d} \mathrm{~J}=7.6 \mathrm{~Hz}, 1 \mathrm{H}), 7.62(\mathrm{dd} \mathrm{J}=8.0,7.6 \mathrm{~Hz}, 1 \mathrm{H}), 7.50(\mathrm{dd}, \mathrm{J}=8.0,7.6 \mathrm{~Hz}, 1 \mathrm{H})$, $7.44(\mathrm{~d} \mathrm{~J}=8.0 \mathrm{~Hz}, 1 \mathrm{H}), 4.70(\mathrm{~s}, 2 \mathrm{H}), 0.25(\mathrm{~s}, 9 \mathrm{H}) .{ }^{13} \mathrm{C} \mathrm{NMR}\left(175 \mathrm{MHz}, \mathrm{CDCl}_{3}\right) \delta$ 168.6, $140.8,133.0,129.6,128.6,124.6,122.8,92.8,75.9,52.5,0.18$. IR (neat) 2954, 2902, 2167, $1712 \mathrm{~cm}^{-1}$; HRMS (ESI-TOF) m/z [M+Cl]-; calculated for $\mathrm{C}_{13} \mathrm{H}_{15} \mathrm{ClNOSi}$ : 264.0617, Found: 264.0688 . 


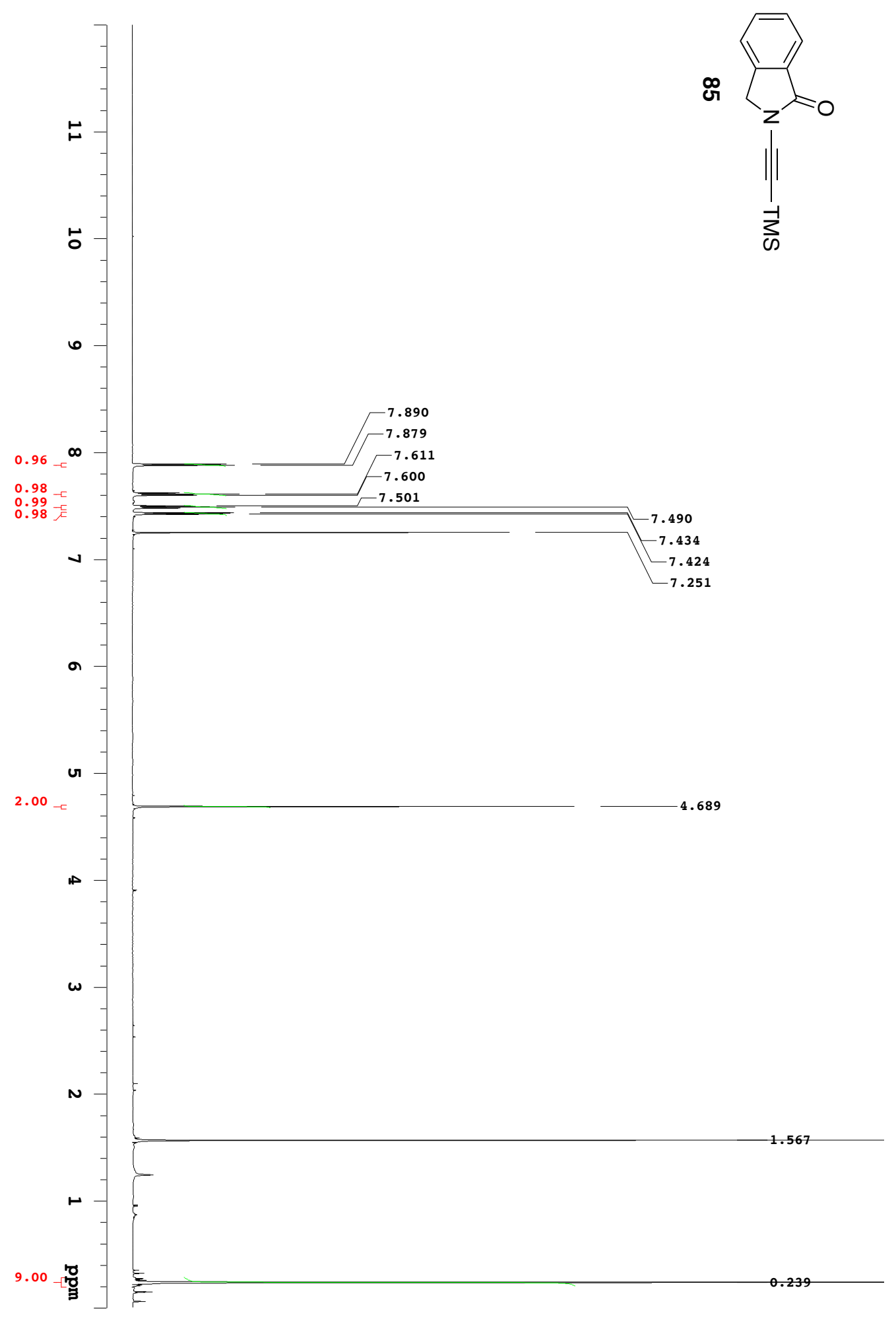




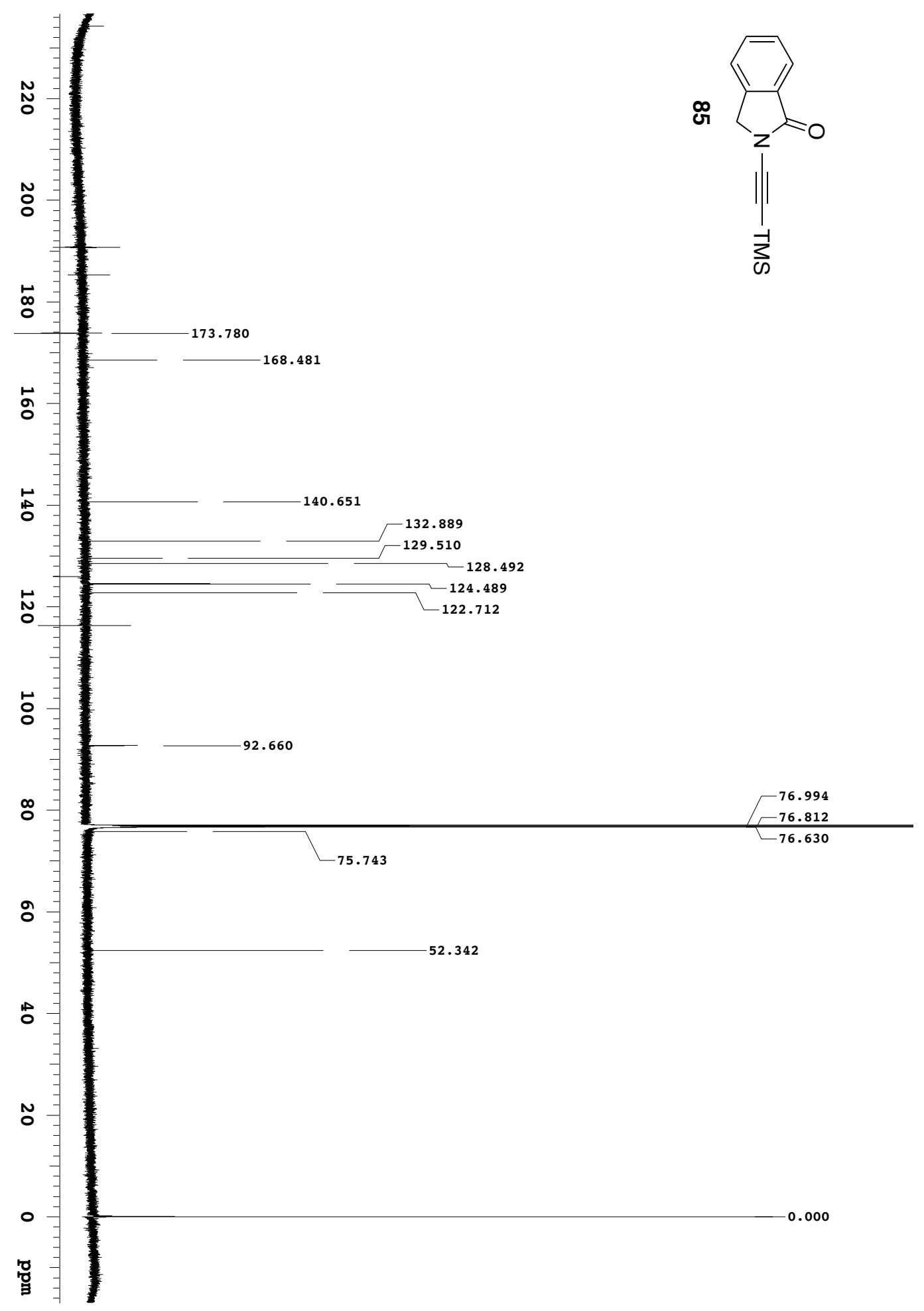




\section{2-Ethynylisoindoline-1,3-dione. 84}

Prepared by the Method of Davies (94\%): ${ }^{66} \mathrm{mp} 165-169{ }^{\circ} \mathrm{C}$ (Lit.33 167-172 ${ }^{\circ} \mathrm{C}$ ). The spectroscopic data was consistent with the literature: ${ }^{65}{ }^{1} \mathrm{H}$ NMR $\left(400 \mathrm{mHz}, \mathrm{CDCl}_{3}\right) \delta 7.92-$ $7.94(\mathrm{~m}, 2 \mathrm{H}), 7.80-7.83(\mathrm{~m}, 2 \mathrm{H}), 3.33(\mathrm{~s}, 1 \mathrm{H})$.

\section{2-Ethynylisoindoline-1-one. 86}

2-(2-(Trimethylsilyl)ethynyl)isoindolin-1-one $85(72.0 \mathrm{mg}, 0.313 \mathrm{mmol})$ was dissolved in THF (3.0 mL) while stirring followed by the addition of tetra-N-butylammonium fluoride (TBAF, $450 \mathrm{~mL}, 1 \mathrm{M}$ solution). Stirring was continued (10 min) until the reaction was complete as indicated by TLC. The crude reaction mixture was directly submitted to gravity-column chromatography (hexanes/ ethyl acetate) and afforded $\mathbf{8 6}$ as a white solid (45 mg, 92\%): mp 92-94 ${ }^{\circ} \mathrm{C} ; \mathrm{R}_{\mathrm{f}} 0.21$ (hexane/ethyl acetate, 4:1); ${ }^{1} \mathrm{H}$ NMR (400 MHz, $\left.\mathrm{CDCl}_{3}\right) \delta 7.91(\mathrm{~d}, \mathrm{~J}=7.2 \mathrm{~Hz}, 1 \mathrm{H}), 7.64(\mathrm{dd}, \mathrm{J}=7.2,7.2 \mathrm{~Hz}, 1 \mathrm{H}), 7.51(\mathrm{dd}, \mathrm{J}=7.2,7.2 \mathrm{~Hz}$, 1H), 7.46 (d J=7.2 Hz, 1H), $4.71(\mathrm{~s}, 2 \mathrm{H}), 3.08(\mathrm{~s}, 1 \mathrm{H}) .{ }^{13} \mathrm{C} \mathrm{NMR}\left(175 \mathrm{MHz}, \mathrm{CDCl}_{3}\right) \delta$ $169.1,140.9,133.2,129.4,128.7,124.7,122.9,73.9,61.7,52.1$. IR (neat) 3268, 2931, 2139, $1718 \mathrm{~cm}^{-1}$. Anal. Calcd for $\mathrm{C}_{10} \mathrm{H}_{7} \mathrm{NO}$ (157.17): C, 76.42; H, 4.49; N, 8.91; Found: C, 76.32; H, 4.68; N, 8.69. 


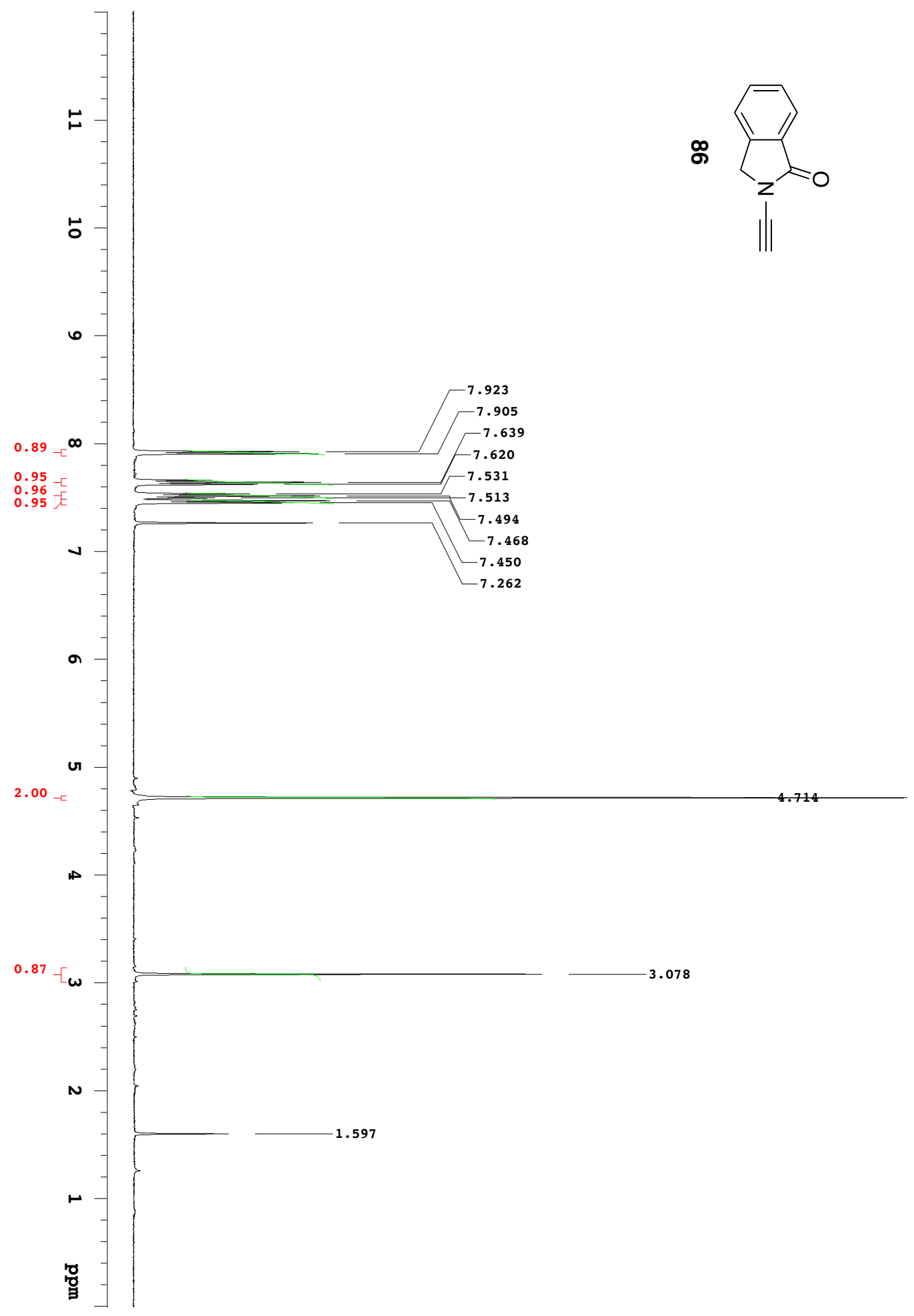




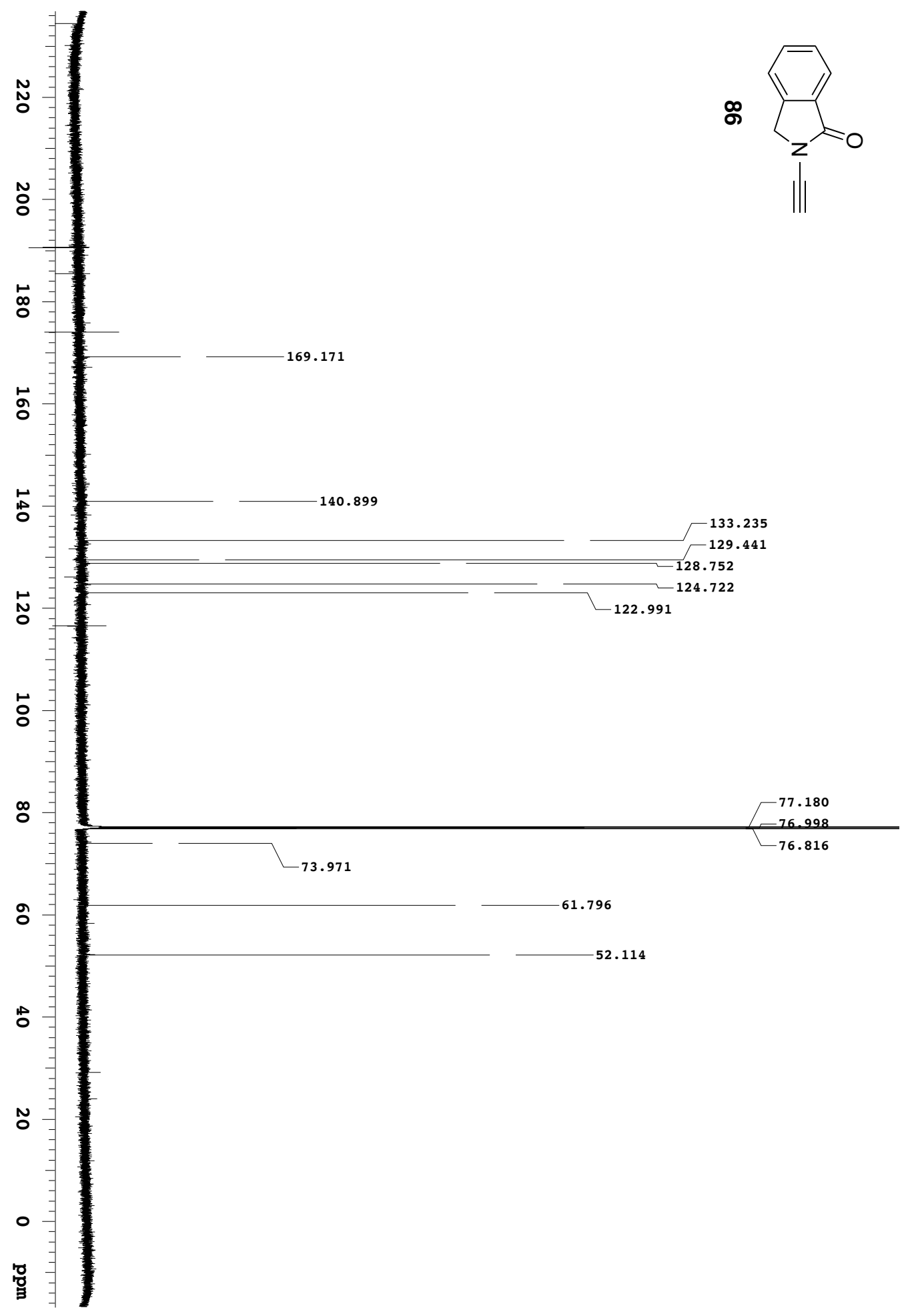




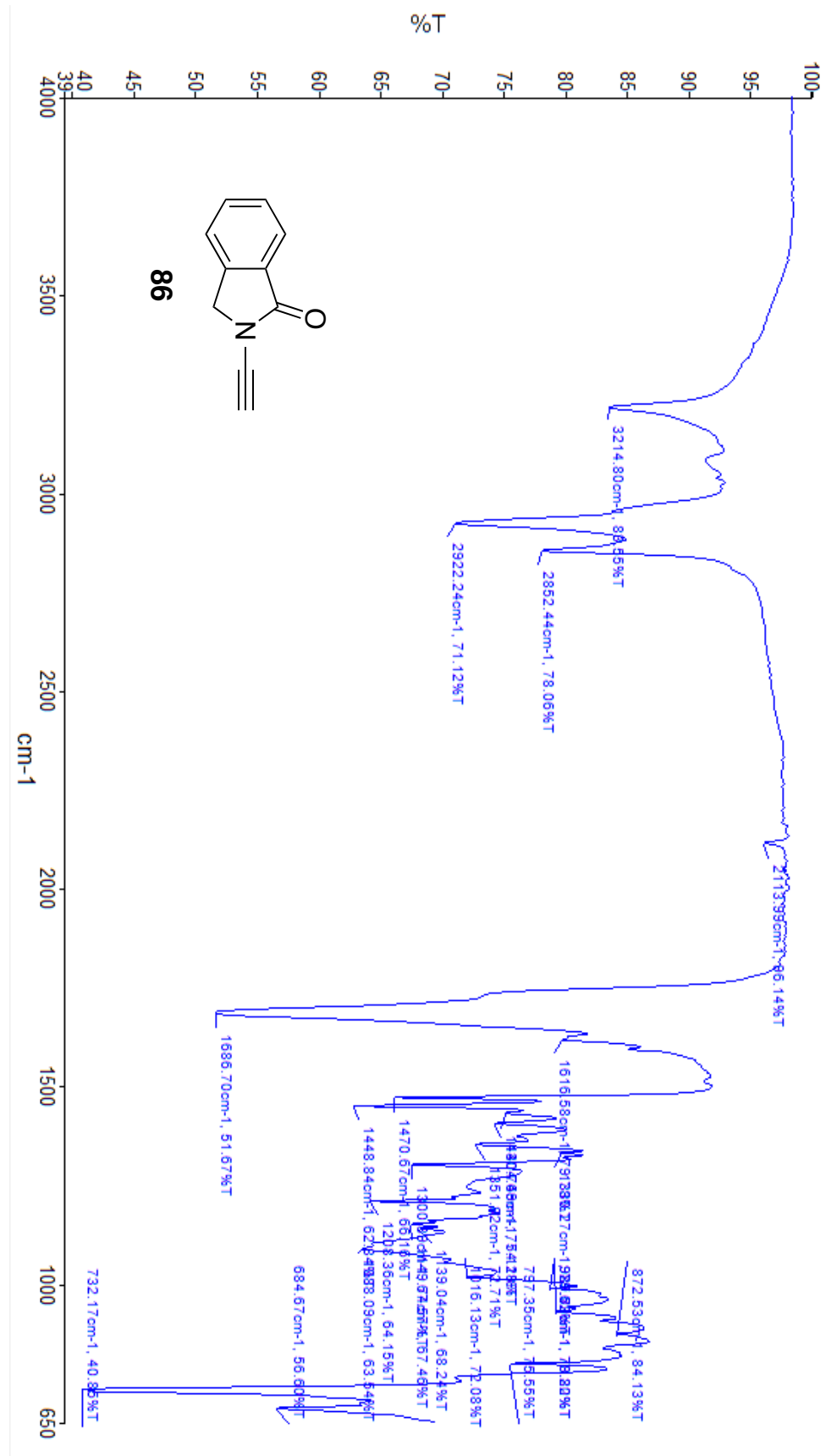




\section{General procedure for the preparation of click products: $81-82,87-88$}

3-Azidopiperidine-2,6-dione $66(0.25-0.5 \mathrm{mmol}, 38-74 \mathrm{mg})$ and phthalimide or isoindolinone alkynes $\mathbf{7 8}, \mathbf{8 0}, \mathbf{8 4}$, or $86(0.275-0.55 \mathrm{mmol}, 1.1$ equiv) were dissolved in $25 \%$ aqueous THF $(2.0 \mathrm{~mL})$. The mixture was stirred $(10 \mathrm{~min})$ before addition of solid $\mathrm{CuSO}_{4}(0.5$ equiv) and sodium ascorbate ( 0.5 equiv) whereupon the reaction mixture became a teal-colored suspension and stirring was continued $(16 \mathrm{~h})$. The reaction mixture was concentrated under rotary evaporation while absorbing onto silica gel (70-230 mesh) and the resulting dry residue was applied to a silica gel chromatography column.

\section{2-((1-(2,6-Dioxopiperidin-3-yl)-1H-1,2,3-triazol-4-yl)methyl)isoindoline-1,3-dione. 81}

The crude reaction mixture was submitted to gravity-column chromatography (chloroform/methanol, 97:3) to give triazole $\mathbf{8 1}$ as a white amorphous powder (56 $\mathrm{mg}$, 67\%): mp 230-232 ${ }^{\circ} \mathrm{C}$; $\mathrm{R}_{\mathrm{f}} 0.44$ (chloroform/methanol, 9:1); ${ }^{1} \mathrm{H}$ NMR (400 MHz, DMSOd6) $\delta 11.16(\mathrm{~s}, 1 \mathrm{H}), 8.16(\mathrm{~s}, 1 \mathrm{H}), 7.83-7.89(\mathrm{~m}, 4 \mathrm{H}), 5.74(\mathrm{dd}, \mathrm{J}=12.8,8.0 \mathrm{~Hz}, 1 \mathrm{H}), 4.83$ (s, 2H), 2.75-2.80 (m, 1H), 2.56-2.63 (m, 2H), 2.20-2.23 (m, 1H). ${ }^{13} \mathrm{C}$ NMR (100 MHz, DMSO-d6) $\delta 172.8,169.7,167.7,142.7,135.0,132.0,123.7,123.6,59.5,33.3,31.1,24.7$. IR (neat) 3220, 2957, 2863, 1732, $1701 \mathrm{~cm}^{-1}$; HRMS (ESI-TOF) m/z [M+H]+; calculated for $\mathrm{C}_{16} \mathrm{H}_{14} \mathrm{~N}_{5} \mathrm{O}_{4}: 340.1046$, Found: 340.0888 . 


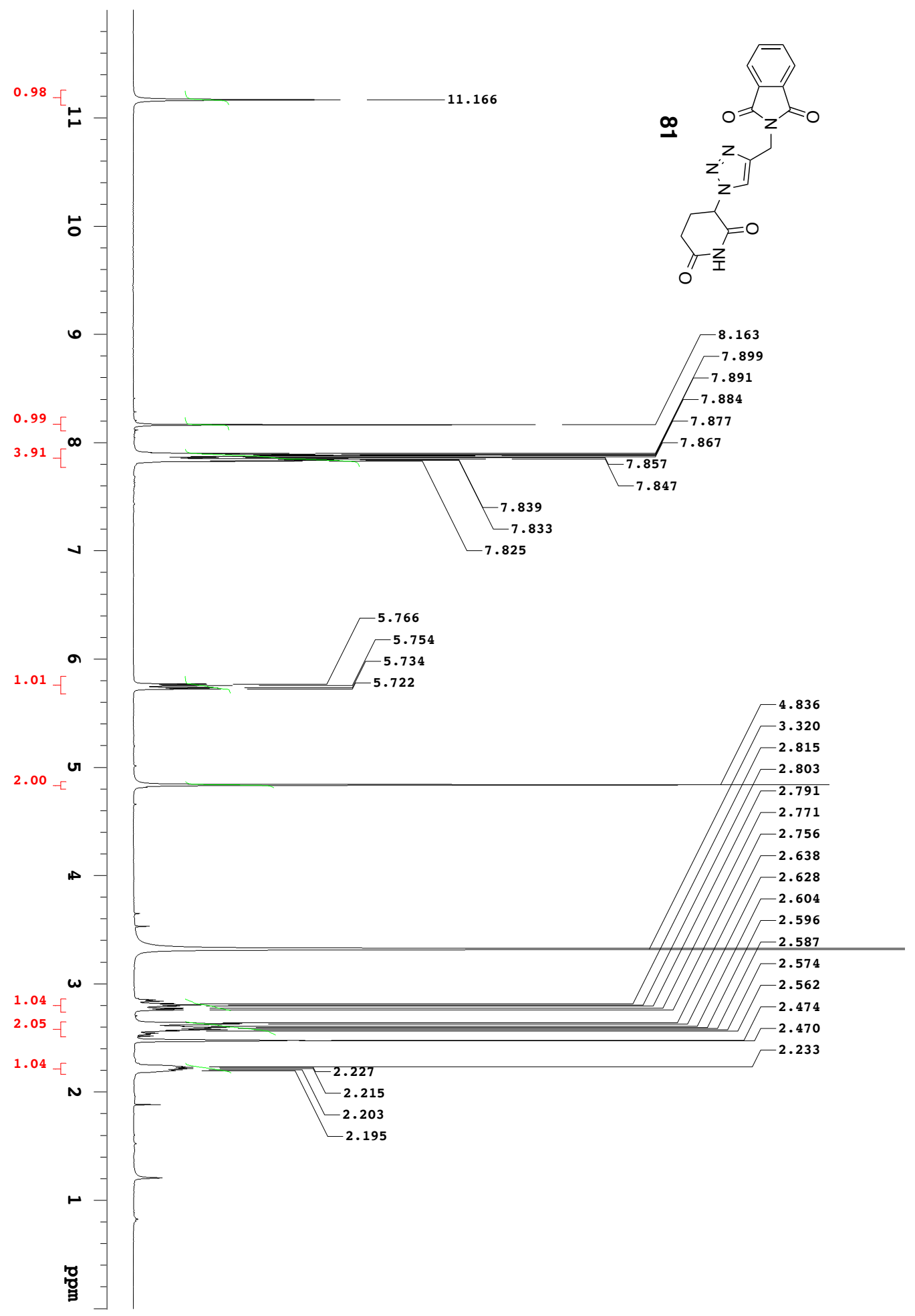




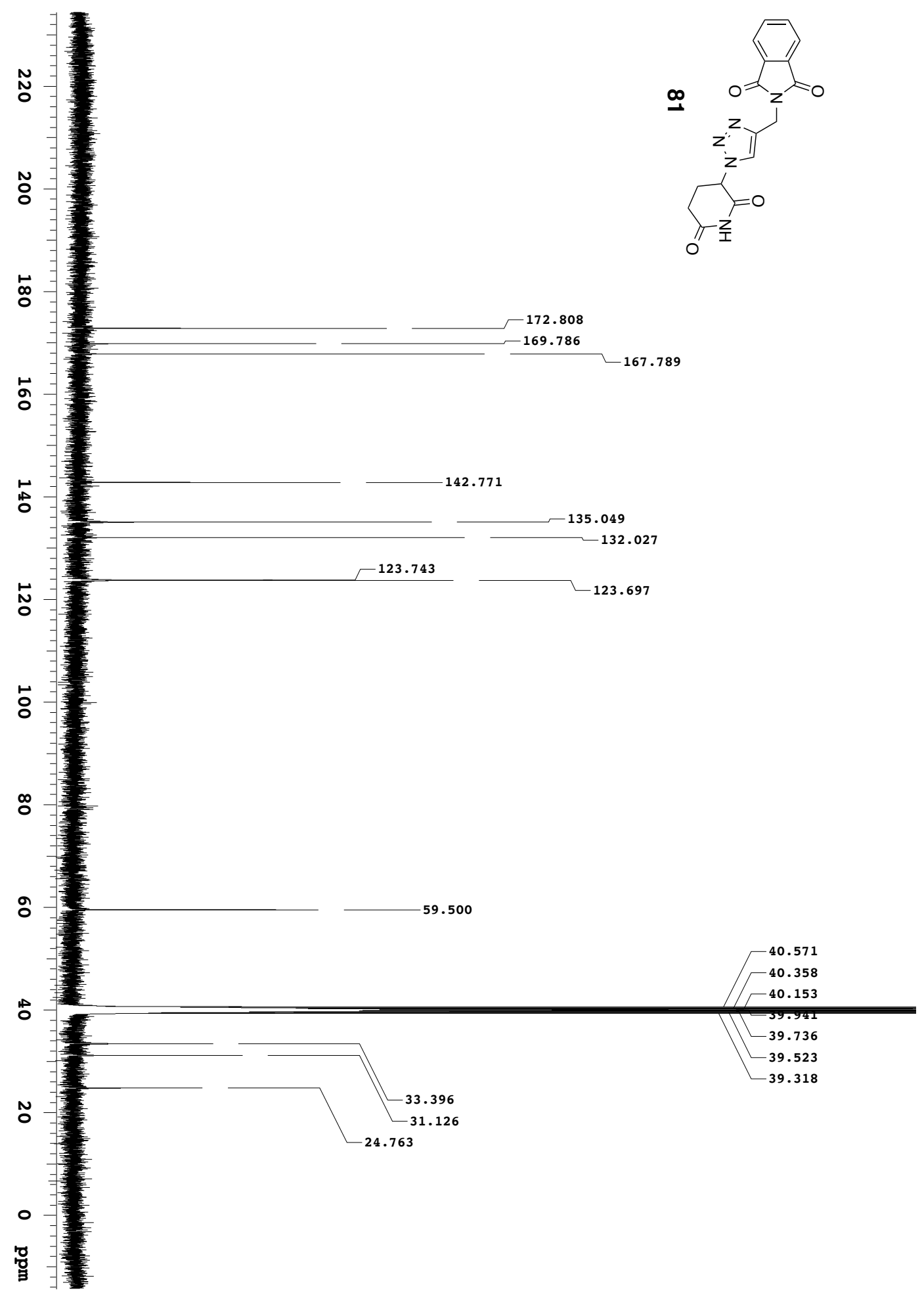




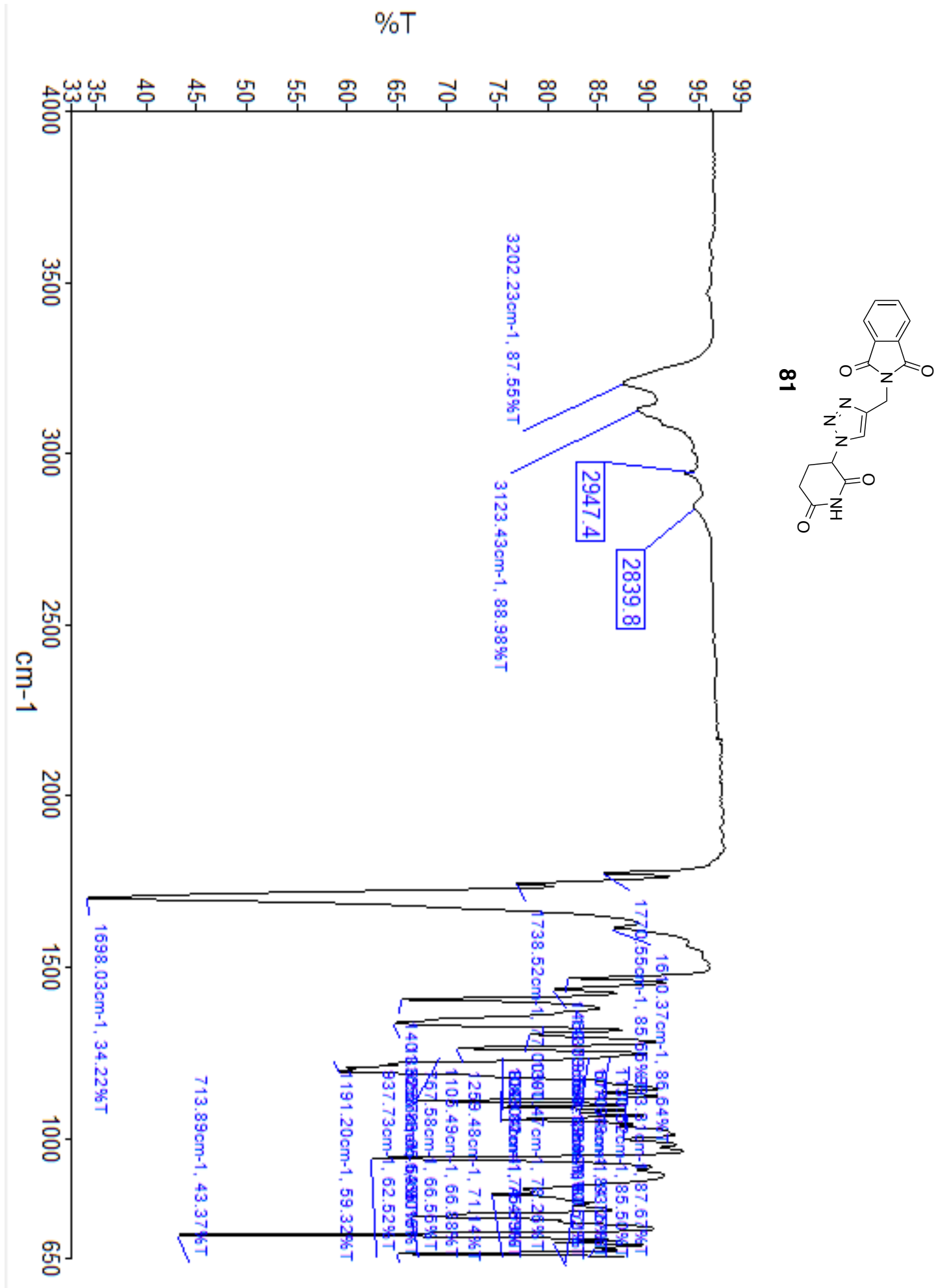




\section{3-(4-((1-Oxoisoindolin-2-yl)methyl)-1H-1,2,3-triazol-1- yl)piperidine-2,6-dione. 82}

The crude reaction mixture was submitted to gravity-column chromatography (chloroform/methanol, 97:3) to give triazole 82 as a white amorphous powder (53 $\mathrm{mg}$, 61\%): mp 212-215 ${ }^{\circ} \mathrm{C}$; Rf 0.39 (chloroform/methanol, 9:1); ${ }^{1} \mathrm{H}$ NMR (400 MHz, DMSOd6) $\delta 11.17(\mathrm{~s}, 1 \mathrm{H}), 8.16(\mathrm{~s}, 1 \mathrm{H}), 7.68(\mathrm{~d}, \mathrm{~J}=7.2 \mathrm{~Hz}, 1 \mathrm{H}), 7.56 \mathrm{e}-.57(\mathrm{~m}, 2 \mathrm{H}), 7.44-7.49(\mathrm{~m}$, 1H), $5.76(\mathrm{dd}, \mathrm{J}=12.8 \mathrm{~Hz}, 5.2 \mathrm{~Hz}, 1 \mathrm{H}), 4.80(\mathrm{~s}, 2 \mathrm{H}), 4.46$ (s, 2H) 2.77-2.82 (m, 1H), 2.592.64 (m, 2H), 2.22-2.47 (m, 1H). ${ }^{13} \mathrm{C}$ NMR (100 MHz, DMSO-d6) $\delta 172.8,169.8,167.5$, $143.5,142.2,132.4,131.9,128.3,123.9,123.8,123.3,59.5,49.9,37.4,31.1,24.7$. IR (neat) 3063, 2916, 2836, 1704, $1666 \mathrm{~cm}^{-1}$. HRMS (ESI-TOF) $\mathrm{m} / \mathrm{z}[\mathrm{M}+\mathrm{H}]+$; calculated for $\mathrm{C}_{16} \mathrm{H}_{16} \mathrm{~N}_{5} \mathrm{O}_{3} 326.1253$, Found: 326.1287. 


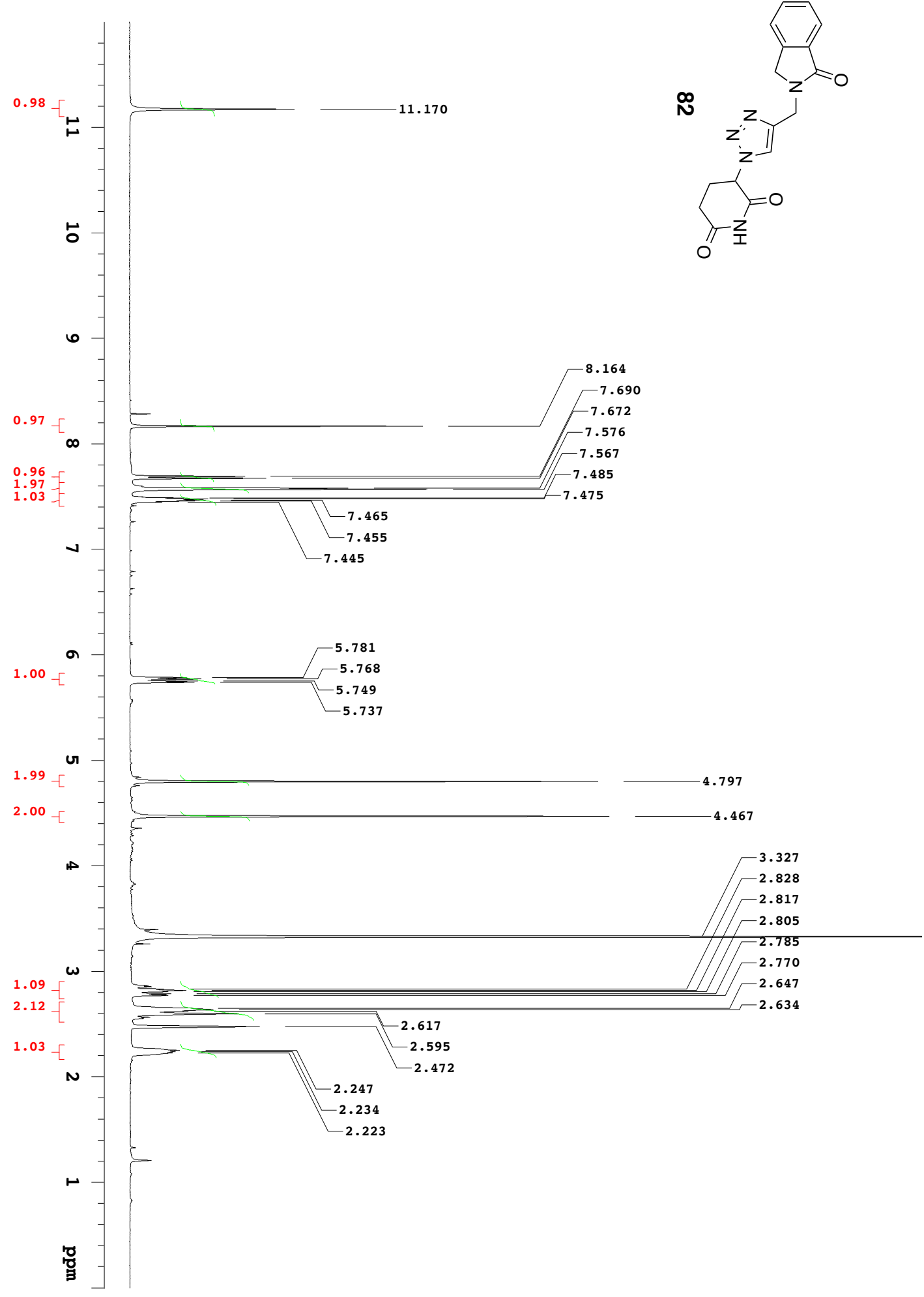




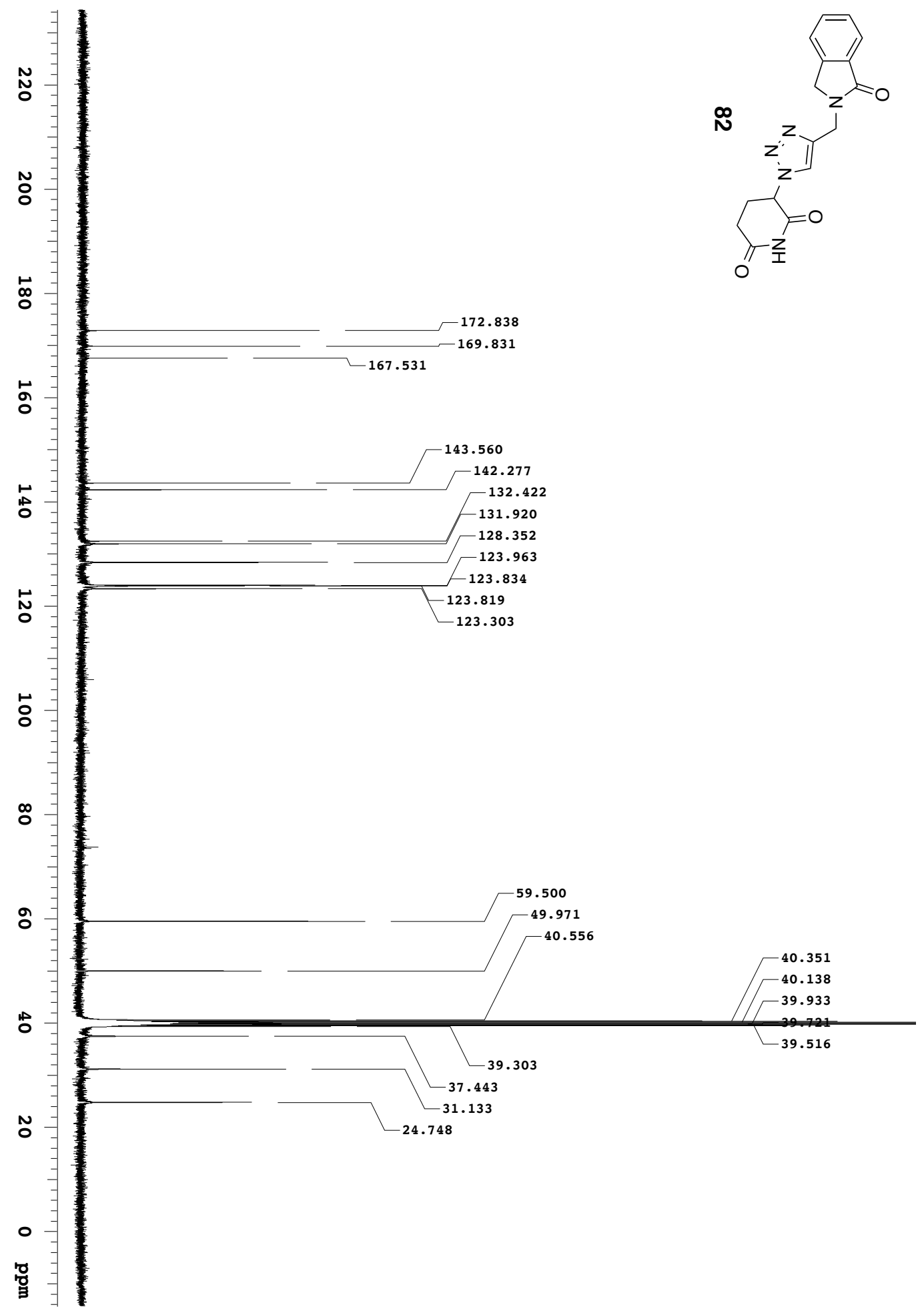




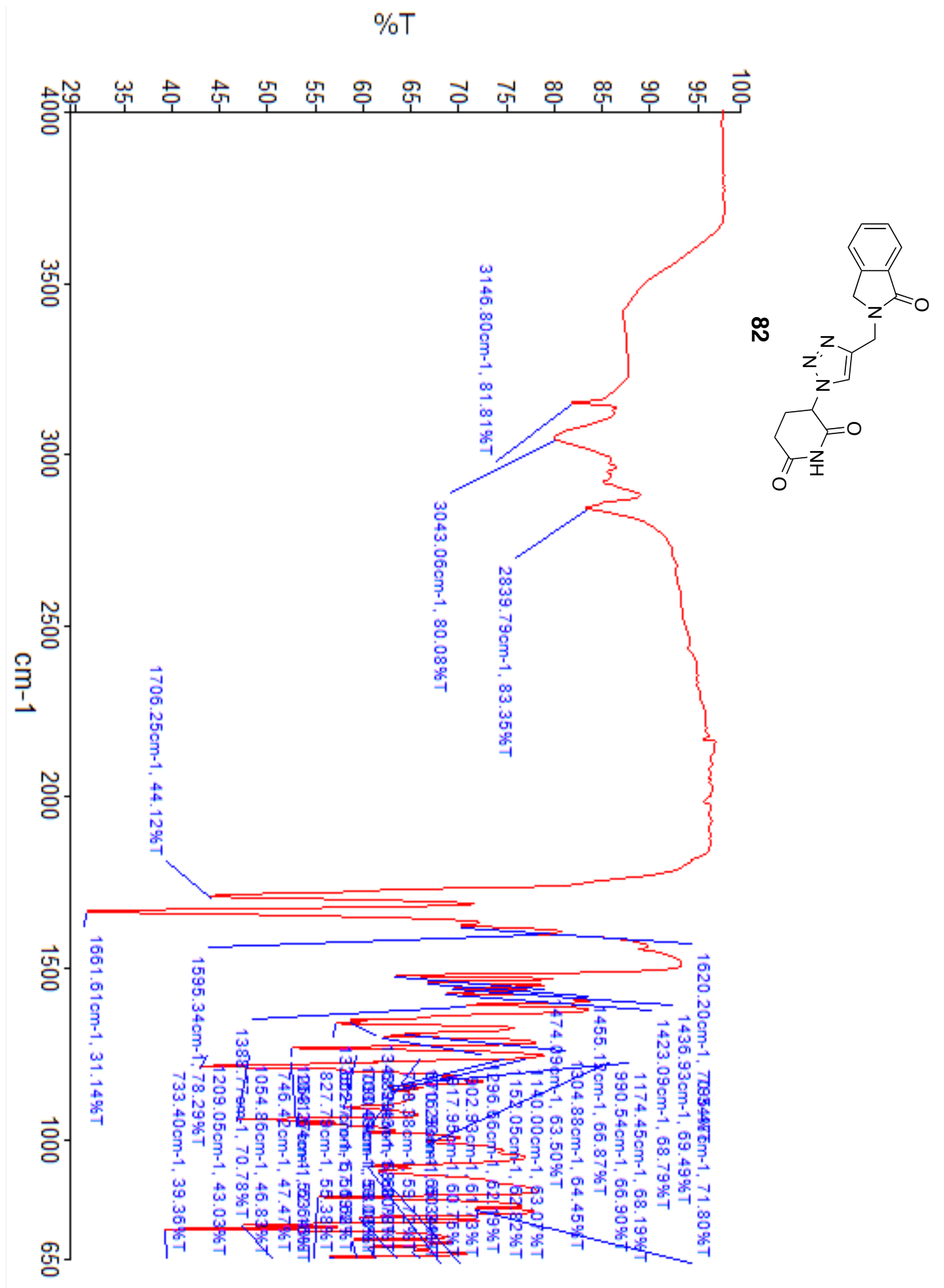




\section{2-(1-(2,6-Dioxopiperidin-3-yl)-1H-1,2,3-triazol-4-yl)isoindoline-1,3-dione. 87}

The crude reaction mixture was submitted to gravity-column chromatography (hexane/ethyl acetate, 1:9) to give triazole 87 as a white amorphous powder (126 mg, 83\%): mp 289-291 ${ }^{\circ} \mathrm{C} ; \mathrm{R}_{\mathrm{f}} 0.38$ (THF/hexane, 2:1); ${ }^{1} \mathrm{H}$ NMR d (400 MHz, DMSO-d6) $\delta 11.25$ (s, 1H), $8.45(\mathrm{~s}, 1 \mathrm{H}), 7.97-8.00(\mathrm{~m}, 2 \mathrm{H}), 7.90-7.94(\mathrm{~m}, 2 \mathrm{H}), 5.90(\mathrm{dd} \mathrm{J}=12.8,5.6 \mathrm{~Hz}, 1 \mathrm{H})$, 2.82-2.86 (m, 1H), 2.66-2.75 (m, 2H), 2.34-2.37 (m, 1H). ${ }^{13} \mathrm{C}$ NMR (100 MHz, DMSOd6) $\delta 172.7,169.5,166.5,136.1,135.5,131.8,124.2,122.9,60.2,31.2,24.6$. IR (neat) 3146, 3067, 2933, 1721, $1696 \mathrm{~cm}^{-1}$. HRMS (ESI-TOF) m/z [M+H]+; calculated for $\mathrm{C}_{15} \mathrm{H}_{12} \mathrm{~N}_{5} \mathrm{O}_{4}:$ 326.0889, Found: 326.0961. 


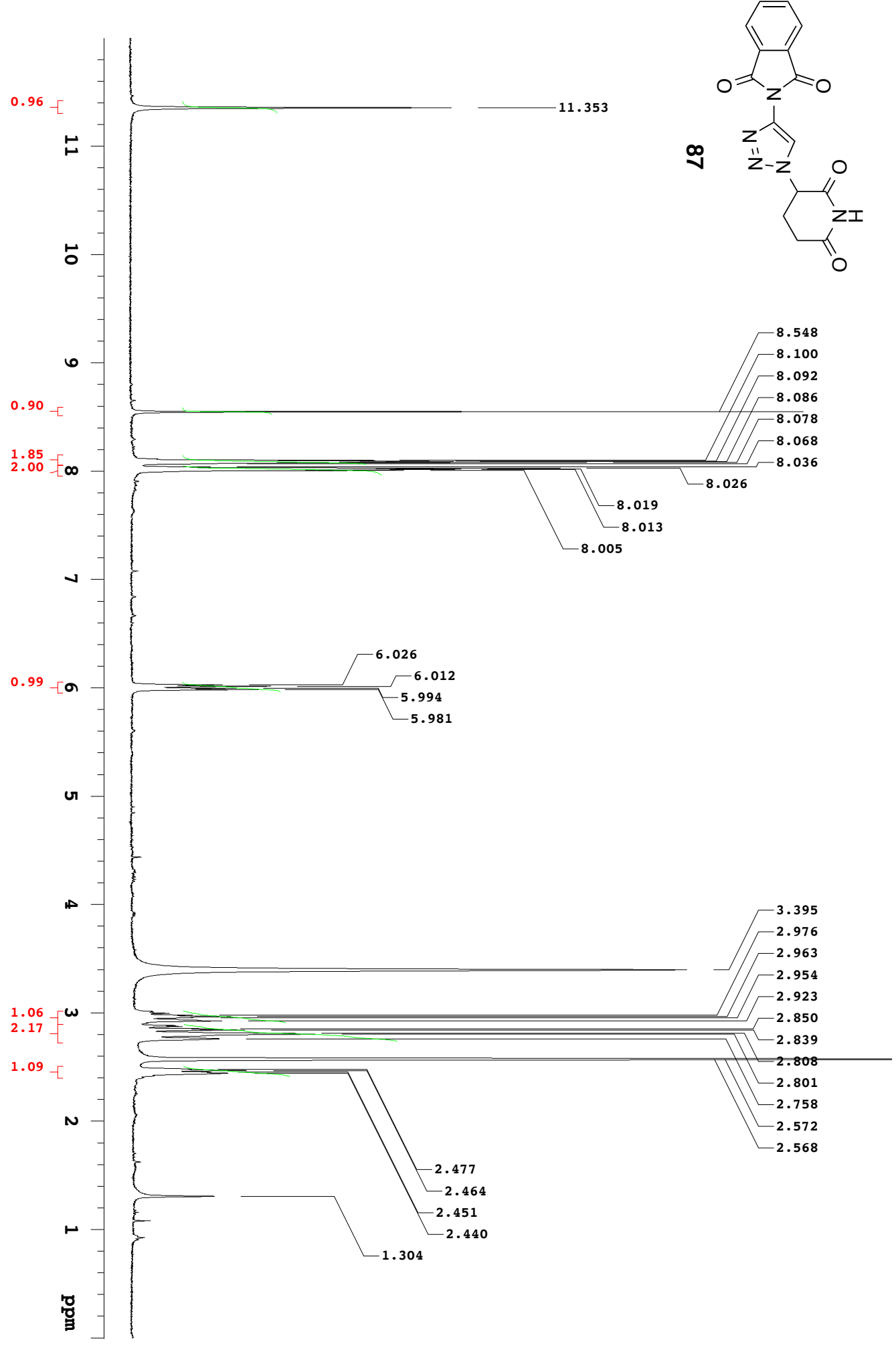




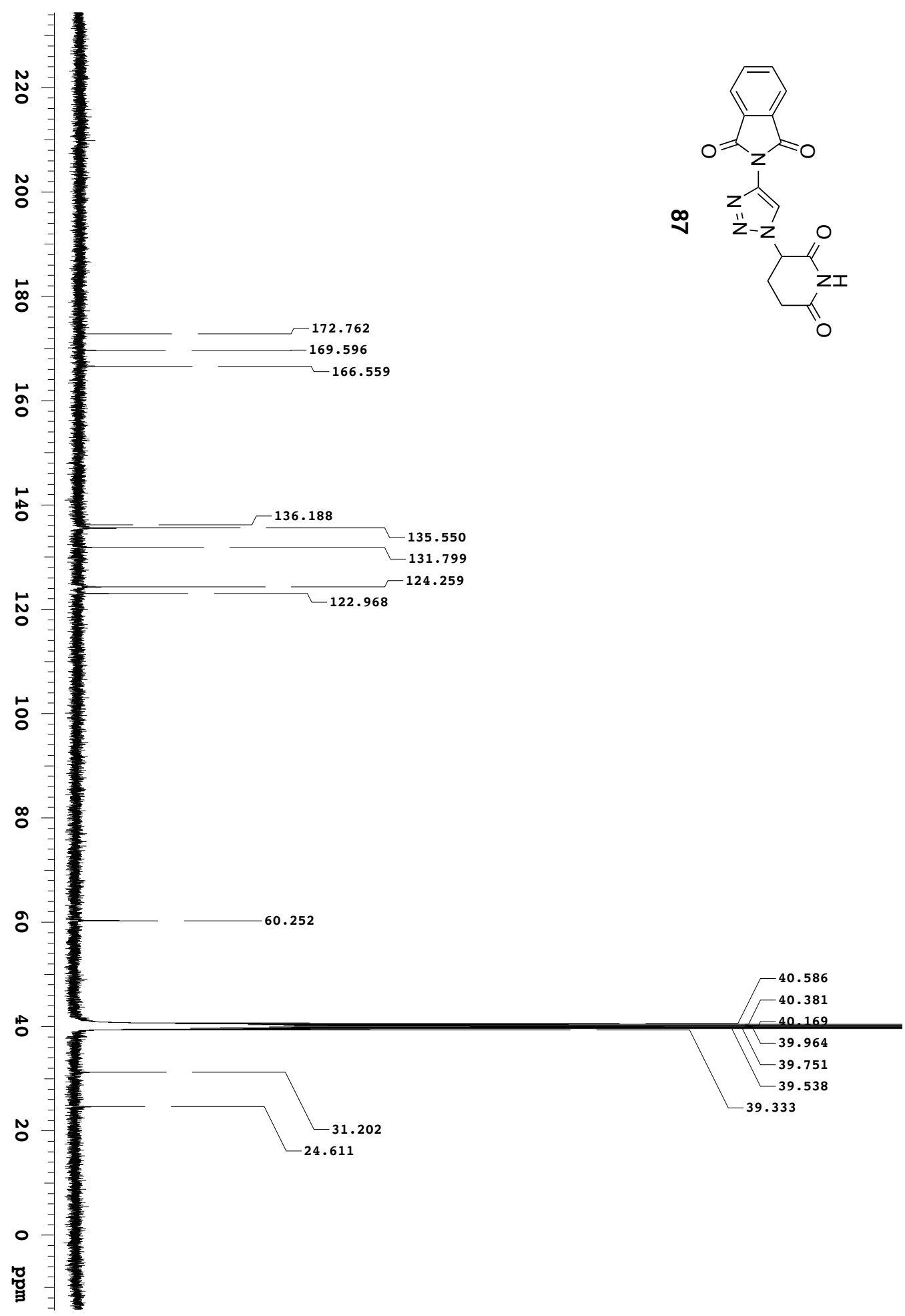




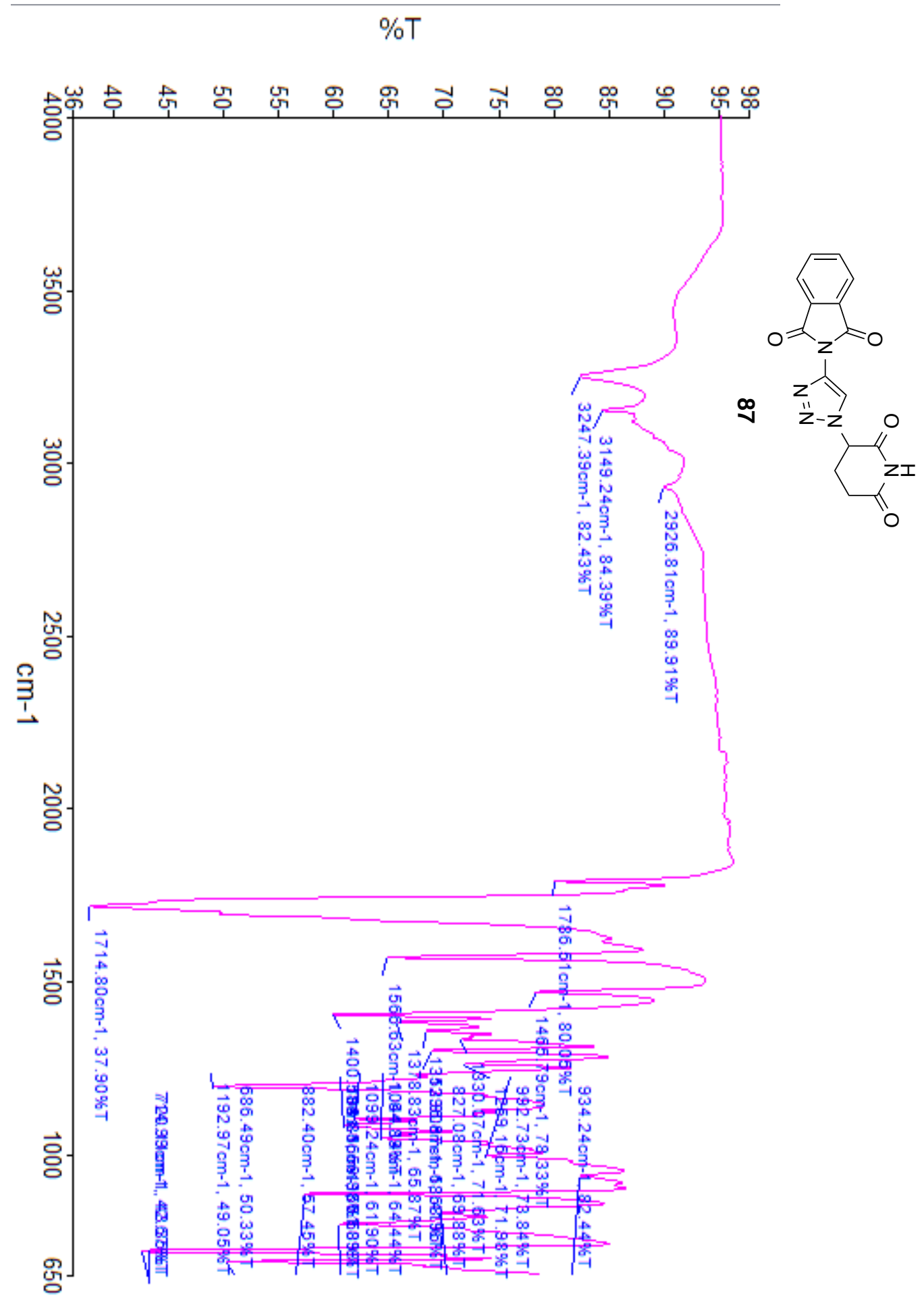




\section{3-(4-(1-Oxoisoindolin-2-yl)-1H-1,2,3-triazol-1-yl)piperidine-2,6-dione. 88}

The crude reaction mixture was submitted to gravity-column chromatography (chloroform/methanol, 95:5) and then recrystallized with methanol to give triazole $\mathbf{8 8}$ as a white amorphous powder (70 mg, 78\%): $\mathrm{mp}$ decomp. $>300 \quad{ }^{\circ} \mathrm{C} ; \quad \mathrm{R}_{\mathrm{f}} \quad 0.41$ (chloroform/methanol, 9:1); ${ }^{1} \mathrm{H}$ NMR (700 MHz, DMSO-d6) $\delta 11.19$ (s, 1H), 8.56 (s, 1H), $7.79(\mathrm{~d} \mathrm{~J}=7.7 \mathrm{~Hz}, 1 \mathrm{H}), 7.67-7.71(\mathrm{~m}, 2 \mathrm{H}), 7.53$ (dd J=7.7, $7.0 \mathrm{~Hz}, 1 \mathrm{H}), 5.85$ (dd J=13.3, $5.6 \mathrm{~Hz}, 1 \mathrm{H}), 2.76-2.84(\mathrm{~m}, 2 \mathrm{H}), 2.64-2.66(\mathrm{~m}, 1 \mathrm{H}), 2.27-2.28(\mathrm{~m}, 1 \mathrm{H}) .{ }^{13} \mathrm{C}$ NMR $(100$ MHz, DMSO-d6) $\delta 172.8,169.7,165.6,143.6,142.4,132.8,131.6,128.7,124.3,123.6$, 113.8, 60.1, 49.4, 31.2, 24.5. IR (neat) 3180, 3087, 2923, 1735, $1697 \mathrm{~cm}^{-1}$. HRMS (ESITOF) m/z [M+H]+; calculated for $\mathrm{C}_{15} \mathrm{H}_{14} \mathrm{~N}_{5} \mathrm{O}_{3}: 312.1097$, Found: 312.1176 . 


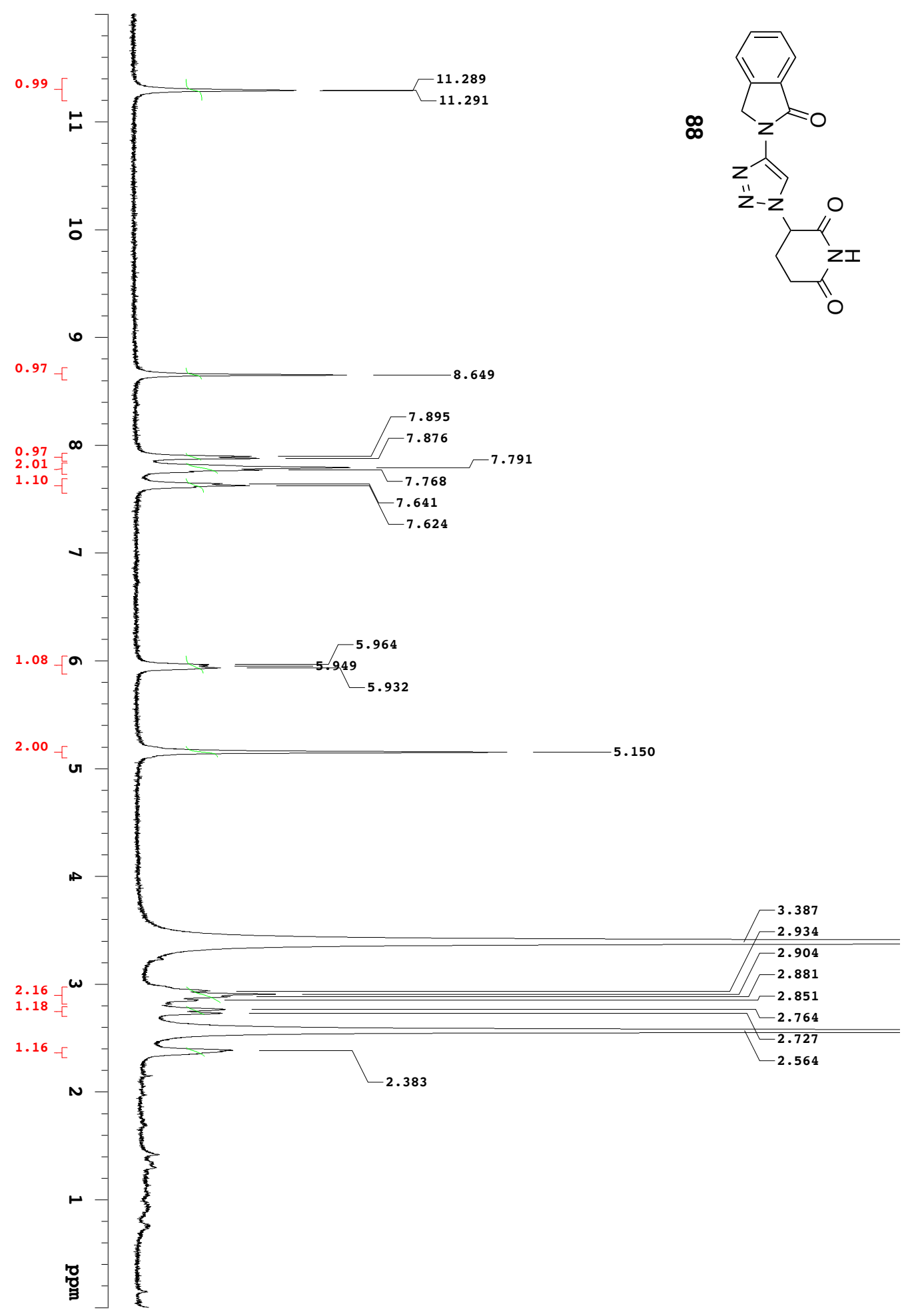




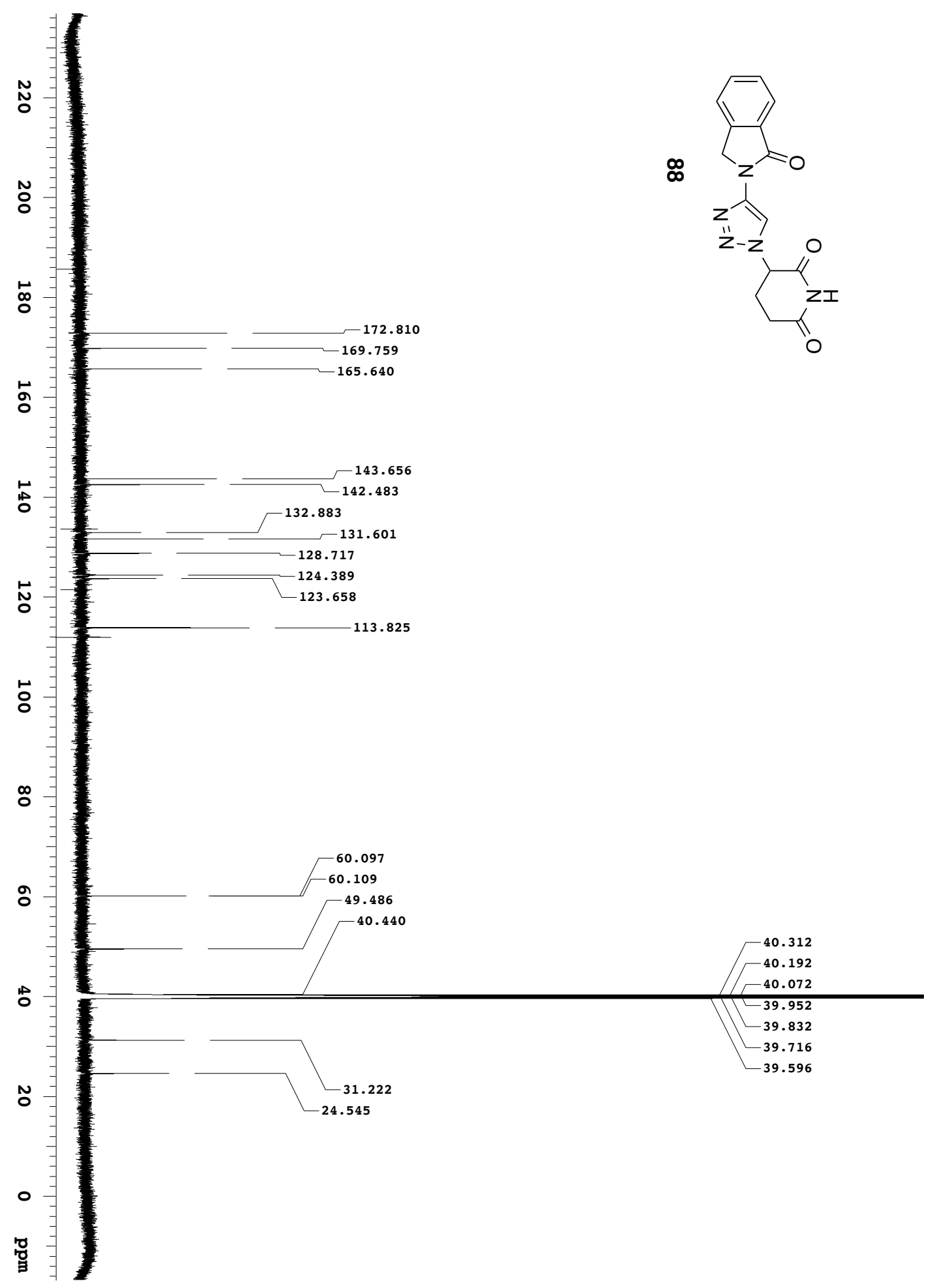




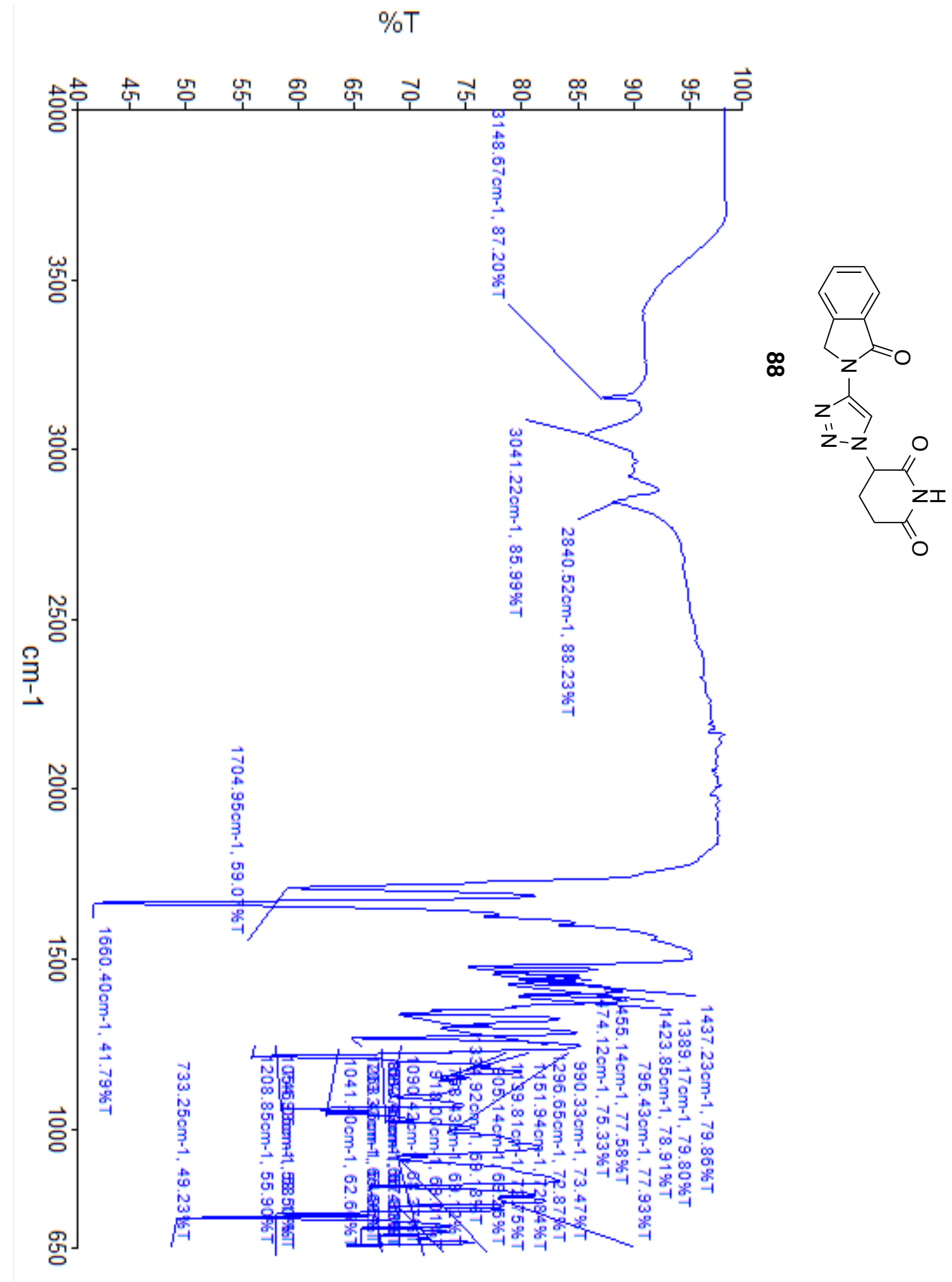




\section{PART B. AMINO ACID SYNTHESIS}




\section{Introduction}

Proteinogenic amino acids are the necessity behind the utilization for a chiral pool of amino acids. Of the chiral pool, 20 essential and non-essential amino acids exist that make up an overwhelming majority of amino acids that are proteinogenic. Outside of the 20 essential amino acids, a bevy of unnatural amino acids have been and are currently being used in a range of biological applications. ${ }^{1}$ Unlike essential amino acids which can be easily extracted, unnatural amino acids must be synthesized to be tested for their utiliziation. Unnatural amino acid synthesis has been increasing dramatically in the recent decades. In the 1980's there were only a handful of unnatural amino acids reported, whereas in recent years there have been hundreds of scientific investigations involving unnatural amino acids. (Figure 16).

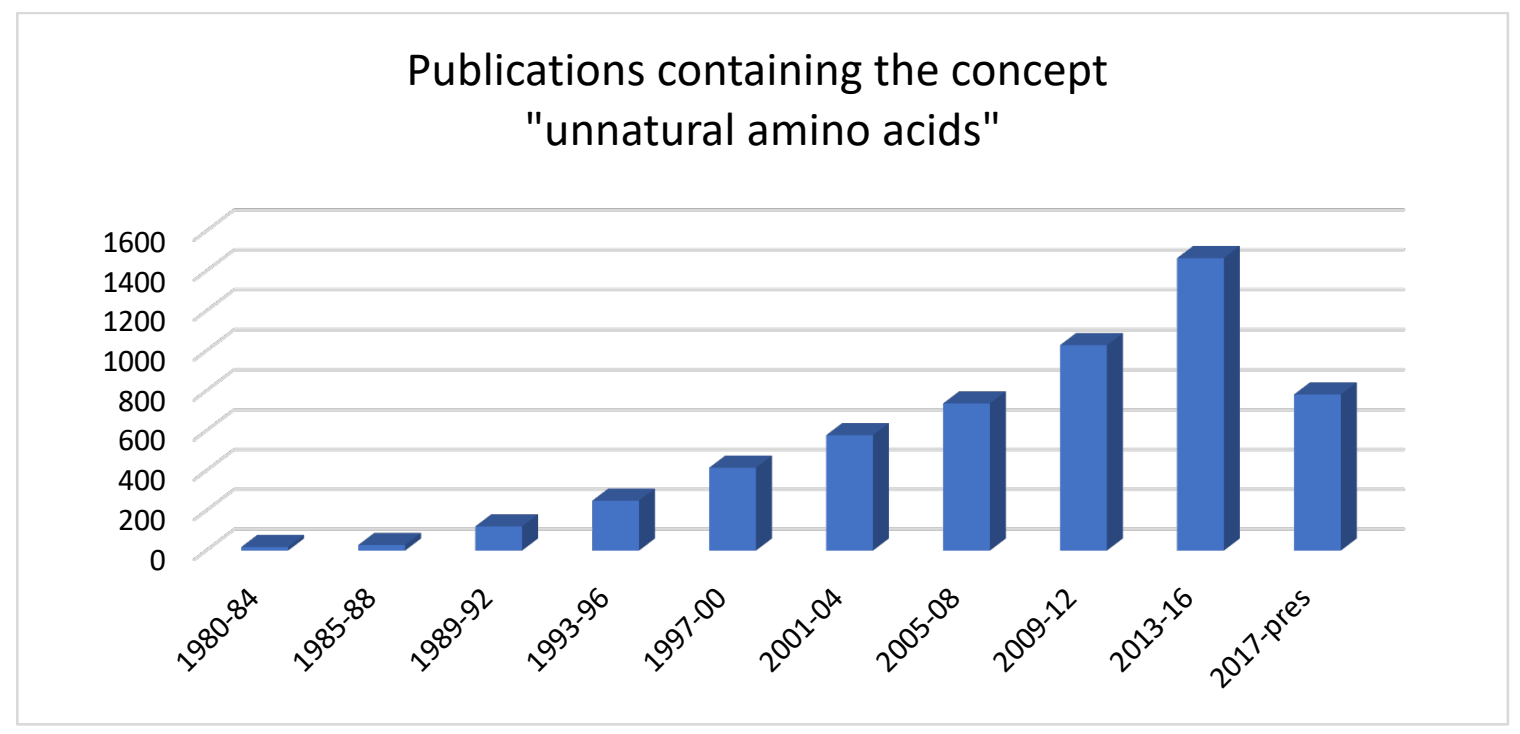

Figure 16. Increasing number of publications throughout the years on unnatural $\alpha$-amino acids. 
Unnatural amino acids have a number of useful properties that are exhibited in biological compounds ranging from altering protein functionality to use as bioconjugates and as reactants to prepare important drug-like molecules. ${ }^{2,3}$ There are a variety of recentlypublished reactions that can be utilized to synthesize unnatural amino acids. The synthesis of unnatural amino acids has evolved dramatically over the years since the first published amino acid by Strecker in $1850 .{ }^{4}$ Amino acids are defined by the presence of three characteristics: an amine, an ester, and a functional side chain. Of the plethora of retrosynthetic approaches to unnatural $\alpha$-amino acid synthesis, amino acid synthesis can
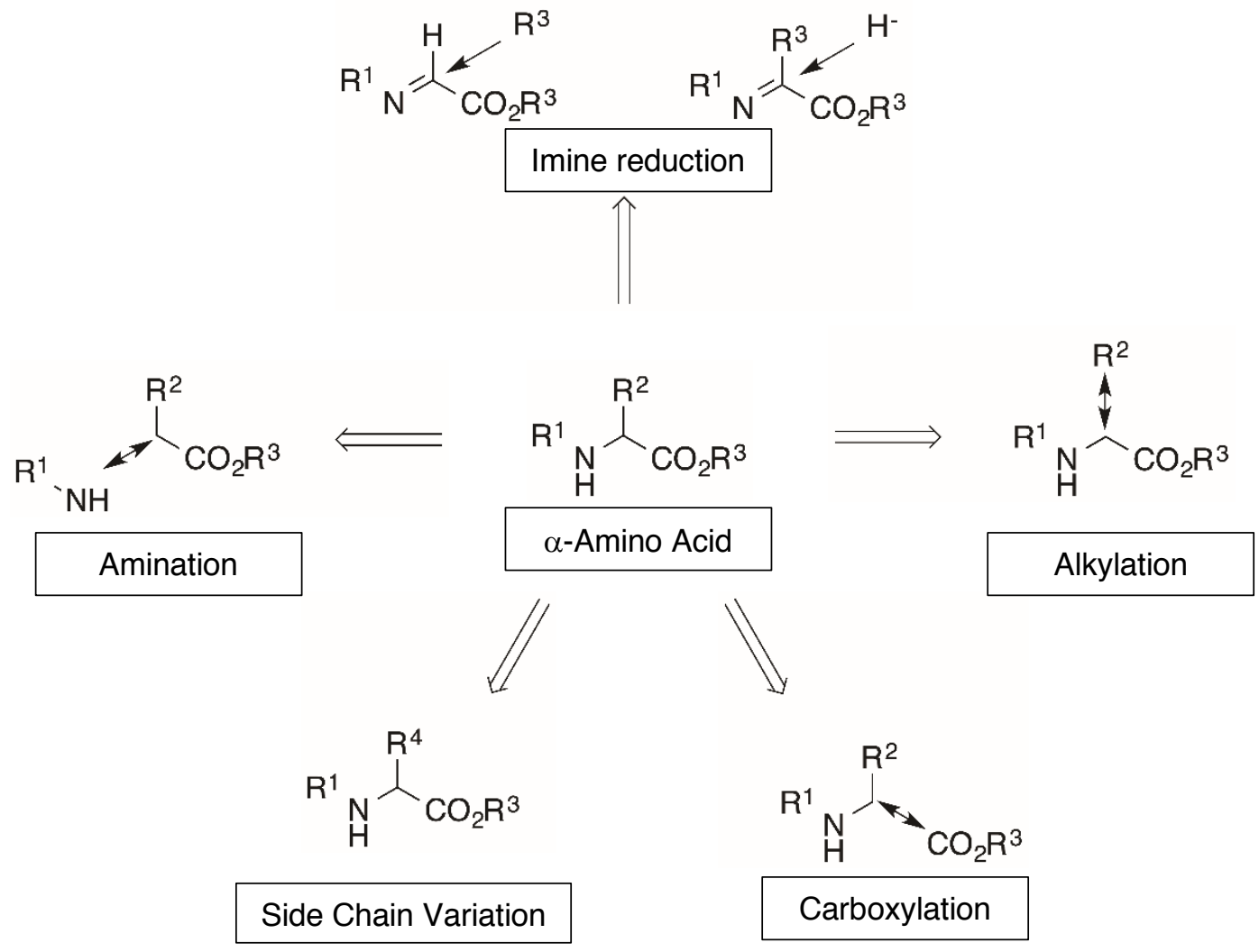

Figure 17. Retrosynthetic approaches to $\alpha$-amino acids.

be broken down into a set group of reactions (Figure 17). The most simplistic approach involves chemistry directly on the side chain to synthesize unnatural amino acids. One such early example was performed in 1958 with the benzylation of the phenolic oxygen of L- 
tyrosine..$^{5}$ Imine reduction can also be performed on an $\alpha$-imino acid in which reduction occurs with either a hetero anion or a hydride to furnish an $\alpha$-amino acid. ${ }^{6-8}$ The other classifications of unnatural amino acid synthesis involve the presence of two of these three defining characteristics and some form of chemical reaction to incorporate the final characteristic. Amination and carboxylation have both been shown to occur through metal catalysis, ${ }^{9-11}$ and amination has also been achieved under Ullman conditions. ${ }^{13}$ Alkylation of $\alpha$-amino acids has been reviewed extensively over the last few years and is accomplished through the utilization of a synthon termed "glycine equivalent," a twocarbon fragment likely containing both a protected nitrogen and carboxylic acid.

Unusual or unnatural amino acids are found within a large number of drugs and biologically active molecules. For clarity, this class of molecules is subdivided into three categories: the unnatural amino acid itself acting as the central component of the drug, unusual amino acids that are contained within linear peptides, and unusual amino acid within cyclic peptides (Figure 18). Of the unnatural amino acids that are central drug compounds, lacosamide $\mathbf{6}$ is a methoxylated serine residue that as the core scaffold. Lacosamide which bears the methoxylated serine residue, is an anticonvulsant that is approved for use in both the United States and Europe. ${ }^{13}$ Many known anticonvulsants act through inhibition of calcium channels. Lacosamide's mechanism of action is currently unknown, although it is hypothesized that lacosamide binds to a protein that subsequently interacts with voltage gated sodium channels. Saxagliptin $\mathbf{5}$ contains a bulky hydroxylated adamantane ring that is gated sodium channels, and an inhibitor of dipeptidyl peptidase IV 

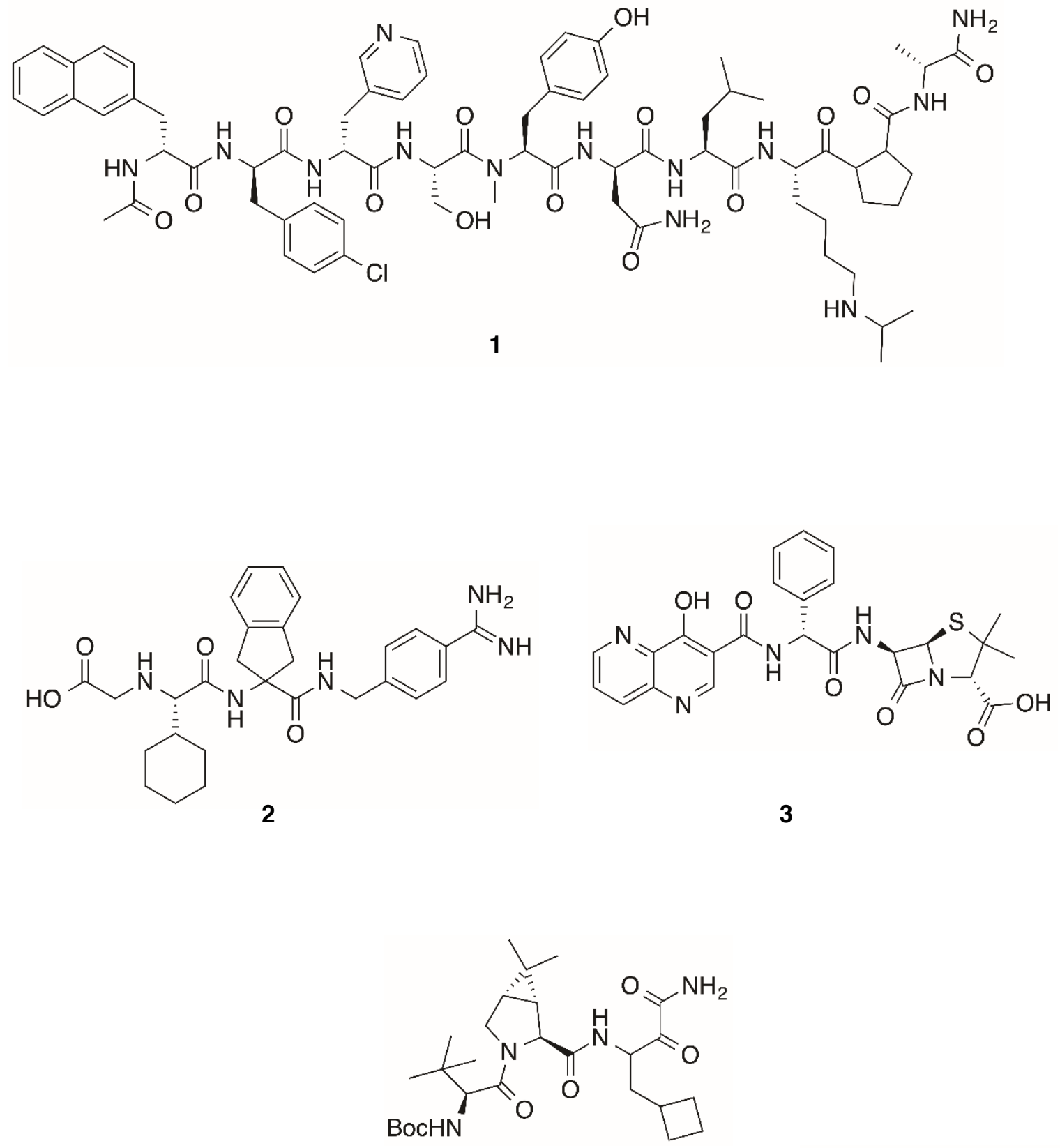

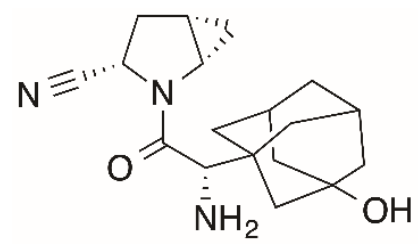

5

4<smiles>COC[C@H](NC(C)=O)C(=O)NCc1ccccc1</smiles> 
<smiles>CC(C)c1nc(CN(C)C(=O)N[C@@H](CCN2CCOCC2)C(=O)N[C@H](CC[C@@H](Cc2ccccc2)NC(=O)CCc2cncs2)Cc2ccccc2)cs1</smiles>

7<smiles>C=C[C@@H]1CC1(NC(=O)[C@@H]1CC(Oc2ncc(OC)c3ccc(Cl)cc23)CN1C(=O)[C@@H](NC(=O)OCc1ccccc1)C(C)(C)C)C(=O)NS(=O)(=O)C1CC1</smiles>

9<smiles>CC(C)[C@H](NC(=O)[C@H](CCCCN)NC(=O)[C@H](Cc1c[nH]c2ccccc12)NC(=O)[C@H](Cc1ccc(O)cc1)NC(=O)[C@H](CSSC[C@H](NC(=O)[C@H](N)Cc1ccc2ccccc2c1)C(=O)N[C@@H](C(N)=O)[C@@H](C)O)NC(=O)[C@H](N)Cc1c[nH]c2ccccc12)C(N)=O</smiles>

11<smiles>CCOC(=O)[C@H](CCc1ccccc1)N[C@@H](C)C(=O)N1Cc2ccccc2C[C@H]1C(=O)O</smiles>

8<smiles>CC[C@H](NC(=O)C[C@H](C)OC(=O)[C@H](NC(=O)[C@@H]1CC(=O)[C@@H](CS[C@@H]2CN3CCC2CC3)CN1C(=O)[C@H](Cc1ccc(N(C)C)cc1)N(C)C(=O)[C@@H]1CCCN1C(=O)[C@H](C)NC(=O)c1ncccc1O)c1ccccc1)C(=O)N[C@@H]1CN2CCC1CC2</smiles>

10<smiles>CSCC[C@H](NC(=O)[C@@H]1Cc2ccccc2CN1C(=O)[C@@H](NC(=O)[C@H](CS)NC(=O)[C@H](N)CCCCN)C(C)C)C(=O)O</smiles>

Figure 18. A small set of biologically active structures that bear at least one and up to eight unnatural amino acids. 
(DDP-IV) and is used for the treatment of type II diabetes. ${ }^{14}$ Inhibitors of DDP-IV regulate the level of incretin, leading to a downstream effect on insulin and blood glucose levels. Of the bulky side groups, one of the most prevalent and commonly used unnatural amino acids is tert-leucine. The unnatural tert-leucine is hydrophobic, sterically bulky, and inflexible and occurs in both natural products and in drugs currently on the market.

Unnatural amino acids are also used in a class of drugs that are comprised of linear peptides, ranging from dipeptides to polypeptide chains. Many linear peptides contain a Damino acid at or near the $C$ - or $N$-terminus in order to be less susceptible to proteolysis. A decapeptide, Abarelix 1 is currently being used for treatment of prostate cancer. ${ }^{15}$ This is done by binding to gonadotropin-releasing hormone and decreasing testosterone levels and thus hindering the growth of prostate cells. Two tripeptides, asunaprevir ${ }^{16}$ and boceprevir, ${ }^{17}$ are under investigation as potential drug candidates. Both of these drugs contain a tertleucine as well as a derivatized proline for the treatment of Hepatitis C Virus (HPV) infection. Asunaprevir 8 is currently in phase III trials and boceprevir 4 was recently removed from the market in favor of drugs with higher inhibitor specificity. The tripeptides act by inhibiting the NS3 protease that destroys downstream proteins, preventing the genome replication of HPV. A class of inhibitors and amino acid-based drugs are observed with a constrained phenylalanine derivative seen as a cyclic amino acid: quinapril, ${ }^{18}$ farnesyl transferase inhibitor, ${ }^{19}$ and activated protein C inhibitor. ${ }^{20}$ Quinapril, 9, is currently being sold as an inhibitor of the angiotensin converting enzyme (ACE) which is used in the treatment of hypertension by allowing for production of angiotensin II. ${ }^{18}$ One of the core structural unnatural amino acids is a 1,2,3,4-tetrahydroisoquinoline carboxylic acid (Tic) derivative 13 (Figure 19a). The Tic derivative can also be seen in a pentapeptide 
farnesyl transferase inhibitor $\mathbf{1 2}$ where the only unnatural amino acid is the replacement of a Phe with a Tic. Synthesizing an inhibitor with Tic as opposed to phenylalanine resulted in a more potent inhibitor of the Ras protein, a protein involved in cellular growth. ${ }^{19}$ Similar to the Tic derivative, another constrained amino-acid derivative observed as an inhibitor is an indane-based (Ind) amino acid 14 (Figure 19b). A tripeptide inhibitor of activated protein $\mathrm{C}$ containing two unnatural amino acids, a cyclohexyl-glycine derivative next to an Ind amino acid, could be used for hemophilic disorders. ${ }^{20}$ The tripeptide 2 was demonstrated to be a potent inhibitor of activated protein $\mathrm{C}$ which results in the generation of thrombin and is potentially useful as a coagulant. As well, unnatural amino acids are observed in the $\beta$-lactams class of antibiotics. Of these $\beta$-lactams, amoxicillin contains an unnatural amino acid as well as a lactam ring composed of a bicyclic dipeptide $\mathbf{3}$. Amoxicillin and other $\beta$-lactams have been extensively investigated and their importance is very well defined. ${ }^{21,22}$

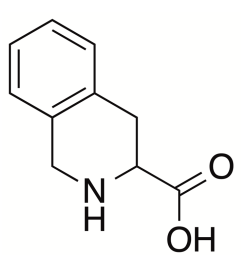

a) 13

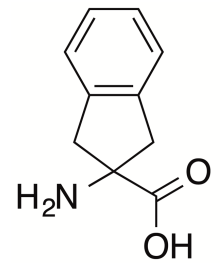

b) 14

Figure 19. Two phenylalanine mimics that are reported to be used as unnatural amino acids are a) Tetrahydroisoquinoline carboxylic acid (Tic) derivative and b) Indane-based (Ind) derivative

Outside of single amino acid drugs and linear peptide drugs, a class of cyclic peptide drugs exist in which the range of a single amino acid is changed to a majority of the cyclic peptides. Cyclic peptides are commonly observed having two cysteines to 
provide a disulfide bridge in a few hormones, including somatostatin. A single substitution to an unnatural amino acid is observed on the cyclic peptide lanreotide, a somatostatin receptor antagonist. Lanreotide contains a single substituted unnatural amino acid, D-2'napthalalanene, on the $\mathrm{N}$-terminus and is used for the treatment of acromegaly. ${ }^{23} \mathrm{Cyclic}$ peptides are also formed through more than just disulfide bridges, including a depsipeptide which is seen in the cyclic natural product-derived peptide quinupristin $10 .{ }^{24}$ The mixture of quinupristin with dalfopristin is sold as the antibiotic, Synercid, in which quinipristin contains multiple unnatural amino acids.

The two-carbon "glycine equivalent" containing a protecting groups do not only provide orthogonal protection, but also provide an increased activation for reactivity of neighboring atoms. Alkylation through activation of the protected glycine equivalents was demonstrated by O'Donnell and co-workers with the versatile benzophenone imine. The O'Donnell strategy utilizes the benzophenone imine, and under anhydrous or phase transfer catalysis, the benzophenone imine undergoes alkylation through a base-catalyzed reaction. Under the mildly basic conditions, the reaction afforded the racemic monoalkylated product (Scheme 10). ${ }^{25-28}$ Modifications of the benzophenone imine at the $C$-terminus were accomplished by utilizing either a solid phase or a polyethylene glycol to mediate a solid phase or liquid-phase synthesis. ${ }^{29}$ Some advantages of these approaches include a support to deprotect the amine and allow further chemistry to occur on the free amine. An asymmetric approach was initially proposed by O'Donnell utilizing chiral auxiliary reagents. ${ }^{30}$ 
<smiles>CCCC(=O)CN=C(c1ccccc1)c1ccccc1</smiles>

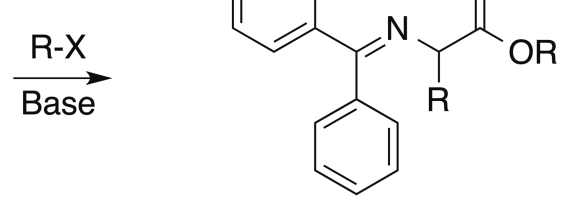<smiles>[R]C(N)C(=O)OCCOC(=O)O</smiles>

Scheme 10. General approach by O’Donnell et al. to synthesize $\alpha$-amino acids.

Cinchonine-derived catalytic salts have been shown to generate enantiomerically enriched amino acid derivative. This approach was modest, generating a $66 \%$ enantiomeric excess (ee) and a greater enantioselective approach has been explored utilizing a range of chiral derivatives to give more enantioselectivity (96\% - 99\% ee). While utilizing the benzophenone imine as a nucleophile has been explored, O'Donnell also showed the versatility of the benzophenone imine to be an electrophile through an acetylated intermediate. This allowed for a nucleophile to displace the acetate on the cationic glycine equivalent. Similar to the enantioselective reactions performed on the anionic glycine equivalent, O'Donnell was the first to investigate enantioselective reactions that were completed with a slight enantiomeric excess on the acetylated benzophenone imine with a palladium catalyst and a chiral pyrrolidine auxiliary. This investigation led to the use of other $\mathrm{N}$-substituted acetylated glycine equivalents to be utilized in an enantioselective reaction which gave optically enriched unnatural amino acids. A range of chiral unnatural amino acids were also synthesized by Myers et al. without a protected amine (Scheme 11). ${ }^{31}$ The protected $C$-terminus glycinamide contains a chiral phenylpropanol which has a chiral induction effect, resulting in an enantioselective alkylation. A more recent synthesis of $\alpha, \alpha$-unnatural amino acids has been demonstrated with a glycine equivalent 
<smiles>C[C@H](c1ccccc1)N(C)C(=O)CN</smiles><smiles>[R]C(N)C(=O)N(C)[C@@H](C)[C@H](O)c1ccccc1</smiles><smiles>[R][C@H](C)O[C@H](C)O</smiles>

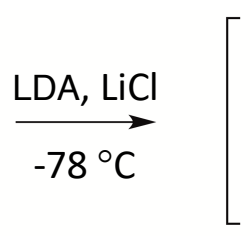<smiles>C[C@H](c1ccccc1)N(C)C(=O)CN</smiles>
$0^{\circ} \mathrm{C}$

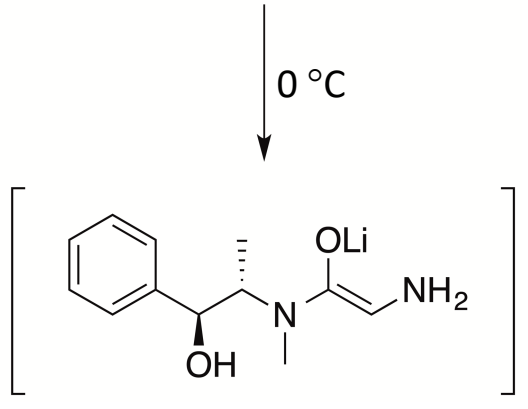

Scheme 11. General approach by Myers et al. to synthesize $\alpha$-amino acids.

Schiff base and a Ni(II) complex. ${ }^{32,33}$ This complex synthesized by Soloshonok et al. has generated a range of $\alpha, \alpha$-unnatural amino acids through a base catalyzed dialkylation to generate a $\alpha, \alpha$-cyclic or symmetrical $\alpha, \alpha$-disubsituted glycine equivalent. The substituted $\mathrm{Ni}$ (II) glycine equivalent is easily cleaved through acid hydrolysis to give the free $\alpha, \alpha$ unnatural amino acid. The Ni(II) complex with the tetradentate ligand has been modified by Brimble et al. to generate an asymmetric approach to chiral $\alpha$-unnatural amino acids (Scheme 12). ${ }^{34}$ Enantioselective reaction was accomplished through the derivatization of a/the pyridine ring on the tetradentate ligand to be a substituted chiral $N$-benzyl pyrrolidine derivative. This Schiff base glycine derivative within the Ni(II) complex was observed to have bis-addition to give $\alpha$-amino acids through a stereoselective alkylation. Similar to these aforementioned reactions of acyclic glycine equivalents, a class of cyclic glycine equivalents have also been utilized and reviewed. In the synthesis of proteinogenic and non-proteinogenic amino acids, it is commonly observed that many of the protecting groups are used to perform multiple tasks by providing orthogonal protection while also activating the methylene of a glycine equivalent. 


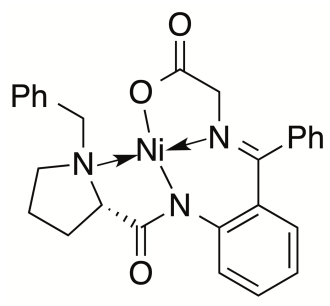

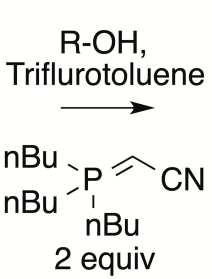

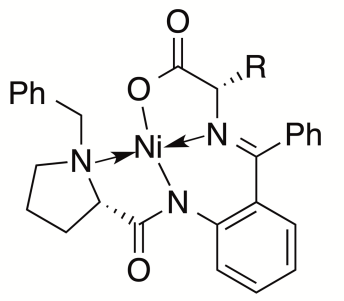

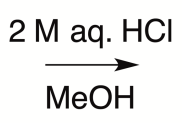

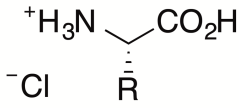

Scheme 12. Modified approach by Brimble et al. to synthesize enantiomerically pure $\alpha$ amino acids.

Protecting groups are not a necessity, as demonstrated by Myers and coworkers, ${ }^{31}$ but are commonly used in synthesizing $\alpha$-amino acids and must undergo deprotection in a one or two step process in order to obtain the amino acid. When a multistep deprotection is necessary, the conditions required to deprotect can generally be less harsh than a onestep deprotection of the large protecting groups usually used in amino acid synthesis. An $N$-isoindolinone falls under a multistep deprotection, having the ability to undergo oxidation to yield a $N$-phthaloyl group. The $N$-isoindolinone group allows the activation of the $\alpha$-methylene of an ethyl- or a tert-butyl ester under basic conditions so that side chains may be installed. The anionic glycine equivalent provides installment of a side chain with a reactive electrophile such as an alkyl or benzyl halide. The newly-formed alkylated $\mathrm{N}$ isoindolinone is then selectively oxidized to a removable $N$-phthaloyl group that has been utilized as a protecting group for peptide chemistry. Detailed studies including the scope of the alkylation reaction and the response of selected substrates to the benzylic oxidation of the $\mathrm{N}$-isoindolinone moieties are reported herein. ${ }^{35}$ 


\section{Results and Discussions}

Our preparation of $\mathrm{N}$-isoindolinone derived esters is the initial building block for this novel synthesis of amino acids (Scheme 13). The addition of sodium hydride (NaH) to $N$-isoindolinone 13 in THF generates the sodium salt which then reacts with either ethyl bromoacetate or tert-butyl bromoacetate to synthesize either ethyl 2-(1-oxoisoindolin-2yl)acetate or tert-butyl 2-(1-oxoisoindolin-2-yl)acetate $\mathbf{1 4 / 1 5}$ respectively. ${ }^{36}$ Both compounds, ethyl 14 (78\%) and tert-butyl 15 (97\%), were obtained in good yields after column chromatography on silica gel (Scheme 13).

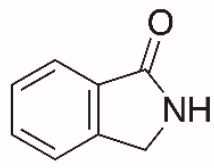

13
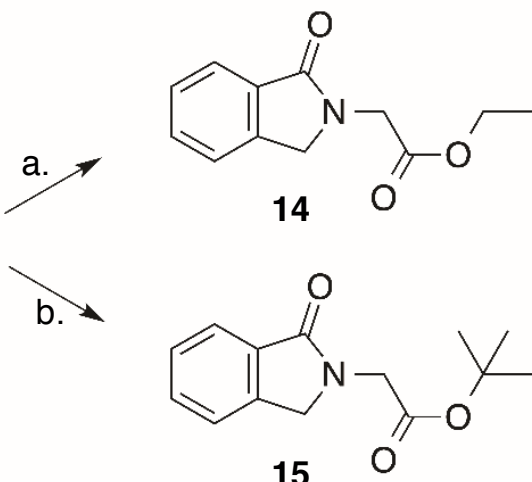

Scheme 13. Preparation of $N$-isoindolinone esters. Reagents/Conditions: (a) NaH/ethyl bromoacetate/ $20{ }^{\circ} \mathrm{C} / 16 \mathrm{~h}(78 \%)$ (b) $\mathrm{NaH} /$ tert-butyl bromoacetate/ $20{ }^{\circ} \mathrm{C} / 16 \mathrm{~h}(78 \%)$

The alkylation of both compounds is mediated through lithium hexamethyl disilazide (LiHMDS) which generates the anion for alkylation with an electrophile. LiHMDS (1.05 to 1.5 equiv) is added to the mixture of ester and electrophile in THF. Bases with increasing strength were explored; cesium carbonate, sodium ethoxide and potassium tert-butoxide, but under similar conditions but gave little to no encouraging results as only starting materials were observable by TLC. The selected bases were explored due to the esters containing two potential sites for the generation of an activated methyl anion, the 
desired carbon $\alpha$ to the ester and the undesired carbon $\alpha$ to benzene. ${ }^{37,38}$ While other bases showed no promise in anion generation, LiHMDS generates both the desired and undesired anion when used in excess and was a byproduct from the reactions (Scheme 14). If multialkylated byproduct were generated and observed by TLC, purification by column chromatography was done to isolate desired product.<smiles>CC(C)(C)CN1Cc2ccccc2C1=O</smiles>

$14 / 15$ a.<smiles>[R]OC(=O)C([R])N1Cc2ccccc2C1=O</smiles>

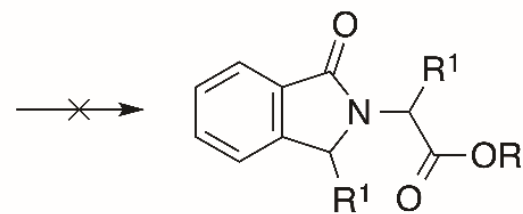

Scheme 14. Preparation of the mono-alkylation of the $N$-isoindolinone amino acid derivative. Reagents and conditions: (a) LiHMDS $/ \mathrm{R}^{1}-\mathrm{X}(\mathrm{X}=\mathrm{C} 1, \mathrm{Br} \mathrm{I}) / \mathrm{THF} /-78{ }^{\circ} \mathrm{C}$ to $\mathrm{rt} / 1-16 \mathrm{~h}$.

A range of electrophiles was used to demonstrate the scope of the base-mediated alkylation of the isoindolinone esters (Table 4.). More specifically, the reactivity and yield were in part dependent upon the reactivity of the electrophile, with the most reactive electrophiles giving products readily and in good yield. When using less reactive electrophiles, the reaction did not go to completion as readily as with more reactive electrophiles and thus resulted in what appeared to be starting ester decomposition with a poorer overall yield. This was the basis for switching from the starting protected ethyl ester to the tert-butyl ester in an attempt to utilize a starting material with a more robust protecting group. A grouping to easily classify the range of electrophiles is the alkyl iodides, yielding primary and secondary esters (70-86\%), the allyl/propargyl bromides, yielding the allyl/propargyl ester products (93 and 78\% respectively), and lastly the benzylic halides, affording the aromatic derived ester products (51-82\%). While evaluating 
the reaction conditions and the protocol, an equivalent of base was added to each reaction and stirred while monitoring by TLC. An additional amount of base was added in intervals to push the reaction to completion and thereby required a different amount of base for each alkyl halide. The requirement for additional base may be due to moisture hindering the strength of the base.

Table 4. Alkylation of the $N$-isoindolinone protected esters<smiles>O=C(O)CN1Cc2ccccc2C1=O</smiles>

$14 / 15$ $\stackrel{\text { a. }}{\longrightarrow}$<smiles>[R]OC(=O)C([R7])N1Cc2ccccc2C1=O</smiles>

16-26

Product (Yield \%)




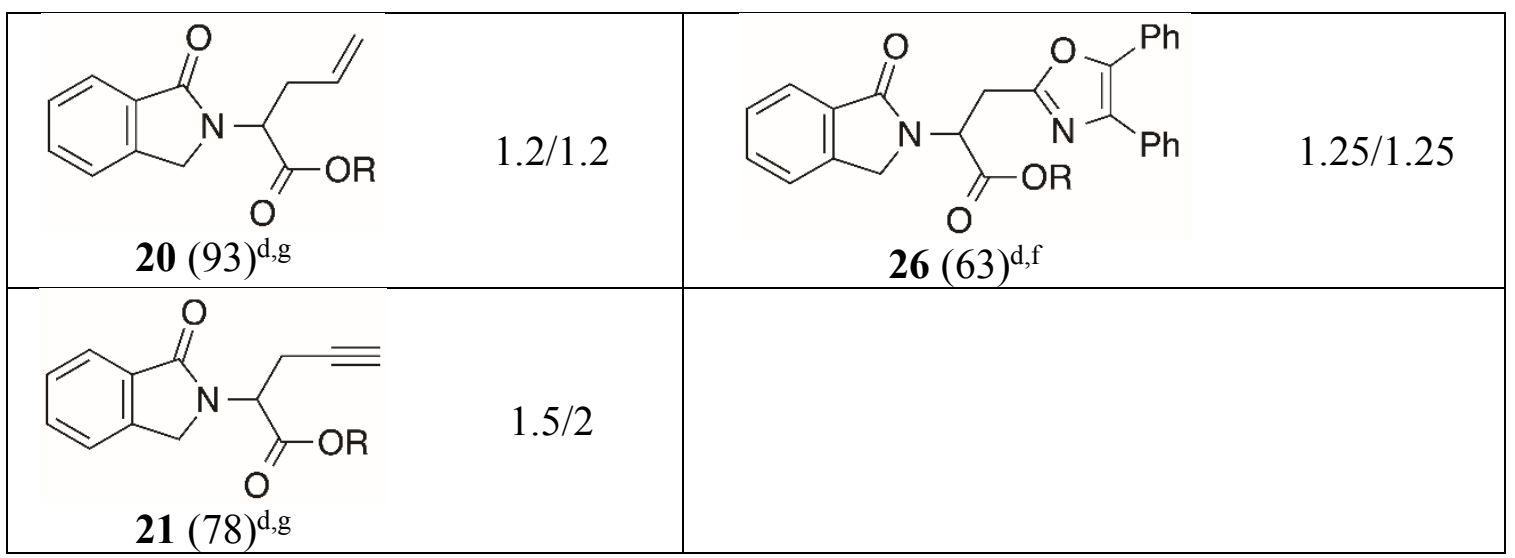

aReagents/Conditions: LiHMDS/THF/then $\mathrm{R}^{1}-\mathrm{X}(\mathrm{X}=\mathrm{Cl}, \mathrm{Br}, \mathrm{I}) /-78 \mathrm{C}$ to $\mathrm{rt} / 1-16 \mathrm{~h}$.

bYields are of isolated, chromatographically pure products. ${ }^{\mathrm{c}}$ Alkyl iodide was used.

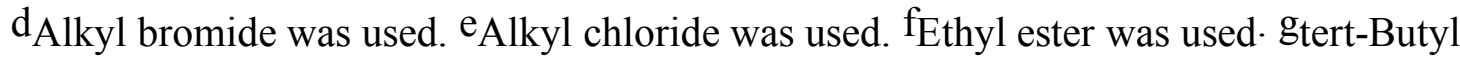
ester was used.

In synthesizing the $\mathrm{N}$-phthaloyl protected amino acid, a benzylic oxidation to convert the isoindolinone to the phthalimide was explored (Table 5) ${ }^{39,40}$ A host of reagents/conditions such as; MCPBA ( $m$-chloroperbenzoic acid) with a combination of oxygens, or 2,2'-bipyridinium chlorochromate (BPCC)/MCPBA, $\mathrm{SeO}_{2}, \mathrm{Oxone}^{\circledR} / \mathrm{KI}$, were used in evaluating the benzylic oxidation of the isoindolinone and were either unreactive or yielded complex mixtures. ${ }^{41}$ An optimal set of reaction conditions using Oxone ${ }^{\circledR} / \mathrm{KBr}$ in acetonitrile:water yielded the desired corresponding $N$-phthaloyl products. The alkylated compounds were dissolved in acetonitrile- $\mathrm{H}_{2} \mathrm{O}(9: 1)$ and $\mathrm{Oxone}^{\circledR}$ (5 equiv.) with potassium bromide ( 0.5 equiv.) added and allowed to stir for 16 hours at an elevated temperature (40$\left.45^{\circ} \mathrm{C}\right)$. The crude reaction mixture was concentrated and extracted from water with dichloromethane, and then reconcentrated followed by purification by gravity column chromatography. The alkylated products were all evaluated, as well the starting unalkylated 
isoindolinone to represent a "glycine equivalent," in their ability to undergo the benzylic oxidation and produce the $N$-phthaloyl ester. The benzylic oxidation using Oxone ${ }^{\circledR} / \mathrm{KBr}$ yielded the corresponding imide in a straightforward process. However, some alkylated isoindolinone products afforded anomalous or unexpected results.

Table 5. Oxidation of the $N$-isoindolinone esters to yield $N$-phthaloyl amino acid derivatives.<smiles>[R]C(=O)C([R7])N1C(=O)c2ccccc2C1=O</smiles>

15-24 27-36

(2)




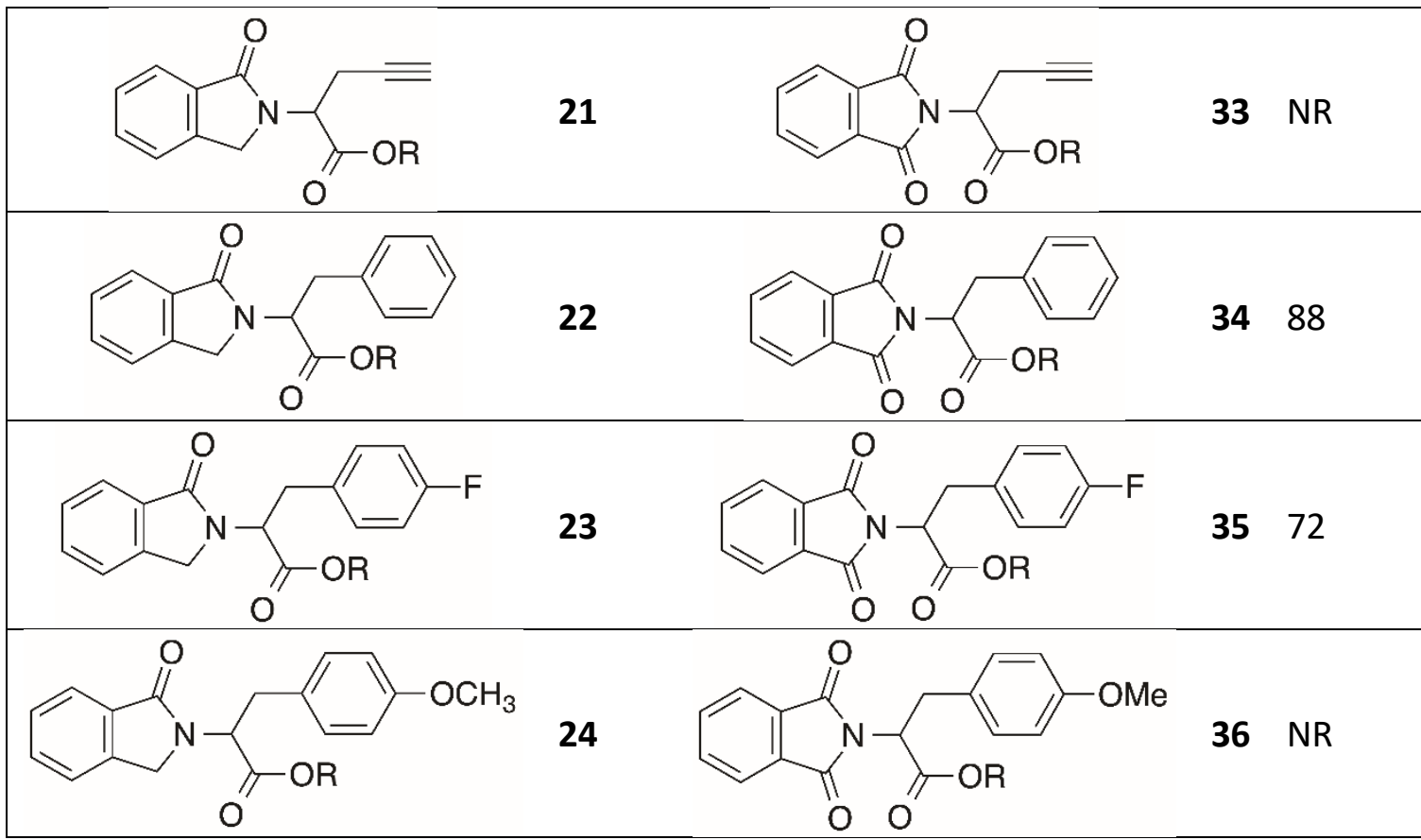

${ }^{\text {a Reagents/Conditions: Oxone }}{ }^{\circledR} / \mathrm{KBr} / \mathrm{MeCN} / \mathrm{H}_{2} \mathrm{O} / 40-45{ }^{\circ} \mathrm{C} / 16$ h. ${ }^{\text {b}}$ Yields are of isolated chromato-graphically-pure product.

A majority of the substrates underwent oxidation to give the desired product, but the allyl, propargyl, and para-mehtoxybenzyl side chain products $\mathbf{3 2 ,} \mathbf{3 3}$, and $\mathbf{3 6}$ failed to respond to oxidation with $\mathrm{Oxone}^{\circledR} / \mathrm{KBr}$ system. The inability for these alkylated isoindolinones to undergo benzylic oxidation is likely due to the electron rich side chains which promoted unwanted reactions. Of the reactions that underwent oxidation, two compounds gave unexpected results after oxidation. The naphthalene methyl isoindolinone underwent oxidation with the optimized conditions to yield the benzylic oxidation as expected $(80 \%)$, but bromination of the naphthalene ring in the 2-positionto give $\mathbf{3 7}$ was observed as well (Scheme 15). 


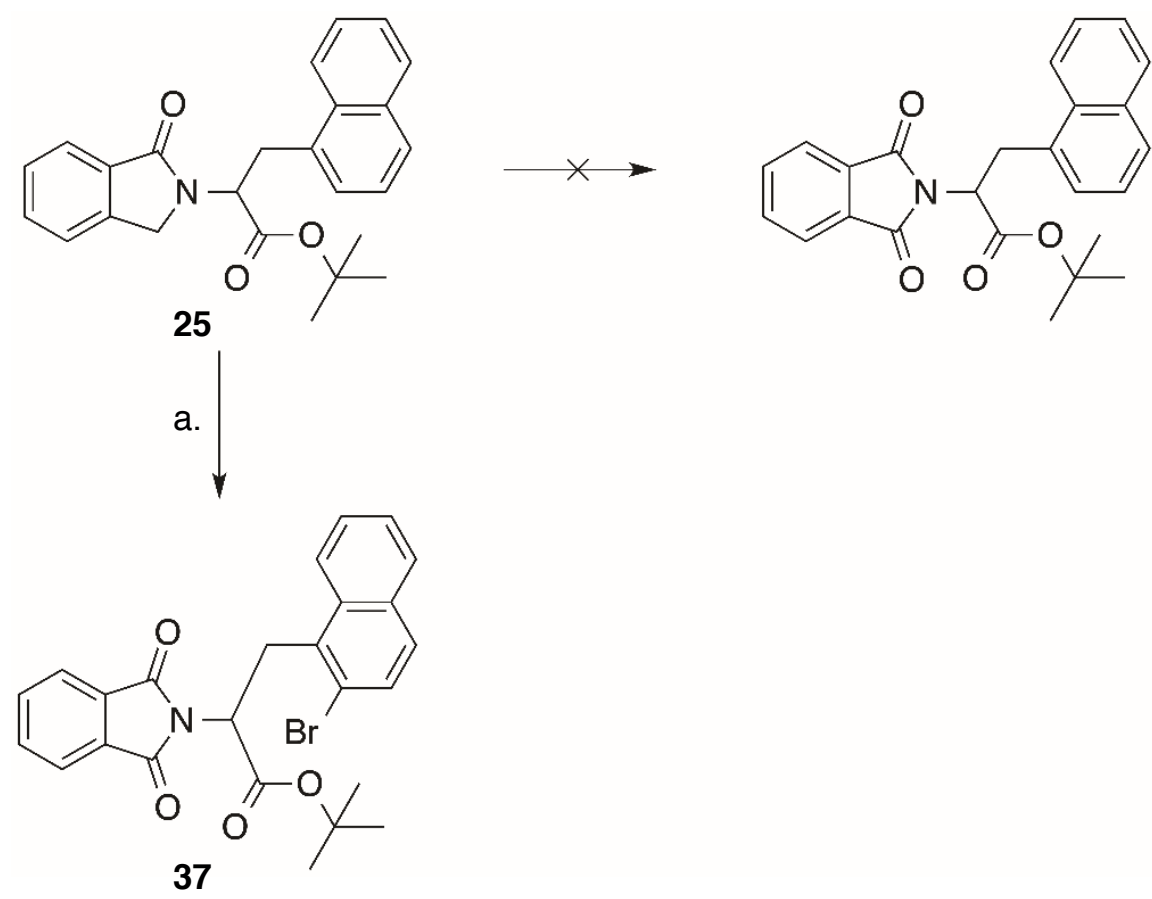

Scheme 15. Benzylic oxidation of isoindolinone napthalene derivative unexpected product. a.) Oxone ${ }^{\circledR} \mathrm{IBX} / \mathrm{KBr} / \mathrm{MeCN}-\mathrm{H}_{2} \mathrm{O} / 40-45^{\circ} \mathrm{C} / 3 \mathrm{~h}$

Isoindolinone ethyl ester 14 was used with LiHMDS and 2-bromomethyl-4,5diphenyloxazole ${ }^{42}$ to yield an isoindolinone oxazole ethyl ester derivative that was isolated in moderate yield (63\%). The $\beta$-oxazol-2-yl-(methyl)-isoindolinone derivative $\mathbf{3 8}$ was anticipated to be used as a masked carboxylic acid containing two different protecting groups for each carboxylic acid and after oxidation the oxazole could be deprotected to generate the phthaloyl protected aspartic acid derivative (Figure 20). ${ }^{43}$<smiles>C=CCC(=O)O</smiles>

Figure 20. Oxazole can be converted to a carboxylic acid. 
Oxidation of the $\beta$-oxazol-2-yl-(methyl)-isoindolinone derivative using Oxone ${ }^{\circledR} / \mathrm{KBr}$ in acetonitrile/water resulted in the oxidation of the isoindolinone to the pththaloyl. An unexpected result of the oxidation was the oxazole cleavage to generate the $\mathrm{N}$ phthaloylasaparine ethyl ester 39 (65\%) (Scheme 16).
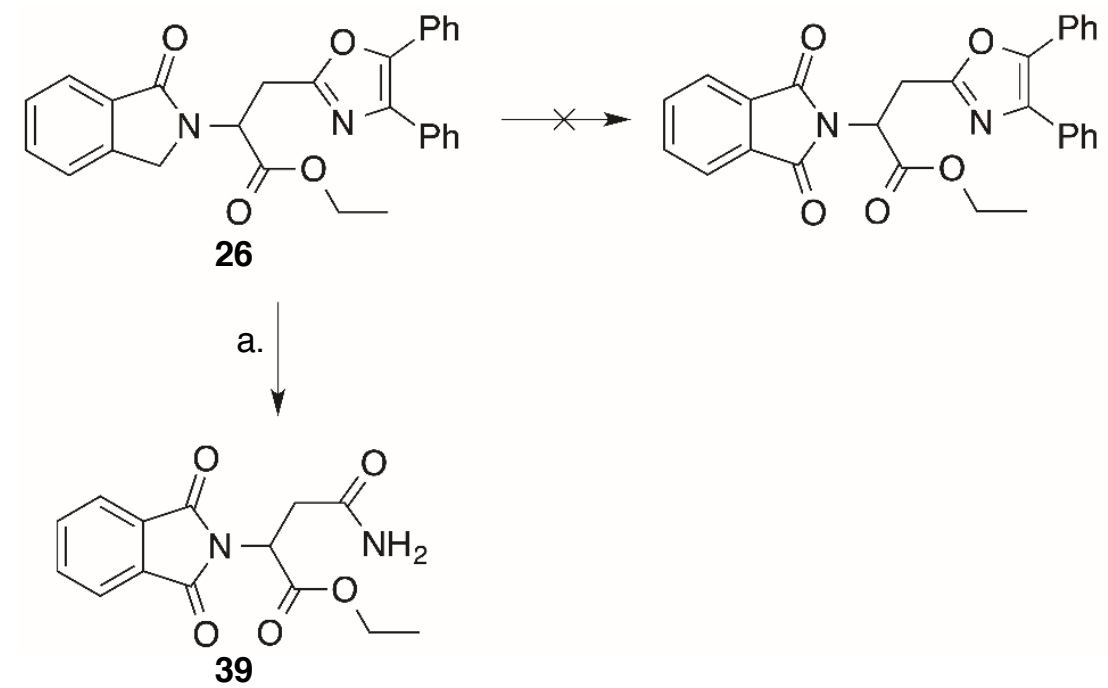

Scheme 16. Benzylic oxidation of isoindolinone oxazole derivative unexpected product.

a.) Oxine ${ }^{\circledR} / \mathrm{KBr} / \mathrm{MeCN}-\mathrm{H}_{2} \mathrm{O} / 40-45^{\circ} \mathrm{C} / 3 \mathrm{~h}$

The greatest determinant for confirming the transformation is through ${ }^{1} \mathrm{H}$ NMR spectroscopy. Analyzing the starting isoindolinone through ${ }^{1} \mathrm{H}$ NMR, the isoindolinone benzylic methylene protons exhibits a signature $A B$ quartet around 4.0-5.0 ppm. Upon oxidation, the disappearance of the $\mathrm{AB}$ quartet and a subsequent emergence of the classic symmetrical phthaloyl peak is observed around 7.5-8.0 ppm (Figure 21). 


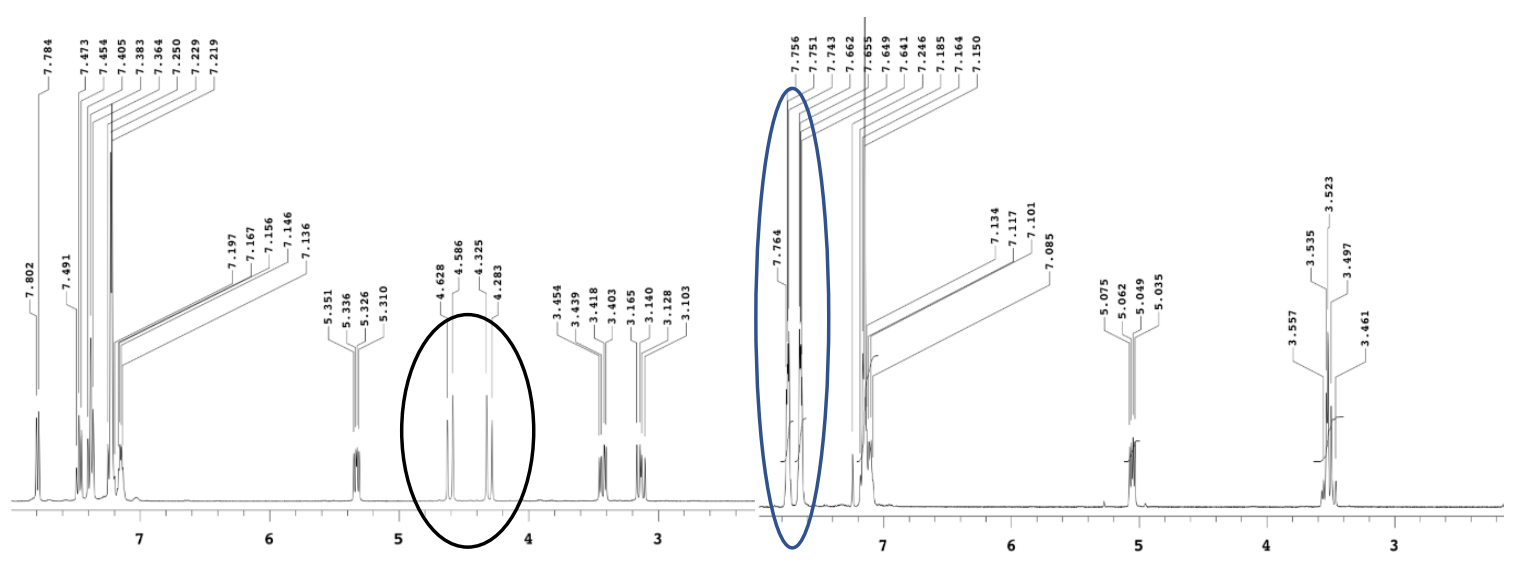

Figure 21. The observational difference in ${ }^{1} \mathrm{H}$ NMR of the starting phenyl isoindolinone (left) to the oxidation $\mathrm{N}$-phthaloyl phenylalanine derivative (right).

To demonstrate the applicability of $N$-phthaloyl protected amino acids, the $N$ phthaloyl phenylalanine tert-butyl ester was converted to a commercially available $N$-BOC phenylalanine tert-butyl ester amino acid derivative (Scheme 17). A change of $N$-phthaloyl to $N$-BOC was first done through deprotection of the phthaloyl. Deprotection was accomplished by adding $N$-phthaloyl phenylalanine derivative to hydrazine hydrate<smiles>CC(C)(C)OC(=O)C(Cc1ccccc1)N1C(=O)c2ccccc2C1=O</smiles>

34
(7)

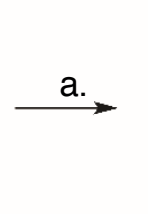

Scheme 17. Conversion of $N$-phthaloyl phenylalanine to a standard $N$-BOC phenylalanine

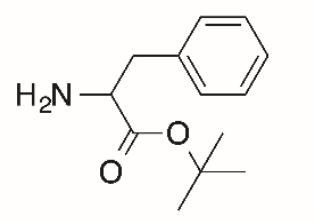

40
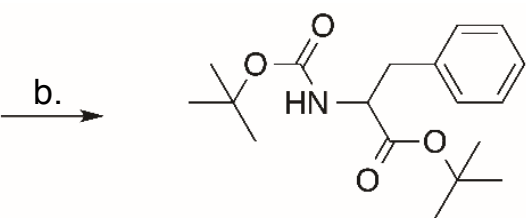

41 derivative. Reagents/Conditions: (a) $\mathrm{N}_{2} \mathrm{H}_{4} / \mathrm{MeOH}-\mathrm{H}_{2} \mathrm{O} / \mathrm{rt} / 16$ h. (b) di-tert-butyl dicarbonate/ $\mathrm{NaHCO}_{3} /$ dioxane/rt/16 h (81\%, over two steps).

(10 equiv.) in methanol. The reaction mixture was stirred for $16 \mathrm{~h}$ then immediately concentrated. The residue was resuspended in dichloromethane to precipitate the free nitrogen phenylalanine derivative. After filtration, the filtrate was dissolved in 1,4-dioxane 
and sodium dicarbonate was added followed by tert-butyl dicarbonate at room temperature. Stirring was continued $(16 \mathrm{~h})$ and upon completion, the mixture was extracted with dichloromethane. The organic layer was submitted to gravity-column chromatography to afford pure $N$-BOC phenylalanine tert-butyl ester $\mathbf{4 1}$ ( $81 \%$ over two steps).

\section{Conclusion}

The applicability of an isoindolinone acting as both a functional group and at activating the orthogonal carbon for further reactions was demonstrated. The $\mathrm{N}$ isoindolinone groups as a nitrogen protector allowed for selective alkylation and underwent benzylic oxidation to give the $N$-phthaloyl group. This approach is the basis for a starting point of $\alpha$-amino acid construction. The oxidation conditions were detrimental to some of the electron-rich substrates, the vinyl- ethynyl- alanine derivatives, and the methoxy phenylalanine derivative did not respond to oxidation. The applicability of $N$-isoindolinone to act as a protecting group for amino acid synthesis has been demonstrated and asymmetric variants could be explored in future studies. (For publication see Appendices p. 277) 


\section{Experimental}

General. Solvents and reagents were ACS grade and were used as commercially supplied. Analytical thin-layer chromatography (TLC) utilized $0.25 \mathrm{~mm}$ pre-cut glass-backed plates (Merck, Silica Gel 60 F254). Thin-layer chromatograms were visualized during chromatographic and extraction runs by rapidly dipping the plates in anisaldehyde/ethanol/sulfuric acid stain or phosphomolybdic acid/ ethanol stain and heating (hot plate). Gravity-column chromatography was carried out using silica gel 60 (E. Merck 7734, 70-230 mesh). Flash-column chromatography was carried out using silica gel 60 (E. Merck 9385-9, 230-400 mesh) using compressed nitrogen. Nuclear magnetic resonance $\left({ }^{1} \mathrm{H}\right.$ and ${ }^{13} \mathrm{C}$ NMR) spectra were recorded with Varian VNMRS 400, 500, or 700 $\mathrm{MHz}$ instruments using $\mathrm{CDCl}_{3}$ as a solvent and TMS as internal standard. Infrared spectra (FTIR) were recorded with a PerkinElmer Spectrum 100 instrument and spectral values are reported as $\mathrm{cm}^{-1}$.

\section{Synthesis of Substituted Isoindolinone Substrate Esters $(14,15)$ for Alkylation:}

\section{Ethyl 2-(1-oxoisoindolin-2-yl)acetate. 14}

A solution of isoindolin-1-one $(1.00 \mathrm{~g}, 7.51 \mathrm{mmol})$ in freshly-distilled THF $(25 \mathrm{~mL})$ was added slowly to a suspension of sodium hydride $(450 \mathrm{mg}, 11.26 \mathrm{mmol}$, freshly washed with hexane) in THF ( $25 \mathrm{~mL}$ ) under $\mathrm{N}_{2}$ at $0{ }^{\circ} \mathrm{C}$ and stirring was continued ( $\left.30 \mathrm{~min}\right)$. To the reaction mixture ethyl bromoacetate $(1.24 \mathrm{~mL}, 11.26 \mathrm{mmol})$ was slowly added and the resulting reaction mixture was allowed to stir at room temperature $(16 \mathrm{~h})$. The reaction mixture was quenched with methanol and concentrated. The obtained crude residue was further purified by gravity column chromatography (hexane/ethyl acetate, 2:1) provided 
pure 14 as an off-white solid $(1.39 \mathrm{~g}, 78 \%) ; \mathrm{mp}=77-79^{\circ} \mathrm{C}\left(\mathrm{Lit} . \mathrm{mp}=78-80{ }^{\circ} \mathrm{C}\right) .{ }^{1} \mathrm{H}$ NMR $\left(400 \mathrm{MHz}, \mathrm{CDCl}_{3}\right) \delta$ 7.87-7.85 (d, $\left.J=7.6 \mathrm{~Hz}, 1 \mathrm{H}\right), 7.57-7.53(\mathrm{~m}, 1 \mathrm{H}), 7.48-7.44(\mathrm{~m}, 2 \mathrm{H})$, $4.518(\mathrm{~s}, 2 \mathrm{H}), 4.39(\mathrm{~s}, 2 \mathrm{H}), 4.22(\mathrm{q}, J=6.8 \mathrm{~Hz}, 2 \mathrm{H}), 1.28(\mathrm{t}, J=6.8 \mathrm{~Hz}, 3 \mathrm{H}) \mathrm{ppm}$. The spectroscopic data was consistent with that previously reported. ${ }^{35}$ 


\section{tert-Butyl 2-(1-oxoisoindolin-2-yl)acetate. 15}

To a suspension of sodium hydride(450 mg, $11.26 \mathrm{mmol})$, freshly-washed with hexane, in freshly-distilled THF $(25 \mathrm{~mL})$, isoindolin-1-one $(1.00 \mathrm{~g}, 7.51 \mathrm{mmol})$ was slowly added a solution in THF $(25 \mathrm{~mL})$ under an $\mathrm{N}_{2}$ atmosphere at $0{ }^{\circ} \mathrm{C}$ and stirred for $30 \mathrm{~min}$. To the resulting reaction mixture tert-butyl bromoacetate $(1.66 \mathrm{~mL}, 11.26 \mathrm{mmol})$ was added and stirring was continued at room temperature $(16 \mathrm{~h})$. The reaction mixture was carefully quenched with methanol and concentrated to obtain a crude residue. The crude product was then further purified by column chromatography (hexanes/ethyl acetate, 4:1) to afford pure 15 as an off-white solid $(1.80 \mathrm{~g}, 97 \%) ; \mathrm{mp}=62-64{ }^{\circ} \mathrm{C} ; \mathrm{R}_{\mathrm{f}}=0.33$ (hexane/ethyl acetate, 2:1); ${ }^{1} \mathrm{H}$ NMR $\left(400 \mathrm{MHz}, \mathrm{CDCl}_{3}\right) \delta$ 7.87-7.85 (d, $\left.J=7.6 \mathrm{~Hz}, 1 \mathrm{H}\right), 7.54-7.52(\mathrm{~m}, 1 \mathrm{H}), 7.47-$ $7.43(\mathrm{~m}, 2 \mathrm{H}), 4.51(\mathrm{~s}, 2 \mathrm{H}), 4.29(\mathrm{~s}, 2 \mathrm{H}), 1.46(\mathrm{~s}, 9 \mathrm{H}) \mathrm{ppm} .{ }^{13} \mathrm{C} \mathrm{NMR}\left(100 \mathrm{MHz}, \mathrm{CDCl}_{3}\right) \delta$ $168.8,168.1,141.6,131.9,131.6,127.9,123.9,122.7,82.2,50.5,44.5,28.1$ ppm. ); FTIR (neat) 2972, 2932, 1738, $1687 \mathrm{~cm}^{-1}$; LRMS calcd for $\mathrm{C}_{14} \mathrm{H}_{17} \mathrm{NO}_{3}(\mathrm{M}+\mathrm{H}) 248$, found 248. 


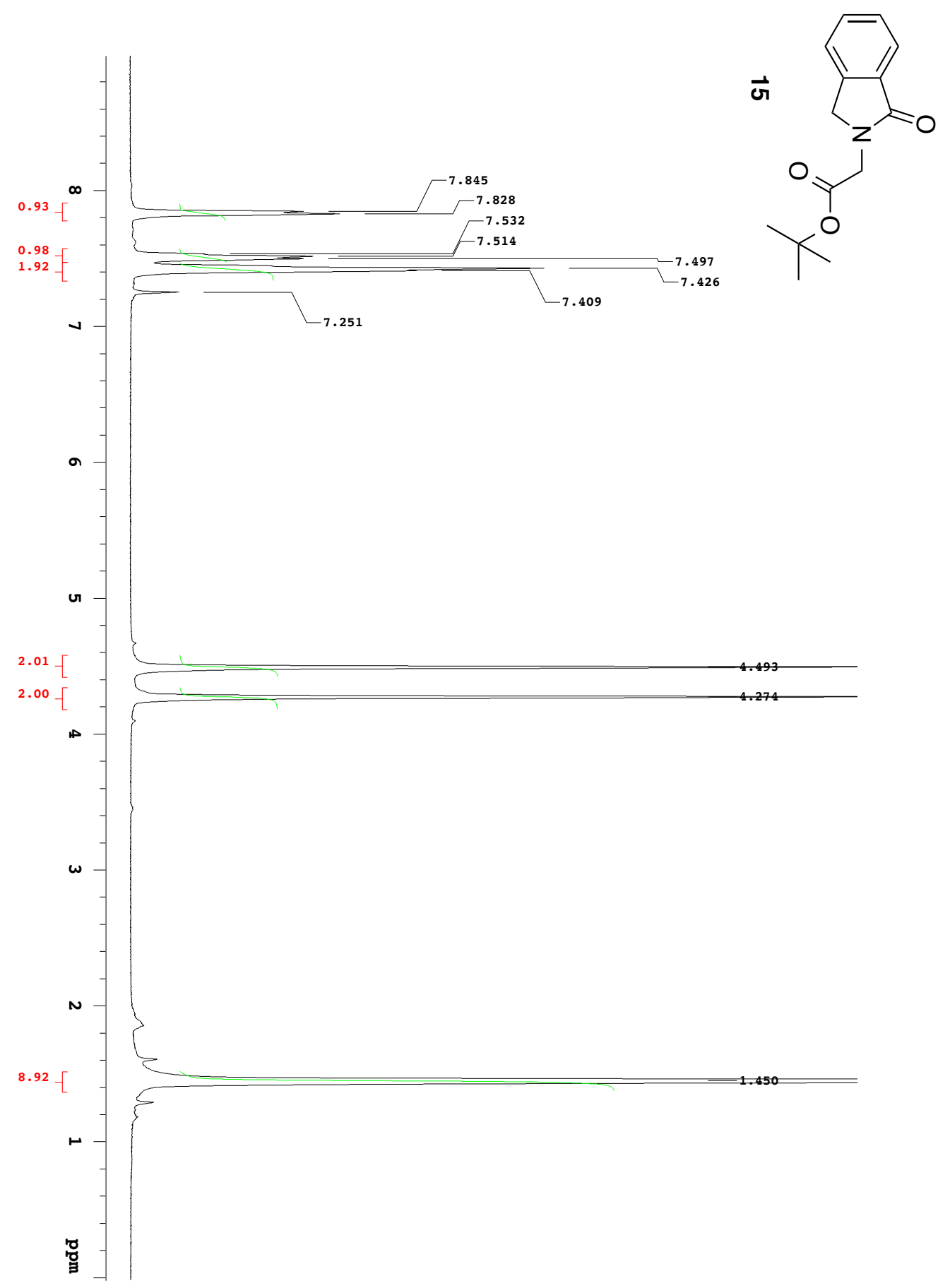




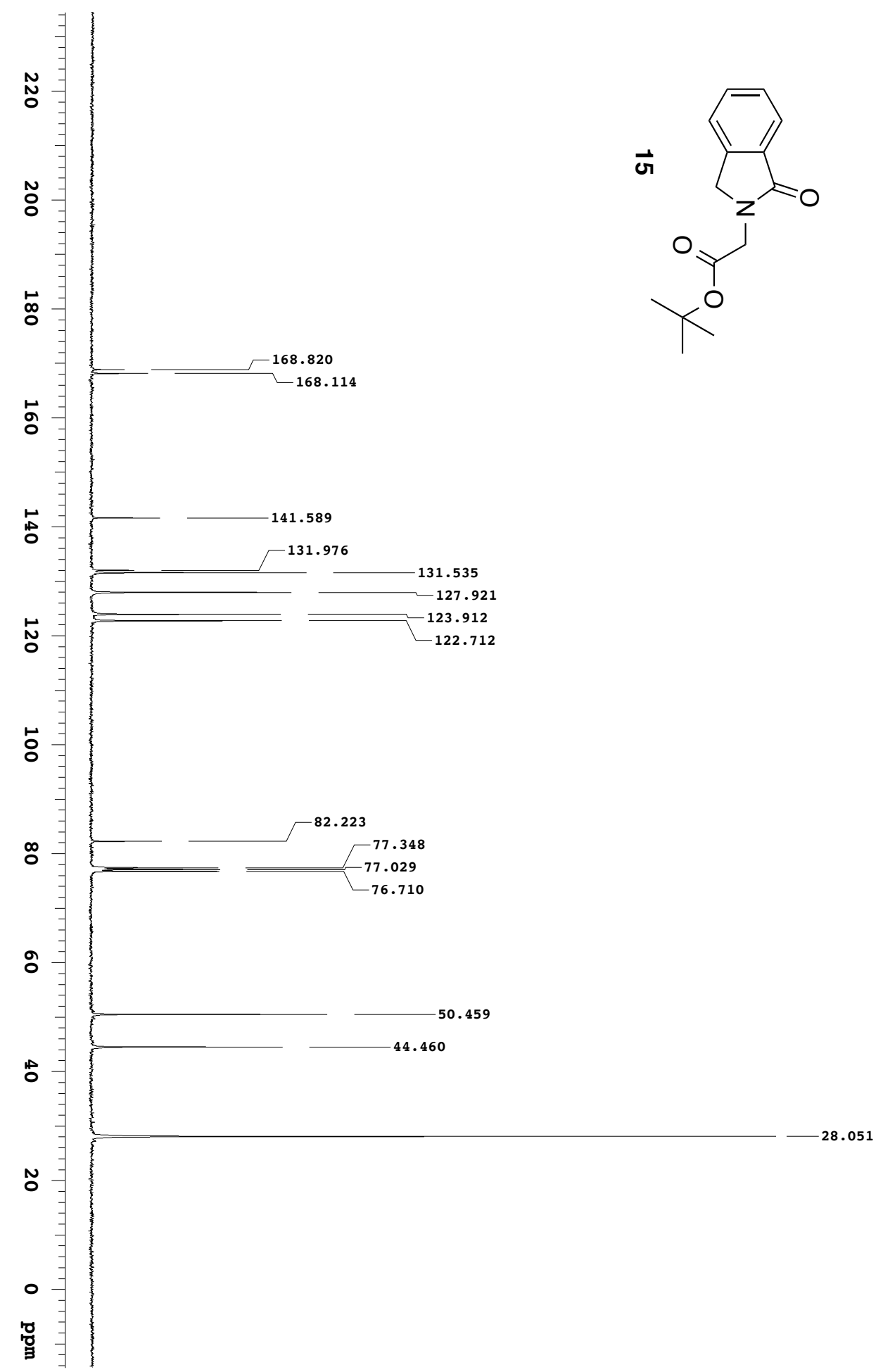




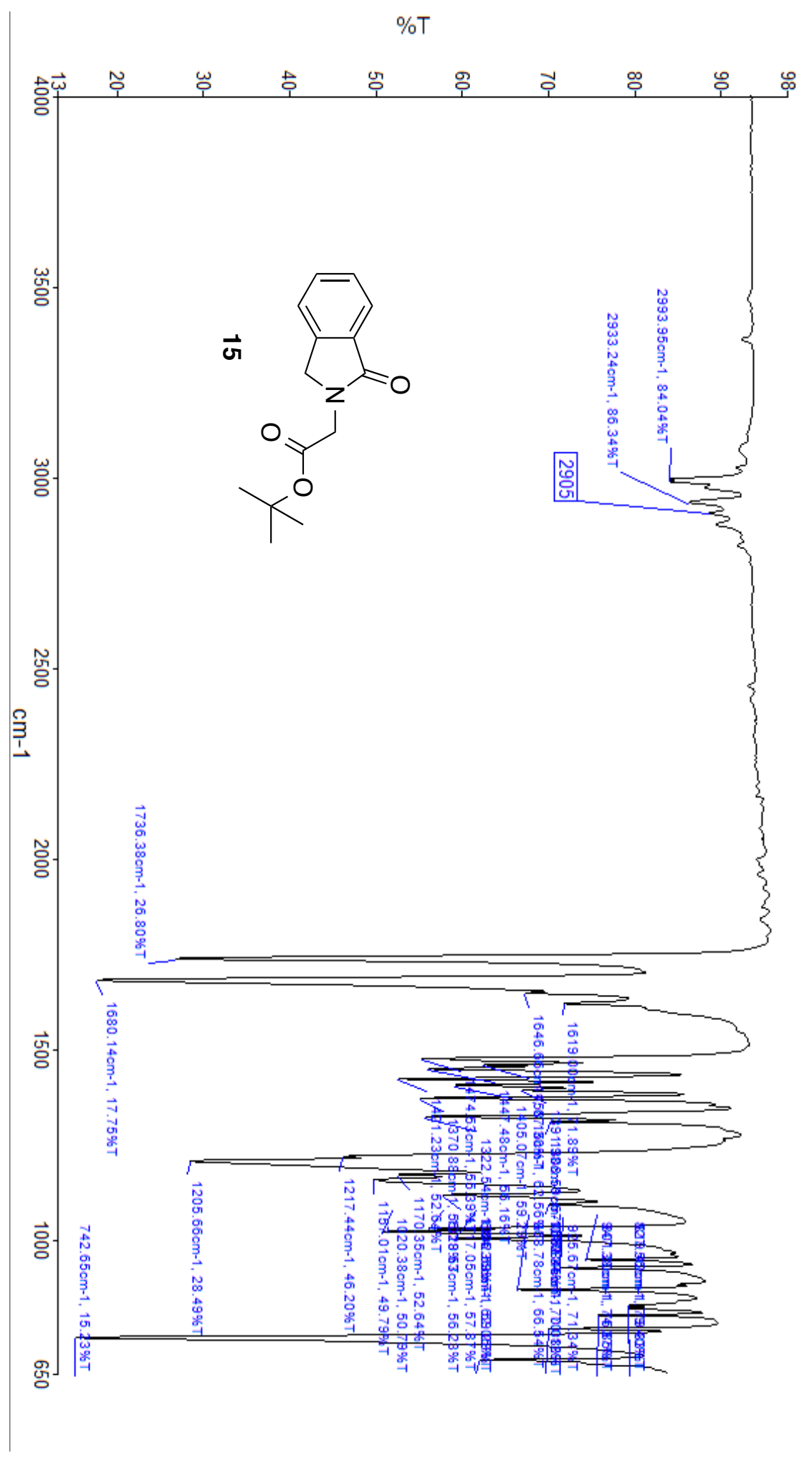




\section{Procedures for the Alkylation of Isoindolinone Esters 14 and 15:}

\section{Ethyl 2-(1-oxoisoindolin-2-yl)propanoate. 16}

To a solution of ethyl 2-(1-oxoisoindolin-2-yl) acetate 14 (50 mg, $0.228 \mathrm{mmol})$ in dry THF $(5.0 \mathrm{~mL})$ iodomethane $(22 \mu \mathrm{L}, 0.684 \mathrm{mmol})$ was added at room temperature under nitrogen. Stirring was continued (10 min) and lithium hexamethyldisilazide $(1.0 \mathrm{M}, 301 \mu \mathrm{L}$, $301 \mathrm{mmol}$ ) in THF was added dropwise by syringe to the reaction mixture under $\mathrm{N}_{2}$ atmosphere resulting to yellow solution. The reaction mixture was stirred (16h) at room temperature. After reaction completion as indicated by TLC, it was quenched with saturated aqueous ammonium chloride solution $(5 \mathrm{~mL})$ and extracted with dichloromethane $(3 \times 10 \mathrm{~mL})$. The organic extracts were combined, dried over anhydrous sodium sulfate and concentrated to obtain a crude residue. Further purification was performed using flash column chromatography (hexane/ethyl acetate, 4:1) to give pure $\mathbf{1 6}$ as a colorless oil (39 $\mathrm{mg}, 73 \%) ; \mathrm{R}_{\mathrm{f}}=0.49($ hexanes/ethylacetate, $1: 1) ;{ }^{1} \mathrm{H} \mathrm{NMR}\left(700 \mathrm{MHz}, \mathrm{CDCl}_{3}\right) \delta 7.86(\mathrm{~d}, J$

$=7.2 \mathrm{~Hz}, 1 \mathrm{H}), 7.55-7.54(\mathrm{~m}, 1 \mathrm{H}), 7.47-7.46(\mathrm{~m}, 2 \mathrm{H}), 5.20-5.19(\mathrm{q}, J=7.0 \mathrm{~Hz}, 1 \mathrm{H}), 4.60$ $(\mathrm{d}, J=16.1 \mathrm{~Hz}, 1 \mathrm{H}), 4.41(\mathrm{~d}, J=16.1 \mathrm{~Hz}, 1 \mathrm{H}), 4.18(\mathrm{q}, J=3.5 \mathrm{~Hz}, 2 \mathrm{H}), 1.57$ (t, $J=3.5 \mathrm{~Hz}$ 3H), $1.25(\mathrm{~d}, J=7.0 \mathrm{~Hz}, 3 \mathrm{H}) \mathrm{ppm} ;{ }^{13} \mathrm{C} \mathrm{NMR}\left(175 \mathrm{MHz}, \mathrm{CDCl}_{3}\right) \delta 171.8,168.6,141.6$, 132.2, 131.5, 127.9, 123.9, 122.8, 61.4, 49.2, 46.7, 15.9, 14.1 ppm; FT-IR (neat) 2980, 2936, 1732, $1687 \mathrm{~cm}^{-1} ; \mathrm{HRMS} \mathrm{m} / z$ calculated for $\mathrm{C}_{13} \mathrm{H}_{15} \mathrm{NO}_{3} 233.1053$, found 233.1055. 


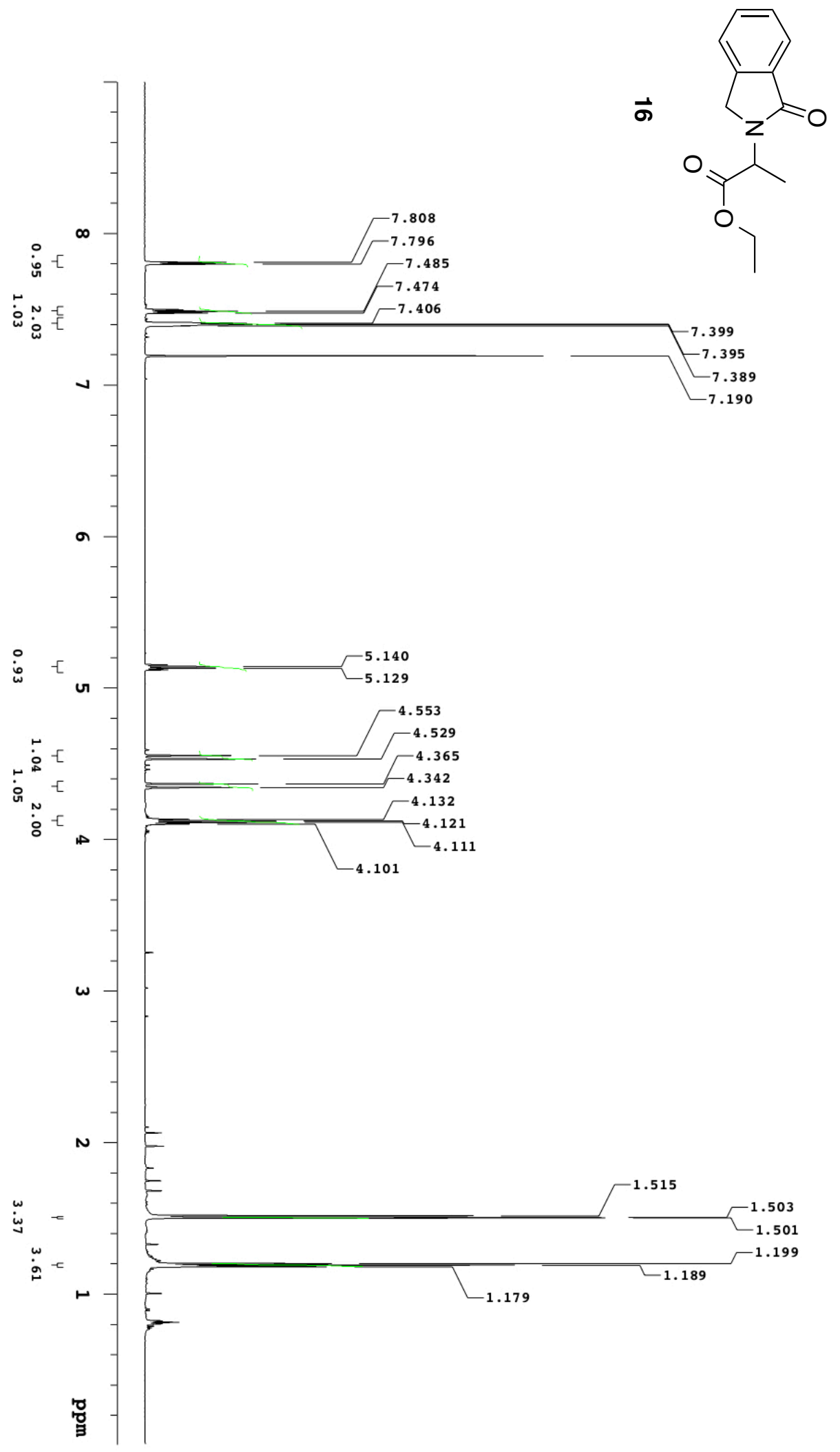




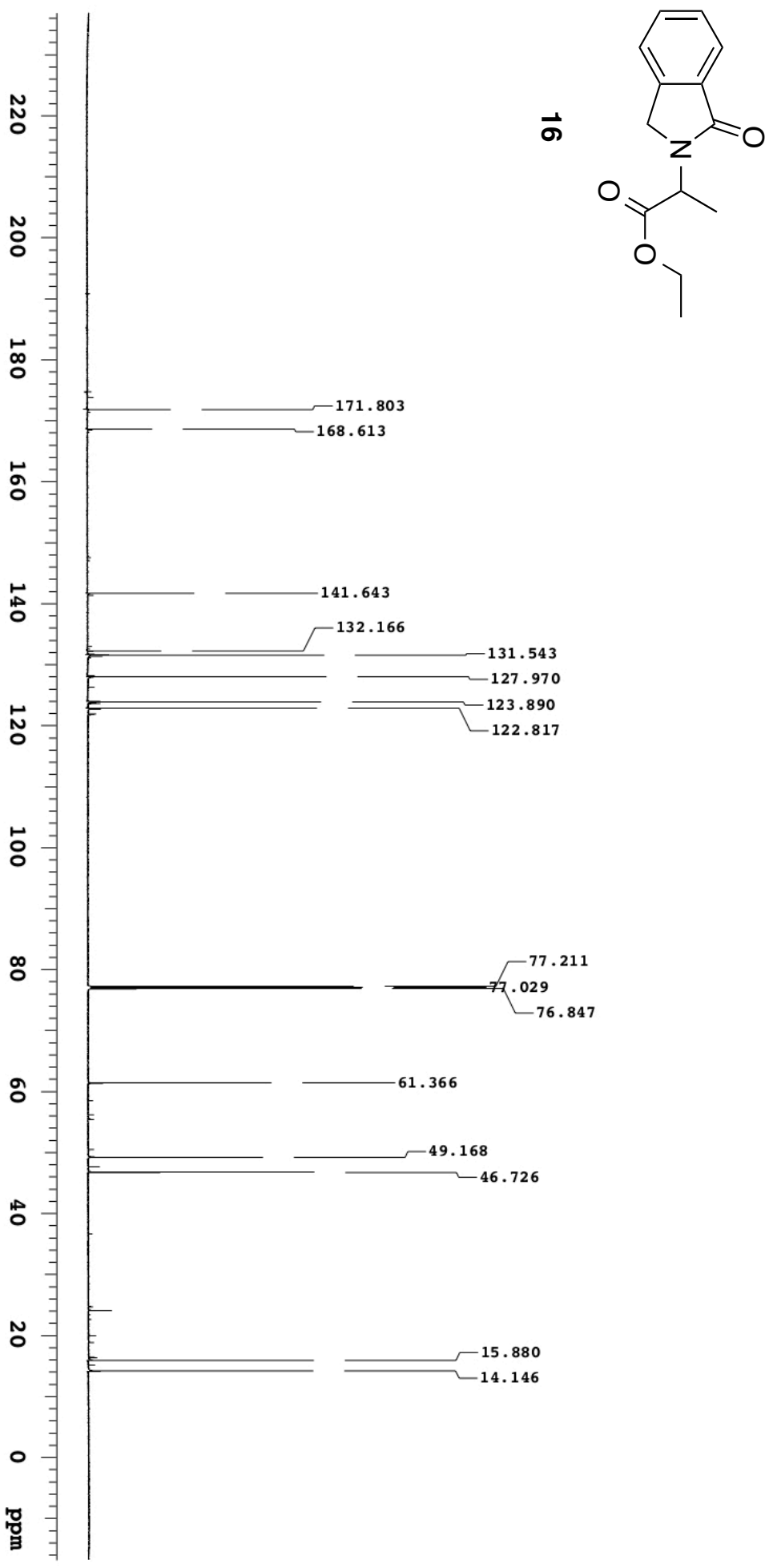




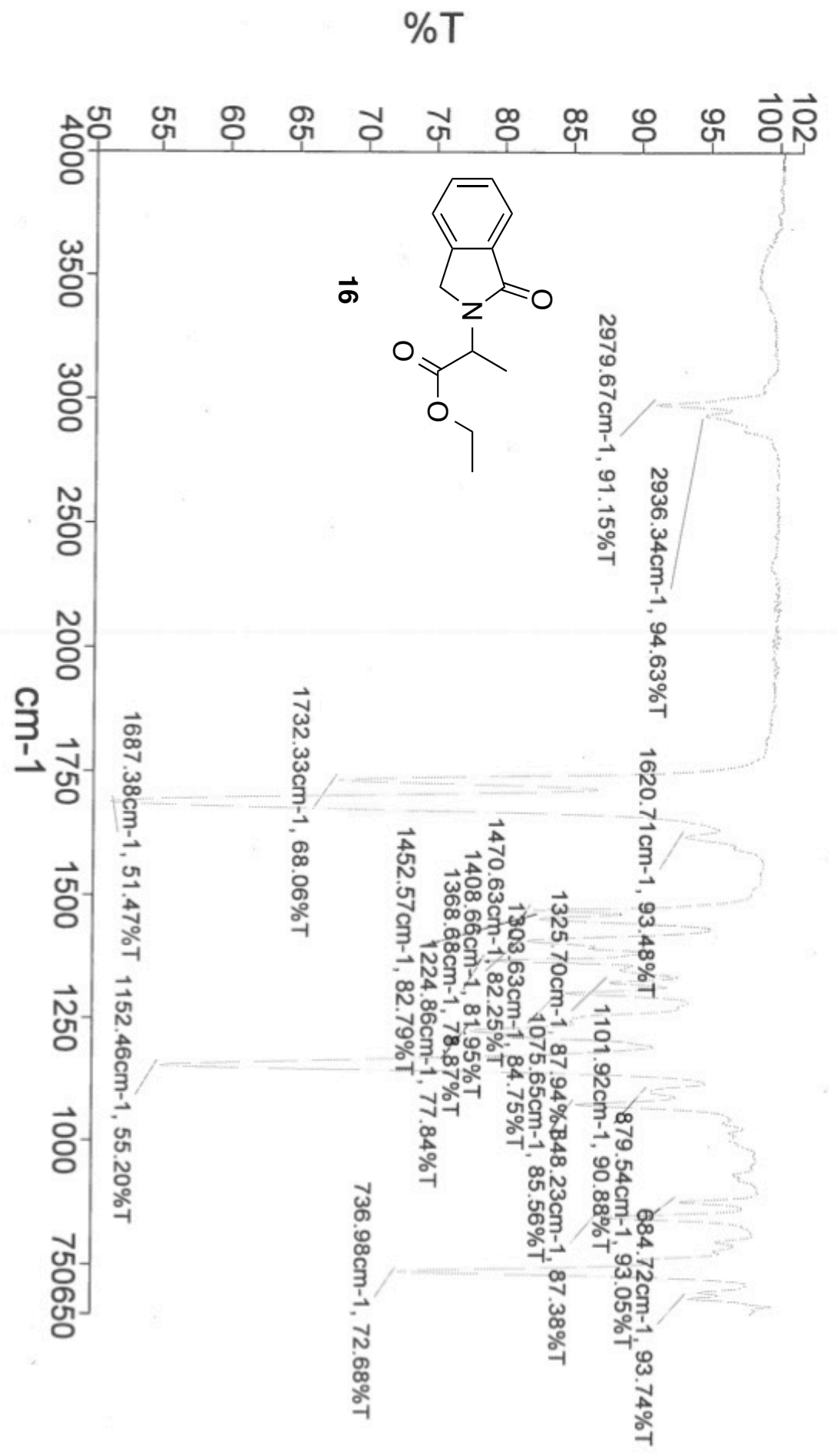




\section{Ethyl 2-(1-oxoisoindolin-2-yl)butanoate. 17}

Ethyl 2-(1-oxoisoindolin-2-yl)acetate $14(50 \mathrm{mg}, 0.23 \mathrm{mmol})$ was dissolved in freshlydistilled THF $(2.0 \mathrm{~mL})$ and the mixture was cooled to $-5{ }^{\circ} \mathrm{C}$. To the clear solution, iodoethane $(90 \mu \mathrm{L}, 1.140 \mathrm{mmol})$ was added and stirring was continued (10 min). Lithium hexamethyldisilazide (1.0M, $242 \mu \mathrm{L}, 0.242 \mathrm{mmol})$ in THF was added dropwise by syringe to the reaction mixture under nitrogen which resulted in a yellow solution. The reaction was stirred (2h) at -5 to $0{ }^{\circ} \mathrm{C}$, brought up to room temperature, quenched with saturated aqueous ammonium chloride solution $(5 \mathrm{~mL})$ and extracted with dichloromethane $(3 \times 10$ $\mathrm{mL}$ ). The extracts were combined, dried over anhydrous sodium sulfate, and concentrated to give a crude residue. Submission of the residue to flash-column chromatography (hexane/ethyl acetate, 3:1) gave pure 17 as colorless oil (40 $\mathrm{mg}, 70 \%) ; \mathrm{R}_{\mathrm{f}}=0.62$ (hexanes/ethylacetate, 1:1); ${ }^{1} \mathrm{H}$ NMR $\left(700 \mathrm{MHz}, \mathrm{CDCl}_{3}\right) \delta 7.87(\mathrm{~d}, J=7.2 \mathrm{~Hz}, 1 \mathrm{H}), 7.56-$ $7.54(\mathrm{~m}, 1 \mathrm{H}), 7.47-7.45(\mathrm{~m}, 2 \mathrm{H}), 5.02-5.00(\mathrm{~m}, 1 \mathrm{H}), 4.66-4.64(\mathrm{~m}, 1 \mathrm{H}), 4.65(\mathrm{~d}, J=16.1 \mathrm{~Hz}$ $1 \mathrm{H}), 4.35(\mathrm{~d}, J=16.1 \mathrm{~Hz}, 1 \mathrm{H}), 4.17(\mathrm{q}, J=7.0 \mathrm{~Hz}, 2 \mathrm{H}), 2.16-1.83(\mathrm{~m}, 2 \mathrm{H}), 1.25(\mathrm{t}, J=7.0$ $\mathrm{Hz}, 3 \mathrm{H}), 0.96(\mathrm{t}, J=7.0 \mathrm{~Hz}, 3 \mathrm{H}) \mathrm{ppm} ;{ }^{13} \mathrm{C} \mathrm{NMR}\left(175 \mathrm{MHz}, \mathrm{CDCl}_{3}\right) \delta 171.5,169.2,141.7$, 132.1, 131.5, 127.9, 123.9, 122.8, 61.3, 61.2, 55.1, 46.7, 46.7, 23.3, 14.2, 10.8 ppm; FT-IR (neat) 2973, 2933, 1736, $1687 \mathrm{~cm}^{-1}$; HRMS $m / z$ calculated for $\mathrm{C}_{14} \mathrm{H}_{17} \mathrm{NO}_{3} 247.1208$, found 247.1206. 


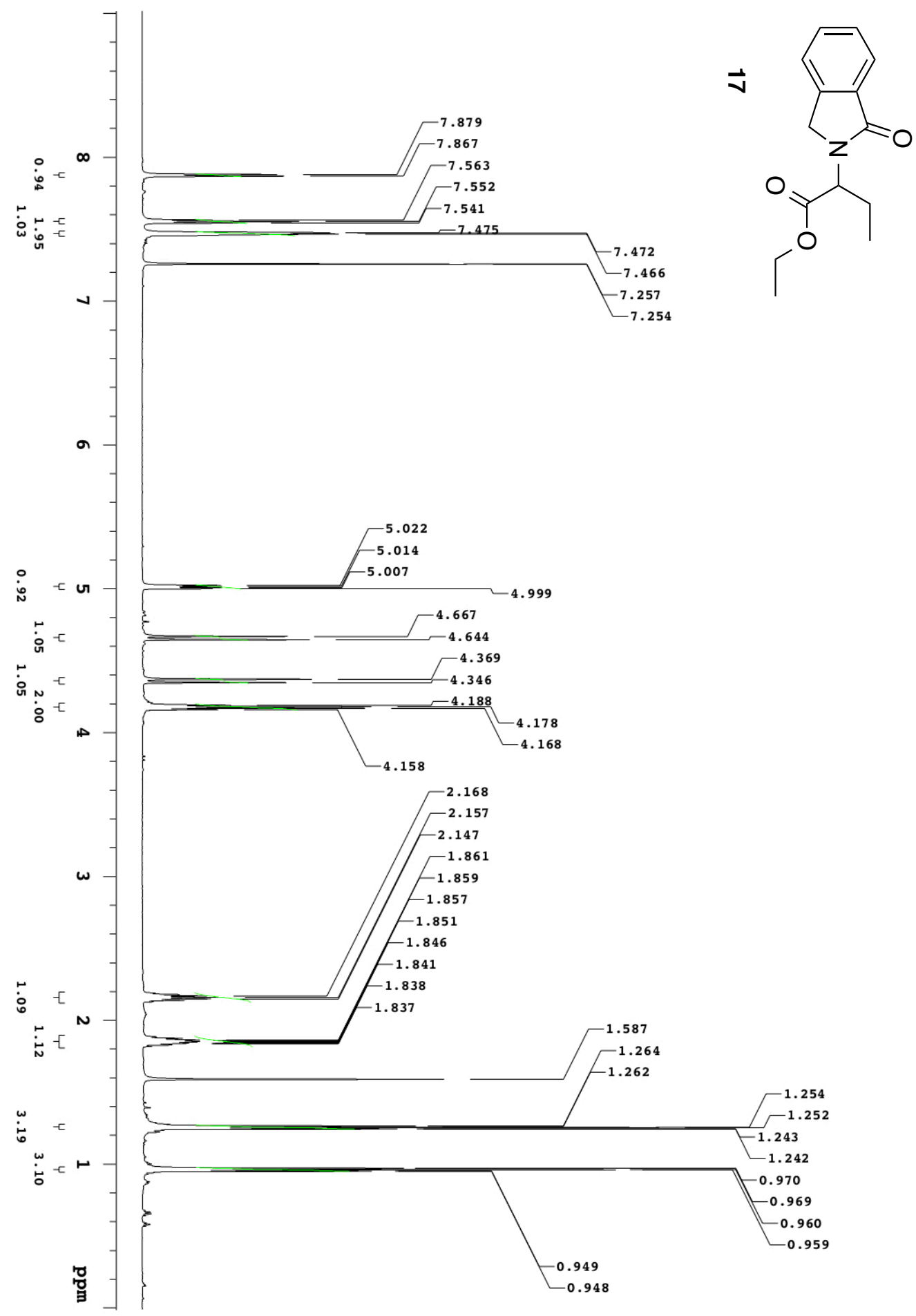




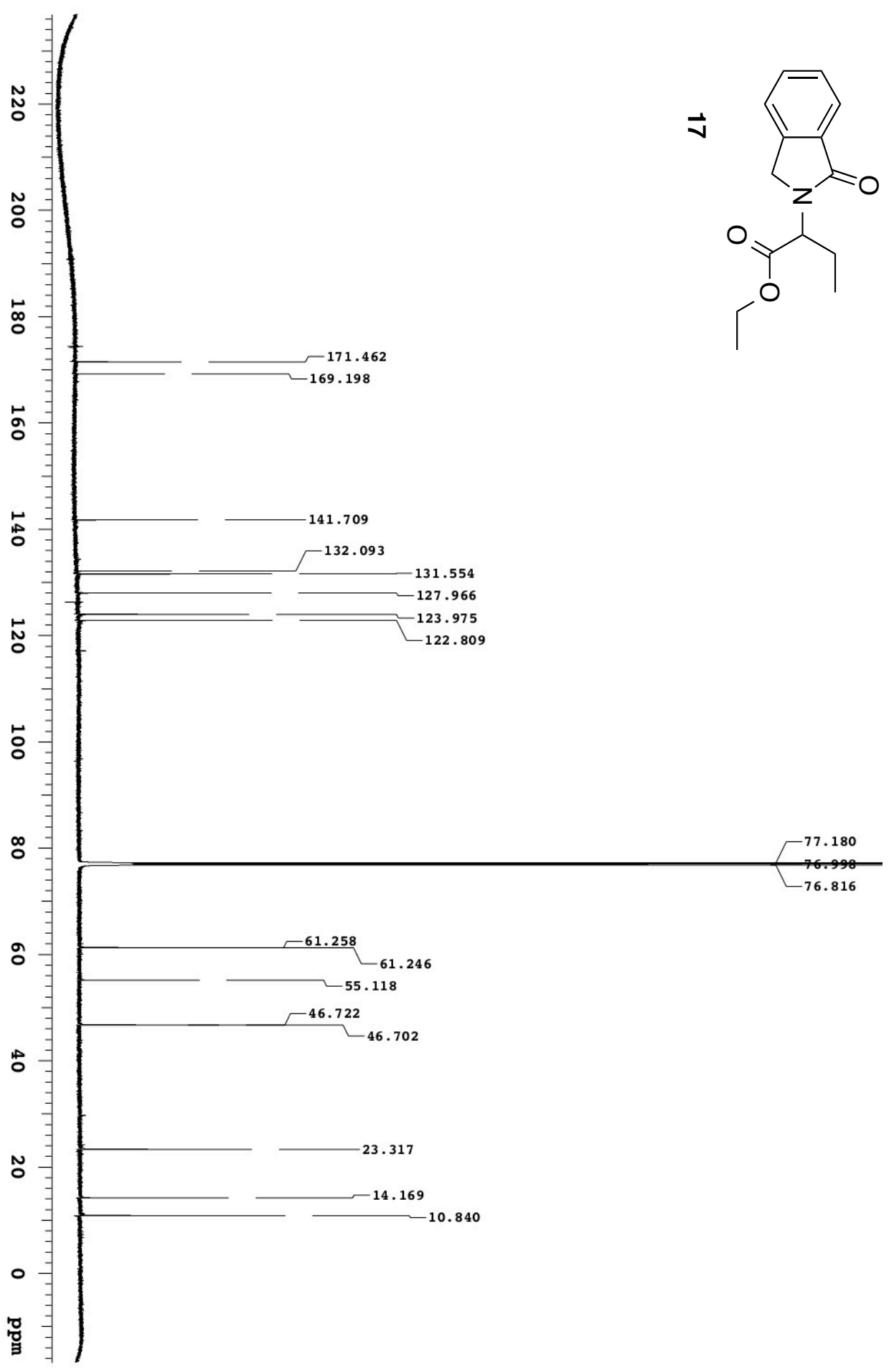




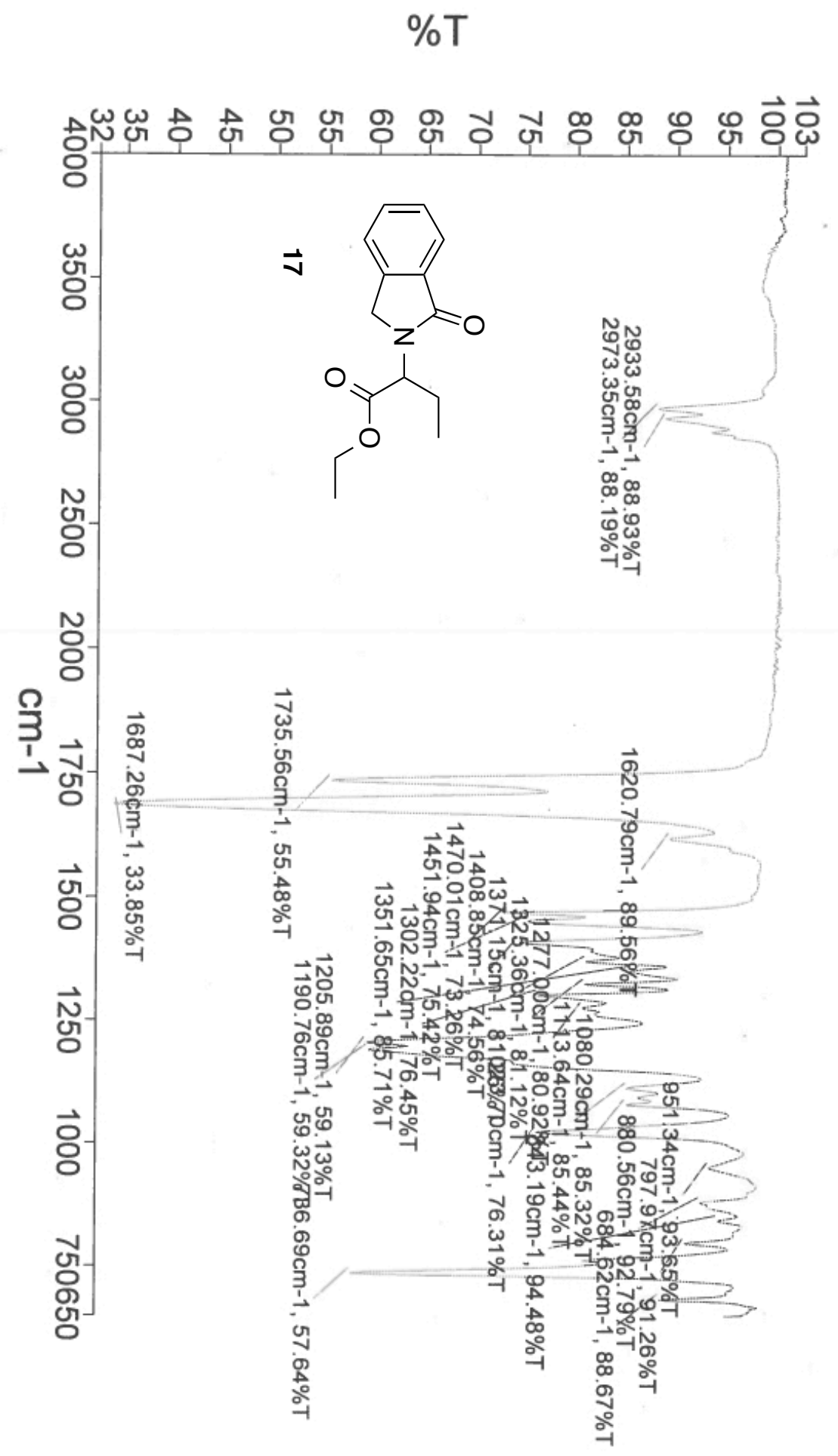




\section{tert-Butyl 2-(1-oxoisoindolin-2-yl)pentanoate. 18}

1-iodopropane $(197 \mu \mathrm{L}, 2.0 \mathrm{mmol})$ was added to solution of tert-Butyl 2-(1-oxoisoindolin2-yl)acetate 15 (100 mg, $0.404 \mathrm{mmol})$ in freshly-distilled THF $(2.0 \mathrm{~mL})$ at $-5{ }^{\circ} \mathrm{C}$ under $\mathrm{N}_{2}$ and the reaction mixture was stirred. Lithium hexamethyldisilazide (1.0M, $484 \mu \mathrm{L}, 0.484$ mmol) in THF was added dropwise by syringe to the reaction mixture under $\mathrm{N}_{2}$. The resulting pale-yellow reaction mixture was stirred $\left(-5\right.$ to $\left.0{ }^{\circ} \mathrm{C}, 5 \mathrm{~h}\right)$ then brought to room temperature and quenched with saturated aqueous ammonium chloride solution $(5 \mathrm{~mL})$. The reaction mixture was extracted with dichloromethane $(3 \times 10 \mathrm{~mL})$. The extracts were combined, dried over anhydrous sodium sulfate and concentrated to give crude product which was purified by flash column chromatography (hexanes/ethyl acetate, 4:1) to afford 18 as a white solid (104 $\mathrm{mg}, 86 \%) ; \mathrm{mp}=70-72{ }^{\circ} \mathrm{C} ; \mathrm{R}_{\mathrm{f}}=0.62$ (hexanes/ethyl acetate, 1:1); ${ }^{1} \mathrm{H}$ NMR $\left(400 \mathrm{MHz}, \mathrm{CDCl}_{3}\right) \delta 7.85(\mathrm{~d}, J=7.2 \mathrm{~Hz}, 1 \mathrm{H}), 7.54-7.50(\mathrm{~m}, 1 \mathrm{H}), 7.45-7.43(\mathrm{~m}$, 2H), 5.01-4.97 (m, 1H), $4.67(\mathrm{~d}, J=16.4 \mathrm{~Hz}, 1 \mathrm{H}), 4.32(\mathrm{~d}, \mathrm{~J}=16.4 \mathrm{~Hz}, 1 \mathrm{H}), 2.02-1.97$ (m, 1H), 1.81-1.78 (m, 1H), $1.42(\mathrm{~s}, 9 \mathrm{H}), 1.37-1.30(\mathrm{~m}, 2 \mathrm{H}), 0.94(\mathrm{t}, J=6.0 \mathrm{~Hz}, 3 \mathrm{H}) \mathrm{ppm} ;{ }^{13} \mathrm{C}$ NMR $\left(100 \mathrm{MHz}, \mathrm{CDCl}_{3}\right) \delta 170.9,169.1,141.8,132.2,131.4,127.8,123.9,122.7,81.8$, 77.3, 77.0, 76.7, 53.9, 46.7, 32.0, 28.0, 19.5, 13.5 ppm; FT-IR (neat) 2963, 2934, 2874, 1731, $1686 \mathrm{~cm}^{-1}$; HRMS m/z calculated for $\mathrm{C}_{17} \mathrm{H}_{23} \mathrm{NO}_{3} 289.1678$, found 289.1676 


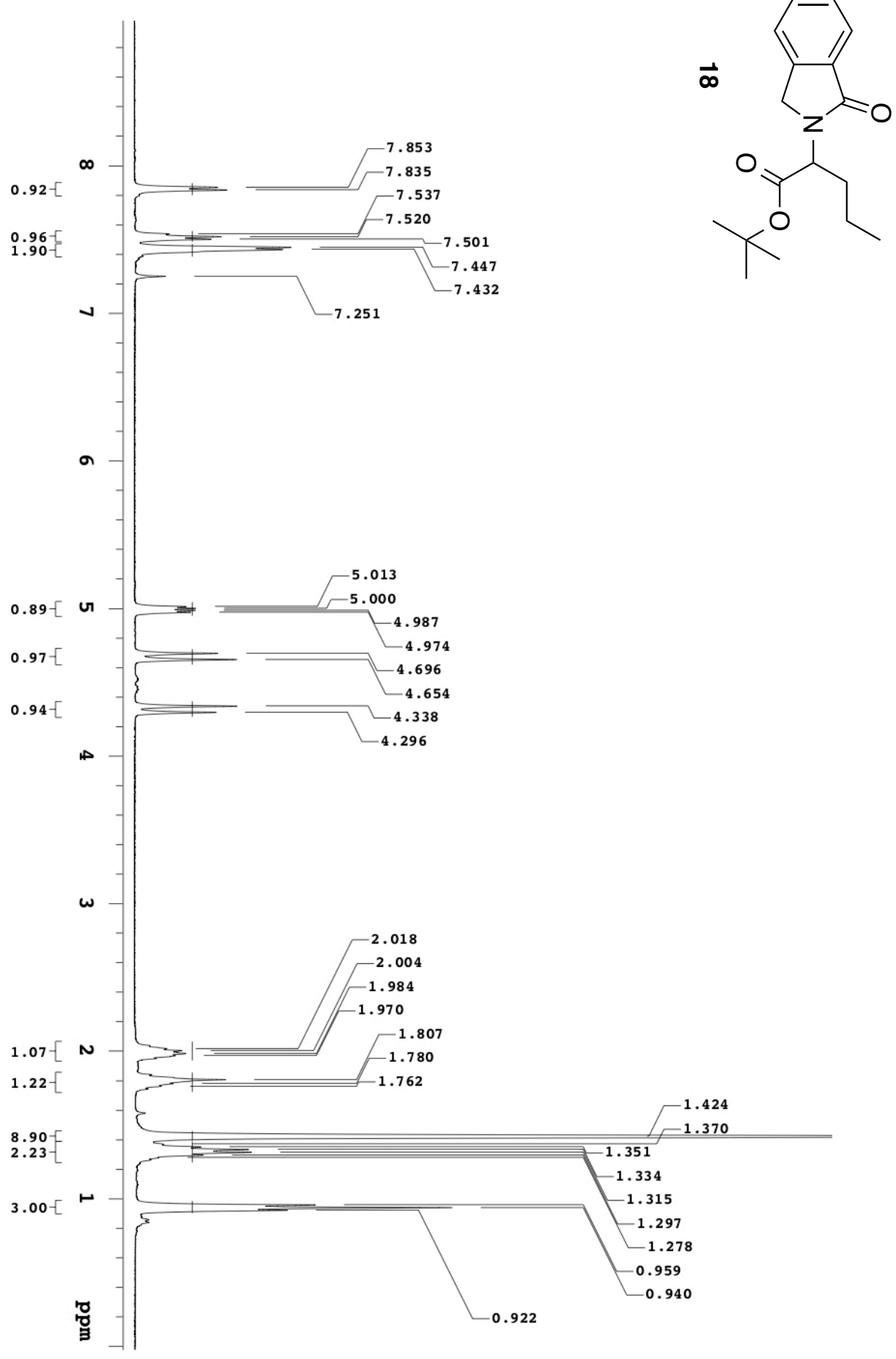




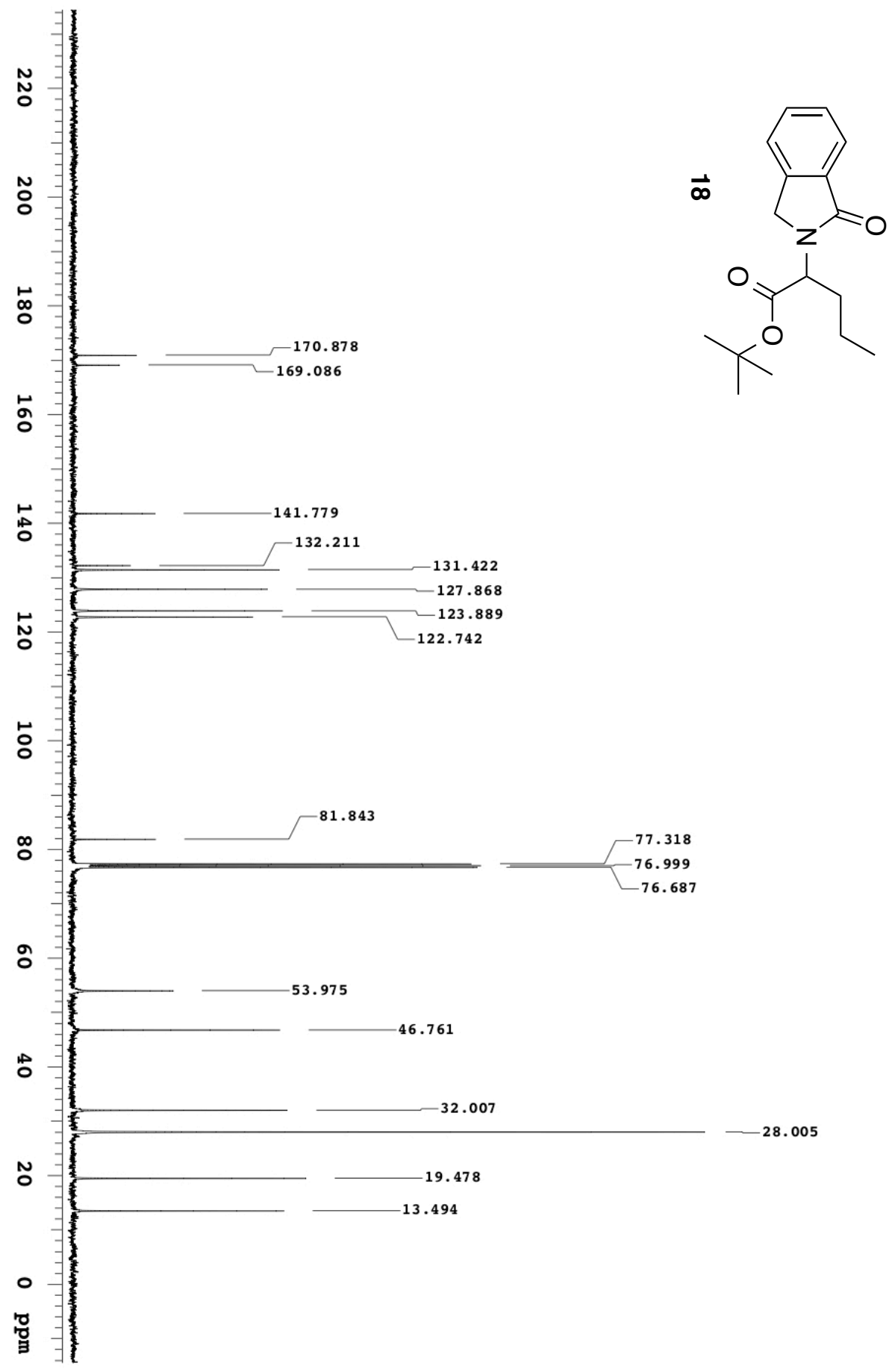




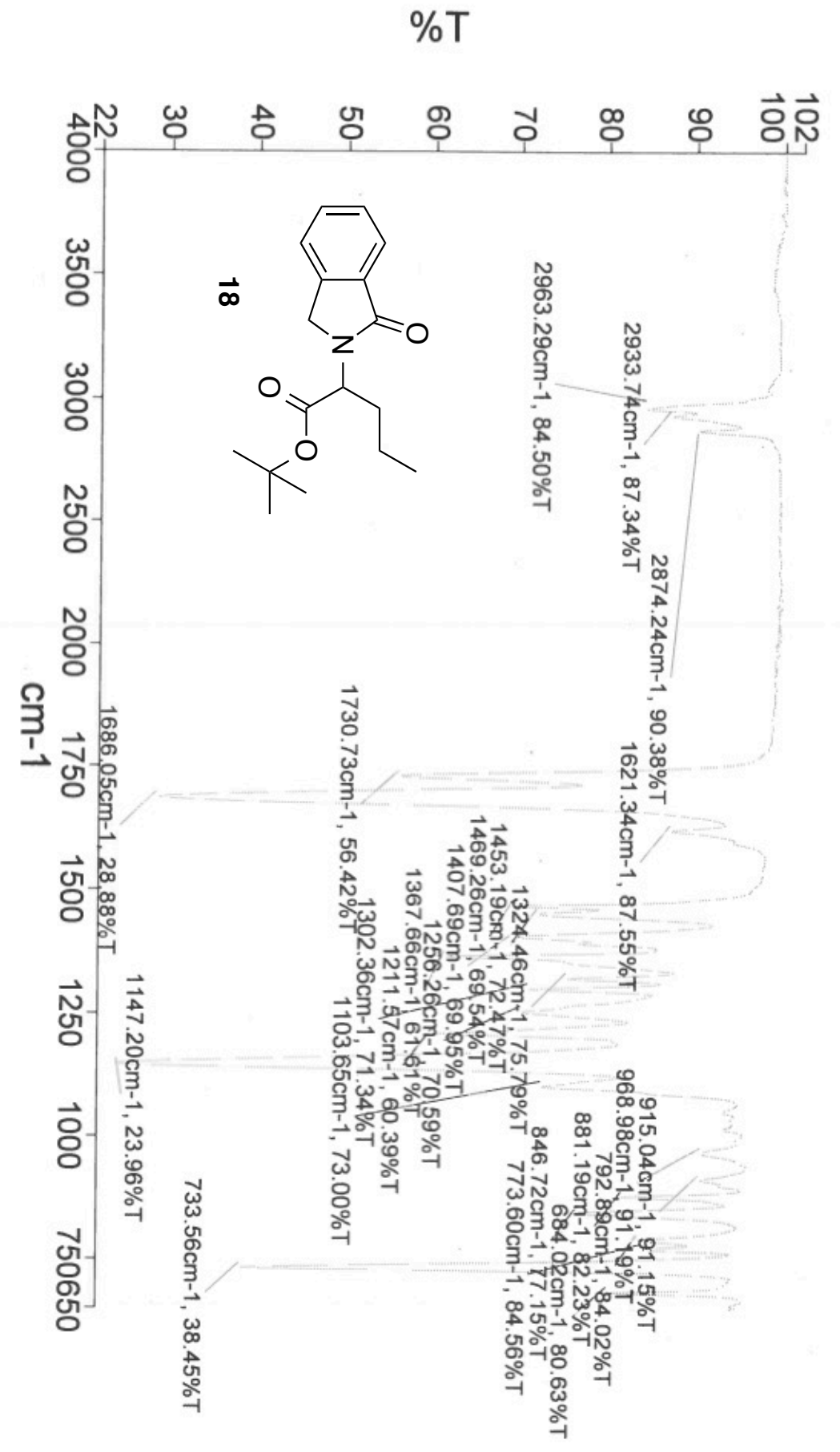




\section{tert-Butyl 2-(1-oxoisoindolin-2-yl)hexanoate. 19}

1-iodobutane $(230 \mu \mathrm{L}, 2.0 \mathrm{mmol})$ was added to a solution of tert-butyl 2-(1-oxoisoindolin2-yl) acetate $15(100 \mathrm{mg}, 0.404 \mathrm{mmol})$ in dry THF $\left(2.0 \mathrm{~mL}\right.$ at $-5^{\circ} \mathrm{C}$ under $\mathrm{N}_{2}$ and stirring was continued (10 $\mathrm{min})$. To the clear solution, lithium hexamethyldisilazide (1.0M, 484 $\mu \mathrm{L}, 0.484 \mathrm{mmol}$ ) in THF was added dropwise by syringe. The yellow reaction mixture was stirred (5h) at -5 to $0{ }^{\circ} \mathrm{C}$ then brought to room temperature. Saturated aqueous ammonium chloride solution $(5 \mathrm{~mL})$ was then added and the reaction mixture was extracted with dichloromethane $(3 \times 10 \mathrm{~mL})$ The organic layers were combined, dried over anhydrous sodium sulfate and concentrated to afford a crude residue which was submitted to gravity column chromatography (hexane/ethyl acetate, 15:1). Pure 19 was obtained as a white solid (96 mg, 78\%); mp $=75-77{ }^{\circ} \mathrm{C} ; \mathrm{R}_{\mathrm{f}}=0.64$ (hexanes/ethyl acetate, $\left.1: 1\right) ;{ }^{1} \mathrm{H} \mathrm{NMR}(400 \mathrm{MHz}$, $\left.\mathrm{CDCl}_{3}\right) \delta 7.86(\mathrm{~d}, J=7.2 \mathrm{~Hz}, 1 \mathrm{H}), 7.53-7.51(\mathrm{~m}, 1 \mathrm{H}), 7.46-7.45(\mathrm{~m}, 2 \mathrm{H}), 5.00-4.96(\mathrm{~m}$, $1 \mathrm{H}), 4.67(\mathrm{~d}, J=16.4 \mathrm{~Hz}, 1 \mathrm{H}), 4.32(\mathrm{~d}, \mathrm{~J}=16.4 \mathrm{~Hz}, 1 \mathrm{H}), 1.42(\mathrm{~s}, 9 \mathrm{H}) 1.42-1.24(\mathrm{~m}, 4 \mathrm{H}), 0.87$ $(\mathrm{t}, J=6.0 \mathrm{~Hz}, 3 \mathrm{H}) \mathrm{ppm} ;{ }^{13} \mathrm{C} \mathrm{NMR}\left(100 \mathrm{MHz}, \mathrm{CDCl}_{3}\right) \delta 170.9,169.1,141.8,132.2,131.4$, $127.9,123.9,122.7,81.8,77.3,77.0,76.7,54.2,46.8,29.6,28.3,28.0,22.1,13.8$ ppm.; FT-IR (neat) 2958, 2932, 2872, 1732, $1688 \mathrm{~cm}^{-1}$; HRMS m/z calculated for $\mathrm{C}_{18} \mathrm{H}_{25} \mathrm{NO}_{3}$ 303.1834, found 303.1837 . 


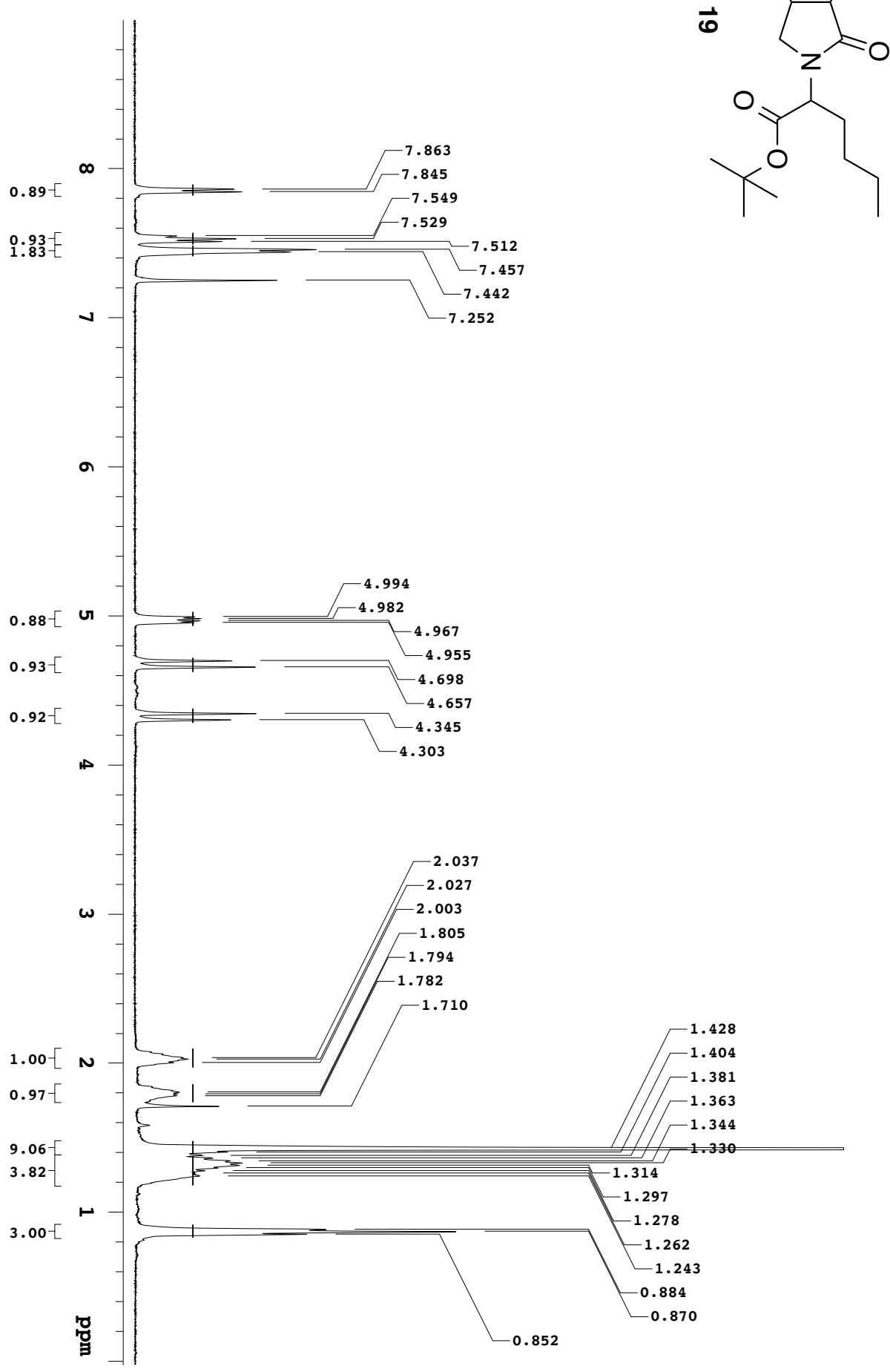




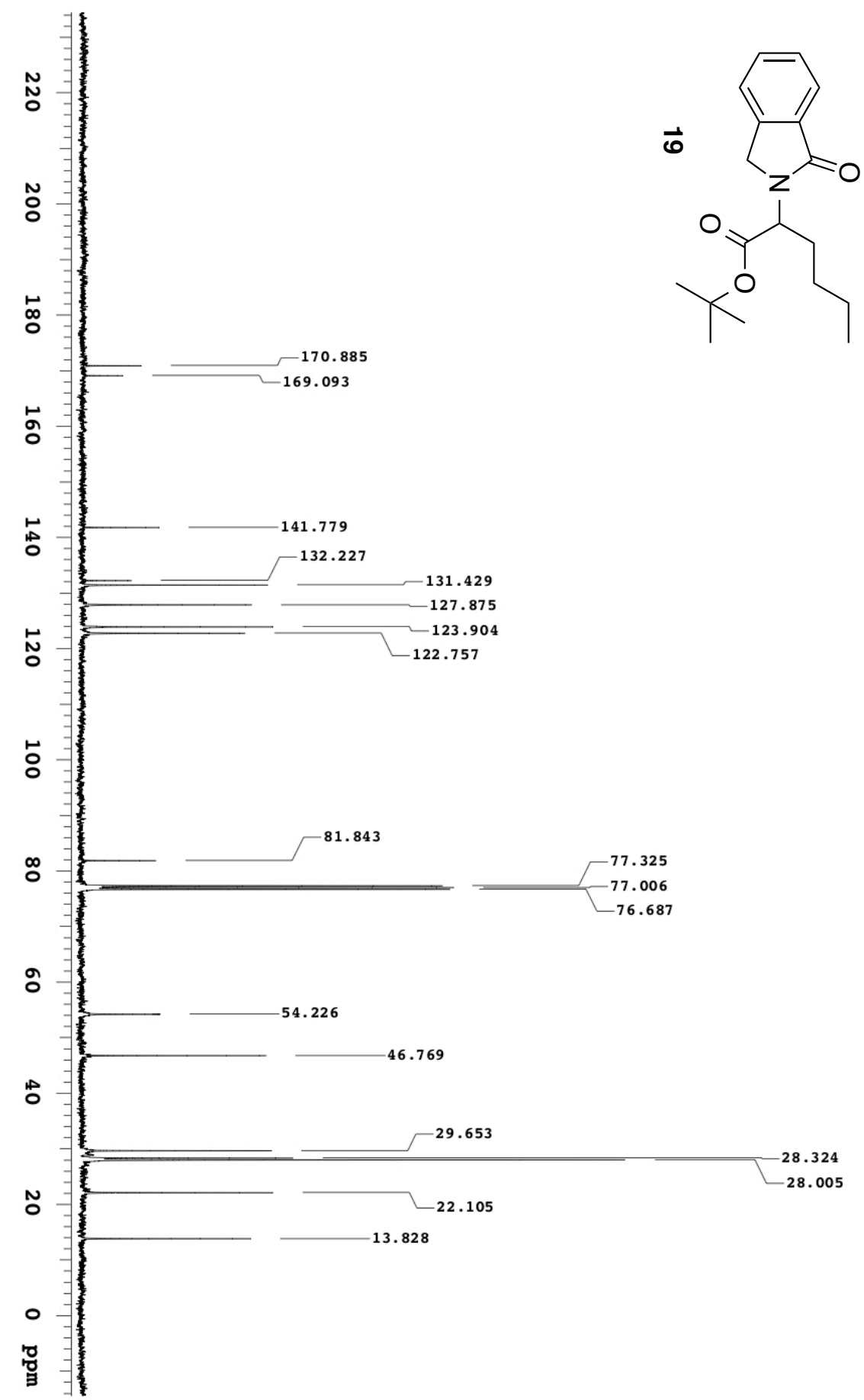




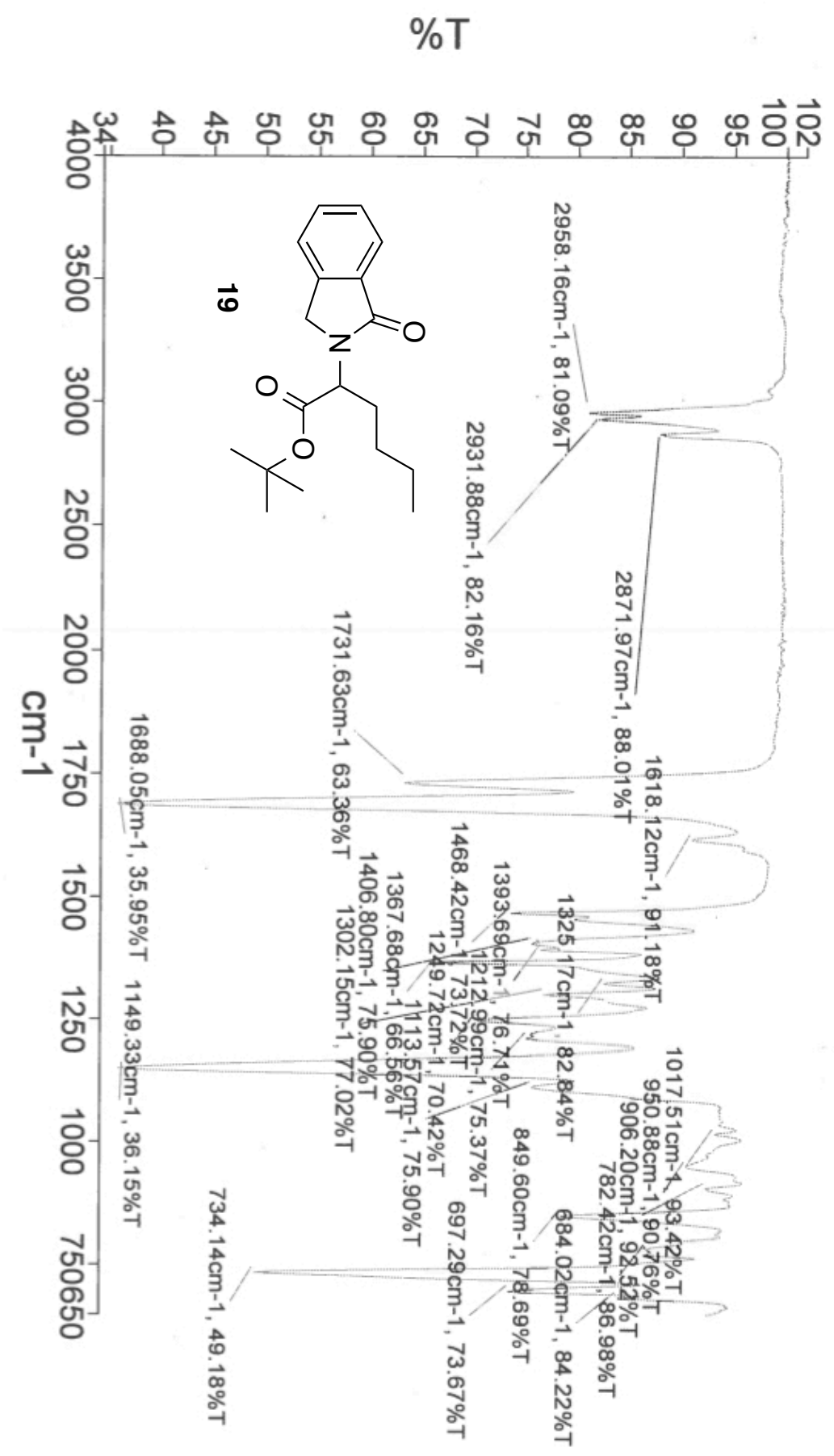




\section{tert-Butyl 2-(1-oxoisoindolin-2-yl)pent-4-enoate. 20}

Allyl bromide (42 $\mu \mathrm{L}, 0.484 \mathrm{mmol})$ was added to a solution of tert-butyl 2-(1oxoisoindolin-2-yl)acetate $15(100 \mathrm{mg}, 0.404 \mathrm{mmol})$ in dry THF $(1.0 \mathrm{~mL})$ under $\mathrm{N}_{2}(-5$ to $\left.0{ }^{\circ} \mathrm{C}\right)$ by syringe. To the clear solution, lithium hexamethyldisilazide $(1.0 \mathrm{M}, 484 \mu \mathrm{L}, 0.484$ $\mathrm{mmol}$ ) in THF was added by syringe and stirring was continued (5h) in the -5 to $0{ }^{\circ} \mathrm{C}$ range. The reaction mixture was brought to room temperature and immediately quenched with saturated aqueous ammonium chloride solution $(5 \mathrm{~mL})$ followed by extraction with dichloromethane $(3 \times 10 \mathrm{~mL})$. The extracts were combined, dried over anhydrous sodium sulfate and concentrated to afford a crude residue which was submitted to gravity column chromatography (hexane/ethyl acetate, 15:1) to give $\mathbf{2 0}$ as a white solid (108 $\mathrm{mg}, \mathbf{9 3 \%}$ ); $\mathrm{mp}=69-71{ }^{\circ} \mathrm{C} ; \quad \mathrm{R}_{\mathrm{f}}=0.61$ (hexane/ethylacetate, $\left.1: 1\right) ;{ }^{1} \mathrm{H} \mathrm{NMR}\left(500 \mathrm{MHz}, \mathrm{CDCl}_{3}\right) \delta 7.85$ $(\mathrm{d}, J=7.0 \mathrm{~Hz}, 1 \mathrm{H}), 7.54-7.51(\mathrm{~m}, 2 \mathrm{H}), 7.45-7.42(\mathrm{~m}, 2 \mathrm{H}), 5.77-5.71(\mathrm{~m}, 1 \mathrm{H}), 5.14-5.11$ (m, 2H), $5.03(\mathrm{~d}, J=10.5 \mathrm{~Hz}, 1 \mathrm{H}), 4.62(\mathrm{~d}, J=16.0 \mathrm{~Hz}, 1 \mathrm{H}), 4.31(\mathrm{~d}, J=16.0 \mathrm{~Hz}, 1 \mathrm{H}), 2.85-$ $2.82(\mathrm{~m}, 1 \mathrm{H}), 2.63-2.57(\mathrm{~m}, 1 \mathrm{H}), 1.43(\mathrm{~s}, 9 \mathrm{H}) \mathrm{ppm} ;{ }^{13} \mathrm{C} \mathrm{NMR}\left(125 \mathrm{MHz}, \mathrm{CDCl}_{3}\right) \delta 170.0$ $169.1,141.8,133.5,132.1,131.5,127.8,123.9,122.7,118.0,82.2,53.7,47.0,24.5,28.0$ ppm; FT-IR (neat) 3080, 2980, 2938, 1731, $1685 \mathrm{~cm}^{-1}$; HRMS $\mathrm{m} / \mathrm{z}$ calculated for $\mathrm{C}_{15} \mathrm{H}_{17} \mathrm{NO}_{3} 287.1521$, found 287.1525. 


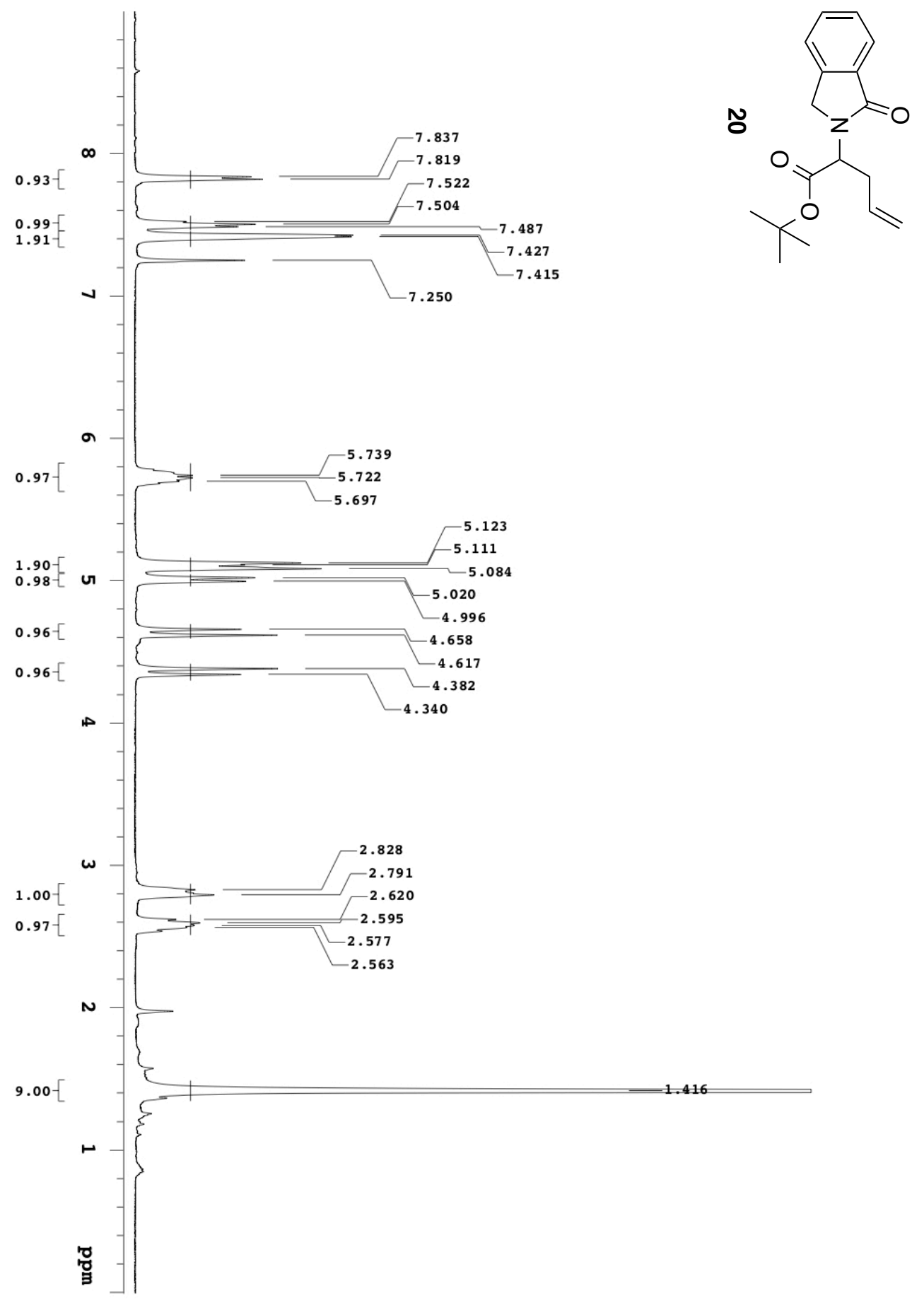




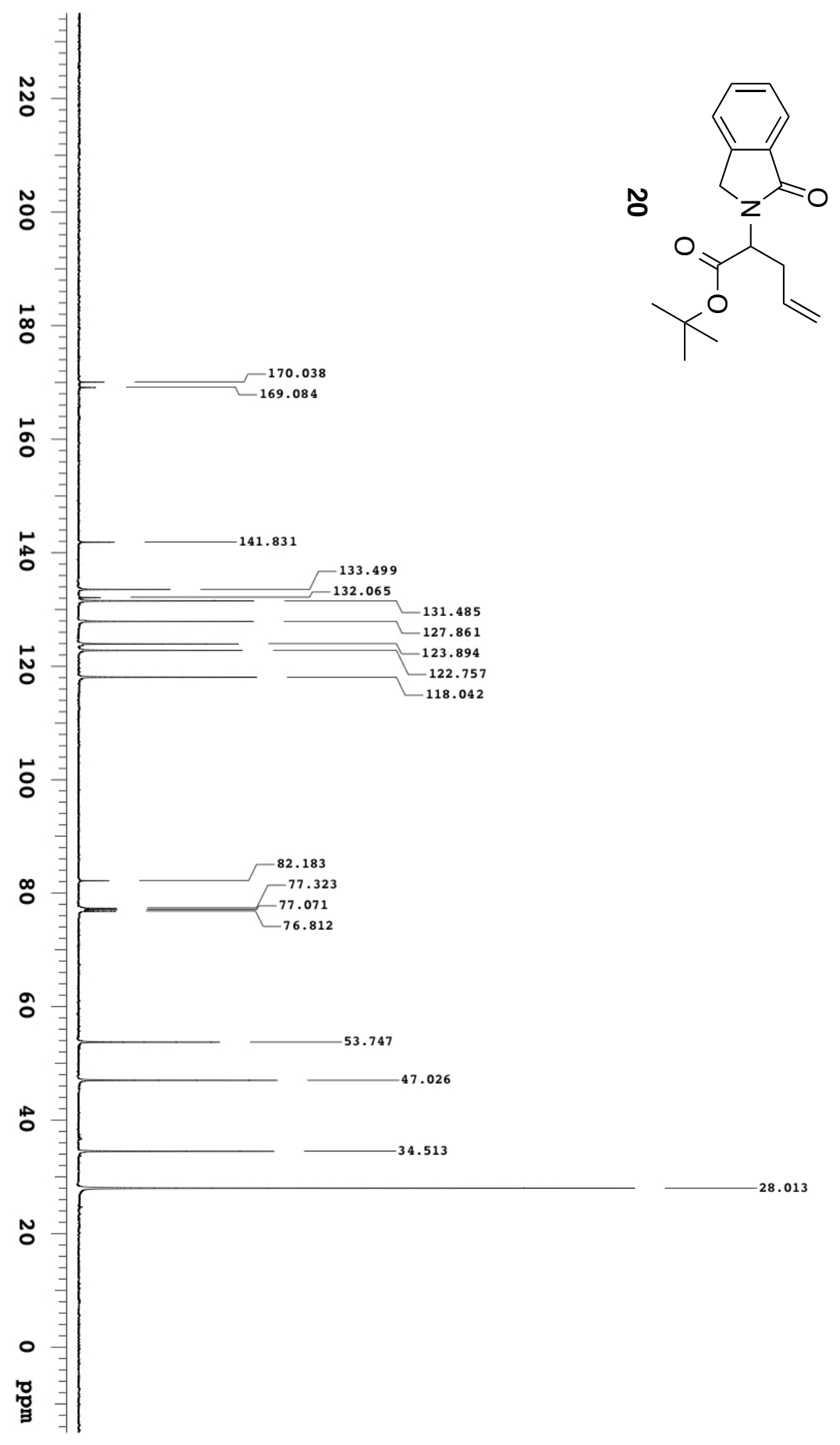




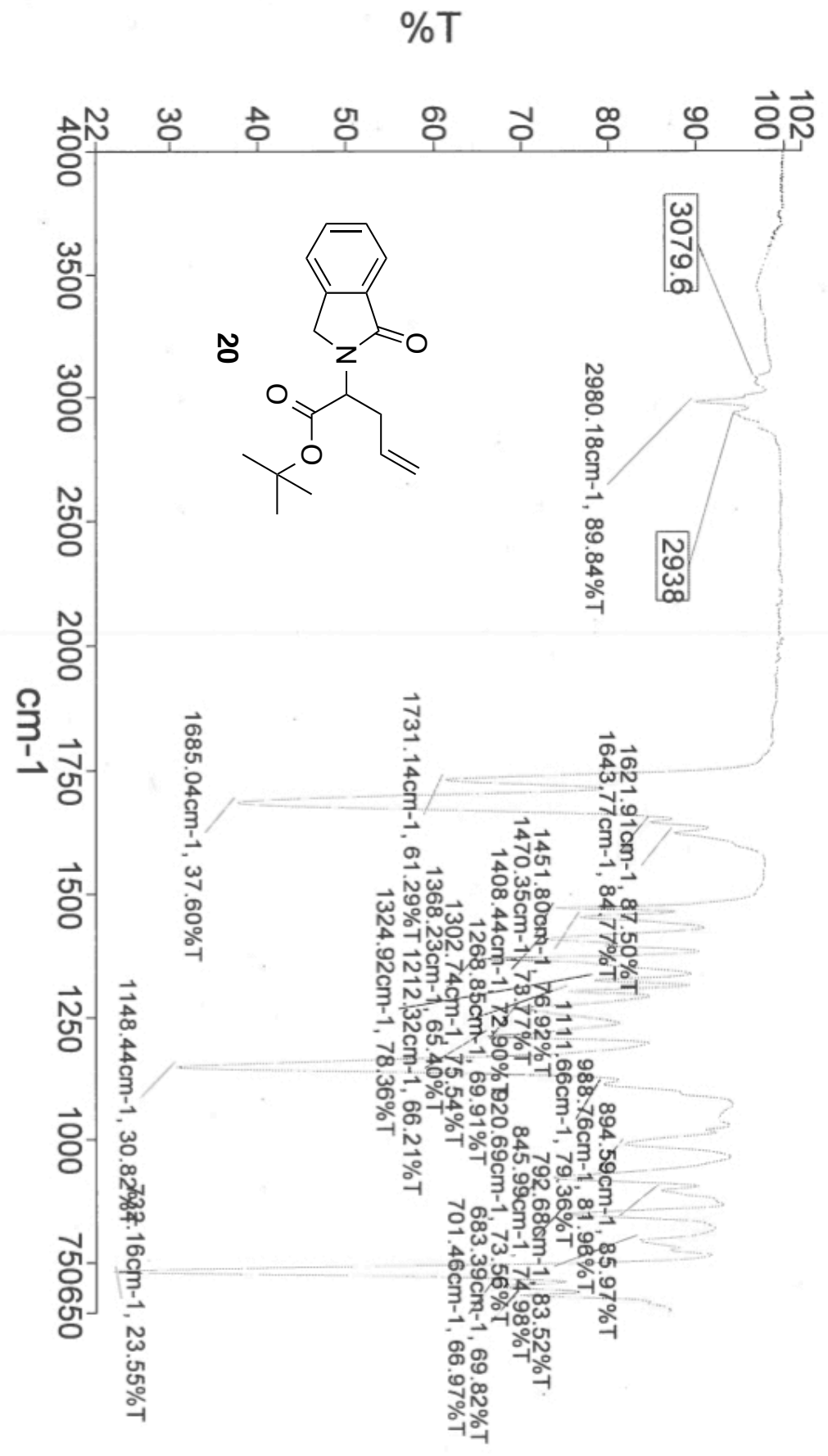




\section{tert-Butyl 2-(1-oxoisoindolin-2-yl)pent-4-ynoate. 21}

tert-Butyl 2-(1-oxoisoindolin-2-yl)acetate 15 (100 mg, $0.404 \mathrm{mmol})$ was dissolved in dry THF (1.0 mL) under $\mathrm{N}_{2}$ then cooled to $-78^{\circ} \mathrm{C}$. A solution of lithium hexamethyldisilazide (1.0M, $606 \mu \mathrm{L}, 0.606 \mathrm{mmol})$ in THF was added dropwise by syringe to give a yellow solution. Propargyl bromide $(46.4 \mu \mathrm{L}, 0.484 \mathrm{mmol})$ was then added dropwise by syringe and the reaction mixture was allowed to warm to room temperature (1h). The slightly orange mixture was quenched with saturated aqueous ammonium chloride solution $(5 \mathrm{~mL})$ and extracted with dichloromethane $(3 \times 10 \mathrm{~mL})$. The concentration of the combined organic extracts provided crude material which was directly applied to gravity column chromatography (hexanes/ethyl acetate, $2: 1$ ) to yield 21 as a pale yellow oil (90 $\mathrm{mg}, 78 \%$ ); $\mathrm{R}_{\mathrm{f}}=0.45$ (hexane/ethyl acetate, $\left.2: 1\right) ;{ }^{1} \mathrm{H}$ NMR $\left(700 \mathrm{MHz}, \mathrm{CDCl}_{3}\right) \delta 7.87-7.85(\mathrm{~d}, J=6.8$ $\mathrm{Hz}, 1 \mathrm{H}), 7.56-7.53(\mathrm{~m}, 1 \mathrm{H}), 7.47-7.43(\mathrm{~m}, 2 \mathrm{H}), 5.20-5.17(\mathrm{dd}, J=3.2 \mathrm{~Hz}, 7.6 \mathrm{~Hz}, 1 \mathrm{H})$, $4.74(\mathrm{~d}, J=8.4 \mathrm{~Hz}, 1 \mathrm{H}), 4.62(\mathrm{~d}, J=8.4 \mathrm{~Hz}, 1 \mathrm{H}), 2.94-2.78(\mathrm{~m}, 2 \mathrm{H}), 2.01(\mathrm{~s}, 1 \mathrm{H}), 1.44(\mathrm{~s}, 9 \mathrm{H})$ ppm; ${ }^{13} \mathrm{C} \mathrm{NMR}\left(125 \mathrm{MHz}, \mathrm{CDCl}_{3}\right) \delta 168.9,168.6,141.9,131.6,127.9,124.0,122.8,82.7$, 79.5, 71.5, 53.1, 47.7, 27.9, 20.8 ppm; FT-IR (neat) 3299, 2978, 2932, 1732, $1685 \mathrm{~cm}^{-1}$; LRMS $m / z$ calculated for $\mathrm{C}_{17} \mathrm{H}_{19} \mathrm{NO}_{3}[\mathrm{M}+\mathrm{H}] 286$, found 286 . 


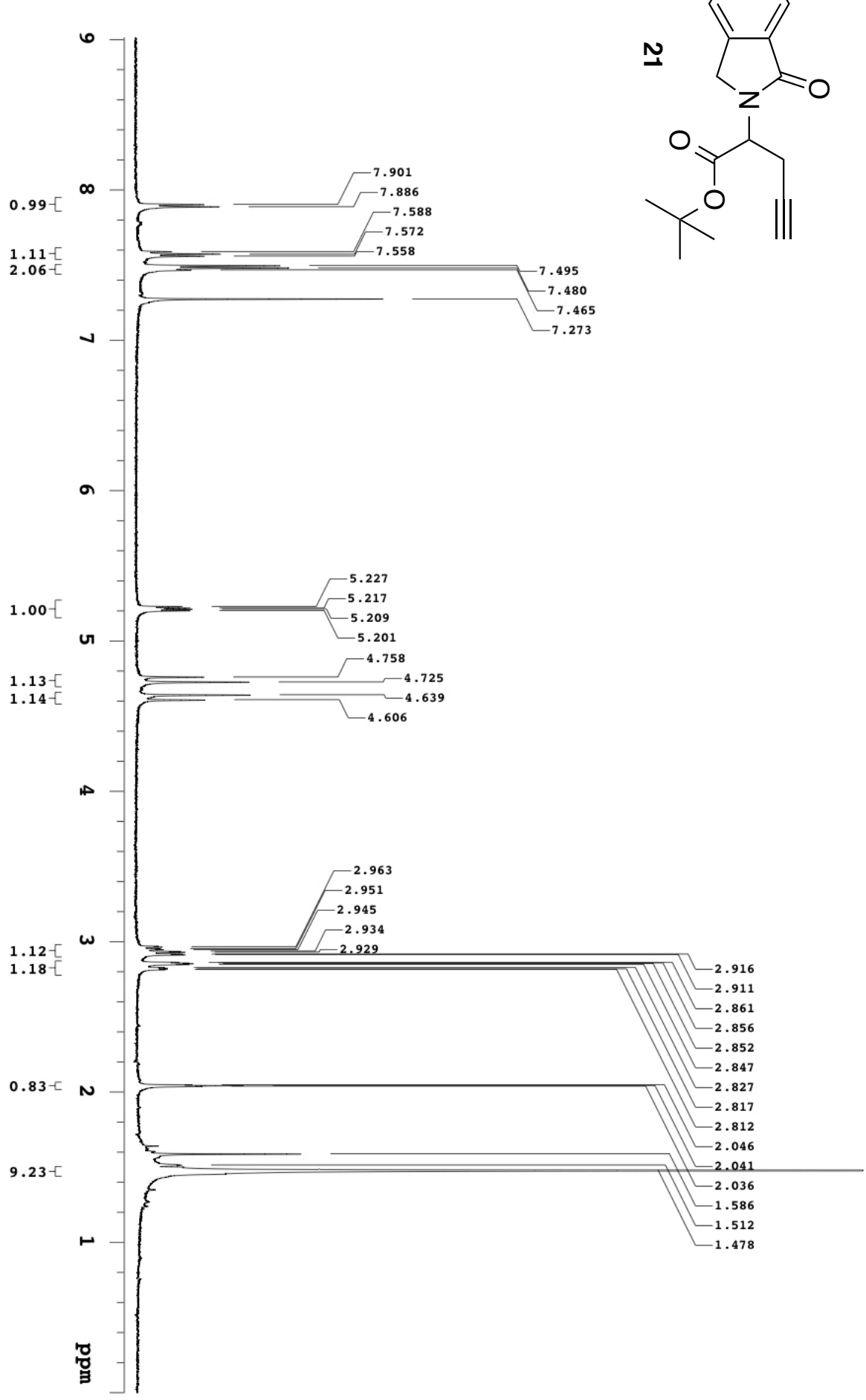




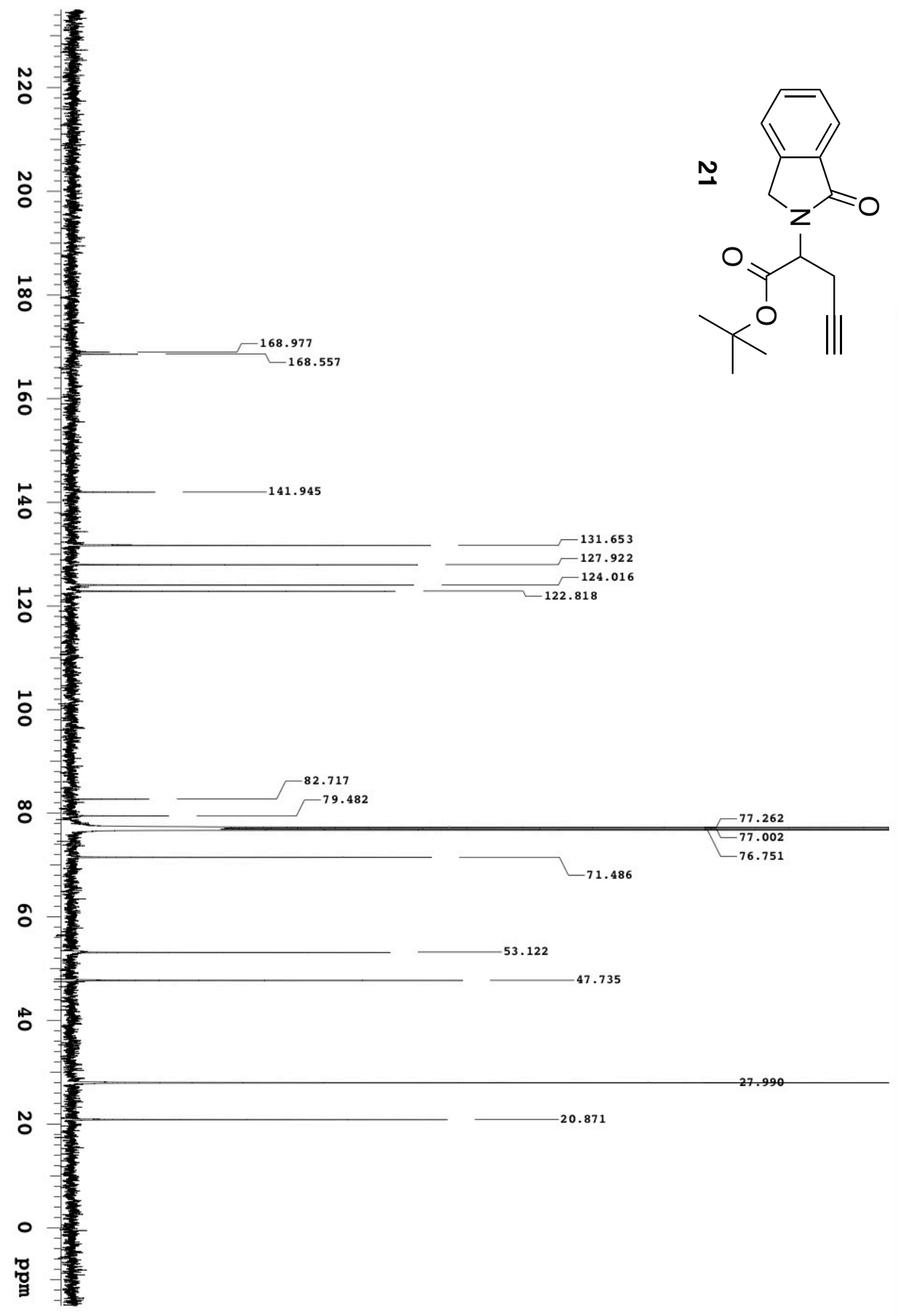




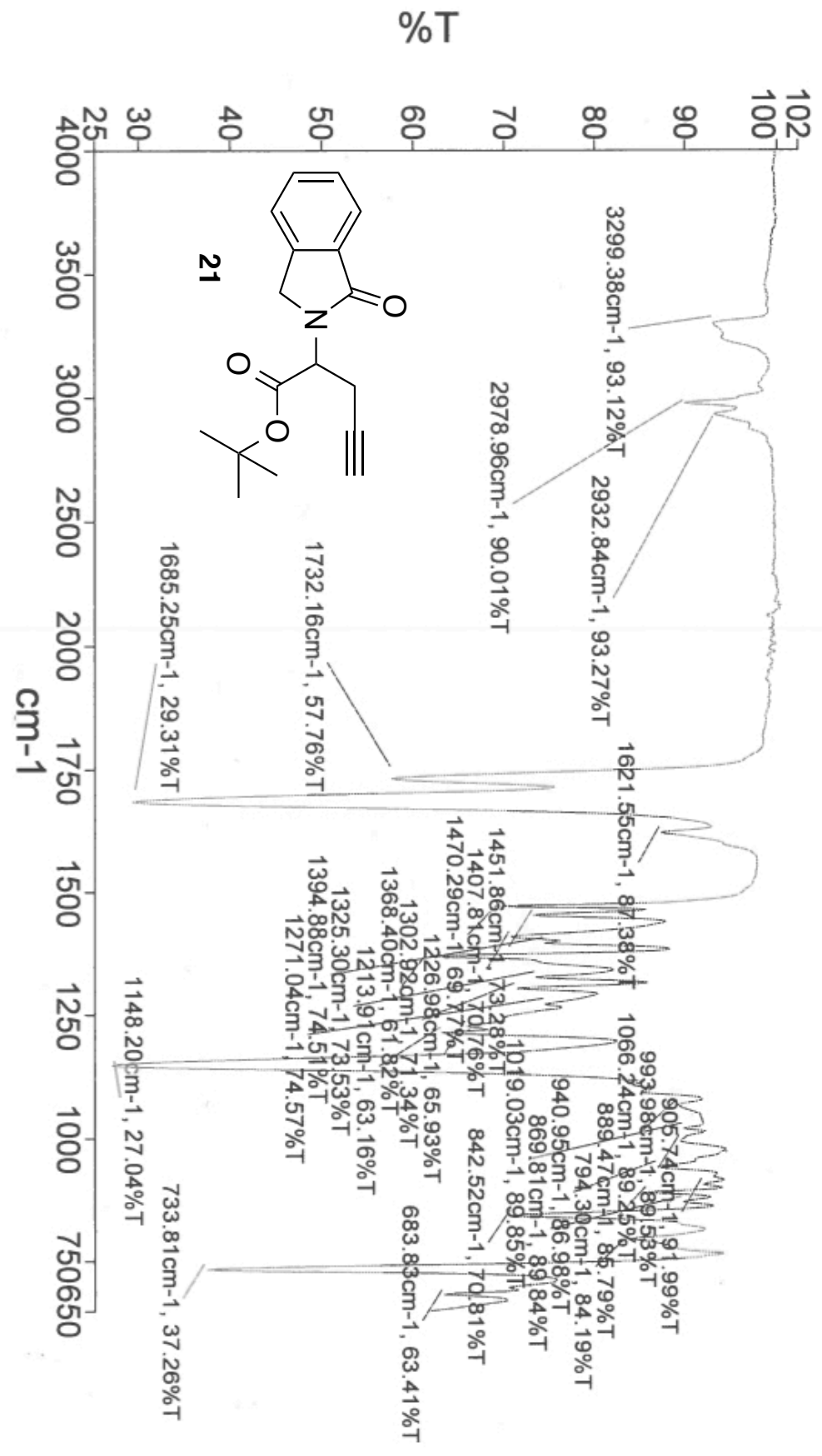




\section{tert-Butyl 2-(1-oxoisoindolin-2-yl)-3-phenylpropanoate. 22}

tert-Butyl 2-(1-oxoisoindolin-2-yl)acetate 15 (100 $\mathrm{mg}, 0.404 \mathrm{mmol})$ was dissolved in freshly-distilled THF $(3.0 \mathrm{~mL})$ under $\mathrm{N}_{2}\left(-78^{\circ} \mathrm{C}\right)$. Lithium hexamethyldisilazide $(1.0 \mathrm{M}$, $606 \mu \mathrm{L}, 0.606 \mathrm{mmol}$ ) in THF was added to the reaction mixture dropwise by syringe and stirring was continued $(10 \mathrm{~min})$. To the yellow solution, benzyl bromide $(57 \mu \mathrm{L}, 0.484$ mmol) was added dropwise by syringe which resulted in a slight discharge of color. The reaction was stirred $(1 \mathrm{~h})$, brought to room temperature and immediately quenched with saturated aqueous ammonium chloride solution $(5 \mathrm{~mL})$. The mixture was extracted with dichloromethane $(3 \times 10 \mathrm{~mL})$ and the organic layers were combined, dried over anhydrous sodium sulfate, and concentrated to give a crude residue. The residue was submitted to flash-column chromatography (hexanes/ethyl acetate, 15:1) to provide pure 22 as a white solid $(111 \mathrm{mg}, 82 \%) ; \mathrm{mp}=94-96{ }^{\circ} \mathrm{C} ; \mathrm{R}_{\mathrm{f}}=0.57$ (hexane/ethylacetate, $\left.1: 1\right) ;{ }^{1} \mathrm{H}$ NMR $(400$ $\left.\mathrm{MHz}, \mathrm{CDCl}_{3}\right) \delta 7.79(\mathrm{~d}, J=7.2 \mathrm{~Hz}, 1 \mathrm{H}), 7.50-7.45(\mathrm{~m}, 1 \mathrm{H}), 7.41-7.36(\mathrm{~m}, 2 \mathrm{H}), 7.25-7.22$ $(\mathrm{m}, 4 \mathrm{H}), 7.17-7.14(\mathrm{~m}, 1 \mathrm{H}), 5.35-5.31(\mathrm{~m}, 1 \mathrm{H}), 4.61(\mathrm{~d}, J=16.8 \mathrm{~Hz}, 1 \mathrm{H}), 4.30(\mathrm{~d}, J=16.8 \mathrm{~Hz}$ 1H), 3.45-3.10 (m, 2H), 1.39 (s, 1H) ppm; ${ }^{13} \mathrm{C}$ NMR (125 MHz, $\left.\mathrm{CDCl}_{3}\right) \delta 170.1,168.9$, 141.7, 136.6, 132.1, 131.4, 123.6, 127.8, 126.8, 123.9, 122.7 ppm; FT- IR (neat) 2983, 2933, 2871, 1742, $1683 \mathrm{~cm}^{-1}$; HRMS m/z calculated for $\mathrm{C}_{21} \mathrm{H}_{23} \mathrm{NO}_{3}$ 337.1678, found 337.1682 . 


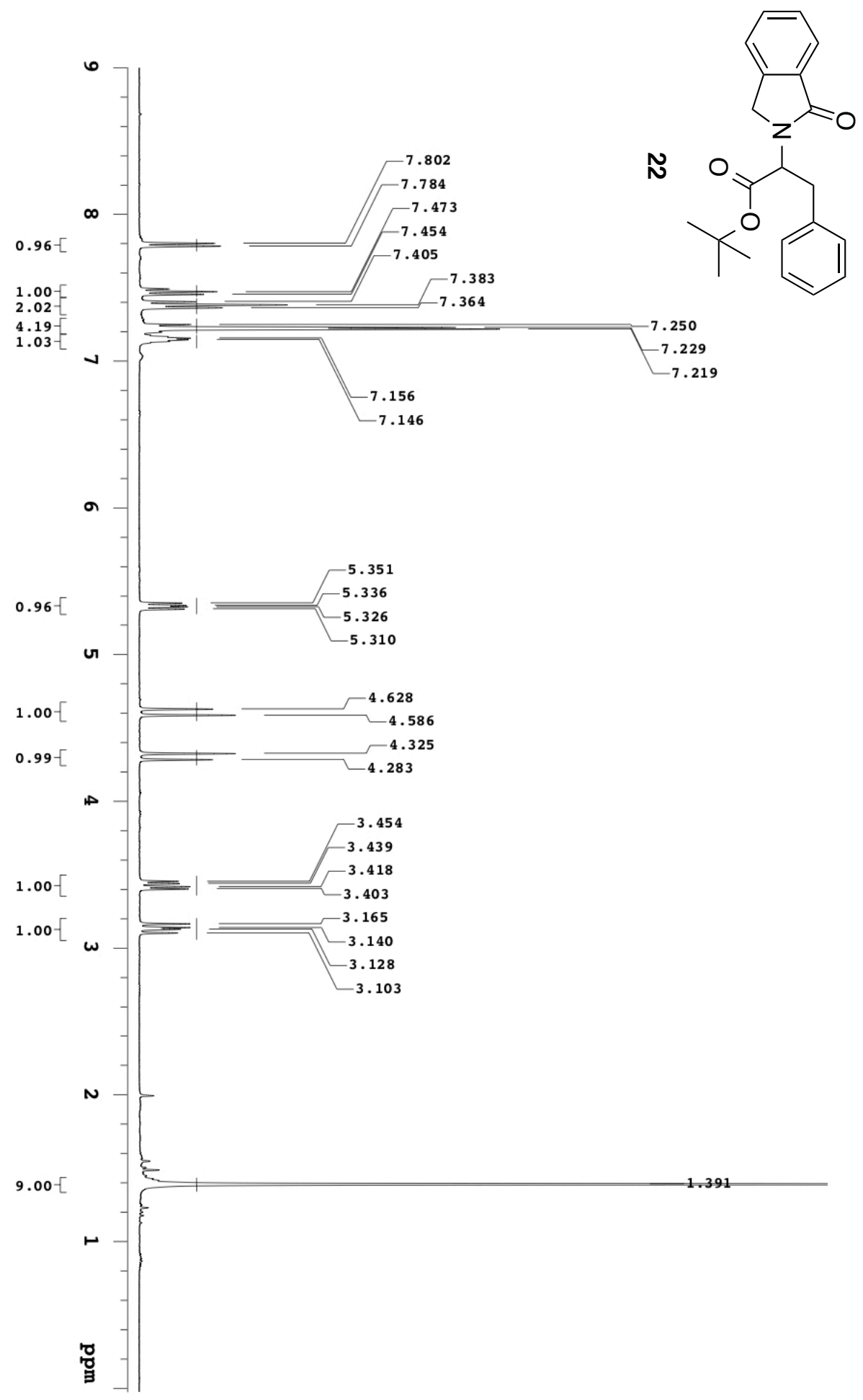




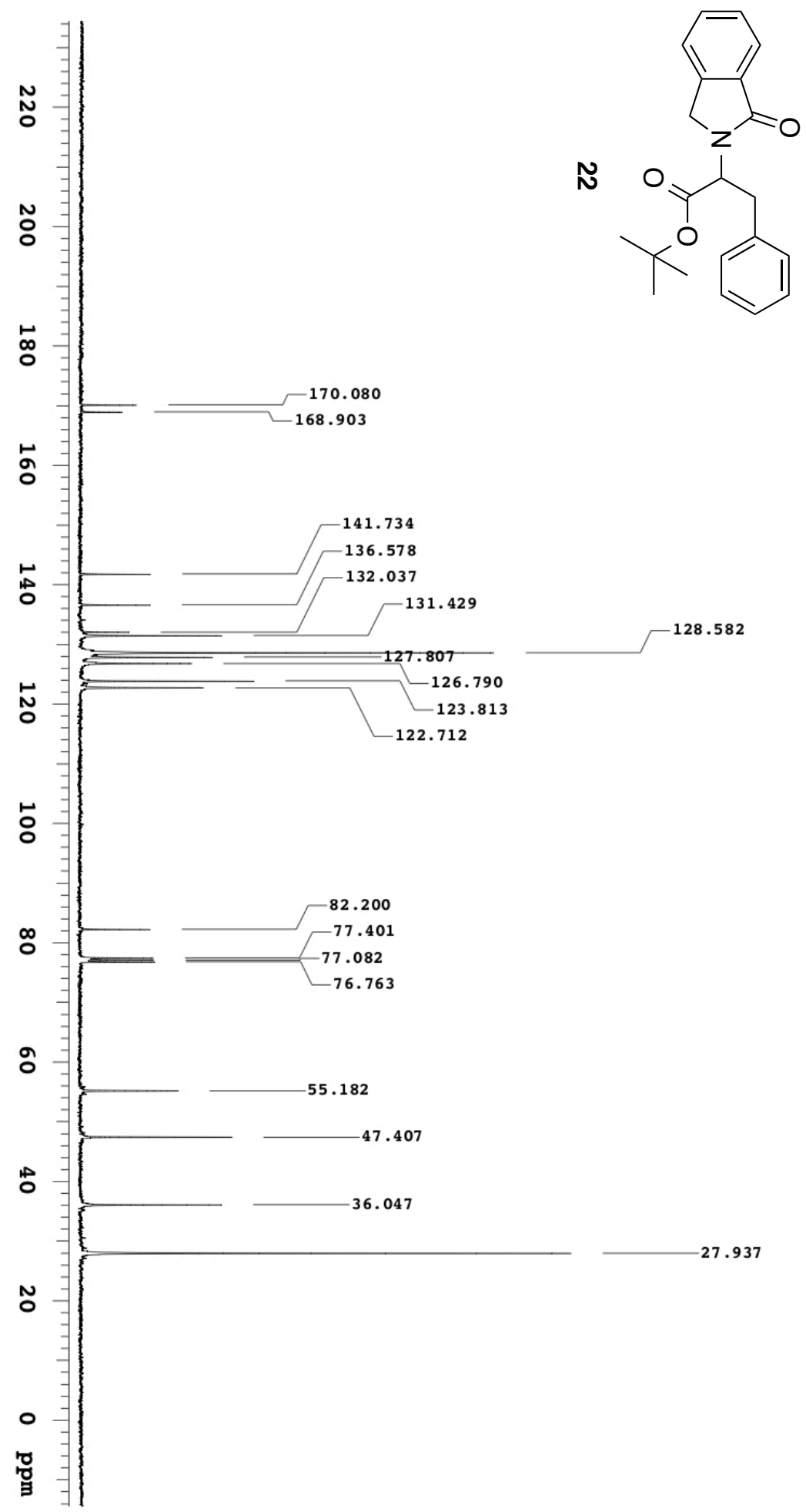




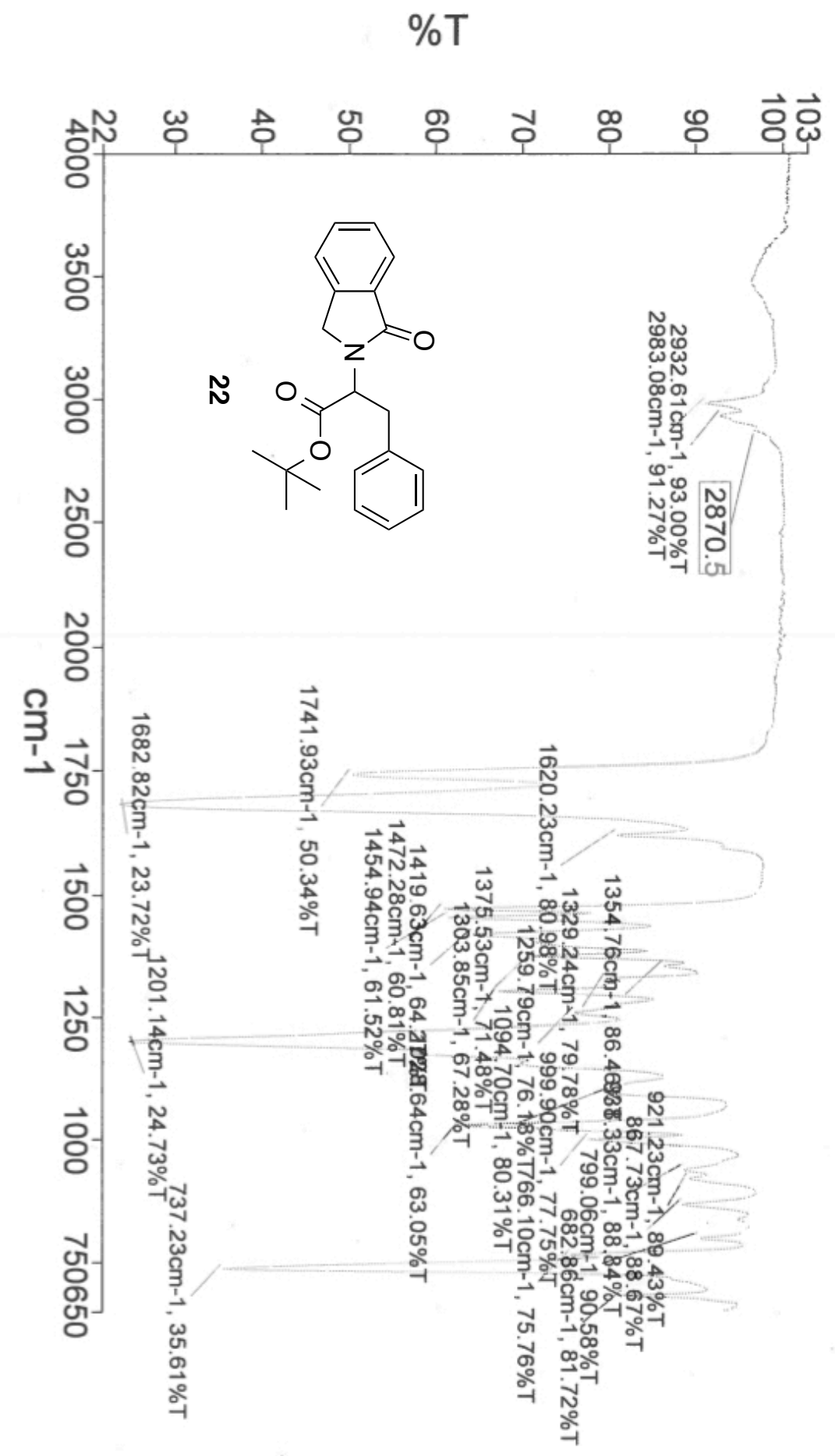


tert-Butyl 3-(4-fluorophenyl)-2-(1-oxoisoindolin-2-yl)propanoate. 23

tert-butyl 2-(1-oxoisoindolin-2-yl)acetate 15 (100 mg, $0.404 \mathrm{mmol})$ was dissolved in freshly-distilled THF and lithium hexamethyldisilazide (1.0M, $505 \mu \mathrm{L}, 0.505 \mathrm{mmol})$ in THF was added by syringe $\left(-78^{\circ} \mathrm{C}\right)$ under $\mathrm{N}_{2}$ and stirred $(10 \mathrm{~min})$. To the reaction mixture, 4-fluorobenzyl chloride $(70 \mu \mathrm{L}, 0.484 \mathrm{mmol})$ was added dropwise by syringe which resulted in a clear yellow solution. The reaction mixture was stirred $(1 \mathrm{~h})$, brought to room temperature and immediately quenched with saturated aqueous ammonium chloride solution $(5 \mathrm{~mL})$. The mixture was extracted with dichloromethane $(3 \times 10 \mathrm{~mL})$ and the extracts were combined, dried over sodium sulfate, and concentrated. Purification of the crude residue was done by flash-column chromatography (hexanes/ethyl acetate, 4:1) to obtain pure 23 as colorless oil ( $86 \mathrm{mg}, 60 \%) ; \mathrm{R}_{\mathrm{f}}=0.55$ (hexane/ethylacetate, $\left.1: 1\right) ;{ }^{1} \mathrm{H}$ NMR $\left(500 \mathrm{MHz}, \mathrm{CDCl}_{3}\right) \delta 7.83(\mathrm{~d}, J=7.0 \mathrm{~Hz}, 1 \mathrm{H}), 7.54-7.51(\mathrm{~m}, 1 \mathrm{H}), 7.45-7.41(\mathrm{~m}, 2 \mathrm{H}), 7.22-$ $7.20(\mathrm{~m}, 2 \mathrm{H}), 6.95-6.92(\mathrm{~m}, 2 \mathrm{H}), 5.32-5.28(\mathrm{~m}, 1 \mathrm{H}), 4.81(\mathrm{~d}, J=16.5 \mathrm{~Hz}, 1 \mathrm{H}), 4.51(\mathrm{~d}$, $J=16.5 \mathrm{~Hz}, 1 \mathrm{H}), 3.43-3.38(\mathrm{~m}, 1 \mathrm{H}), 3.14-3.10(\mathrm{~m}, 1 \mathrm{H}), 1.43(\mathrm{~s}, 9 \mathrm{H}) \mathrm{ppm} ;{ }^{13} \mathrm{C}$ NMR $(125$ $\left.\mathrm{MHz}, \mathrm{CDCl}_{3}\right) \delta 169.9,168.9,162.7,160.8,141.6,132.1(\mathrm{~d}, J=43.0 \mathrm{~Hz}), 131.5,130.1(\mathrm{~d}$, $J=8.62 \mathrm{~Hz}), 127.9,123.9,122.7,115.5(\mathrm{~d}, J=20.8 \mathrm{~Hz}), 82.39,55.36,47.38,35.30,27.96$ ppm; FT-IR (neat) 2979, 2932, 1732, $1671 \mathrm{~cm}^{-1}$; HRMS $\mathrm{m} / z$ calculated for $\mathrm{C}_{21} \mathrm{H}_{22} \mathrm{FNO}_{3}$ 355.1584 , found 355.1588 


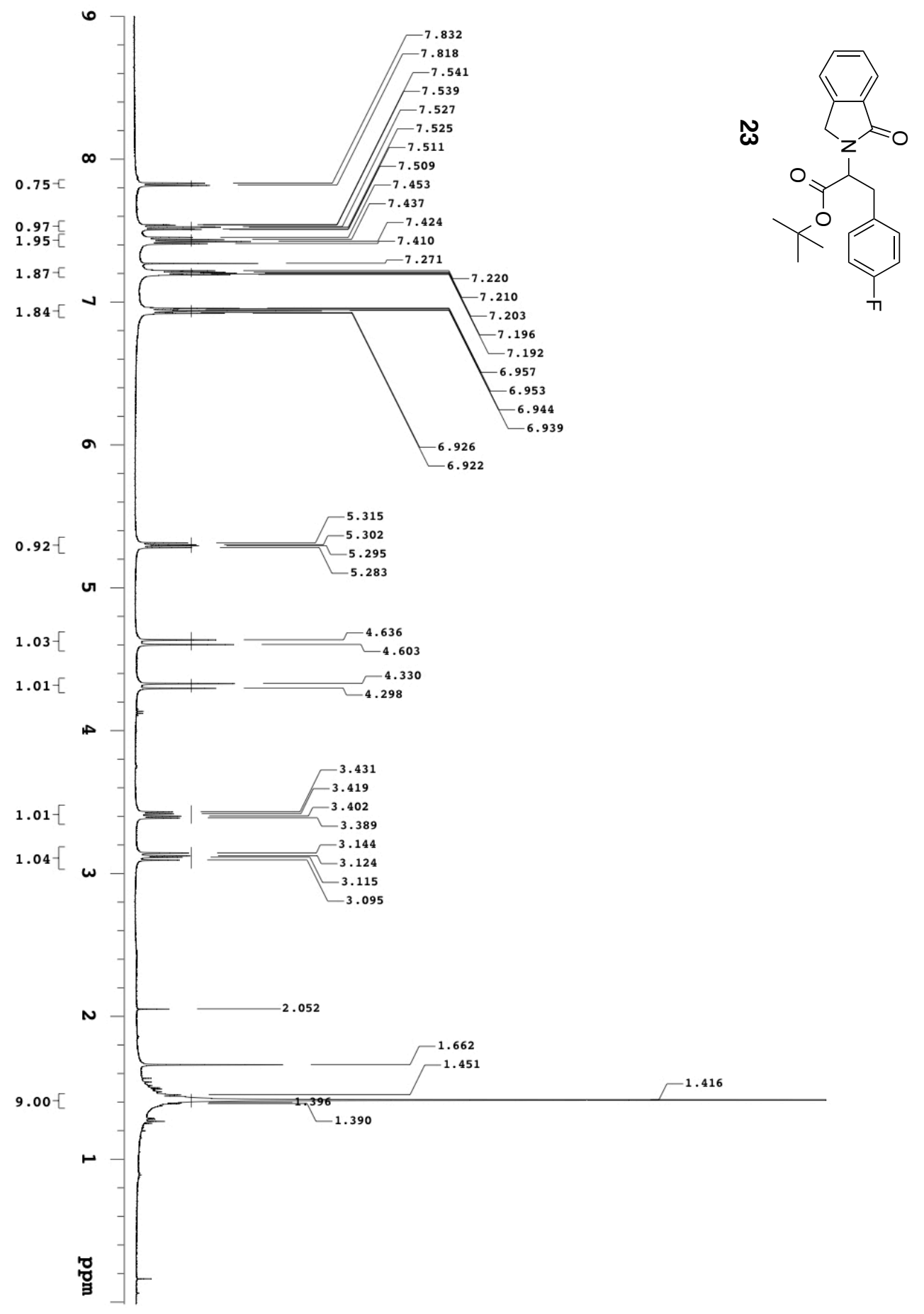




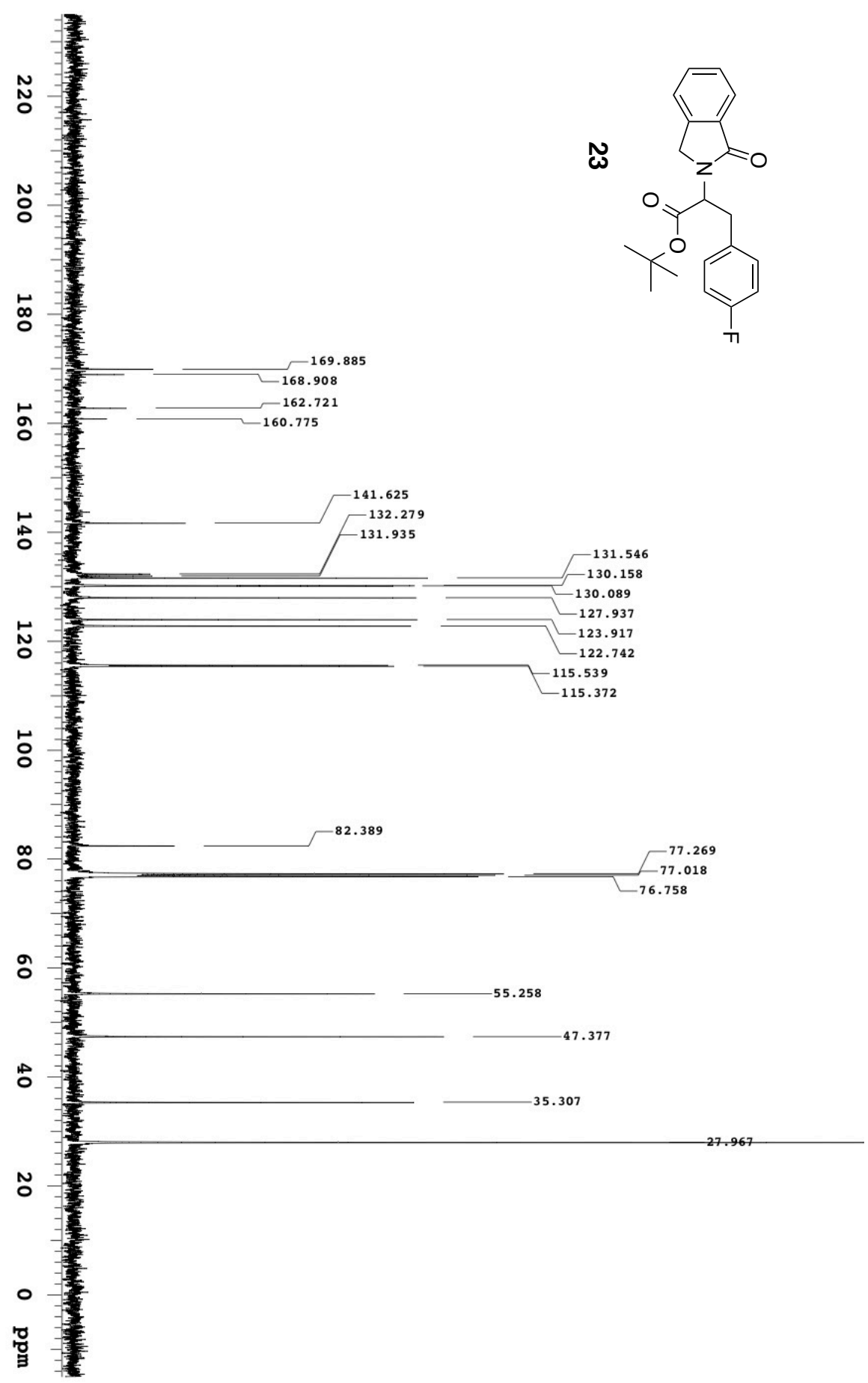




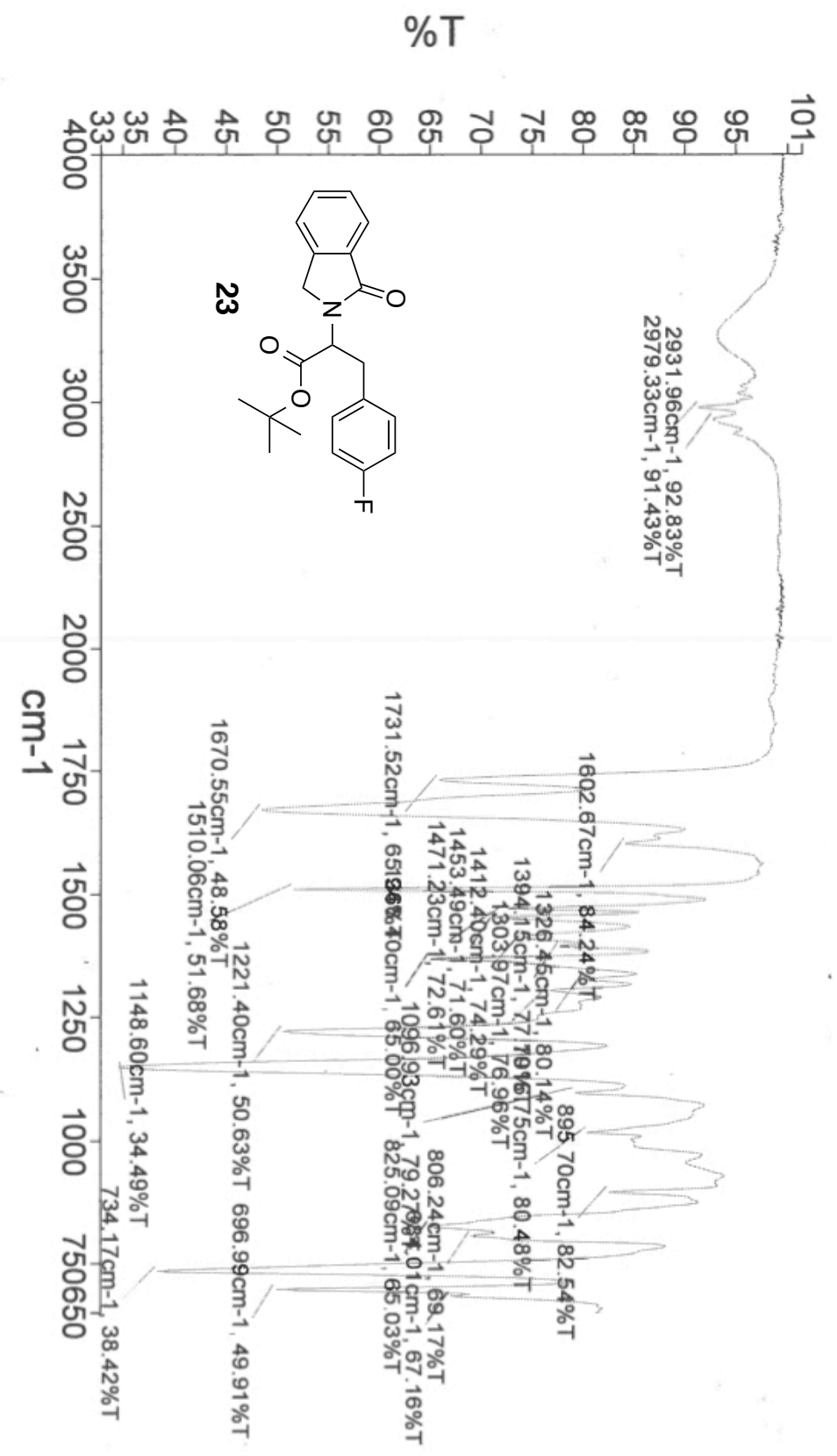




\section{tert-Butyl 3-(4-methoxyphenyl)-2-(1-oxoisoindolin-2-yl)propanoate. 24}

tert-butyl 2-(1-oxoisoindolin-2-yl)acetate 15 (100 mg, $0.404 \mathrm{mmol})$ was dissolved in freshly-distilled THF (3 mL) and lithium hexamethyldisilazide (1.0M, $484 \mu \mathrm{L}, 0.484$ mmol) was added in THF under $\mathrm{N}_{2}\left(-78{ }^{\circ} \mathrm{C}\right)$ by syringe. Stirring was continued (10 min) then 4- methoxybenzyl chloride $(65.6 \mu \mathrm{L}, 0.484 \mathrm{mmol})$ was added to the reaction mixture dropwise by syringe which resulted in a yellow reaction mixture. The reaction mixture was stirred (1h) at $-78{ }^{\circ} \mathrm{C}$ and then slowly warmed to room temperature followed by an immediate quench with saturated aqueous ammonium chloride $(5 \mathrm{~mL})$. The reaction mass was extracted with dichloromethane $(3 \times 10 \mathrm{~mL})$, the extracts were combined then dried over anhydrous sodium sulfate. Concentration of the dried extracts provided a crude residue which was submitted to flash column chromatography (hexanes/ethyl acetate, 4:1). Pure 24 was obtained as a colorless oil $(88 \mathrm{mg}, 61 \%) ; \mathrm{R}_{\mathrm{f}}=0.53$ (toluene/ethyl acetate, 4:1); ${ }^{1} \mathrm{H}$ NMR $\left(500 \mathrm{MHz}, \mathrm{CDCl}_{3}\right) \delta 7.82(\mathrm{~d}, J=7.0 \mathrm{~Hz}, 1 \mathrm{H}), 7.53-7.52(\mathrm{~m}, 2 \mathrm{H}), 7.50-7.35(\mathrm{~m}$, 9H), 7.27-6.79 (m, 4H), 5.33-5.29 (m, 1H), $4.63(\mathrm{~d}, J=16.5 \mathrm{~Hz}, 1 \mathrm{H}), 4,32(\mathrm{~d}, J=16.5 \mathrm{~Hz}$ 1H), 3.74-3.73 (s, 3H), 3.41-3.36 (m, 1H), 3.11-3.07 (m, 1H), 1.47-1.43 (m, 9H) ppm; ${ }^{13} \mathrm{C}$ NMR $\left(125 \mathrm{MHz}, \mathrm{CDCl}_{3}\right) \delta 170.2,168.9,158.4,141.8,132.1,131.4,129.6,128.5,127.8$, $123.8,122.7,114.02,114.02,82.2,55.3,55.2,47.4,35.2,27.9$ ppm; FT-IR (neat) 2977, 2933, 2837, 1732, $1688 \mathrm{~cm}^{-1}$; HRMS $\mathrm{m} / z$ calculated for $\mathrm{C}_{22} \mathrm{H}_{25} \mathrm{NO}_{4}$ 367.1784, found 367.1786. 


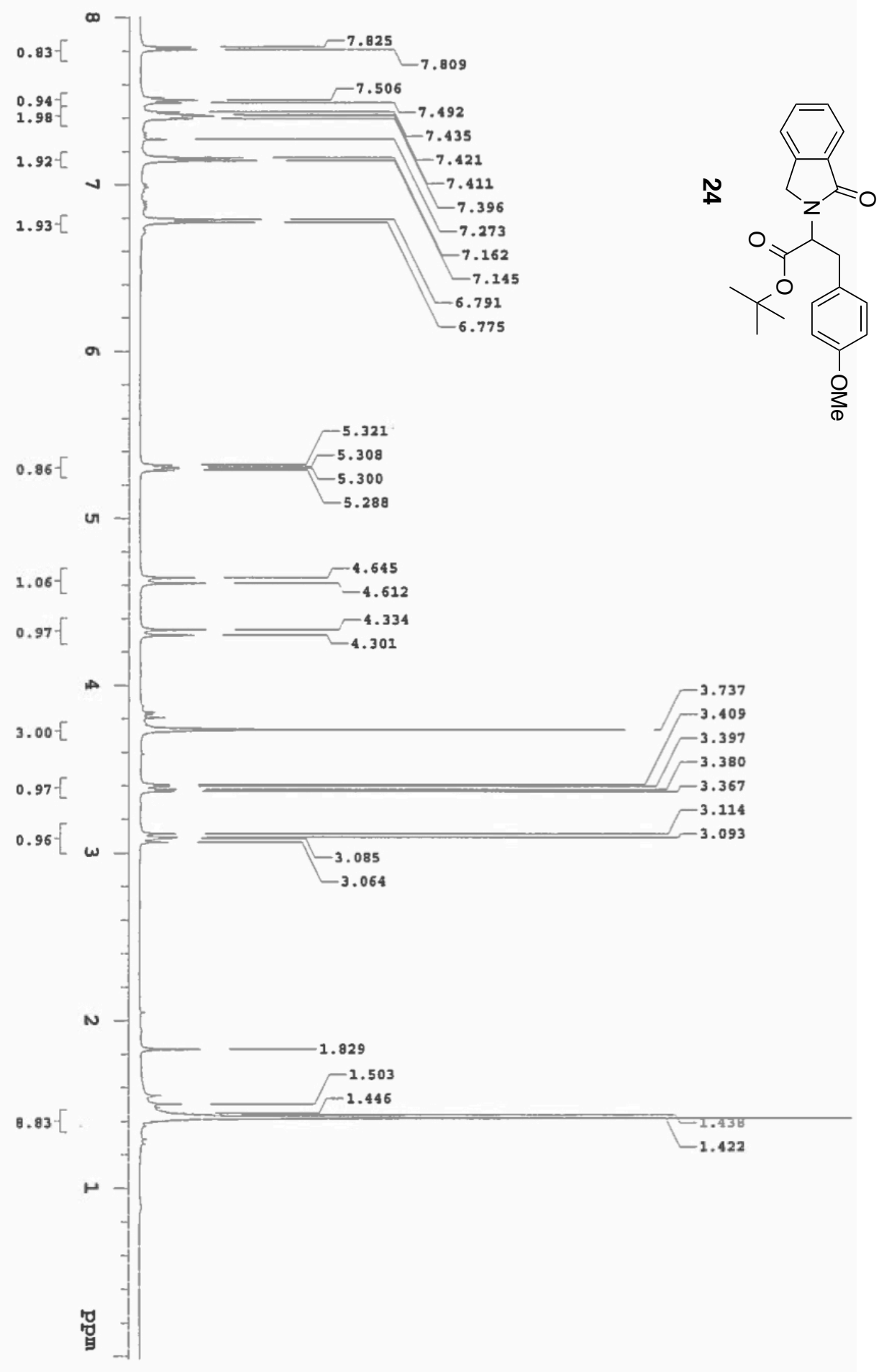




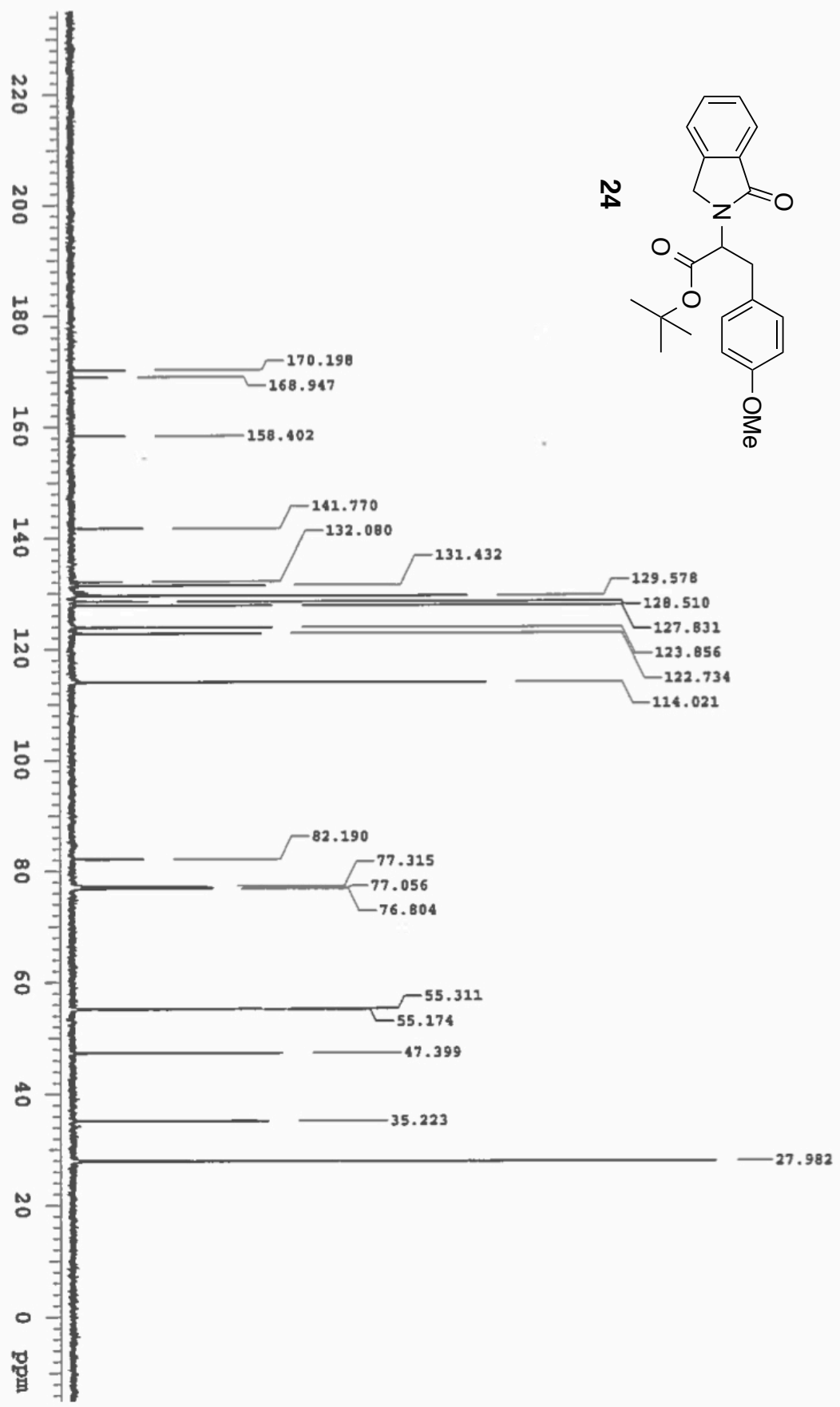




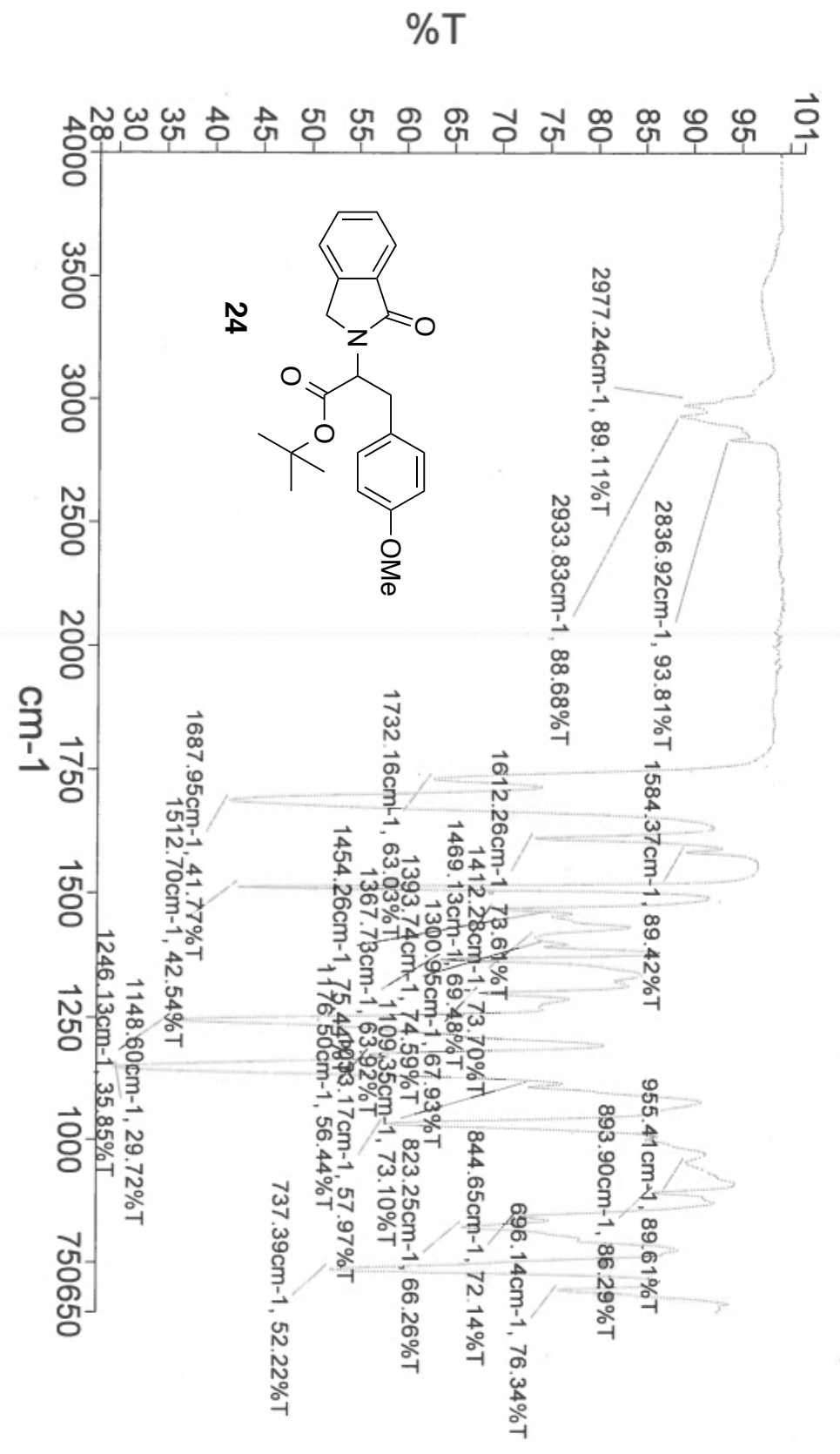




\section{tert-Butyl 3-(naphthalen-1-yl)-2-(1-oxoisoindolin-2-yl)propanoate. 25}

tert-Butyl 2-(1-oxoisoindolin-2-yl)acetate 15 (100 $\mathrm{mg}, 0.404 \mathrm{mmol})$ was dissolved in freshly-distilled THF (35 mL) and cooled to $-5{ }^{\circ} \mathrm{C} \mathrm{N}_{2}$. 1-Chloromethyl naphthalene (60 $\mu \mathrm{L}, 0.404 \mathrm{mmol}$ ) was then added to the reaction mixture by syringe and stirring was continued $(10 \mathrm{~min})$. To the solution, lithium hexamethyldisilazide (1.0M, $606 \mu \mathrm{L}, 0.606$ mmol) in THF was added dropwise by syringe. The reaction mixture was stirred $(1 \mathrm{~h})$ at 5-0 ${ }^{\circ} \mathrm{C}$, slowly brought to room temperature then quenched with saturated ammonium chloride solution $(5 \mathrm{~mL})$. The reaction mass was extracted with dichloromethane $(3 \mathrm{x} 10$ $\mathrm{mL}$ ) and the extracts were combined, dried over sodium sulfate and concentrated. The residual crude solid mass was submitted to flash column chromatography (hexanes/ethyl acetate, 5:1) to afford pure the pure 25 as a colorless oil $(79 \mathrm{mg}, 51 \%) ; \mathrm{R}_{\mathrm{f}}=0.49$ (hexanes/ethyl acetate, $2: 1) ;{ }^{1} \mathrm{H} \mathrm{NMR}\left(500 \mathrm{MHz}^{\mathrm{CDCl}} 3\right) \delta 8.20(\mathrm{~d}, J=13.5 \mathrm{~Hz}, 1 \mathrm{H}), 7.87$ $7.85(\mathrm{~m}, 2 \mathrm{H}), 7.73(\mathrm{~d}, J=7.5 \mathrm{~Hz}, 1 \mathrm{H}), 7.61-7.60(\mathrm{~m}, 1 \mathrm{H}), 7.58-7.50(\mathrm{~m}, 2 \mathrm{H}), 7.46-7.45$ (m, 1H), 7.43-7.40 (m, 1H), 7.36-7.32 (m, 2H), 5.48-5.45 (m, 1H), $4.62(\mathrm{~d}, J=12.0 \mathrm{~Hz}, 1 \mathrm{H})$, $4.43(\mathrm{~d}, J=12.0 \mathrm{~Hz}, 1 \mathrm{H}), 3.86-3.83(\mathrm{~m}, 1 \mathrm{H}), 3.68-3.65(\mathrm{~m}, 1 \mathrm{H}), 1.38(\mathrm{~s}, 9 \mathrm{H}) \mathrm{ppm} ;{ }^{13} \mathrm{C} \mathrm{NMR}$ $\left(125 \mathrm{MHz} \mathrm{CDCl}_{3}\right) \delta 170.1,168.9,141.8,133.8,132.6,132.2,131.8,131.5,128.9,127.9$, $127.7,126.5,126.4,125.7,125.4,123.8,123.2,122.8,82.3,77.3,77.0,76.8,55.1,47.7$, 33.1, 27.9 ppm; FT-IR (neat) 3055, 2980, 2938, 1734, $1690 \mathrm{~cm}^{-1}$; HRMS m/z calculated for $\mathrm{C}_{25} \mathrm{H}_{25} \mathrm{NO}_{3} 387.1834$, found 387.1835 . 


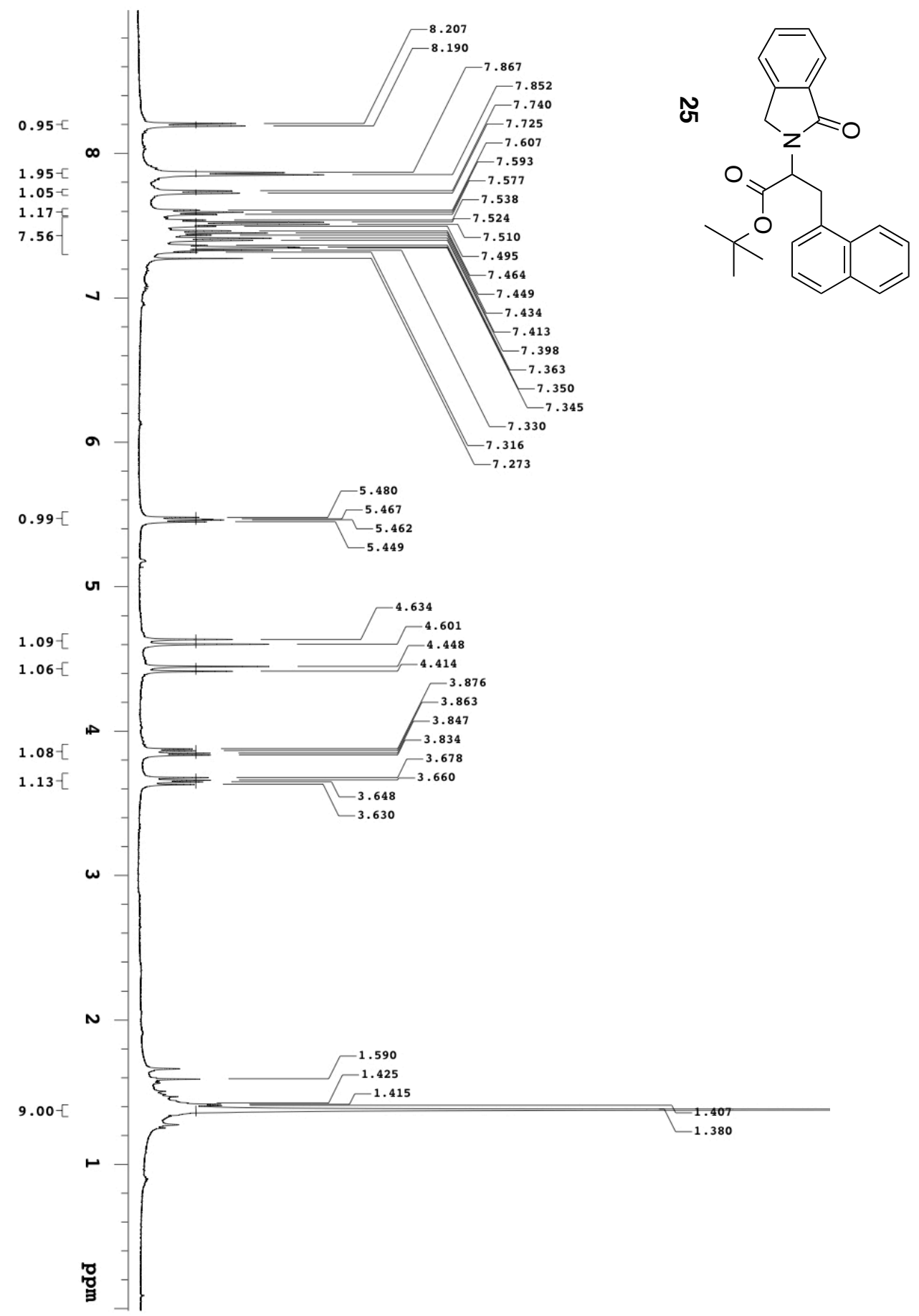




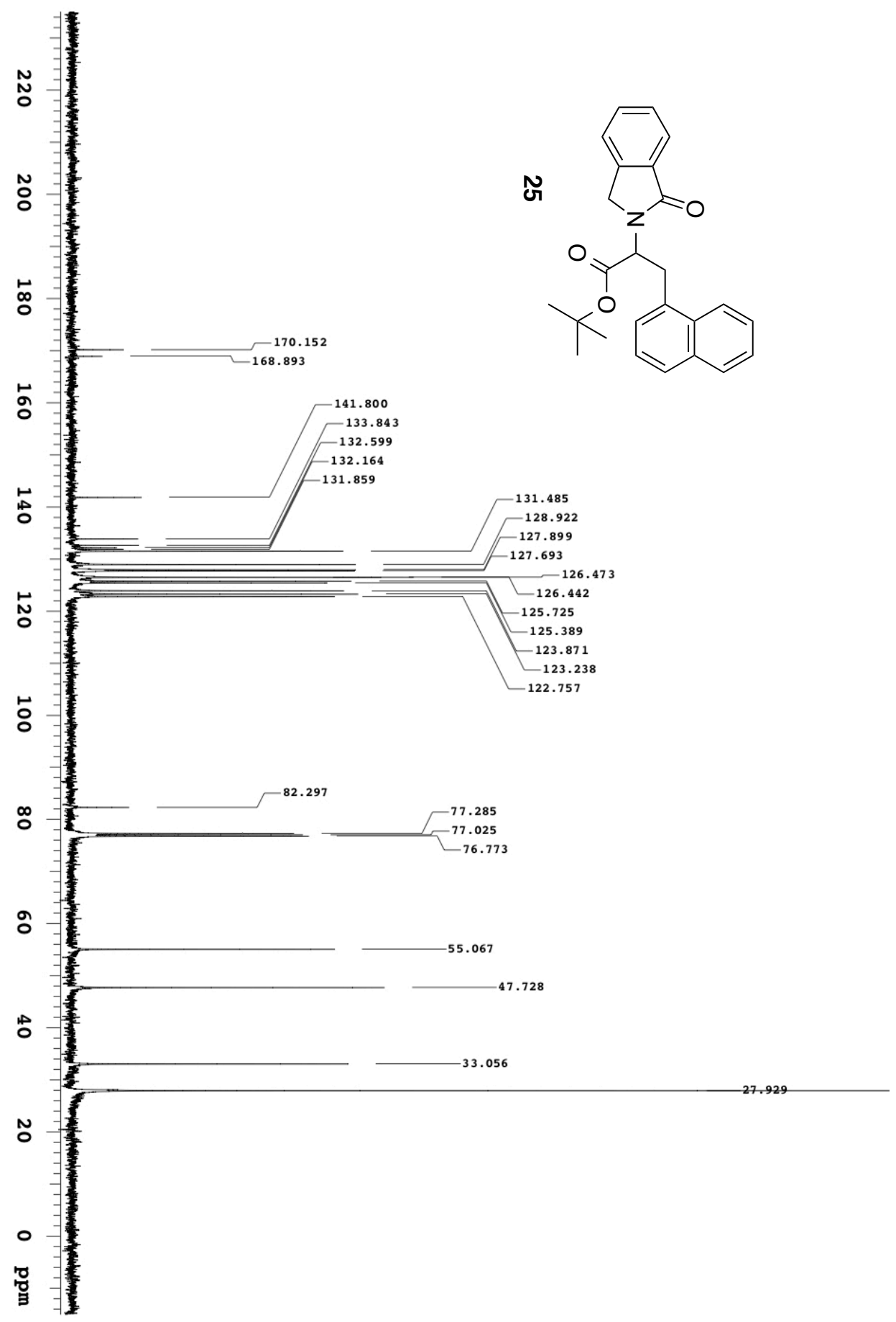




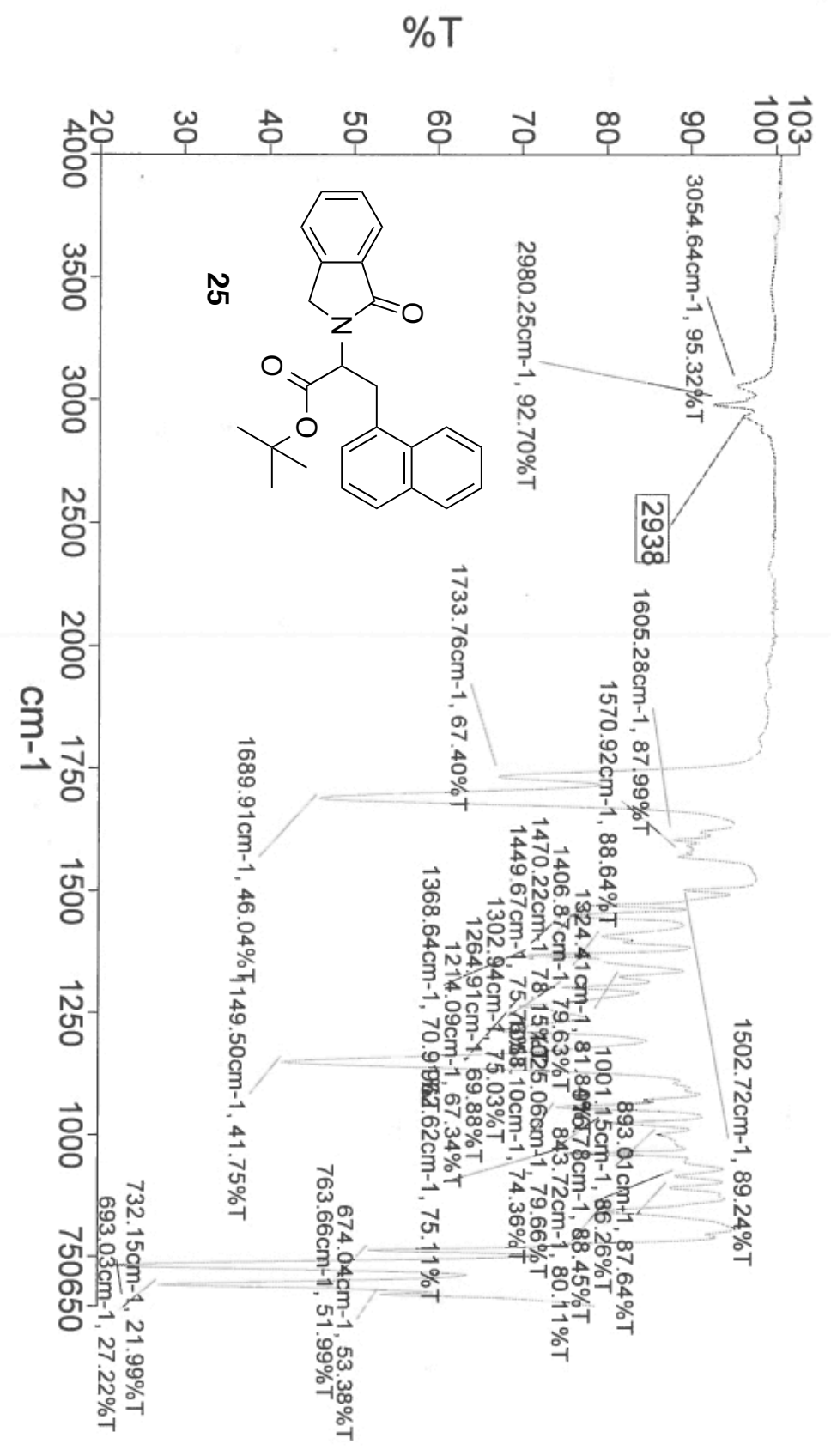




\section{Ethyl 3-(4,5-diphenyloxazol-2-yl)-2-(1-oxoisoindolin-2-yl)propanoate. 26}

Ethyl 2-(1-oxoisoindolin-2-yl)acetate 14 (100 mg, $0.456 \mathrm{mmol})$ was dissolved in freshlydistilled $\operatorname{THF}(5.0 \mathrm{~mL})$ and 2-(bromomethyl)-4,5-diphenyloxazole 38 (179 $\mathrm{mg}, 0.570$ mmol) was added at room temperature. Stirring was continued (10 min), then lithium hexamethyldisilazide $(1.0 \mathrm{M}, 570 \mu \mathrm{L}, 0.570 \mathrm{mmol})$ in THF was added dropwise by syringe to the reaction mixture which then turned yellow. The reaction mixture was stirred $(16 \mathrm{~h})$, quenched with saturated aqueous ammonium chloride solution $(5 \mathrm{~mL})$ and extracted with dichloromethane $(3 \times 10 \mathrm{~mL})$. The organic extracts were combined, dried over anhydrous sodium sulfate and concentrated to give crude material which was submitted to gravity column chromatography (hexanes/ethyl acetate, 3:1). The pure 26 was obtained as a colorless oil (126 mg, 63\%); $\mathrm{R}_{\mathrm{f}}=0.52$ (hexanes/ethylacetate, $\left.2: 1\right) ;{ }^{1} \mathrm{H}$ NMR $(500 \mathrm{MHz}$, $\left.\mathrm{CDCl}_{3}\right) \delta 7.86(\mathrm{~d} J=7.5 \mathrm{~Hz}, 1 \mathrm{H}), 7.58-7.52(\mathrm{~m}, 3 \mathrm{H}), 7.48-7.45(\mathrm{~m}, 4 \mathrm{H}), 7.34-7.29(\mathrm{~m}$ $6 \mathrm{H}), 5.63-5.60(\mathrm{~m}, 1 \mathrm{H}), 4.69(\mathrm{~d}, J=16.0 \mathrm{~Hz}, 1 \mathrm{H}), 4.63(\mathrm{~d}, J=16.) \mathrm{Hz}, 1 \mathrm{H}), 4.26(\mathrm{q}, J=7.0$ $\mathrm{Hz}, 2 \mathrm{H}), 3.70-3.66(\mathrm{~m}, 1 \mathrm{H}), 3.60-3.55(\mathrm{~m}, 1 \mathrm{H}), 1.27(\mathrm{t}, J=7.0 \mathrm{~Hz}, 3 \mathrm{H}) \mathrm{ppm} ;{ }^{13} \mathrm{C} \mathrm{NMR}$ $\left(125 \mathrm{MHz} \mathrm{CDCl}_{3}\right) \delta 169.7,168.9,159.0,146.1,141.9,135.1,132.2,131.8,131.7,128.6$ $128.5,128.1,128.0,127.8,126.5,124.0,122.9,61.9,52.5,48.0,29.1,14.1$ ppm; FT-IR (neat) $3066,2979,2931,1735,1693 \mathrm{~cm}^{-1}$; HRMS m/z calculated for $\mathrm{C}_{28} \mathrm{H}_{24} \mathrm{~N}_{2} \mathrm{O}_{4} 452.1736$, found 452.1736 . 


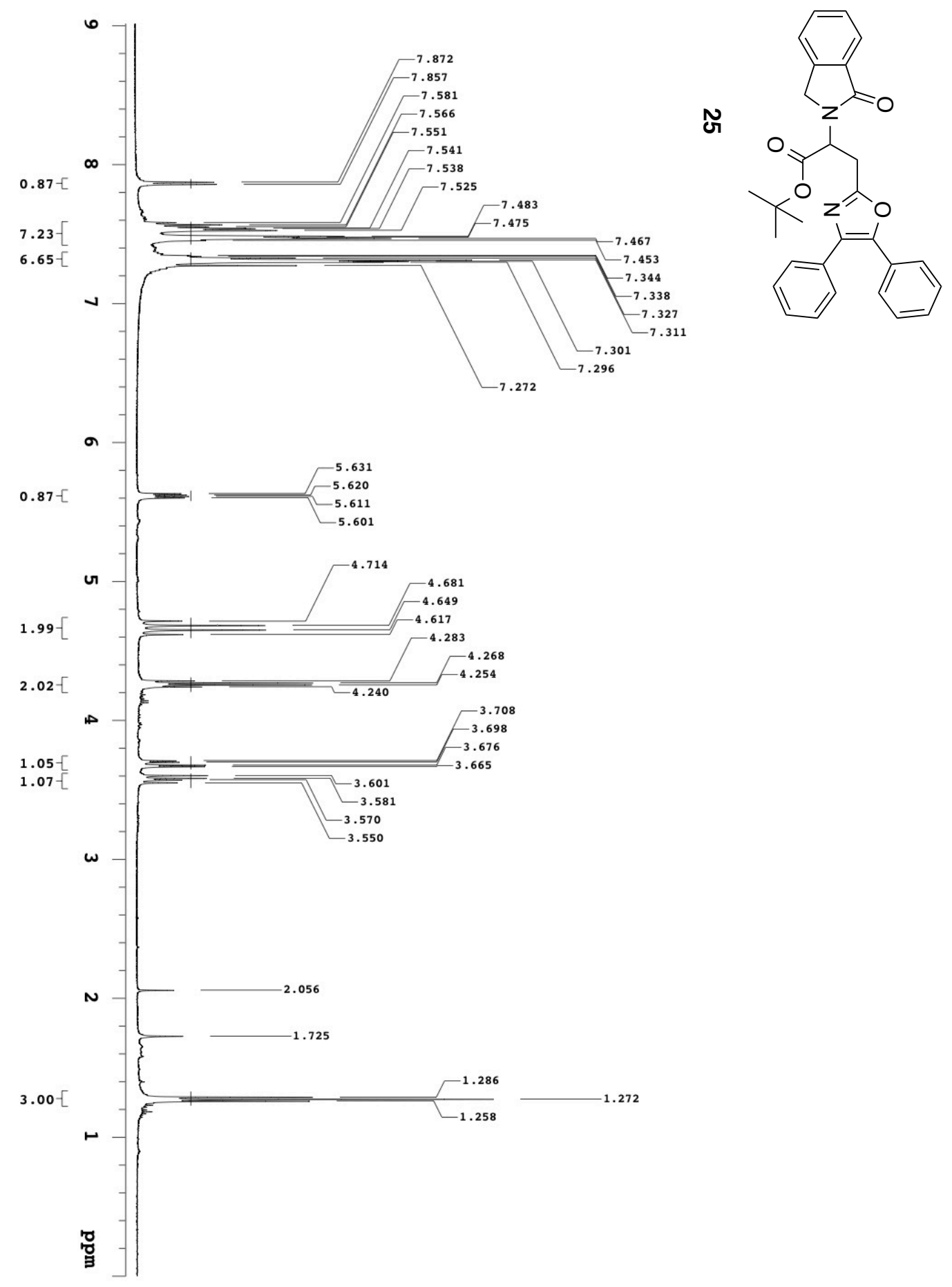




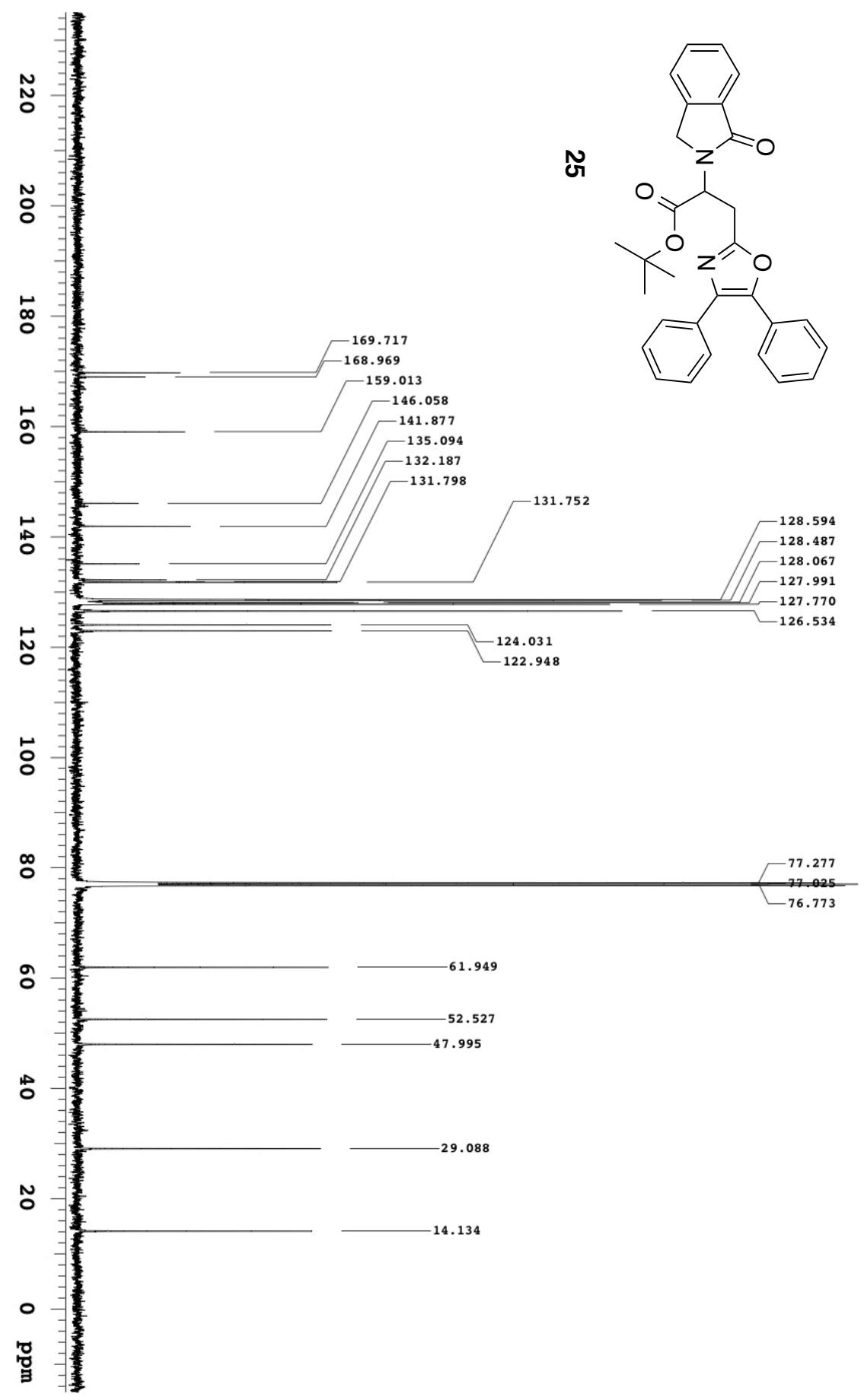




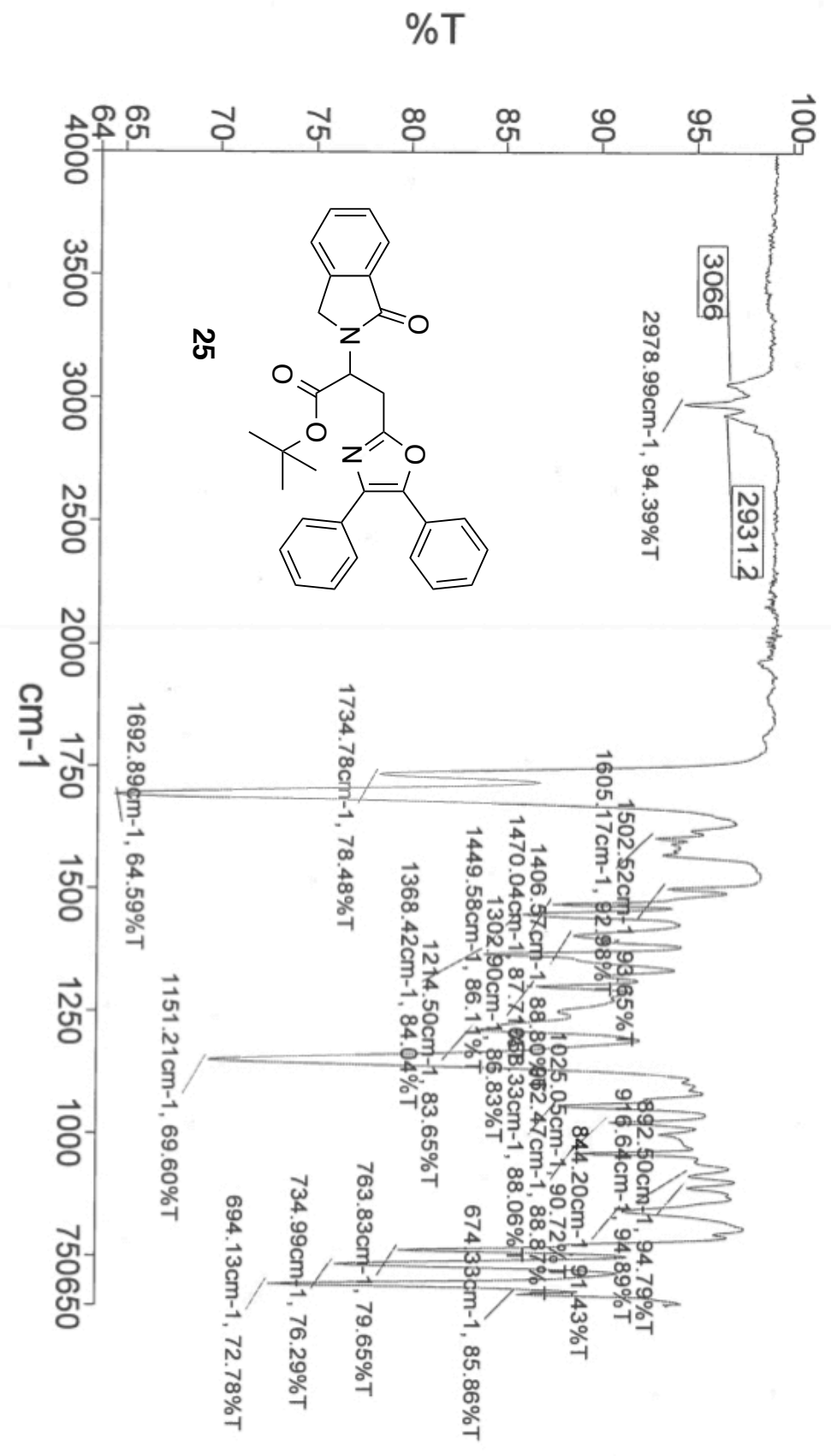


General procedure for oxidation of the $\mathrm{N}$-isoindolinone substrate, 15-26 to the $\mathrm{N}$ phthaloyl-protected amino acid derivatives 27-31, 34-35:

To a clear solution of compounds 15-26 (1 equiv) in acetonitrile- $\mathrm{H}_{2} \mathrm{O}(9: 1)$ was added Oxone $^{\circledR}(5.0$ equiv) and potassium bromide ( 0.5 equiv). The resulting reaction mixture was stired at $40-45^{\circ} \mathrm{C}(16 \mathrm{~h})$. After completion of reaction, solvent was concentrated and the residual material was partitioned between water $(15 \mathrm{~mL})$ and dichloromethane $(20 \mathrm{~mL})$. The organic layer was separated, dried over anhydrous magnesium sulfate and evaporated to obtain crude residue which was submitted to gravity-column chromatography using hexanes/ethyl acetate as an eluent to afford pure 27-31, 34-35.

tert-Butyl 2-(1,3-dioxoisoindolin-2-yl)acetate. ${ }^{44} 27$

Off-white solid (44 mg, 88\%); mp $=95-97{ }^{\circ} \mathrm{C} \quad\left[\right.$ Lit. 96-96.8 $\left.{ }^{\circ} \mathrm{C}\right] \mathrm{R}_{\mathrm{f}}=0.38$ (hexanes/ethyl acetate, $3: 1) ;{ }^{1} \mathrm{H}$ NMR (400 MHz, $\left.\mathrm{CDCl}_{3}\right): \delta$ 7.90-7.88 (m, 2H), 7.76-7.74 (m, 2H), 4.35 (s, 2H), $1.48(\mathrm{~s}, 9 \mathrm{H}) \mathrm{ppm} ;{ }^{13} \mathrm{C} \mathrm{NMR}\left(125 \mathrm{MHz}, \mathrm{CDCl}_{3}\right): \delta 167.6,166.3,134.1,132.1$, 123.5, 82.8, 39.7, 27.9 ppm; FT-IR (neat): 2993, 1778, 1741, 1710, 1415, $1152 \mathrm{~cm}^{-1}$.

Ethyl 2-(1,3-dioxoisoindolin-2-yl)propanoate. ${ }^{44} 28$

Off-white solid (26 mg, 70\%); mp $=60-62^{\circ} \mathrm{C}$ [Lit. 61.5-62.5 ${ }^{\circ} \mathrm{C}$; $\mathrm{R}_{\mathrm{f}}=0.36$ (hexanes/ethyl acetate, 3:1); ${ }^{1} \mathrm{H}$ NMR (400 MHz, $\left.\mathrm{CDCl}_{3}\right): \delta$ 7.86-7.84 (m, 2H), 7.73-7.71 (m, 2H), 4.94 $(\mathrm{q}, J=7.6 \mathrm{~Hz}, 1 \mathrm{H}), 4.21-4.16(\mathrm{~m}, 2 \mathrm{H}), 1.67(\mathrm{~d}, J=7.2 \mathrm{~Hz}, 3 \mathrm{H}), 1.21(\mathrm{t}, J=7.2 \mathrm{~Hz}, 3 \mathrm{H})$ ppm; ${ }^{13} \mathrm{C}$ NMR (125 MHz, $\left.\mathrm{CDCl}_{3}\right): \delta$ 169.7, 167.5, 134.1, 131.9, 123.5, 61.8, 47.6, 15.3, 14.1 ppm; FT-IR (neat): 2993, 1783, 1709, 1468, 1385, $1019 \mathrm{~cm}^{-1}$. 


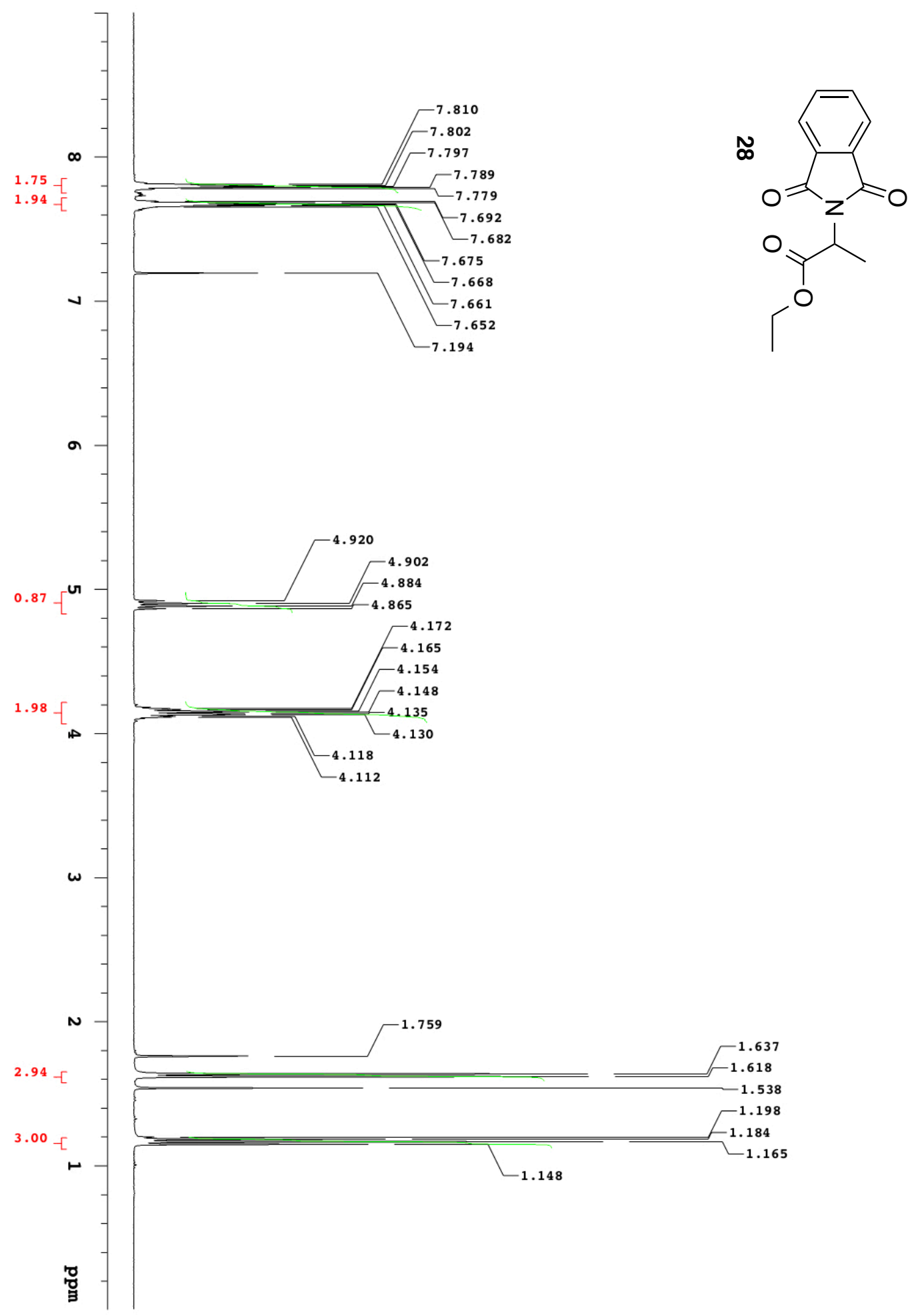




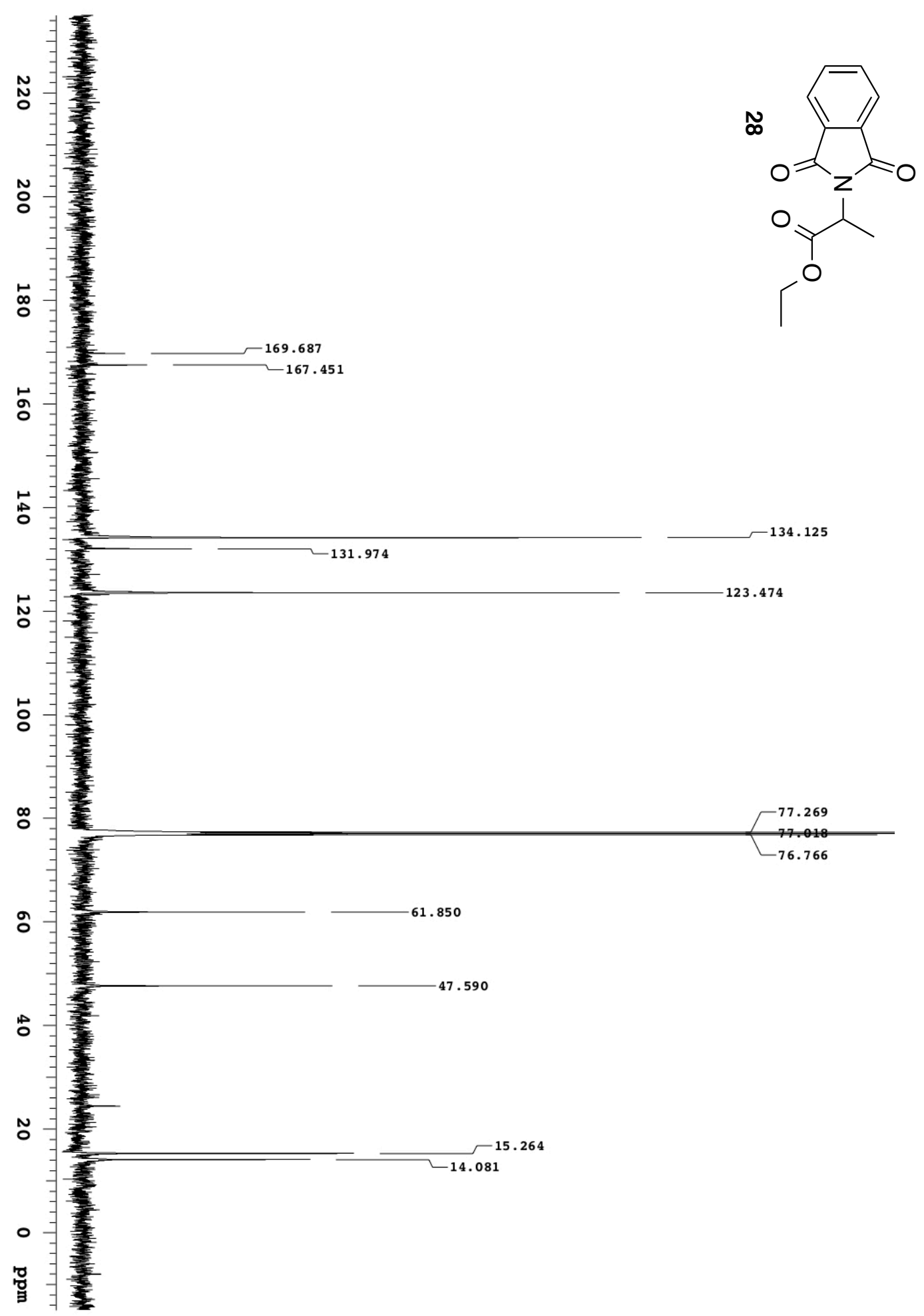




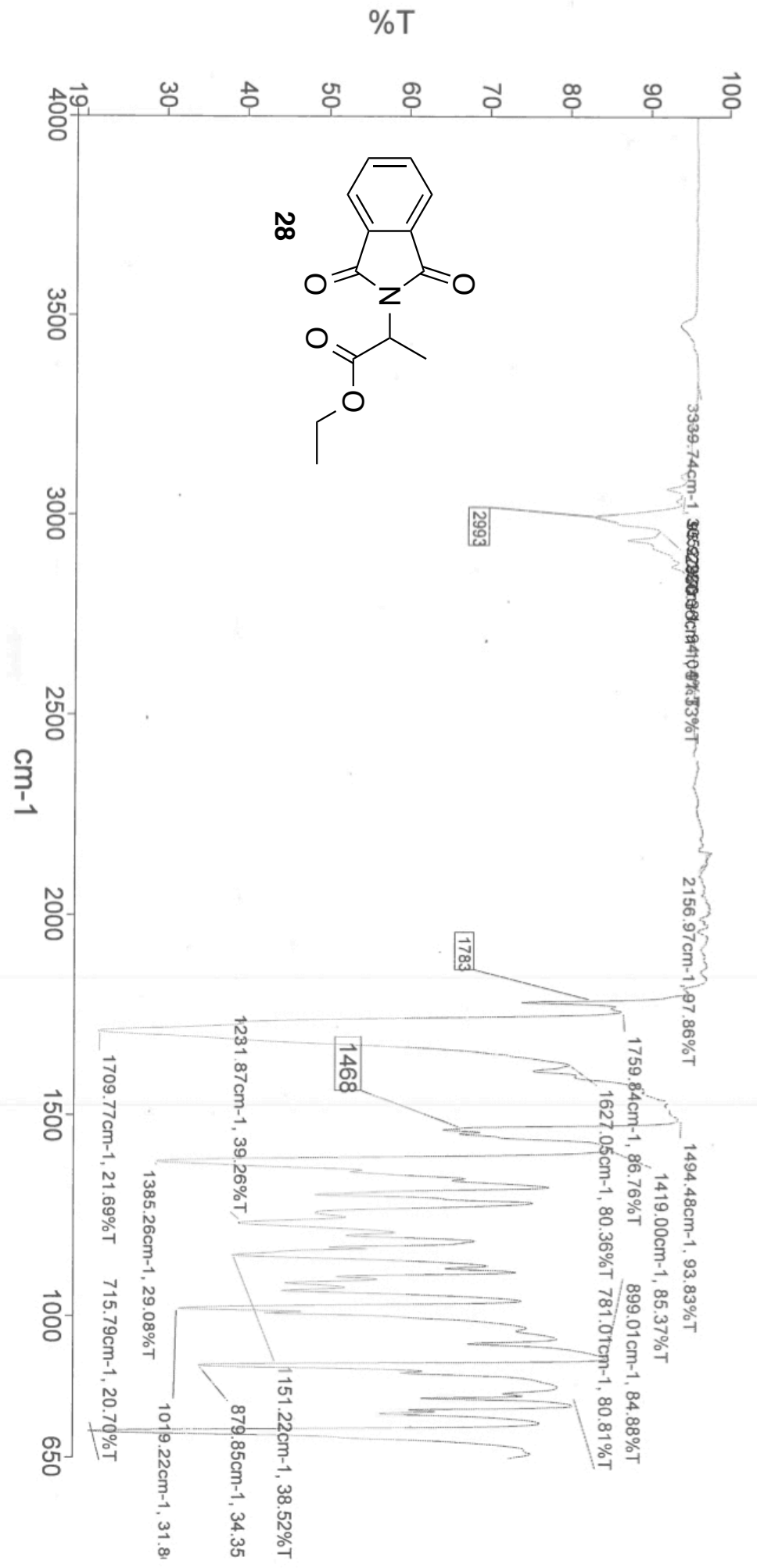




\section{Ethyl 2-(1,3-dioxoisoindolin-2-yl)butanoate. ${ }^{44} 29$}

Colorless oil (12 mg, 76\%); $\mathrm{R}_{\mathrm{f}}=0.44$ (hexanes/ethyl acetate, $\left.3: 1\right) ;{ }^{1} \mathrm{H}$ NMR $(400 \mathrm{MHz}$, $\left.\mathrm{CDCl}_{3}\right): \delta 7.88-7.86(\mathrm{~m}, 2 \mathrm{H}), 7.76-7.73(\mathrm{~m}, 2 \mathrm{H}), 4.75(\mathrm{dd}, J=5.6 \mathrm{~Hz}, 10.0 \mathrm{~Hz}, 1 \mathrm{H}), 4.20$ (q, $J=7.2 \mathrm{~Hz}, 2 \mathrm{H}), 2.31-2.22(\mathrm{~m}, 2 \mathrm{H}), 1.22(\mathrm{t}, J=7.2 \mathrm{~Hz}, 3 \mathrm{H}), 0.94(\mathrm{t}, J=7.2 \mathrm{~Hz}, 3 \mathrm{H})$ ppm; ${ }^{13} \mathrm{C}$ NMR (125 MHz, $\left.\mathrm{CDCl}_{3}\right): \delta 169.3,167.8,134.1,131.8,123.5,61.7,53.8,22.1$, 14.1, 10.9 ppm FT-IR (neat): 2977, 1777, 1740, 1710, 1467, 1383, $1023 \mathrm{~cm}^{-1}$. 


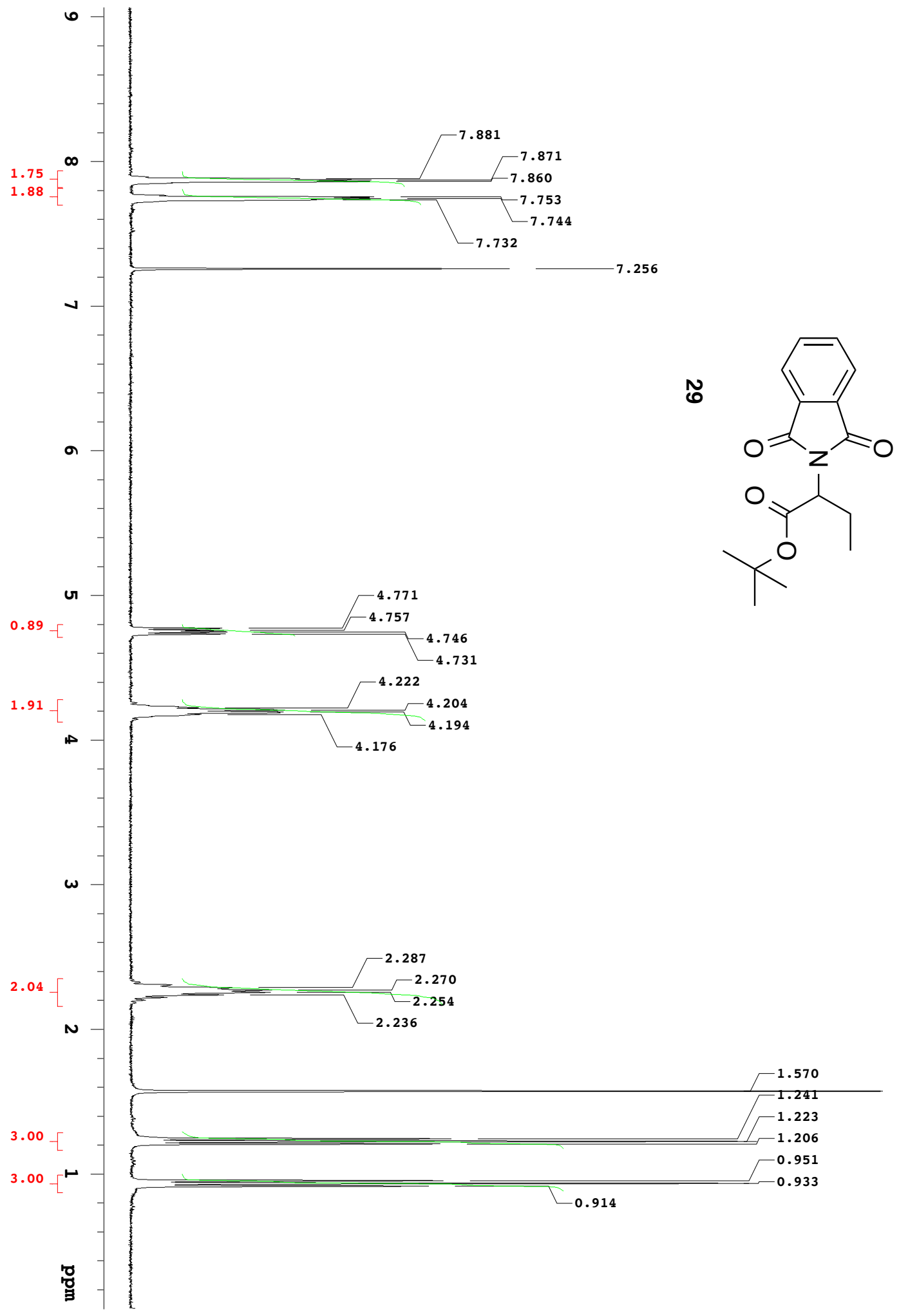




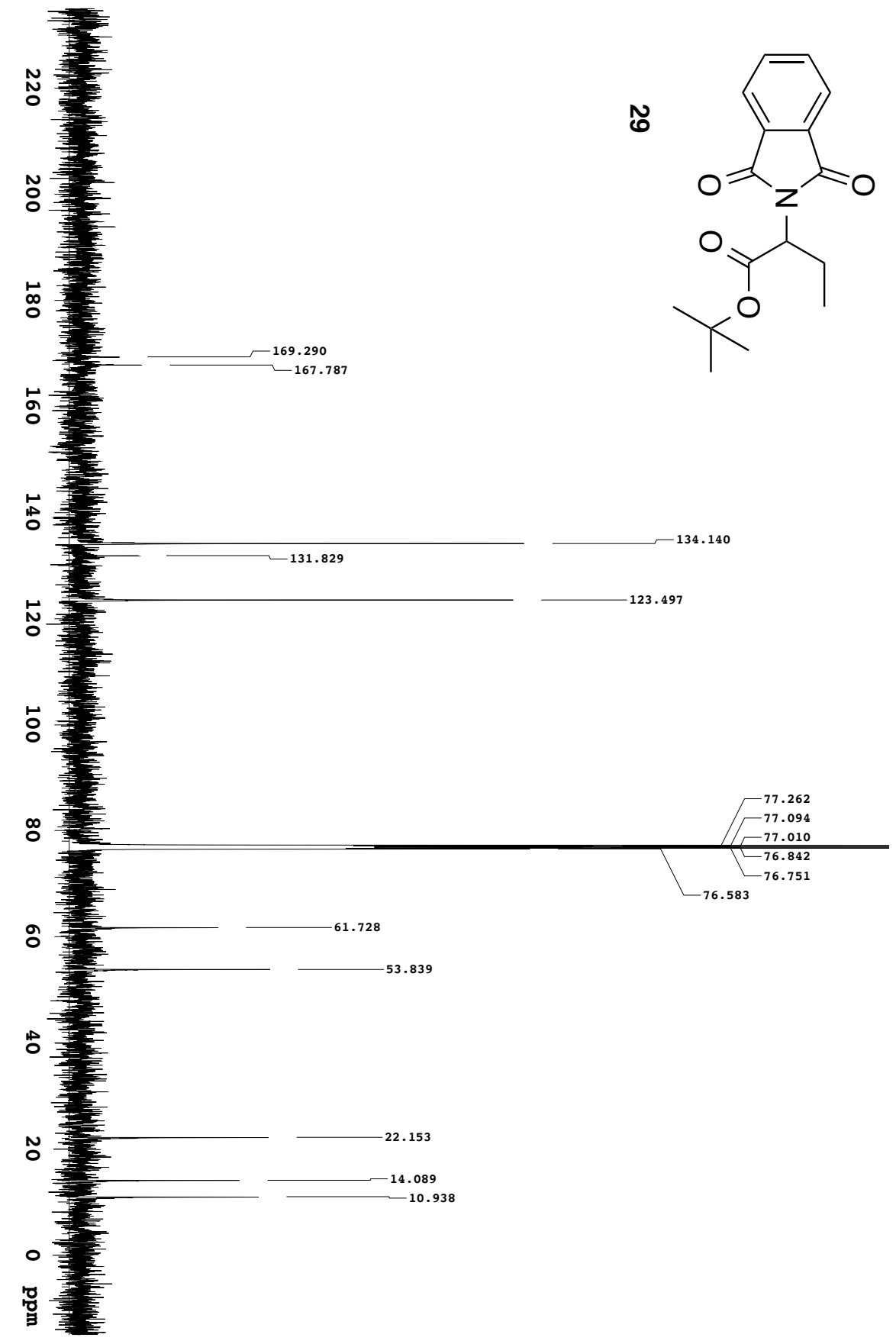




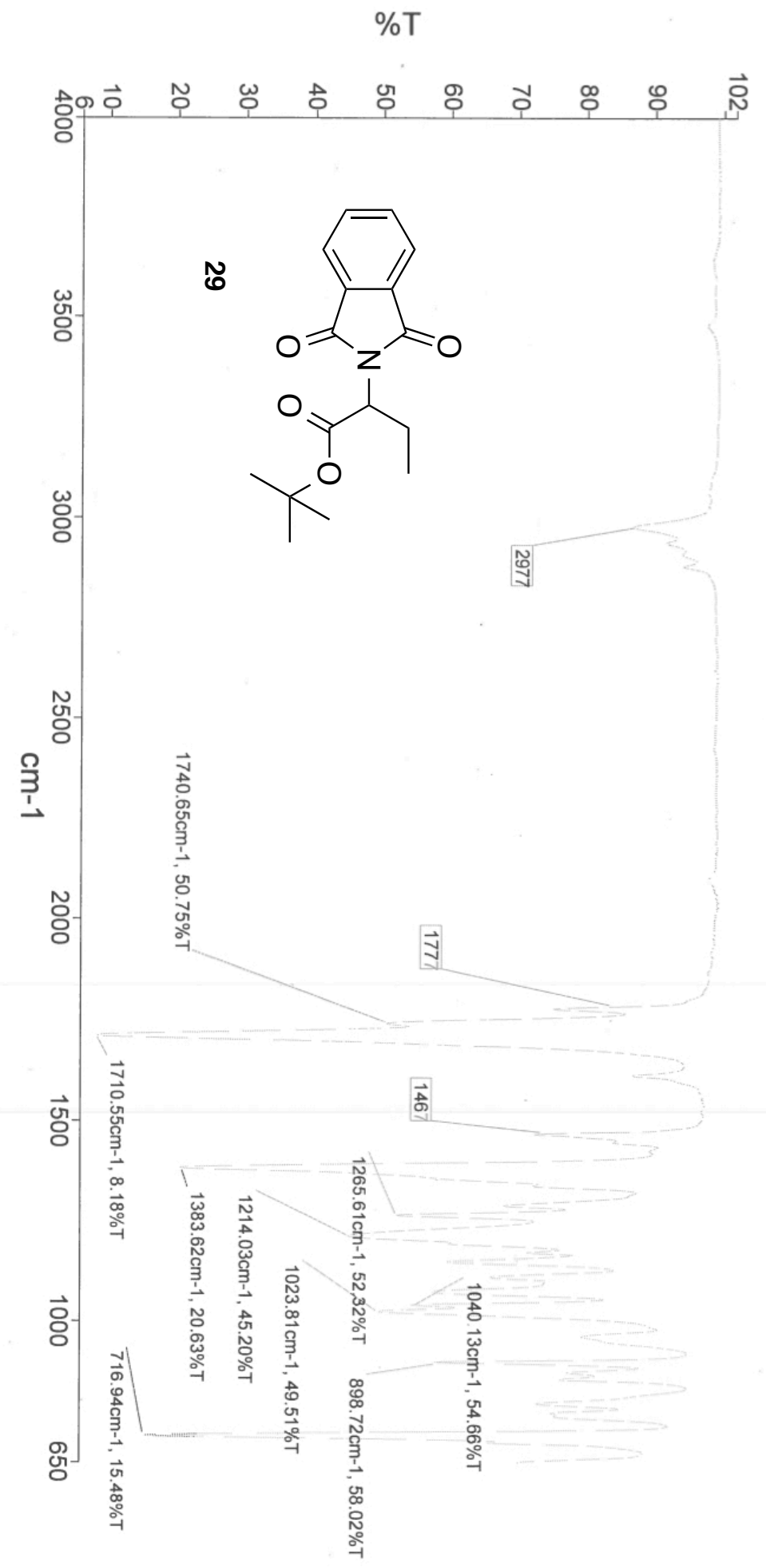


tert-Butyl 2-(1,3-dioxoisoindolin-2-yl)pentanoate. 30

Colorless oil (25.6 mg, 98\%); $\mathrm{R}_{\mathrm{f}}=0.39$ (hexanes/ethyl acetate, $\left.3: 1\right) ;{ }^{1} \mathrm{H}$ NMR (400 MHz, $\left.\mathrm{CDCl}_{3}\right): \delta 7.86-7.84(\mathrm{~m}, 2 \mathrm{H}), 7.73-7.71(\mathrm{~m}, 2 \mathrm{H}), 4.75(\mathrm{dd}, J=4.8 \mathrm{~Hz}, 11.2 \mathrm{~Hz}, 1 \mathrm{H}), 2.27-$ $2.15(\mathrm{~m}, 1 \mathrm{H}), 2.13-2.06(\mathrm{~m}, 1 \mathrm{H}), 1.41(\mathrm{~s}, 9 \mathrm{H}), 1.35-1.26(\mathrm{~m}, 2 \mathrm{H}), 0.92(\mathrm{t}, J=7.2 \mathrm{~Hz}, 3 \mathrm{H})$ ppm; ${ }^{13} \mathrm{C}$ NMR $\left(125 \mathrm{MHz}, \mathrm{CDCl}_{3}\right): \delta$ 168.5, 167.9, 134.0, 131.9, 123.4, 82.3, 52.8, 30.6, 27.9, 19.7, 13.4 ppm; FT-IR (neat): 2967, 1778, 1736, 1711, 1384, $1147 \mathrm{~cm}^{-1}$; HRMS calcd. for $\mathrm{C}_{17} \mathrm{H}_{21} \mathrm{NO}_{4}$ 303.1471; found 303.1468. 


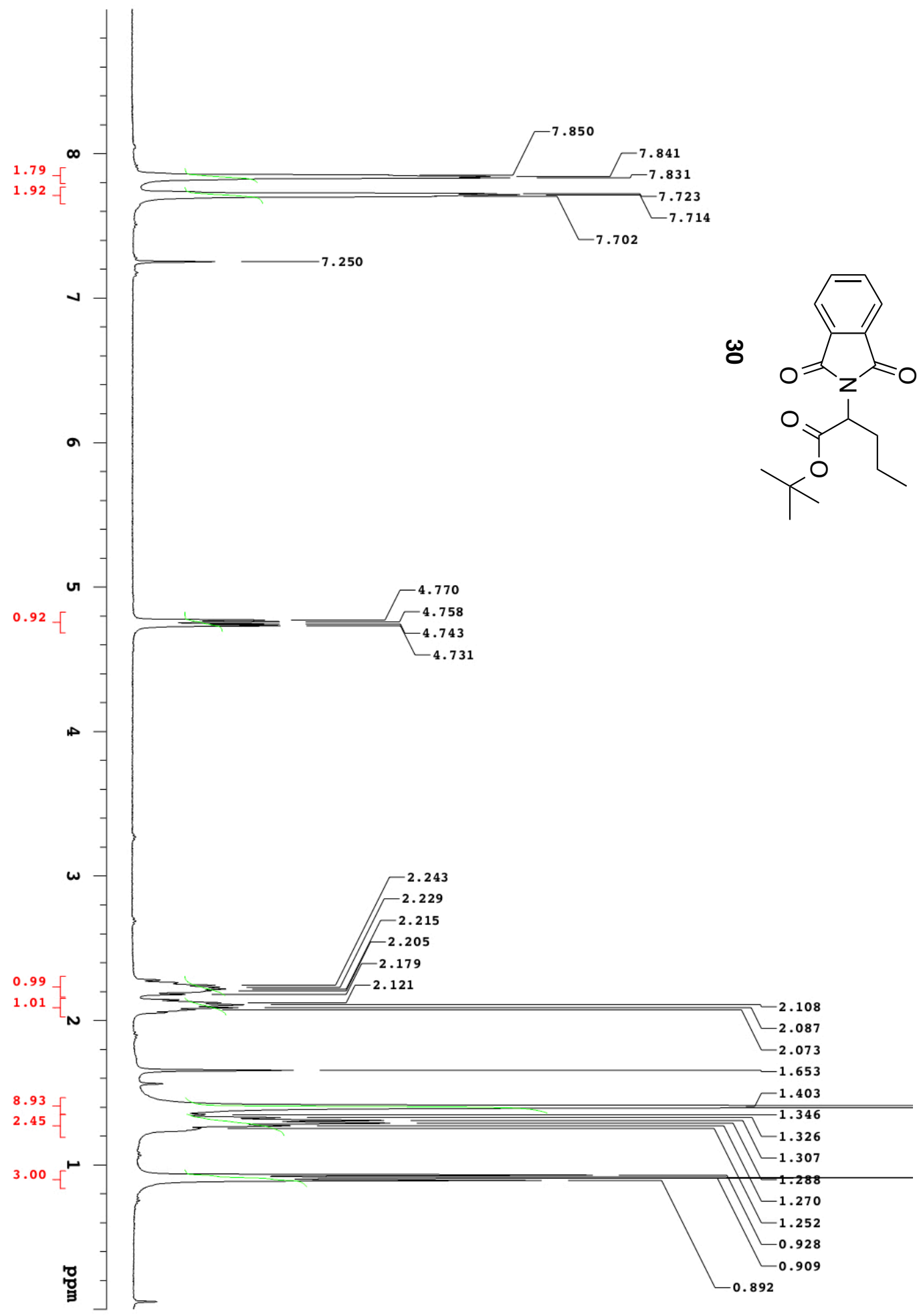




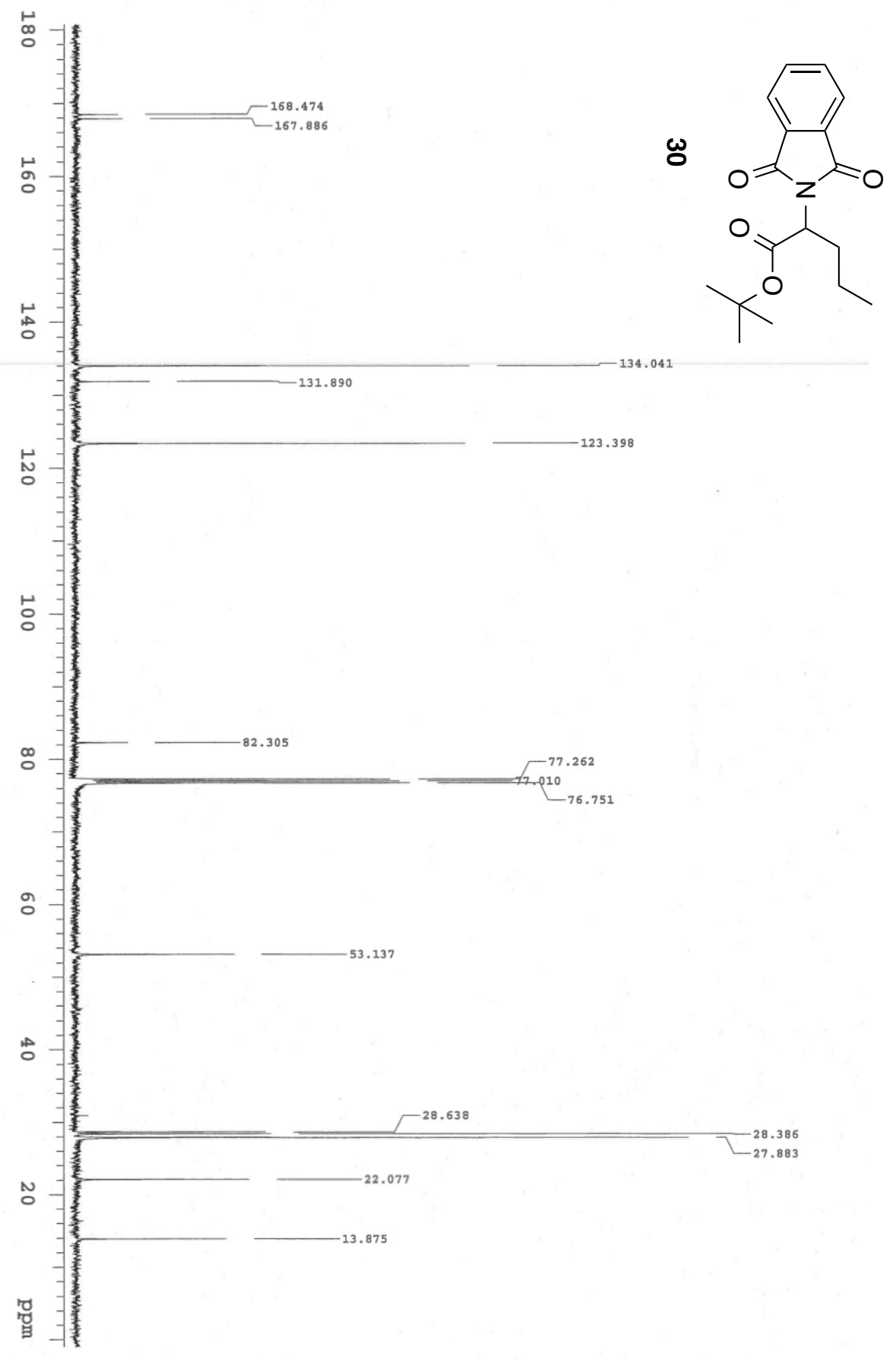




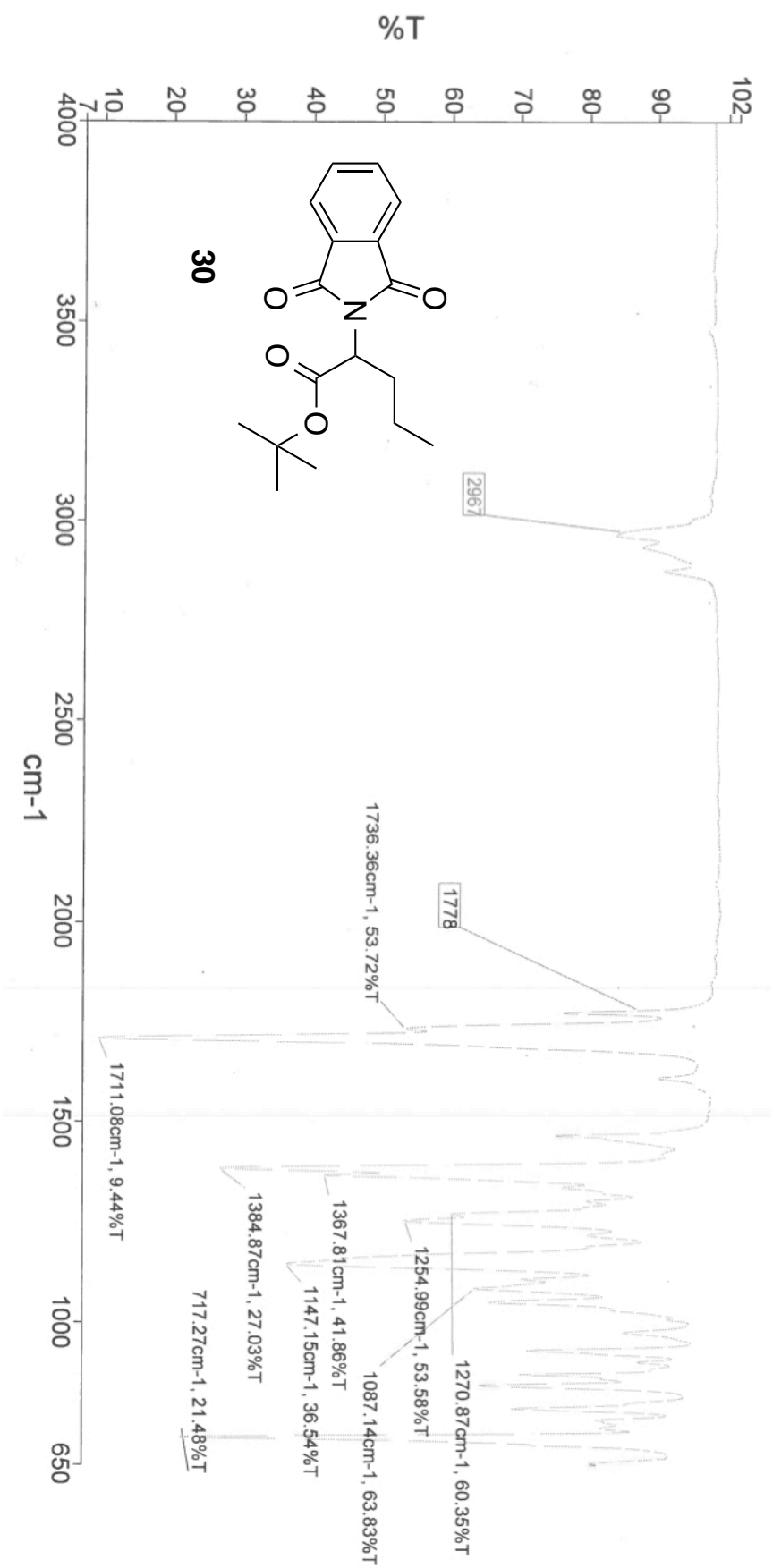




\section{tert-Butyl 2-(1,3-dioxoisoindolin-2-yl)hexanoate. 31}

Colorless oil (21 mg, 80\%); $\mathrm{R}_{\mathrm{f}}=0.47$ (ethyl hexanes/ethyl acetate, 3:1); ${ }^{1} \mathrm{H}$ NMR (400 $\left.\mathrm{MHz}, \mathrm{CDCl}_{3}\right): \delta 7.85-7.82(\mathrm{~m}, 2 \mathrm{H}), 7.73-7.70(\mathrm{~m}, 2 \mathrm{H}), 4.71(\mathrm{dd}, J=4.4 \mathrm{~Hz}, 10.4 \mathrm{~Hz}, 1 \mathrm{H})$, 2.26-2.13 (m, 2H), $1.40(\mathrm{~s}, 9 \mathrm{H}), 1.37-1.20(\mathrm{~m}, 4 \mathrm{H}), 0.84(\mathrm{t}, J=7.6 \mathrm{~Hz}, 3 \mathrm{H}) \mathrm{ppm} ;{ }^{13} \mathrm{C} \mathrm{NMR}$ $\left(125 \mathrm{MHz}, \mathrm{CDCl}_{3}\right): \delta 168.5,167.9,134.0,131.9,123.4,82.3,53.1,28.6,28.4,27.9,22.1$, 13.9 ppm; FT-IR (neat): 2960, 1778, 1737, 1712, 1385, $1150 \mathrm{~cm}^{-1}$; HRMS calcd. for $\mathrm{C}_{18} \mathrm{H}_{23} \mathrm{NO}_{4} 317.1627$; found 317.1628. 


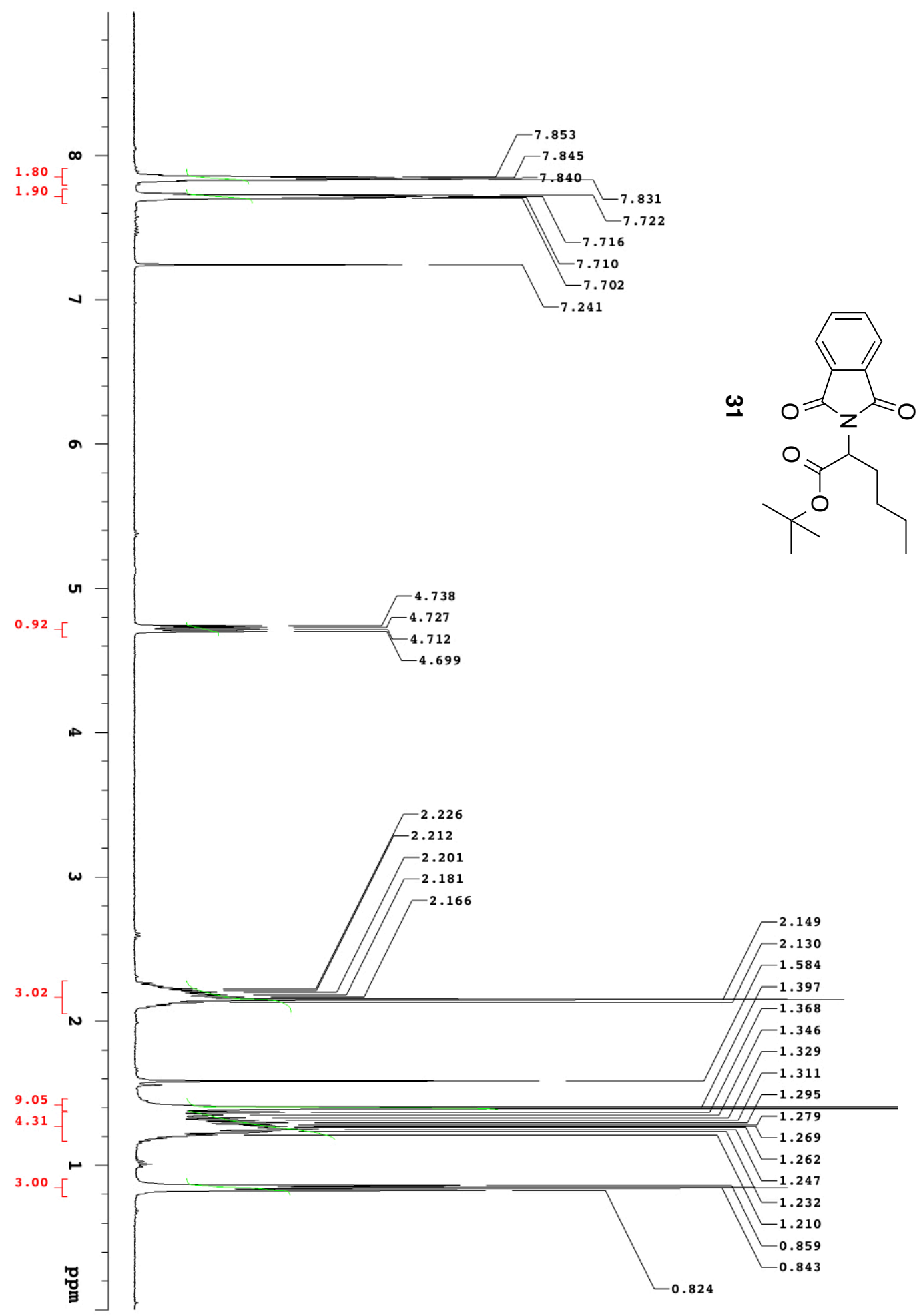




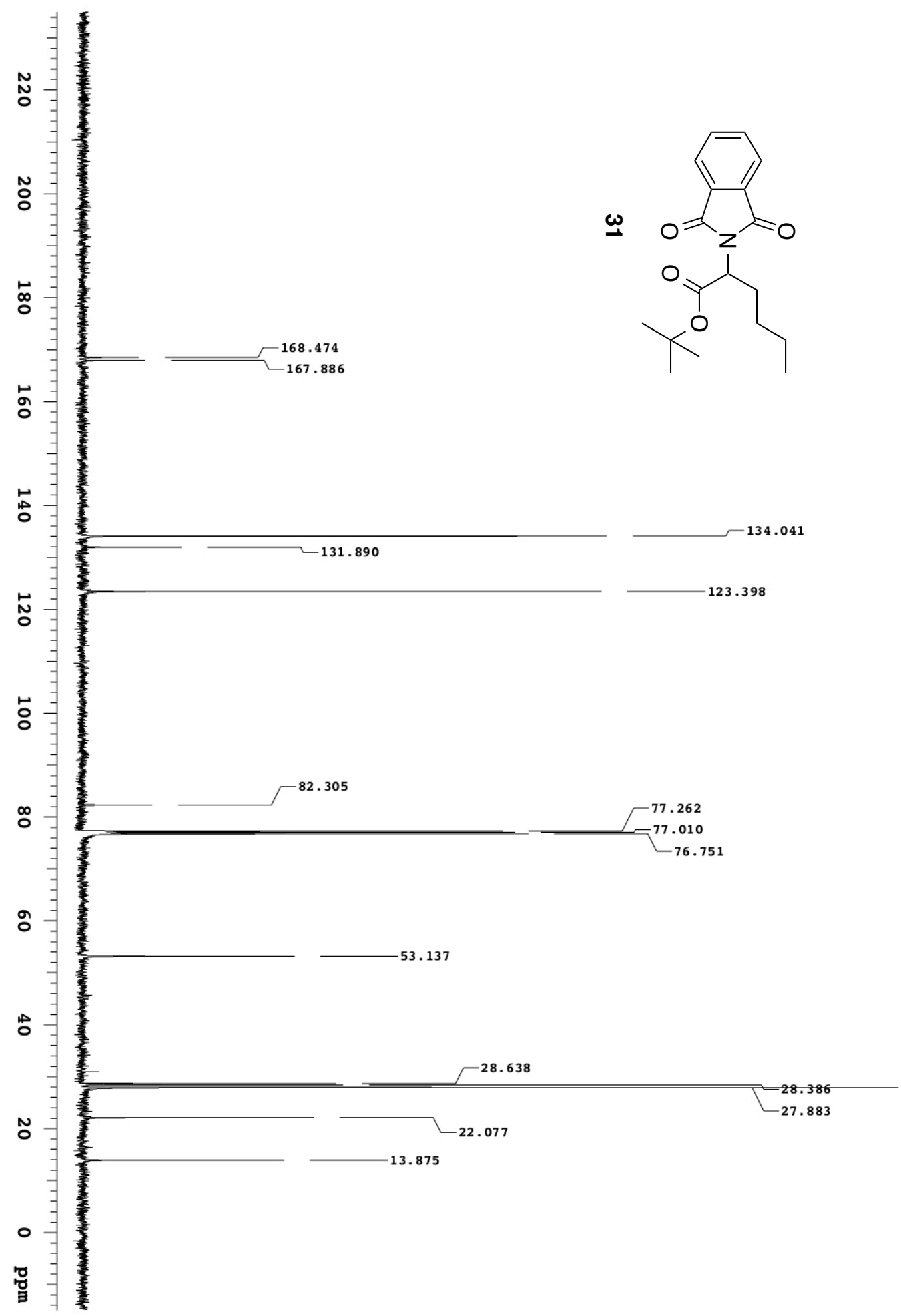




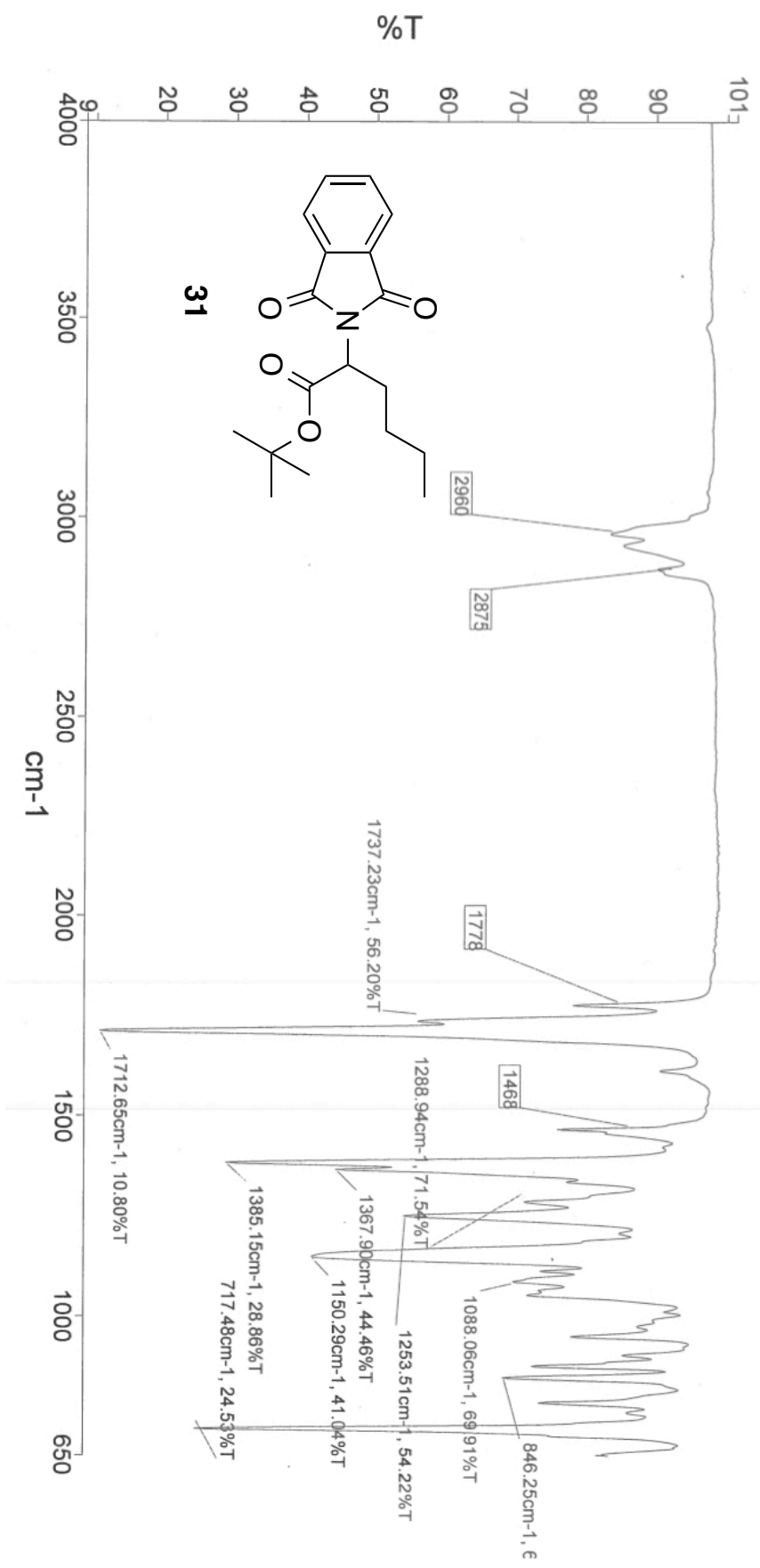


tert-Butyl 2-(1,3-dioxoisoindolin-2-yl)-3-phenylpropanoate. ${ }^{46} 34$

Colorless oil (23 mg, 88\%); $\mathrm{R}_{\mathrm{f}}=0.47$ (hexanes/ethyl acetate, 3:1); ${ }^{1} \mathrm{H}$ NMR (400 MHz, $\left.\mathrm{CDCl}_{3}\right): \delta 7.76-7.74(\mathrm{~m}, 2 \mathrm{H}), 7.66-7.64(\mathrm{~m}, 2 \mathrm{H}), 7.16-7.10(\mathrm{~m}, 5 \mathrm{H}), 5.05(\mathrm{dd}, J=5.2 \mathrm{~Hz}$, $10.4 \mathrm{~Hz}, 1 \mathrm{H}), 3.53-3.49(\mathrm{~m}, 2 \mathrm{H}), 1.43(\mathrm{~s}, 9 \mathrm{H}) \mathrm{ppm} ;{ }^{13} \mathrm{C} \mathrm{NMR}\left(125 \mathrm{MHz}, \mathrm{CDCl}_{3}\right): \delta 167.8$, 167.6, 137.1, 133.9, 131.6, 128.8, 128.5, 126.7, 123.3, 82.8, 54.1, 34.7, 27.9 ppm; FT-IR (neat): $2980,1774,1736,1712,1385,1151 \mathrm{~cm}^{-1}$. 


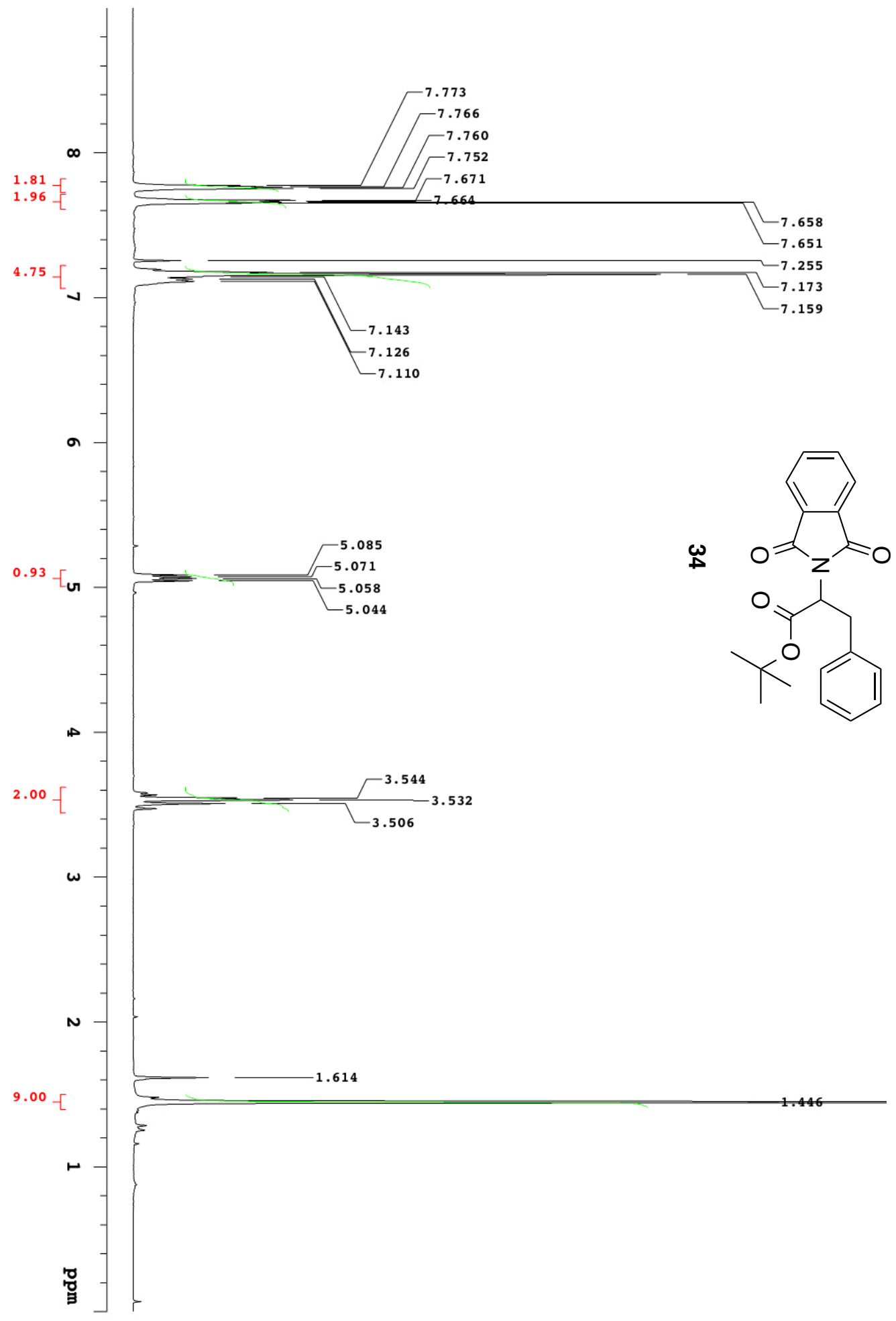




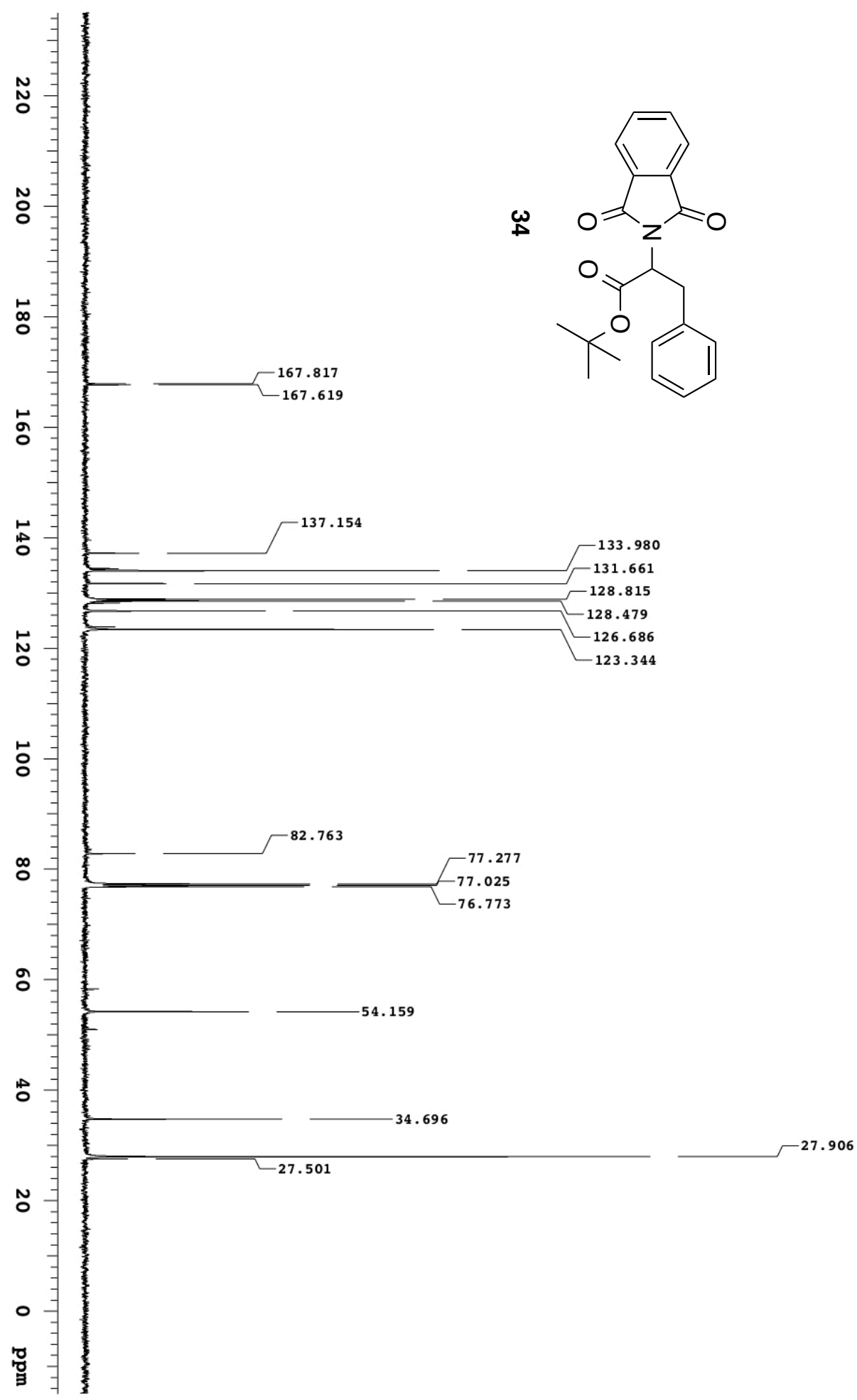




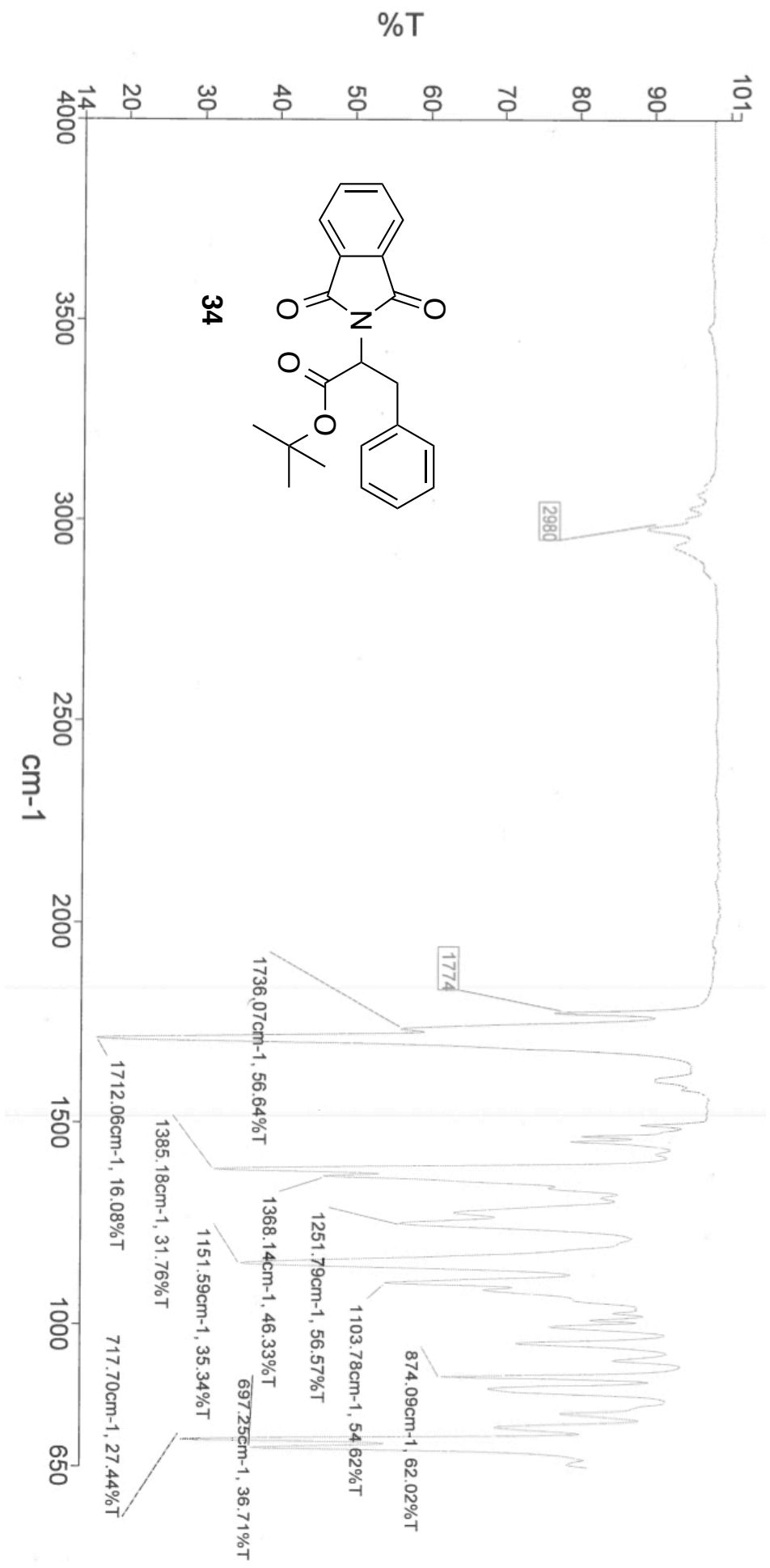


tert-Butyl 2-(1,3-dioxoisoindolin-2-yl)-3-(4-fluorophenyl)propanoate. 35

Colorless oil (24 mg, 72\%); $\mathrm{R}_{\mathrm{f}}=0.37$ (hexanes/ethyl acetate, 3:1); ${ }^{1} \mathrm{H}$ NMR (400 MHz, $\left.\mathrm{CDCl}_{3}\right): \delta$ 7.77-7.75 (m, 2H), 7.68-7.66 (m, 2H), $7.09(\mathrm{dd}, J=5.6 \mathrm{~Hz}, 8.4 \mathrm{~Hz}, 2 \mathrm{H}), 6.84$ $(\mathrm{dd}, J=8.0 \mathrm{~Hz}, 8.8 \mathrm{~Hz}, 2 \mathrm{H}), 4.99(\mathrm{dd}, J=6.4 \mathrm{~Hz}, 10.0 \mathrm{~Hz}, 1 \mathrm{H}), 3.48-3.46(\mathrm{~m}, 2 \mathrm{H}), 1.43$ (s, 9H) ppm; $\left.{ }^{13} \mathrm{C} \mathrm{NMR} \mathrm{(125} \mathrm{MHz,} \mathrm{CDCl}_{3}\right): \delta 167.6$ (overlapped), 161.7 (d, $J=243.12 \mathrm{~Hz}$ ), 134.1, 132.8, 131.6, 130.3 (d, $J=7.6 \mathrm{~Hz}), 123.4,115.4$ (d, $J=21.0 \mathrm{~Hz}), 82.9,54.1,33.9$, 27.9 ppm; FT-IR (neat): 2980, 1776, 1737, 1714, 1386, $1154 \mathrm{~cm}^{-1}$; HRMS calcd. for $\mathrm{C}_{21} \mathrm{H}_{20} \mathrm{FNO}_{4}$ 369.1376; found 369.1365. 


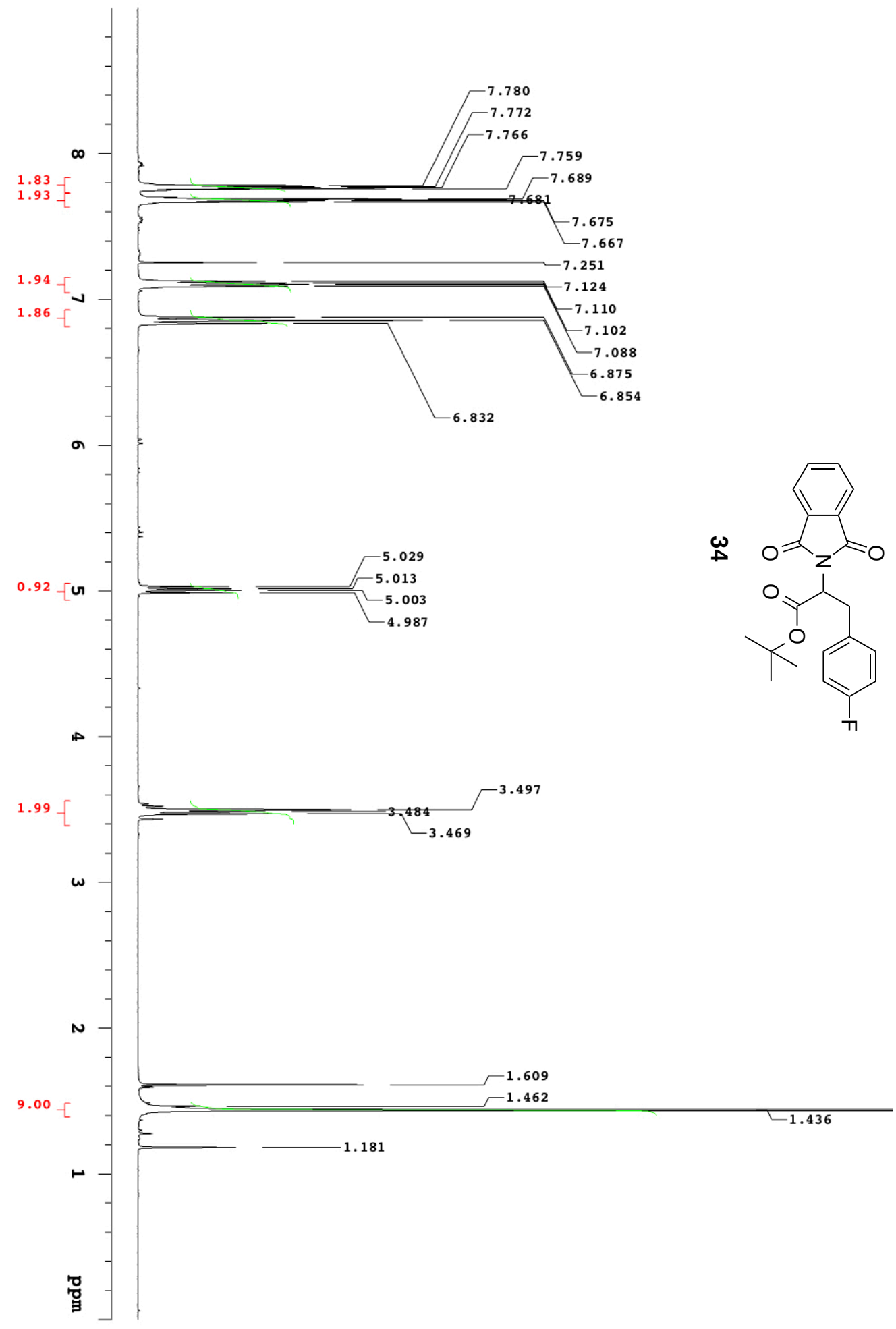




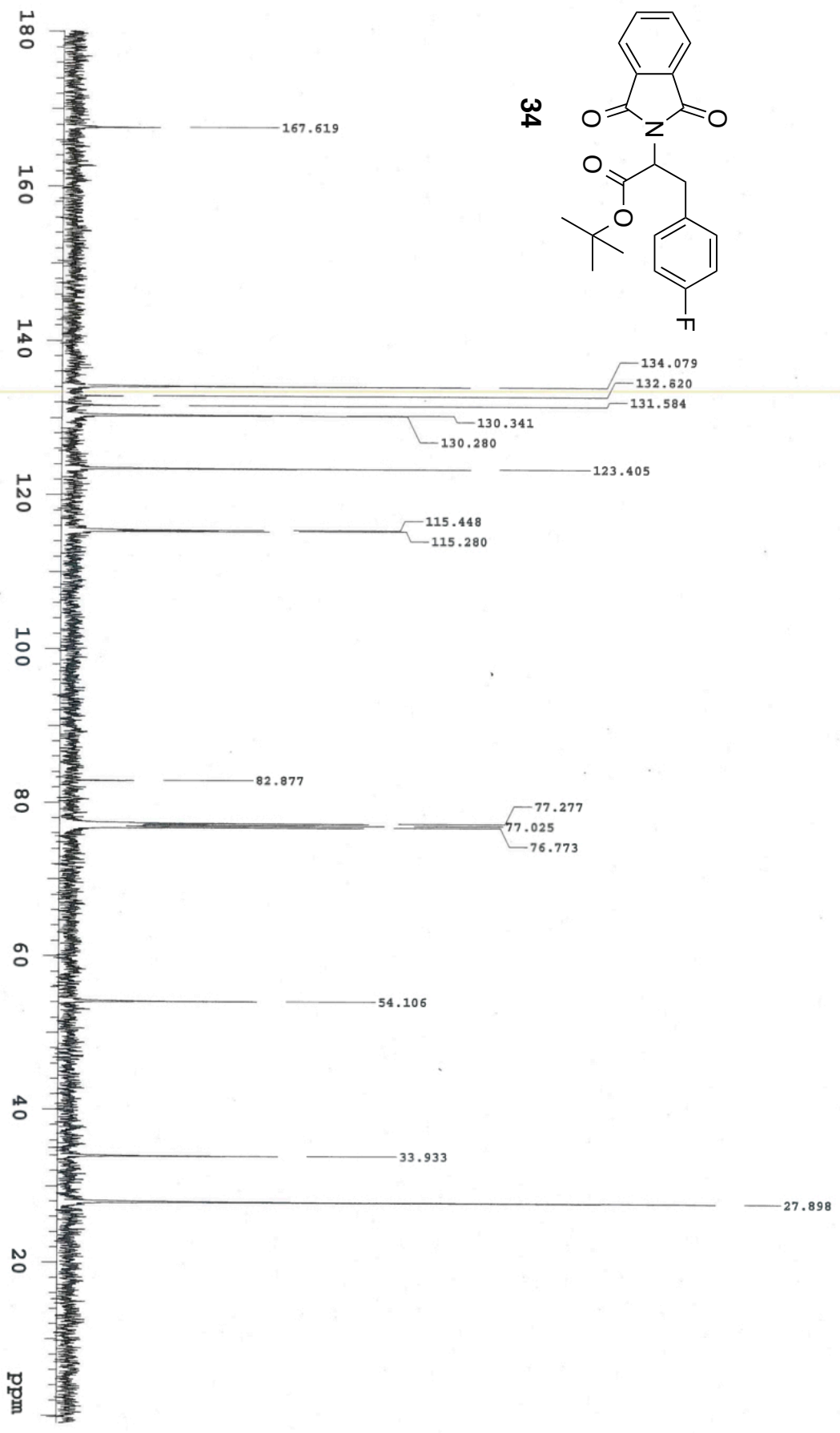




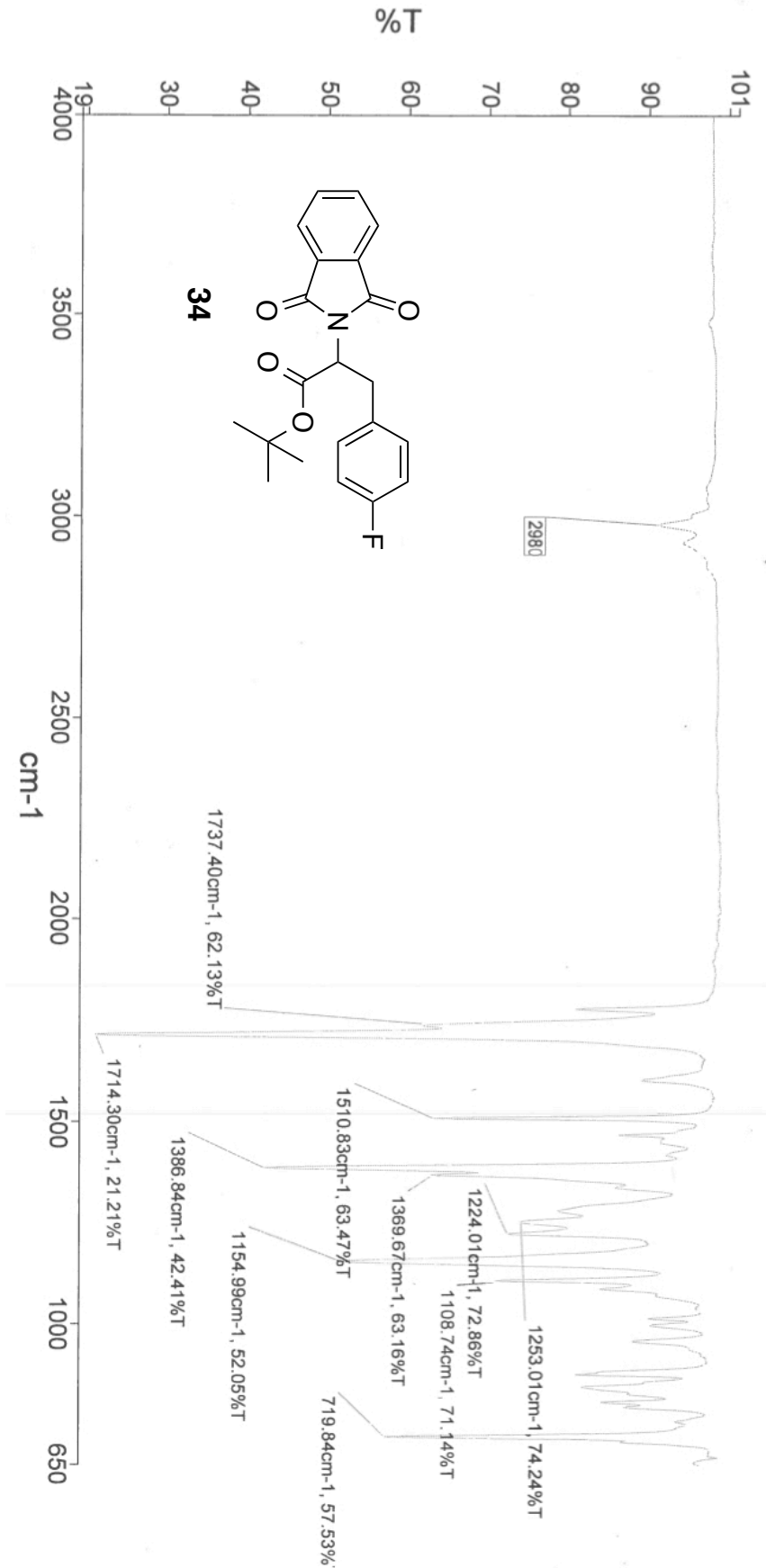


tert-Butyl 3-(2-bromonaphthalen-1-yl)-2-(1,3-dioxoisoindolin-2-yl)propanoate. 37

Colorless oil (17 mg, 80\%); $\mathrm{R}_{\mathrm{f}}=0.54$ (hexanes/ethyl acetate, $\left.3: 1\right) ;{ }^{1} \mathrm{H}$ NMR (400 MHz, $\left.\mathrm{CDCl}_{3}\right): \delta 8.24-8.21(\mathrm{~m}, 1 \mathrm{H}), 8.09-8.07(\mathrm{~m}, 1 \mathrm{H}), 7.75-7.71(\mathrm{~m}, 2 \mathrm{H}), 7.68-7.65(\mathrm{~m}, 2 \mathrm{H})$, 7.58-7.51 (m, 4H), 7.08 (d, $J=7.2 \mathrm{~Hz}, 1 \mathrm{H}), 5.19$ (dd, $J=4.8 \mathrm{~Hz}, 11.6 \mathrm{~Hz}, 1 \mathrm{H}), 4.06$ (dd, $J=4.8 \mathrm{~Hz}, 14.8 \mathrm{~Hz}, 1 \mathrm{H}), 3.85(\mathrm{dd}, J=11.6 \mathrm{~Hz}, 14.8 \mathrm{~Hz}, 1 \mathrm{H}), 1.45(\mathrm{~s}, 9 \mathrm{H}) \mathrm{ppm} ;{ }^{13} \mathrm{C} \mathrm{NMR}$ (125 MHz, $\left.\mathrm{CDCl}_{3}\right): \delta 167.7,167.5,134.1,133.5,132.9,132.1,131.6,129.3,128.2,127.5$, 127.2, 127.1, 123.6, 123.4, 122.3, 83.1, 53.3, 31.7, 27.9 ppm; FT-IR (neat): 2975, 1776, 1736, 1713, 1384, $1152 \mathrm{~cm}^{-1}$; HRMS calcd. for $\mathrm{C}_{25} \mathrm{H}_{23} \mathrm{BrNO}_{4} 479.0732$, found 479.0727 . 


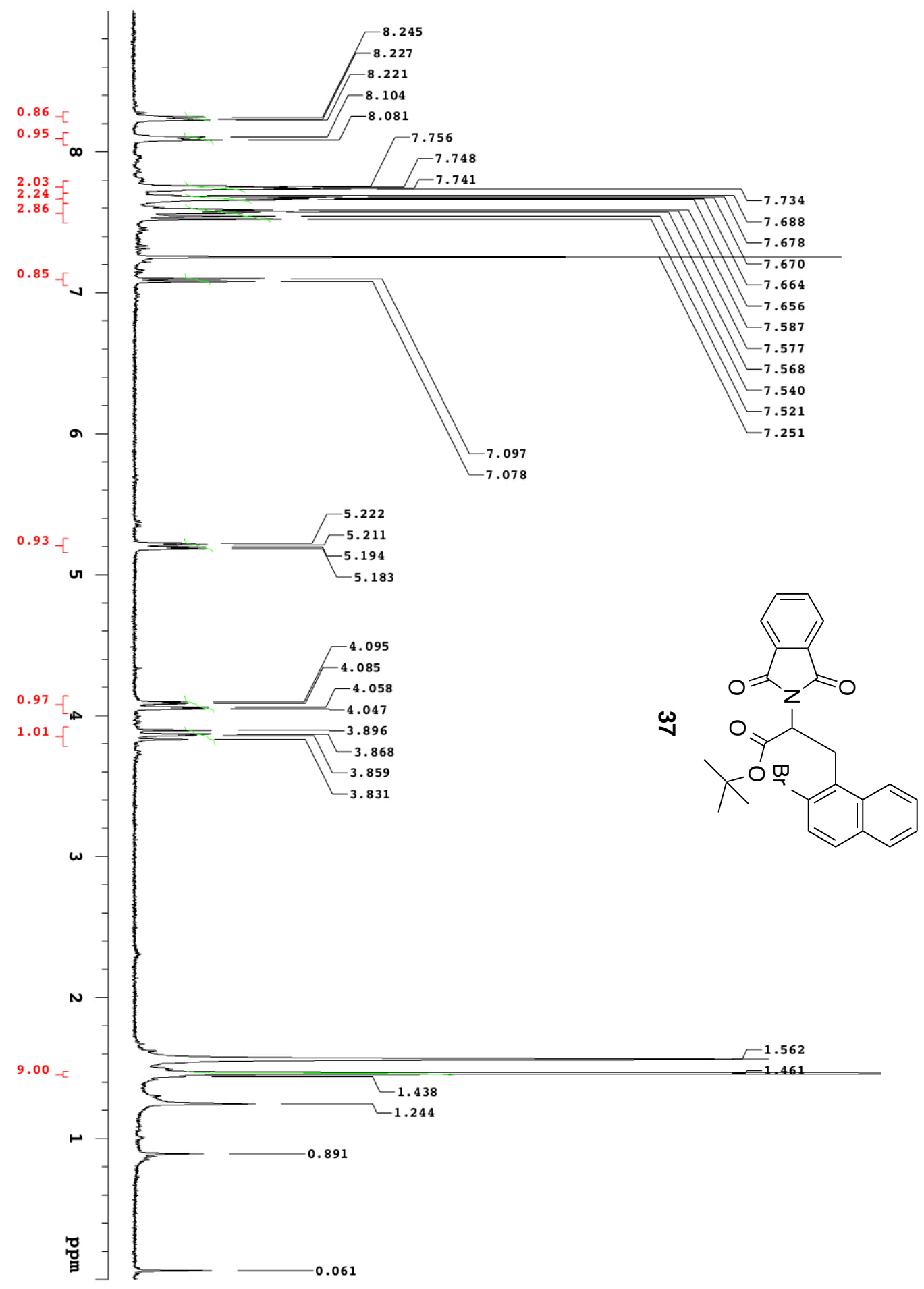




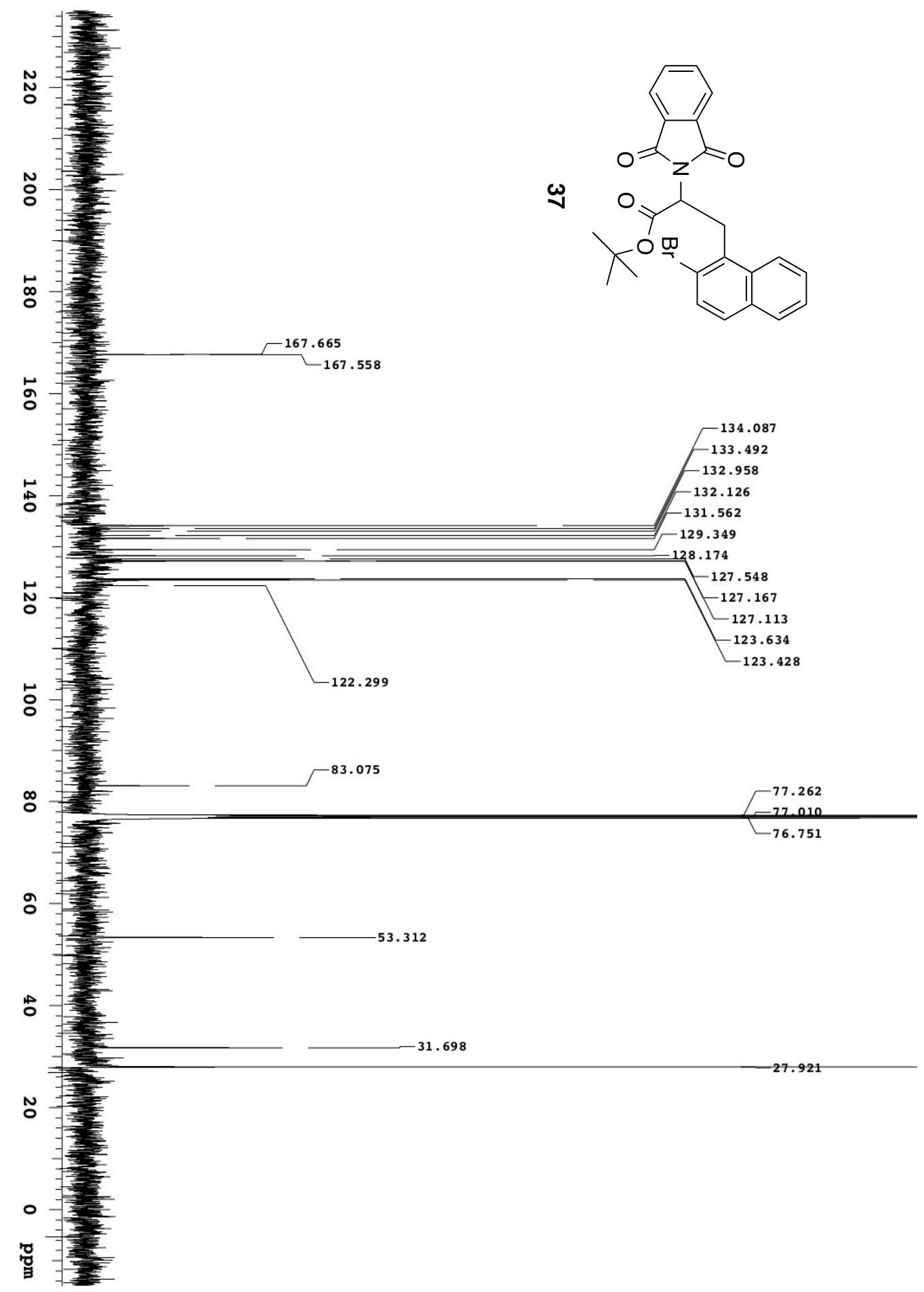




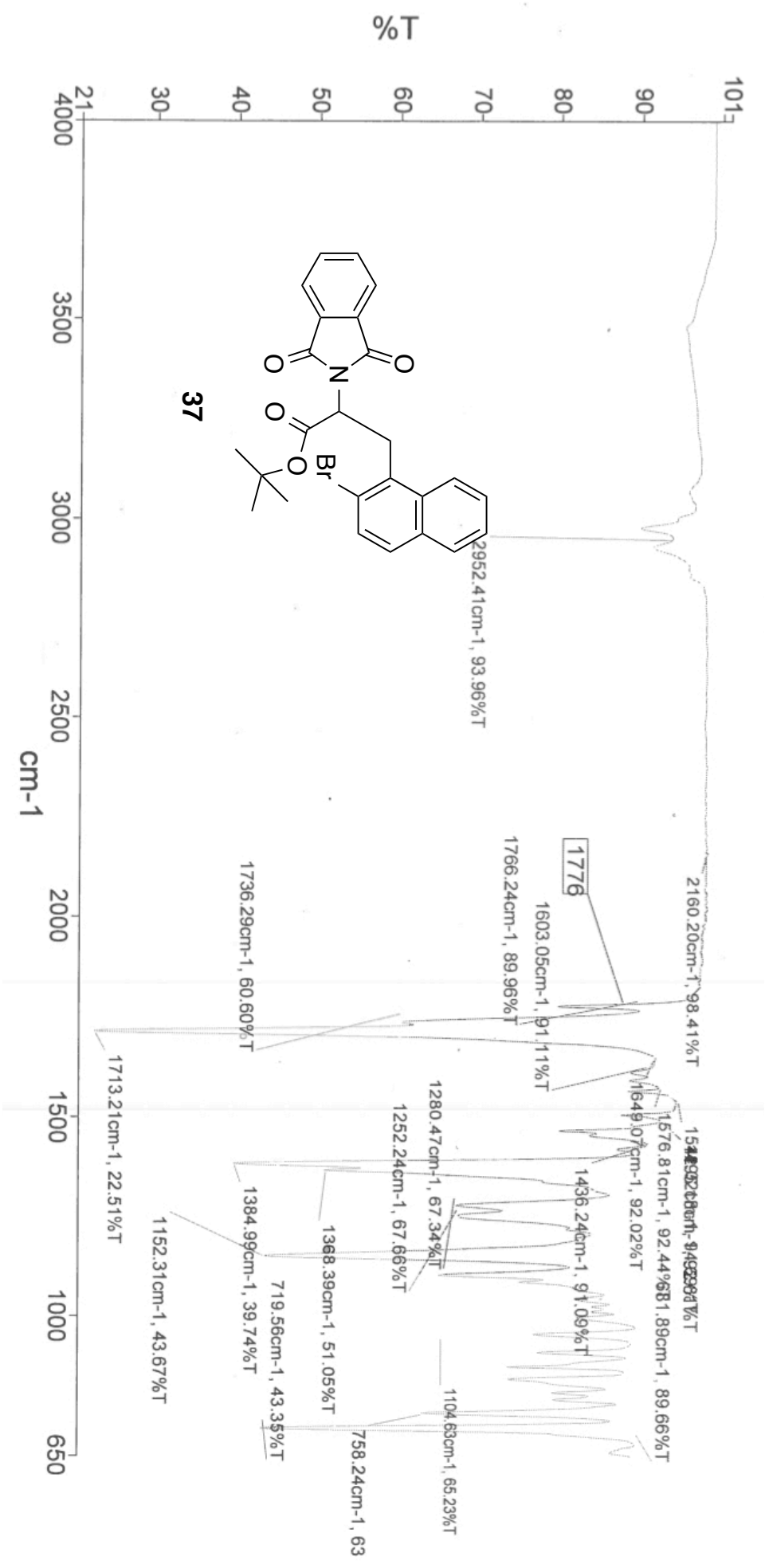




\section{Ethyl 4-amino-2-(1,3-dioxoisoindolin-2-yl)-4-oxobutanoate. 39}

Off-white solid (33 mg, 65\%); mp $=107-109{ }^{\circ} \mathrm{C} ; \mathrm{R}_{\mathrm{f}}=0.3$ (chloroform/ethanol, 9:1); ${ }^{1} \mathrm{H}$ NMR (400 MHz, $\left.\mathrm{CDCl}_{3}\right): \delta$ 7.85-7.83 (m, 2H), 7.74-7.70 (m, 2H), $5.74(\mathrm{~s}, 1 \mathrm{H}), 5.57(\mathrm{~s}$, $1 \mathrm{H}), 5.44(\mathrm{t}, J=8.0 \mathrm{~Hz}, 1 \mathrm{H}), 4.17(\mathrm{q}, J=3.6 \mathrm{~Hz}, 2 \mathrm{H}), 3.23(\mathrm{dd}, J=6.4 \mathrm{~Hz}, 15.6 \mathrm{~Hz}, 1 \mathrm{H})$, $3.02(\mathrm{dd}, J=8.4 \mathrm{~Hz}, 15.6 \mathrm{~Hz}, 1 \mathrm{H}), 1.18(\mathrm{t}, J=7.6 \mathrm{~Hz}, 3 \mathrm{H}) \mathrm{ppm} ;{ }^{13} \mathrm{C} \mathrm{NMR}(125 \mathrm{MHz}$, $\left.\mathrm{CDCl}_{3}\right): \delta 170.9,168.7,167.4,134.3,131.8,123.6,62.3,48.7,35.2,14.0 \mathrm{ppm}$; FT-IR (neat): 3399, 3195, 2963, 1778, 1736, 1708, 1388, $1181 \mathrm{~cm}^{-1}$; HRMS calcd. for $\mathrm{C}_{14} \mathrm{H}_{14} \mathrm{~N}_{2} \mathrm{O}_{5} 290.0903$; found 290.0907. 


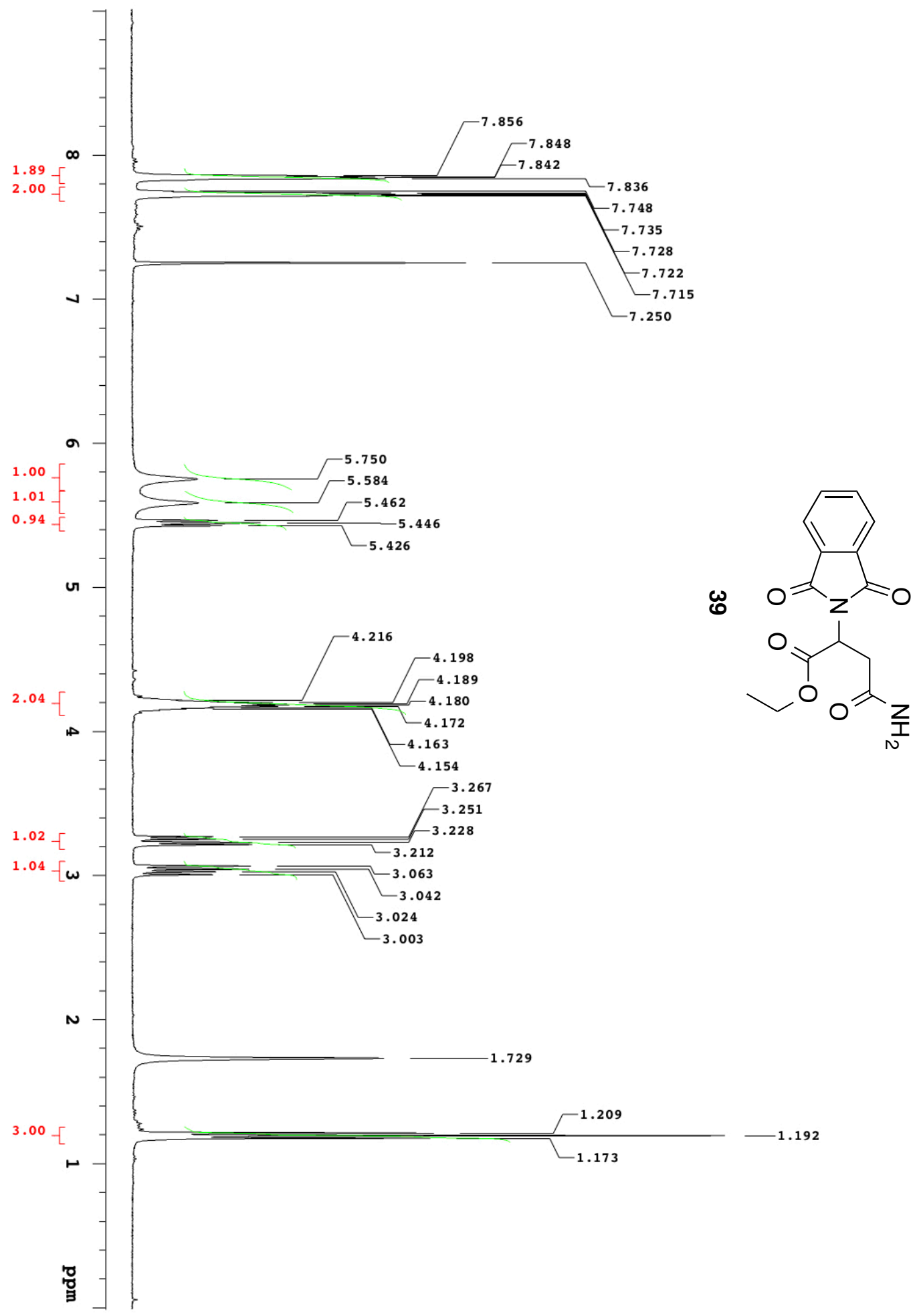




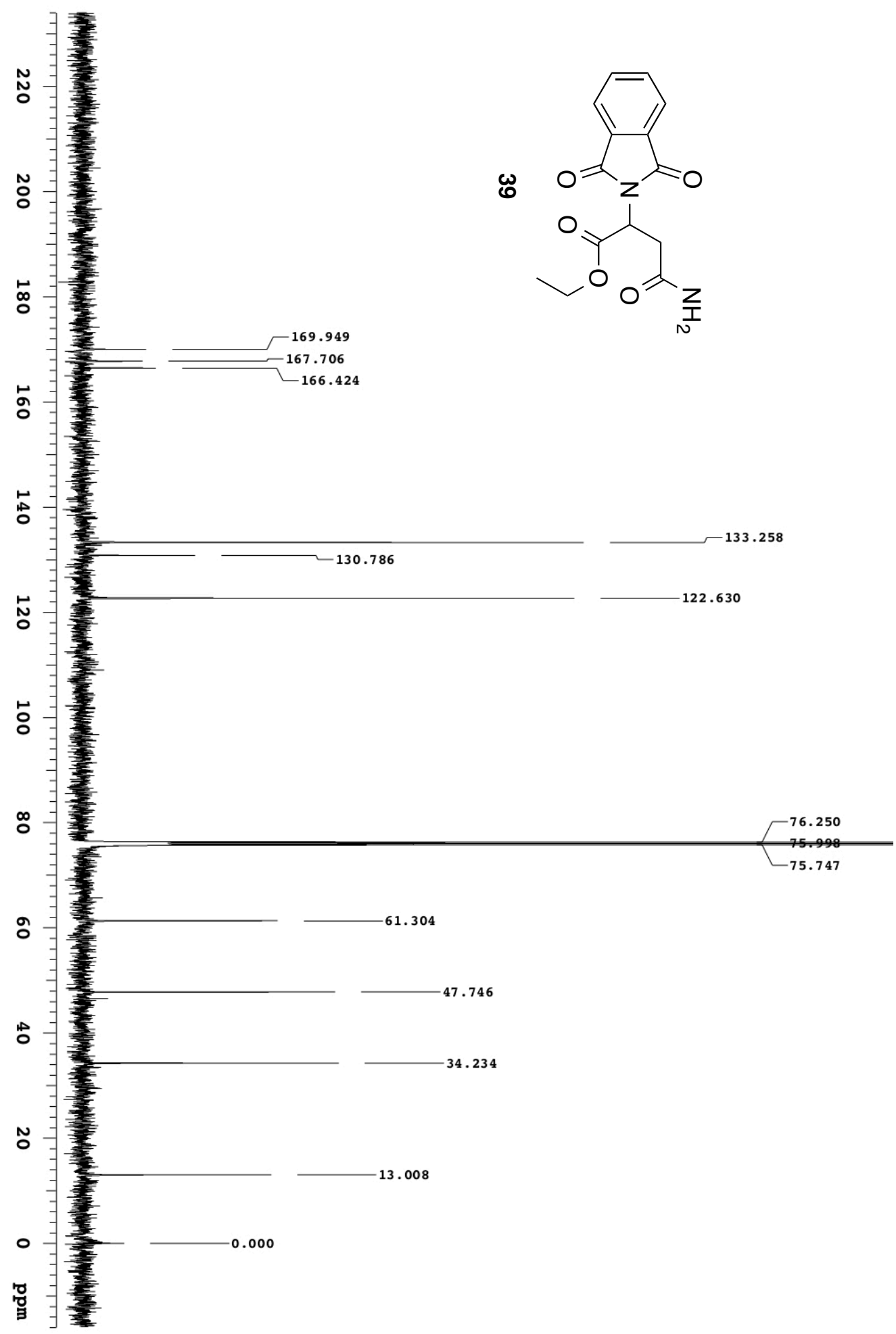




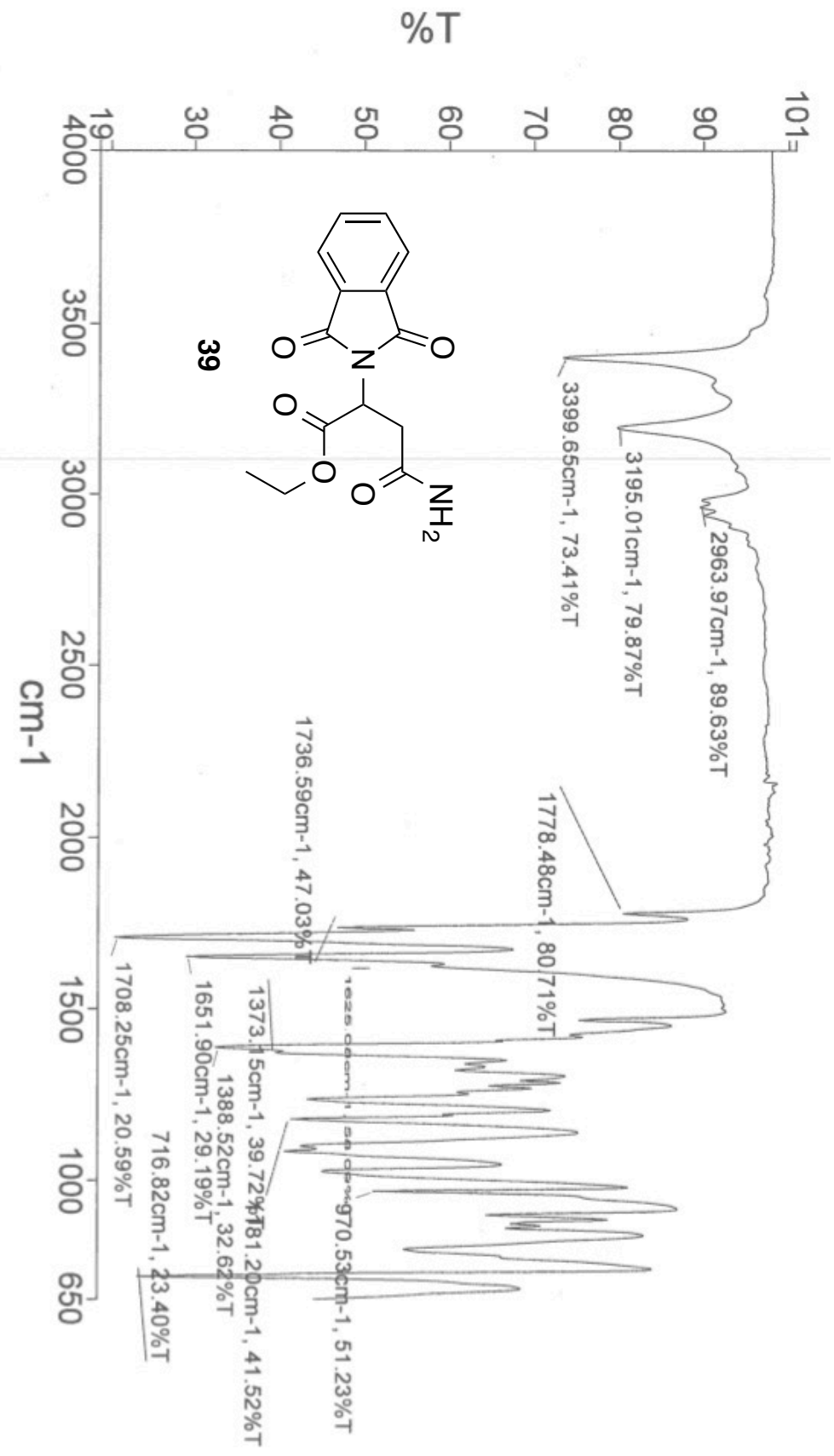




\section{tert-Butyl (tert-butoxycarbonyl)phenylalaninate. ${ }^{47} 41$}

To the solution of $\mathrm{N}$-phthaloyl $34(50 \mathrm{mg}, 0.14 \mathrm{mmol})$ in methanol (10 mL) was added hydrazine hydrate ( $70 \mu \mathrm{L}, 10$ equiv) followed by stirring $(16 \mathrm{~h})$ at room temperature. After completion of reaction as confirmed by TLC (hexanes/ethyl acetate, 8:2), the reaction mixture was concentrated to give a white residue. Dichloromethane $(15 \mathrm{~mL})$ was added to the residue followed by stirring $(15 \mathrm{~min})$ at room temperature. Filtration and concentration of the filtrate gave a colorless oily residue $(31 \mathrm{mg})$. The residue was dissolved in 1,4-dioxane $(10 \mathrm{~mL})$ and to the solution was added sodium bicarbonate $(14.1$ $\mathrm{mg}, 0.14 \mathrm{mmol})$ followed by tert-butyl dicarbonate $(31.0 \mathrm{mg}, 0.14 \mathrm{mmol})$ at room temperature. The resulting reaction mixture was stirred $(16 \mathrm{~h})$ at room temperature. After completion of reaction as confirmed by TLC (hexane/ethyl acetate, 8:2), the solvent was evaporated, and the residue was partitioned between dichloromethane $(10 \mathrm{~mL})$ and water $(10 \mathrm{~mL})$. The organic layer was separated, dried over anhydrous sodium sulfate and evaporated to obtain crude a residue which was submitted to gravity-column chromatography (hexanes/ethyl acetate, 8:2) to afford pure 41 as a colorless oil (37 mg, $81 \%) ; \mathrm{R}_{\mathrm{f}}=0.56$ (hexanes/ethyl acetate, $\left.7.5: 2.5\right) ;{ }^{1} \mathrm{H} \mathrm{NMR}\left(400 \mathrm{MHz}, \mathrm{CDCl}_{3}\right): \delta 7.28-7.19$ (m, 3H), 7.16-7.14 (m, 2H), $4.97(\mathrm{~d}, J=8.4 \mathrm{~Hz}, \mathrm{NH}), 4.43(\mathrm{dd}, J=6.4 \mathrm{~Hz}, 14.0 \mathrm{~Hz}), 3.03$ (d, $J=6.0 \mathrm{~Hz}, 2 \mathrm{H}), 1.40$ (s, $9 \mathrm{H}), 1.38$ (s, 9H) ppm; FT-IR (neat): 2978, 2933, 1713, 1496, $1455,1366 \mathrm{~cm}^{-1}$. 


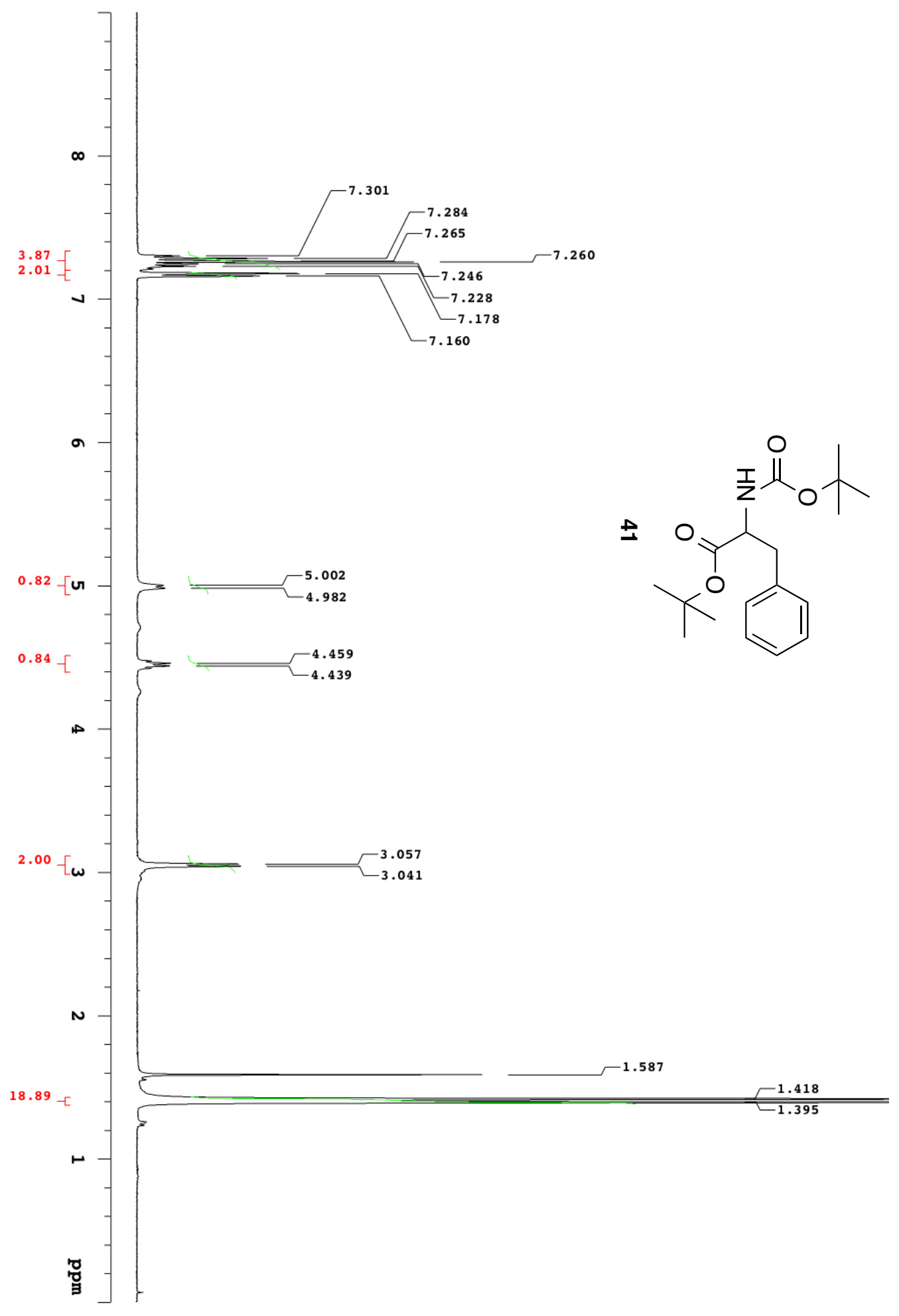




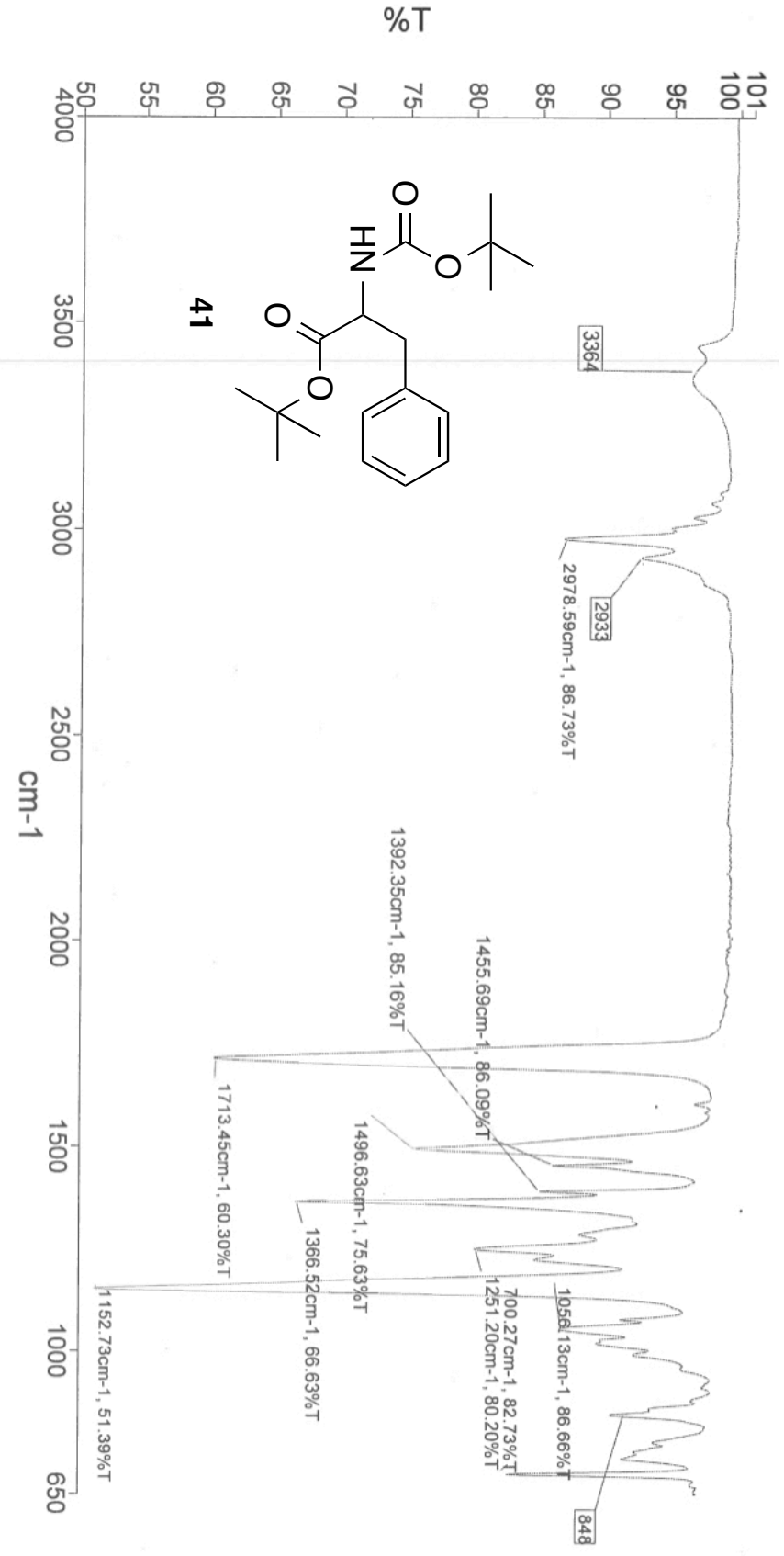




\section{PART C. DAST MEDIATED ALKOXYLATION}




\section{Introduction}

The isoindolinone is a functional heterocycle found in medicinal chemistry and observed in natural products. ${ }^{1-3}$ On the isoindolinone core, substitution with a carbon or heteroatom framework is observed on the benzene ring, the heterocyclic nitrogen atom, and/or especially on the benzylic methylene in many biologically active compounds. The isoindolinone core as an alkoxylated derivative is apparent in a range of active compounds such as antivirals (Figure 22a) ${ }^{4}$ inhibitors of protein-protein interaction (Figure 22b), ${ }^{5}$ muscarinic receptor ligands (Figure 22c) ${ }^{6-7}$ cytotoxic and cytostatic agents. ${ }^{8}$ While examining investigative studies for chiral auxiliaries that utilized substituted isoindolinones, a mild bond formation was examined on the benzylic position of chiral $\mathrm{N}$ substituted isoindolinones was examined. There have been multiple approaches that utilize a hydroxylactam derived from an isoindolinone to undergo bond formation from the generation of an acyliminium ion through acid catalysis or with a Lewis acid in which the

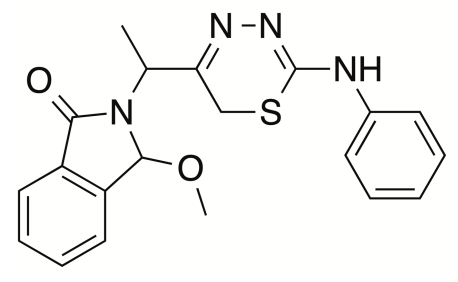

(a) 1
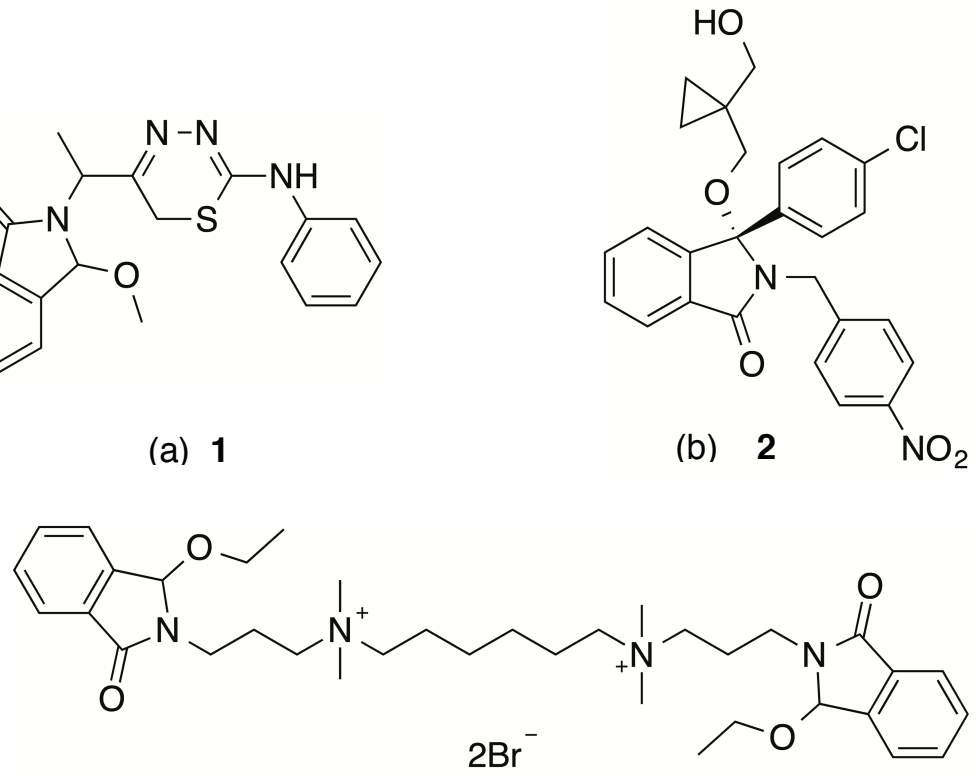

(c) 3

Figure 22. Alkoxyisoindolinone products that are active as a.) antiviral agent, b.) proteinprotein interaction inhibitor, and c.) muscarinic receptor ligand. 
acyliminium ion can easily undergo a nucleophilic reaction with alcohols and thiols. ${ }^{9-13}$ Outside of the acyliminium ion approach, hydroxylactam can undergo chlorination to form a stronger electrophile for subsequent reactions involving an anionic nucleophile. ${ }^{5,6}$ Both of these approaches successfully utilize the hydroxylactam which is easily obtained from the reduction of the corresponding phthalimides by sodium borohydride, diisobutylaluminum hydride, or aluminum amalgam. ${ }^{14}$ The reaction of an hydroxyisoindolinone with an alcohol is a direct approach to synthesize functional alkoxyisoindolinones and is most commonly done through strong acid or metal catalysis. ${ }^{15-}$ ${ }^{18}$ Both of these sets of reaction conditions readily synthesize alkoxyisoindolinones but sometimes occur under harsh conditions.

Diethylaminosulfur trifluoride (DAST) is a mild fluorinating agent which has been utilized to prepare fluorinated analogues from a range of medicinal compounds and natural products. ${ }^{19}$ Fluorination with DAST is done on both alcohols and aldehydes to yield monofluorinated analogues from alcohol or gem-difluorinated analogues from aldehyde and has been the major topic of interest for the use of DAST. The mechanism for fluorination by DAST has two possibilities (Scheme 18) ${ }^{20,21}$. The first is direct fluorine nucleophile displacement, ${ }^{22}$ and the second relies on the formation of a carbocation where fluorine is a nucleophile. ${ }^{23}$ In fluorination reactions of chiral stereogenic centers bearing an alcohol, DAST promotes stereoinversion reactions on a range of compounds containing a chiral alcohol. With the chiral alcohols, the mechanism involves DAST coordinating with a chiral alcohol and disposition of the DAST-alcohol complex is done by a fluorine nucleophile and has been reported to be completed stereoselectively. 

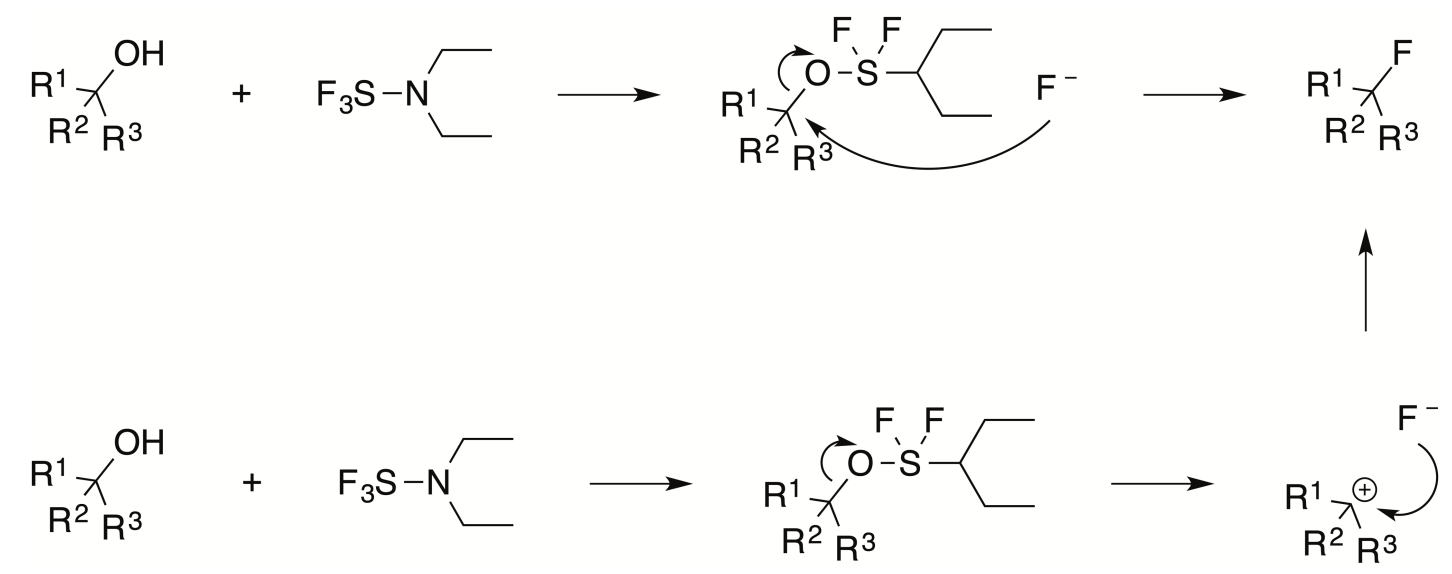

Scheme 18. Plausible DAST mediated mechanism through a.) nucleophile displacement and b.) through carbocation formation

In some of the early reports of using DAST, an ether formation was reported by Johnson in 1982 (Scheme 19). ${ }^{24}$ Johnson was able to utilize DAST to form an ether bond between two diarylcarbinols by stirring them together with the addition of DAST. More recently groups have reported ether formation as a minor pathway to substantial by-product towards expected fluorination..$^{25,26}$ It is likely that ether formation competes with fluorination in cases where formation of a carbocation is highly stabilized, and this is seen
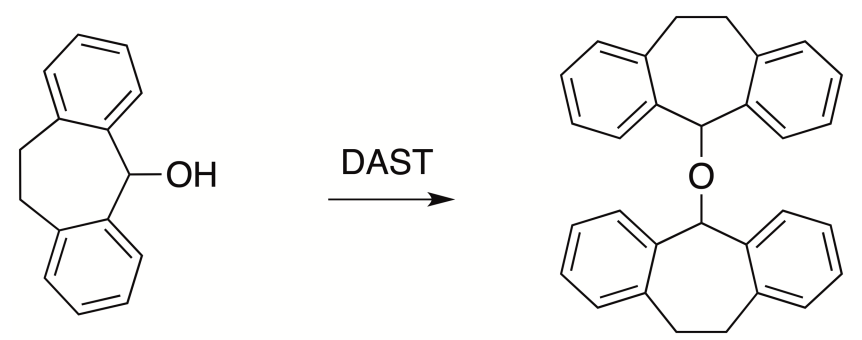

Scheme 19. DAST mediated ether formation presented by Johnson.

in the cases reported with benzyl alcohols that have the additional stability of a carbocation intermediate. Alcohols will readily undergo fluorination with DAST and preclude ether formation, likely due to the stability and reactivity of the alcohol. 
We report herein that hydroxylactam used with DAST and the addition of a range of alcohols leads to a new ether bond in generation of alkoxylactams (alkoxyisoindolinones) in good to excellent yields (Scheme 20). The yields obtained with
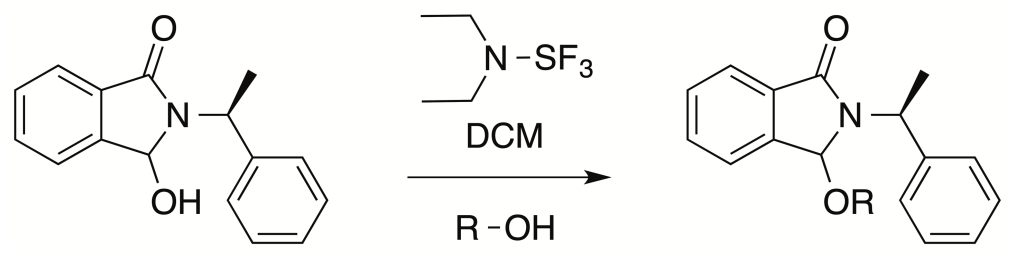

Scheme 20. DAST mediated alkoxylation.

an acid-catalyzed ether formation when using $p$-toluenesulfonic acid or camphorsulfonic acids are greater than or comparable to DAST mediation. Under both DAST and acid catalysis of chiral $\mathrm{N}$-phenethyl hydroxylactams, the reactions generate alkosyisoindolinone products as a diastereomeric mixture. Due to the chiral $\mathrm{N}$-phenethy group, benzylic alkoxylated products generates an unequal ratio of diastereomeric products from the racemic hydroxyl starting material. ${ }^{27}$

\section{Results and Discussions}

Preliminary studies were to investigate the effectiveness of alkoxylation with a 3hydroxy-2-((S)-1-phenylethyl)isoindolin-1-one 7 as a starting material. The described route to the synthesis of alkoxyisoindolinones utilizes the diastereomeric mixture of $\mathbf{7}$ (Scheme 21) ${ }^{28,29}$ Though $\alpha$-hydroxyisoindolinone is not commercially-available, a twostep synthesis is accomplished by reacting commercially-available phthalic anhydride with (S)-1-phenylethan-1-amine neat at $90{ }^{\circ} \mathrm{C}$ overnight, followed by the final closure of the benzamidic acid by the addition of acetic acid and increase of the temperature to $130{ }^{\circ} \mathrm{C}$ (16 h). Purification of chiral (S)-2-(1-phenylethyl)isoindoline-1,3-dione is achieved 
through gravity column chromatography yielding white crystals. Hydroxylactam 7 is prepared by regioselective reduction of chiral (S)-2-(1-phenylethyl)isoindoline-1,3-dione 6 utilizing less than one equivalent of sodium borohydride in methanol at -5 to $0{ }^{\circ} \mathrm{C}$ for 30 minutes to yield 3-hydroxy-2-((S)-1-phenylethyl)isoindolin-1-one 7. Under these conditions, 7 undergoes a workup and is purified by column chromatography to provide a mixture of diastereomers.<smiles>O=C1OC(=O)c2ccccc21</smiles>

4<smiles>CC(N)c1ccccc1</smiles>

5 $\stackrel{\text { a. i. }}{\underset{\text { ii. }}{\longrightarrow}}$

ii.<smiles>CC=C1CCN(Cc2ccccc2)C1=O</smiles>

6

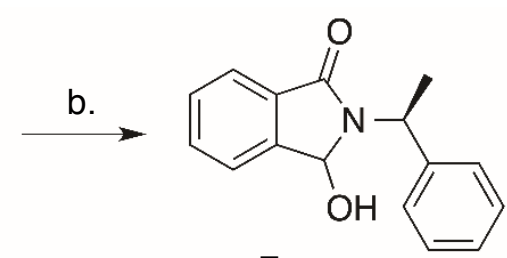

7

Scheme 21. Preparation of Hydroxyisoindolinone. Reagents/Conditions: (a) (i) Neat/90

$$
{ }^{\circ} \mathrm{C} / 20 \mathrm{~h} \text {, (ii) } \mathrm{Ac}_{2} \mathrm{O} / 110{ }^{\circ} \mathrm{C} / 16 \mathrm{~h} \text {; (b) } \mathrm{NaBH}_{4} / \mathrm{MeOH} / 2 \mathrm{~h}
$$

A variety of alcohols were subjected to an alkoxylation reaction using DAST in the novel application. This approach takes advantage of the ability of diethylaminosulfur trifluoride to complex with hydroxyl groups and generate an acyliminium ion. A wide array of alcohols were utilized to probe the scope of the reaction. When determining the scope of the reaction, alkoxylation of 7 was performed initially by complexation of the diethylaminosulfur trifluoride with the starting material under an inert atmosphere, $\mathrm{N}_{2}(\mathrm{~g})$, at $-15^{\circ} \mathrm{C}$ and allowed to stir overnight to room temperature. Diethylaminosulfur trifluoride can yield a stable complex with the hydroxyl of the 3-hydroxy-2-((S)-1phenylethyl)isoindolin-1-one to generate either a DAST-hydroxyl complex or a stabilized acyliminium ion, with both being plausible intermediates when utilizing DAST for fluorination. The alcohol is added dropwise to the reaction mixture and allowed to stir at room temperature until completion, (4-8 hours) and monitored by TLC. The 
alkoxyisoindolinones, 8-17 are synthesized in moderate to good yields (60-91\%) utilizing diethylaminosulfur trifluoride (Table 6). All alkoxylated products are purified with flash column chromatography and contain a mixture of inseparable diastereomers in a ratio (55:45 to $65: 35)$ determined by $\mathrm{H}^{1}$ NMR. The most selective alkoxyisoindolinone synthesized was seen with trichloroethanol having an 80:20 diastereomeric ratio. The range of diastereomers synthesized follows a loose trend in which the least selective alcohol is the benzyl alcohols, followed by the aliphatic alcohols, and lastly the most selective alcohol is trichloroethanol. The trend suggests that the benzyl alcohols are less selective and is likely due to the benzyl derivatives being stabilized through $\pi$ - $\pi$ interactions when the alcohol is approaching from the more hindered side.

Table 6. Products from hydroxyisoindolinone and alcohol with diethylaminosulfur trifluoride.
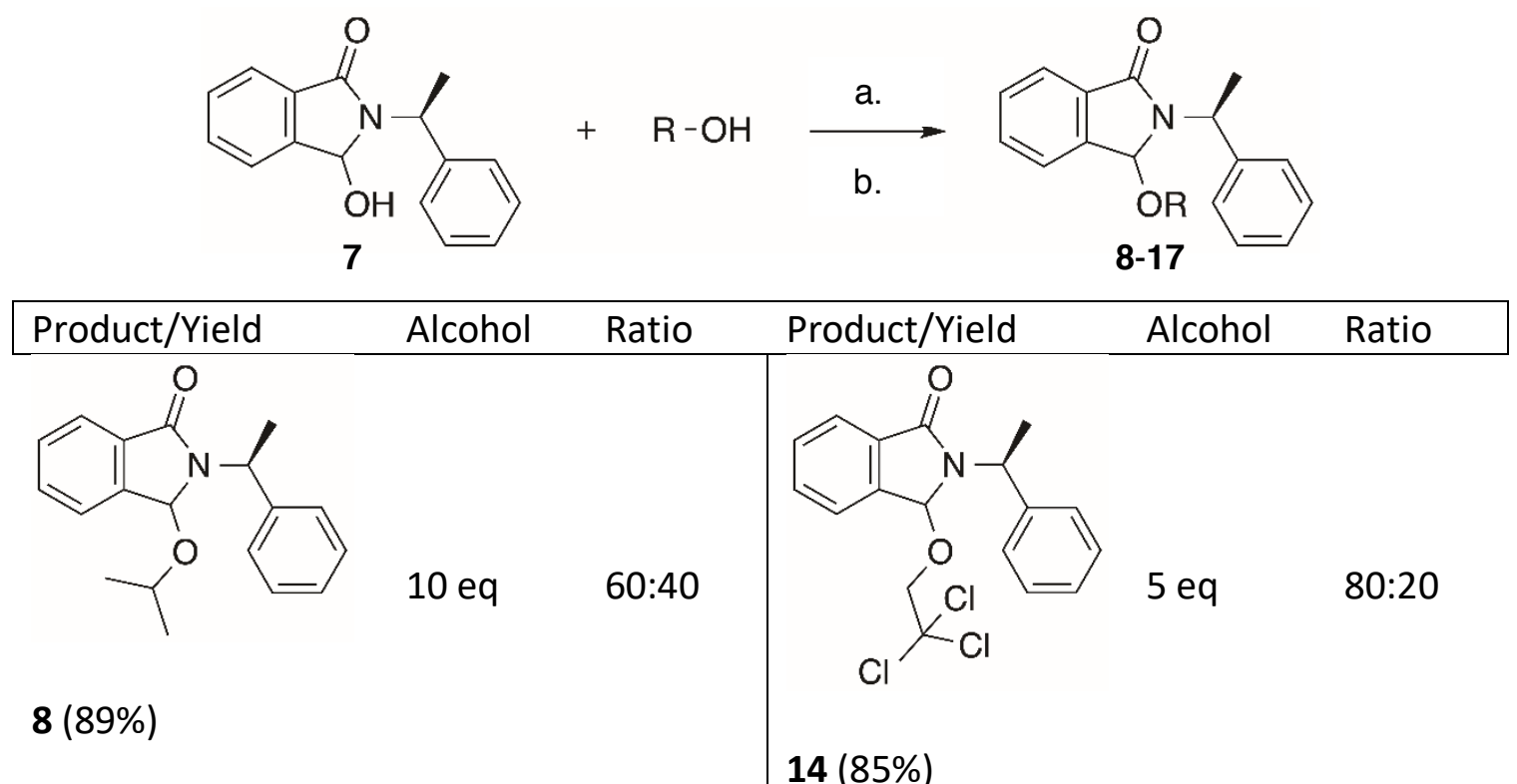

14 (85\%) 

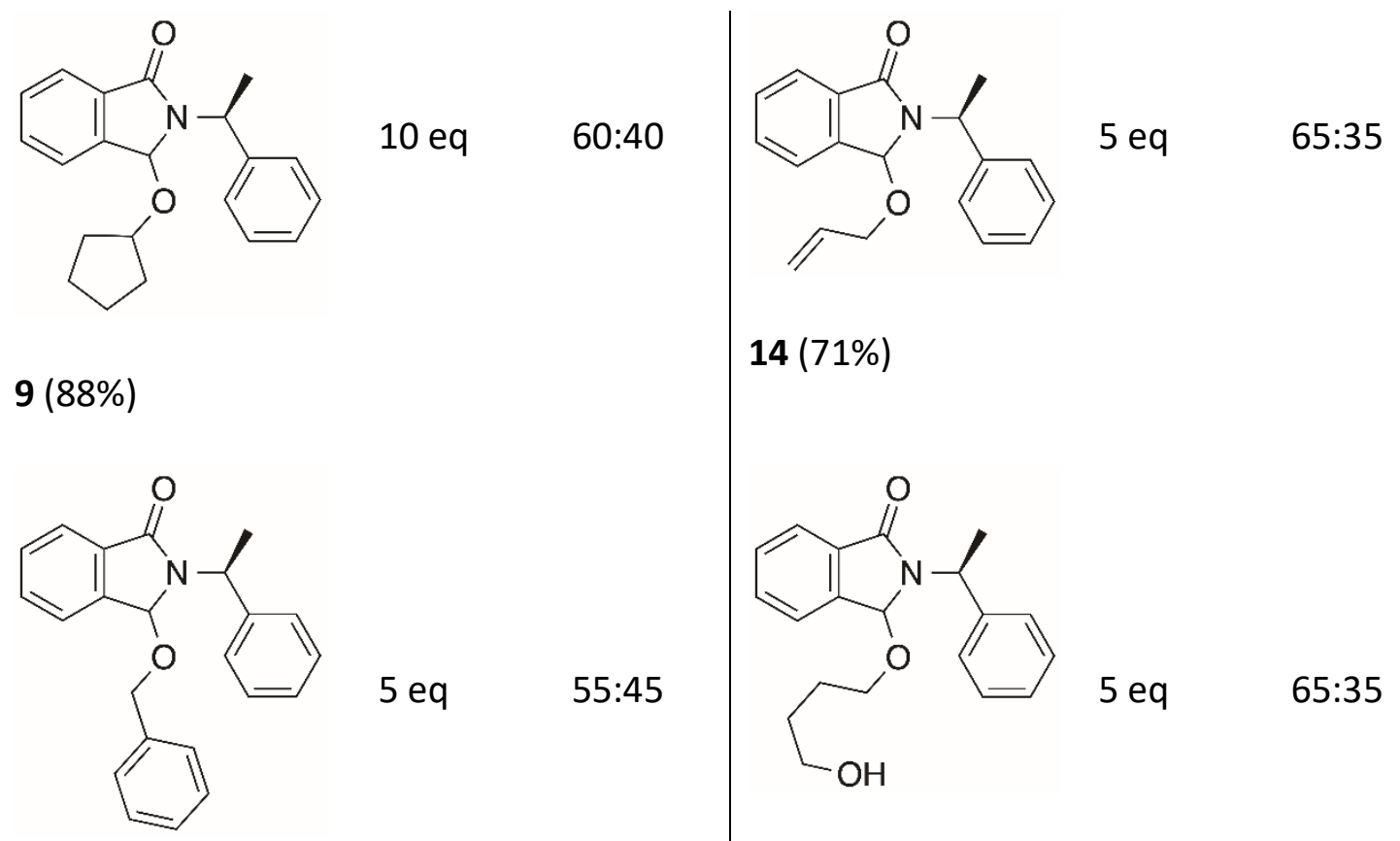

14 (71\%)

10 (80\%)

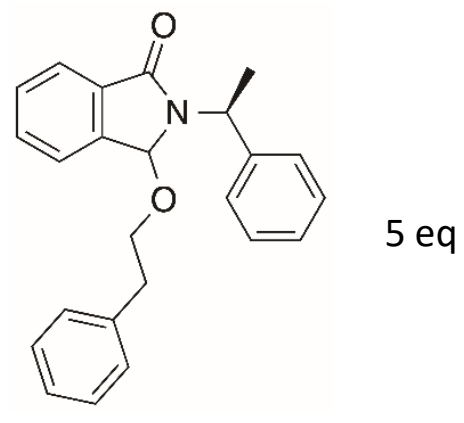

$55: 45$

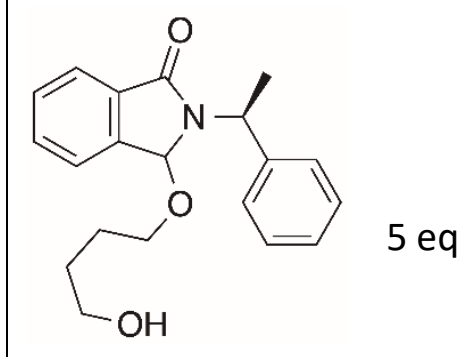

65:35

15 (77\%)

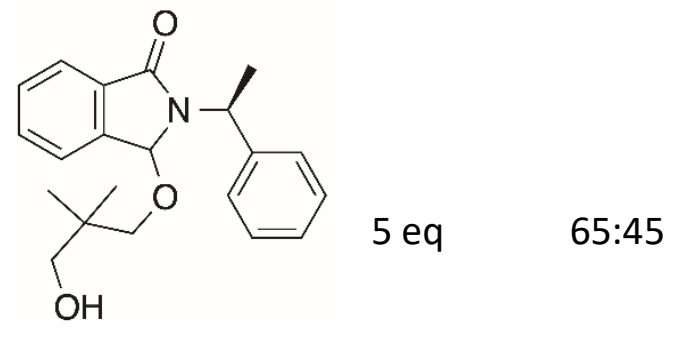

16 (83\%)

11 (91\%)<smiles>COc1ccc(COC2c3ccccc3C(=O)N2C(C)c2ccccc2)cc1</smiles><smiles>CC(c1ccccc1)N1C(=O)c2ccccc2C1OCc1c2ccccc2cc2ccccc12</smiles>

$60: 40$

$12(60 \%)$ 


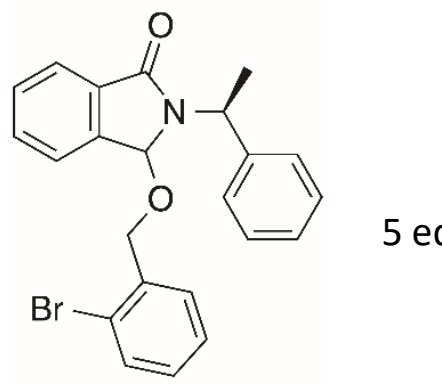

$65: 35$

$13(71 \%)$

Reagents/Conditions: (a) DAST/DCM $/ 0{ }^{\circ} \mathrm{C} / 2-6 \mathrm{hr}$. (b) $\mathrm{ROH} / 0{ }^{\circ} \mathrm{C} / 2-6 \mathrm{hr}$.

In proposing a likely mechanism, the pure diastereomer, $(S)$-3-hydroxy-2-((S)-1phenylethyl)isoindolin-1-one is utilized in determining whether the nucleophilic attack of the alcohol is either an $\mathrm{S}_{\mathrm{N}} 1$ or $\mathrm{S}_{\mathrm{N}} 2$ mechanism. The pure diastereomer was selectively crystallized in 9:1 diethyl ether:hexane as demonstrated by Daich et al ${ }^{10}$ The pure diastereomer was subjected to the reaction conditions with diethylaminosulfur trifluoride as previously described. After stirring overnight, an addition of $\beta$-phenethanol (3 equiv.) was added and allowed to stir until completion through monitoring with TLC. Knowing that DAST can undergo fluorination by direct nucleophilic substitution, the pure diastereomer was utilized as the starting reagent as a means of analyzing whether an $\mathrm{N}$ acyliminium ion was generated and alcohol attack $\left(\mathrm{S}_{\mathrm{N}} 1\right)$ or if direct displacement of the alcohol-DAST complex occurred $\left(\mathrm{S}_{\mathrm{N}} 2\right)$. Thus, when envisioning a direct nucleophilic attack with the $\beta$-phenethanol present, a complexation between the DAST and the free alcohol can be proposed (Scheme 22). Much like how DAST undergoes fluorination, it was expected that the free alcohol would displace the DAST-hydroxyl complex on the molecule. This occurrence would have resulted in direct stereoconversion on the hydroxyl carbon and would be identifiable by $\mathrm{H}^{1} \mathrm{NMR} .{ }^{30,31}$ Upon purification of the product that utilized pure 


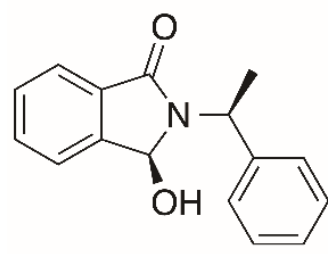

18
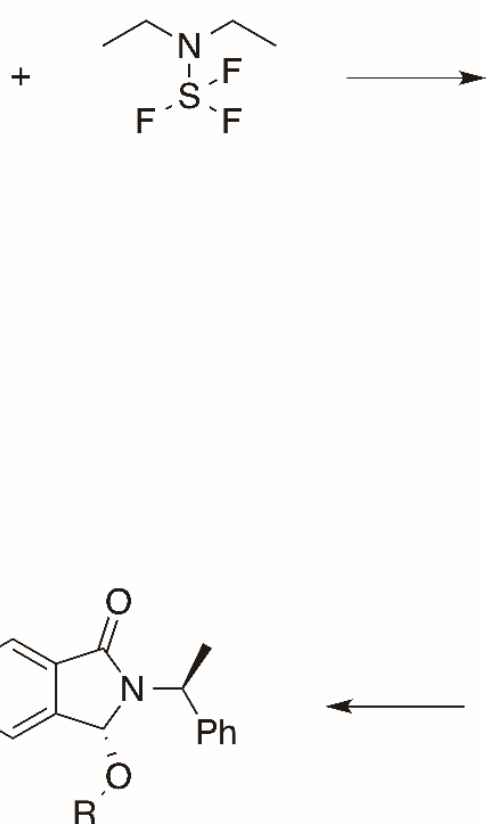

$\mathrm{R}$
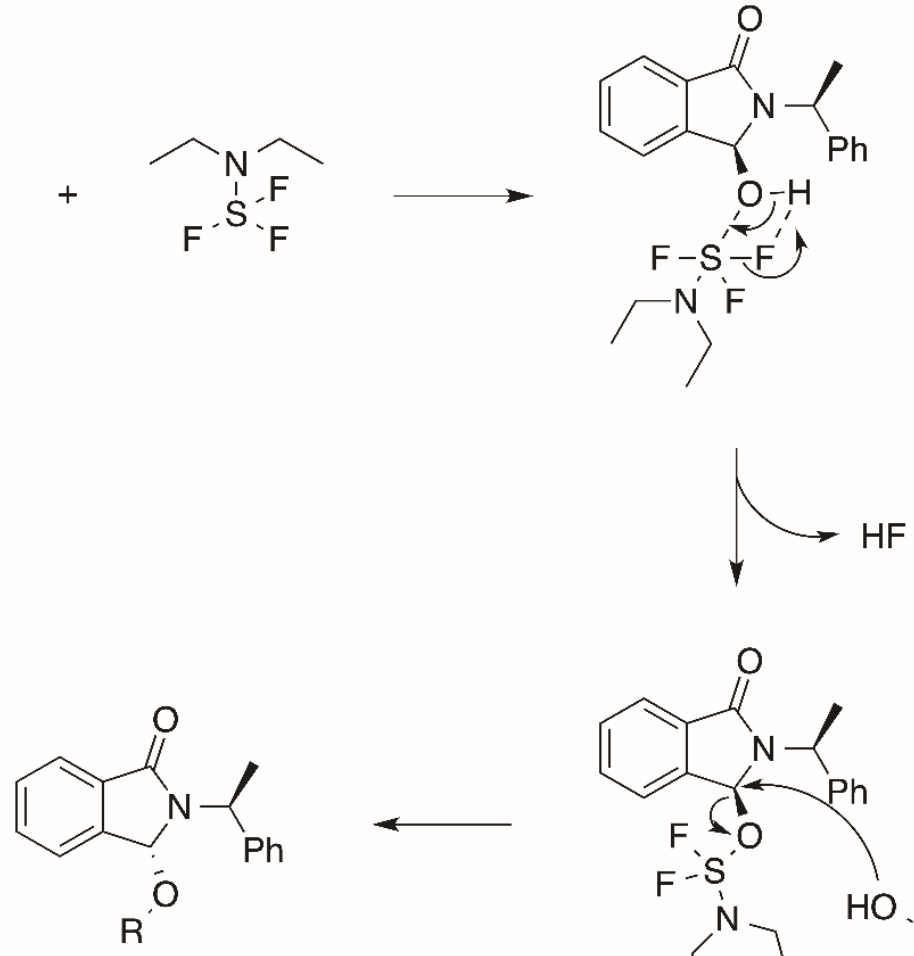

Scheme 22. Proposed $\mathrm{S}_{\mathrm{N}} 2$-like reaction mechanism through a DAST complexation.

diastereomer $(S)$-3-hydroxy-2-((S)-1-phenylethyl)isoindolin-1-one and $\beta$-phenethanol, a diastereoisomeric mixture (60:40) was observed. The lack of a diastereomer in a high percentage suggest that the DAST-hydroxyl complex is at least not the predominant pathway in synthesizing alkoxyisoindolinone derivatives. This observation likely suggests deoxygenation occurs and therefore, a stable $\mathrm{N}$-acyliminium ion which is generated and is subsequently alkoxylated.

While there is no evidence of direct nucleophilic attack through the DASThydroxyl complex, a mixture of major and minor diastereomers are formed, which can be predicted to be a result of the generation of an $N$-acyliminium ion $\left(\mathrm{S}_{\mathrm{N}} 1\right)$. This pathway utilizes a Felkin-Ahn $\operatorname{model}^{7}$ that accurately depicts the reasoning for an unequal 
distribution of diastereomers observed (Scheme 23). The DAST complexes to the free hydroxyl of the pure enantiomer and subsequently is able to act as a stable leaving group and generate the highly stabilized $N$-acyliminium ion. The stabilized $N$-acyliminium ion allows for a non-stereoselective alkoxylation due to the chiral $N$-phenethyl handle. Chiral induction is observed in the synthesized product where a major diastereomer is favored.<smiles>CC(c1ccccc1)N1C(=O)c2ccccc2[C@H]1O</smiles>

18

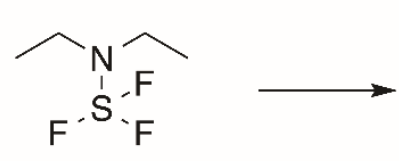<smiles>[CH]</smiles><smiles>CCN(CC)S(F)(F)(F)(F)O[C@H]1c2ccccc2C(=O)N1C(C)c1ccccc1</smiles>

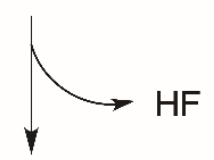<smiles>CC(=O)c1ccccc1O</smiles>

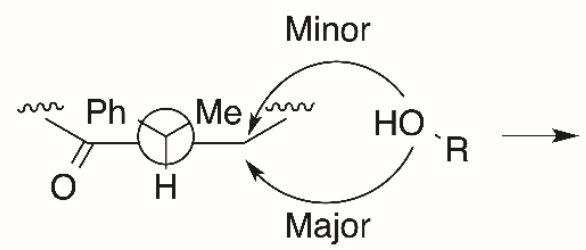

$O=N^{\oplus} \quad \begin{aligned} & \text { Felkin-Ahn } \\ & \text { Projection }\end{aligned}$<smiles>[R]OC1c2ccccc2C(=O)N1[C@H](C)c1ccccc1</smiles>

$\mathrm{R}$<smiles>[R]O[C@H]1c2ccccc2C(=O)N1[C@@H](C)c1ccccc1</smiles>

Scheme 23. Proposed mechanism utilizing DAST to generate an $\mathrm{N}$-acyliminium ion. 
The induction is rationalized through the Felkin-Ahn model and one enantiomer will be favored strictly due to the accessibility of a nucleophilic addition taking place. The addition of the alcohol must come in from either the top face or the bottom face. The approach from either side contains a difference in gauche interactions due to the chiral handle, $\mathrm{N}$ phenethyl. Unequal distribution is likely due to the generation of the $\mathrm{N}$-acyliminium ion formation, in which the reaction proceeds through a SN1 mechanism.

To confirm that the DAST mechanism proceeds solely through a generated acyliminium ion, an acid catalyzed reaction was used to validate the postulated mechanism. Alkoxylation of the hydroxylactam was completed by utilizing an acid catalyzed reaction. Camphorsulfonic acid (CSA) was used as the catalyst and reacted with select alcohols used from the DAST reaction. The aforementioned alkoxyisoindolinones 15-17 were then synthesized with a catalytic amount of CSA and were prepared in moderate yields 75 83\% (Table 7). Nearly identical diastereomeric ratios are seen between the DAST and CSA mediated alkoxylation reactions. Thus, confirming the DAST mediated reaction goes through the stable $\mathrm{N}$-acyliminium ion formation.

The use of diethylaminosulfur trifluoride and the use of camphorsulfonic acid both resulted in $\alpha$-amidoalkoxylation through the generation of a stable $\mathrm{N}$-acyliminium ion. Both reaction conditions generated a mixture of diastereomers in comparable ratios that are inseparable by column chromatography at good to modest yields. The advantages of using camphorsulfonic acid are the catalytic amount and the ability to generate the $\mathrm{N}$ acyliminium ion in the presence of the alcohol co-reactant. While advantages of utilizing camphorsulfonic acid exist, DAST can be used in the presence of acid sensitive functional groups within molecules. DAST also has been previously reported to solely induce 
alkoxylation and generally provided a higher yield than camphorsulfonic acid from comparing the alkoxylated analogues.

Table 7. Products from hydroxyisoindolinone and alcohol with camphorsulfonic acid.
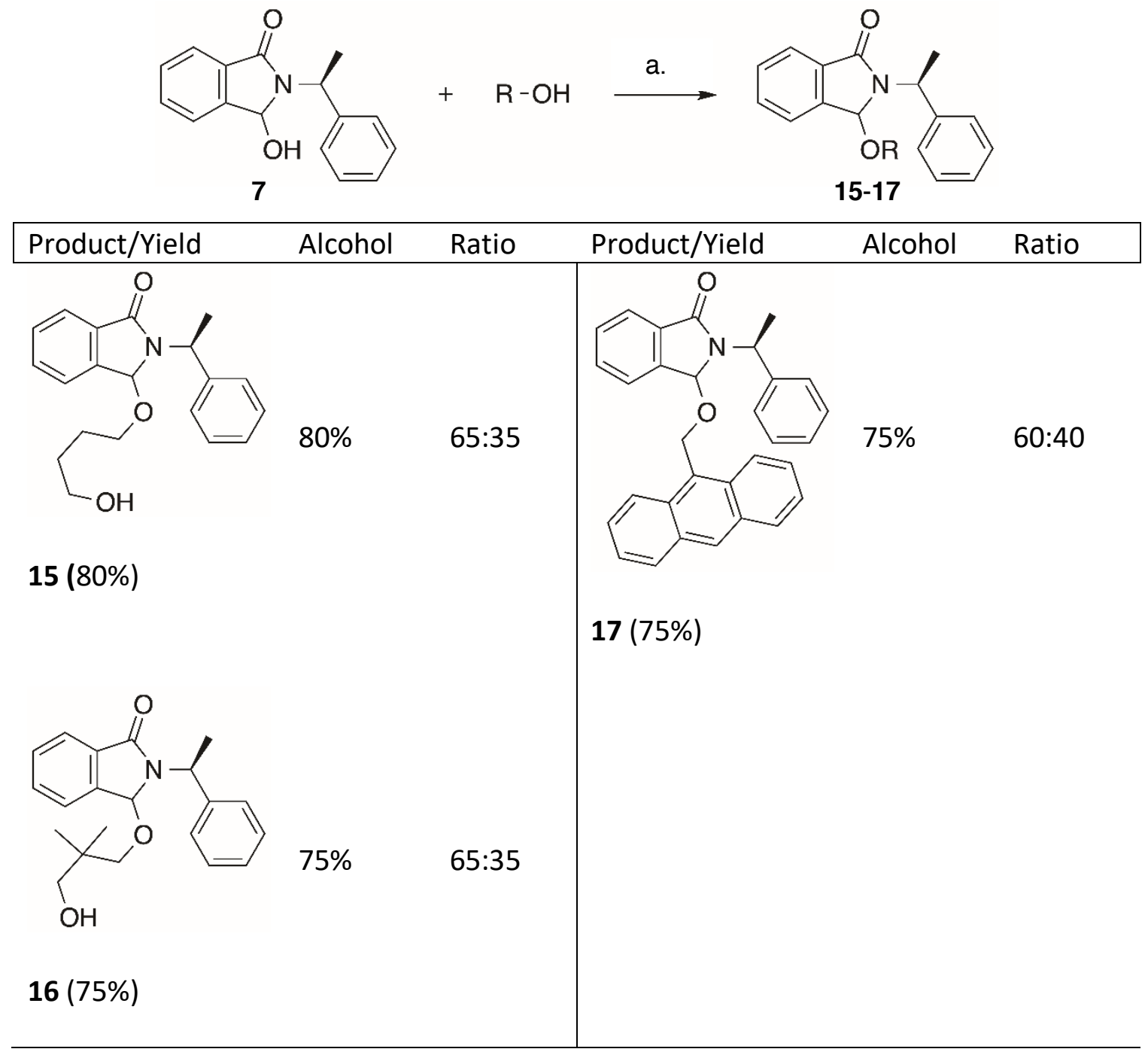

Reagents/Conditions: (a) $\mathrm{CSA} / \mathrm{DCM} / 0^{\circ} \mathrm{C} / 2-6 \mathrm{hr}$.

While alkoxylation with the use of DAST is unable to generate a stereospecific reaction, a route to isolate the pure enantiomer $\mathbf{1 8}$ from fractional crystallization for an esterification reaction was accomplished (Scheme 24). The esterification reaction was accomplished under slightly basic conditions (pyridine, $100 \mu \mathrm{L}$ ) and with acetic anhydride 
$(50 \mu \mathrm{L})$. The acetylation reaction yielded the diastereomerically pure product $(S)$-3-oxo-2$\left((S)-1-\right.$ phenylethyl)isoindolin-1-yl acetate 20 with an optical rotation of $[\alpha]_{\mathrm{D}}+36^{\circ}(\mathrm{c}=$

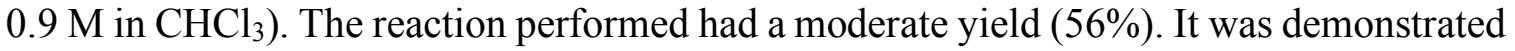
that the pure enantiomer is capable of undergoing chemical reactions that will maintain the chiral center without epimerizing to yield a diastereomeric ratio.

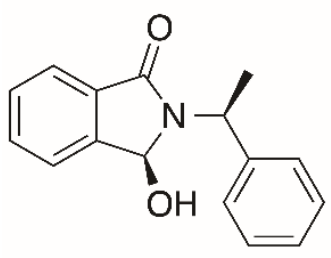

18

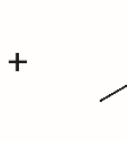

19

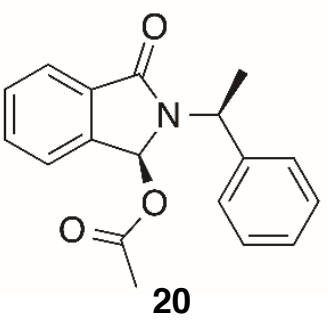

20

Scheme 24. Preparation of $(S)$-3-oxo-2-((S)-1-phenylethyl)isoindolin-1-yl acetate. (a)

Pyridine/RT/24 h (56\% yield)

Envisioning a reaction by which an alkoxide is generated and subsequently attacks an alkyl halide would allow for desired products to be diastereomerically pure. Conversely, the generation of the alkoxide from the diastereochemically-pure compound with sodium hydride $(\mathrm{NaH})$ in THF and the addition of benzyl bromide did not generate the desired benzyl alkoxyisoindolinone. A racemic mixture of hydroxylactams was the only observed product from the attempted alkoxylation reaction. This is likely due to the formation of an aldemide under highly basic conditions causing epimerization of the hydroxyl functional group.

In determining the stability of the stereocenter of the hydroxyl carbon, an epimerization study on the hydroxyl carbon of the enantiomerically pure compound was noted in an $\mathrm{H}^{1}$ NMR experiment utilizing a slightly stronger base, triethylamine. The epimerization study was performed by adding (S)-3-hydroxy-2-((S)-1phenylethyl)isoindolin-1-one $\mathbf{1 8}(10 \mathrm{mg})$ in $\mathrm{CDCl}_{3}(1 \mathrm{~mL})$ to be analyzed in an $\mathrm{H}^{1} \mathrm{NMR}$ 
tube. Triethylamine was added (5 equiv, $27 \mu \mathrm{L})$ to the pure hydroxylactam and epimerization was seen to occur over the course of 24 hours. The doublet $(\delta 1.84,3 \mathrm{H})$ corresponding to the phenethyl chiral handle was the standard in determining the percent of epimerization occurring (Figure 23a). Over the first 3 hours no quantifiable change had been observed, but after 24 hours, (Figure 23b) 18\% conversion was observed of one enantiomer to a mixture of diastereomers.
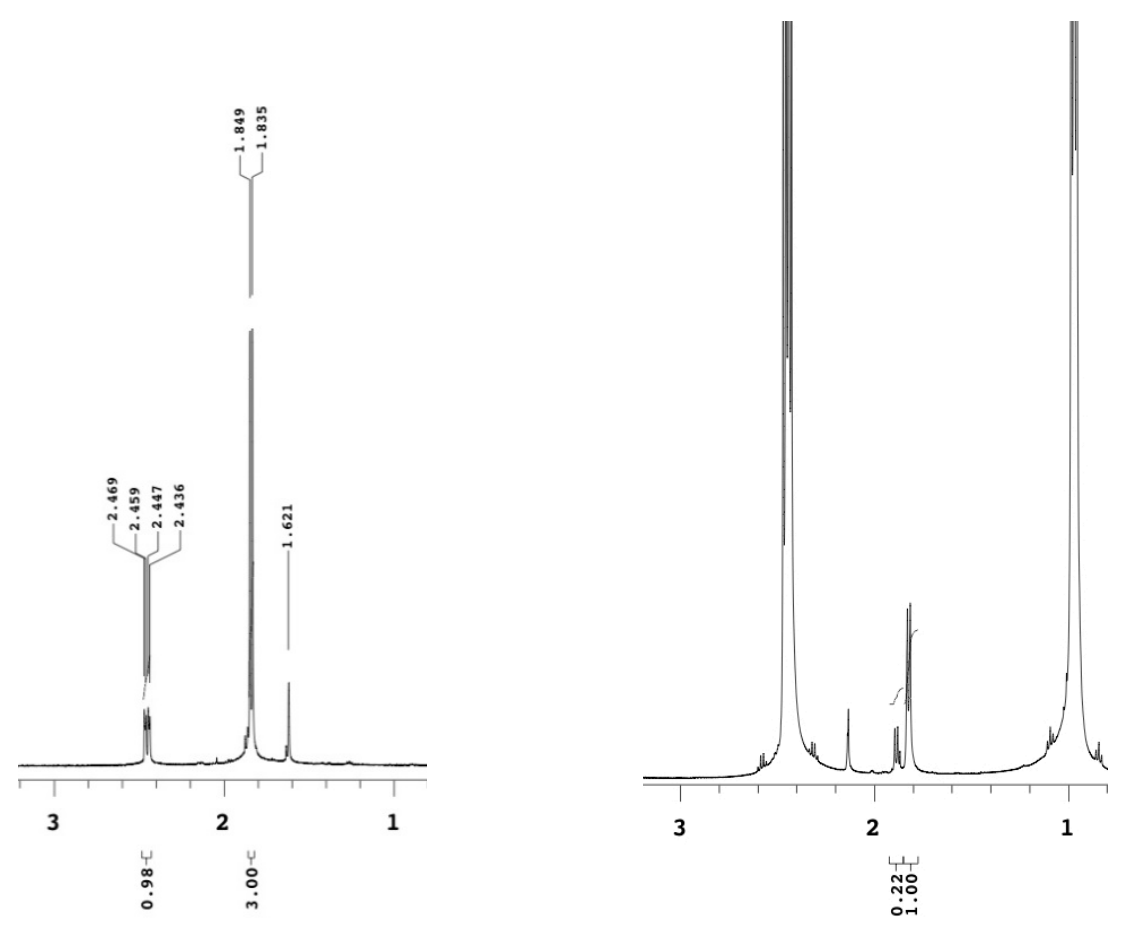

Figure 23. Epimerization study converting the starting pure enantiomer (left) with 5 equivalents of triethylamine to a mixture of diastereomers (right).

In tandem, the acylation and the epimerization studies suggest that a weak base could allow alkoxylation to occur while retaining its stereocenter, but the chosen base must also be weak enough to not cause epimerization. All structures of the products synthesized were confirmed by ${ }^{1} \mathrm{H}$ and ${ }^{13} \mathrm{C}$ NMR including elemental analysis. 


\section{Conclusions}

We have demonstrated an efficient route to 3-alkoxyisoindolinones from an hydroxylactam mediated with a fluorinating reagent DAST in place of a strong acid. Synthesis of the alkoxyisoindolinone is mediated by an acyliminium ion that DAST generates through complexation with hydroxyl of the hydroxylactam. The chiral phenethylamine has minor chiral induction and dependent on the alcohol attaching to the acyliminium a minor and major product is observable and the diastereomeric ratio can be quantified by ${ }^{1} \mathrm{H}$ NMR. (For publication see Appendices p. 281) 


\section{Experimental}

General. Solvents and reagents were ACS grade and were used as commercially supplied. Analytical thin-layer chromatography (TLC) utilized $0.25 \mathrm{~mm}$ pre-cut glass-backed plates (Merck, Silica Gel 60 F254). Thin-layer chromatograms were visualized during chromatographic and extraction runs by rapidly dipping the plates in anisaldehyde/ethanol/sulfuric acid stain or phosphomolybdic acid/ ethanol stain and heating (hot plate). Gravity-column chromatography was carried out using silica gel 60 (E. Merck 7734, 70-230 mesh). Nuclear magnetic resonance ( ${ }^{1} \mathrm{H}$ and ${ }^{13} \mathrm{C}$ NMR) spectra were recorded with Varian VNMRS 400, 500, or $700 \mathrm{MHz}$ instruments using $\mathrm{CDCl}_{3}$ as a solvent and TMS as internal standard. Infrared spectra (FTIR) were recorded with a PerkinElmer Spectrum 100 instrument and spectral values are reported $\mathrm{as} \mathrm{cm}^{-1}$.

\section{(S)-2-(1-phenylethyl)isoindoline-1,3-dione: 6}

Phthalic anhydride $(2.44 \mathrm{~g}, 16.5 \mathrm{mmol})$ was added to $(S)$-phenethylamine $(2.00 \mathrm{~g}, 16.5$ mmol) neat and allowed to stir $16 \mathrm{hr}$ at $90{ }^{\circ} \mathrm{C}$. Acetic anhydride $(15 \mathrm{~mL})$ was added and allowed to stir $48 \mathrm{hr}$ at $110{ }^{\circ} \mathrm{C}$. The crude reaction mixture was directly submitted to gravity-column chromatography hexane:ethyl acetate(4:1) to afford pure 6 as white crystalline product $(2.86 \mathrm{~g}, 65 \%)$. Optical rotation was $[\alpha]_{\mathrm{D}}-62^{\circ}\left(\mathrm{c}=0.5 \mathrm{M}\right.$ in $\left.\mathrm{CHCl}_{3}\right) .^{26}$

\section{3-hydroxy-2-((S)-1-phenylethyl)isoindolin-1-one: 7}

(S)-2-(1-phenylethyl)isoindoline-1,3-dione (500 mg, 1.99mmol) was dissolved in methanol $(20 \mathrm{~mL})$ at $-5-0{ }^{\circ} \mathrm{C}$. Sodium borohydride $(225.8 \mathrm{mg}, 5.97 \mathrm{mmol})$ was added slowly to the solution and allowed to stir for 30 minutes. Reaction was quenched using aqueous $10 \%$ hydrochloric acid $(1 \mathrm{~mL})$. Reaction was concentrated then washed with sodium bicarbonate 
$(4 \mathrm{~mL})$ and extracted with dichloromethane $(3 \times 10 \mathrm{~mL})$. Solution was concentrated to yield 7 as white crystals (460 mg, 92\%). ${ }^{26}$

\section{General procedure for synthesis of 3-alkoxy-2-((S)-1-phenylethyl)isoindolin-1-one: 7-} 17

3-hydroxy-2-((S)-1-phenylethyl)isoindolin-1-one (150 mg, $0.592 \mathrm{mmol})^{\mathrm{a}}$ or $(100 \mathrm{mg}, 0.395$ $\mathrm{mmol})^{\mathrm{b}}$ was dissolved in dichloromethane $(3.0 \mathrm{~mL})$ under inert atmosphere $\left(\mathrm{N}_{2}\right)$ while stirring followed by the addition diethylaminosulfurtrifluoride (DAST, $240 \mu \mathrm{L}, 1.776$ mmol, 3 eq). Stirring was continued overnight ( $16 \mathrm{hr}$ ) and alcohol was added and stirred until the reaction was complete as indicated by TLC (4-8 hr). The crude reaction mixture was directly submitted to gravity-column chromatography.

For compounds 7-17 either ${ }^{\mathrm{a}}$ or $^{\mathrm{b}}$ is used to denote the scale of the reaction.

General procedure for synthesis of 3-alkoxy-2-((S)-phenylethyl)isoindolin-1-one: 1517

3-hydroxy-2-((S)-1-phenylethyl)isoindolin-1-one (100mg, $0.395 \mathrm{mmol})$ was dissolved in dichloromethane $(3.0 \mathrm{~mL})$ with alcohol $(1.2 \mathrm{eq})$ in the presence of camphorsulfonic $\operatorname{acid}(20 \%$ eq). Stirring was continued overnight ( $4-6 \mathrm{hr})$ until the reaction was complete as indicated by TLC (4-8 hr). The crude reaction mixture was directly submitted to gravitycolumn chromatography. 


\section{3-isopropoxy-2-((S)-1-phenylethyl)isoindolin-1-one. ${ }^{\text {a }} 7$}

Colorless oil (158 mg, 89\%); $\mathrm{R}_{\mathrm{f}}=0.44$ (hexane/ethyl acetate, 4:1); IR 3029, 2976, 2927, $2886,1698 \mathrm{~cm}^{-1}$ A mixture of two inseparable diastereomers $(\mathrm{dr}=3: 2){ }^{1} \mathrm{H}$ NMR (500 $\mathrm{MHz}, \mathrm{CDCl}_{3}$, major) $\delta$ 7.81-7.84 (m, 1H), 7.25-7.55 (m, 8H), $5.68(\mathrm{q}, \mathrm{J}=7.0 \mathrm{~Hz}, 1 \mathrm{H}), 5.53$ (s, 1H), 3.66-3.70 (m, 1H), $1.83(\mathrm{~d}, \mathrm{~J}=6.5 \mathrm{~Hz}, 3 \mathrm{H}), 1.18(\mathrm{~d}, \mathrm{~J}=6.0 \mathrm{~Hz}, 3 \mathrm{H}), 1.05(\mathrm{~d}, \mathrm{~J}=$ $6.0 \mathrm{~Hz}, 3 \mathrm{H}){ }^{1} \mathrm{H} \mathrm{NMR}\left(500 \mathrm{MHz}, \mathrm{CDCl}_{3}\right.$, minor) $\delta$ 7.81-7.84 (m, 1H), 7.25-7.55 (m, 8H), $5.76(\mathrm{~s}, 1 \mathrm{H}), 5.15(\mathrm{q}, J=7.0 \mathrm{~Hz}, 1 \mathrm{H}), 3.66-3.70(\mathrm{~m}, 1 \mathrm{H}), 1.98(\mathrm{~d}, J=7.5 \mathrm{~Hz}, 3 \mathrm{H}), 1.15(\mathrm{~d}$, $J=6.5 \mathrm{~Hz}, 3 \mathrm{H}), 0.92(\mathrm{~d}, J=6.5 \mathrm{~Hz}, 3 \mathrm{H}) .{ }^{13} \mathrm{C} \mathrm{NMR}\left(500 \mathrm{MHz}, \mathrm{CDCl}_{3}\right) \delta$ 168.0, 127.7, $143.0,142.3,140.5,132.9,132.1,131.9,131.8,129.7,129.5,128.5,128.4,128.2,127.5$, 127.2, 126.6, 123.5, 123.4, 123.3, 85.9 (major), 85.6 (minor), 69.4, 68.7, 52.0, 50.2, 23.9,

23.7, 23.2, 3.0, 18.9, 18.9. HRMS (FTMS + p ESI) $m / z[\mathrm{M}+\mathrm{Na}]^{+}$; calculated for $\mathrm{C}_{19} \mathrm{H}_{21} \mathrm{O}_{2} \mathrm{NNa} 318.1465$, Found: 318.1468 


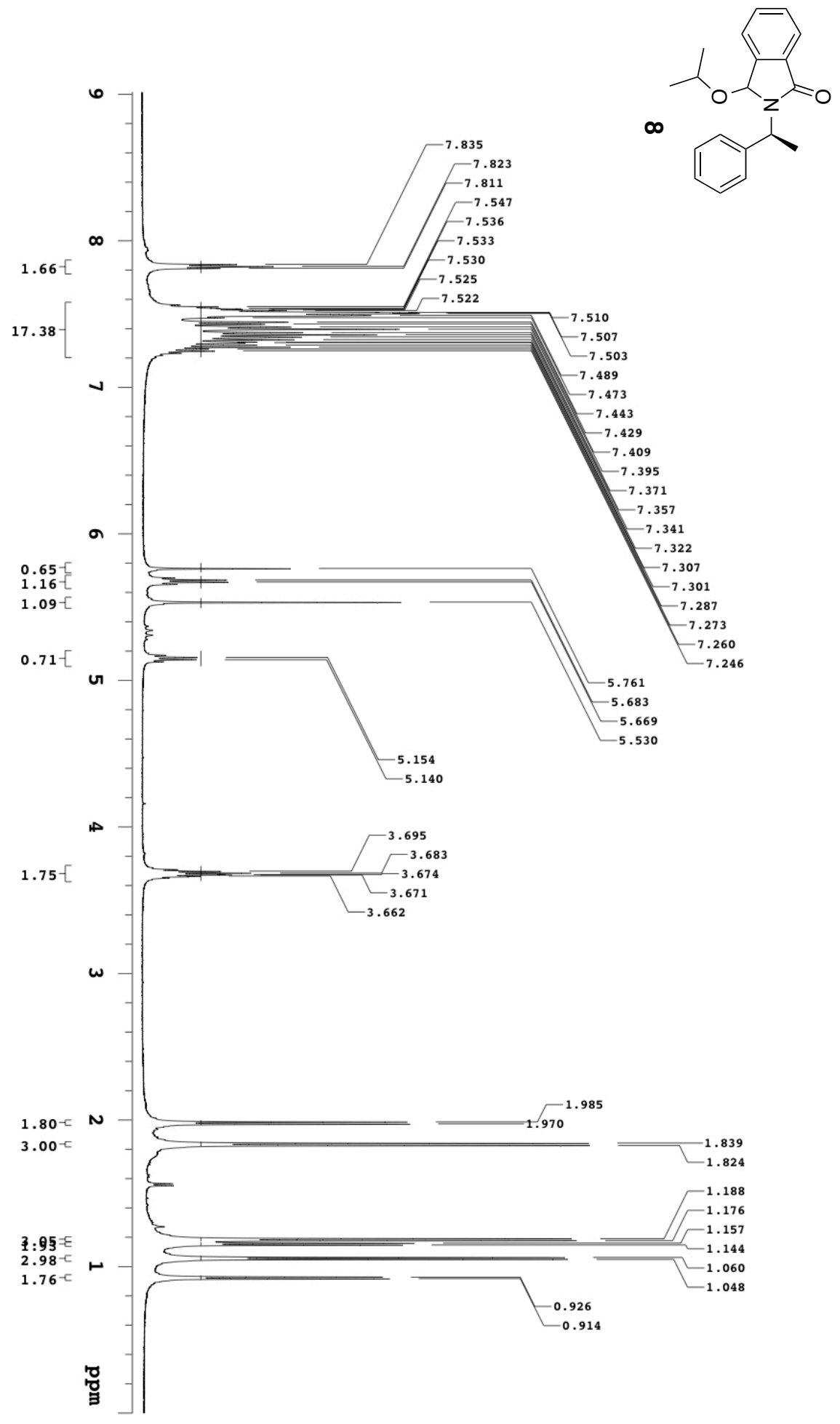




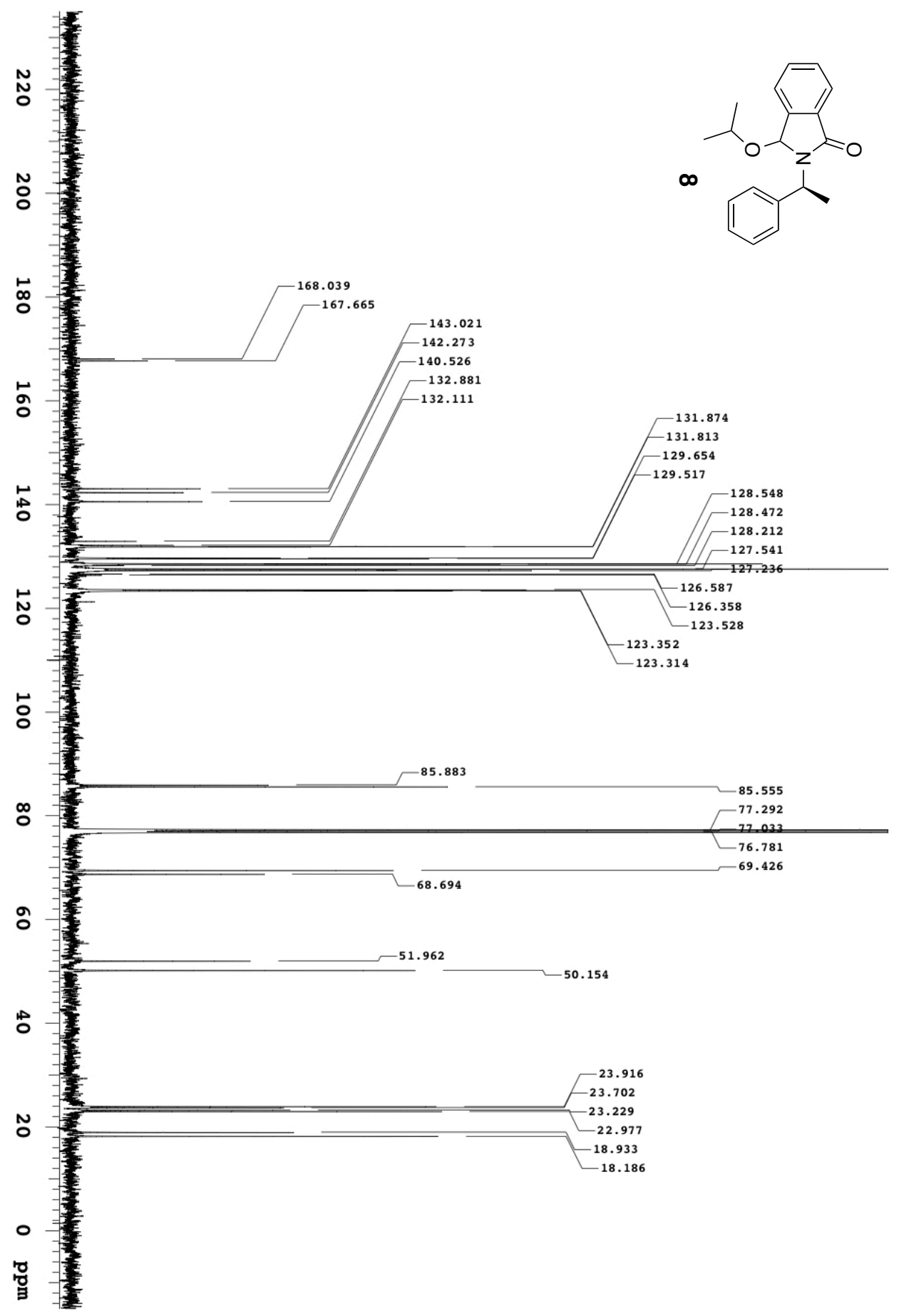




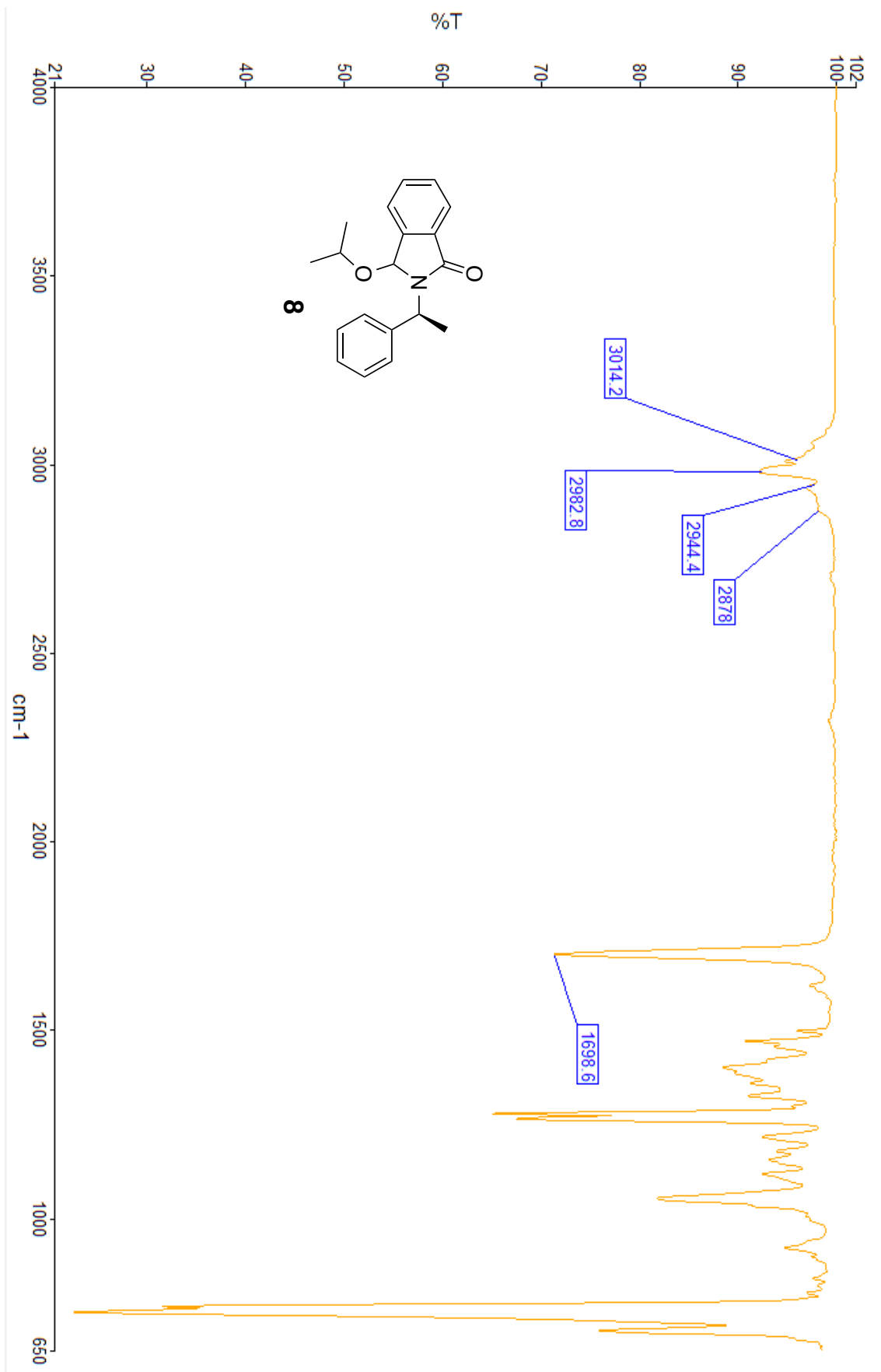




\section{3-(cyclopentyloxy)-2-((S)-1-phenylethyl)isoindolin-1-one. ${ }^{\text {a }} 8$}

Colorless oil (167 mg, 88\%); $\mathrm{R}_{\mathrm{f}}=0.48$ (hexane/ethyl acetate, 4:1); IR 3030, 2999, 2959, $2871,1697 \mathrm{~cm}^{-1}$ A mixture of two inseparable diastereomers $(\mathrm{dr}=3: 2){ }^{1} \mathrm{H} \mathrm{NMR}(500$ $\mathrm{MHz}, \mathrm{CDCl}_{3}$, major) $\delta 7.81-7.84(\mathrm{~m}, 1 \mathrm{H}), 7.25-7.55(\mathrm{~m}, 8 \mathrm{H}), 5.68(\mathrm{q}, J=7.5 \mathrm{~Hz}, 1 \mathrm{H}), 5.54$ (s, 1H), 3.91-3.93 (m, 1H), $1.81(\mathrm{~d}, J=7.0 \mathrm{~Hz}, 3 \mathrm{H}), 1.31-1.74(\mathrm{~m}, 8 \mathrm{H}) .{ }^{1} \mathrm{H}$ NMR $(500$ $\mathrm{MHz}, \mathrm{CDCl}_{3}$, minor) $\delta 7.81-7.84(\mathrm{~m}, 1 \mathrm{H}), 7.25-7.55(\mathrm{~m}, 8 \mathrm{H}), 5.81(\mathrm{~s}, 1 \mathrm{H}), 5.17(\mathrm{q}, J=7.0$ $\mathrm{Hz}, 1 \mathrm{H}), 3.78-3.80(\mathrm{~m}, 1 \mathrm{H}), 1.96(\mathrm{~d}, J=7.0 \mathrm{~Hz}, 3 \mathrm{H}) 1.31-1.74(\mathrm{~m}, 8 \mathrm{H}) . \mathrm{C}^{13} \mathrm{NMR}(500$ $\left.\mathrm{MHz}, \mathrm{CDCl}_{3}\right) \delta 168.1,167.8,142.6,142.2,140.5,132.9,132.3,131.7,129.7,129.6,128.6$, $128.4,127.7,127.6,127.3,127.2,126.6,123.8,123.8,123.5,123.3,86.0$ (major), 85.8 (minor), 51.7, 50.3, 33.7, 33.5, 33.4, 33.3, 23.6, 23.4, 23.2, 18.7, 18.3. HRMS (FTMS + p ESI) $m / z[\mathrm{M}+\mathrm{Na}]^{+}$; calculated for $\mathrm{C}_{21} \mathrm{H}_{23} \mathrm{O}_{2} \mathrm{NNa} 344.1621$, Found 344.1624. 


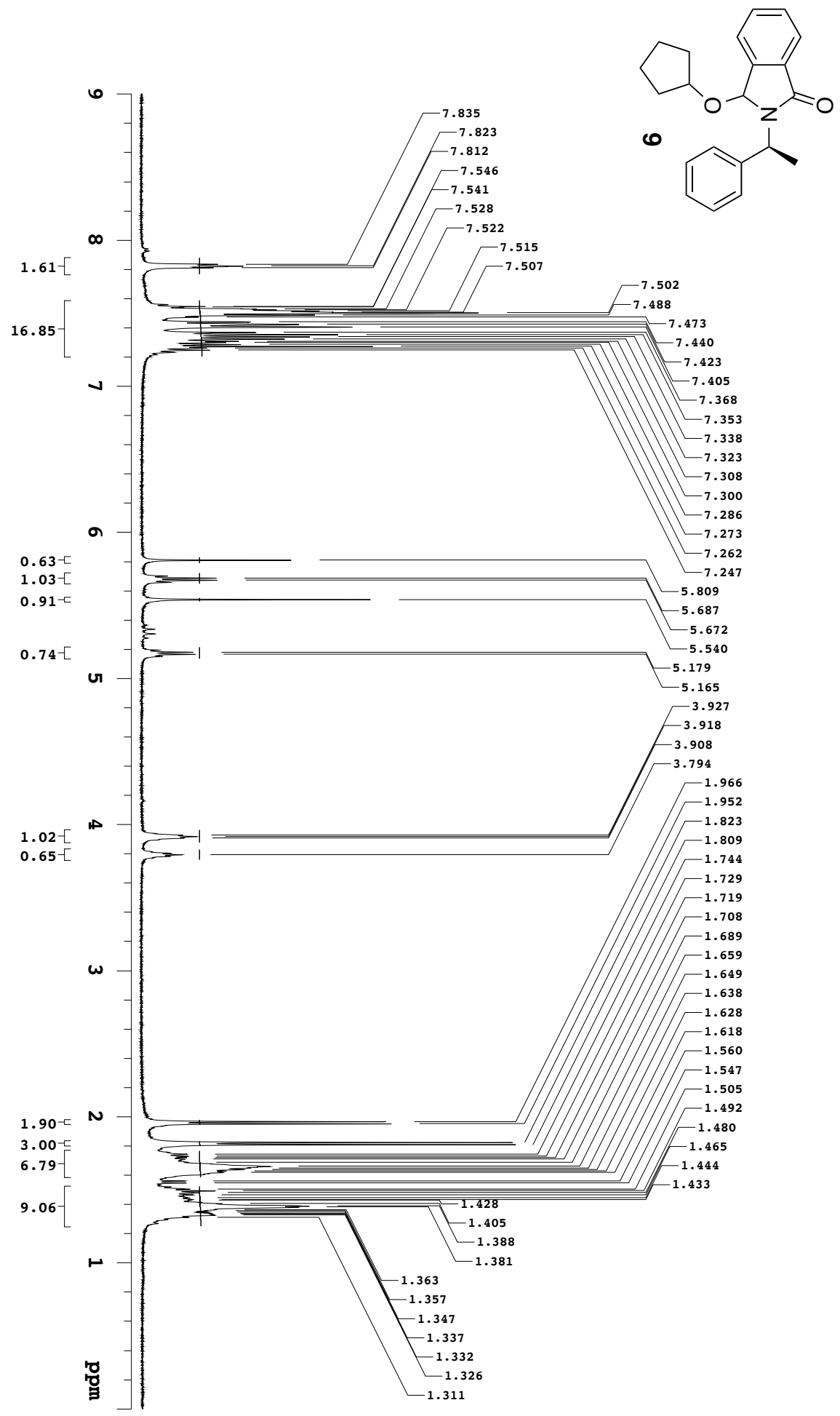




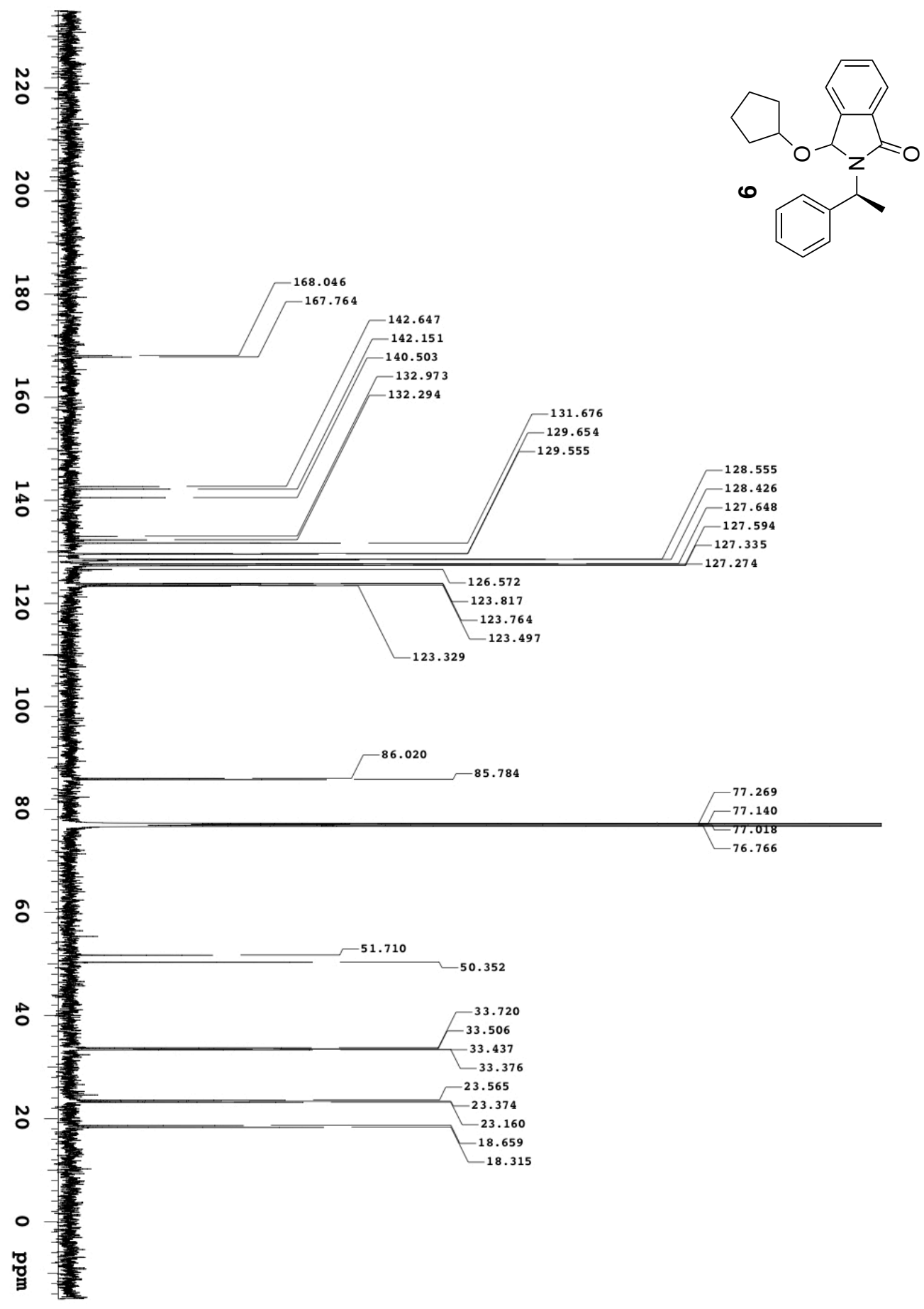




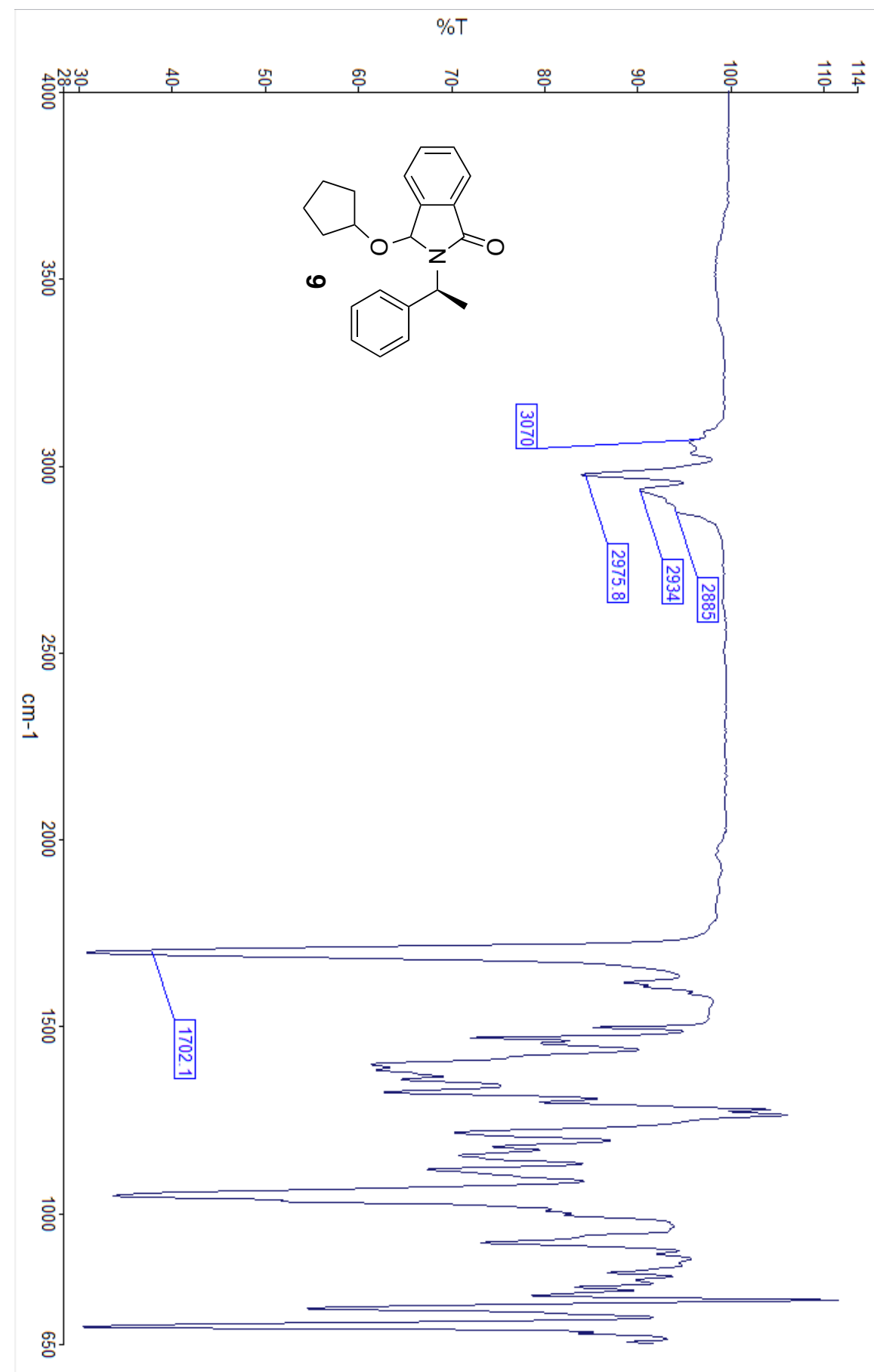




\section{3-(benzyloxy)-2-((S)-1-phenylethyl)isoindolin-1-one. ${ }^{\text {a }} 9$}

Colorless oil (108 mg, 80\%); $\mathrm{R}_{\mathrm{f}}=0.47$ (hexane/ethyl acetate, 4:1) IR 3031, 2928, 2886, $2875,1698 \mathrm{~cm}^{-1}$ A mixture of two inseparable diastereomers $(\mathrm{dr}=3: 2){ }^{1} \mathrm{H}$ NMR $(500$ $\mathrm{MHz}, \mathrm{CDCl}_{3}$, major) $\delta$ 7.88-7.89 (m, 1H), 7.21-7.60 (m, 12H), 6.92-6.94 (m, 1H), $5.79(\mathrm{~s}$, 1H), $5.73(\mathrm{q}, J=7.0 \mathrm{~Hz}, 1 \mathrm{H}), 4.32(\mathrm{~d}, J=11.0 \mathrm{~Hz}, 1 \mathrm{H}), 3.97(\mathrm{~d}, J=11.0 \mathrm{~Hz}, 1 \mathrm{H}), 1.84(\mathrm{~d}$, $J=7.0 \mathrm{~Hz}, 3 \mathrm{H}) .{ }^{1} \mathrm{H} \mathrm{NMR}\left(500 \mathrm{MHz}, \mathrm{CDCl}_{3}\right.$, minor) $\delta$ 7.88-7.89 (m, 1H), 7.21-7.60 (m, 12H), 6.92-6.94 (m, 1H), 6.19 (s, 1H), 5.47 (q, $J=7.5 \mathrm{~Hz}, 1 \mathrm{H}), 3.73(\mathrm{~d}, J=11.0 \mathrm{~Hz}, 1 \mathrm{H})$, $3.62(\mathrm{~d}, J=11.0 \mathrm{~Hz}, 1 \mathrm{H}), 1.91(\mathrm{~d}, J=7.0 \mathrm{~Hz}, 3 \mathrm{H}) . \mathrm{C}^{13} \mathrm{NMR}\left(500 \mathrm{MHz}, \mathrm{CDCl}_{3}\right) \delta 167.8$, $141.7,141.0,140.7,140.3,137.4,137.2,133.1,132.6,132.1,130.0,129.9,128.7,128.4$, $127.8,127.7,127.6,127.5,123.7,123.6,123.4,110.0,85.8$ (major), 85.6 (minor), 64.1, 63.9, 50.7, 50.6, 18.1, 17.5. HRMS (FTMS + p ESI) $m / z[\mathrm{M}+\mathrm{Na}]^{+}$; calculated for $\mathrm{C}_{23} \mathrm{H}_{21} \mathrm{O}_{2} \mathrm{NNa} 366.1465$, Found 366.1469 


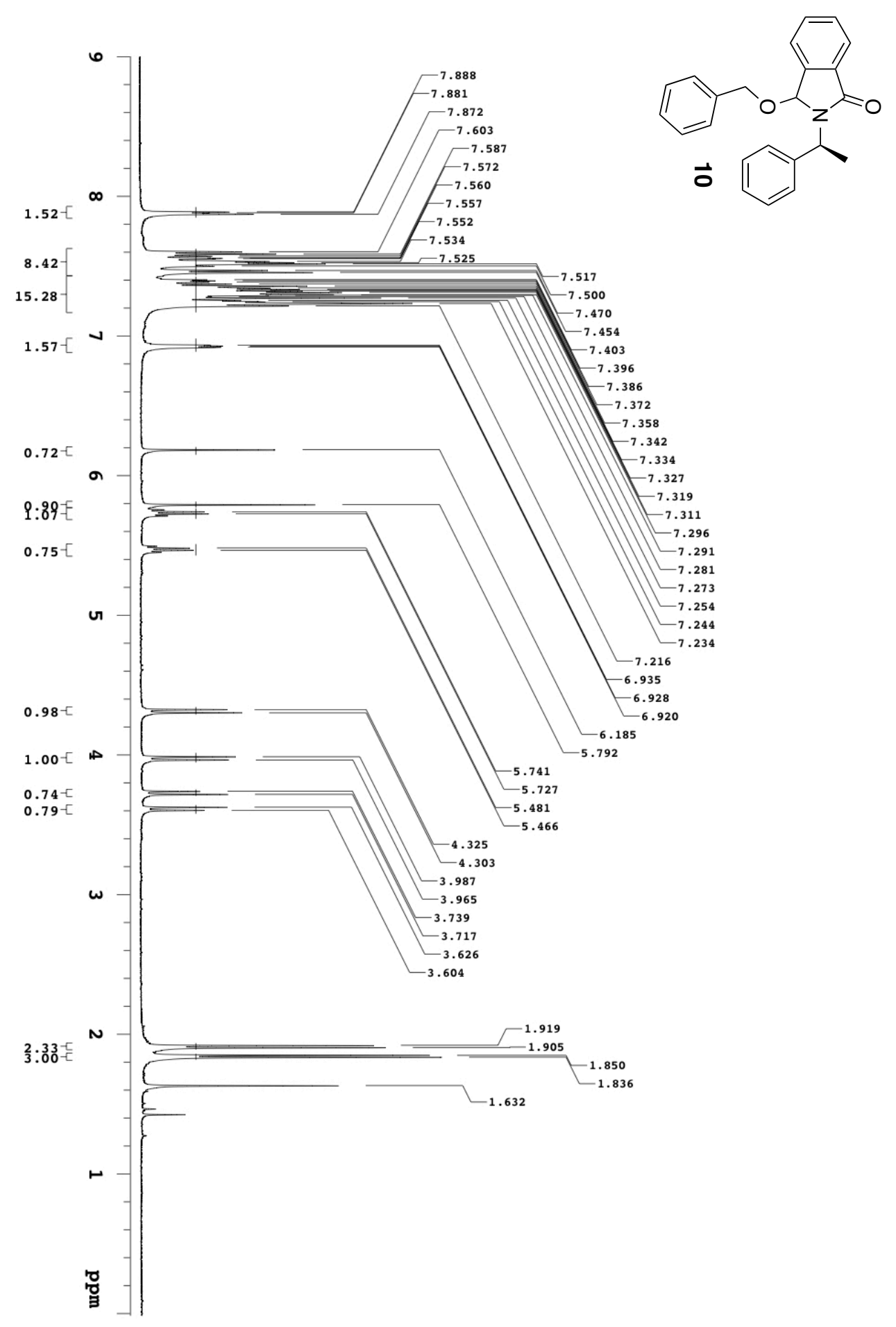




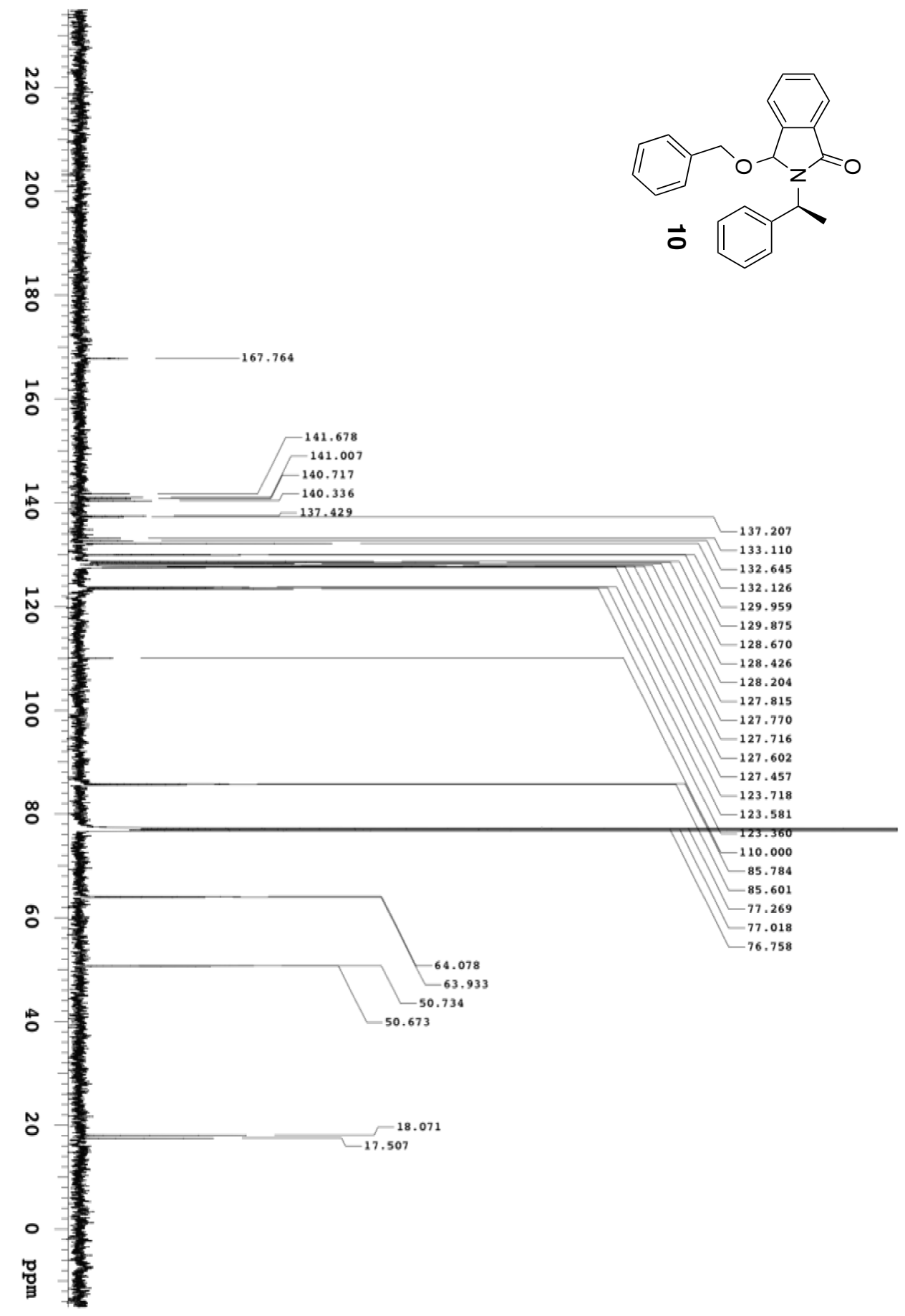




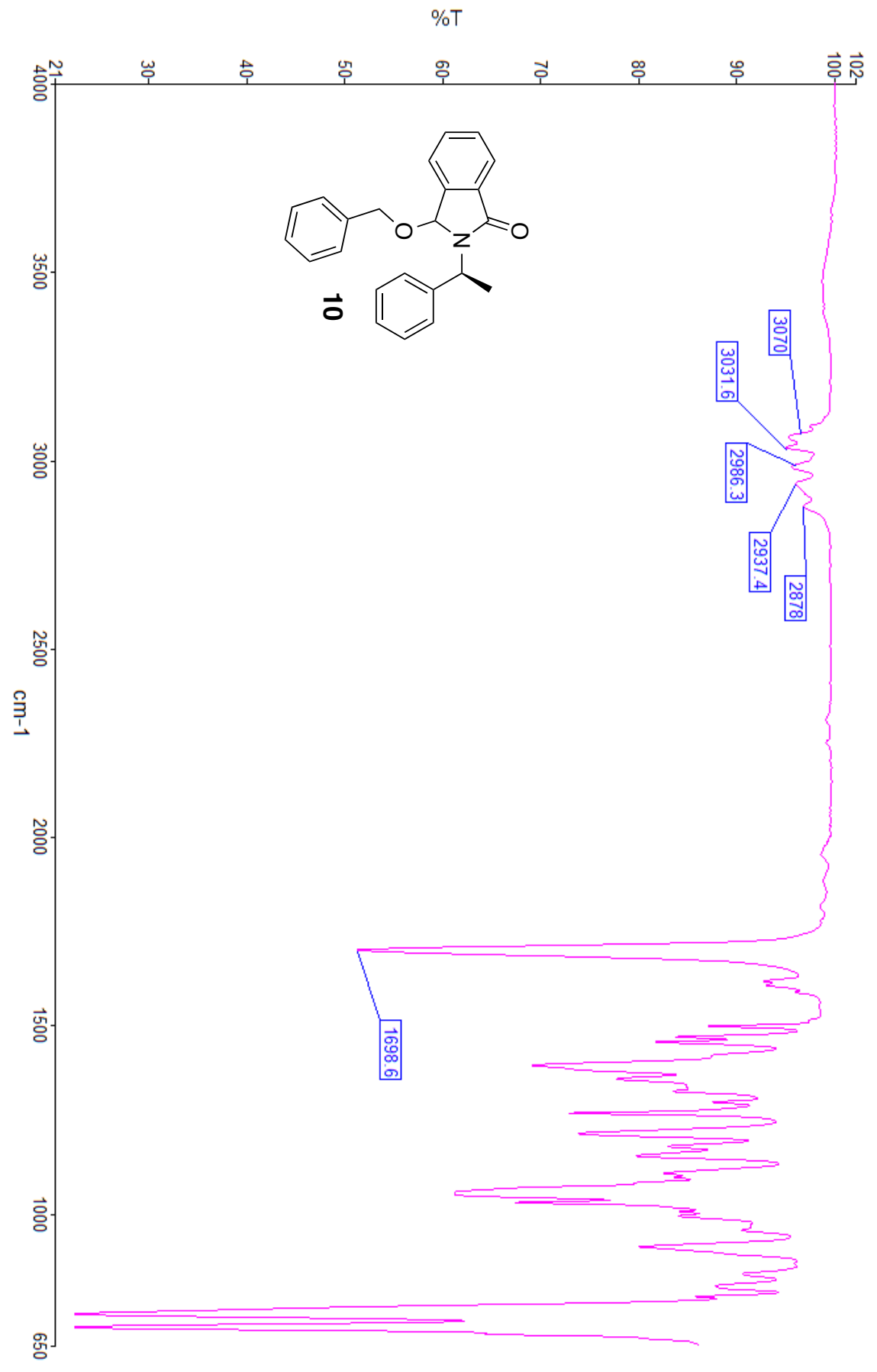




\section{3-phenethoxy-2-((S)-1-phenylethyl)isoindolin-1-one. ${ }^{\text {b }} 10$}

Colorless oil (193 mg, 91\%); $\mathrm{R}_{\mathrm{f}}=0.67$ (hexane/ethyl acetate, 4:1); IR 3066, 3028, 2937, $2875,1698 \mathrm{~cm}^{-1}$ A mixture of two inseparable diastereomers $(\mathrm{dr}=3: 1.6){ }^{1} \mathrm{H} \mathrm{NMR}(500$ $\mathrm{MHz}, \mathrm{CDCl}_{3}$, major) $\delta$ 7.81-7.82 (m, 1H), 7.11-7.59 (m, 12H), $6.94(\mathrm{~d}, J=8.0 \mathrm{~Hz}, 1 \mathrm{H})$, $5.64(\mathrm{q}, J=7.0 \mathrm{~Hz}, 1 \mathrm{H}), 5.61(\mathrm{~s}, 1 \mathrm{H}) 3.47(\mathrm{dd}, J=16.0,7.0 \mathrm{~Hz}, 1 \mathrm{H}), 3.09$ (dd, $J=16.0$, $7.0 \mathrm{~Hz}, 1 \mathrm{H}), 2.79-2.88(\mathrm{~m}, 2 \mathrm{H}), 1.72(\mathrm{~d}, J=7.5 \mathrm{~Hz}, 3 \mathrm{H}) .{ }^{1} \mathrm{H}$ NMR $\left(500 \mathrm{MHz}, \mathrm{CDCl}_{3}\right.$, minor) $\delta 7.81-7.82(\mathrm{~m}, 1 \mathrm{H}), 7.11-7.59(\mathrm{~m}, 13 \mathrm{H}), 6.03(\mathrm{~s}, 1 \mathrm{H}), 5.35(\mathrm{q}, J=7.5 \mathrm{~Hz}, 1 \mathrm{H})$, 2,79-2.88 (m, 2H) 2.40-2.46 (m, 1H), 2.28-2.32(m, 1H), $1.85(\mathrm{~d}, J=7.0 \mathrm{~Hz}, 3 \mathrm{H}) .{ }^{13} \mathrm{CNMR}$ $\left(125 \mathrm{MHz}, \mathrm{CDCl}_{3}\right) \delta 167.7,141.0,140,4$ 138.40, 132.6, 131.9, 129.8, 129.7, 129.0, 128.9, $128.6,128.4,128.2,127.8,127.7,127.6,127.4,126.4,126.3,123.6,123.5,123.2,85.7$ (major), 85.3 (minor), 62.9, 62.5, 50.7, 50.3, 26.1, 25.5, 17.9, 17.4. HRMS (FTMS + p ESI) $m / z[\mathrm{M}+\mathrm{Na}]^{+}$; calculated for $\mathrm{C}_{24} \mathrm{H}_{23} \mathrm{O}_{2} \mathrm{NNa} 380.1621$, Found 380.1624. 


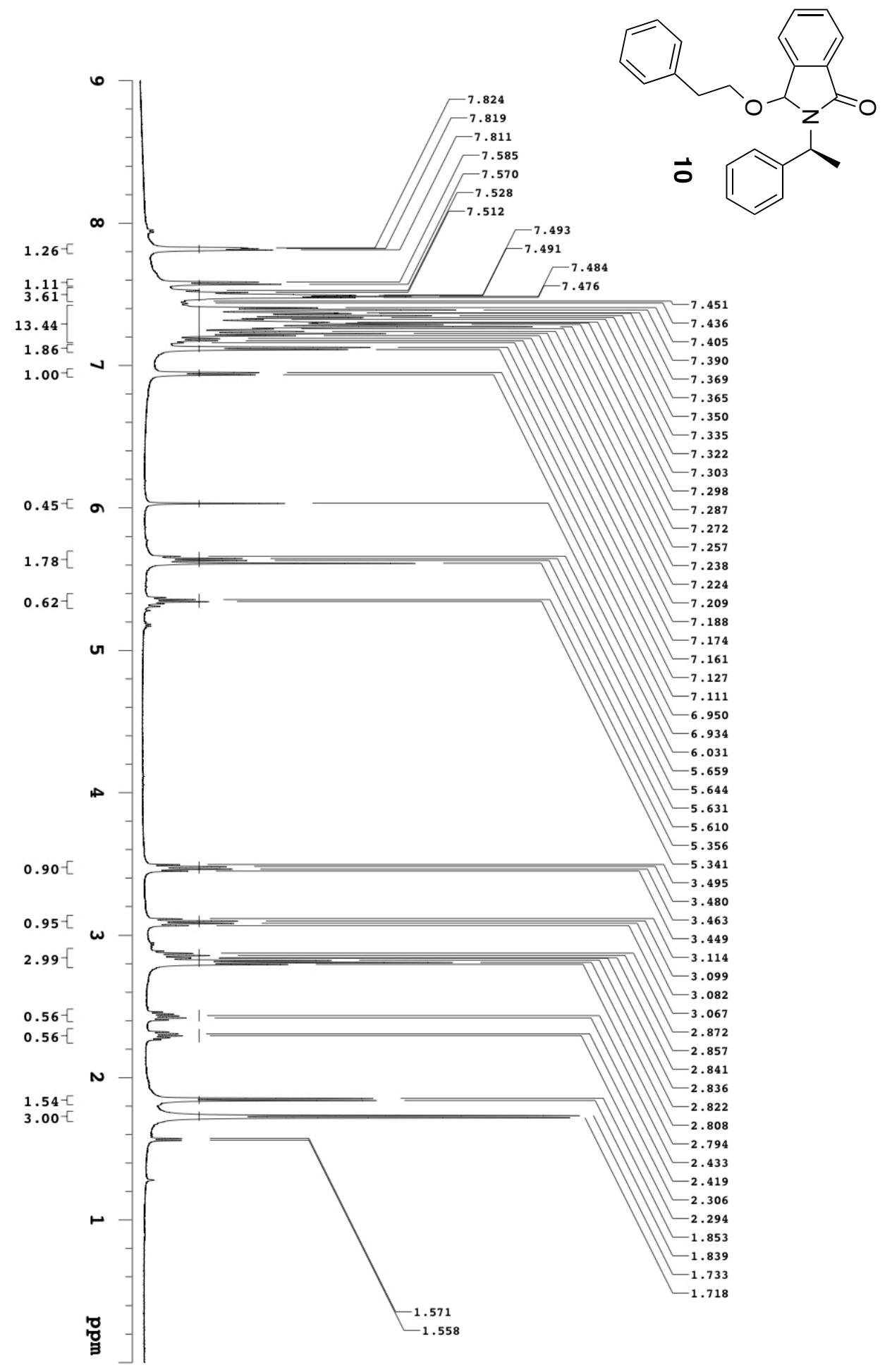




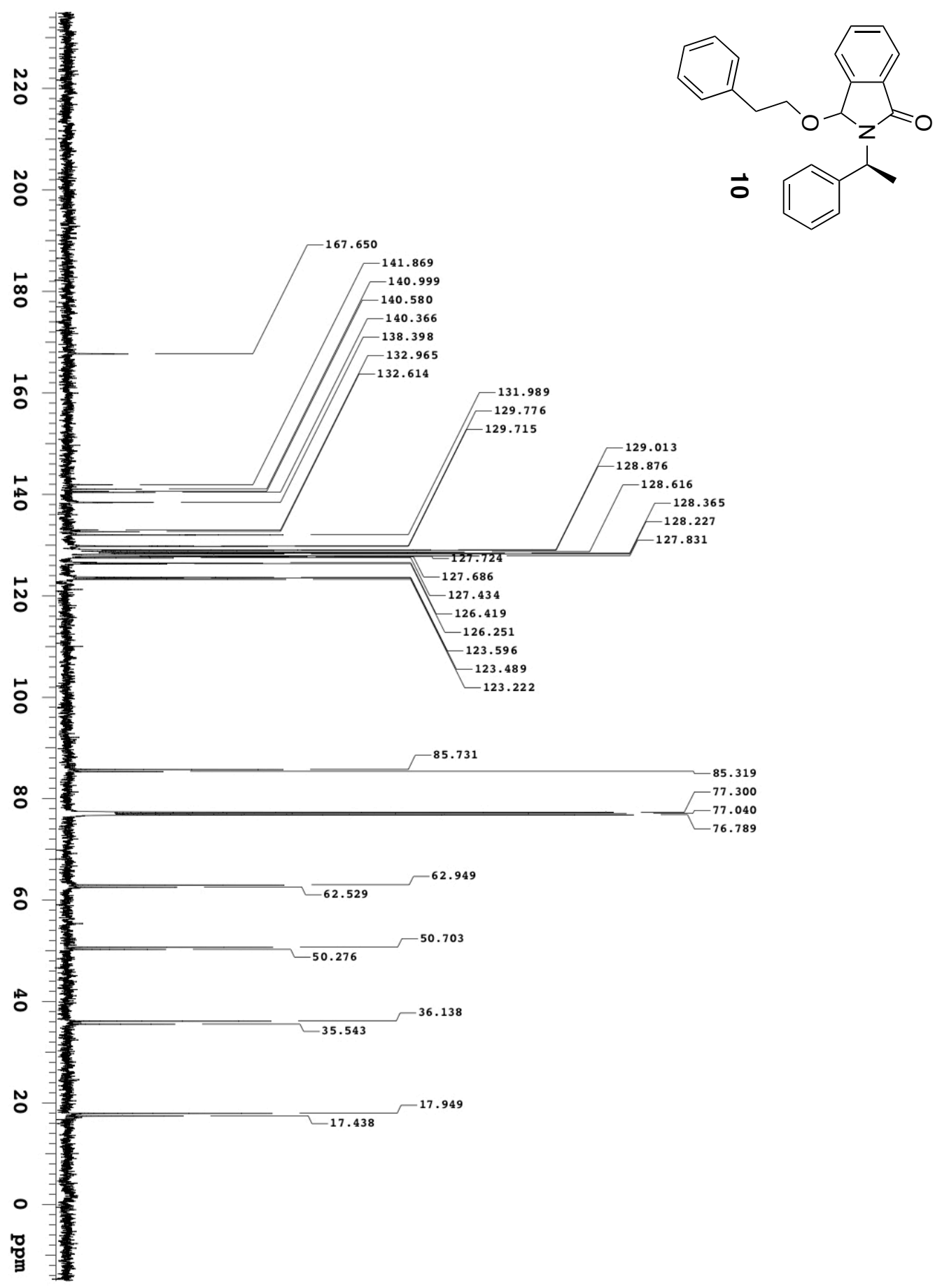




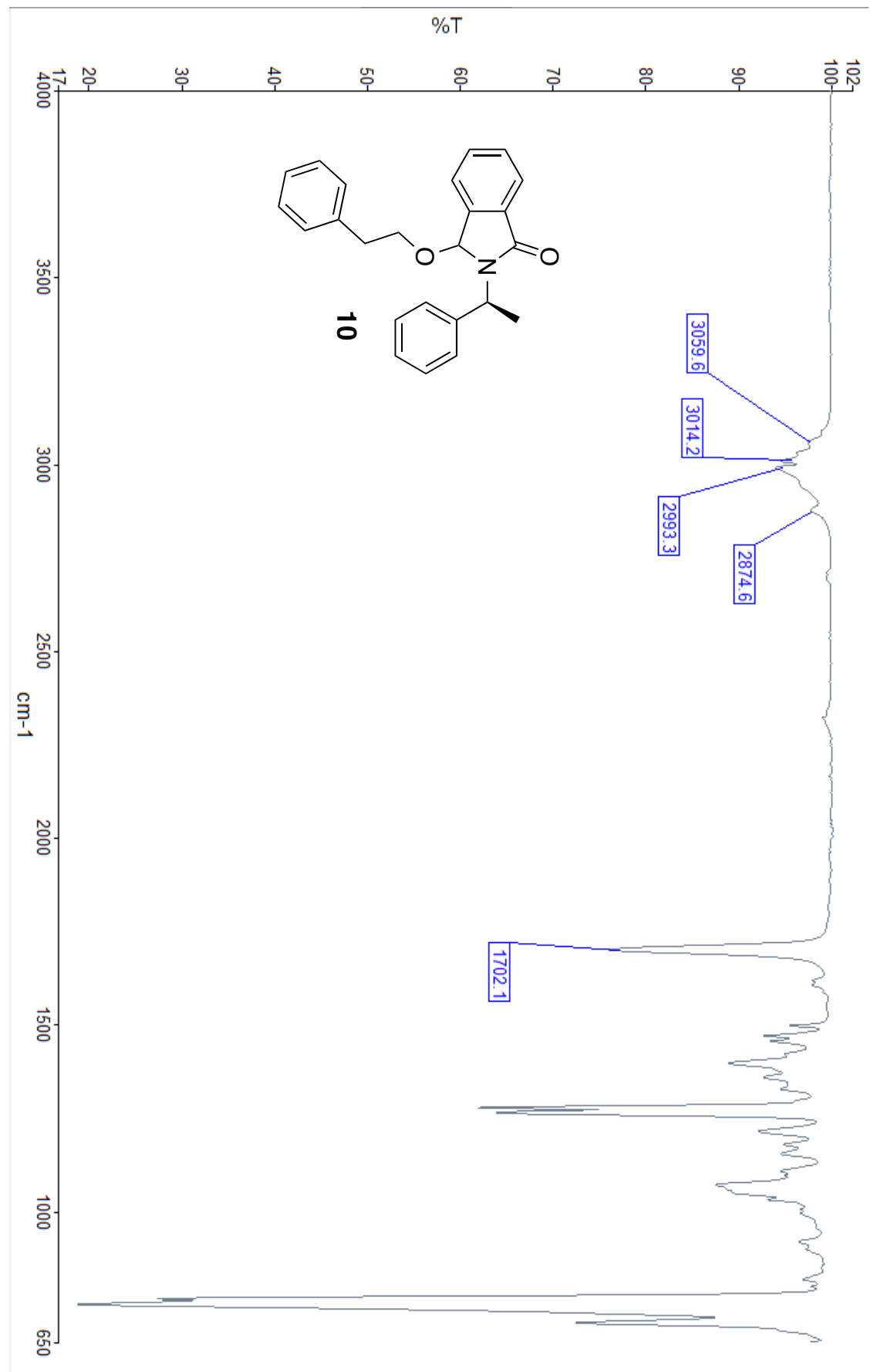




\section{3-((4-methoxybenzyl)oxy)-2-((S)-1-phenylethyl)isoindolin-1-one. ${ }^{b} 11$}

Colorless oil (88 mg, 60\%); $\mathrm{R}_{\mathrm{f}}=0.37$ (hexane/ethyl acetate, 4:1) IR 3063, 2989, 2941, $2843,1702 \mathrm{~cm}^{-1}$ A mixture of two inseparable diastereomers $(\mathrm{dr}=3: 2){ }^{1} \mathrm{H}$ NMR $(500$ $\mathrm{MHz}, \mathrm{CDCl}_{3}$, major) $\delta$ 7.87-7.88 (m, 1H), 7.14-7.60 (m, 8H), 6.77-6.83 (m, 3H), 6.50-6.53 $(\mathrm{m}, 1 \mathrm{H}), 5.79(\mathrm{~s}, 1 \mathrm{H}) 5.73(\mathrm{q}, J=8.0 \mathrm{~Hz}, 1 \mathrm{H}), 4.29(\mathrm{~d}, J=11.5 \mathrm{~Hz}, 1 \mathrm{H}), 3.95(\mathrm{~d}, J=11.5$ $\mathrm{Hz}, 1 \mathrm{H}), 3.81$ (s, 3H), $1.84(\mathrm{~d}, J=7.0 \mathrm{~Hz}, 3 \mathrm{H}) .{ }^{1} \mathrm{HNMR}\left(500 \mathrm{MHz}, \mathrm{CDCl}_{3}\right.$, minor) $\delta 7.87-$ $7.88(\mathrm{~m}, 1 \mathrm{H}), 7.14-7.60(\mathrm{~m}, 8 \mathrm{H}), 6.77-6.83(\mathrm{~m}, 3 \mathrm{H}), 6.50-6.53(\mathrm{~m}, 1 \mathrm{H}), 6.19(\mathrm{~s}, 1 \mathrm{H}), 5.47$ $(\mathrm{q}, \mathrm{J}=7.0 \mathrm{~Hz}, 1 \mathrm{H}), 3.77(\mathrm{~s}, 3 \mathrm{H}), 3.69(\mathrm{~d}, \mathrm{~J}=11.0 \mathrm{~Hz}, 1 \mathrm{H}), 3.57(\mathrm{~d}, \mathrm{~J}=11.0 \mathrm{~Hz}, 1 \mathrm{H}), 1.91$ $(\mathrm{d}, \mathrm{J}=7.0 \mathrm{~Hz}, 3 \mathrm{H}) .{ }^{13} \mathrm{CNMR}\left(125 \mathrm{MHz}, \mathrm{CDCl}_{3}\right) \delta 167.5,159.7,141.7,141.0,140.7,140.3$, $139.0,138.8,133.1,132.6,132.1123 .0,129.5,129.2,128.7,128.4,127.8,127.7,127.5$, 123.7, 123.6, 123.4, 120.0, 119.8, 113.2, 113.1, 113.0, 85.8 (major), 85.6 (minor), 63.9, 63.8, 55.2, 30.7, 18.1, 17.5. HRMS (FTMS + p ESI) $m / z[\mathrm{M}+\mathrm{Na}]^{+}$; calculated for $\mathrm{C}_{24} \mathrm{H}_{23} \mathrm{O}_{3} \mathrm{NNa} 396.1570$, Found 396.1573. 


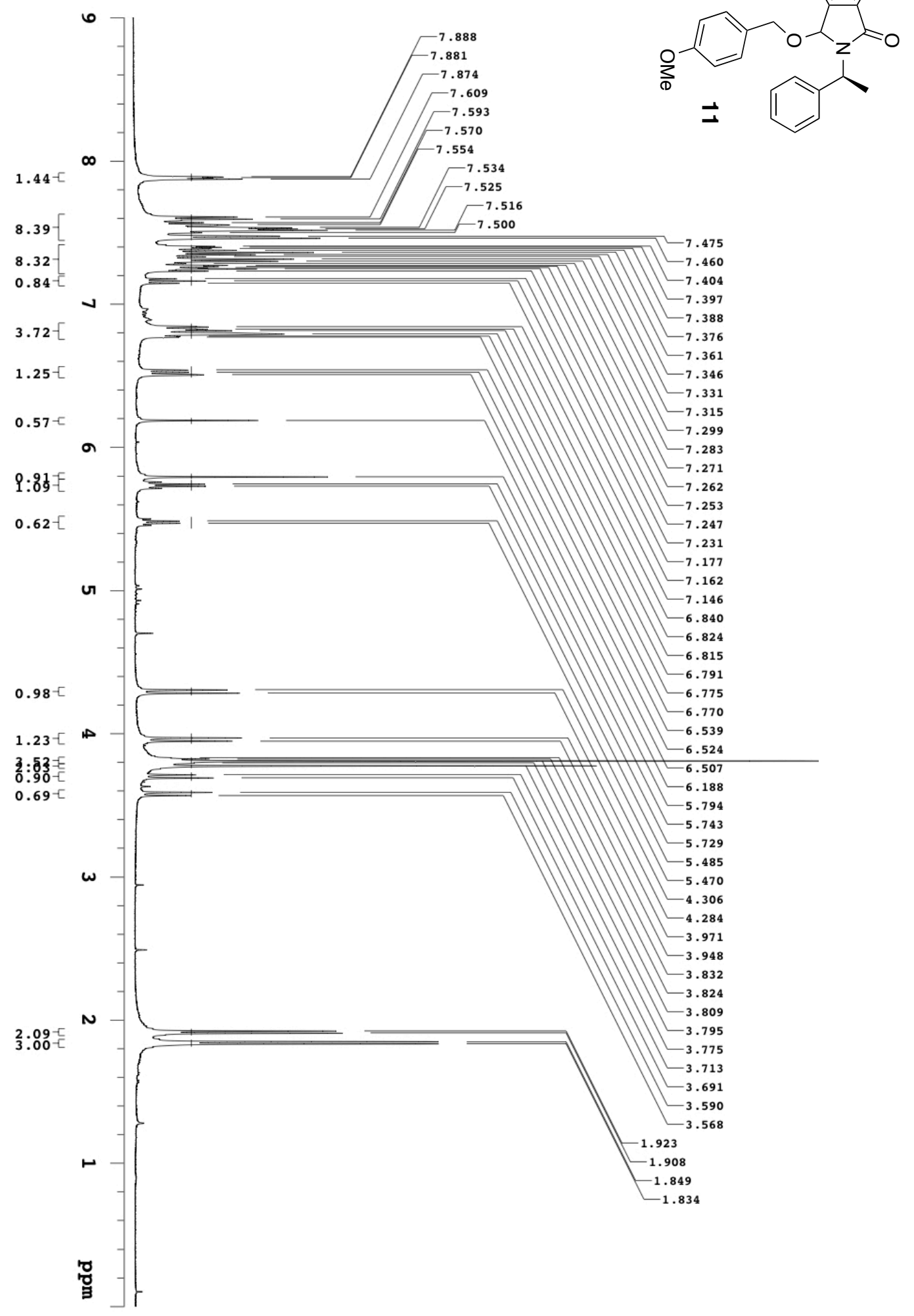




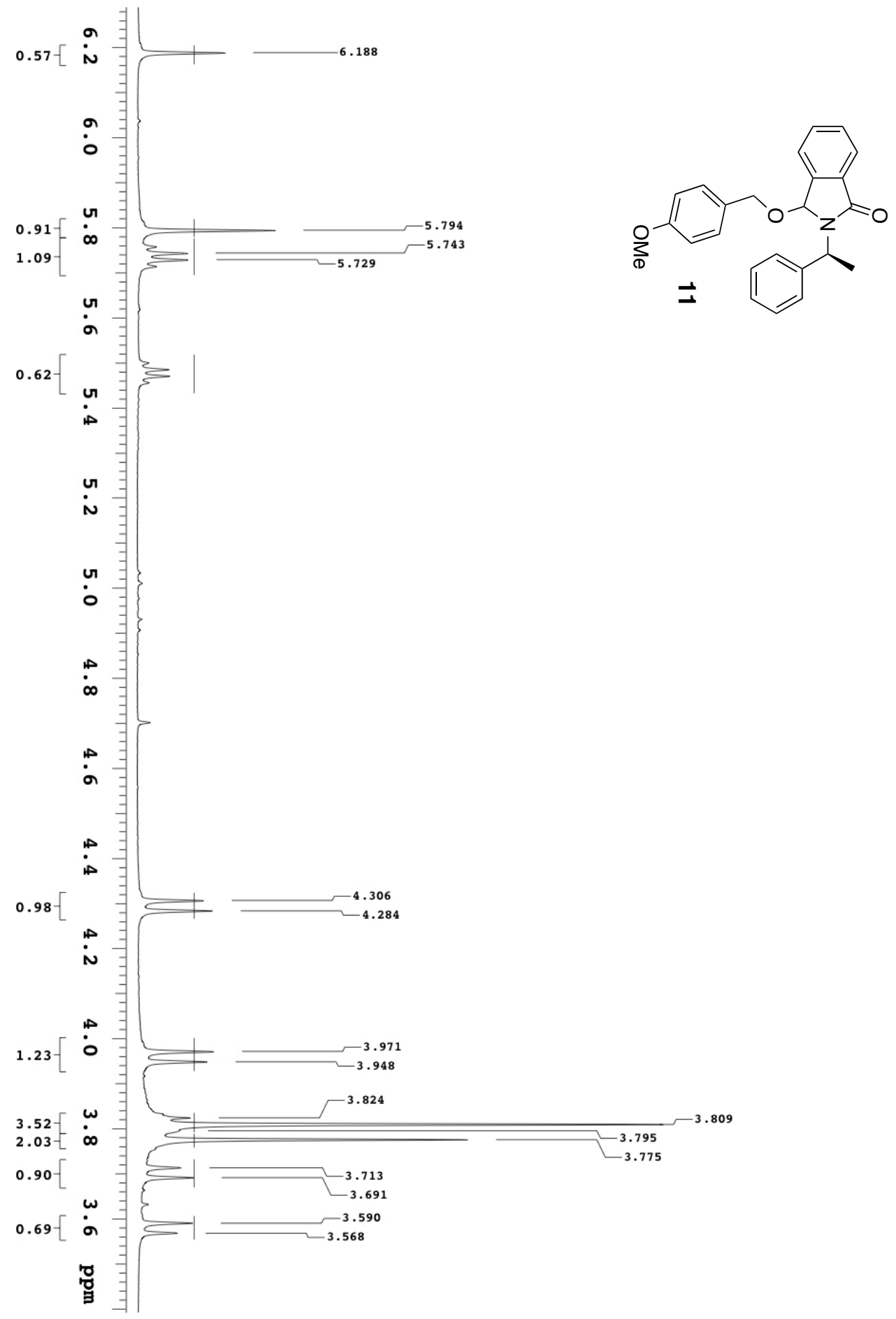




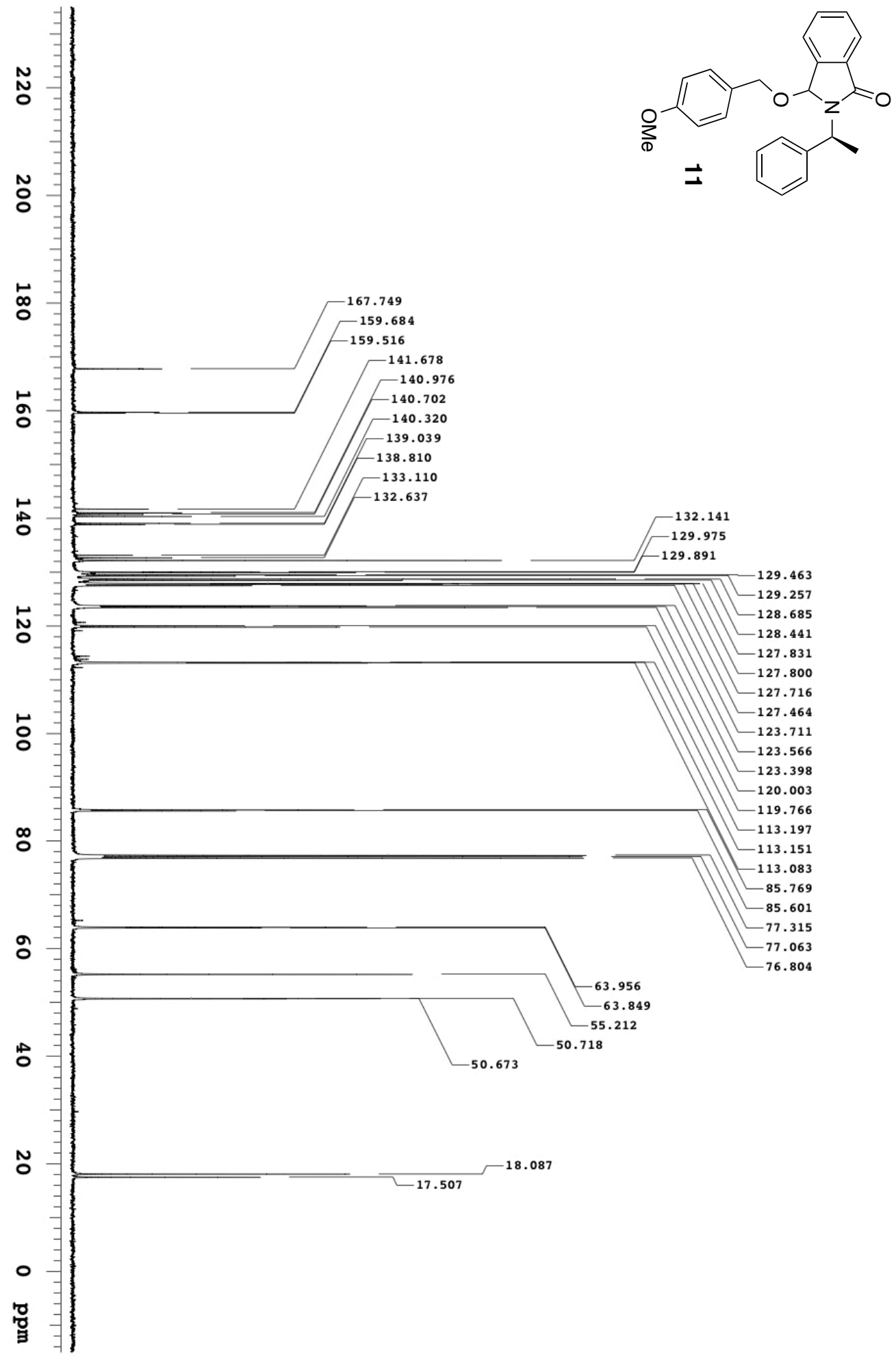




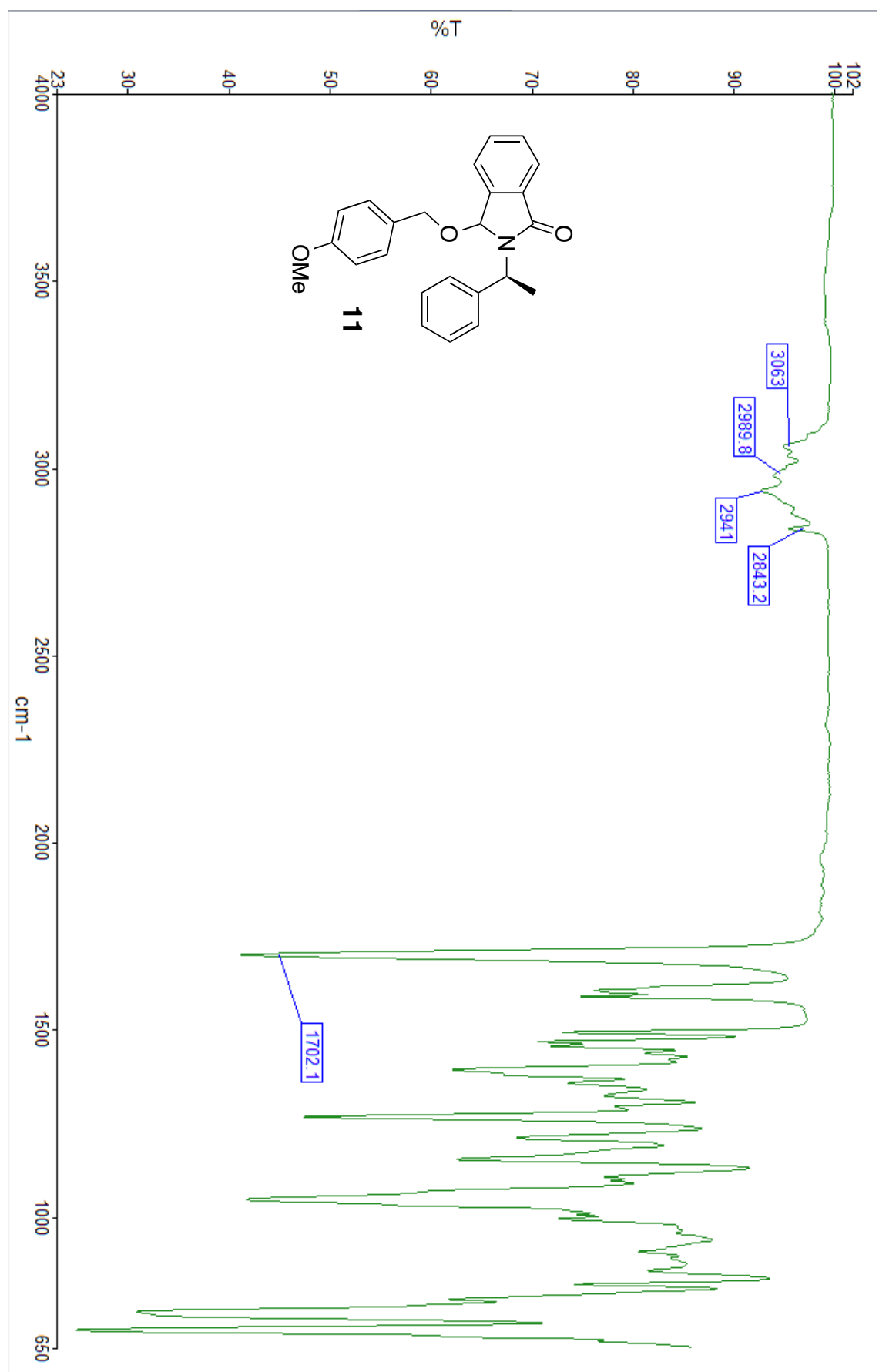




\section{3-((2-bromobenzyl)oxy)-2-((S)-1-phenylethyl)isoindolin-1-one. ${ }^{\mathrm{b}} 12$}

Colorless oil (118 mg, 71\%); $\mathrm{R}_{\mathrm{f}}=0.29$ (hexane/ethyl acetate, 9:1) IR 3077, 3035, 2984, $2937,1686 \mathrm{~cm}^{-1}$ A mixture of two inseparable diastereomers $(\mathrm{dr}=3: 2){ }^{1} \mathrm{H}$ NMR (500 $\mathrm{MHz}, \mathrm{CDCl}_{3}$, major) $\delta$ 7.88-7.90 (m, 1H), 7.10-7.56 (m, 12H), $5.89(\mathrm{~s}, 1 \mathrm{H}), 5.75(\mathrm{q}, J=$ $7.0 \mathrm{~Hz}, 1 \mathrm{H}), 4.40(\mathrm{~d}, J=12.0 \mathrm{~Hz}, 1 \mathrm{H}), 4.07$ (d, $J=12.5 \mathrm{~Hz}, 1 \mathrm{H}), 1.83(\mathrm{~d}, J=7.5 \mathrm{~Hz}, 3 \mathrm{H})$. ${ }^{1} \mathrm{HNMR}\left(500 \mathrm{MHz}, \mathrm{CDCl}_{3}\right.$, minor) $\delta$ 7.88-7.90 (m, 1H), 7.10- $7.56(\mathrm{~m}, 11 \mathrm{H}) 5.47$ (q, $J=$ $7.0 \mathrm{~Hz}, 1 \mathrm{H}), 4.06$ (d, $J=12.5 \mathrm{~Hz}, 1 \mathrm{H}), 3.87$ (d, $J=12.5 \mathrm{~Hz}, 1 \mathrm{H}), 1.92(\mathrm{~d}, J=7.5 \mathrm{~Hz}, 3 \mathrm{H})$. ${ }^{13} \mathrm{C} \mathrm{NMR}\left(125 \mathrm{MHz}, \mathrm{CDCl}_{3}\right) \delta 167.9,167.8,141.6,140.7,140.4,140.3,136.9,136.7$, $132.9,132.5,132.3,132.2,132.1,130.1,130.0,129.4,129.2,129.1,128.9,128.7,128.4$, $127.8,127.5,127.4,127.3,127.1,123.8,123.6,123.5,123.4,122.8,122.7,85.7$ (major), 85.5 (minor), 63.7, 63.6, 50.7, 50.6, 18.1, 17.6. HRMS (FTMS + p ESI) $m / z[\mathrm{M}+\mathrm{Na}]^{+}$; calculated for $\mathrm{C}_{23} \mathrm{H}_{20} \mathrm{O}_{2} \mathrm{NBrNa} 444.0570$, Found 444.0572. 


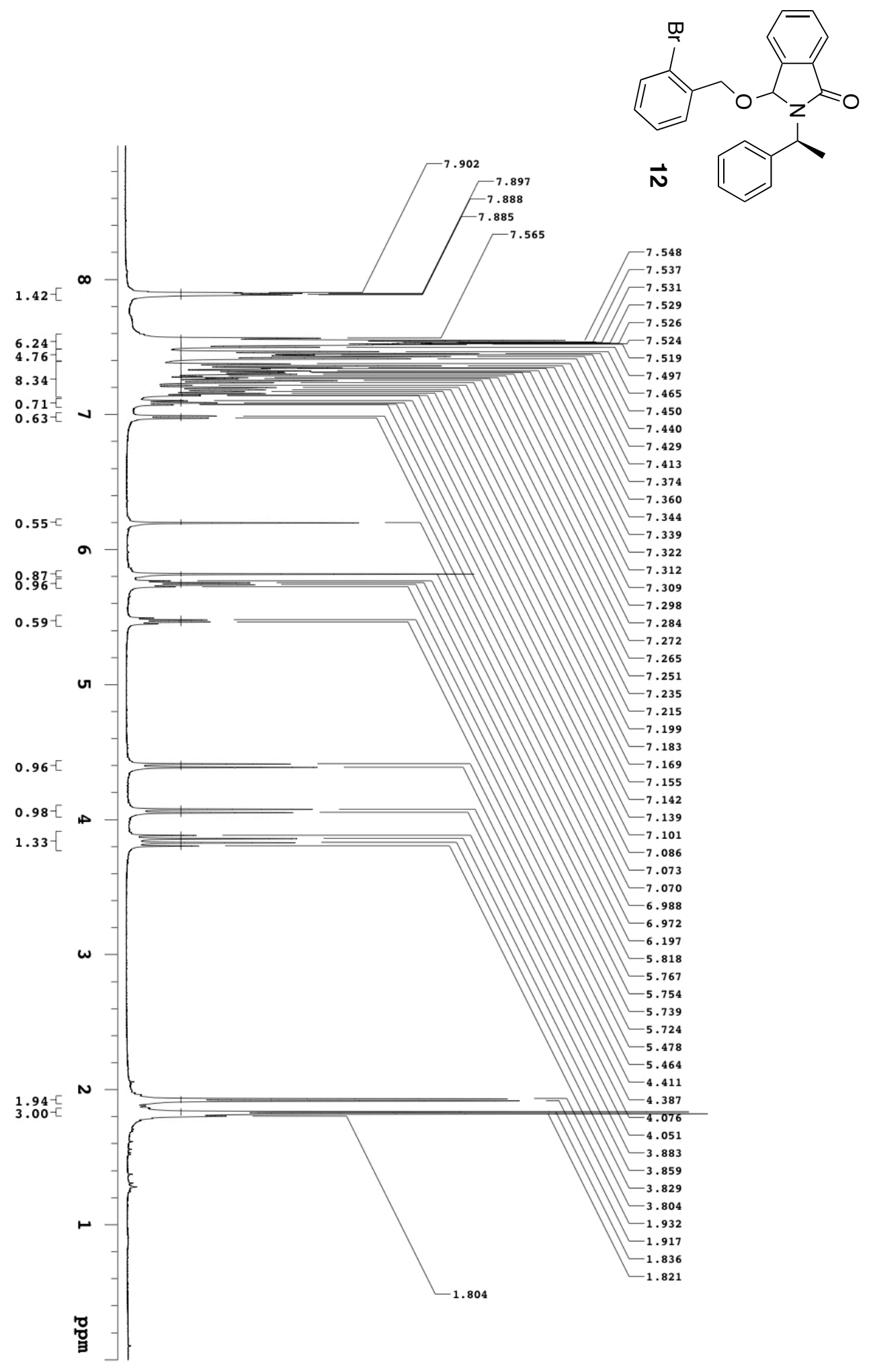




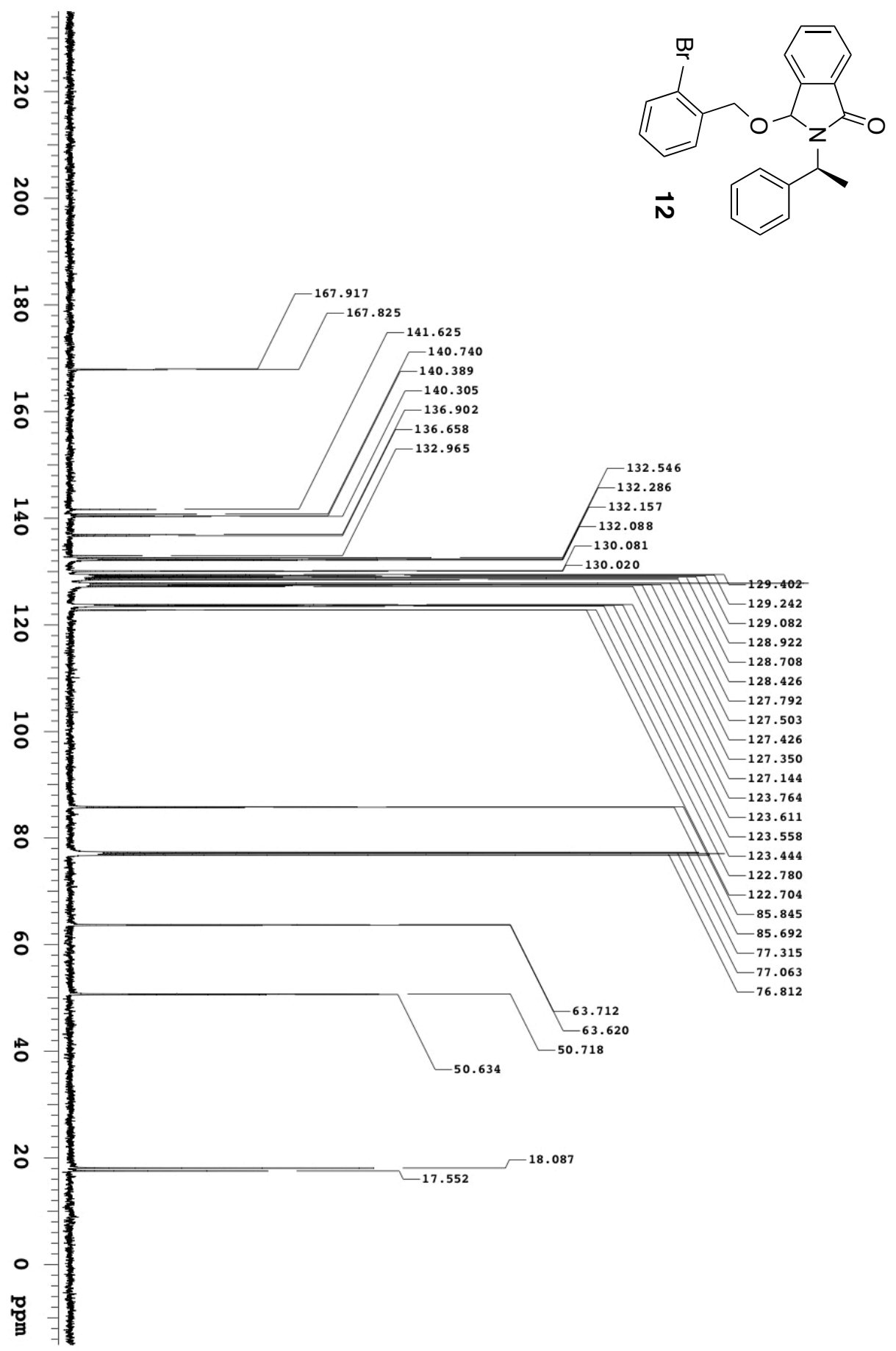




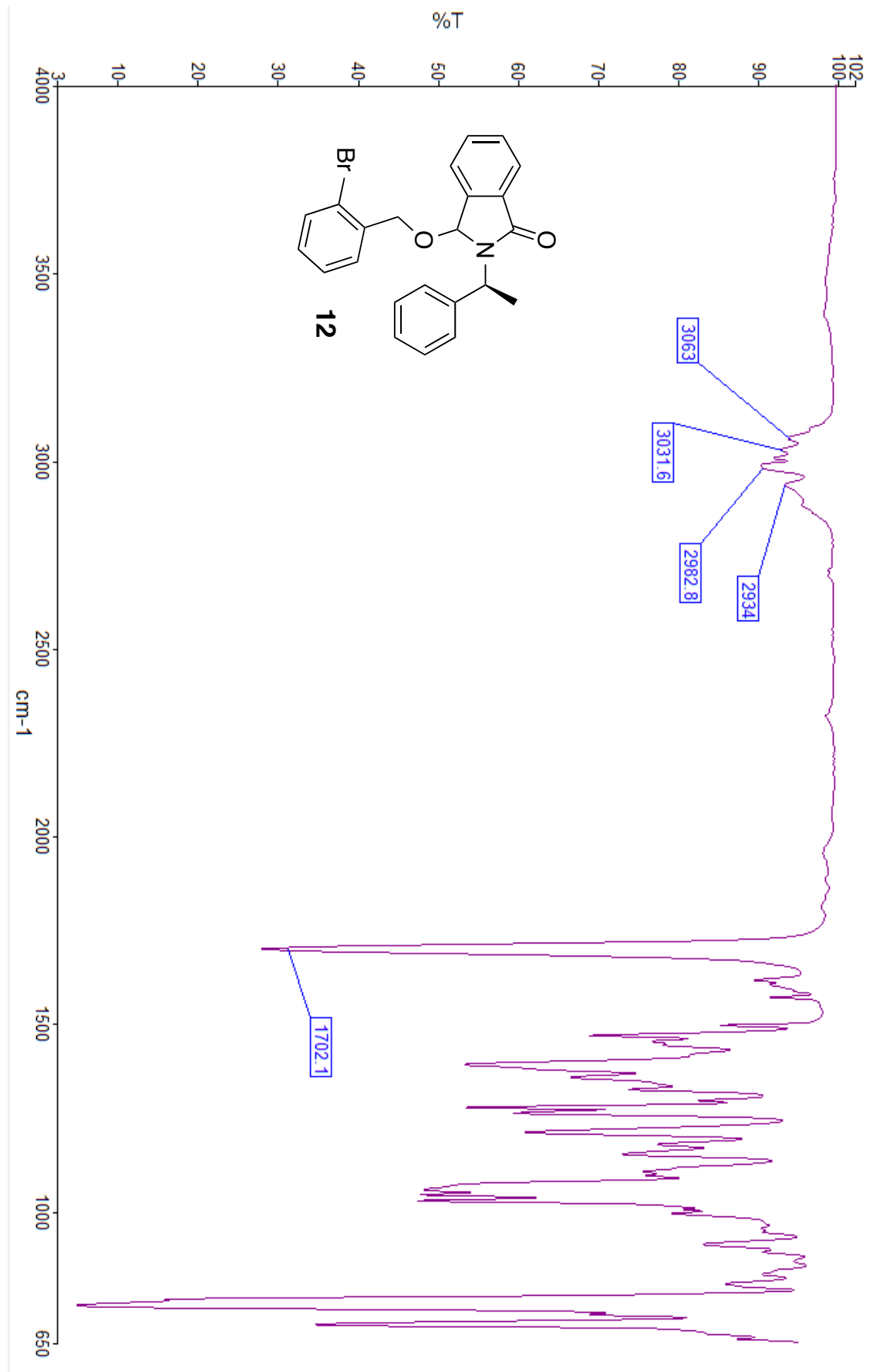




\section{2-((S)-1-phenylethyl)-3-(2,2,2-trichloroethoxy)isoindolin-1-one. ${ }^{\mathrm{b}} 13$}

Colorless oil (129 mg, 85\%); $\mathrm{R}_{\mathrm{f}}=0.47$ (hexane/ethyl acetate, 2:1) IR 3046, 3035, 2980, 2936, $1677 \mathrm{~cm}^{-1}$ A mixture of two inseparable diastereomers $(\mathrm{dr}=3: 1){ }^{1} \mathrm{H}$ NMR $(500$ $\mathrm{MHz}, \mathrm{CDCl}_{3}$, major) $\delta$ 7.87-7.88 (m, 1H), 7.27-7.62 (m, 8H), $5.88(\mathrm{~s}, 1 \mathrm{H}), 5.72(\mathrm{q}, J=7.5$ $\mathrm{Hz}, 1 \mathrm{H}), 3.94$ (d, $J=10.5 \mathrm{~Hz}, 1 \mathrm{H}), 3.44$ (d, $J=10.5 \mathrm{~Hz}, 1 \mathrm{H}), 1.89$ (d, $J=7.0 \mathrm{~Hz}, 3 \mathrm{H}) .{ }^{1} \mathrm{H}$ NMR (500 MHz, $\mathrm{CDCl}_{3}$, minor) $\delta$ 7.87-7.88 (m, 1H), 7.27-7.62 (m, 8H), $6.24(\mathrm{~s}, 1 \mathrm{H}), 5.48$ $(\mathrm{q}, J=7.5 \mathrm{~Hz}, 1 \mathrm{H}), 3.18(\mathrm{~d}, J=10.5 \mathrm{~Hz}, 1 \mathrm{H}), 3.08(\mathrm{~d}, J=10.5 \mathrm{~Hz}, 1 \mathrm{H}), 1.93(\mathrm{~d}, J=7.0$ $\mathrm{Hz}, 3 \mathrm{H}) .{ }^{13} \mathrm{C} \mathrm{NMR}\left(125 \mathrm{MHz}, \mathrm{CDCl}_{3}\right) \delta 167.6,141.1,139.9,139.5,139.1,132.9,132.7$, $132.5130 .6,130.5,128.8,128.7,128.0,127.7,127.6,124.0,123.9,123.7,95.9,85.7$ (major), 85.5 (minor), 74.2, 73.9, 50.9, 18.0, 17.4. HRMS (FTMS + p ESI) $m / z[\mathrm{M}+\mathrm{Na}]^{+}$; calculated for $\mathrm{C}_{18} \mathrm{H}_{16} \mathrm{O}_{2} \mathrm{NCl}_{3} \mathrm{Na} 406.0139$, Found 406.0142. 


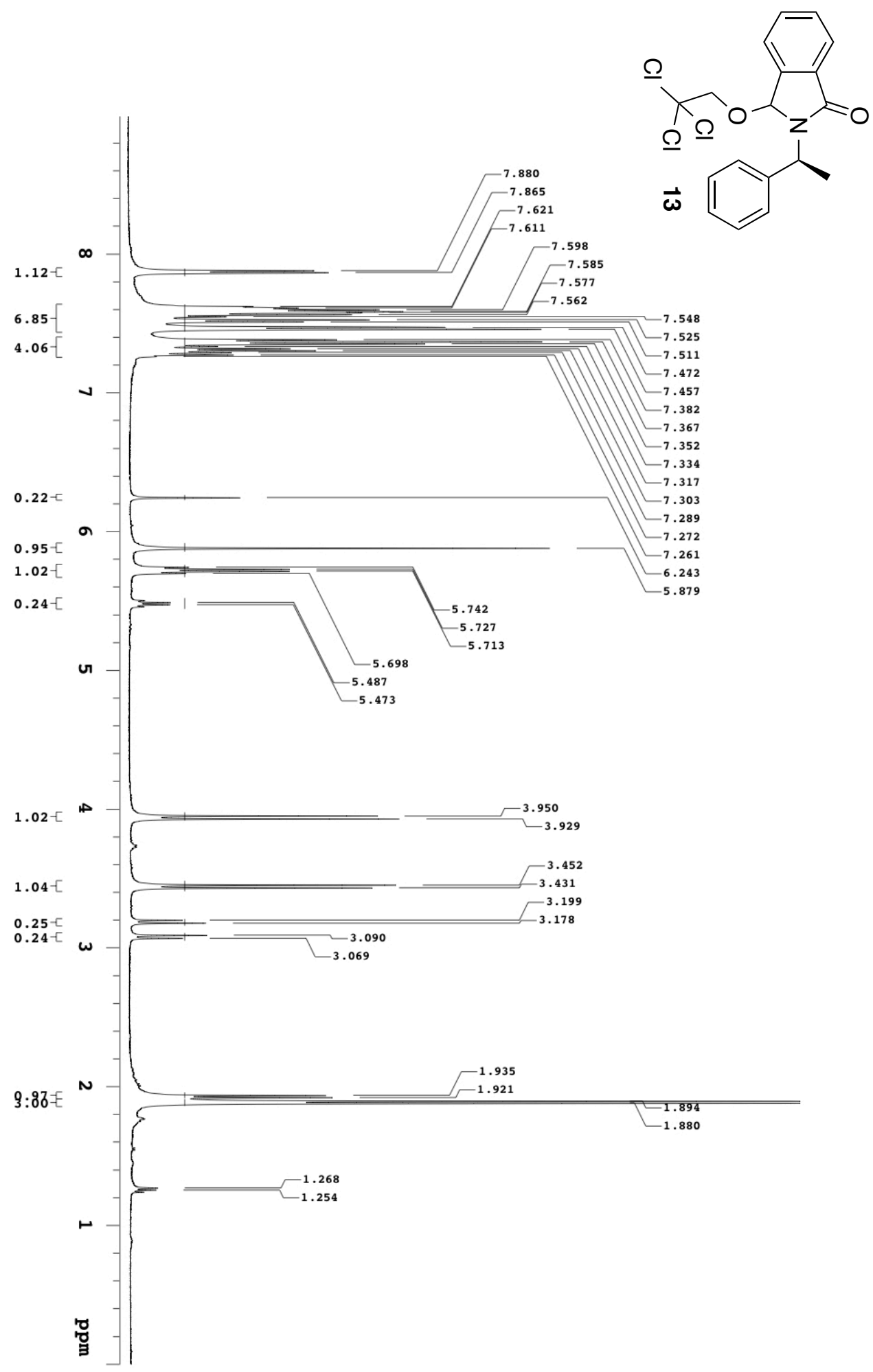




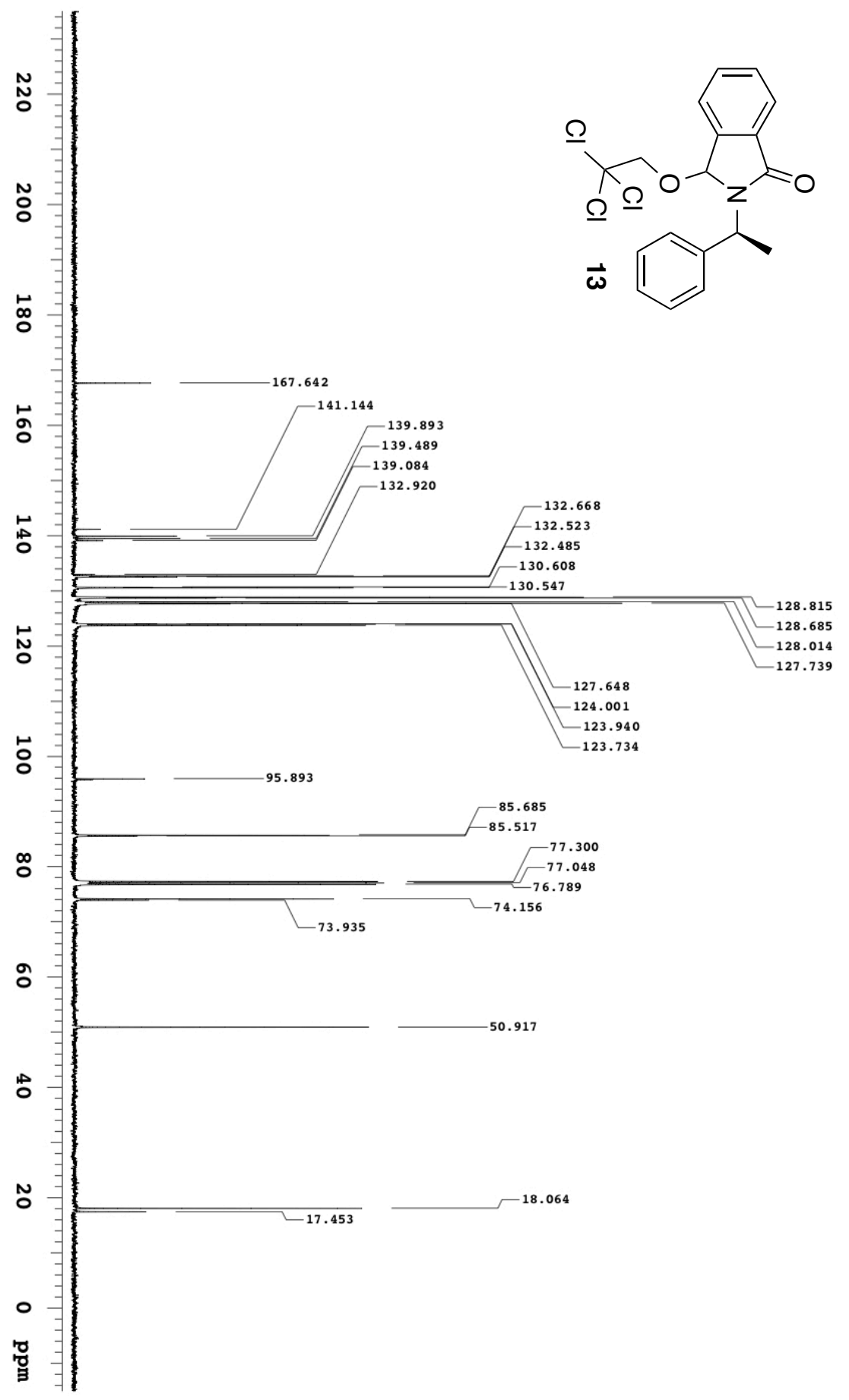




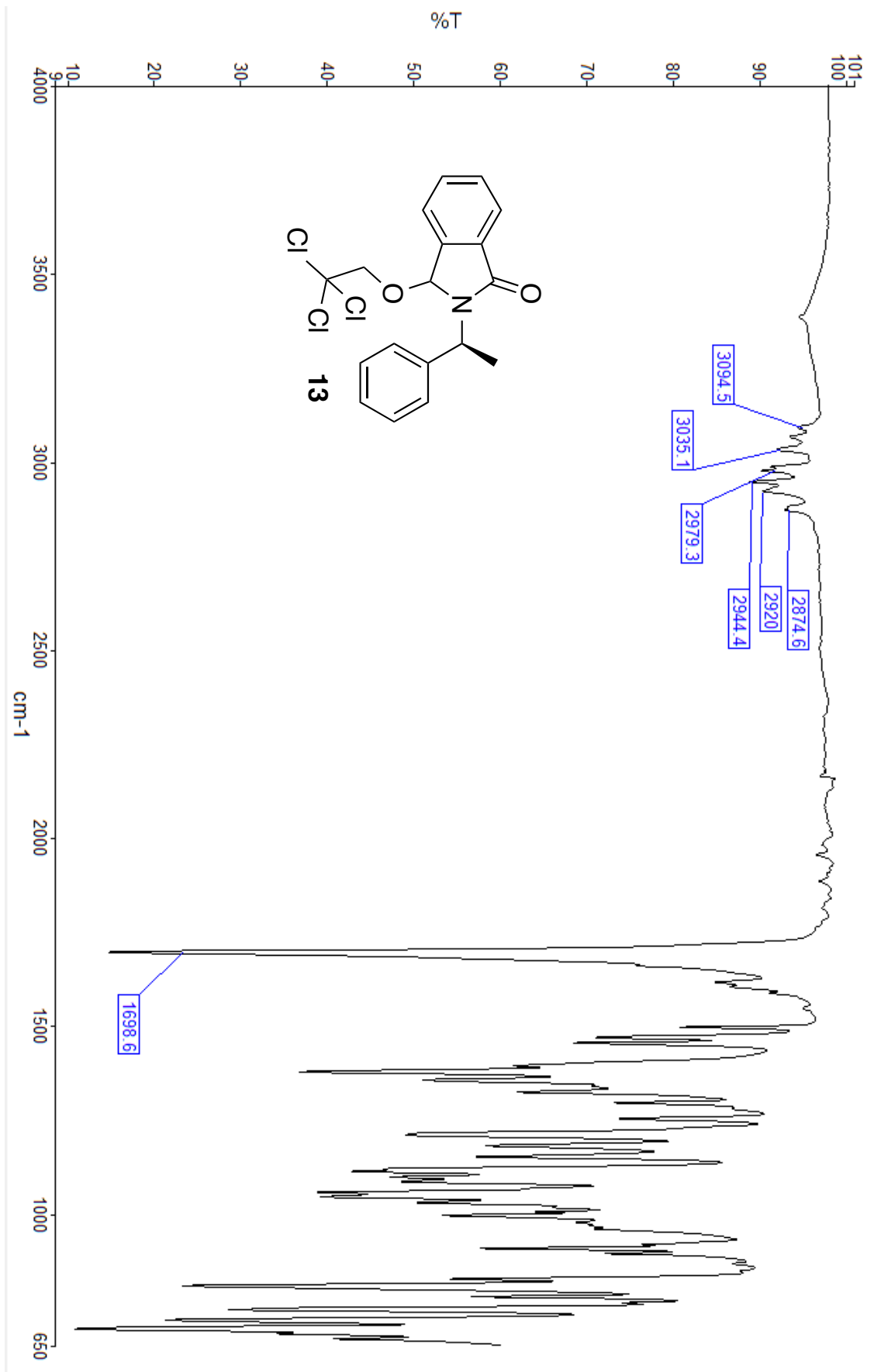




\section{3-(allyloxy)-2-((S)-1-phenylethyl)isoindolin-1-one. ${ }^{\mathrm{b}} 14$}

Colorless oil (81 mg, 70\%); $\mathrm{R}_{\mathrm{f}}=0.45$ (hexane/ethyl acetate, 9:1) IR 3041, 3010, 2976, 2942, $1700 \mathrm{~cm}^{-1}$ A mixture of two inseparable diastereomers $(\mathrm{dr}=3: 2){ }^{1} \mathrm{H}$ NMR (500 $\mathrm{MHz}, \mathrm{CDCl}_{3}$, major) $\delta$ 7.84-7.85 (m, 1H), 7.24-7.58 (m, 8H), 5.80-5.84 (m, 1H), $5.70(\mathrm{q}$, $J=7.5 \mathrm{~Hz}, 1 \mathrm{H}), 5.67(\mathrm{~s}, 1 \mathrm{H}) 4.94-4.99(\mathrm{~m}, 1 \mathrm{H}), 3.54(\mathrm{dd}, J=11.0,5.5 \mathrm{~Hz}, 1 \mathrm{H}), 3.45(\mathrm{dd}$, $J=11.0,5.5 \mathrm{~Hz}, 1 \mathrm{H}), 1.80(\mathrm{~d}, J=7.0 \mathrm{~Hz}, 3 \mathrm{H}) .{ }^{1} \mathrm{HNMR}\left(500 \mathrm{MHz}, \mathrm{CDCl}_{3}\right.$, minor $) \delta 7.84-$ $7.85(\mathrm{~m}, 1 \mathrm{H}), 7.24-7.58(\mathrm{~m}, 8 \mathrm{H}), 6.09(\mathrm{~s}, 1 \mathrm{H}), 5.44(\mathrm{q}, J=7.0 \mathrm{~Hz}, 1 \mathrm{H}), 5.37-5.40(\mathrm{~m}, 1 \mathrm{H})$ $5.23(\mathrm{~d}, J=7.0 \mathrm{~Hz}, 2 \mathrm{H}), 4.94-4.99(\mathrm{~m}, 1 \mathrm{H}), 3.20(\mathrm{dd}, J=13.5,7.5 \mathrm{~Hz}, 1 \mathrm{H}), 3.10(\mathrm{dd}, J=$ 13.5, 7.5 Hz, 1H), 1.89 (d, $J=7.5 \mathrm{~Hz}, 3 \mathrm{H}) .{ }^{13} \mathrm{C} \mathrm{NMR}\left(125 \mathrm{MHz}, \mathrm{CDCl}_{3}\right) \delta$ 167.7, 167.6, $141.7,140.9,140.6,140.2,133.8,133.6,133.0,132.6,132.0,129.9,129.8,128.6,128.4$, $128.2,127.9,127.8,127.7,127.4,126.6,123.7,123.5,123.3,117.1,117.0,85.5$ (major), 85.3 (minor), 62.9, 62.8, 50.5, 50.4, 17.9, 17.4. HRMS (FTMS + p ESI) $m / z[\mathrm{M}+\mathrm{Na}]^{+}$; calculated for $\mathrm{C}_{19} \mathrm{H}_{19} \mathrm{O}_{2} \mathrm{NNa} 316.1308$, Found 316.1304. 


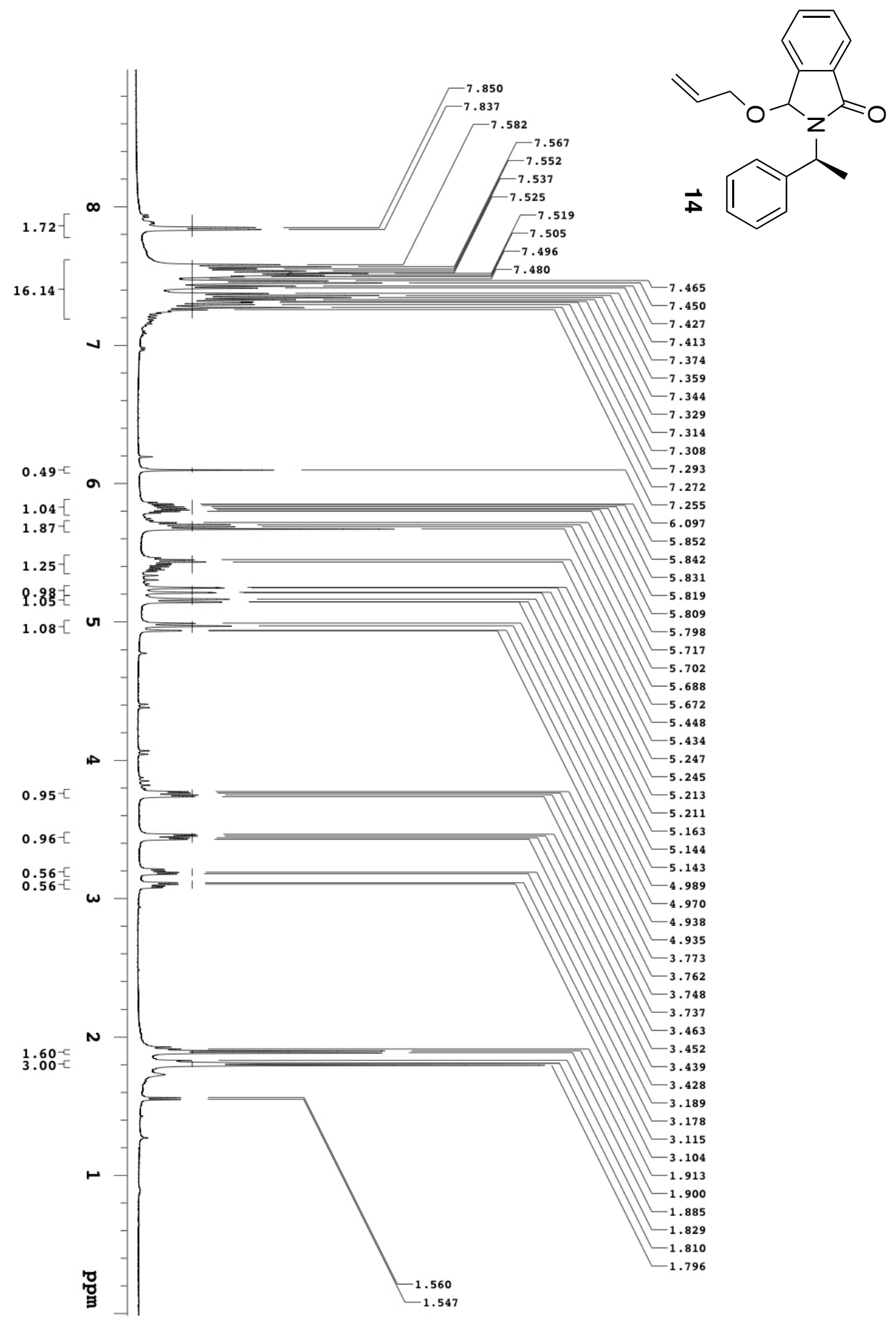




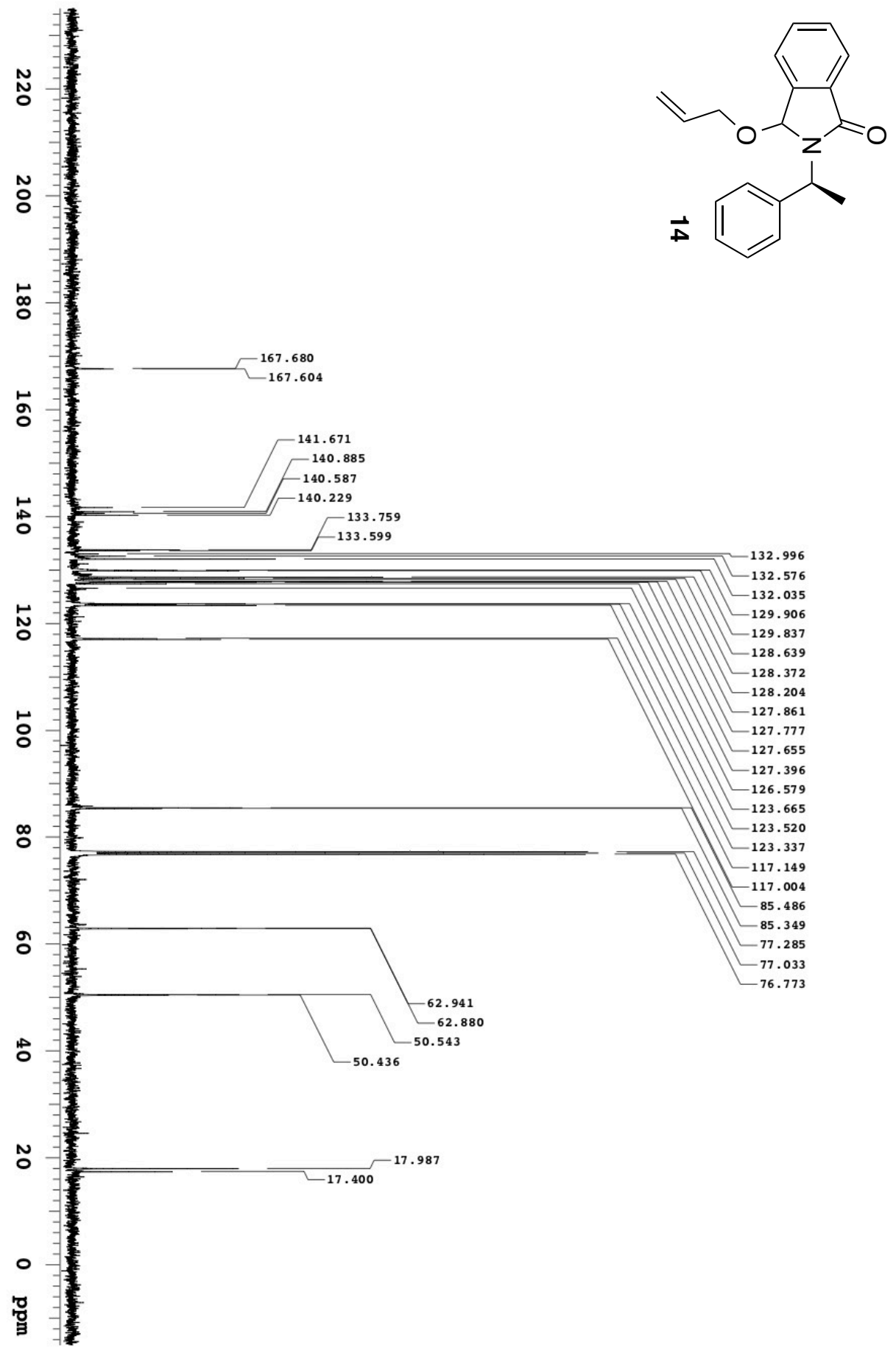




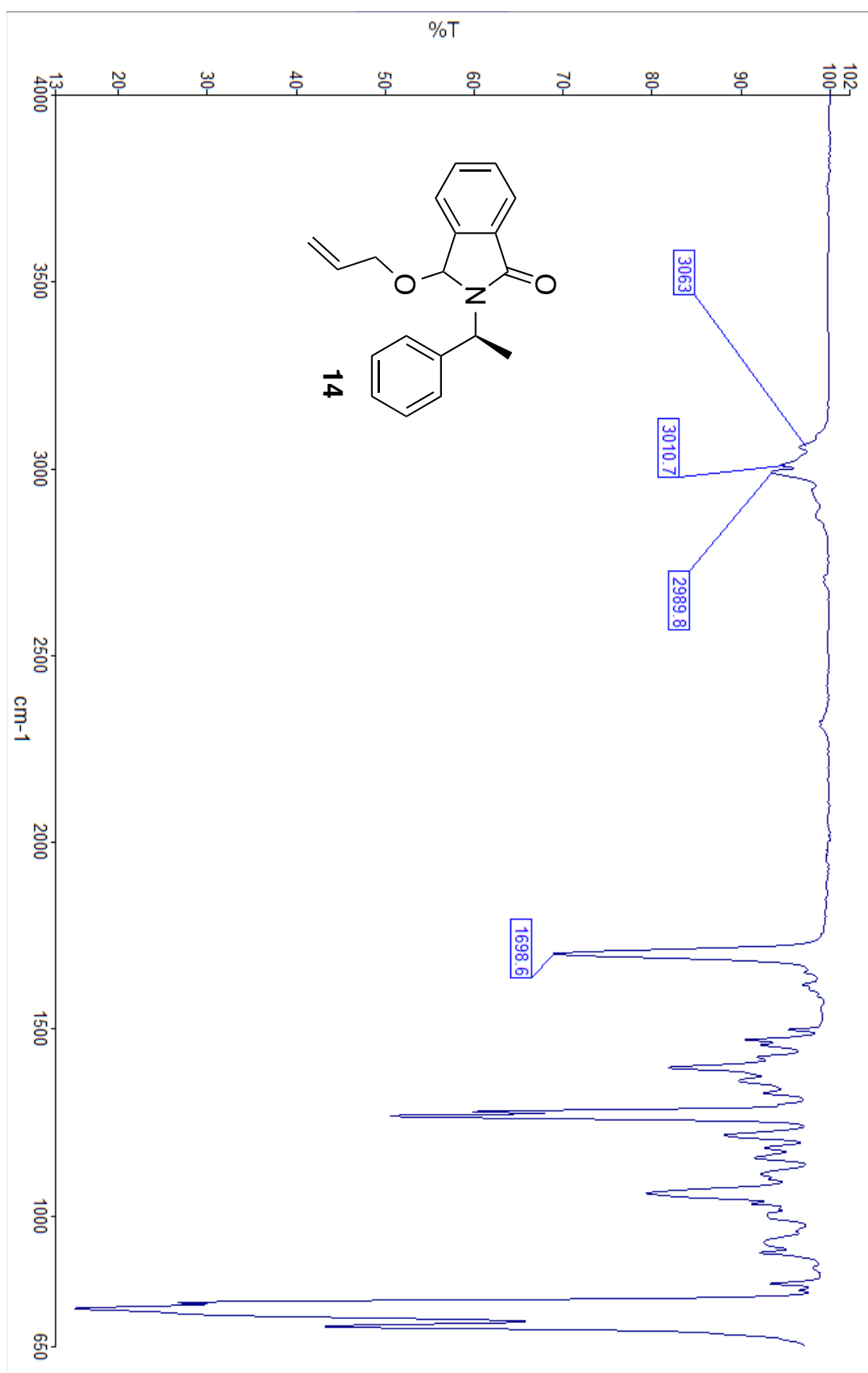




\section{3-(4-hydroxybutoxy)-2-((S)-1-phenylethyl)isoindolin-1-one. ${ }^{\text {b }} 15$}

Colorless oil (103 mg, 80\%); $\mathrm{R}_{\mathrm{f}}=0.19$ (hexane/ethyl acetate, 2:1); IR 3405 br, 2940, 2874, $2836,1683 \mathrm{~cm}^{-1}$ A mixture of two inseparable diastereomers $(\mathrm{dr}=3: 2){ }^{1} \mathrm{H}$ NMR $(500$ $\mathrm{MHz}, \mathrm{CDCl}_{3}$, major) $\delta 7.81-7.83(\mathrm{~m}, 1 \mathrm{H}), 7.22-7.24(\mathrm{~m}, 8 \mathrm{H}), 5.65(\mathrm{q}, J=6.5 \mathrm{~Hz}, 1 \mathrm{H}), 5.62$ $(\mathrm{s}, 1 \mathrm{H}), 3.86-3.89(\mathrm{~m}, 1 \mathrm{H}), 3.60-3.71(\mathrm{~m}, 3 \mathrm{H}), 3.41-3.46(\mathrm{~m}, 1 \mathrm{H}), 3.28-3.30(\mathrm{~m}, 1 \mathrm{H}) 2.87-$ $2.89(\mathrm{~m}, 1 \mathrm{H}), 1.57-2.0(4 \mathrm{H}), 1.23-1.34(\mathrm{~m}, 2 \mathrm{H}) .{ }^{1} \mathrm{HNMR}\left(500 \mathrm{MHz}, \mathrm{CDCl}_{3}\right.$, minor) $\delta 7.81-$ $7.83(\mathrm{~m}, 1 \mathrm{H}), 7.22-7.24(\mathrm{~m}, 8 \mathrm{H}), 6.03(\mathrm{~s}, 1 \mathrm{H}), 5.43$ (q, $J=6.0 \mathrm{~Hz}, 1 \mathrm{H}), 3.60-3.71(\mathrm{~m}, 3 \mathrm{H})$, 3.41-3.46 (m, 1H) 2.60-2.68 (m, 2H), 1.57-2.0 (m, 4H), 1.15-1.18 (m, 1H), 1.09-1.10 (m, 1H). ${ }^{13} \mathrm{CNMR}\left(125 \mathrm{MHz}, \mathrm{CDCl}_{3}\right) \delta 167.8,141.8,141.3,140.9,140.5,133.1,132.7,132.2$, $130.0,129.9,128.8,128.5,127.9,127.8,127.5,123.8,123.7,123.3,85.8$ (major), 85.4 (minor), 62.7, 62.6, 61.9, 61.7, 50.8, 50.3, 29.7, 29.5, 26.2, 25.7, 18.1, 17.5. HRMS (FTMS + p ESI) $m / z[\mathrm{M}+\mathrm{Na}]^{+}$; calculated for $\mathrm{C}_{20} \mathrm{H}_{23} \mathrm{O}_{3} \mathrm{NNa} 348.1570$, Found 348.1573 


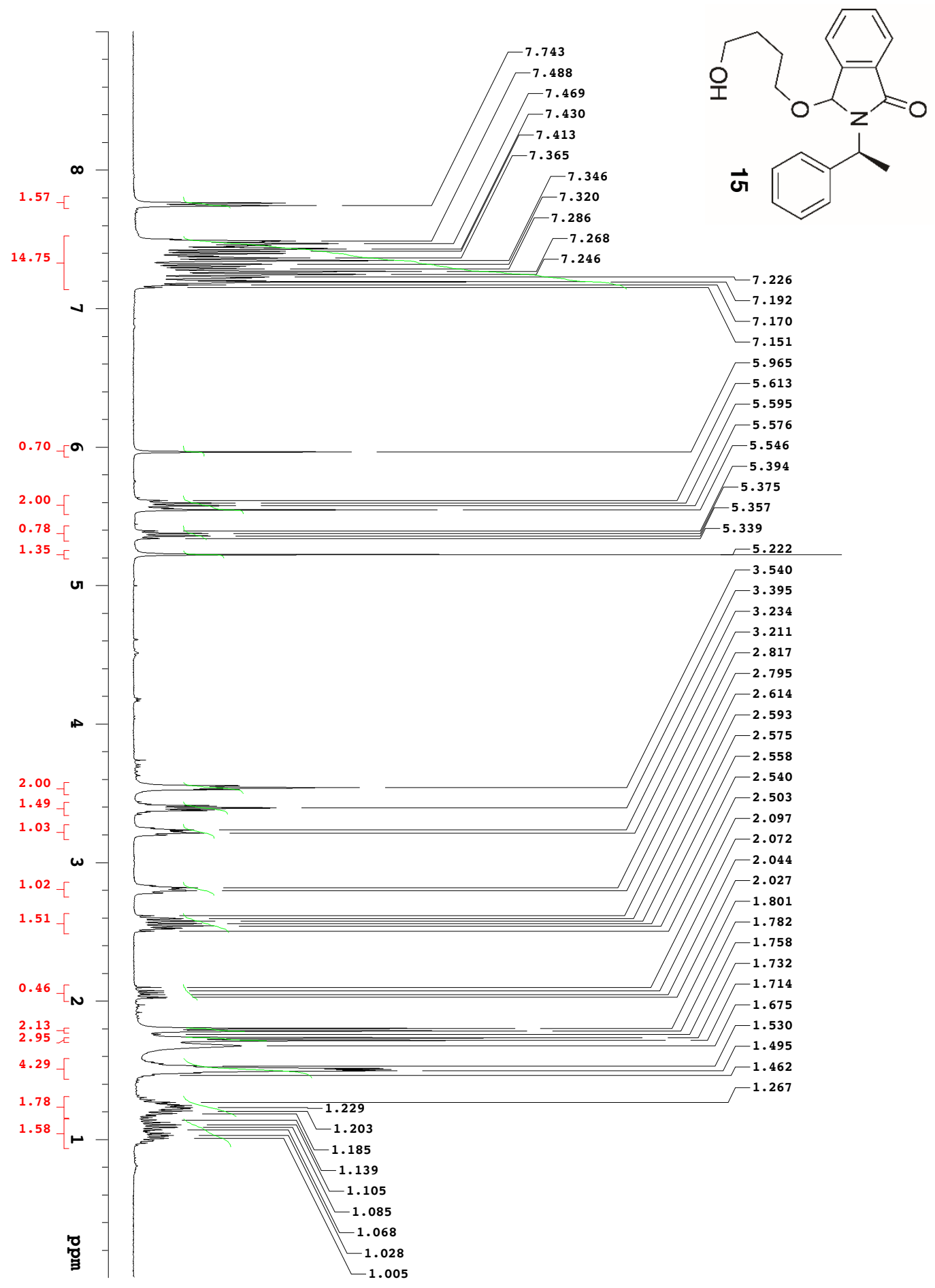




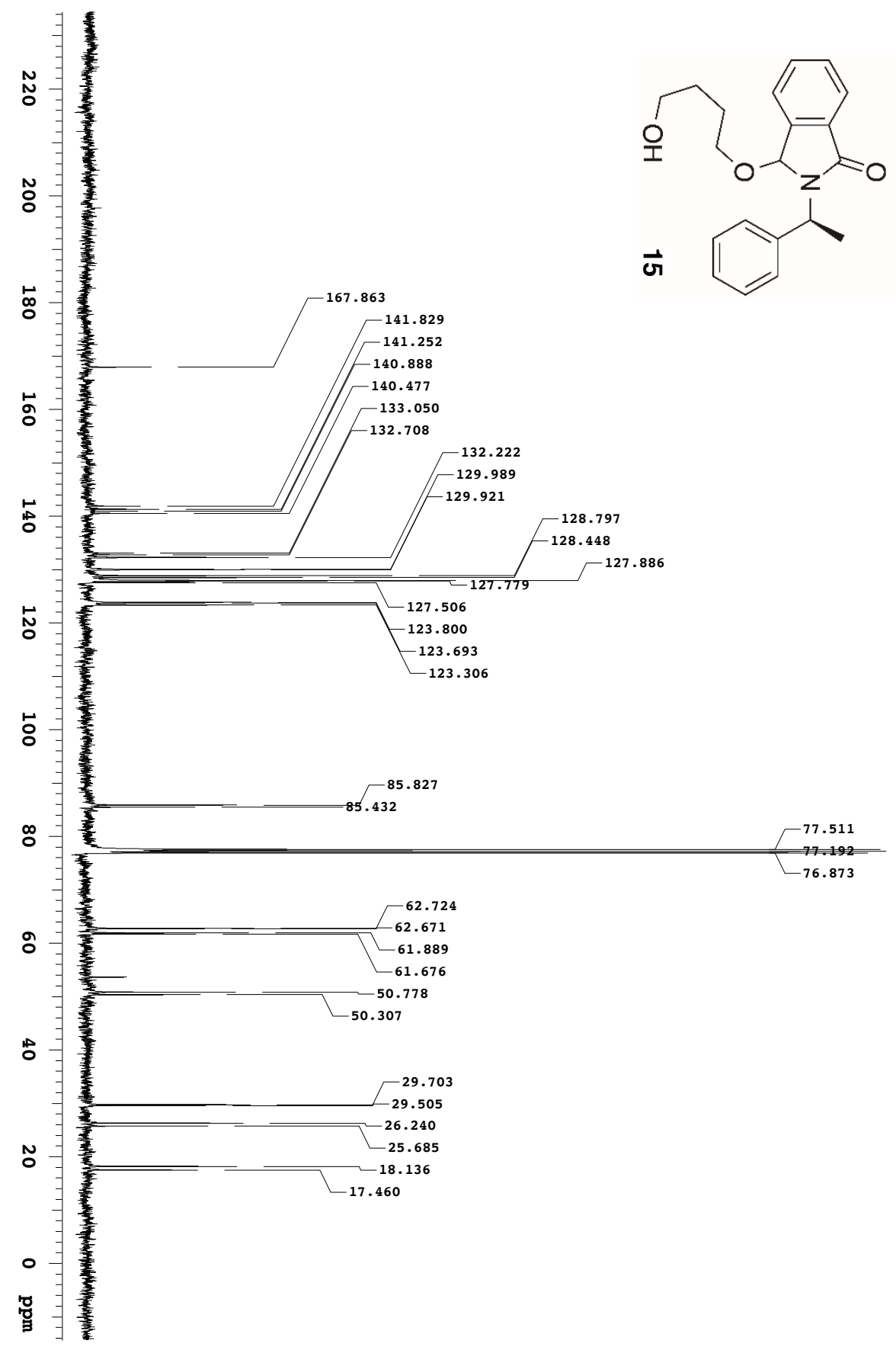




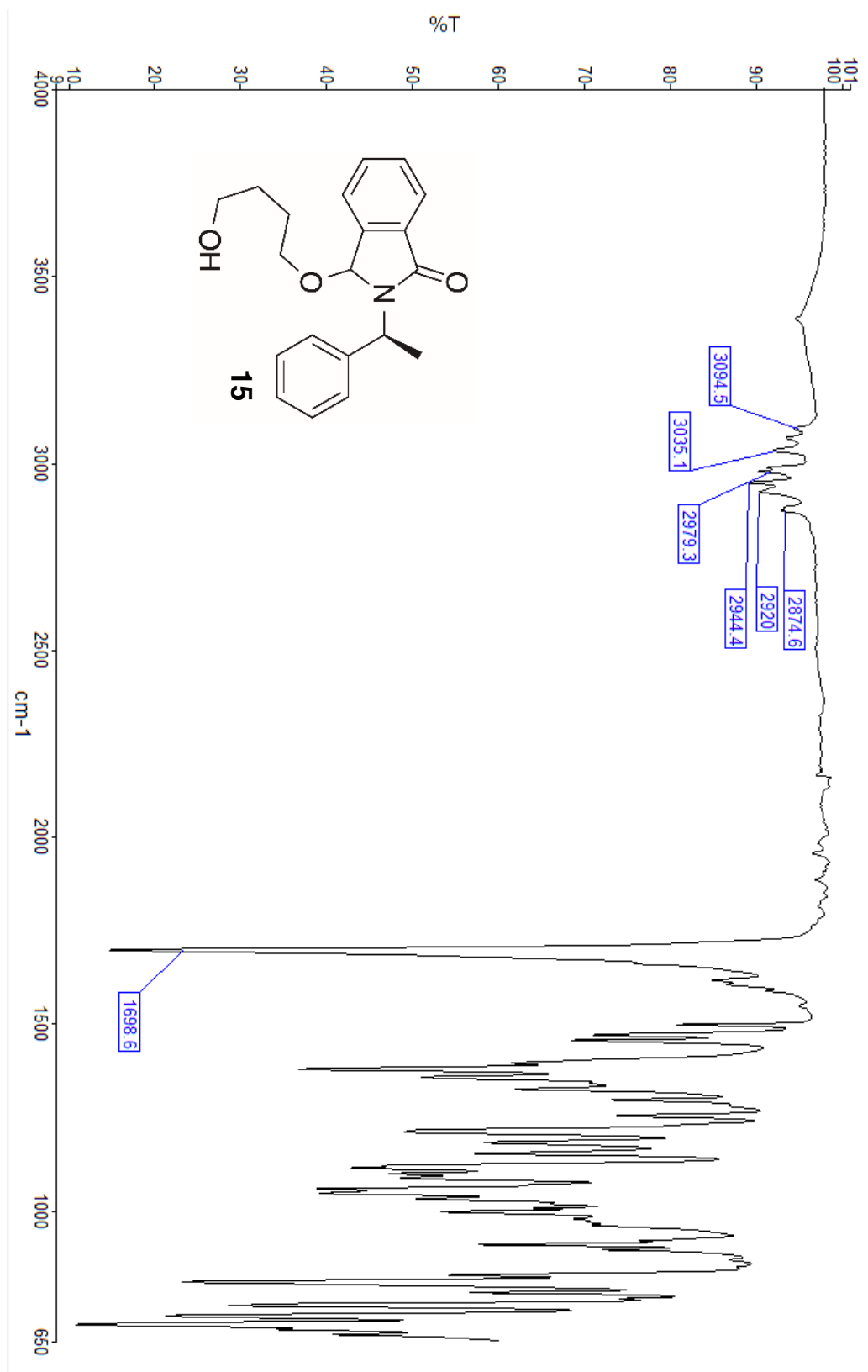




\section{3-(3-hydroxy-2,2-dimethylpropoxy)-2-((S)-1-phenylethyl)isoindolin-1-one. 16}

Colorless oil (101 mg, 75\%); $\mathrm{R}_{\mathrm{f}}=0.25$ (hexane/ethyl acetate, 2:1); IR 3449 br, 3061, 2973, $2870,1686 \mathrm{~cm}^{-1}$ A mixture of two inseparable diastereomers $(\mathrm{dr}=3: 1.6){ }^{1} \mathrm{H} \mathrm{NMR}(500$ $\mathrm{MHz}, \mathrm{CDCl}_{3}$, major) $\delta$ 7.84-7.85 (m, $\left.1 \mathrm{H}\right), 7.27-7.58(\mathrm{~m}, 8 \mathrm{H}), 5.66(\mathrm{q}, J=7.0 \mathrm{~Hz}, 1 \mathrm{H}), 5.64$ (s, 1H), 3.36-3.44 (m, 2h) $3.22(\mathrm{~d}, J=9.0 \mathrm{~Hz}, 1 \mathrm{H}), 2.68(\mathrm{~d}, J=9.0 \mathrm{~Hz}, 1 \mathrm{H}), 2.02$ (br s, 1H), 1.85 (d, $J=7.5 \mathrm{~Hz}, 3 \mathrm{H}), 0.87$ (s, 3H), 0.85 (s, 3H). ${ }^{1} \mathrm{H}$ NMR (500 MHz, CDCl minor) $\delta$ 7.84-7.85 (m, 1H), 7.27-7.58 (m, 8H), $6.00(\mathrm{~s}, 1 \mathrm{H}), 5.36(\mathrm{q}, J=7.0 \mathrm{~Hz}, 1 \mathrm{H}), 3.15-$ $3.17(\mathrm{~m}, 2 \mathrm{H}), 2.59$ (d, $J=9.0 \mathrm{~Hz}, 1 \mathrm{H}), 2.54(\mathrm{~d}, J=9.0 \mathrm{~Hz}, 1 \mathrm{H}), 1.89$ (d, $J=7.5 \mathrm{~Hz}, 3 \mathrm{H})$, 1.76 (br s, 1H), $0.70(\mathrm{~s}, 3 \mathrm{H}), 0.63(\mathrm{~s}, 3 \mathrm{H}) .{ }^{13} \mathrm{C} \mathrm{NMR}\left(125 \mathrm{MHz}, \mathrm{CDCl}_{3}\right) \delta$ 167.8, 141.7, $141.1,140.7,140.3,133.1,132.7,132.2,132.1,130.0,129.9,128.7,128.5,127.8,127.7$ 127.5, 123.7, 123.5, 123.2, 123.0, 85.7 (major), 85.5 (minor), 70.8, 70.5, 69.8, 50.8, 50.7, 35.9, 35.6, 21.8, 21.6, 18.0, 17.8. HRMS (FTMS + p ESI) $m / z[\mathrm{M}+\mathrm{Na}]^{+}$; calculated for $\mathrm{C}_{21} \mathrm{H}_{25} \mathrm{O}_{3} \mathrm{NNa} 362.1727$, Found 362.1730 


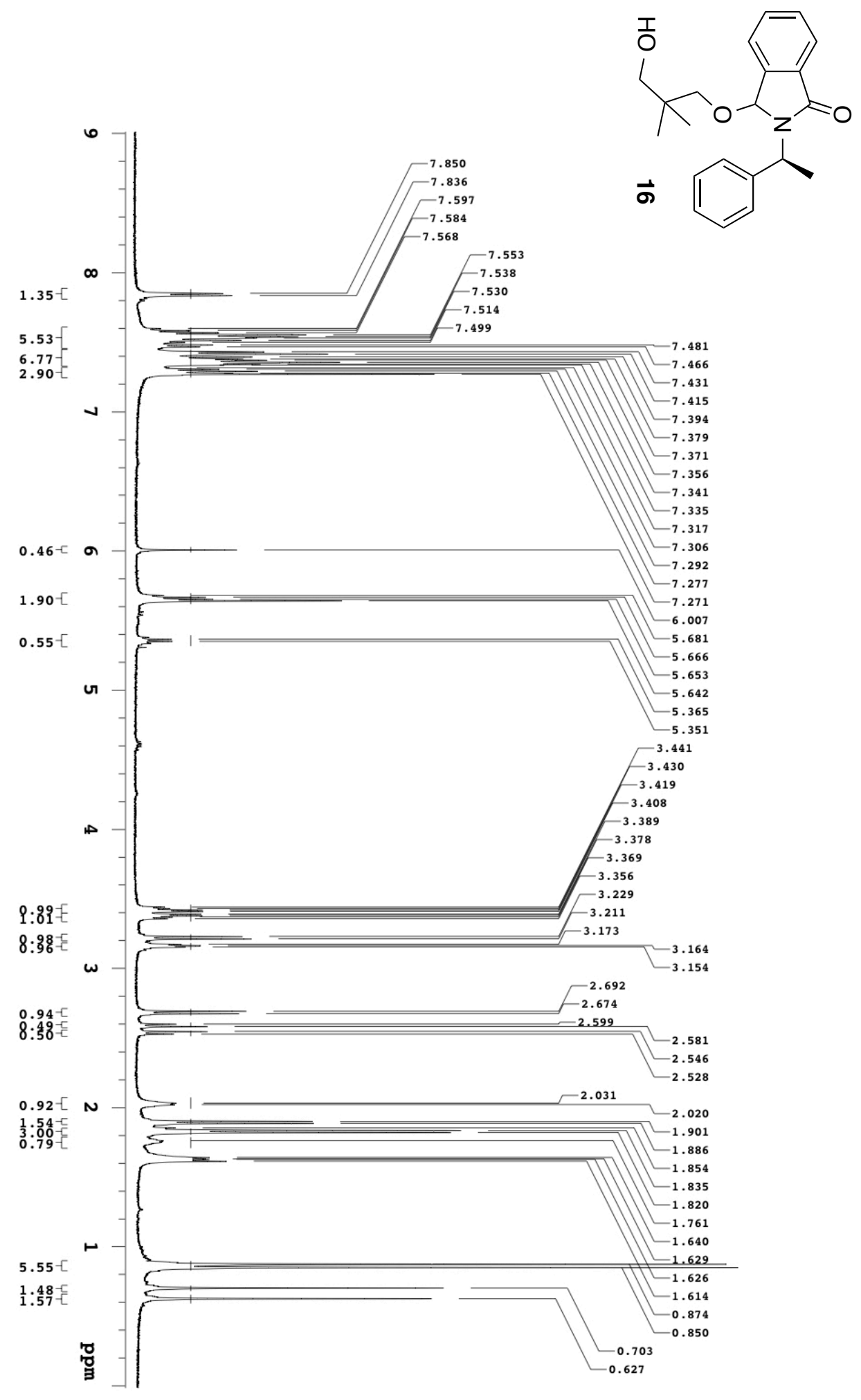




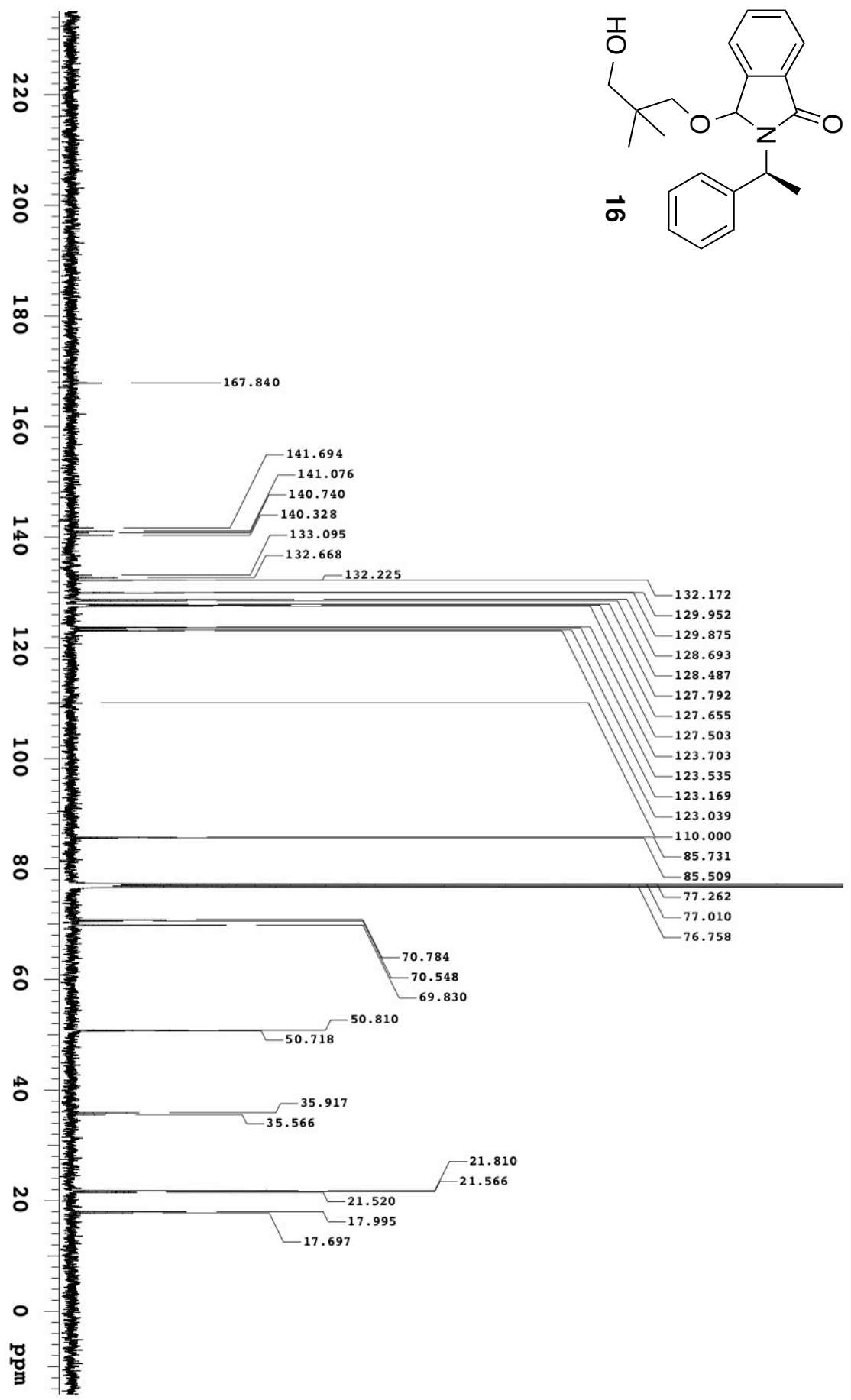




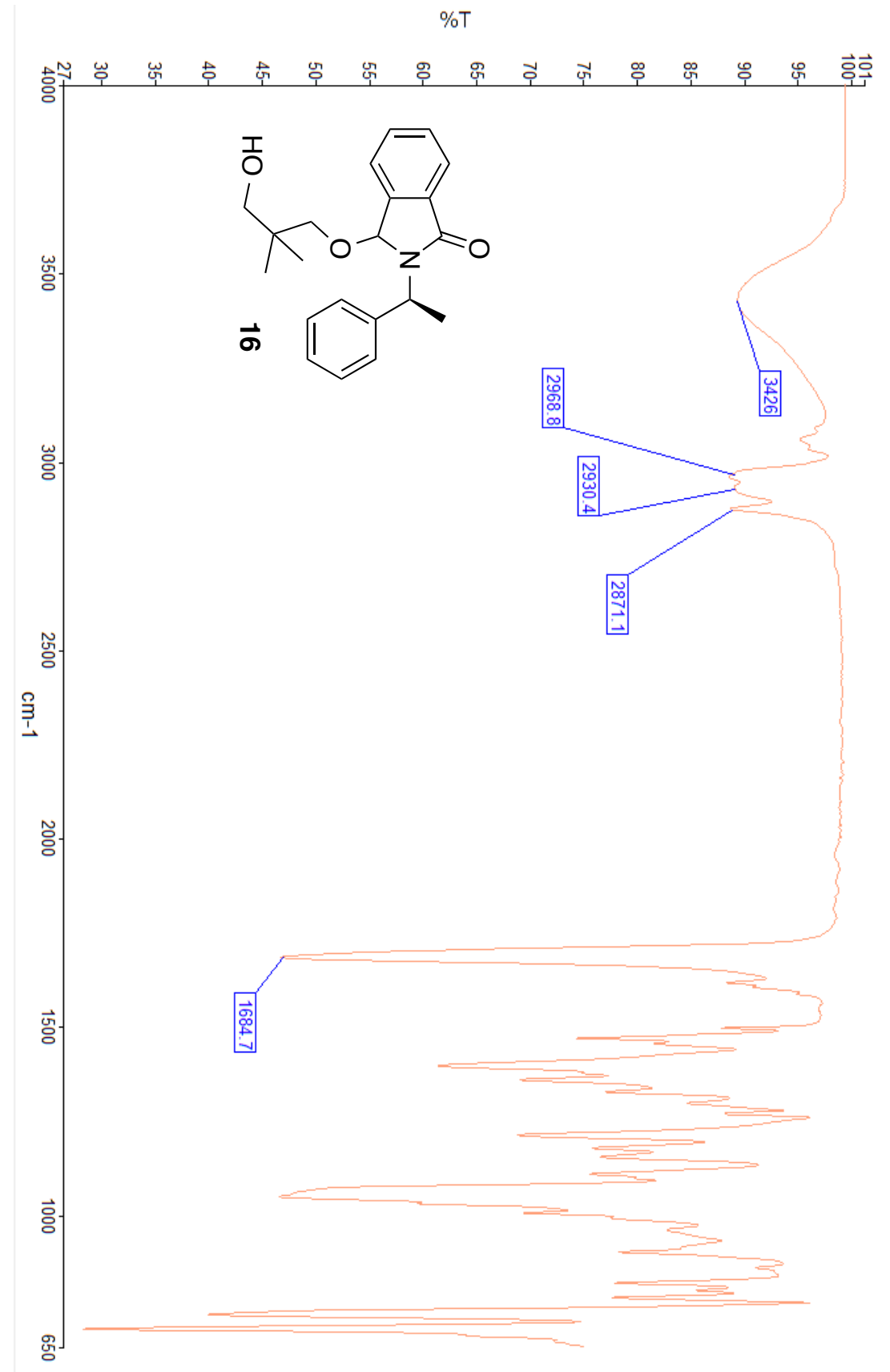




\section{3-(anthracen-9-ylmethoxy)-2-((S)-1-phenylethyl)isoindolin-1-one. ${ }^{\text {b }} 17$}

Pale yellow solid ( $138 \mathrm{mg}, 78 \%$ ); $\mathrm{mp} 85-87^{\circ} \mathrm{C} ; \mathrm{R}_{\mathrm{f}}=0.25$ (hexane/ethyl acetate, $2: 1$ ); IR $3056,3035,2927,2854,1696 \mathrm{~cm}^{-1}$ A mixture of two inseparable diastereomers $(\mathrm{dr}=3: 2)$ ${ }^{1} \mathrm{H}$ NMR (400 MHz, $\mathrm{CDCl}_{3}$, major) $\delta 8.43(\mathrm{~s}, 1 \mathrm{H}), 7.95-7.96(\mathrm{~m}, 3 \mathrm{H}), 7.86-7.89(\mathrm{~m}, 1 \mathrm{H})$, 7.26-7.72 (m, 12H), 6.98 (d, $J=7.2 \mathrm{~Hz}, 1 \mathrm{H}), 5.86(\mathrm{~s}, 1 \mathrm{H}), 5.80$ (q, $J=7.2 \mathrm{~Hz}, 1 \mathrm{H}), 5.34$ $(\mathrm{d}, J=12.0 \mathrm{~Hz}, 1 \mathrm{H}), 5.12(\mathrm{~d}, J=12.0 \mathrm{~Hz}, 1 \mathrm{H}), 1.90(\mathrm{~d}, J=7.6 \mathrm{~Hz}, 3 \mathrm{H}) .{ }^{1} \mathrm{H}$ NMR $(400$ $\mathrm{MHz}, \mathrm{CDCl}_{3}$, minor) $\delta 8.39(\mathrm{~s}, 1 \mathrm{H}), 7.95-7.96(\mathrm{~m}, 3 \mathrm{H})$, 7.86-7.89 (m, 1H), 7.26-7.72 (m, $12 \mathrm{H}), 7.18(\mathrm{~d}, J=7.2 \mathrm{~Hz}, 1 \mathrm{H}), 6.10(\mathrm{~s}, 1 \mathrm{H}), 5.40(\mathrm{q}, J=7.2 \mathrm{~Hz}, 1 \mathrm{H}), 4.85(\mathrm{q}, J=7.6 \mathrm{~Hz}$, 2H), $2.04(\mathrm{~d}, J=7.2 \mathrm{~Hz}, 3 \mathrm{H}) .{ }^{13} \mathrm{C} \mathrm{NMR}\left(125 \mathrm{MHz}, \mathrm{CDCl}_{3}\right) \delta 168.4,168.3,142.0,141.4$, $140.9,140.7,133.2,132.5,132.0,131.9,131.4,130.5,130.4,129.9,129.8,129.0,128.9$, $128.8,128.6,128.5,128.3,127.7,127.6,126.5,126.1,124.9,124.9,124.2,124.0,123.8$, 123.7, 123.6, 86.3 (major), 86.0 (minor), 58.0, 57.1, 51.6, 51.0, 18.5, 18.3. HRMS (FTMS + p ESI) $m / z[\mathrm{M}+\mathrm{Na}]^{+}$; calculated for $\mathrm{C}_{31} \mathrm{H}_{25} \mathrm{O}_{2} \mathrm{NNa} 466.1778$, Found 466.1780 


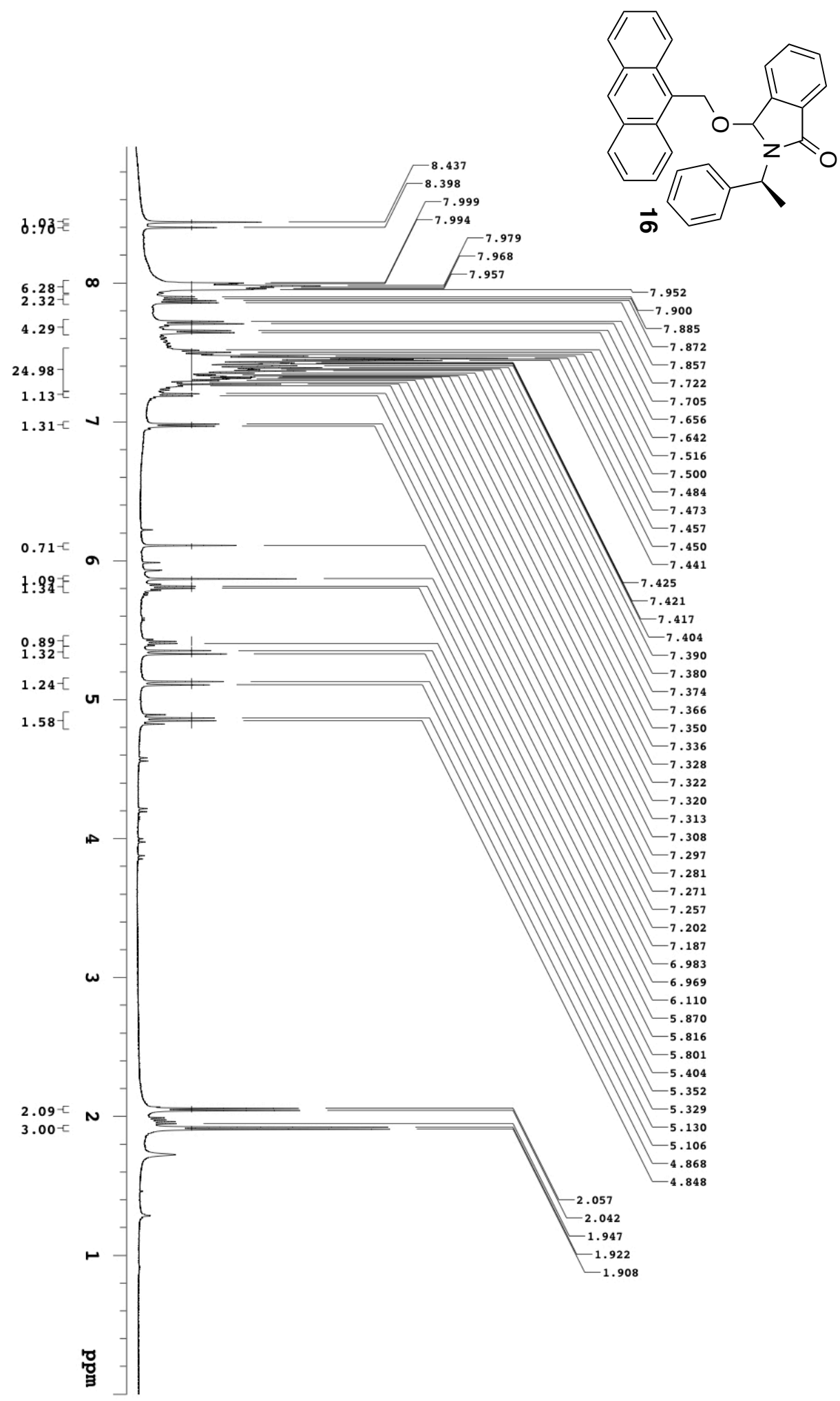




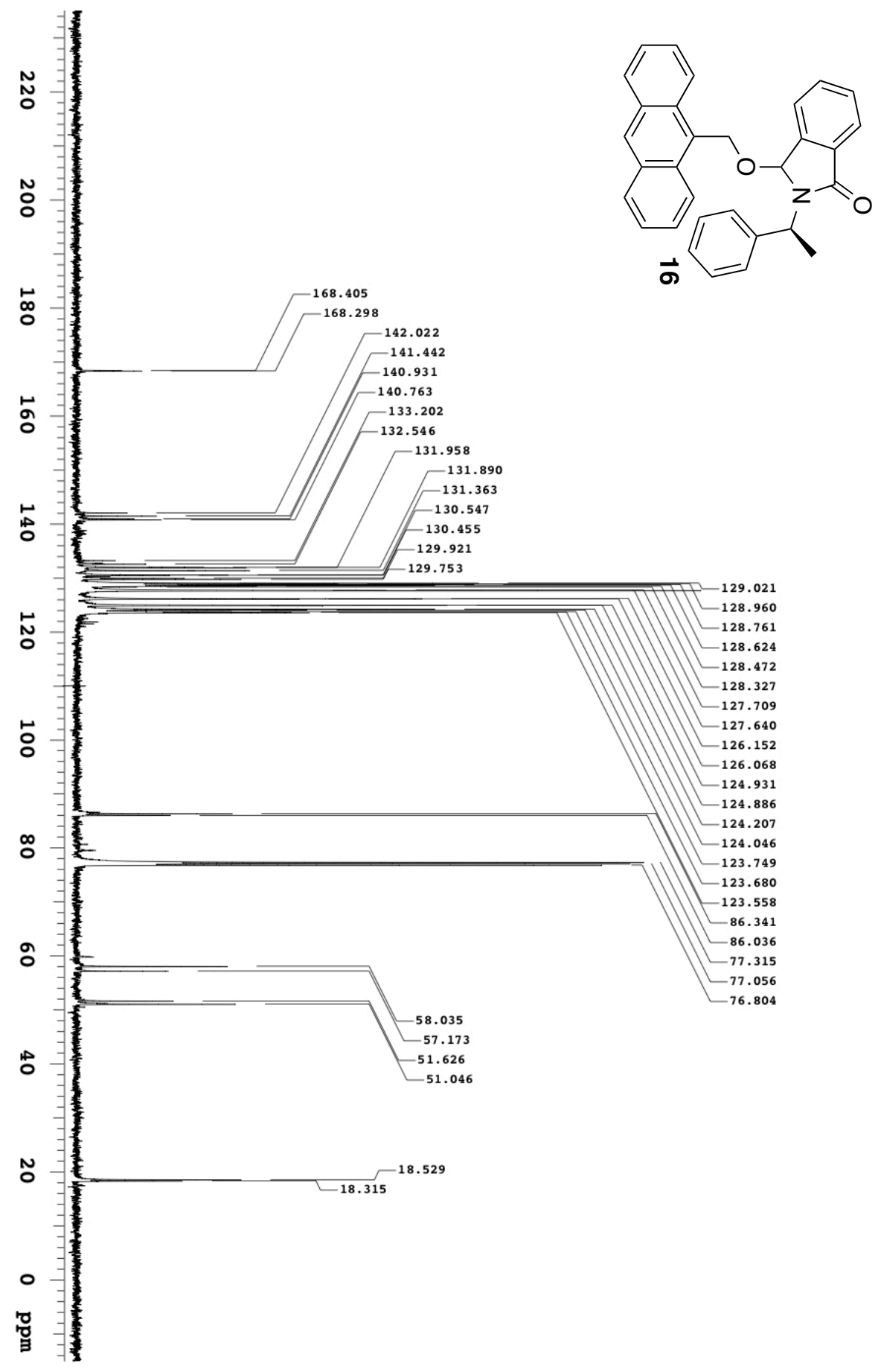




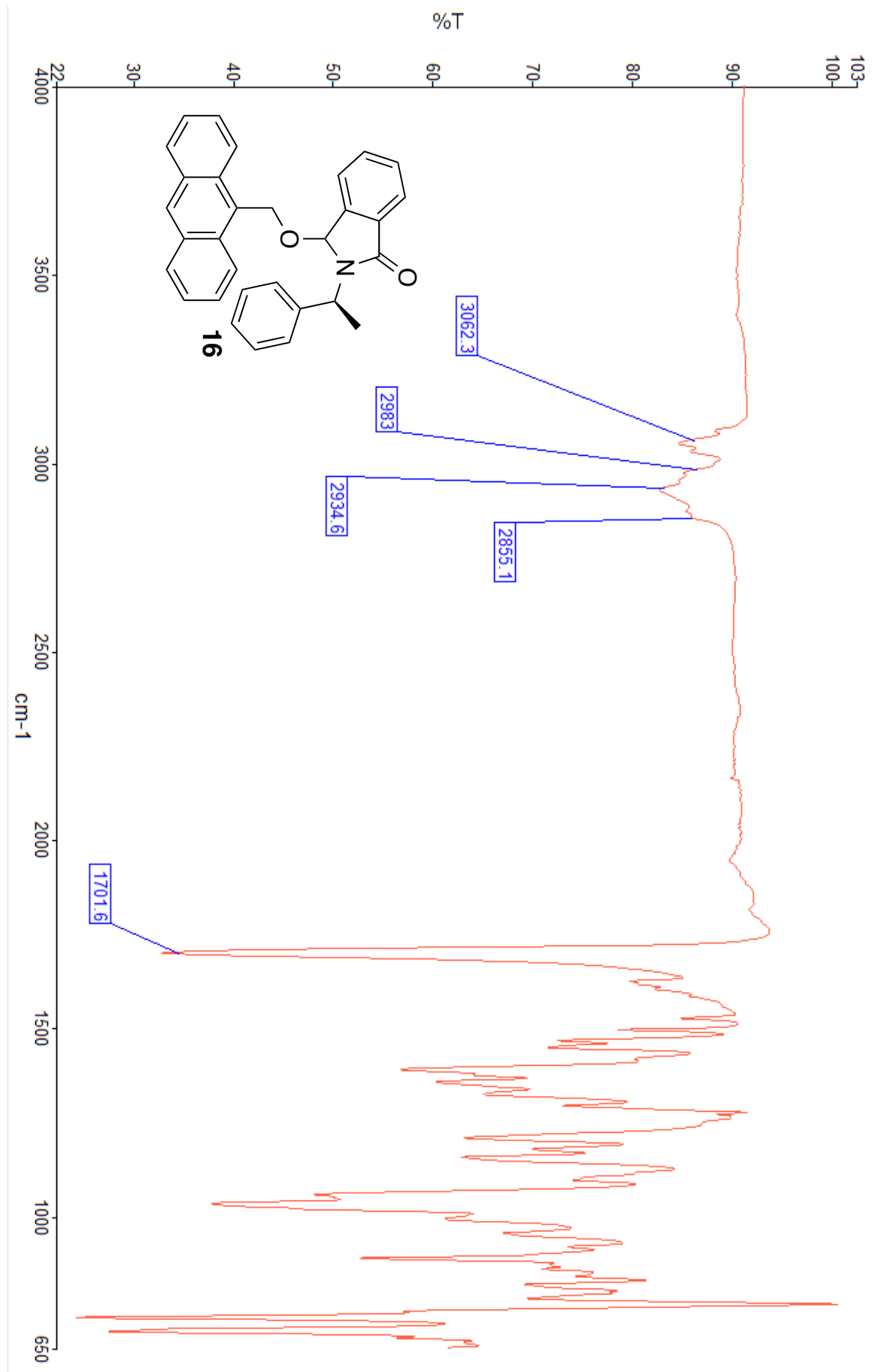




\section{REFERENCES}

\section{Part A:}

1. Kunz, W.; Keller, H.; Mückter, H. Arzneimittelforsch 1956, 6, 426-430.

2. Corey, E. J.; Czakó, B.; Kurti, L. In Molecules and Medicine; John Wiley and Sons: New Jersey, NJ, 2017; p197.

3. McBride, W. Lancet 1961, 278, 1358.

4. Lenz, W.; Pfeiffer, R. A.; Kosenow, W.; Hayman, D. J. Lancet 1962. 279, 45-46.

5. Fabro, S.; Schumacher, H.; Smith, R. L.; Williams, R. T. Life Sci. 1964, 3, 987992.

6. Claus, G. H.; Newman, M. D. Teratology 1986, 13, 555-573

7. Lenz, W. Teratology 1988, 28, 208-215

8. Sheskin, J. Clin. Pharmacol. Ther. 1965, 6, 303-306.

9. Sheskin, J. Int. J. Dermatol. 1980, 19, 318-322.

10. Sampaio, EP.; Kaplan G, Miranda A. J. Infect. Dis. 1993, 168, 408-414.

11. Paterson, DL.; Georghiou, PR.; Allworth, AM. Clin. Infect. Dis. 1995, 20, 250254.

12. Gutierrez-Rodriguez, O. Arthritis Rheum 1984, 27, 1118-1121.

13. Atra, E.; Sato, EI. Clin. Exp. Rheum. 1993, 11, 487-493.

14. Vogelsang, GB.; Hess, AD.; Santos, GW. Bone Marrow Transplant 1988, 3, 393 398.

15. Wood, PMD.; Proctor, SJ. Leuk. Res. 1990, 14, 395-399.

16. Muller, GW.; Corral, LG.; Shire, MG.; Wang, H.; Moreira, A.; Kaplan, G.; Stirling, J. Med. Chem. 1996, 39, 3238-3240. 
17. Muller, GW.; Chen, R.; Huan, S.; Corral, LG.; Wong, LM.; Patterson, RT.; Chen, Y.; Kaplan, G.; Stirling, DI. Bioorg. Med. Chem. Lett. 1999, 9, 1625-1630.

18. Olsen, K.; Hall, T.; Horton, J.; Khung, C.; Hosley, H. Clin. Pharmacol Ther. 1965, 62, 292-297.

19. Singhal, S.; Mehta, J.; Desikan, R.; Ayers, D.; Roberson, P.; Eddlemon, P.; Munshi, N.; Anaissie E.; Wilson, C.; Dhopapkar, M.; Zeldis, J.; Barlogie, B. N. Engl. J. Med. 1999, 341, 1565-1571.

20. Palumbo, A.; Facon, T.; Sonneveld, P.; Blade, J.; Offidani, M.; Gay, F.; Moreau, P.; Waage, A.; Spencer, A.; Ludwig, H.; Boccadoro, M.; Harousseau, J. Blood 2008, 111, 3968-3977.

21. Ito, T.; Ando, H.; Suzuki, T.; Ogura, T.; Hotta, K.; Imamura, Y.; Yamaguchi, Y.; Handa, H. Science 2010, 327, 1345-1350.

22. Nguyen, T.V.; Lee, J.E.; Sweredoski, M.J.; Yang, S.-J.; Jeon, S.-J.; Harrison, J.S.; Yim, J.-H.; Lee, S.G.; Handa, H.; Kuhlman, B.; Jeong, J.-S.; Reitsma, J.M.; Park, C.-S.; Hess, S.; Deshaies, R. Mol. Cell. 2016, 61, 809-820.

23. Chamberlain, P.; Lopez-Girona, A.; Miller, K.; Carmel, G.; Pagarigan, B.; ChieLeon, B.; Rychak, E.; Corral, L. G.; Ren, Y. J.; Wang, M.; Riley, M.; Delker, S. L.; Ito, T.; Ando, H.; Mori, T.; Hirano, Y.; Handa, H.; Hakoshima, T.; Daniel, T. O.; Cathers, B. E. Nat. Struct. Mol. Biol. 2014, 21, 803-809.

24. Zhu, YX.; Braggio, E.; Shi, C.; Kortuem, KM.; Bruins, LA.; Schmidt, JE.; Chang, XB.; Langlais, P.; Luo, M.; Jedlowski,P.; LaPlant, B.; Laumann, K.; Fonseca, R.; Bergsagel, PL.; Mikhael, J.; Lacy, M.; Champion, MD.: Stewart, AK. Blood. 2014, 124, 536-545. 
25. Kronke, J.; Fink, EC.; Hollenbach, PW.; Macbeth, KJ.; Hurst, SN.; Udeshi, ND.; Chamberlain, PP.; Mani, DR.; Gandhi, AK.; Svinkina, T.;Schneider, RK.; McConkey, M.; Jaras, M.; Griffiths, E,; Wetzelr, M.; Bulllinger, L.; Cathers, BE; Carr, SA.; Chopra, R.; Ebert, BL. Nature 2015, 523, 183-188.

26. Lu, J.; Qian, Y.; Altieri, M.; Dong, H.; Wang, J.; Raina, K.; Hines, J.; Winkler, J.; Crew, A.; Coleman, K.; Crews, C. Chem. Biol. 2015, 22, 755-763.

27. Jönsonn, N.A. Acta. Pharma. Suecia 1972, 9, 521-542.

28. Parman, T.; Wiley, M.J.; Wells, P.G. Nat. Med. 1999, 5, 582-585.

29. Hansen, J.M.; Harris, C. Antioxid. Redox Signaling 2004, 6, 1-14.

30. Neubert, R.; Hinz, N.; Neubert, D. Life Sci. 1995, 58, 295-316.

31. Stephens, T.D. Teratology 1988, 38, 229-239.

32. Stephens, T.D.; Fillmore, B.J. Teratology 1988, 61, 189-195.

33. McCredie, J.; McBride, W.G. Clin Radiol. 1973, 24, 204-211.

34. Moreira, A.L.; Sampaio, E.P.; Zmuidzinas, A.; Frindt, P.; Smith,K.A.; Kaplan, G. J. Exp. Med. 1993, 177, 1675-1680.

35. Payvandi, F.; Wu, L.; Haley, M. Cell. Immunol. 2004, 230, 81-88.

36. Keller, H.; Kunz, W. Products of the Amino-Piperidine-2-6-Dione Series. U.S. Patent 2,830,991, Apr. 15, 1958

37. Fickentsher, K.; Kirfel, A.; Will, G.; Köhler, F. Mol. Pharmacol. 1977. 13, 133141.

38. Helm, F. C.; Frankus, E.; Friderichs, E.; Grandums, I.; Floé, L. Arzneim. Forsch./Drug Res. 1981. 31, 941-949 
39. Tamilarasan, K.P.; Kolluru, G.K.; Rajaram, M.; Indhumathy, M.; Saranya, R.; Chatterjee, S. BMC Cell Biol. 2006, 7, 1-13.

40. Yabu, T.; Tomimoto, H.; Taguchi, Y.; Yamaoka, S.; Igarashi, Y.; Okazaki, T. Blood 2005, 106, 125-134.

41. Ema, M.; Ise, R.; Kato, H. Reprod. Toxicol. 2010, 29, 49-56.

42. Merker, H.J.; Heger, W.; Sames, K.; Sturje, H.; Neubert, D. Arch. Toxicol. 1988, $61,165-179$.

43. Lee, C.J.; Shibata, N.; Wiley, M.J.; Wells, P.G. Toxicol. Sci. 2011, 122, 157-169.

44. Lee, C.J.; Goncalves, L.L; Wells, P.G. Toxicol. Sci., 2011, 122, 146-156.

45. Whitsel, A.I.; Johnson, C.B.; Forehand, C.J. Teratology 2002, 66, 153-163.

46. Jurand, A. J. Embryol. Exp. Morphol. 1966, 16, 289-300.

47. Niwayama, S.; Turk, B. E.; Liu, J. O. J. Med. Chem. 1996, 39, 3044-3045.

48. Zhu, X.; Giordano, T.; Yu, Q.; Holloway, H. W.; Perry, T. A.; Lahiri, D. K.; Brossi, A.; Greig, N. H. J. Med. Chem. 2003, 46, 5222-5229.

49. He, W.; Engstrom, L.; Walker, S.; Vogelsang, G.; Leong, K. W. Synthesis of Thalidomide Analogs and Their Biological Potential for Treatment of Graft Versus Host Disease (GVHD). Abstracts of Papers, 206 ${ }^{\text {th }}$ National Meeting, American Chemical Society, Chicago, IL, 1993; American Chemical Society; Washington, D.C. 1993; MEDI 216.

50. Kaplan, G.; Sampaio, E. P. Method of Treating Abnormal Concentrations of TNF- $\alpha$. U.S. Patent 5,385,901. Jan. 31, 1995.

51. Muller, G. W.; Corral, L. G.; Shire, M. G.; Wang, H.; Moreira, A.; Kaplan, G.; Stirling, D. J. Med. Chem. 1996, 39, 3238-3240. 
52. Muller, G. W.; Shire, M. G.; Wong, L. M.; Corral, L. G.; Patterson, R. T.; Chen, Y.; Stirling, D. I. Bioorg. Med. Chem. Lett. 1998, 8, 2669-2674.

53. Corral, L. G.; Muller, G. W.; Moreira, A. L.; Chen, Y.; Wu, M.; Stirling, D.; Kaplan, G. Mol. Med. 1996, 2, 506-515.

54. Muller, G. W.; Schafer, P. H.; Man, H. W.; Ge, C.; Xu, J. Solid Forms Comprising (+)-2-[I-(3-ethoxy-4-methoxyphenyl-2-methylsulfonylethyl]-4acetylaminoisoindoline-1,3-dione, Compositions Thereof, and Uses Thereof. U.S. Patent 2008/00402. Mar. 27, 2008

55. Muller, G. W.; Stirling, D. I.; Chan, R. Isoindolines, Method of Use, and Pharmaceutical Compositions. U.S. Patent 6,281,230B1 June 24, 1996

56. Muller, G. W.; Chen, R.; Huang, S. Y.; Corral, L. G.; Wong, L. M.; Patterson, R. T.; Chen, Y.; Kaplan, G.; Stirling, D. L. Bioorg. Med. Chem. Lett. 1999, 9, $1625-$ 1630.

57. Christian, M.; Laskin, O.; Sharper, V.; Hoberman, A.; Stirling, D.; Latriano, L. Birth Defects Research B. 2007, 80, 188-207.

58. Yamamoto, T.; Tokunaga, E.; Nakamura, S.; Shibata, N.; Toru, T. Chem. Pharm. Bull. 2010. 58, 110-112.

59. Yamamoto, T.; Suzuki, Y.; Ito, E.; Tokunaga, E.; Shibata, N. Org. Lett. 2011, 13, $470-473$.

60. Nichimura, K.; Hashimoto, Y.; Iwasaki, S. Chem. Pharm. Bull. 1994, 42, $1157-$ 1159.

61. Osipov, S. N.; Tsouker, P.; Hennig, L.; Burger, K. 3-Trifluoromethyl- and 3difluoromethyl-Thalidomides. Tetrahedron 2004, 60, 271-274. 
62. Ng, S. S. W.; Gütschow, M.; Weiss, M.; Hauschildt, S.; Teubert, U.; Hecker, T. K.; Luzzio, F. A.; Kruger, E. A.; Eger, K.; Figg, W. D. Cancer Res. 2003. 63, 3189-3194.

63. Seley, K. L.; Zhang, L.; Hagos, A.; Quirk, S. J. Org. Chem. 2002, 67, 3365-3373.

64. Schiedel, M.; Herp, D.; Hammelmann, S.; Swyter, S.; Lehotzky, A.; Robaa, D.; Oláh, J.; Ovádi, J.; Sippl, W.; Jung, M. J. Med. Chem. 2018, 61, 482-491.

65. Ronnebaum, J. M.; Luzzio, F. A. Tetrahedron 2016, 72, 6136-6146.

66. Alford, J. S.; Davies, H. M. L. Org. Lett. 2012, 14, 6020-6023.

67. Clayton, J.; Ma, F.; Van Wagenen, B.; Ukkiramapandian, R.; Egle, I.; Empfield, J.; Isaac, M.; Slassi, A.; Steelman, G.; Urbanek, R.; Walsh, S. WO 2006020879. Chem. Abstr. 2006, 144, 254003.

68. Worrell, B. T.; Malik, J. A.; Fokin, V. V. Science 2013, 26, 457-456. 


\section{PART B:}

1. Craik, D. J.; Fairlie, D. P.; Liras, S.; Price, D. Chem. Biol. Drug Des. 2013, 81, 136.

2. Blakovich, M. A. J. Med. Chem. 2016, 59, 10807-10836.

3. Scott, W. L.; Alsina, J.; Audu, C. O.; Babaev, E.; Cook, L.; Dage, J. L.; Goodwin, L. A.; Martynow, J. G.; Matosiuk, D.; Royo, M. J. Comb. Chem. 2008, 11, 14-33.

4. Strecker, A. Annalen der Chemie und Pharmacie. 1850, 75, 27-45.

5. Wünsch, E.; Fries, G.; Zwick, A. Beiträge zur Peptidsynthese 1958, 91, 542-547.

6. Li, Y.; Xu, M. -H. Org. Lett. 2012, 14, 2062-2065.

7. Mita, T.; Sato, Y. J. Synth. Org. Chem. Jpn. 2013, 71, 1163-1171.

8. Aguiam, N.R.; Castro, V. I.; Ribeiro, A. I. F.; Fernandes, R. D. V.; Carvalho, C. M.; Costa, S. P. G.; Pereira-Lima, S. M. M. A. Tetrahedron 2013, 69, 9161-9167.

9. Wang, C.; Liu, S.; Xing, D.; Wang, X.; Wu, X.; Hu, W. Tetrahedron 2013, 69, 11203-11208.

10. Ali, A.; Fathalla, W. Curr. Org. Chem. 2013, 17, 1903-1909.

11. Jiang, C.; Covell, D. J.; Stepan, A. F.; Plummer, M. S.; White, M. C. Org. Lett. 2012, 14, 1386-1389.

12. Ma, D.; Cai, Q. Accounts of Chemical Research 2008, 41, 1450-1460.

13. Andurkar, S. V.; Stables, J. P.; Kohn, H. Bioorg. Med. Chem. 1999, 7, 2381-2389.

14. Augeri, D. J.; Robl, J. A.; Betebenner, D. A.; Magnin, D. R.; Khanna, A.; Robertson, J.G.; Wang, A.; Simpkins, L. M.; Taunk, P.; Huang, Q.; Han, S. P.; Abboa-Offei, B.; Cap, M.; Xin, L.; Tao, L.; Tozzo, E.; Welzel, G. E.; Egan, D. 
M.; Marcinkeviciene, J.; Chang, S. Y.; Biller, S. A.; Kirby, M. S.; Parker, R. A.; Hamann, L. G. J. Med. Chem. 2005, 48, 5021-5025.

15. Mongiat-Artus, P.; Teillac, P. Expert Opin. Pharmacother. 2004, 5, 2171-2179.

16. Scola, P.M.; Sun, L.Q.; Wang, A.X.; Chen, J.; Sin, N.; Venables, B.L.; Sit, S.Y.;

Chen, Y.; Cocuzza, A.; Bilder, D.M.; D’Andrea, S.V.; Zheng, B.; Hewawasam, P.; Tu, Y.; Friborg, J.; Falk, P.; Hernandez, D.; Levine, S.; Chen, C.; Yu, F.; Sheaffer, A.K.; Zhai, G.; Barry, D.; Knipe, J.O.; Han, Y.H.; Schartman, R.; Donoso, M.; Mosure, K.; Sinz, M.W.; Zvyaga, T.; Good, A.C.; Rajamani, R.; Kish, K.; Tredup, J.; Klei, H.E.; Gao, Q.; Mueller, L.; Colonno, R.J.; Grasela, D.M.; Adams, S.P.; Loy, J.; Levesque, P.C.; Sun, H.; Shi, H.; Sun, L.; Warner, W.; Li, D.; Zhu, J.; Meanwell, N.A.; McPhee, F. J. Med. Chem. 2014, 57, 17301752.

17. Rotella, D.P.; Expert Opin. Drug Discov. 2013, 8, 1439-1447.

18. Klutchko, S.; Blankley, C.J.; Fleming, R.W.; Hinkley, J.M.; Werner, A.E.; Nordin, I.; Holmes, A.; Hoefle, M.L.; Cohen, D.M.; Essenburg, A.D.; Kaplan, H.R. J. Med. Chem. 1986, 29, 1953-1961.

19. Clerc, F.F.; Guitton, J.D.; Fromage, N.; Levièvre, Y.; Duchesne, M.; Tocqué, B.; James-Surcouf, E.; Commerçon, A.; Becquart, J. Bioorg. Med. Chem. Lett. 1995, $5,1779-1784$.

20. Nanteuil, G.N.; Gloanec, P.; Béguin, S.; Giesen, P.L.A.; Hemker, H.C.; Mennecier, P.; Rupin, A.; Verbeuren, T.J. J. Med. Chem. 2006, 49, 5047-5050. 21. Fischer, J.; Gannelin, C.R.; In Analogue-based Drug Discovery; John Wiley \& Sons: New Jersey, NJ, 2017; p490. 
22. Neu, H.C.; Labthavikul, P.; Antimicrobial Agents and Chemotherapy 1982, 21, 906-911.

23. Decristoforo, C.; Knopp, R.; von Guggenberg, E.; Rupprich, M.; Dreger, T.; Hess, A.; Virgolini, I.; Haubner, R. Nucl. Med. Commun. 2007, 28, 870-875.

24. Lamb, H.M.; Figgitt, D.P.; Faulds, D. Drugs 1999, 58, 1061-1097.

25. O’Donnell, M.J.; Eckrich, T.M. Tetrahedron Lett. 1978, 47, 4625-4628.

26. O’Donnell, M.J.; Bennett, W.D.; Bruder, W.A.; Jacobsen, W.N.; Knuth, K.; LeClef, B.; Polt, R.L.; Bordwell, F.G.; Mrozack, S.R.; Cripe, T.A. J. Am. Chem. Soc. 1988, 110, 8520-8525.

27. O’Donnell, M.J.; Falmagne, J.B. Tetrahedron Lett. 1985, 26, 699-702.

28. O’Donnell, M.J.; Boniece, J.M.; Earp, S.E. Tetrahedron Lett. 1978, 30, 26412644.

29. O’Donnell, M.J.; Delgado, F.; Drew, M.D.; Pottorf, R.S.; Zhou, C.; Scott, W.L. Tetrahedron Lett. 1999, 40, 5831-5835.

30. O’Donnell, M.J.; Drew, M.D.; Cooper, J.T.; Delgado, F.; Zhou, C. J. Am. Chem. Soc. 2002, 124, 9348-9349.

31. Myers, A.G.; Gleason, J.L.; Yoon, T.; Kung, D.W. J. Am. Chem. Soc. 1997, 119, 656-673.

32. Soloshonok, V.A.; Cai, C.; Hruby, V.J. J. Org. Chem. 2000, 65, 6688-6696.

33. Ellis, T. K.; Martin, C. H.; Tsai, G. M.; Ueki, H.; Soloshonok, V. A. J. Org Chem. 2003, 68, 6208-6214.

34. Drouet, F.; Noiser, A. F.; Harris, C. S.; Furkert, D. P.; Brimble, M. A. Eur. J. Org. Chem. 2014, 6, 1195-1201. 
35. Patil, P. C.; Luzzio, F. A.; Ronnebaum, J. M. Tetrahedron Lett. 2017, 58, 37303733.

36. Aubert, T.; Farnier, M.; Guilard, R. Can. J. Chem. 1990, 68, 842-851.

37. Luzzio, F. A.; Piatt, Z. D. Tetrahedron Lett. 1998, 39, 2285-2288.

38. Couture, A.; Deniau, E.; Ionescu, D.; Grandclaudon, P. Tetrahedron Lett. 1998, 39, 2319-2320.

39. Luzzio, F. A.; In Weinreb SM, ed. Science of Synthesis, vol. 21. Stuttgart: Georg Thieme. 2005, 301-303.

40. Luzzio, F. A.; Zacherl, D.P.; Figg, W. D. Tetrahedron Lett. 1999, 40, 2087-2090.

41. Moriyama, K.; Takemura, M.; Togo, H. Org Lett. 2012, 14, 2414-2417.

42. Patil, P. C.; Luzzio, F. A. Tetrahedron Lett. 2016, 57, 757-759.

43. Patil, P. C.; Luzzio, F. A. Tetrahedron Lett. 2017, 58, 1280-1282.

44. Asano K, Matsubara S. Heterocycles 2010, 80, 989-1002.

45. Yu L, Wang F. Gaodeng Xuexiao Huaxue Xuebao 1987, 8, 336-340.

46. Taschner E, Sololwska T, Biernat JF, Chimiak A, Wasielewski C, Rzeszotarska B. Justus Liebigs Ann Chem 1963, 663, 197-202.

47. Evans V, Mahon MF, Webster RL. Tetrahedron 2014, 70, 7593-7597. 


\section{PART C:}

1. Galustian, C.; Dalgleish, A. Expert Opin Pharmacother. 2009, 10, 125-133.

2. Riedinger, C.; Endicott, J. A.; Kemp, S. J. J. Am. Chem. Soc. 2008, 130, 1603816044.

3. Speck, K.; Magauer, T.; Beilstein J. Org. Chem. 2013, 9, 2048-2078.

4. Yang, Y.; Feng, Z.; Jiang, J.; Yang, Y.; Pan, X.; Zhang, P. Chem. Pharm. Bull. 2011, 59, 1016-1019.

5. Hardcastle, I. R.; Ahmed, S. U.; Atkins, H.; Farnie, G.; Golding, B. T.; Griffin, R. J.; Guyenne, S.; Hutton, C.; Kallblad, P.; Kemp, S. J.; Kitching, M. S.; Newell, D. R.; Norbedo, S.; Northen, J. S.; Reid, R. J.; Saravanan, K.; Willems, H. M.; Lunec, J. J. Med. Chem. 2006, 49, 6209-6221.

6. Watson, A.; Liu, J.; Bennaceur, K.; Drummond, C.; Endicott, J.; Golding, B.; Griffin, R.; Haggerty, K.; Lu, X.; McDonnell, J.; Newell, D.; Noble, M.; Revill, C.; Riedinger, C.; Xu, Q.; Zhao, Y.; Lunec, J.; Hardcastle, I. R. Bioorg. Med. Chem. Lett. 2011, 21, 5916-5919.

7. Cid, H. M.; Trankle, C.; Bauman, K.; Pick, R.; Mies-Klomfass, E.; Kostenis, E.; Mohr, K.; Holgrabe, U. J. Med. Chem. 2000, 43, 2155-2164.

8. Ortín, I.; González, J.; de la Cuesta, E.; Manguan-García, C.; Perona, R.; Avendaño, C. Bioorg. Med. Chem. 2008, 16, 9065-9078.

9. Chihab-Eddine, A.; Daïch, A.; Jilale, A.; Decroix, B. J. Heterocyl. Chem., 2000, $37,1543-1548$.

10. Chihab-Eddine, A.; Daïch, A.; Jilale, A.; Decroix, B. Heterocycles, 2002, 58, 449456. 
11. Cul, A.; Chihab-Eddine, A.; Pesquet, A.; Marchelín, Š.; Daïch, A. J. Heterocycl. Chem., 2003, 40, 499-505.

12. Yamada, S.; Takahashi, Y. Tetrahedron Lett. 2009, 50, 5395-5398.

13. Aliyenne, A.; Pin, F; Nimbarte, V.; Lawson, A.; Comesse, S.; Sanselme, M.; Tognetti, V.; Joubert, L.; Daïch, A. Eur. J. Org. Chem. 2016, 21, 3592-3602.

14. Luzzio, F. A. ; Piatt Zacherl, D. P. Tetrahedron Lett. 1998, 39, 2285-2288.

15. Natte, K..; Chen, J.; Li, H.; Neumann, H.; Beller, M.; Wu, X. Chem. Eur. J. 2014, $20,14184-14188$

16. Rao, H.; Rao, A. J. Org. Chem. 2015, 80, 1506-1516.

17. Cabrero-Antonino, J.; Sorribes, I.; Junge, K; Beller, M. Angew. Chem. Int. Ed, 2016, 55, 387-391.

18. Cabrero-Antonino, J.; Adam, R.; Papa, V.; Holsten, M.; Junge, K.; Beller, M. Chem. Sci., 2017, 8, 5536-5546.

19. Monsen, P. J.; Luzzio, F. A. ARKIVOC 2017, part I, 117-147.

20. Liang, T.; Neumann, C. N.; Ritter, T. Angew. Chem., Int. Ed. 2013, 52, 82148264

21. Shellhamer, D. F.; Anstine, D. T.; Gallego, K. M.; Ganesh, B. R.; Hanson, A. A.; Hanson, K. A.; Henderson, R. D.;Prince, J. M.; Heasley, V. L. J. Chem. Soc., Perkin Trans. 2 1995, 861- 866.

22. A. Sutherland, J. C. Vederas, Chem. Commun. 1999, 1739-1740.

23. . Shellhamer, D. F.; Briggs, A. A; Miller, B. M.; Prince, J. M.; Scott, D. H.; Heasley, V. L. J. Chem. Soc., Perkin Trans. 2 1996, 973-977

24. Johnson, A. L. J. Org. Chem. 1982, 47, 5220-5222. 
25. Khrimian, A. P.; DeMilo, A. B.; Waters, R. M.; Liquido, N. J.; Nicholoson, J. M. J. Org. Chem. 1994, 59, 8034-8039.

26. Yin, J.; Zarkowsky, D. S.; Thomas, D. W.; Zhao, M. M.; Huffman, M. A. Org. Lett. 2004, 6, 1465-1468.

27. Ronnebaum, J. M.; Luzzio, F. A. ARKIVOC (Accepted pending minor edits)

28. Luzzio, F. A.; Piatt-Zacherl, D. P. Tetrahedron Lett. 1999, 40, 2087-2090.

29. Chihab-Eddine, A.; Daich, A.; Jilale, A.; Decroix, B. Heterocycles 1999, 51, 2907-2914.

30. Leroy, J.; Hebert, E.; Wakselman, C. J. Org. Chem. 1979, 44, 3406-3408.

31. Liang, T.; Neumann, C.; Ritter, T. Angew. Chem., Int. Ed., 2013, 52, 8214-8264. 


\section{Appendix}




\begin{tabular}{|c|c|}
\hline & Abbreviations \\
\hline $\mathrm{Ac}_{2} \mathrm{O}$ & Acetic anhydride \\
\hline $\mathrm{AcOH}$ & Acetic acid \\
\hline ACE & Angiotensin Converting Enzyme \\
\hline BPCC & 2,2'-bipyridinium chlorochromate \\
\hline $\mathrm{Br}_{2}$ & Molecular Bromine \\
\hline BRD4 & Bromodomain-containing \\
\hline $\mathrm{CHCl}_{3}$ & Chloroform \\
\hline $\mathrm{Cs}_{2} \mathrm{CO}_{3}$ & Cesium Carbonate \\
\hline CSA & Camphorsulfonic Acid \\
\hline $\mathrm{Cu}$ & Copper \\
\hline $\mathrm{Cu}(\mathrm{OAc})_{2}$ & Copper Acetate \\
\hline $\mathrm{CuSO}_{4}$ & Copper sulfate \\
\hline DAST & Diethylaminosulfur trifluoride \\
\hline DCM & Dichloromethane \\
\hline DMSO & Dimethylsulfoxide \\
\hline ENL & Erythema Nodosum Leprosum \\
\hline ESI & Electrospray Ionization \\
\hline Et & Ethyl \\
\hline FT-IR & Fourier Transform Infrared Spectroscopy \\
\hline G & Grams \\
\hline $\mathrm{H}$ & Hours \\
\hline HRMS & High Resolution Mass Spectrometry \\
\hline $\mathrm{Hz}$ & Hertz \\
\hline IBX & 2-lodobenzoic acid \\
\hline IFN- $\gamma$ & Interferon $\gamma$ \\
\hline IKZF & Ikaros family zinc finger \\
\hline IMiDs & Immunomodulatory Drugs \\
\hline $\mathrm{KBr}$ & Potassium Bromide \\
\hline LiHMDS & Lithium Hexamethyl disilazide \\
\hline LRMS & Low Resolution Mass Spectrometry \\
\hline MCPBA & $m$-chloroperbenzoic acid \\
\hline $\mathrm{Me}_{2} \mathrm{CO}$ & Acetone \\
\hline $\mathrm{MeCN}$ & Acetonitrile \\
\hline $\mathrm{MeOH}$ & Methanol \\
\hline mg & Milligram \\
\hline $\mathrm{mL}$ & Milliliters \\
\hline $\mathrm{mmol}$ & Millimole \\
\hline Mp & Melting Point \\
\hline $\mathrm{N}_{2}$ & Nitrogen gas \\
\hline
\end{tabular}




$\begin{array}{ll}\mathrm{N}_{2} \mathrm{H}_{4} & \text { Hydrazine } \\ \mathrm{Na}_{2} \mathrm{CO}_{3} & \text { Sodium Carbonate } \\ \mathrm{NaH} & \text { Sodium Hydride } \\ \mathrm{NaN}_{3} & \text { Sodium azide } \\ \mathrm{NMR} & \text { Nuclear Magnetic Resonance } \\ \mathrm{Phth} & \text { Phthaloyl } \\ \mathrm{PMB} & p \text {-Methoxybenzyl } \\ \mathrm{PMB}-\mathrm{Cl} & \text { 4-Methoxybenzyl Chloride } \\ \mathrm{PROTAC} & \text { Proteolysis-targeting chimera } \\ \mathrm{rt} & \text { Room temperature } \\ \mathrm{SeO} & \\ \mathrm{TBAF} & \text { Selenium Oxide } \\ t \mathrm{Bu} & \text { Tetra- } n \text {-butylammonium Fluoride } \\ \text { THF } & \text { tert-Butyl } \\ \text { TLC } & \text { Tetrahydrofuran } \\ \text { TNF- } \alpha & \text { Thin-Layer Chromatography } \\ \text { TOF } & \text { Tumor Necrosis Factor } \alpha \\ \text { TsOH } & \text { Time of Flight } \\ & p \text {-Toluenesulfonic Acid }\end{array}$




\section{Synthesis of 1,2,3-triazole 'click' analogues of thalidomide}

\section{Jarrid M. Ronnebaum, Frederick A. Luzzio *}

Department of Chemistry, University of Louisville, 2320 South Brook Street, Louisville, KY 40292, USA

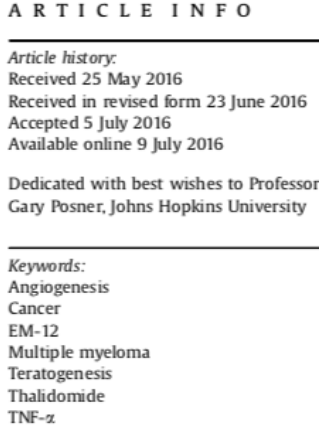

A B S T R A C T

Click analogues of thalidomide were prepared from 3-azidoglutarimide and a diverse array of arylacetylenes and $N$-ethynyl/ $N$-propargyl phthalimide derivatives. The sequence necessitated a new and scalable synthesis of the key click intermediate 3-azidoglutarimide. The dipolar cycloaddition reactions scalable synthesis of the key click intermediate 3 -azidoglutarimide. The dipolar cycloaddition reactions
between the azidoglutarimide and the alkynyl coupling partners utilized a copper sulfate/sodium ascorbate reagent system in aqueous tetrahydrofuran and were first explored using substituted arylalkynes. Along with the click analogues of thalidomide, the click counterparts of the teratogenic and antiangiogenic thalidomide analogue EM-12 were prepared.

C 2016 Elsevier Ltd. All rights reserved.

\section{Introduction}

In contrast to its notoriety as a potent embryotoxin, the diverse biological effects of thalidomide $\mathbf{1}$ (Fig. 1) have proven beneficial. ${ }^{1,2}$ The compound is an approved antilepromatic, and together with some of its analogues are active as immunosuppressants, immunomodulators, anti-inflammatories and anticancer agents. ${ }^{3}$ As an experimental therapeutic, the antiangiogenic properties of thalidomide and closely-related analogues have gained much attention in the anticancer community. ${ }^{4-8}$ The implication that $\mathbf{1}$ undergoes metabolic activation as an antiangiogenic agent was a consequence of in vivo metabolic studies in the rabbit and ex vivo studies with human microsomal preparations. ${ }^{9-13}$ At present, the structural elucidation and identity of the active antiangiogenic (or even teratogenic) species, if those indeed exist, has not been ascertained as well as its interaction with any purported molecular target. ${ }^{14,15}$ Even though the suspected metabolites of thalidomide have been bioassay targets, most analogues have been prepared and evaluated for diverse activities without any considerations of metabolism in mind. ${ }^{16,17}$ From the outset, however, a number of basic structural requirements became evident and were considered during the design of the most potent thalidomide analogues: ${ }^{18}$ (1) the

- Corresponding author. E-mail address: faluzz01@louisville.edu (F.A. Luzzio) ttp://dx doiorg/101016/itet 201607019 0040-4020/0 2016 Elsevier Ltd. All rights reserved.

phthalimide portion of the molecule had to possess an intact fivemember phthalimide or phthalimidine (lactam) ring: (2) the sixmember glutarimide portion of the molecule had to possess an intact glutarimide ring with both carbonyls; (3) the imide $(\mathrm{N}-\mathrm{H})$ nitrogen had to possess the free hydrogen-not replaced with ' $\mathrm{R}$ ' groups; (4) single or multiple substitutions on the aryl ring of the phthalimide while observing requirements 1-3 (above). While item 4 (above) has led to analogues of greater activity, this was specifically the case with the therapeutically-approved thalidomide analogues pomalidomide $\mathbf{2}$ and lenalidomide $\mathbf{3}$ (Fig. 1), compounds
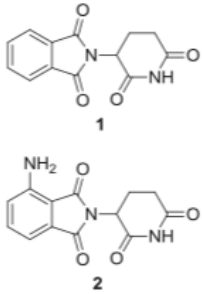

Fig. 1. Thalidomide analogues
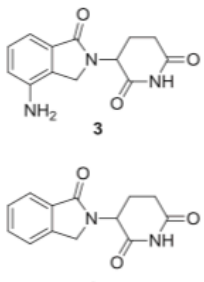

4 
which are used to treat multiple myeloma. ${ }^{19-21}$ The structural basis for lenalidomide was derived from the well-known thalidomide analogue EM-124 (Fig. 1), one of the early analogues investigated as a teratogen 22,23 and later found to have both anti-TNF- $\alpha$ and antiangiogenic activity. ${ }^{24,25}$ Remarkably, very little change in the structure of 1 was responsible for delivering analogues of high therapeutic potency in $\mathbf{2}$ and $\mathbf{3}$. While analogues involving substitution at just about every atom of the thalidomide core have been prepared, no thalidomide analogues designed with a 'spacer' in between the phthalimide and glutarimide sections of the molecule have been examined. The concept is reminiscent of the 'fleximer' analogues in nucleoside chemistry whereby there is a heteroatom or carbon linker between portions of a nucleobase or a nucleobase and a sugar. ${ }^{26}$ In the thalidomide series, such spacers could be in the form of an alkyl group, multivalent heteroatom or a carbocyclic or heterocyclic moiety (Fig. 2, 5a-c). In terms of simplicity in synthesis, a carbon-based 'homoalkyl' analogue of thalidomide (5a) would be the most difficult to synthesize and would require carbon-carbon bond construction within the glutarimide framework. Heteroatoms such as nitrogen, oxygen, sulfur or phosphorus placed between the glutarimide and phthalimide rings (5b) may compromise stability while carbocycles between both rings $(\mathbf{5 c})$ will also require a significant synthetic commitment. The 1,2,3-triazole linker in 6 (Fig. 2), formed by the click reaction of an $\mathrm{N}$-substituted phthalimido azide, acetylene or propargyl group with a glutarimide-substituted acetylene or azide would be the most viable route. ${ }^{27-29}$ Moreover, the triazole-linked compounds may yield interesting bioassay results since these analogues exhibit both intact phthalimide and glutarimide rings and one or both moieties may associate with the molecular target. ${ }^{30}$ Due to the ease of preparing many azides and acetylenes with simple substitution, the click route could be put to practice with relative ease and would only necessitate the exploration and adjustment of the conditions for the cycloaddition reaction. We describe herein the preparation of the first triazole spacer click analogues of thalidomide and its closely-related bioactive analogue EM-12 as well as their click homologues having a triazole-methylene spacer unit.

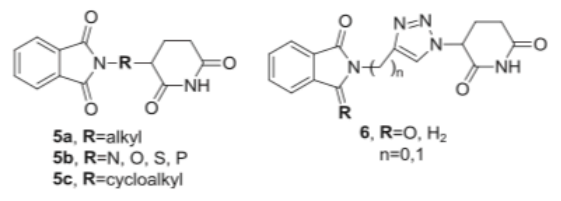

Fig. 2. Thalidomide analogues having phthalimide-glutarimide 'spacers".

\section{Results and discussion}

Our route to the 1,2,3-triazole series of thalidomide analogues 6 utilizes the 3-azido-substituted glutarimide 9 (Scheme 1). Commercially-available glutarimide $\mathbf{7}$ is reacted with bromine in chloroform at $100{ }^{\circ} \mathrm{C}$ which afforded the sensitive 3bromoglutarimide $\mathbf{8}$ as a low-melting solid. ${ }^{31}$ The $\alpha$-bromolactam $\mathbf{8}$ was directly treated with excess sodium azide in acetone to provide the 3-azidoglutarimide $\mathbf{9}$ as an off-white solid in $53 \%$ yield (overall from glutarimide). The azidoglutarimide $\mathbf{9}$ was first evaluated for its reactivity with phenylacetylene $\mathbf{1 0}$ in a click reaction mediated by cupric sulfate/sodium ascorbate (Table 1). Using the reaction conditions established with $\mathbf{9}$ and taking into consideration the success realized with earlier-investigated fluorinated analogues, ${ }^{17}$ several commercially-available fluoro- and trifluoromethyl-substituted arylalkynes 11-14 were reacted with

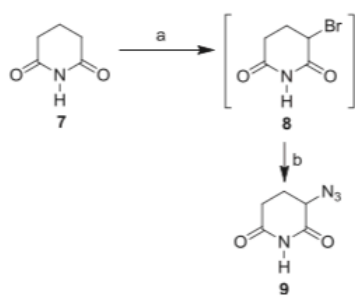

Scheme 1. Preparation of azidoglutarimide 9. Reagents/Conditions: (a) $\mathrm{Br}_{2} / \mathrm{CHCl}_{3} /$ 100 'C/45 min; (b) $\mathrm{NaN}_{3} / \mathrm{Me}_{2} \mathrm{CO} / \mathrm{rt} / 16 \mathrm{~h}$ (53\% from 7).

Table 1

Click products of arylacetylenes $\mathbf{1 0 - 1 4}$ with azidoglutarimide 9
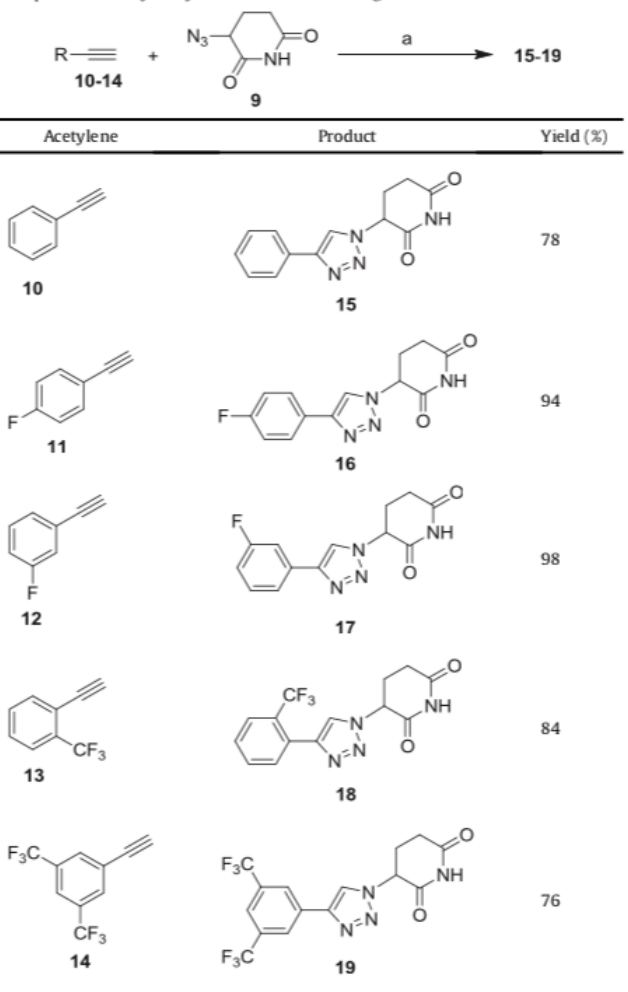

Reagents/conditions: (a) $\mathrm{CuSO}_{4} /$ sodium ascorbate/ $/ \mathrm{THF} / \mathrm{H}_{2} \mathrm{O} / \mathrm{rt} / 16 \mathrm{~h}$

the glutarimide azide $\mathbf{9}$ and afforded the corresponding click products 15-19 (Table 1 ). The yield of the click products ranged from 76 to $98 \%$ and all the compounds were tractable solids and easily purified by column chromatography on silica gel. The synthesis of the phthalimide/isoindolinone and $\mathrm{N}$-ethynyl/ $\mathrm{N}$-propargyl thalidomide reacting partners 24-27 are detailed in Scheme 2. The $\mathbf{N}$-ethynylphthalimide click partner $\mathbf{2 4}$ was prepared from 


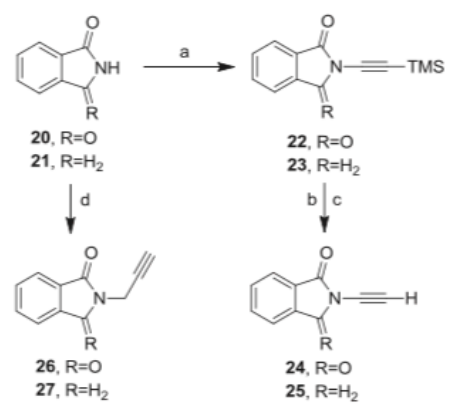

Scheme 2 Synthesis of $\mathrm{N}$-ethynyl and $\mathrm{N}$-propargyl phthalimides and isoindolinones 24-27. Reagents/Conditions: (a) ethynyltrimethylsilane $/ \mathrm{Cu}(\mathrm{OAc})_{2} / \mathrm{O}_{2} / \mathrm{pyridine} / \mathrm{Na}_{2} \mathrm{CO}$

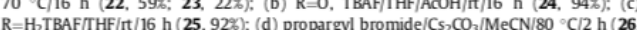
$69 \% ; 27,65 \%$ ).

phthalimide $\mathbf{2 0}$ and TMS-acetylene by the method of Davies (Scheme 2). ${ }^{32}$ Therefore, treatment of $\mathbf{2 0}$ with copper acetate, pyridine and ethynyltrimethylsilane in an atmosphere of oxygen provided the intermediate $\mathrm{N}$-(trimethylsilylethynyl) phthalimide 22 as a crystalline solid. Desilylation of the intermediate TMS ethynylphthalimide $\mathbf{2 2}$ was accomplished with TBAF/acetic acid and provided the unstable ethynyl phthalimide $\mathbf{2 4}$ (Scheme 2). Not surprisingly, isoindolinone $\mathbf{2 1}$, with its less-acidic or otherwise less-reactive proton, acted less favorably in the Davies ethynylation reaction and gave the trimethylsilyl isoindolinone $\mathbf{2 3}(22 \%)$ under similar conditions as $\mathbf{2 2}$. In contrast to $\mathbf{2 2}$, desilylation of $\mathbf{2 3}$ with TBAF only (THF/rt) gave the $\mathrm{N}$-ethynyl isoindolinone $\mathbf{2 5}$ (92\%) as a crystalline solid. The $\mathrm{N}$-propargylation of phthalimide $\mathbf{2 0}$ and isoindolinone 21, which gave the corresponding click partners 26 and 27, was more straightforward than the $\mathrm{N}$-ethynylation of $\mathbf{2 0}$ or 21. Phthalimide and isoindolinone intermediates $\mathbf{2 6}$ and $\mathbf{2 7}$ were both prepared by the reaction of $\mathbf{2 0}$ or $\mathbf{2 1}$ with propargyl bromide in the presence of cesium carbonate in acetonitrile (Scheme 2) ${ }^{15}$ Both propargylated intermediates (26, 69\%, 27, 65\%) were obtained as crystalline compounds after column chromatography. The reaction of ethynyl phthalimide $\mathbf{2 4}$ and azidoglutarimide $\mathbf{9}$ gave click thalidomide derivative $\mathbf{6 a}$ as a crystalline solid (83\%) after purification by column chromatography (Table 2). Using the same reaction conditions as $\mathbf{6 a}$, the ethynyl isoindolinone $\mathbf{2 5}$ and azidoglutarimide $\mathbf{9}$ afforded the click EM-12 analogue $\mathbf{6 b}$ (78\%) a a crystalline solid after column chromatography. Similarly, the $N$ propargyl phthalimide $\mathbf{2 6}$ and the $\mathrm{N}$-propargylisoindolinone $\mathbf{2 6}$ were clicked with azidoglutarimide $\mathbf{9}$ giving the homomethylene thalidomide analogue $\mathbf{6 c}$ and the homomethylene EM-12 analogue 6d in $67 \%$ and $61 \%$ yield respectively. The regiochemistry of the dipolar cycloaddition click reaction involves products in which the substitution could be 1,4- or 1,5- on the triazole ring depending on the reaction conditions or reagents. All of the click products described herein (Tables 1 and 2) were formed as a result of copper I) catalysis which gives exclusively the 1,4- or 'anti'-substituted 1,2,3-triazole. ${ }^{28}$

\section{Conclusions}

Synthetic routes to click analogues of thalidomide and its descarbonyl analogue EM-12 are detailed which utilize the key in termediate 3-azidoglutarimide along with $\mathrm{N}$-ethynyl and $\mathrm{N}$ propargyl analogues of phthalimide as reacting components. The dipolar cycloaddition chemistry of the azidoglutarimide was

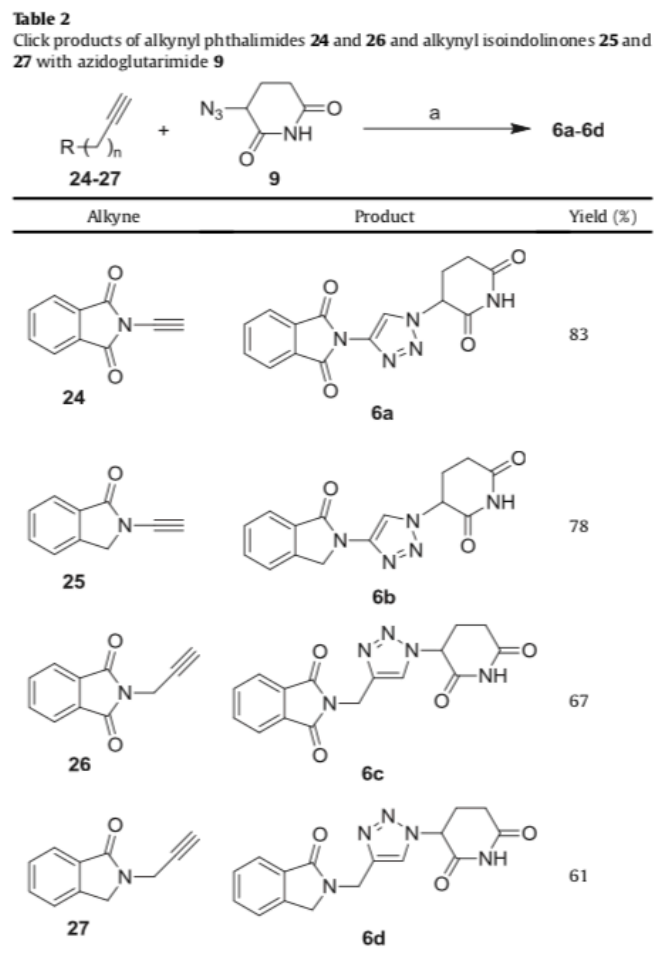

Reagents/conditions: (a) $\mathrm{CuSO}_{4} /$ sodium ascorbate/ $/ \mathrm{THF} / \mathrm{H}_{2} \mathrm{O} / \mathrm{rt} / 16 \mathrm{~h}$.

explored using arylalkynes containing electron-withdrawing groups in place of the phthalimide group and yielded cycloaddition products in high yield using the $\mathrm{CuSO}_{4} /$ sodium ascorbate reaction conditions. The click thalidomide analogues will be evaluated in a full range of bioassay types and these results will be reported in due course.

\section{Experimental}

Solvents and reagents are ACS grade and were used as commercially supplied. Analytical thin-layer chromatography (TLC) utilized $0.25 \mathrm{~mm}$ pre-cut glass-backed plates (Merck, Silica Gel 60 F254). Thin-layer chromatograms were visualized during chromatographic and extraction runs by rapidly dipping the plates in anisaldehyde/ethanol/sulfuric acid stain or phosphomolybdic acid/ ethanol stain and heating (hot plate). Gravity-column chromatography was carried out using silica gel 60 (E. Merck 7734, $70-230$ mesh). Flash-column chromatography utilized silica gel 60 (E. Merck 9385, 230-400 mesh) with nitrogen gas pressurization. Melting points were taken on a Thomas Hoover apparatus. Extracts and chromatographic fractions were concentrated with a Büchi rotavapor under water aspirator vacuum. Nuclear magnetic resonance $\left({ }^{1} \mathrm{H}\right.$ and ${ }^{13} \mathrm{C}$ NMR $)$ spectra were recorded with Varian VNMRS 400 or $700 \mathrm{MHz}$ instruments using $\mathrm{CDCl}_{3}$ as a solvent and TMS as internal standard. Infrared spectra (FTIR) were recorded with a Perkin-Elmer Spectrum 100 instrument and spectral values are 
reported as $\mathrm{cm}^{-1}$. The measurement of high-resolution mass spectra (HRMS) were performed at the Texas A\&M University Laboratory for Biological Mass Spectrometry. Elemental analysis was performed by Galbraith Laboratories, Knoxville, TN.

\subsection{3-Azidopiperidine-2,6-dione 9}

To a $48 \mathrm{~mL}$ glass pressure reaction vessel fitted with a Teflon screw cap was added piperidine-2,6-dione $(2.00 \mathrm{~g}, 17.7 \mathrm{mmol})$ and $\mathrm{Br}_{2}(2.82 \mathrm{~g}, 0.90 \mathrm{~mL}, 17.7 \mathrm{mmol})$ in chloroform $(15 \mathrm{~mL})$. The reaction mixture was then heated in a Kugelröhr oven at $110^{\circ} \mathrm{C}(45 \mathrm{~min})$. The solvent was removed and the crude bromoglutarimide 7 was then dissolved in acetone $(5 \mathrm{~mL})$ followed by the addition of sodium azide ( $3.44 \mathrm{~g}, 53.1 \mathrm{mmol}$ ) whereupon the reaction mixture turned blue-purple. The reaction mixture was stirred at room temperature $(24 \mathrm{~h})$ and then directly applied to a silica gel column. Elution with hexane/ethyl acetate (1:1) gave a mixture of unreacted 3-bromopiperidine-2,6-dione $\mathbf{7}$ and 3-azidopiperidine-2,6-dione 8 (1:1). The mixture of azide $\mathbf{8}$ and unreacted bromide $\mathbf{7}$ was again dissolved in acetone $(5 \mathrm{~mL})$ and sodium azide (1.15 g, $17.7 \mathrm{mmol})$ was added and stirring of the blue-purple reaction mixture was continued at room temperature $(24 \mathrm{~h})$. Column chromatography (hexane/ethyl acetate, 1:1) of the reaction mixture gave pure 3azidopiperidine-2,6-dione $\mathbf{9}$ as an off-white amorphous solid ( $1.44 \mathrm{~g}, 53 \%$ from glutarimide): $\mathrm{mp} 144-145^{\circ} \mathrm{C} ; R_{f} 0.24$ (TLC stains blue with heat); ${ }^{1} \mathrm{H}$ NMR $\left(400 \mathrm{MHz}, \mathrm{CDCl}_{3}\right) \delta 4.21$ (dd, $J=9.6 \mathrm{~Hz}$, $8.4 \mathrm{~Hz}, 1 \mathrm{H}), 2.78(\mathrm{dt}, J=18.4 \mathrm{~Hz}, 5.6 \mathrm{~Hz}, 1 \mathrm{H}) 2.63-2.54(\mathrm{~m}, 1 \mathrm{H})$, $2.23-2.16(\mathrm{~m}, 1 \mathrm{H}), 2.04-1.95(\mathrm{~m}, 1 \mathrm{H}) .{ }^{13} \mathrm{C}$ NMR $\left(400 \mathrm{MHz}, \mathrm{CDCl}_{3}\right)$ $\delta$ 170.7, 169.2, 58.2, 29.1, 24.0. FTIR (neat) 3090, 2112, 1710 , $1676 \mathrm{~cm}^{-1}$; HRMS (ESI-TOF) $\mathrm{m} / \mathrm{z}[\mathrm{M}+\mathrm{H}]^{+}$calcd for $\mathrm{C}_{5} \mathrm{H}_{6} \mathrm{~N}_{4} \mathrm{O}_{2}$ : 155.0491, Found: 155.0569

\subsection{General procedure for the preparation of click compounds 15-19}

To a stirred solution of 3-azidopiperidine-2,6-dione $\mathbf{9}(20.0 \mathrm{mg}$ $0.13 \mathrm{mmol})$ and arylalkyne $\mathbf{1 0}-\mathbf{1 4}(\mathbf{0 . 1 4 3} \mathrm{mmol})$ in tetrahydrofuran $(750 \mu \mathrm{L})$ was added aqueous copper sulfate $(52 \mathrm{mM}, 0.013 \mathrm{mmol}$, $250 \mu \mathrm{L})$. Sodium ascorbate $(12.8 \mathrm{mg}, 0.065 \mathrm{mmol}$ ) was then added ten minutes after the addition of the $\mathrm{CuSO}_{4}$ solution. The reaction mixture was stirred ( $16 \mathrm{~h}$ ) at room temperature followed by direct application to a gravity silica gel column and elution with chloroform/methanol (95:5). Combination and concentration of the chromatographic fractions gave the pure triazoles $15-19$ as white or off-white amorphous solids.

\subsection{3-(4-Phenyl-1H-1,2,3-triazol-1-yl)piperidine-2,6-dione 15}

3-(4-Phenyl-1 H-1,2,3-triazol-1-yl)piperidine-2,6-dione 15 was obtained as a white amorphous solid ( $26 \mathrm{mg}, 78 \%)$ : $\mathrm{mp} 208-210^{\circ} \mathrm{C}$; $R_{f} 0.28$ (chloroform/methanol, 9:1); ${ }^{1} \mathrm{H}$ NMR (400 MHz, DMSO- $d_{6}$ ) $\delta 11.25(\mathrm{~s}, 1 \mathrm{H}), 8.66(\mathrm{~s}, 1 \mathrm{H}), 7.82-7.84(\mathrm{~d}, J=7.2 \mathrm{~Hz}, 2 \mathrm{H}), 7.42-7.46$ (m, 2H), 7.30-7.34 (m, 1H), 5.84 (dd, J=13.2, 5.2 Hz, 1H), 2.83-2.91 $(\mathrm{m}, 1 \mathrm{H}) 2.65-2.76(\mathrm{~m}, 2 \mathrm{H}) 2.34-2.36(\mathrm{~m}, 1 \mathrm{H}) ;{ }^{13} \mathrm{C}$ NMR $(100 \mathrm{MHz}$, DMSO- $\left.d_{6}\right): \delta 172.8,169.9,146.7,131.0,129.4,128.4,125.5,122.0$, 59.6, 31.1, 24.8: IR (neat) 3090, 2930,1732, 1699, $1676 \mathrm{~cm}^{-1}$; HRMS (ESI-TOF) $m / z[\mathrm{M}+\mathrm{H}]^{+}$; calcd for $\mathrm{C}_{13} \mathrm{H}_{13} \mathrm{~N}_{4} \mathrm{O}_{2}: 257.1039$, Found: 257.1140 .

\subsection{3-(4-(4-Fluorophenyl)-1H-1,2,3-triazol-1-yl)piperidine- 2,6-dione 16}

3-(4-(4-Fluorophenyl)-1H-1,2,3-triazol-1-yl)piperidine-2,6dione 16 was obtained as a white amorphous solid (64 mg, 94\%): mp 221-222 ${ }^{\circ} \mathrm{C}$; $R_{f} 0.32$ (chloroform/methanol, 9:1); ${ }^{1} \mathrm{H}$ NMR $\left(400 \mathrm{MHz}, \mathrm{DMSO}-d_{6}\right) \delta 11.24(\mathrm{~s}, 1 \mathrm{H}), 8.64(\mathrm{~s}, 1 \mathrm{H}) 7.84-7.88(\mathrm{~m}, 2 \mathrm{H})$ $7.25-7.30(\mathrm{~m}, 2 \mathrm{H}), 5.83(\mathrm{dd}, J=12.4,4.8 \mathrm{~Hz}, 1 \mathrm{H}), 2.82-2.90(\mathrm{~m}, 1 \mathrm{H})$ $2.62-2.70(\mathrm{~m}, 2 \mathrm{H}), 2.32-2.35(\mathrm{~m}, 1 \mathrm{H}){ }^{13} \mathrm{C}$ NMR $(100 \mathrm{MHz}$, DMSO$\left.d_{6}\right): \delta 172.8,169.8,163.5,161.0,145.8,127.6(\mathrm{~d}, J=7.6 \mathrm{~Hz}), 122.0,116.4$ (d, $J=22.0 \mathrm{~Hz}$ ), 59.6, 31.1, 24.8. IR (neat) 3194, 3105, 2916, 1731, $1708 \mathrm{~cm}^{-1}$. HRMS (ESI-TOF) $\mathrm{m} / z[\mathrm{M}+\mathrm{H}]^{+}$; calcd for $\mathrm{C}_{13} \mathrm{H}_{12} \mathrm{FN}_{4} \mathrm{O}_{2}$ : 275.0944, Found: 275.1014

\subsection{3-(4-(3-Fluorophenyl)-1H-1,2,3-triazol-1-yl)piperidine- 2,6-dione 17}

3-(4-(3-Fluorophenyl)-1H-1,2,3-triazol-1-yl)piperidine-2,6dione 17 was obtained as a white solid (35 mg, 98\%): $\mathrm{mp}$ 199-201 ${ }^{\circ} \mathrm{C}$; $R_{f} 0.375$ (chloroform/methanol, 9:1); ${ }^{1} \mathrm{H}$ NMR $\left(400 \mathrm{MHz}\right.$, DMSO$\left.-d_{6}\right) \delta 11.25(\mathrm{~s}, 1 \mathrm{H}), 8.74(\mathrm{~s}, 1 \mathrm{H}), 7.65-7.69(\mathrm{~m}, 1 \mathrm{H})$ $7.46-7.51(\mathrm{~m}, 2 \mathrm{H}), 7.13-7.18(\mathrm{~m}, 1 \mathrm{H}), 5.85(\mathrm{dd}, J=12.4,4.4 \mathrm{~Hz}, 1 \mathrm{H})$, $2.83-2.89(\mathrm{~m}, 1 \mathrm{H}), 2.62-2.71(\mathrm{~m}, 2 \mathrm{H}), 2.34-2.37(\mathrm{~m}, 1 \mathrm{H}){ }^{13} \mathrm{C}$ NMR $\left(100 \mathrm{MHz}, \mathrm{DMSO}-d_{6}\right): \delta 172.9,169.8,164.2,161.8,145.7,132.4$ (d, $J=154.9 \mathrm{~Hz}), 122.9,121.6,115.2(\mathrm{~d}, J=21.3 \mathrm{~Hz}), 112.1(\mathrm{~d}, J=15.9 \mathrm{~Hz})$ 59.7, 31.1, 24.8. IR (neat) 3098, 2917, 2853, 1732, $1705 \mathrm{~cm}^{-1}$. HRMS (ESI-TOF) $m / z[\mathrm{M}+\mathrm{H}]^{+}$; calcd for $\mathrm{C}_{13} \mathrm{H}_{12} \mathrm{FN}_{4} \mathrm{O}_{2}: 275.0944$, Found: 275.0837.

\subsection{3-(4-(2-(Trifluoromethyl)phenyl)-1H-1,2,3-triazol-1-yl)} piperidine-2,6-dione 18

3-(4-(2-(Trifluoromethyl)phenyl)-1H-1,2,3-triazol-1-yl)piperidine-2,6-dione was obtained as a white solid (36 mg, $84 \%$ ): $\mathrm{mp}$ 155-157 ${ }^{\circ} \mathrm{C} ; \quad R_{f} 0.37$ (chloroform/methanol, 9:1); ${ }^{1} \mathrm{H}$ NMR $\left(400 \mathrm{MHz}, \mathrm{DMSO}-d_{6}\right) \delta 11.23(\mathrm{~s}, 1 \mathrm{H}), 8.41(\mathrm{~s}, 1 \mathrm{H}), 7.74-7.85(\mathrm{~m}, 3 \mathrm{H})$, $7.60-7.63(\mathrm{~m}, 1 \mathrm{H}), 5.89$ (dd, $J=12.8,5.2 \mathrm{~Hz}, 1 \mathrm{H}), 2.83-2.90(\mathrm{~m}, 1 \mathrm{H})$, $2.65-2.78(\mathrm{~m}, 2 \mathrm{H}), 2.31-2.36(\mathrm{~m}, 1 \mathrm{H}){ }^{13} \mathrm{C}$ NMR $(100 \mathrm{MHz}$, DMSO$\left.d_{6}\right): \delta 172.9,169.8,143.7,133.1,132.2,129.8(\mathrm{q}, J=2.2 \mathrm{~Hz}), 129.3,126.8$ (q, $J=30.4 \mathrm{~Hz}), 126.7$ (q, J=6.1 Hz), 124.8 (q, J=3.1 Hz), 124.4 (q, $J=271.8 \mathrm{~Hz}$ ), 59.7, 31.2, 24.8. IR (neat) 3220, 3094, 2957, 1732 , $1701 \mathrm{~cm}^{-1}$. HRMS (ESI-TOF) $\mathrm{m} / z[\mathrm{M}-\mathrm{H}]^{-}$; calcd for $\mathrm{C}_{14} \mathrm{H}_{10} \mathrm{~F}_{3} \mathrm{~N}_{4} \mathrm{O}_{2}$ 323.0756, Found: 323.0714.

\subsection{3-(4-(3,5-Bis(trifluoromethyl)phenyl)-1H-1,2,3-triazol-1- yl)piperidine-2,6-dione 19}

3-(4-(3,5-bis(Trifluoromethyl)phenyl)-1H-1,2,3-triazol-1-yl)piperidine-2,6-dione 19 was obtained as a white solid (38 mg, 76\%): mp 115-117 ${ }^{\circ} \mathrm{C}$; $R_{f} 0.29$ (chloroform/methanol, 9:1); ${ }^{1} \mathrm{H}$ NMR $\left(400 \mathrm{MHz}, \mathrm{DMSO}-\mathrm{d}_{6}\right) \delta 11.29(\mathrm{~s}, 1 \mathrm{H}), 9.07(\mathrm{~s}, 1 \mathrm{H}), 8.50(\mathrm{~s}, 2 \mathrm{H}), 8.07(\mathrm{~s}$, $1 \mathrm{H}), 5.91(\mathrm{dd}, J=12.8,5.2 \mathrm{~Hz}, 1 \mathrm{H}), 2.84-2.89(\mathrm{~m}, 1 \mathrm{H}), 2.66-2.73(\mathrm{~m}$, $2 \mathrm{H}), 2.38-2.41(\mathrm{~m}, 1 \mathrm{H}){ }^{13} \mathrm{C}$ NMR $\left(100 \mathrm{MHz}\right.$, DMSO- $\left.d_{6}\right): \delta 172.8$ $169.7,144.1,133.5,131.5$ (q, $J=32.6 \mathrm{~Hz}), 125.7,124.2,123.2$ (q, $J=271.9 \mathrm{~Hz}$ ), 121.7, 59.8, 31.1, 24.7. IR (neat) 3219, 3094, 2872, 1733 . $1704 \mathrm{~cm}^{-1}$. HRMS (ESI-TOF) $\mathrm{m} / \mathrm{z}[\mathrm{M}-\mathrm{H}]^{-}$; calcd for $\mathrm{C}_{15} \mathrm{H}_{9} \mathrm{~F}_{6} \mathrm{~N}_{4} \mathrm{O}_{2}$ 391.0630, Found: 391.0707 .

\subsection{Isoindolin-1-one 21}

In a $100 \mathrm{~mL}$ round bottom flask phthalimide 20 (5.00 g. $34.0 \mathrm{mmol}$ ) was dissolved in acetic acid $(25 \mathrm{~mL}$ ). A slurry of tin metal (9.68 g, $81.6 \mathrm{mmol}$ ) and concentrated hydrochloric acid $(12.5 \mathrm{~mL})$ was added to the phthalimide solution. The reaction mixture was heated under reflux at $120^{\circ} \mathrm{C}(6 \mathrm{~h})$ then diluted with dichloromethane $(75 \mathrm{~mL})$ and washed with brine $(3 \times 25 \mathrm{~mL})$. Concentration of the extract followed by gravity-column chromatography (chloroform/methanol, 95:5) gave pure isoindolin-1-one as an off-white solid ( $1.75 \mathrm{~g}, 39 \%$ yield): $\mathrm{mp} 154-156{ }^{\circ} \mathrm{C}$ (Lit. ${ }^{35}$ $\left.150-152{ }^{\circ} \mathrm{C}\right)$. The spectroscopic data was consistent with the literature: ${ }^{34}{ }^{1} \mathrm{H}$ NMR $\left(400 \mathrm{MHz}, \mathrm{CDCl}_{3}\right) \delta 7.87(\mathrm{~d}, J=8 \mathrm{~Hz}, 1 \mathrm{H})$, $7.75-7.59(\mathrm{~m}, 1 \mathrm{H}), 7.47-7.49(\mathrm{~m}, 2 \mathrm{H}), 4.47(\mathrm{~s}, 2 \mathrm{H})$. 


\subsection{2-(2-(Trimethylsilyl)ethynyl)isoindoline-1,3-dione 22}

Prepared by the method of Davies (59\%): ${ }^{32} \mathrm{mp} 92-94{ }^{\circ} \mathrm{C}$ (Lit. $^{33}$ $94-96^{\circ} \mathrm{C}$ ). The spectroscopic data was consistent with the literature: ${ }^{32}{ }^{1} \mathrm{H}$ NMR $\left(400 \mathrm{MHz}, \mathrm{CDCl}_{3}\right) \delta 7.90-7.93(\mathrm{~m}, 2 \mathrm{H}), 7.78-7.81$ $(\mathrm{m}, 2 \mathrm{H}), 0.273(\mathrm{~s}, 9 \mathrm{H})$.

\subsection{2-(2-(Trimethylsilyl)ethynyl)isoindolin-1-one 23}

To a $250 \mathrm{~mL}$ round bottom flask $\mathrm{Cu}(\mathrm{OAc})_{2}(76.4 \mathrm{mg}, 0.42 \mathrm{mmol}$ ), isoindolin-1-one ( $1.00 \mathrm{~g}, 7.51 \mathrm{mmol}), \mathrm{Na}_{2} \mathrm{CO}_{3}(216 \mathrm{mg}, 4.2 \mathrm{mmol}$ ), and $4 \mathrm{~A}$ molecular sieves $(2.0 \mathrm{~g})$ were combined. A solution of pyridine ( $324 \mathrm{~mL}, 4.2 \mathrm{mmol}$ ) in toluene $(30 \mathrm{~mL}$ ) was added to the reaction flask followed by sweeping with three volumes of $\mathrm{O}_{2}$. The reaction flask was placed in an oil bath and stirred for $1 \mathrm{~h}\left(70^{\circ} \mathrm{C}\right)$ until the reaction mixture was a bright green color. A solution of ethynyltrimethylsilane $(298 \mu \mathrm{L}, 2.1 \mathrm{mmol})$ in dry toluene $(2 \mathrm{~mL})$ was added to the mixture over $30 \mathrm{~min}$. The reaction mixture was allowed to stir $(4 \mathrm{~h})$ during which time the reaction mixture changed to a black suspension. The reaction mixture was filtered through Celite ${ }^{3}$, concentrated under reduced pressure and purified by flash column chromatography (hexane/ethyl acetate, 5:1) to yield 23 as a fluffy white amorphous solid (106 mg, 22\%): mp $134-136{ }^{\circ} \mathrm{C} ; R_{f} 0.33$ (hexane/ethyl acetate, $\left.4: 1\right) ;{ }^{1} \mathrm{H} \mathrm{NMR}(400 \mathrm{MHz}$, $\left.\mathrm{CDC}_{3}\right) \delta 7.89(\mathrm{~d} J=7.6 \mathrm{~Hz}, 1 \mathrm{H}), 7.62(\mathrm{dd} J=8.0,7.6 \mathrm{~Hz}, 1 \mathrm{H}), 7.50(\mathrm{dd}$ $J=8.0,7.6 \mathrm{~Hz}, 1 \mathrm{H}), 7.44(\mathrm{~d} J=8.0 \mathrm{~Hz}, 1 \mathrm{H}), 4.70(\mathrm{~s}, 2 \mathrm{H}), 0.25(\mathrm{~s}, 9 \mathrm{H}) .{ }^{13} \mathrm{C}$ NMR $\left(175 \mathrm{MHz}, \mathrm{CDCl}_{3}\right) \delta 168.6,140.8,133.0,129.6,128.6,124.6$, $122.8,92.8,75.9,52.5,0.18$. IR (neat) $2954,2902,2167,1712 \mathrm{~cm}^{-1}$ HRMS (ESI-TOF) $\mathrm{m} / \mathrm{z}[\mathrm{M}+\mathrm{Cl}]^{-}$; calculated for $\mathrm{C}_{13} \mathrm{H}_{15}^{35} \mathrm{CINOSi}$ 264.0617, Found: 264.0688

\subsection{2-Ethynylisoindoline-1,3-dione 24}

Prepared by the Method of Davies (94\%): ${ }^{32} \mathrm{mp} 165-169{ }^{\circ} \mathrm{C}$ (Lit. ${ }^{33} 167-172^{\circ} \mathrm{C}$ ). The spectroscopic data was consistent with the literature: ${ }^{32}{ }^{1} \mathrm{H}$ NMR $\left(400 \mathrm{mHz}, \mathrm{CDCl}_{3}\right) \delta 7.92-7.94(\mathrm{~m}, 2 \mathrm{H})$ $7.80-7.83(\mathrm{~m}, 2 \mathrm{H}), 3.33(\mathrm{~s}, 1 \mathrm{H})$.

\subsection{2-Ethynylisoindoline-1-one 25}

2-(2-(Trimethylsilyl)ethynyl)isoindolin-1-one $23(72.0 \mathrm{mg}$, $0.313 \mathrm{mmol}$ ) was dissolved in THF $(3.0 \mathrm{~mL}$ ) while stirring followed by the addition of tetra- $N$-butylammonium fluoride (TBAF, $450 \mu \mathrm{L}$, $1 \mathrm{M}$ solution). Stirring was continued (10 $\mathrm{min})$ until the reaction was complete as indicated by TLC. The crude reaction mixture was directly submitted to gravity-column chromatography (hexanes] ethyl acetate) and afforded 25 as a white solid (45 mg, 92\%): mp 92-94 ${ }^{\circ} \mathrm{C} ; R_{f} 0.21$ (hexane/ethyl acetate, $\left.4: 1\right) ;{ }^{1} \mathrm{H}$ NMR $(400 \mathrm{MHz}$, $\left.\mathrm{CDCl}_{3}\right) \delta 7.91(\mathrm{~d} J=7.2 \mathrm{~Hz}, 1 \mathrm{H}), 7.64(\mathrm{dd} J=7.2,7.2 \mathrm{~Hz}, 1 \mathrm{H}), 7.51$ (dd $J=7.2,7.2 \mathrm{~Hz}, 1 \mathrm{H}), 7.46(\mathrm{~d} J=7.2 \mathrm{~Hz}, 1 \mathrm{H}), 4.71(\mathrm{~s}, 2 \mathrm{H}), 3.08(\mathrm{~s}, 1 \mathrm{H}) .{ }^{13} \mathrm{C}$ NMR $\left(175 \mathrm{MHz}, \mathrm{CDCl}_{3}\right) \delta 169.1,140.9,133.2,129.4,128.7,124.7$ 122.9, 73.9, 61.7, 52.1. IR (neat) 3268, 2931, 2139, $1718 \mathrm{~cm}^{-1}$. Anal Calcd for $\mathrm{C}_{10} \mathrm{H}_{7} \mathrm{NO}$ (157.17): C, 76.42; H, 4.49; N, 8.91; Found: C. 76.32; H, 4.68; N, 8.69.

\subsection{2-(Prop-2-yn-1-yl)isoindoline-1,3-dione 26}

Prepared by the method of Clayton (69\%): ${ }^{34} \mathrm{mp} 146-148{ }^{\circ} \mathrm{C}$ (Lit. ${ }^{36} 149-150{ }^{\circ} \mathrm{C}$ ). The spectroscopic data was consistent with the literature: ${ }^{36}{ }^{1} \mathrm{H}$ NMR $\left(400 \mathrm{MHz}, \mathrm{CDCl}_{3}\right) \delta 7.80-7.91(\mathrm{~m}, 2 \mathrm{H})$, $7.74-7.76(\mathrm{~m}, 2 \mathrm{H}), 4.47(\mathrm{~s}, 2 \mathrm{H}), 2.24(\mathrm{~s}, 1 \mathrm{H})$.

\subsection{2-(Prop-2-yn-1-yl)isoindolin-1-one 27}

Isoindolin-1-one 21 (250 mg. $1.85 \mathrm{mmol}$ ) was dissolved in acetonitrile $(9 \mathrm{~mL})$ and cesium carbonate $(2.40 \mathrm{~g}, 7.39 \mathrm{mmol})$ was added followed by propargyl bromide ( $308 \mu \mathrm{L}, 2.77 \mathrm{mmol}$ ). The reaction mixture was stirred at reflux $(2 \mathrm{~h})$. The reaction mixture was then dissolved in $\mathrm{CH}_{2} \mathrm{C}_{2}(10 \mathrm{~mL})$ and washed with water $(3 \times 15 \mathrm{~mL})$. The organic layer was dried $\left(\mathrm{Na}_{2} \mathrm{SO}_{4}\right)$, filtered and concentrated under reduced pressure. Gravity-column chromatography of the residual oil (hexane/ethyl/acetate, 2:1) gave $\mathbf{2 7}$ as a yellow solid (205 mg. 65\%): mp 79-81 ${ }^{\circ} \mathrm{C} ; R_{f} 0.66$ (ethyl acetate); ${ }^{1} \mathrm{H}$ NMR $(400 \mathrm{MHz}$, $\left.\mathrm{CDCl}_{3}\right) \delta 7.82(\mathrm{~d} \mathrm{~J}=8.0 \mathrm{~Hz}, 1 \mathrm{H}), 7.52(\mathrm{dd} J=8.0,7.2 \mathrm{~Hz}, 1 \mathrm{H}) 7.41-7.45$ $(\mathrm{m}, 2 \mathrm{H}), 4.47(\mathrm{~s}, 2 \mathrm{H}), 4.24(\mathrm{~s}, 2 \mathrm{H}), 2.28(\mathrm{~s}, 1 \mathrm{H}),{ }^{13} \mathrm{C} \mathrm{NMR}(100 \mathrm{MHz}$, $\left(\mathrm{CDCl}_{3}\right) \delta 167.9,141.2,132.1,131.6,128.1,123.8,122.8,78.1,72.5,49.1$, 31.7. IR (neat) $3290,3243,2118,1701 \mathrm{~cm}^{-1}$; HRMS (ESI-TOF) $\mathrm{m} / \mathrm{z}$ $[\mathrm{M}+\mathrm{H}]^{+}$; calculated for $\mathrm{C}_{11} \mathrm{H}_{10} \mathrm{NO} 172.0762$, Found: 172.0857

\subsection{General procedure for the preparation of click products 6a-6d}

3-Azidopiperidine-2,6-dione 9 ( $0.25-0.5 \mathrm{mmol}, 38-74 \mathrm{mg})$ and phthalimide or isoindolinone alkynes $\mathbf{2 4}, \mathbf{2 6}, \mathbf{2 5}$ or $\mathbf{2 7}$ ( $0.275-0.55 \mathrm{mmol}, 1.1$ equiv) were dissolved in $25 \%$ aqueous THF $(2.0 \mathrm{~mL})$. The mixture was stirred $(10 \mathrm{~min})$ before addition of solid $\mathrm{CuSO}_{4}$ ( 0.5 equiv) and sodium ascorbate ( 0.5 equiv) whereupon the reaction mixture became a teal-colored suspension and stirring was continued $(16 \mathrm{~h})$. The reaction mixture was concentrated under rotary evaporation while absorbing onto silica gel (70-230 mesh) and the resulting dry residue was applied to a silica gel chromatography column.

4.16. 2-(1-(2,6-Dioxopiperidin-3-yl)-1H-1,2,3-triazol-4-yl)isoindoline-1,3-dione $6 a$

The crude reaction mixture was submitted to gravity-column chromatography (hexane/ethyl acetate, 1:9) to give triazole $\mathbf{6 a}$ as a white amorphous powder ( $126 \mathrm{mg}, 83 \%)$ : mp 289-291 ${ }^{\circ} \mathrm{C} ; R_{f} 0.38$ (THF/hexane, 2:1); ${ }^{1} \mathrm{H}$ NMR $\delta\left(400 \mathrm{MHz}\right.$, DMSO- $\left.d_{6}\right) \delta 11.25(\mathrm{~s}, 1 \mathrm{H})$, $8.45(\mathrm{~s}, 1 \mathrm{H}), 7.97-8.00(\mathrm{~m}, 2 \mathrm{H}), 7.90-7.94(\mathrm{~m}, 2 \mathrm{H}), 5.90$ (dd $J=12.8$, $5.6 \mathrm{~Hz}, 1 \mathrm{H}), 2.82-2.86(\mathrm{~m}, 1 \mathrm{H}), 2.66-2.75(\mathrm{~m}, 2 \mathrm{H}), 2.34-2.37(\mathrm{~m}$, $1 \mathrm{H}) .{ }^{13} \mathrm{C}$ NMR $\left(100 \mathrm{MHz}\right.$, DMSO- $\left.d_{6}\right) \delta 172.7,169.5,166.5,136.1,135.5$, $131.8,124.2,122.9,60.2,31.2,24.6$. IR (neat) $3146,3067,2933,1721$, $1696 \mathrm{~cm}^{-1}$. HRMS (ESI-TOF) $\mathrm{m} / \mathrm{z}[\mathrm{M}+\mathrm{H}]^{+}$; calculated for $\mathrm{C}_{15} \mathrm{H}_{12} \mathrm{~N}_{5} \mathrm{O}_{4}$ 326.0889, Found: 326.0961 .

\subsection{3-(4-(1-Oxoisoindolin-2-yl)-1H-1,2,3-triazol-1-yl)piperi- dine-2,6-dione $6 b$}

The crude reaction mixture was submitted to gravity-column chromatography (chloroform/methanol, 95:5) and then recrystallized with methanol to give triazole $\mathbf{6 b}$ as a white amorphous powder (70 mg, 78\%): mp decomp. $>300^{\circ} \mathrm{C}$; $R_{f} 0.41$ (chloroform/methanol, 9:1): ${ }^{1} \mathrm{H}$ NMR $\left(700 \mathrm{MHz}\right.$, DMSO- $\left.d_{6}\right) \delta 11.19(\mathrm{~s}, 1 \mathrm{H}), 8.56(\mathrm{~s}, 1 \mathrm{H}), 7.79$ $(\mathrm{d} J=7.7 \mathrm{~Hz}, 1 \mathrm{H}), 7.67-7.71(\mathrm{~m}, 2 \mathrm{H}), 7.53(\mathrm{dd} J=7.7,7.0 \mathrm{~Hz}, 1 \mathrm{H}), 5.85$ (dd $J=13.3,5.6 \mathrm{~Hz}, 1 \mathrm{H}), 2.76-2.84(\mathrm{~m}, 2 \mathrm{H}), 2.64-2.66(\mathrm{~m}, 1 \mathrm{H}), 2.27-2.28$ $(\mathrm{m}, 1 \mathrm{H}) .{ }^{13} \mathrm{C}$ NMR $\left(100 \mathrm{MHz}, \mathrm{DMSO}-d_{6}\right) \delta 172.8,169.7,165.6,143.6$, $142.4,132.8,131.6,128.7,124.3,123.6,113.8,60.1,49.4,31.2,24.5$. IR (neat) $3180,3087,2923,1735,1697 \mathrm{~cm}^{-1}$. HRMS (ESI-TOF) $\mathrm{m} / \mathrm{z}$ $[\mathrm{M}+\mathrm{H}]^{+}$; calculated for $\mathrm{C}_{15} \mathrm{H}_{14} \mathrm{~N}_{5} \mathrm{O}_{3} 312.1097$, Found: 312.1176

\subsection{2-((1-(2,6-Dioxopiperidin-3-yl)-1H-1,2,3-triazol-4-yl)} methyl)isoindoline-1,3-dione $6 c$

The crude reaction mixture was submitted to gravity-column chromatography (chloroform/methanol, 97:3) to give triazole $\mathbf{6 c}$ as a white amorphous powder ( $56 \mathrm{mg}, 67 \%): \mathrm{mp} 230-232{ }^{\circ} \mathrm{C} ; R_{f}$ 0.44 (chloroform/methanol, 9:1); ${ }^{1} \mathrm{H}$ NMR (400 MHz, DMSO- $d_{6}$ ) $\delta 11.16(\mathrm{~s}, 1 \mathrm{H}), 8.16(\mathrm{~s}, 1 \mathrm{H}), 7.83-7.89(\mathrm{~m}, 4 \mathrm{H}), 5.74$ (dd $J=12.8$, $8.0 \mathrm{~Hz}, 1 \mathrm{H}), 4.83(\mathrm{~s}, 2 \mathrm{H}), 2.75-2.80(\mathrm{~m}, 1 \mathrm{H}), 2.56-2.63(\mathrm{~m}, 2 \mathrm{H})$, $2.20-2.23(\mathrm{~m}, 1 \mathrm{H}) .{ }^{13} \mathrm{C}$ NMR (100 MHz, DMSO- $\left.d_{6}\right) \delta 172.8,169.7$, 
$1677,142.7,135.0,132.0,123.7,123.6,59.5,33.3,311,24.7$. IR (neat) $3220,2957,2863,1732,1701 \mathrm{~cm}^{-1}$; HRMS (ESI-TOF) $\mathrm{m} / \mathrm{z}[\mathrm{M}+\mathrm{H}]^{+}$; calculated for $\mathrm{C}_{16} \mathrm{H}_{14} \mathrm{~N}_{5} \mathrm{O}_{4} 340.1046$, Found: 340.0888

\subsection{3-(4-((1-0xoisoindolin-2-yl)methyl)-1H-1,2,3-triazol-1- yl)piperidine-2,6-dione $6 \mathrm{~d}$}

The crude reaction mixture was submitted to gravity-column chromatography (chloroform/methanol, 97:3) to give triazole $\mathbf{6 d}$ as a white amorphous powder (53 mg, 61\%): $\mathrm{mp} 212-215{ }^{\circ} \mathrm{C} ; R_{f}$ 0.39 (chloroform/methanol, 9:1); ${ }^{1} \mathrm{H}$ NMR (400 MHz, DMSO- $d_{6}$ ) $\delta 11.17(\mathrm{~s}, 1 \mathrm{H}), 8.16(\mathrm{~s}, 1 \mathrm{H}), 7.68(\mathrm{~d} J=7.2 \mathrm{~Hz}, 1 \mathrm{H}), 7.56-7.57(\mathrm{~m}, 2 \mathrm{H})$, $7.44-7.49(\mathrm{~m}, 1 \mathrm{H}), 5.76(\mathrm{dd} J=12.8 \mathrm{~Hz}, 5.2 \mathrm{~Hz}, 1 \mathrm{H}), 4.80(\mathrm{~s}, 2 \mathrm{H}), 4.46$ (s, $2 \mathrm{H}) 2.77-2.82(\mathrm{~m}, 1 \mathrm{H}), 2.59-2.64(\mathrm{~m}, 2 \mathrm{H}), 2.22-2.47(\mathrm{~m}, 1 \mathrm{H}) \cdot{ }^{13} \mathrm{C}$ NMR $\left(100 \mathrm{MHz}\right.$, DMSO- $\left.d_{6}\right) \delta 172.8,169.8,167.5,143.5,142.2,132.4$, $131.9,128.3,123.9,123.8,123.3,59.5,49.9,37.4,31.1,24.7$. IR (neat) $3063,2916,2836,1704,1666 \mathrm{~cm}^{-1}$. HRMS (ESI-TOF) $m / z[\mathrm{M}+\mathrm{H}]^{+}$. calculated for $\mathrm{C}_{16} \mathrm{H}_{16} \mathrm{~N}_{5} \mathrm{O}_{3} 326.1253$, Found: 326.1287 .

\section{Acknowledgements}

The measurement of high resolution mass spectra by Dr. Bo Wang of the Texas A\&M University Laboratory for Biological Mass Spectrometry is acknowledged.

\section{References and notes}

1. Corey, E. .: Crakó, B.; Kürti, L. In Molecules and Medicine; John Wiley and Sons:

New Jersey, NJ, 2007; p 197.
2. Vargesson, N. Birth Defects Res. 2015, 105, 140-156.

3. Luzzio, F. A; Figg. W. D. Expt. Opin. Ther. Patent 2004, 14, 215-229.

4. D'Amato, R. J; Loughnan, M. S; Flynn, E.; Folkman, J. Proc Natl. Acad. Sci. US.A. 1994, 91, 4082-4085,

5. Walczak, J. R. Carducci, M. A. Expert Opin Investig. Drugs 2002, 11, 1737-1748. Eleutherakis-Papaiakovou, V:; Bamias, A: Dimopoulos, M. A. Ann. Oncol 2004, $15,1151-1160$.

7. Gasparini, G.; Longo, R; Fanelli, M.; Teicher, B. J. Clin. Oncol. 2005, 23, 1295-1311.

Jacques, V.; Czamik, A. W.; Judge, T. M.; Van der Ploeg, L. H. T: DeWitt, S. H. Proc. Natl. Acad. Sci. U.SA. 2015, 112, E1471-E1479

9. Braun, A. G.; Harding, E. A.; Weinreb, S. L. Toxicol Appl Pharmacol. 1986, 82 175-179.

10. Bawer, K. S. Dixon, S. C. Figg, W. D. Biochem Phamacol 1998, 55, 1827-1834.

11. Eriksson, Y: Björkman, S: Roth, B.; Biörk, H: Höglund, P. L. Pharm. Pharmacol

1998, $50,1409-1416$

12. Ando, Y.; Fuse, E.; Figg, W. D. Cin. Cancer. Res. 2002, 8, 1964-1973.
13. Luzzio, F. A.: Mayorov, A. V.; Ng, S. S. W.; Kruger, E. A.; Figg, W. D. J. Med. Chem 2003, 46, 3793-3799,

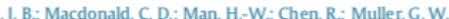
Stirling, D;: Dalgleish, A. G. Br. f. Cancer 2002, 87, 1166-1172

15. Ito, T; Ando, H; Handa, H. Cell MoL Life Sci. 2011, 68, 1569-1579

Beedie, S. L; Peer, C. J: Pisle, S. L; Gardner, E. R.; Mahony, C.; Barnett, S. Ambrozak, A; Gütschow, M:
Ther. 2015, 14, 2228-2237

17. Ng. S. S. W.; Gutschow, M.; Weiss, M.; Hauschildt, S.; Teubert, U.; Luzzio, F. A.; Kruger, E. A.; Figg. W. D. Cancer Res. 2003, 63, 3189-3194.

M. Patterson $R$ T. Chen Y: Kaplan, G. Stirling D. L Bioorg Med. Chem. Lett 1999, $1625-1630$.

19. San Miguel,J.; Weisel, K: Moreau, P: Lacy, M.; Song, K.: DelForge, M.; Karlin, L: Goldschmidt, H.; Banos, A.; Oriol, A.; Alegre, A.; Chen, C.; Cavo, M.; Garderet, L: va, V.; Matinez-Lopez, I; Belch, A.: Palumbo, A.; Schey, S. Sonneveld, P. 1055-1066.

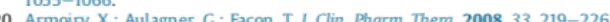

21. Abdcl-Razcq, H. N.; Mousa, S. A. Drugs Futurc 2004, 29, 10591063 ,

22. Heger, W-Schmal, H-J. Klug, S. Felles, A: Nau, H.: Merker, H-J; Neubert, D. Teratogenesis, Carcinog. Mutagen. 1994, 14,115-122.

23. Schumacher, H. H.; Terapane, J.; Jordan, R. L; Wilson, J. G. Teratology 1970, S, 233-240.

24. (a) Joussen, A. M.; Gemann, T.; Kirchof, B.. Graefes Arch. Clin. Exp. Ophthal mol . 237, 952-961 (b) Abstr. 1992, 117, 226313. (c) Luzzio. F. A.; Piatt Zacherl, D.; Figg, W. D. Tetrahtdron Lett. 1999, 40, 2087-2090

25. McHugh, S. M.; Rowland, T. L. Cin. Exp. Immunol 1999, 110, 151-154.

6. Seley, K. L; Thang, L; Hagos, A.; Quirk, S. J Org Chem 2002 . $67,3365-3373$. Rostovtsev, V. V.; Green, L G.; Fokin, V. V.; Sharpless, K. B. Angew. Chem., Int. Ed

. Them. Soc. Rev. 2007, 36, 1249-1262.

9. Meldal, M- Tornøe, C. W. Chem. Rev. 2008, 108, 2952-3015.

30. (a) For example, the 'click' triazole linker in carbohydrate chemistry forms many interesting extended scaffolds with a broad spectrum of applicability Tiwari, V. K.- Mishra, B. B.- Mishra, K. B. Mishra, N. Singh. A. S. Chen, X.Chem Rev. 2016, 116, 3086-3240; (b) For an example of using click chemistry to link pre-formed thalidomide molecules to complex scaffolds, See Kampmann, S. S: Skelton, B. W.; Yeoh, G. C; Abraham, L. J; Lengkeek, N. A.; Stubbs, K. A.; Heath, C. A.; Stewart, S. G. Tetrahedron 2015, 71, 8140-8149.

31. Denonne, F., Celanire, S.; Valade, A.; Defays, S.; Durieux, V. Wo 2009092764 Chem. Abstr. 2009, 151, 22116

32. Alford, J. S.; Davies, H. M. L. Org. Lett. 2012, 14, 6020-6023.

3. For another route to 22 and 24 See Sueda, T; Oshima, A.; Teno, N. Org. Lett 3996-3999 We found the Sueda route less convenient than that of

34. Clayton, J.; Ma, F.; Van Wagenen, B.; Ukkiramapandian, R:; Egle, L; Empfield, J: Isaac, M.; Slassi, A.; Steelman, G.; Urbanek, R.; Walsh, S. Wo 2006020879 Chem. Abstr. 2006, 144, 254003.

年, Cocolas, G. H.; Hal, L. H. J. Med Chem, 1983, 26, 243-246.

36. Jackson, W. R.; Perimutter, P.; Smallridge, A. J. Aust. J. Chem. 1998, 41 1201-1208. 
Selective alkylation/oxidation of $\mathrm{N}$-substituted isoindolinone derivatives: Synthesis of $N$-phthaloylated natural and unnatural $\alpha$-amino acid analogues

Pravin C. Patil, Frederick A. Luzzio*, Jarrid M. Ronnebaum

Department of Chemistry, University of Louisville, 2320 South Brook Street, Louisville, KY 40292, USA

\section{A R T I C L E I N F O}

Article history:

Received 14 July 2017

Revised 11 July 2017

Revised 11 August 2017

Available online 17 August 2017

Keywords:

Amino acids

soindolinones

Oxidation

Protecting groups

\begin{abstract}
A B S T R A C T
The interchangeability of the isoindolinone group as a nitrogen protecting group for amino acid intermediates is demonstrated by the preparation of several natural and unnatural $\alpha$-amino acid derivatives using a two-carbon $\mathrm{N}$-isoindolinone (phthalimidine) scaffold. Using a selective benzylic oxidation, the $\mathrm{N}$-isoindolinone group is then converted to the $\mathrm{N}$-phthaloyl group for convenient removal (65-98\%). For preparation of the isoindolinone products which were to be the substrates for benzylic oxidation, a range of side chains were installed on the isoindolinone-protected glycine equivalent on deprotonation to demonstrate the utility of the $N$-protected isoindolinone synthon (51-93\%). While the ensuing benzylic oxidation is employed successfully for converting the $\mathrm{N}$-isoindolinone group to the $\mathrm{N}$-phthaloyl zylic oxidation is employed successfully for converting the $N$-isoindolinone group to the $N$-phthaloyl
group in simple substrates, substrates bearing unsaturated or electron-rich side chains respond poorly to the oxidation.
\end{abstract}

C 2017 Elsevier Ltd. All rights reserved.

\section{Introduction}

In multistep synthesis, it is possible for protecting groups to perform multiple roles by providing both orthogonal protection as well as activation of neighboring atoms for further bond formation. ${ }^{1}$ A notable case in point is the development of the versatile benzophenone imine $\left(\mathrm{RN}=\mathrm{CPh}_{2}, \mathrm{R}=\right.$ carboxymethylene) derivatives of glycine by O'Donnell and co-workers for the preparation of diverse $\alpha$-amino acids. ${ }^{2}$ Thus, the two-carbon fragments having both the masked nitrogen and the ester functions falls into the category of synthons termed "glycine equivalents." ${ }^{3}$ The design and utilization of glycine equivalents allows for the de novo preparation of a plethora of natural and unnatural amino acids. ${ }^{4}$ While the need for the de novo synthesis of natural $\alpha$-amino acids most frequently includes isotopic analogues, the requirement for unnatural or otherwise non-proteinogenic amino acids may stem from the areas of protein engineering, drug design or enzyme modification. ${ }^{5}$ Nevertheless, many de novo syntheses require that the $\alpha$ methylenes or methines of glycine equivalents may be activated to give either anions or cations which then facilitate the attachment of the requisite 'natural or unnatural' side chains. ${ }^{6}$ While glycine equivalents typically bear both a protected nitrogen and

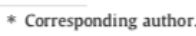

E-mail address: faluzz01 louisville.edu (FA. Luzzio).

http://dxdoi.org/10.1016/jtetlet 2017.08032

0040-4039/0 2017 Elsevier Ltd. All rights reserved. carboxyl group with the $\alpha$-methylene group available for $\mathrm{C}$ - $\mathrm{C}$ bond formation, one must note that protection of the nitrogen is not an

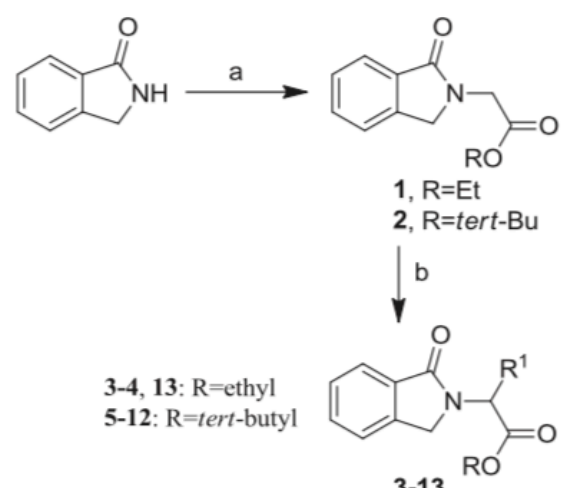

Scheme 1. Preparation of 1,2 and alkylated $N$ isoindol-inon-y esters 3-13. Reagents/Conditions: (a) $\mathrm{NaH} /$ ethyl or tert-butyl bromoacetate $/ 20^{\circ} \mathrm{C} / 16 \mathrm{~h}(1,78 \%$ : $2,97 \%)$ (b) LiHMDS $/ \mathrm{R}^{1}-\mathrm{X}(\mathrm{X}=\mathrm{C} 1, \mathrm{Br} \mathrm{I}) / \mathrm{THF} /-78^{\circ} \mathrm{C}$ to $\mathrm{rt} / 1-16 \mathrm{~h}$. 
absolute necessity-as demonstrated by the chiral amino alcoholderived glycinamide synthons developed by Myers and cowork ers. ${ }^{7}$ When $\mathrm{N}$ or $\mathrm{O}$ protection is warranted, the removal of these types of protecting groups is a distinct consideration and can be one or two-step processes. If the requirements are multistep, the overall process typically renders the deprotection protocol easier when addressing the removal of a particularly robust protecting group-i.e., those typically used for withstanding the more vigorous chemical reactions. While the $\mathrm{N}$-isoindolinone group is not a protecting group per se, the capability of converting it into the well-known $\mathrm{N}$-phthaloyl group would place it in that class of derivatives. We report herein that an adjoining $\mathrm{N}$-isoindolinone

rable 1

Alkylation of the $\mathrm{N}$-isoindolinone-protected esters 1, 2 to give amino acid derivatives 3-13

1,2

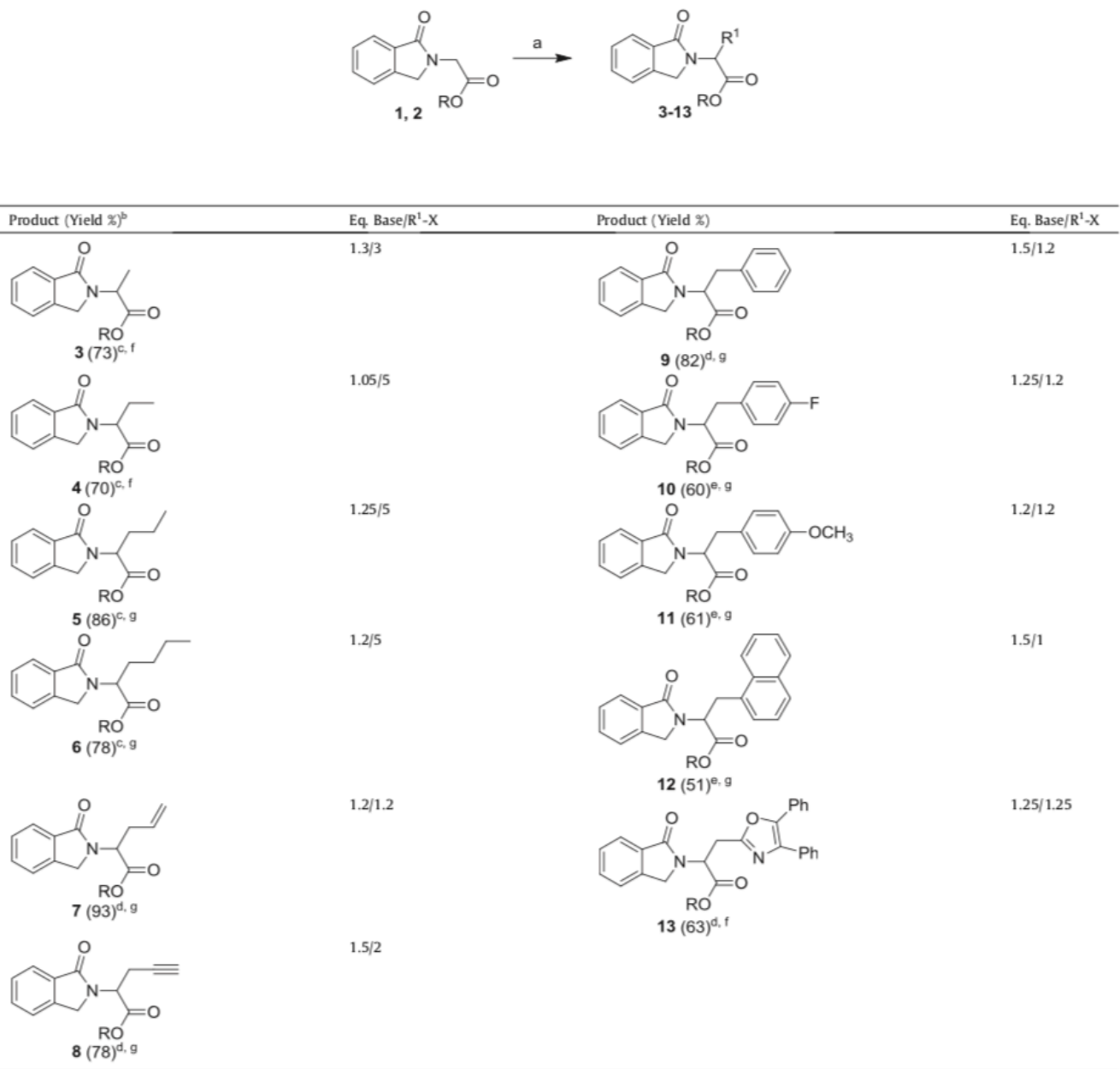

group allows the $\alpha$-methylene of an ethyl- or a tert-butyl ester to be deprotonated under basic conditions and facilitates the installation of side chains through the addition of reactive electrophiles such as alkyl halides. After the installation of the new side chain, the $\mathrm{N}$-isoindolinone group is then selectively oxidized to the easily-removable $\mathrm{N}$-phthaloyl group which is an established protecting group in peptide chemistry. We have reported that the overall process involving the alkylation $/ \mathrm{N}$-isoindolinone- $\mathrm{N}$-phthaloyl interconversion is effective for preparing ethynylalanine derivatives en route to triazolylalanine analogues via click chemistry. ${ }^{8}$ More detailed studies are included in this Letter where we report the scope of the alkylation reaction as well as details

Reagents/Conditions: LiHMDS/THF/then $\mathrm{R}^{1}-\mathrm{X}(\mathrm{X}=\mathrm{Cl}, \mathrm{Br}, \mathrm{I}) /-78{ }^{\circ} \mathrm{C}$ to $\mathrm{rt} / 1-16 \mathrm{~h}$. ${ }^{\mathrm{b}}$ Yields are of isolated, chromatographically pure products. "Alkyl iodide was used. ${ }^{\mathrm{d}} \mathrm{Alky}$ bromide was used. "Alkyl chloride was used. fEthyl ester $\mathbf{1}$ was used ${ }^{8}$ tert-Butyl ester $\mathbf{2}$ was used. 
involving the response of selected substrates to the benzylic oxidation of the $\mathrm{N}$-isoindolinone moiety.

\section{Results and discussion}

Our synthesis begins with the preparation of $\mathrm{N}$-isoindolinonederived esters $\mathbf{1}$ and $\mathbf{2}$ (Scheme 1 ) ${ }^{9}$ Generation of the sodium salt of isoindolinone (NaH/THF) followed by slow addition of either ethyl bromoacetate or tert-butyl bromoacetate afforded the $\mathrm{N}$ isoindolinonoyl esters $\mathbf{1}$ and $\mathbf{2}$ as solid materials in yields of $78 \%$ and $97 \%$ respectively after column chromatography on silica gel. The alkylation reactions involved base mediated anion generation using lithium hexamethyl disilazide (LiHMDS) and entailed a fairly standard protocol entailing addition of LHMDS to a mixture of the electrophile and ester $\mathbf{1}$ or $\mathbf{2}$ (Table 1). Under similar conditions, bases such as potassium tert-butoxide, sodium ethoxide and cesium carbonate did not give promising results. The usage of base was critical as isoindolinones can suffer deprotonation of the benzylic methylene, ${ }^{10}$ hence the possibility of multiple alkylated products which result in complex mixtures. While the employment of the ethyl ester 1 with reactive alkyl halides gave the expected products in modest to good yields, less reactive alkyl halides gave poor yields and what appeared to be decomposition of the starting ester 1 during the course of the reaction. For purposes of clarity, we organized the electrophiles and their products (3-13, Table 1) into three groups. These included the alkyl iodides, affording products 3-6 (70-86\%), the allyl/propargyl bromides, giving products 7 and $\mathbf{8}(93,78 \%$, respectively), and finally the benzylic electrophile which provided the aromatic-derived products 9-13 (51-82\%). For the alkylation reactions, individual procedures for all compounds are presented in the Supplementary Data.

A number of reagents/conditions were evaluated for the benzylic oxidation of the lactam moiety of alkylation products 3-13 to the corresponding $\mathrm{N}$-phthaloyl derivatives 14-20 (Scheme 2). With attention to expense and ease of protocol, systems such as MCPBA ( $m$-chloroperbenzoic acid) and combinations of oxygen, or 2,2'-bipyridinium chlorochromate (BPCC)/MCPBA, $\mathrm{SeO}_{2}$ Oxone ${ }^{\star} / \mathrm{Kl}$ were unreactive or gave complex mixtures. Finally, an optimal system composed of Oxone ${ }^{\star} / \mathrm{KBr}$ in acetonitrile-water gave the best results in benzylic oxidation thereby delivering the $\mathrm{N}$-phthaloyl products 14-20 (Table 2). ${ }^{12}$ While substrate 2 (Table 2 ) is the starting material for alkylation and is not an alkylation product per se, it does represent a 'glycine equivalent' and for purposes of completeness it was included in the oxidations and gave the $N$-phthaloyl ester 14 . It should be noted that the Oxone ${ }^{*} / \mathrm{KB}$ system is the first application of this type of oxidant to an isoindolinone to give the corresponding imide. ${ }^{8,11}$ While the benzylic oxidations to the phthalimides appear to be a straightforward process, some examples were not without anomalous or unexpected results.

The failure of substrates $\mathbf{7 , 8}$ and $\mathbf{1 1}$ to respond to the Oxone ${ }^{\infty}$ $\mathrm{KBr}$ system may stem from the relatively electron-rich nature of the allyl, propargyl and 4-methoxybenzyl side chains of these substrates. Using optimized conditions, oxidation of the naphthyl-

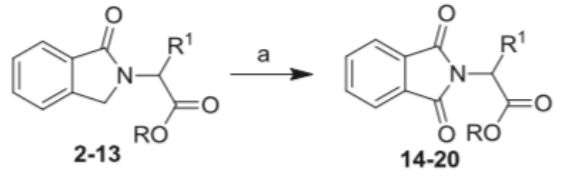

Scheme 2 Selective oxidation of $\mathrm{N}$-isoindolinon-yl esters 2-13 to phthalimides 14-20. Reagents/Conditions: Oxone ${ }^{*} / \mathrm{KBr} / \mathrm{MeCN}-\mathrm{H}_{2} \mathrm{O} / 40-45^{\circ} \mathrm{C} / 16$ h (70-98\%, Se Table 2). methyl isoindolinone derivative 12 did effect the expected conversion of the benzylic methylene to the carbonyl, but with accompanying bromination on the 2-position of the naphthyl ring to afford the monobromo derivative $\mathbf{2 1}$ (80\%) (Scheme 3). Using isoindolinone ethyl ester 1, LiHMDS and 2-bromomethyl-4,5diphenyloxazole $\mathbf{2 3}$ as a co-reactant, ${ }^{13}$ the expected $\beta$-oxazol-2yl-(methyl)-substituted derivative $\mathbf{1 3}$ was isolated (63\%, Table 1$)$. Considering that the 2-substituted-4,5-diphenyloxazole group is a masked carboxyl equivalent, ${ }^{14}$ the alkylation reaction gave essentially the aspartate derivative $\mathbf{1 3}$ with both carboxyl groups protected. Oxidation of 13 with Oxone $/ \mathrm{KBr}$ in acetonitrile/water

\section{Table 2}

Oxidation of the $\mathrm{N}$-isoindolinone group of esters 2-13 to give the $\mathrm{N}$-phthaloyl group of amino acid derivatives $14-20$

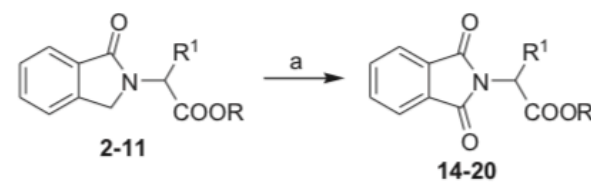

\begin{tabular}{|c|c|}
\hline Substrate $^{b}$ & Product (Yield \%) $)^{c}$ \\
\hline $2, \mathrm{R}^{1}=\mathrm{H}$ & PhthN $\underbrace{\mathrm{H}}_{\text {COOR }}$ \\
\hline 3, $\mathrm{R}^{1}=\mathrm{CH}_{3}$ & PhthN $\underbrace{\mathrm{CH}_{3}}_{\mathrm{COOR}}$ \\
\hline $4, \mathrm{R}^{1}=\mathrm{C}_{2} \mathrm{H}_{5}$ & PhthN $\underbrace{\mathrm{C}_{2} \mathrm{H}_{5}}_{16(76)}$ \\
\hline $5, \mathrm{R}^{1}=\mathrm{C}_{3} \mathrm{H}_{7}$ & NPhth $\underbrace{\mathrm{C}_{3} \mathrm{H}_{7}-n}_{\text {COOR }}$ \\
\hline $6, \mathrm{R}^{1}=\mathrm{C}_{4} \mathrm{H}_{9}$ & NPhth $\underbrace{\mathrm{C}_{4} \mathrm{H}_{9}-n}_{\text {COOR }}$ \\
\hline $\begin{array}{l}7, R^{1}=\text { allyl } \\
8, R^{1}=\text { propargyl } \\
9, R^{1}=\text { benzyl }\end{array}$ & $\begin{array}{l}\text { NR } \\
\text { NR }\end{array}$ \\
\hline & $\begin{array}{c}\text { COOR } \\
19(88)\end{array}$ \\
\hline 10, $\mathrm{R}^{1}=$ 4-fluorobenzyl & PhthN- \\
\hline $11, R^{1}=4$-methoxybenzyl & NR \\
\hline
\end{tabular}


12<smiles>[R]C=CC1CCCC1C(=O)OC(C)(C)C</smiles>

21

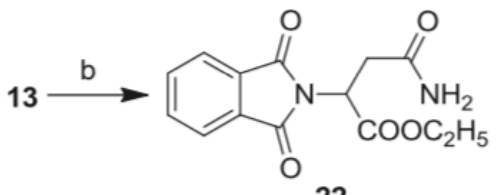

22

Scheme 3. Benzylic oxidation of selected of substrates 12 and 13. Reagents Conditions: (a) Oxone ${ }^{*} \mathrm{IBX} / \mathrm{KBr} \mathrm{MeCN}-\mathrm{H}_{2} \mathrm{O} / 40-45^{\circ} \mathrm{C} / 16 \mathrm{~h}$. (b) Oxine ${ }^{*} / \mathrm{KBr} / \mathrm{MeCN}$ $\mathrm{H}_{2} \mathrm{O} / 40-45^{\circ} \mathrm{C} / 3 \mathrm{~h}$.

19

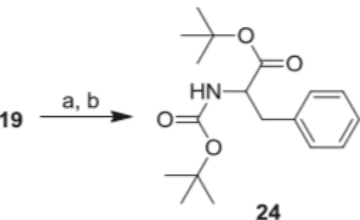

scheme 4. Conversion of 19 to a standard phenylalanine derivative 24 Reagents Conditions: (a) $\mathrm{N}_{2} \mathrm{H}_{4} / \mathrm{MeOH}-\mathrm{H}_{2} \mathrm{O} / \mathrm{tr} / 16 \mathrm{~h}$. (b) di-tert-butyl dicarb-onate $/ \mathrm{NaHCO}_{3}$ dioxane/rt/16 h $(81 \%$ a and b).Table 1. Alkylation of the $\mathrm{N}$-isoindolinone-protected esters 1, 2 to give amino acid derivatives 3-13.

transformed the $\mathrm{N}$-isoindolinone group into the $\mathrm{N}$-phthaloyl group, but also resulted in oxazole cleavage to give the $\mathrm{N}$-phthaloylasparagine ester 22 (65\%) (Scheme 3). A straightforward adaptation of the overall method for peptide chemistry is shown in Scheme 4. The $\mathrm{N}$-phthaloyl phenylalanine derivative 19 was treated with hydrazine hydrate $\left(\mathrm{MeOH}-\mathrm{H}_{2} \mathrm{O}\right)$ followed by direct treatment with di-tert-butyl dicarbonate $\left(\mathrm{NaHCO}_{3} /\right.$ dioxane). Thus, the racemic $\mathrm{N}$ BOC phenylalanine tert-butyl ester derivative $\mathbf{2 4}$ was obtained in $81 \%$ yield over two steps whereby the spectral properties of the $\mathrm{N}$-BOC amino acid ester $\mathbf{2 4}$ matched those as previously reported (See Supplementary Material).

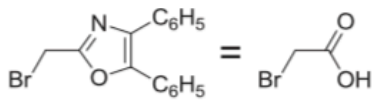

23

In summary, the expedient of the $\mathrm{N}$-isoindolinone group as a nitrogen protecting group for a two carbon 'glycine equivalent' is demonstrated by submission of the scaffold to a series of selective alkylation reactions. Removal of the $\mathrm{N}$-isoindolinone group is facilitated by conversion to the more labile $\mathrm{N}$-phthaloyl group through a selective benzylic oxidation using Oxone ${ }^{x}$. Using a diverse array of alkylating agents, the $\mathrm{N}$-isoindolyl-protected 'glycine equivalent' served as a starting point for $\alpha$-amino acid construction and proved to be robust through further manipulation. An added bonus may be the increased stability of the isoindolinone group to mildly acidic conditions as compared to the O'Donnell derivatives. While the majority of isoindolinone substrates did afford the corresponding $\mathrm{N}$-phthaloylated products upon oxidation, the vinylalanine-, ethynylalanine- and electron-rich substrates such as methoxyphenylalanine analogues did not respond to oxidation. A noteworthy example was the de novo preparation of the asparagine derivative $\mathbf{2 2}$ which resulted from both the benzylic oxidation and an oxazole cleavage. While the isoindolinone core has been common to medicinal compounds, ${ }^{15}$ experimental therapeutics ${ }^{16}$ and natural products, ${ }^{17}$ its employment as a protecting group has received no attention. An asymmetric variant of the isoindolinone oxidation scheme is under investigation and the results will be reported in due course.

\section{Acknowledgments}

The measurement of high and low resolution mass spectra by Dr. Michael Walla of the Mass Spectrometry Laboratory, Department of Chemistry and Biochemistry, University of South Carolina is acknowledged. Financial support from the NIH/NIDCR through grant 1 RO1DE023206 is gratefully acknowledged.

\section{A. Supplementary data}

General procedures and supplementary data (FTIR, ${ }^{1} \mathrm{H}$ NMR, ${ }^{13} \mathrm{C}$ NMR) for compounds 1, 2, 3-13 and 14-22 and HRMS data for all new compounds. Supplementary data associated with this article can be found, in the online version, at http://dx doi.org/10.1016/j. tetlet.2017.08.032.

\section{References}

1. Greene TW. Wuts PGM. Protective groups in organic synthesis. 3rd ed. New York: John Wiley \& Sons: 1999.

2. O'Donnell MI, Bennett WD, Bruder WA, et al. J Am Chem Soc. 1988:110:8520-8525

3. Patek M. Int J Peptide Protein Res. 1993:42:97-117,

4. For selected reviews See: Noisier AFM, Brimble MA. Chem Rev. 2014:114:8775-8806;

Najera C, Sansano JM. Chem Rev. 2007; 107:4584-4671:

Kazmaier U. In: Hughes AB, ed. Amino Acids, Peptides and Proteins in Organic Chemistry. Weinhein: Wiley-VCH; 2009:1-34.

5. (a) Saghyan AS, Langer P. Asymmetric Synthesis of Non-Proteinogenic Amino (b) Stevenami A. Whey vert, 2016.261:

Gergani B, Lattanzio M. Biorg Med

6. For an example of a 'cationic glycine equivalent' See: O'Donnell MI. Delgado F.

(a) Myers AG, Gleason Ih Yoon T. Kung DW. JAm Chem Soc. 1997:119:656-673: (b) Seiple IB, Merrer IAM, Sussman RI. Zhang Z Myers AG. Angew Chem Int Ed. 2014:53:4642-4647.

8. Patil PC, Luzzio FA Synlett. In this report, the $\mathrm{N}$-isoindolinone group was found to be stable to the aqueous hydroxide conditions used to cleave the ester group of the alkylated amino acid scaffolds; 2017. DOI: 10.1055/s-0036-1588510; Art

ID st-2017-b0340-c.
9. (a) Aubert T, Famier M, Guilard R. Can J Chem. 1990;68:842-851; Golec G, Charifson P, Charrier J-D, Binch HUS. Chem Abstr. 2003;2003:9917 h. D232846A

10. (a) Luzzio FA. Piatt Zacherl D. Tetrahedron Lett. 1998:39:2285-2288: (b) Couture A, Deniau E, lonescu D, Grandclaudon P. Tetrahedron Lett. 1998:39:2319-2320.

11. (a) Luzzio FA. In: Weinreb b) Luzzio FA, Zacher DP. F

Fetr. 1999;40:2087-2090,

.

14. Patil PC, Luzzio FA. Tetrahedron Lett. 2017:58:1280-128.

5. Galustian C, Dalglessh A. Expert Opin Pharmacother. 2009;10:125-133.

6. Riedinger $C$, Endicott JA, Kemp S, et at. Am Chem Soc. 2008;130:16038-16044.

17. Speck K, Magauer T. Beilstein J Org Chem. 2013:9:2048-2078. 


\section{Arrivoc

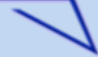

Archive for

Organic Chemistry
The Free Internet Journal

for Organic Chemistry

\section{DAST-mediated preparation of $\mathrm{N}$-substituted 3-alkoxyisoindolinones}

Jarrid M. Ronnebaum and Frederick A. Luzzio*

Department of Chemistry, University of Louisville, 2320 South Brook St., Louisville, KY 40292, USA

Email:faluzz01@louisville.edu

Dedicated to Professor E. J. Corey on the occasion of his $90^{\text {th }}$ birthday

Received mm-dd-yyyy

Accepted mm-dd-yyyy

Published on line mm-dd-yyyy

Dates to be inserted by editorial office

Abstract

3-Alkoxy-2-phenylethylisoindolinones are conveniently prepared by reacting the corresponding hydroxylactams with diethylaminosulfur trifluoride (DAST) in the presence of a range of alcohols. The DAST-mediated reaction did not result in any reactant fluorination but smooth installation of the alkoxy group derived from the reactant alcohol on the benzylic position of the heterocycle. The central starting hydroxylactam substrate was prepared from the corresponding chiral phthalimide, 2-((S)-1-phenylethyl)-isoindoline-1,3-dione, by selective reduction using either aluminum amalgam or sodium borohydride. The resultant diasteriomeric mixture of hydroxylactams were used in the DAST alkoxylation reaction and were compared with a more conventional method of alkoxylation using the protic acid camphorsulfonic acid.

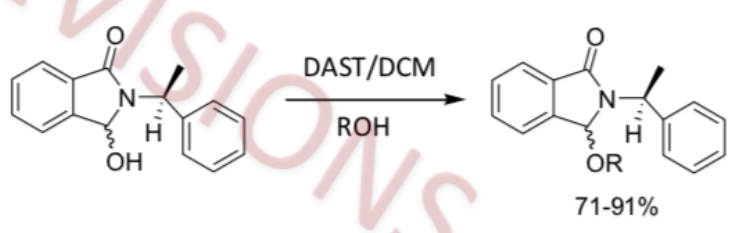

Keywords: DAST, imides, iminium ions, isoindolinones, 


\section{Introduction}

Isoindolinones form a central heterocyclic scaffold in natural products and medicinal chemistry. A number of compounds bearing the isoindolinone core are of interest as antivirals, ${ }^{1}$ inhibitors of protein-protein interaction, ${ }^{2,3}$ muscarinic receptor ligands, ${ }^{4}$ cytotoxins and cytostatic agents. ${ }^{5}$ Substitution on the isoindolinone core, both heteroatom and carbon, may take the form of bonds to the aromatic ring, the heterocyclic nitrogen and the benzylic positions. During the course of our studies of substituted isoindolinones as chiral auxiliaries, we examined methods of mild bond formation to the benzylic position of $N$-substituted isoindolinones. Normally, nucleophiles such as alcohols or thiols work very well when used in conjunction with a method which generates the corresponding acyliminium ions from the corresponding hydroxylactams..$^{6-10}$ In turn, hydroxylactams are easily accessed by selective reduction of the corresponding phthalimides with sodium borohydride, diisobutylaluminum hydride or aluminum amalgam. ${ }^{11}$ Given the usual starting materials, which comprise both hydroxylactams and alcohols, the formation of the corresponding alkoxylactams can be accomplished through the agency of acid or metal catalysts. ${ }^{12-15}$ While they are harsh and often involve the release of acid, halogenating agents such as thionyl chloride also work well to facilitate the formation of alkoxyisoindolinones from hydroxylactams. ${ }^{2,3}$ Diethylaminosulfur trifluoride (DAST) is a mild fluorinating agent which can be used to prepare a distinct array of fluorinated analogues of natural products and medicinal compounds from the corresponding alcohols. While the preparation of the monofluorides and gem-difluorides using DAST has been well-documented, the preparation of ethers with this reagent has been also explored and is the topic of several early reports. ${ }^{16-18}$ Inasmuch as ether formation from alcohols using DAST is most notably a consequence of mechanistic variation, the diversion of pathway may be preponderant with some substrates over others. For example, with the use of DAST and some highly reactive substrates such as allylic or benzylic alcohols, fluorination of the alcohols may preclude ether formation. We report herein that hydroxylactam 1 used in conjunction with simple alcohols and DAST leads to the corresponding alkoxylactams (alkoxyisoindolinones) 3-13 (Scheme 1) in good to excellent yields.

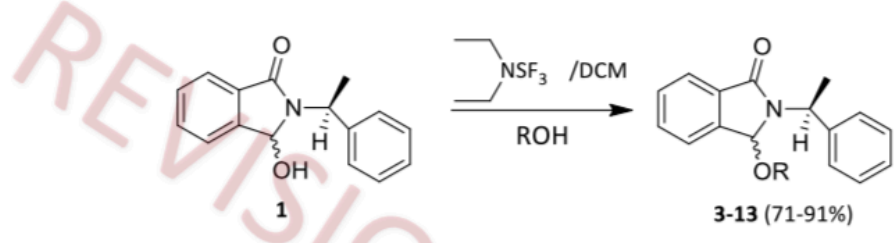

Scheme 1. DAST-mediated alkoxylation of hydroxylactam 1.

The yields are comparable to or greater than those which utilize the very commonly-used $p$-toluenesulfonic acid or camphorsulfonic acids, however the reaction does afford diastereomeric mixtures of the corresponding 3alkoxyisoindolinones. The product distribution of the alkoxylation reaction is not surprising given that the benzylic position which is occupied by the hydroxyl group offers unique reactivity toward the reagent in preference to the substrate alcohols. 


\section{Results and Discussion}

Phthaloylation of the chiral amine (S)-(-)- $\alpha$-methylbenzylamine $\left([\alpha]_{D}-39^{\circ} \text {, neat }\right)^{19,20}$ with phthalic anhydride followed by reduction of the resultant chiral phthalimide $\mathbf{2}$ with sodium borohydride gave the substrate hydroxylactam 1 as a diastereomeric mixture (Scheme 2). While the hydroxylactam mixture could be separated by crystallization, the mixture was used directly in the alkoxylation reaction. ${ }^{7}$ The alkoxylation entails addition of DAST to a room-temperature solution of the hydroxylactam $1\left(\mathrm{CH}_{2} \mathrm{Cl} 2\right)$, followed by stirring (16 h), then addition of the reactant alcohol followed by stirring (4-8 h). All alkoxylated products were easily purified by flash column chromatography on silica gel, whereby the ratios of diastereomers ranged from 55/45 to 65/35 as determined by ${ }^{1} \mathrm{H}$ NMR (Table 1). Although no diastereoselectivity was preferred, the highest ratio $(80: 20)$ was that which used 2,2,2-trichloroethanol as a reactant (See Entry 6, Table 1).

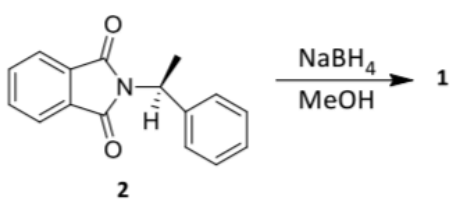

Scheme 2. Reduction of phthalimide $\mathbf{2}$ to hydroxylactam $\mathbf{1}$.

Table 1. Reaction of selected alcohols with hydroxylactam 1.

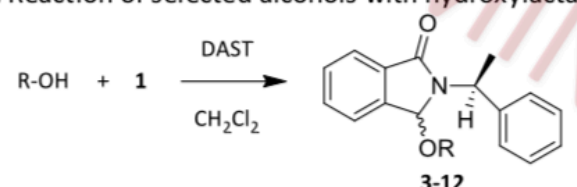

3-12

\begin{tabular}{|c|c|c|c|}
\hline Entry & Substrate Alcohol (ROH)/Equivalents & Ratio $^{\text {a }}$ & Compound/Yield $(\%)^{\mathrm{b}}$ \\
\hline 1 & 2-propanol/10 & $60: 40$ & $3 / 89$ \\
\hline 2 & cyclopentanol/10 & $60: 40$ & $4 / 88$ \\
\hline 3 & phenylmethanol/5 & $55: 45$ & $\mathbf{5} / 80$ \\
\hline 4 & 2-phenylethanol/5 & $65: 35$ & $6 / 91$ \\
\hline 5 & (4-methoxyphenyl)methanol/5 & $55: 45$ & $7 / 60$ \\
\hline 6 & 2,2,2-trichloroethanol/5 & $80: 20$ & $8 / 85$ \\
\hline 7 & 2-propene-1-ol/5 & $65: 35$ & $9 / 71$ \\
\hline 8 & 1,4-butanediol/5 & $65: 35$ & $10 / 77$ \\
\hline 9 & 2,2-dimethyl-1-propanediol/5 & $65: 35$ & $11 / 83$ \\
\hline 10 & Anthracen-9-ylmethanol/5 & $60: 40$ & $12 / 79$ \\
\hline 11 & (2-bromophenyl)methanol/5 & $65: 35$ & $13 / 71$ \\
\hline
\end{tabular}

${ }^{\text {a }}$ Ratios were determined by ${ }^{1} \mathrm{H}$ NMR

bYields are for chromatographically pure products.

For comparison, a subset of reactions using selected substrate alcohols and catalyzed by camphorsulfonic acid (CSA), were performed with the hydroxylactam 1 and 1,4-butanediol, 2,2-dimethyl-1,3-propanediol and 
anthracenylmethanol thereby affording products 10,11 and 12 respectively after chromatographic purification (Table 2, Entries 1,2,3). While acid-mediated alkoxylation of the isoindolinone core may occur through the accepted acyliminium ion mechanism (Scheme 2), the DAST-mediated reaction may progress through the same intermediate (A) which is enhanced by the benzylic position of the isoindolinone (Scheme 2).

Table 2. Reaction of selected alcohols with hydroxylactam 1 mediated by CSA.

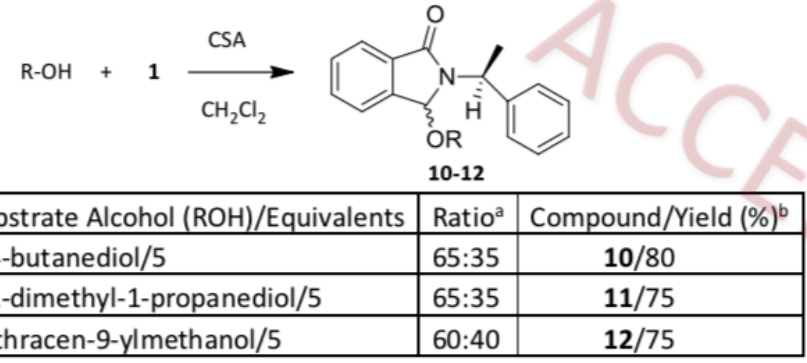

a Ratios were determined by ${ }^{1} \mathrm{H}$ NMR

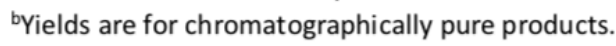

With secondary alcohol substrates, fluorination by DAST gives the corresponding fluorinated compounds with inversion of configuration, quite possibly through displacement of intermediate $\mathbf{B} .{ }^{21,22}$ Consequently, one may argue that if intermediate $\mathbf{B}$ did indeed exist in the alkoxylation reaction, a high diastereomeric ratio of alkoxyisoindolinones may result, so it is highly likely that the reaction proceeds through intermediate $\mathbf{A}$ (Scheme 3).

Scheme 3. Mechanistic pathways of DAST-mediated alkoxylation.

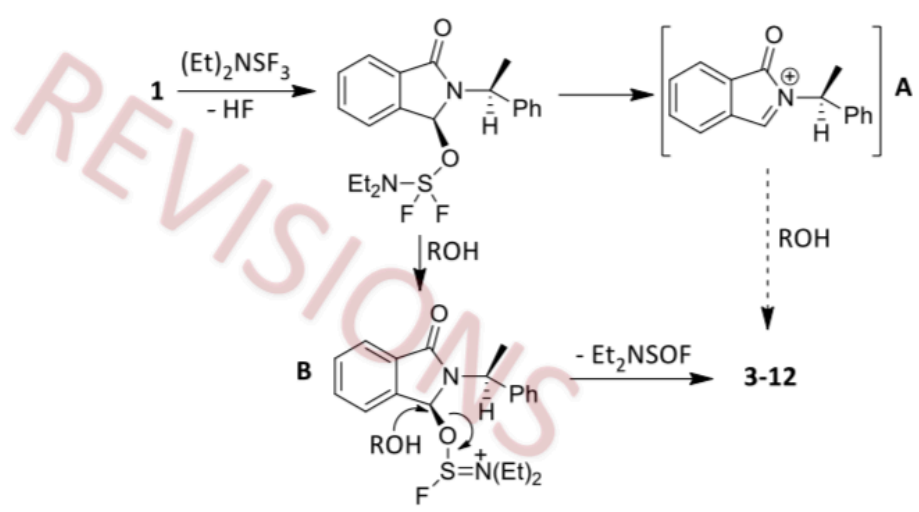

In theory, one may presume that the inverse sequence whereby the alkoxide of a typical hydroxylactam followed by addition of an alkyl halide will give the desired alkoxyisoindolinones. As reported earlier by other groups, the diastereomeric hydroxylactams $\mathbf{1}$ could be separated by crystallization after reduction of $\mathbf{2}$, and the separated diastereomers have been used in several reactions to explore diastereoselectivity. ${ }^{7}$ However, generation of the alkoxide of $\mathbf{1}(\mathrm{NaH} / \mathrm{THF}$ ) from diastereomerically pure $\mathbf{1}$, followed by addition of benzyl bromide did not provide the desired benzyloxyisoindolinone, but only an epimeric mixture of hydroxylactams. Presumably, formation of 
the alkoxide resulted in opening to the corresponding aldamide, which then equlibrates on closing, resulting in epimerization.

\section{Conclusions}

We have detailed an efficient route to 3-alkoxyisoindolinones from hydroxylactams and alcohols which does not require the use of acid but utilizes the mediation of the reactive fluorinating reagent DAST. The alkoxylation proceeds by means of an acyliminium ion intermediate which is attacked by the reactant alcohol to yield the product. Despite the fact that the substrate bears a chiral group derived from $\alpha$-phenethylamine, diastereomeric mixtures result from the reaction.

\section{Experimental Section}

General. Solvents and reagents are ACS grade and were used as commercially supplied. Analytical thin-layer chromatography (TLC) utilized $0.25 \mathrm{~mm}$ pre-cut glass-backed plates (Merck, Silica Gel $60 \mathrm{~F}_{254}$ ). Thin-layer chromatograms were visualized during chromatographic and extraction runs by rapidly dipping the plates in anisaldehyde/ethanol/sulfuric acid stain or phosphomolybdic acid/ ethanol stain and heating (hot plate). Gravity-column chromatography was carried out using silica gel 60 (E. Merck 7734, 70-230 mesh). Nuclear magnetic resonance $\left({ }^{1} \mathrm{H}\right.$ and ${ }^{13} \mathrm{C}$ NMR) spectra were recorded with Varian VNMRS 400 or $500 \mathrm{MHz}$ instruments using $\mathrm{CDCl}_{3}$ as a solvent and TMS as internal standard. Infrared spectra (FTIR) were recorded with a Perkin-Elmer Spectrum 100 instrument and spectral values are reported as $\mathrm{cm}^{-1}$. High resolution mass spectrometry (HRMS) were performed by the Indiana University Mass Spectrometry Facility, Bloomington, Indiana.

General procedure for synthesis of 3-alkoxy-2-((S)-1-phenylethyl)isoindolin-1-ones (3-13). 3-Hydroxy-2-((S)-1phenylethyl)isoindolin-1-one 1 (150 mg, 0.592 mmol, Entries 1-3, Table 1) or (100mg, 0.395 mmol, Entries 4-11, Table 1) was dissolved in dichloromethane $(3.0 \mathrm{~mL})$ under an inert atmosphere $\left(\mathrm{N}_{2}\right)$ while stirring followed by the addition diethylaminosulfur trifluoride (DAST, $240 \mu \mathrm{L}, 1.776 \mathrm{mmol}, 3 \mathrm{eq}$ ). Stirring was continued overnight $(16 \mathrm{hr})$ and the alcohol was added ( 10 or 5 eq.) and stirring was continued until the reaction was complete as indicated by TLC ( $4-8 \mathrm{hr})$. The crude reaction mixture was directly submitted to gravity-column chromatography and the entire series of products were eluted with hexane/ethyl acetate, $4: 1$. Combination and concentration of the individual fractions gave the pure products detailed in Table 1.

General procedure for synthesis of 3-alkoxy-2-((S)-phenylethyl)isoindolin-1-ones (10-12). 3-Hydroxy-2-((S)-1phenylethyl)isoindolin-1-one 1 (100 mg, 0.395 mmol, Entries 1-3, Table 2) was dissolved in dichloromethane (3.0 $\mathrm{mL}$ ) with alcohol (1.2 eq) in the presence of camphorsulfonic acid ( $20 \%$ eq). Stirring was continued overnight (4$6 \mathrm{hr}$ ) until the reaction was complete as indicated by TLC ( $4-8 \mathrm{hr})$. The crude reaction mixture was directly submitted to gravity-column chromatography and the entire series of products were eluted with hexane/ethyl acetate, $4: 1$ ). Combination and concentration of the individual fractions gave the pure products detailed in Table 2.

3-Isopropoxy-2-((S)-1-phenylethyl)isoindolin-1-one (3): Colorless oil (158 mg, 89\%); $R_{f}=0.44$ (hexane/ethyl acetate, 4:1); IR 3029, 2976, 2927, 2886, $1702 \mathrm{~cm}^{-1}$. ${ }^{1} \mathrm{HNMR}$ ( $500 \mathrm{MHz}, \mathrm{CDCl}_{3}$, major) $\delta$ 7.81-7.84 (m, 1H), 7.25$7.55(\mathrm{~m}, 8 \mathrm{H}), 5.68(\mathrm{q}, J=7.0 \mathrm{~Hz}, 1 \mathrm{H}), 5.53(\mathrm{~s}, 1 \mathrm{H}), 3.66-3.70(\mathrm{~m}, 1 \mathrm{H}), 1.83(\mathrm{~d}, J=6.5 \mathrm{~Hz}, 3 \mathrm{H}), 1.18(\mathrm{~d}, J=6.0 \mathrm{~Hz}$, $3 \mathrm{H}), 1.05(\mathrm{~d}, J=6.0 \mathrm{~Hz}, 3 \mathrm{H}) . \mathrm{H}^{1} \mathrm{NMR}\left(500 \mathrm{MHz}, \mathrm{CDCl}_{3}\right.$, minor) $\delta 7.81-7.84(\mathrm{~m}, 1 \mathrm{H}), 7.25-7.55(\mathrm{~m}, 8 \mathrm{H}), 5.76(\mathrm{~s}, 1 \mathrm{H})$, 
$5.15(\mathrm{q}, J=7.0 \mathrm{~Hz}, 1 \mathrm{H}), 3.66-3.70(\mathrm{~m}, 1 \mathrm{H}), 1.98(\mathrm{~d}, J=7.5 \mathrm{~Hz}, 3 \mathrm{H}), 1.15(\mathrm{~d}, J=6.5 \mathrm{~Hz}, 3 \mathrm{H}), 0.92(\mathrm{~d}, J=6.5 \mathrm{~Hz}, 3 \mathrm{H})$. ${ }^{13} \mathrm{CNMR}\left(125 \mathrm{MHz}, \mathrm{CDCl}_{3}\right) \delta 168.0,127.7,143.0,142.3,140.5,132.9,132.1,131.9,131.8,129.7,129.5,128.5$, 128.4, 128.2, 127.5, 127.2, 126.6, 123.5, 123.4, 123.3, 85.9 (major), 85.6 (minor), 69.4, 68.7, 52.0, 50.2, 23.9, 23.7, 23.2, 3.0, 18.9, 18.9. HRMS (FTMS + p ESI) $\mathrm{m} / z$ [M + Na] $]^{+}$; calculated for $\mathrm{C}_{19} \mathrm{H}_{21} \mathrm{O}_{2} \mathrm{NNa} 318.1465$, Found: 318.1468

3-(Cyclopentyloxy)-2-((S)-1-phenylethyl)isoindolin-1-one (4): Colorless oil (167 mg, 88\%); $R_{f}=0.48$

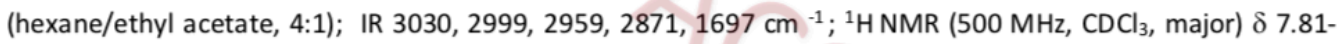
$7.84(\mathrm{~m}, 1 \mathrm{H}), 7.25-7.55(\mathrm{~m}, 8 \mathrm{H}), 5.68(\mathrm{q}, J=7.5 \mathrm{~Hz}, 1 \mathrm{H}), 5.54(\mathrm{~s}, 1 \mathrm{H}), 3.91-3.93(\mathrm{~m}, 1 \mathrm{H}), 1.81(\mathrm{~d}, J=7.0 \mathrm{~Hz}, 3 \mathrm{H})$, 1.31-1.74 (m, 8H). ${ }^{1} \mathrm{H} \mathrm{NMR}\left(500 \mathrm{MHz}, \mathrm{CDCl}_{3}\right.$, minor) $\delta$ 7.81-7.84 (m, 1H), 7.25-7.55 (m, 8H), $5.81(\mathrm{~s}, 1 \mathrm{H}), 5.17$ (q, $J=7.0 \mathrm{~Hz}, 1 \mathrm{H}), 3.78-3.80(\mathrm{~m}, 1 \mathrm{H}), 1.96(\mathrm{~d}, J=7.0 \mathrm{~Hz}, 3 \mathrm{H}) 1.31-1.74(\mathrm{~m}, 8 \mathrm{H}) .{ }^{13} \mathrm{CNMR}\left(125 \mathrm{MHz}, \mathrm{CDCL}_{3}\right) \delta 168.1$, $167.8,142.6,142.2,140.5,132.9,132.3,131.7,129.7,129.6,128.6,128.4,127.7,127.6,127.3,127.2,126.6$, 123.8, 123.8, 123.5, 123.3, 86.0 (major), 85.8 (minor), 51.7, 50.3, 33.7, 33.5, 33.4, 33.3, 23.6, 23.4, 23.2, 18.7, 18.3. HRMS (FTMS + p ESI) $m / z[\mathrm{M}+\mathrm{Na}]^{+}$; calculated for $\mathrm{C}_{21} \mathrm{H}_{23} \mathrm{O}_{2} \mathrm{NNa} 344.1621$, Found 344.1624.

3-(Benzyloxy)-2-((S)-1-phenylethyl)isoindolin-1-one (5): Colorless oil (108 mg, 80\%); $R_{f}=0.47$ (hexane/ethyl acetate, 4:1) IR 3031, 2928, 2886, 2875, $1698 \mathrm{~cm}^{-1} .{ }^{1} \mathrm{H} \mathrm{NMR}\left(500 \mathrm{MHz}, \mathrm{CDCl}_{3}\right.$, major) $\delta 7.88-7.89$ (m, $\left.1 \mathrm{H}\right), 7.21$ $7.60(\mathrm{~m}, 12 \mathrm{H}), 6.92-6.94(\mathrm{~m}, 1 \mathrm{H}), 5.79(\mathrm{~s}, 1 \mathrm{H}), 5.73(\mathrm{q}, J=7.0 \mathrm{~Hz}, 1 \mathrm{H}), 4.32(\mathrm{~d}, J=11.0 \mathrm{~Hz}, 1 \mathrm{H}), 3.97(\mathrm{~d}, J=11.0$ $\mathrm{Hz}, 1 \mathrm{H}), 1.84(\mathrm{~d}, J=7.0 \mathrm{~Hz}, 3 \mathrm{H}) .{ }^{1} \mathrm{H} N M R\left(500 \mathrm{MHz}, \mathrm{CDCl}_{3}\right.$, minor) $\delta$ 7.88-7.89 (m, 1H), 7.21-7.60 (m, 12H), 6.92$6.94(\mathrm{~m}, 1 \mathrm{H}), 6.19(\mathrm{~s}, 1 \mathrm{H}), 5.47(\mathrm{q}, J=7.5 \mathrm{~Hz}, 1 \mathrm{H}), 3.73(\mathrm{~d}, J=11.0 \mathrm{~Hz}, 1 \mathrm{H}), 3.62(\mathrm{~d}, J=11.0 \mathrm{~Hz}, 1 \mathrm{H}), 1.91(\mathrm{~d}, J=$ $7.0 \mathrm{~Hz}, 3 \mathrm{H}) .{ }^{13} \mathrm{C}$ NMR $\left(125 \mathrm{MHz}, \mathrm{CDCl}_{3}\right) \delta 167.8,141.7,141.0,140.7,140.3,137.4,137.2,133.1,132.6,132.1$, $130.0,129.9,128.7,128.4,127.8,127.7,127.6,127.5,123.7,123.6,123.4,110.0,85.8$ (major), 85.6 (minor), $64.1,63.9,50.7,50.6,18.1,17.5$. HRMS (FTMS + p ESI) $\mathrm{m} / 2[\mathrm{M}+\mathrm{Na}]^{+}$; calculated for $\mathrm{C}_{23} \mathrm{H}_{21} \mathrm{O}_{2} \mathrm{NNa} 366.1465$, Found 366.1469

3-Phenethoxy-2-((S)-1-phenylethyl)isoindolin-1-one (6): Colorless oil (193 mg, 91\%); $R_{f}=0.67$ (hexane/ethyl acetate, 4:1); IR 3066, 3028, 2937, 2875, $1698 \mathrm{~cm}^{-1} .{ }^{1} \mathrm{H} \mathrm{NMR}\left(500 \mathrm{MHz}, \mathrm{CDCl}_{3}\right.$, major) $\delta 7.81-7.82(\mathrm{~m}, 1 \mathrm{H})$, 7.11-7.59 (m, 12H), $6.94(\mathrm{~d}, J=8.0 \mathrm{~Hz}, 1 \mathrm{H}), 5.64(\mathrm{q}, J=7.0 \mathrm{~Hz}, 1 \mathrm{H}), 5.61(\mathrm{~s}, 1 \mathrm{H}) 3.47(\mathrm{dd}, J=16.0,7.0 \mathrm{~Hz}, 1 \mathrm{H})$, 3.09 (dd, $J=16.0,7.0 \mathrm{~Hz}, 1 \mathrm{H}), 2.79-2.88(\mathrm{~m}, 2 \mathrm{H}), 1.72(\mathrm{~d}, J=7.5 \mathrm{~Hz}, 3 \mathrm{H}) .{ }^{1} \mathrm{H} \mathrm{NMR}\left(500 \mathrm{MHz}, \mathrm{CDCl}_{3}\right.$, minor) 87.81-7.82 (m, $1 \mathrm{H}), 7.11-7.59(\mathrm{~m}, 13 \mathrm{H}), 6.03(\mathrm{~s}, 1 \mathrm{H}), 5.35(\mathrm{q}, J=7.5 \mathrm{~Hz}, 1 \mathrm{H}), 2,79-2.88(\mathrm{~m}, 2 \mathrm{H})$ 2.40-2.46 (m, 1H), 2.28-2.32(m, 1H), 1.85 (d, J = 7.0 Hz, 3H). ${ }^{13} \mathrm{C} \mathrm{NMR}\left(125 \mathrm{MHz}, \mathrm{CDCl}_{3}\right) \delta 167.7,141.0,140,4$ 138.40, 132.6, 131.9, 129.8, 129.7, 129.0, 128.9, 128.6, 128.4, 128.2, 127.8, 127.7, 127.6, 127.4, 126.4, 126.3, 123.6, 123.5, 123.2, 85.7 (major), 85.3 (minor), 62.9, 62.5, 50.7, 50.3, 26.1, 25.5, 17.9, 17.4. HRMS (FTMS + p ESI) $\mathrm{m} / z$ [M + $\mathrm{Na}]^{+}$; calculated for $\mathrm{C}_{24} \mathrm{H}_{23} \mathrm{O}_{2} \mathrm{NNa} 380.1621$, Found 380.1624 .

3-((4-Methoxybenzyl)oxy)-2-((S)-1-phenylethyl)isoindolin-1-one (7): Colorless oil (88 mg, 60\%); $R_{f}=0.37$ (hexane/ethyl acetate, 4:1). IR 3063, 2989, 2941, 2843, $1702 \mathrm{~cm}^{-1} .{ }^{1} \mathrm{H}$ NMR (500 MHz, CDCl , major) $\delta 7.87-7.88$ $(\mathrm{m}, 1 \mathrm{H}), 7.14-7.60(\mathrm{~m}, 8 \mathrm{H}), 6.77-6.83(\mathrm{~m}, 3 \mathrm{H}), 6.50-6.53(\mathrm{~m}, 1 \mathrm{H}), 5.79(\mathrm{~s}, 1 \mathrm{H}) 5.73(\mathrm{q}, J=8.0 \mathrm{~Hz}, 1 \mathrm{H}), 4.29(\mathrm{~d}, J=$ $11.5 \mathrm{~Hz}, 1 \mathrm{H}), 3.95(\mathrm{~d}, J=11.5 \mathrm{~Hz}, 1 \mathrm{H}), 3.81(\mathrm{~s}, 3 \mathrm{H}), 1.84(\mathrm{~d}, J=7.0 \mathrm{~Hz}, 3 \mathrm{H}) .{ }^{1} \mathrm{H}$ NMR $\left(500 \mathrm{MHz}, \mathrm{CDCl}_{3}\right.$, minor) $\delta$ 7.87-7.88 (m, 1H), 7.14-7.60 (m, 8H), 6.77-6.83 (m, 3H), 6.50-6.53 (m, 1H), $6.19(\mathrm{~s}, 1 \mathrm{H}), 5.47(\mathrm{q}, \mathrm{J}=7.0 \mathrm{~Hz}, 1 \mathrm{H})$, $3.77(\mathrm{~s}, 3 \mathrm{H}), 3.69$ (d, J = $11.0 \mathrm{~Hz}, 1 \mathrm{H}), 3.57(\mathrm{~d}, \mathrm{~J}=11.0 \mathrm{~Hz}, 1 \mathrm{H}), 1.91$ (d, J = 7.0 Hz, 3H). ${ }^{13} \mathrm{CNMR}\left(125 \mathrm{MHz}, \mathrm{CDCl}_{3}\right)$ $\delta 167.5,159.7,141.7,141.0,140.7,140.3,139.0,138.8,133.1,132.6,132.1123 .0,129.5,129.2,128.7,128.4$,

Page 6

${ }^{\circ}$ ARKAT USA, Inc 
127.8, 127.7, 127.5, 123.7, 123.6, 123.4, 120.0, 119.8, 113.2, 113.1, 113.0, 85.8 (major), 85.6 (minor), 63.9, 63.8, 55.2, 30.7, 18.1, 17.5. HRMS (FTMS + p ESI) $\mathrm{m} / 2[\mathrm{M}+\mathrm{Na}]^{+}$; calculated for $\mathrm{C}_{24} \mathrm{H}_{23} \mathrm{O}_{3} \mathrm{NNa} 396.1570$, Found 396.1573.

2-((S)-1-Phenylethyl)-3-(2,2,2-trichloroethoxy)isoindolin-1-one (8): Colorless oil (129 mg, 85\%); $R_{f}=0.47$ (hexane/ethyl acetate, 2:1) IR 3046, 3035, 2980, 2936, $1677 \mathrm{~cm}^{-1} .{ }^{1} \mathrm{H} \mathrm{NMR}\left(500 \mathrm{MHz}, \mathrm{CDCl}_{3}\right.$, major) $\delta 7.87-7.88$ (m, 1H), 7.27-7.62 (m, 8H), $5.88(\mathrm{~s}, 1 \mathrm{H}), 5.72(\mathrm{q}, J=7.5 \mathrm{~Hz}, 1 \mathrm{H}), 3.94$ (d, $J=10.5 \mathrm{~Hz}, 1 \mathrm{H}), 3.44$ (d, J = 10.5 Hz, 1H), $1.89(\mathrm{~d}, J=7.0 \mathrm{~Hz}, 3 \mathrm{H}) .{ }^{1} \mathrm{H} \mathrm{NMR}\left(500 \mathrm{MHz}, \mathrm{CDCl}_{3}\right.$, minor) $\delta 7.87-7.88(\mathrm{~m}, 1 \mathrm{H}), 7.27-7.62(\mathrm{~m}, 8 \mathrm{H}), 6.24(\mathrm{~s}, 1 \mathrm{H}), 5.48$ (q, $J=7.5 \mathrm{~Hz}, 1 \mathrm{H}$ ), 3.18 (d, $J=10.5 \mathrm{~Hz}, 1 \mathrm{H}), 3.08$ (d, $J=10.5 \mathrm{~Hz}, 1 \mathrm{H}), 1.93$ (d, $J=7.0 \mathrm{~Hz}, 3 \mathrm{H}) .{ }^{13} \mathrm{CNMR}(125 \mathrm{MHz}$, $\left.\mathrm{CDCl}_{3}\right) \delta 167.6,141.1,139.9,139.5,139.1,132.9,132.7,132.5$ 130.6, 130.5, 128.8, 128.7, 128.0, 127.7, 127.6, 124.0, 123.9, 123.7, 95.9, 85.7 (major), 85.5 (minor), 74.2, 73.9, 50.9, 18.0, 17.4. HRMS (FTMS + p ESI) $\mathrm{m} / z$ [M + $\mathrm{Na}]^{+}$; calculated for $\mathrm{C}_{18} \mathrm{H}_{16} \mathrm{O}_{2} \mathrm{NCl}_{3} \mathrm{Na} 406.0139$, Found 406.0142 .

3-(Allyloxy)-2-((S)-1-phenylethyl)isoindolin-1-one (9): Colorless oil $(81 \mathrm{mg}, 70 \%) ; \mathrm{R}_{\mathrm{f}}=0.45$ (hexane/ethyl acetate, 9:1) IR 3041, 3010, 2976, 2942, $1700 \mathrm{~cm}^{-1}$. ${ }^{1} \mathrm{H}$ NMR (500 MHz, $\mathrm{CDCl}_{3}$, major) $\delta 7.84-7.85$ (m, $\left.1 \mathrm{H}\right), 7.24-$ $7.58(\mathrm{~m}, 8 \mathrm{H}), 5.80-5.84(\mathrm{~m}, 1 \mathrm{H}), 5.70(\mathrm{q}, J=7.5 \mathrm{~Hz}, 1 \mathrm{H}), 5.67(\mathrm{~s}, 1 \mathrm{H}) 4.94-4.99(\mathrm{~m}, 1 \mathrm{H}), 3.54$ (dd, $J=11.0,5.5 \mathrm{~Hz}$, $1 \mathrm{H}), 3.45$ (dd, $J=11.0,5.5 \mathrm{~Hz}, 1 \mathrm{H}), 1.80(\mathrm{~d}, J=7.0 \mathrm{~Hz}, 3 \mathrm{H}) .{ }^{1} \mathrm{H} \mathrm{NMR}\left(500 \mathrm{MHz}, \mathrm{CDCl}_{3}\right.$, minor) $\delta 7.84-7.85(\mathrm{~m}, 1 \mathrm{H})$, 7.24-7.58 (m, 8H), 6.09 (s, $1 \mathrm{H}), 5.44(\mathrm{q}, J=7.0 \mathrm{~Hz}, 1 \mathrm{H}), 5.37-5.40(\mathrm{~m}, 1 \mathrm{H}), 5.23(\mathrm{~d}, J=7.0 \mathrm{~Hz}, 2 \mathrm{H}), 4.94-4.99(\mathrm{~m}$, $1 \mathrm{H}$ ), 3.20 (dd, $J=13.5,7.5 \mathrm{~Hz}, 1 \mathrm{H}$ ), 3.10 (dd, $J=13.5,7.5 \mathrm{~Hz}, 1 \mathrm{H}), 1.89$ (d, $J=7.5 \mathrm{~Hz}, 3 \mathrm{H}) .{ }^{13} \mathrm{C} \mathrm{NMR}(125 \mathrm{MHz}$, $\left.\mathrm{CDCl}_{3}\right) \delta 167.7,167.6,141.7,140.9,140.6,140.2,133.8,133.6,133.0,132.6,132.0,129.9,129.8,128.6,128.4$, 128.2, 127.9, 127.8, 127.7, 127.4, 126.6, 123.7, 123.5, 123.3, 117.1, 117.0, 85.5 (major), 85.3 (minor), 62.9, 62.8, $50.5,50.4,17.9$, 17.4. HRMS (FTMS + p ESI) $\mathrm{m} / 2[\mathrm{M}+\mathrm{Na}]^{+}$; calculated for $\mathrm{C}_{19} \mathrm{H}_{19} \mathrm{O}_{2} \mathrm{NNa} 316.1308$, Found 316.1304 .

3-(4-Hydroxybutoxy)-2-((S)-1-phenylethyl)isoindolin-1-one (10): Colorless oil (103 mg, 80\%); $\mathrm{R}_{\mathrm{f}}=0.19$ (hexane/ethyl acetate, 2:1); IR $3405 \mathrm{br}, 2940,2874,2836,1683 \mathrm{~cm}^{-1}$. ${ }^{1} \mathrm{H} \mathrm{NMR}\left(500 \mathrm{MHz}, \mathrm{CDCl}_{3}\right.$, major) $\delta 7.81$ $7.83(\mathrm{~m}, 1 \mathrm{H}), 7.22-7.24(\mathrm{~m}, 8 \mathrm{H}), 5.65(\mathrm{q}, J=6.5 \mathrm{~Hz}, 1 \mathrm{H}), 5.62(\mathrm{~s}, 1 \mathrm{H}), 3.86-3.89(\mathrm{~m}, 1 \mathrm{H}), 3.60-3.71(\mathrm{~m}, 3 \mathrm{H}), 3.41-$ $3.46(\mathrm{~m}, 1 \mathrm{H}), 3.28-3.30(\mathrm{~m}, 1 \mathrm{H})$ 2.87-2.89 (m, $1 \mathrm{H}), 1.57-2.0(4 \mathrm{H}), 1.23-1.34(\mathrm{~m}, 2 \mathrm{H}) .{ }^{1} \mathrm{H}$ NMR $\left(500 \mathrm{MHz}, \mathrm{CDCl}_{3}\right.$, minor) $\delta 7.81-7.83(\mathrm{~m}, 1 \mathrm{H}), 7.22-7.24(\mathrm{~m}, 8 \mathrm{H}), 6.03(\mathrm{~s}, 1 \mathrm{H}), 5.43(\mathrm{q}, J=6.0 \mathrm{~Hz}, 1 \mathrm{H}), 3.60-3.71(\mathrm{~m}, 3 \mathrm{H}), 3.41-3.46$ $(\mathrm{m}, 1 \mathrm{H}) 2.60-2.68(\mathrm{~m}, 2 \mathrm{H}), 1.57-2.0(\mathrm{~m}, 4 \mathrm{H}), 1.15-1.18(\mathrm{~m}, 1 \mathrm{H}), 1.09-1.10(\mathrm{~m}, 1 \mathrm{H}) .{ }^{13} \mathrm{C} \mathrm{NMR}\left(125 \mathrm{MHz}, \mathrm{CDCl}_{3}\right) \delta$ $167.8,141.8,141.3,140.9,140.5,133.1,132.7,132.2,130.0,129.9,128.8,128.5,127.9,127.8,127.5,123.8$, 123.7, 123.3, 85.8 (major), 85.4 (minor), 62.7, 62.6, 61.9, 61.7, 50.8, 50.3, 29.7, 29.5, 26.2, 25.7, 18.1, 17.5. HRMS (FTMS + p ESI) $\mathrm{m} / z[\mathrm{M}+\mathrm{Na}]^{+}$; calculated for $\mathrm{C}_{20} \mathrm{H}_{23} \mathrm{O}_{3} \mathrm{NNa} 348.1570$, Found 348.1573

3-(3-Hydroxy-2,2-dimethylpropoxy)-2-((S)-1-phenylethyl)isoindolin-1-one (11): Colorless oil (101 mg, 75\%); $R_{f}$ $=0.25$ (hexane/ethyl acetate, 2:1); IR $3449 \mathrm{br}, 3061,2973,2870,1686 \mathrm{~cm}^{-1} .{ }^{1} \mathrm{H} \mathrm{NMR}$ ( $500 \mathrm{MHz}, \mathrm{CDCl}_{3}$, major) $\delta$ 7.84-7.85 (m, $1 \mathrm{H}), 7.27-7.58(\mathrm{~m}, 8 \mathrm{H}), 5.66(\mathrm{q}, J=7.0 \mathrm{~Hz}, 1 \mathrm{H}), 5.64(\mathrm{~s}, 1 \mathrm{H}), 3.36-3.44(\mathrm{~m}, 2 \mathrm{~h}) 3.22(\mathrm{~d}, J=9.0 \mathrm{~Hz}$, $1 \mathrm{H}), 2.68(\mathrm{~d}, J=9.0 \mathrm{~Hz}, 1 \mathrm{H}), 2.02(\mathrm{br} \mathrm{s}, 1 \mathrm{H}), 1.85(\mathrm{~d}, J=7.5 \mathrm{~Hz}, 3 \mathrm{H}), 0.87(\mathrm{~s}, 3 \mathrm{H}), 0.85(\mathrm{~s}, 3 \mathrm{H}) .{ }^{1} \mathrm{H} \mathrm{NMR}(500 \mathrm{MHz}$, $\mathrm{CDCl}_{3}$, minor) $\delta 7.84-7.85(\mathrm{~m}, 1 \mathrm{H}), 7.27-7.58(\mathrm{~m}, 8 \mathrm{H}), 6.00(\mathrm{~s}, 1 \mathrm{H}), 5.36(\mathrm{q}, J=7.0 \mathrm{~Hz}, 1 \mathrm{H}), 3.15-3.17(\mathrm{~m}, 2 \mathrm{H}), 2.59$ (d, $J=9.0 \mathrm{~Hz}, 1 \mathrm{H}$ ), 2.54 (d, $J=9.0 \mathrm{~Hz}, 1 \mathrm{H}$ ), 1.89 (d, $J=7.5 \mathrm{~Hz}, 3 \mathrm{H}), 1.76$ (br s, $1 \mathrm{H}$ ), $0.70(\mathrm{~s}, 3 \mathrm{H}), 0.63(\mathrm{~s}, 3 \mathrm{H}) .{ }^{13} \mathrm{C}$ $\operatorname{NMR}\left(125 \mathrm{MHz}, \mathrm{CDCl}_{3}\right) \delta 167.8,141.7,141.1,140.7,140.3,133.1,132.7,132.2,132.1,130.0,129.9,128.7,128.5$, 127.8, 127.7, 127.5, 123.7, 123.5, 123.2, 123.0, 85.7 (major), 85.5 (minor), 70.8, 70.5, 69.8, 50.8, 50.7, 35.9, 35.6, 21.8, 21.6, 18.0, 17.8. HRMS (FTMS + p ESI) $\mathrm{m} / 2[\mathrm{M}+\mathrm{Na}]^{+}$; calculated for $\mathrm{C}_{21} \mathrm{H}_{25} \mathrm{O}_{3} \mathrm{NNa} 362.1727$, Found 362.1730 
3-(Anthracen-9-ylmethoxy)-2-((S)-1-phenylethyl)isoindolin-1-one (12): Pale yellow solid ( 138mg, 78\%); mp 85-

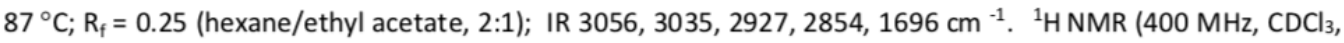
major) $\delta 8.43(\mathrm{~s}, 1 \mathrm{H}), 7.95-7.96(\mathrm{~m}, 3 \mathrm{H}), 7.86-7.89(\mathrm{~m}, 1 \mathrm{H}), 7.26-7.72(\mathrm{~m}, 12 \mathrm{H}), 6.98(\mathrm{~d}, J=7.2 \mathrm{~Hz}, 1 \mathrm{H}), 5.86(\mathrm{~s}$, $1 \mathrm{H}), 5.80(\mathrm{q}, J=7.2 \mathrm{~Hz}, 1 \mathrm{H}), 5.34(\mathrm{~d}, J=12.0 \mathrm{~Hz}, 1 \mathrm{H}), 5.12(\mathrm{~d}, J=12.0 \mathrm{~Hz}, 1 \mathrm{H}), 1.90(\mathrm{~d}, J=7.6 \mathrm{~Hz}, 3 \mathrm{H}) .{ }^{1} \mathrm{H} \mathrm{NMR}$ $\left(400 \mathrm{MHz}_{2} \mathrm{CDCl}_{3}\right.$, minor) $\delta 8.39(\mathrm{~s}, 1 \mathrm{H}), 7.95-7.96(\mathrm{~m}, 3 \mathrm{H}), 7.86-7.89(\mathrm{~m}, 1 \mathrm{H}), 7.26-7.72(\mathrm{~m}, 12 \mathrm{H}), 7.18(\mathrm{~d}, J=7.2$ $\mathrm{Hz}, 1 \mathrm{H}), 6.10(\mathrm{~s}, 1 \mathrm{H}), 5.40$ (q, J = 7.2 Hz, 1H), 4.85 (q, J = 7.6 Hz, 2H), 2.04 (d, J = 7.2 Hz, 3H). ${ }^{13} \mathrm{CNMR}(125 \mathrm{MHz}$, $\left.\mathrm{CDCl}_{3}\right) \delta 168.4,168.3,142.0,141.4,140.9,140.7,133.2,132.5,132.0,131.9,131.4,130.5,130.4,129.9,129.8$, 129.0, 128.9, 128.8, 128.6, 128.5, 128.3, 127.7, 127.6, 126.5, 126.1, 124.9, 124.9, 124.2, 124.0, 123.8, 123.7, 123.6, 86.3 (major), 86.0 (minor), 58.0, 57.1, 51.6, 51.0, 18.5, 18.3. HRMS (FTMS + p ESI) $\mathrm{m} / \mathrm{z}[\mathrm{M}+\mathrm{Na}]^{+}$; calculated for $\mathrm{C}_{31} \mathrm{H}_{25} \mathrm{O}_{2} \mathrm{NNa} 466.1778$, Found 466.1780 .

3-((2-Bromobenzyl)oxy)-2-((S)-1-phenylethyl)isoindolin-1-one (13): Colorless oil (118 mg, 71\%); $R_{f}=0.29$ (hexane/ethyl acetate, 9:1) IR 3077, 3035, 2984, 2937, $1686 \mathrm{~cm}^{-1} .{ }^{1} \mathrm{H} \mathrm{NMR}\left(500 \mathrm{MHz}, \mathrm{CDCl}_{3}\right.$, major) $\delta 7.88-7.90$ $(\mathrm{m}, 1 \mathrm{H}), 7.10-7.56(\mathrm{~m}, 12 \mathrm{H}), 5.89(\mathrm{~s}, 1 \mathrm{H}), 5.75(\mathrm{q}, J=7.0 \mathrm{~Hz}, 1 \mathrm{H}), 4.40(\mathrm{~d}, J=12.0 \mathrm{~Hz}, 1 \mathrm{H}), 4.07(\mathrm{~d}, J=12.5 \mathrm{~Hz}$, $1 \mathrm{H}), 1.83(\mathrm{~d}, J=7.5 \mathrm{~Hz}, 1 \mathrm{H}) .{ }^{1} \mathrm{H} \mathrm{NMR}\left(500 \mathrm{MHz} \mathrm{CDCl}_{3}\right.$, minor) $\delta 7.88-7.90(\mathrm{~m}, 1 \mathrm{H}), 7.10-7.56(\mathrm{~m}, 11 \mathrm{H}) 5.47(\mathrm{q}, J$ $=7.0 \mathrm{~Hz}, 1 \mathrm{H}), 4.06$ (d, $J=12.5 \mathrm{~Hz}, 1 \mathrm{H}), 3.87(\mathrm{~d}, J=12.5 \mathrm{~Hz}, 1 \mathrm{H}), 1.92(\mathrm{~d}, J=7.5 \mathrm{~Hz}, 3 \mathrm{H}) .{ }^{13} \mathrm{CNMR}\left(125 \mathrm{MHz}, \mathrm{CDCl}_{3}\right)$ $\delta 167.9,167.8,141.6,140.7,140.4,140.3,136.9,136.7,132.9,132.5,132.3,132.2,132.1,130.1,130.0,129.4$, $129.2,129.1,128.9,128.7,128.4,127.8,127.5,127.4,127.3,127.1,123.8,123.6,123.5,123.4,122.8,122.7$, 85.7 (major), 85.5 (minor), 63.7, 63.6, 50.7, 50.6, 18.1, 17.6. HRMS (FTMS + p ESI) $m / z$ [M + Na] $]^{+}$; calculated for $\mathrm{C}_{23} \mathrm{H}_{20} \mathrm{O}_{2} \mathrm{NBrNa}$ 444.0570, Found 444.0572.

\section{Acknowledgements}

Support for JMR through a Department of Chemistry Teaching Assistantship is acknowledged.

\section{References}

1) Yang, Y.; Feng, Z.; Jiang, J.; Yang, Y.; Pan, X.; Zhang, P. Chem. Pharm. Bull., 2011, 59, 1016-1019 https://doi.org/10.1248/cpb.59.1016

2) Hardcastle, I.; Ahmed, S.; Atkins, H.; Farnie, G.; Golding, B.; Griffin, R.; Guyenne, S.; Hutton, C.; Källblad, P.; Kemp, S.; Kitching, N.; Newell, D.; Norbedo, S.; Northen, J.; Reid, R.; Saravanan, K.; Willems, H.; Lunec, J. J. Med. Chem., 2006, 49, 6209-6221 http://doi.org/10.1021/im0601194

3) Watson, A.; Liu, J; Bennaceur, K.; Drummond, C.; Endicott, J.; Golding, B.; Griffin, R.; Haggerty, K.; Lu, X; McDonnell, J.; Newell, D.; Noble, M.; Revill, C.; Reidinger, C.; Xu, Q; Zhao, Y.; Lunec, J.; Hardcastle, I. Bioorg. Med. Chem. Lett., 2011, 21, 5916-5919. http://doi.org/10.1016/i.bmcl.2011.07.084

4) Cid, H.; Tränkle, C.; Bauman, K.; Pick, R.; Mies-Klomfass, E.; Kostenis, E.; Mohr, K.; Holzgrabe, U. J. Med. Chem., 2000, 43, 2155-2164. http://doi.org/10.1021/im991136e

5) Ortín, I.; González, J.; de la Cuesta, E.; Manguan-García, C.; Perona, R.; Avendaño, C. Bioorg. Med. Chem. 2008, 16, 9065-9078. https://doi.org/10.1016/i.bmc.2008.07.083

6) Chihab-Eddine, A.; Daïch, A.; Jilale, A.; Decroix, B. J. Heterocylcic Chem., 2000, 37, 1543-1548. 
https://doi.org/10.1002/ihet.5570370622

7) Chihab-Eddine, A.; Daïch, A.; Jilale, A.; Decroix, B. Heterocycles, 2002, 58, 449-456. http://doi.org/10.3987/COM-02-S(M)43

8) Cul, A.; Chihab-Eddine, A.; Pesquet, A.; Marchelín, Š.; Daïch, A. J. Heterocyclic Chem., 2003, 40, 499505. https://doi.org/10.1002/ihet.5570400314

9) Yamada, S.; Takahashi, Y. Tetrahedron Letters, 2009, 50, 5395-5398. https://doi.org/10.1016/i.tetlet.2009.07.042

10) Aliyenne, A.; Pin, F; Nimbarte, V.; Lawson, A.; Comesse, S.; Sanselme, M.; Tognetti, V.; Joubert, L.; Daïch, A. Eur. J. Org. Chem. 2016, 21, 3592-3602. https://doi.org/10.1002/ejoc. 201600530

11) Luzzio, F. A. ; Piatt Zacherl, D. P. Tetrahedron Lett. 1998, 39, 2285-2288. https://doi.org/10.1016/S00404039(98)00293-7

12) Natte, K..; Chen, J.; Li, H.; Neumann, H.; Beller, M.; Wu, X. Chem. Eur. J. 2014, 20, 14184-14188 http://dx.doi.org/10.1002/chem.201404446

13) Rao, H.; Rao, A. J. Org. Chem. 2015, 80, 1506-1516. http://doi.org/10.1021/i0502446k

14) Cabrero-Antonino, J.; Sorribes, I.; Junge, K; Beller, M. Angew. Chem. Int. Ed, 2016, 55, 387-391. https://doi.org/10.1002/anie.201508575

15) Cabrero-Antonino, J.; Adam, R.; Papa, V.; Holsten, M.; Junge, K.; Beller, M. Chem. Sci., 2017, 8, 55365546. https://doi.org/10.1039/C7SC01175I

16) Johnson, A. L.. J. Org. Chem. 1982, 47, 5220-5222. https://doi.org/10.1021/i000147a041

17) Khrimian, A. P. ; DeMilo, A. B. ; Waters, R. M. ; Liquido, N. J. ; Nicholoson, J. M. J. Org. Chem. 1994, 59, 8034-8039. https://doi.org/10.1021/i000090a035

18) Yin, J. ; Zarkowsky, D. S. ; Thomas, D. W. ; Zhao, M. M. ; Huffman, M. A. Org. Lett. 2004, 6, 1465-1468. https://doi.org/10.1021/ol049672a

19) Luzzio, F. A. ; Piatt-Zacherl, D. P. Tetrahedron Lett. 1999, 40, 2087-2090. https://doi.org/10.1016/S00404039(99)00152-5

20) Chihab-Eddine, A. ; Daich, A. ; Jilale, A. Decroix, B. Heterocycles 1999, 51, 2907-2914. https://doi.org/10.3987/COM-99-8701

21) Leroy, J. ; Hebert, E. ; Wakselman, C. J. Org. Chem. 1979, 44, 3406-3408. https://doi.org/10.1021/jo01333a030

22) Liang, T.; Neumann, C.; Ritter, T. Angew. Chem. Int. Ed., 2013, 52, 8214-8264. https://doi.org/10.1002/anie.201206566 


\section{CURRICULUM VITAE}

\begin{tabular}{ll}
\multicolumn{2}{c}{ JARRID RONNEBAUM } \\
\hline 8707 Big Tree Circle, Apt. H & $812-212-4544$ (cell) \\
Louisville, KY 40220 & $502-852-6066$ (lab) \\
& Jarrid.Ronnebaum@louisville.edu \\
EDUCATION & \\
\hline
\end{tabular}

University of Louisville, Louisville, KY, USA

2014-Present Ph.D., Chemistry - Organic Chemistry

Dissertation Topic: Synthetic Methods and Applications of Nitrogen Heterocycles to

Biologically-Active Compounds

Advisor: Dr. Frederick A. Luzzio

Butler University, Indianapolis, IN, USA

2010-2014 B.S. Chemistry

Research Topic: RUI-Synthesis and applications of cyclic boronic half acids

Advisor: Dr. LuAnne McNulty

\section{RESEARCH SKILLS}

Organic synthesis under ambient and airfree conditions.

Spectroscopic analysis and interpretation, infrared spectroscopy, mass spectroscopy, multinuclear magnetic resonance (NMR), gas chromatography, and GC-MS.

Lead teaching assistant: performed optimization of teaching laboratory experiments for an advanced organic synthesis and analysis class.

\section{RESEARCH TOPICS}

"Click" Thalidomide Analogues

Synthesis of thalidomide analogues from novel starting materials and utilization of those with a copper-catalyzed azide-alkyne cycloaddition to make an array of analogues for biological testing.

\section{Amino Acid Synthesis}

Using isoindolinone to act as a masked protecting group for a glycine equivalent to synthesize a range of natural/unnatural amino acid derivatives and with benzylic oxidation of the isoindolinone provides the protected amino acid.

\section{Alkoxyisoindolinone Synthesis}

Synthesis of alkoxyisoindoline from hydroxyisoindolinone facilitated by diethylaminosulfur trifluoride through a likely mechanism involving a stable $\mathrm{N}$-acyliminium ion. 


\section{Publications}

Ronnebaum, J. M.; Luzzio, F. A. Tetrahedron, 2016, 72, 6136-6141

Patil, P. C.; Luzzio, F. A.; Ronnebaum, J. M. Tetrahedron Lett. 2017, 58, 3730-3733

Ronnebaum, J. M.; Luzzio, F. A. ARKIVOC (Accepted pending minor revisions)

\section{TEACHING EXPERIENCE}

University of Louisville, Louisville, KY, USA

2014 - Present Graduate Teaching Assistant Organic/Advanced Organic Labs

Butler University, Indianapolis, IN, USA

$2013-2014 \quad$ Lab Teaching Assistant

Organic Chemistry

\section{AWARDS}

Doctoral Dissertation Completion Award

Spring 2019 Semester

\section{UndergRaduATE STUdent MentorshiP}

Henry C. Brun Spring 2018 Semester

Henry worked underneath me where I taught him how to effectively: monitor reactions via TLC, running column chromatography when need to purify, and collect required spectra for publication. 